Portland State University

PDXScholar

$1-1-1985$

\title{
The measurement of change in well-being in a longitudinal study of pre- and post-retirees
}

Marie P. Beaudet

Portland State University

Follow this and additional works at: https://pdxscholar.library.pdx.edu/open_access_etds Let us know how access to this document benefits you.

\section{Recommended Citation}

Beaudet, Marie P., "The measurement of change in well-being in a longitudinal study of pre- and postretirees" (1985). Dissertations and Theses. Paper 784.

https://doi.org/10.15760/etd.784

This Dissertation is brought to you for free and open access. It has been accepted for inclusion in Dissertations and Theses by an authorized administrator of PDXScholar. Please contact us if we can make this document more accessible: pdxscholar@pdx.edu. 
THE MEASUREMENT OF CHANGE IN WELL-BEING

IN A LONGITUDINAL SIUDY OF PRE- AND POST-RETIREES

by

MARIE P. BEALDET

A dissertation submitted in partial fulfillment of the requirements for the degree of

DOCTOR OF PHILOSOPHY

in

URBAN STUDIES

Portland State University

(C) 1985 Marie P. Beaudet 
TO THE OFFICE OF GRADUATE STUDIES AND RESEARCH:

The members of the Committee approve the dissertation of Marie P. Beaudet presented May 1, 1985

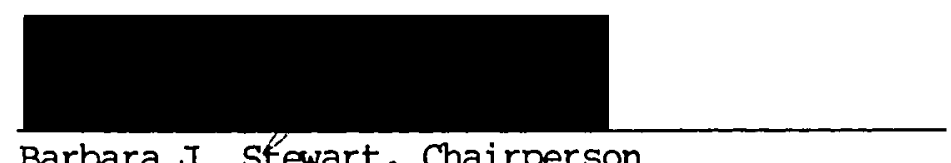

Barbara J. stewart, Chairperson

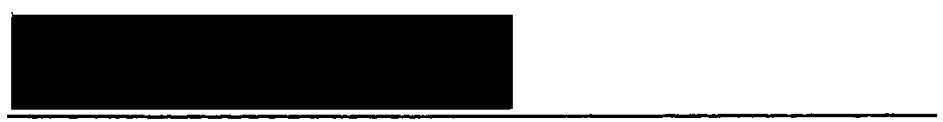

Leonard D Cain

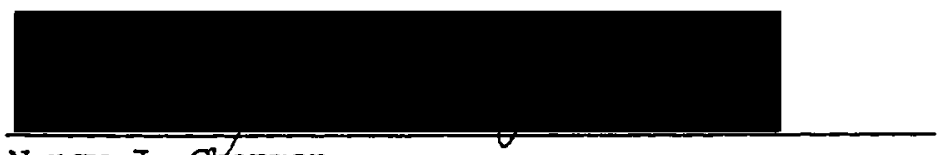

Nancy J. Ehapman

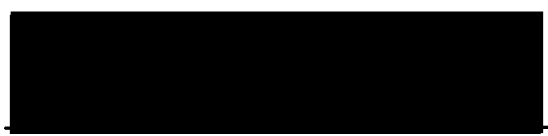

James A. Paulson

APPROVED:
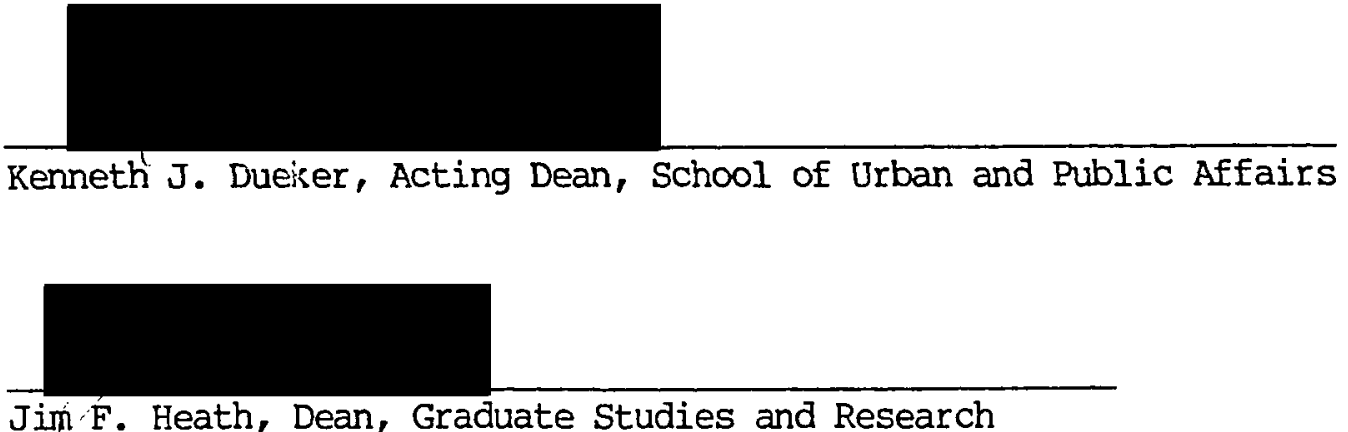
AN ABSTRACT OF THE DISSERTATION OF Marie P. Beaudet for the Doctor of Philosophy in Urban Studies presented May 1, 1985.

Title: The Measurement of Change in Well-being in a Longitudinal Study of Pre- and Post-retirees.

APPROVED BY MEMBERS OF THE DISSERTATION COMMITTEE:

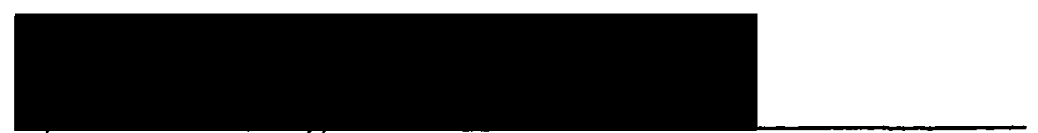

Barbara J. Stewart, Chairperson
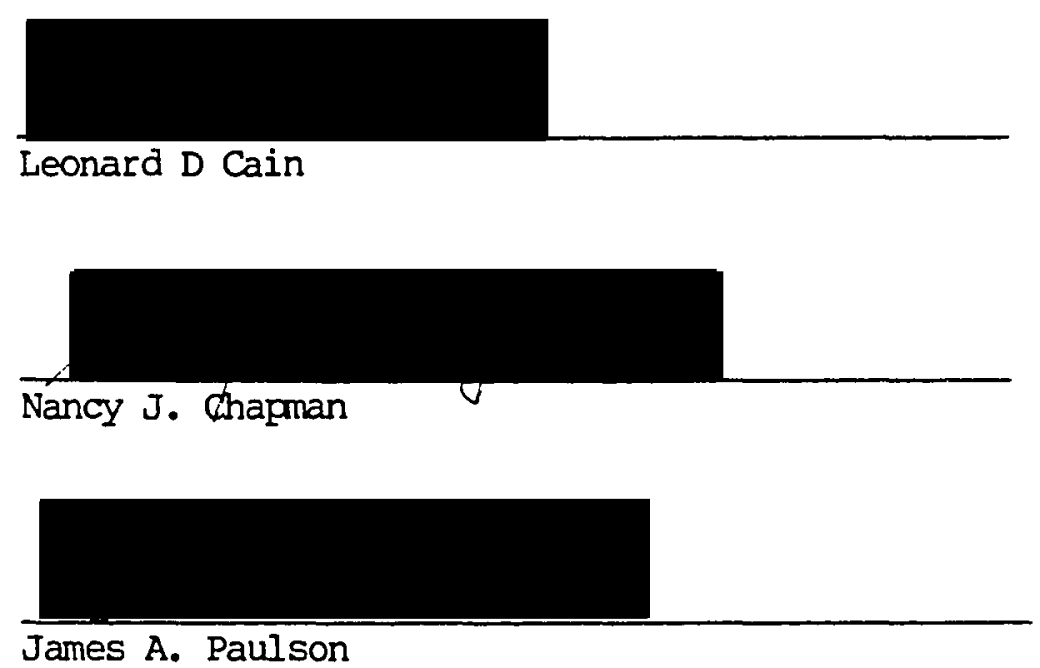

The primary focus of this dissertation is an empirical investigation of three approaches to the measurement of longitudinal change. For the present study, difference scores, residual change scores, and percentage gain scores are compared to determine if their use results in similar findings when the 
relationships between three resource areas (health, social, and financial) and subjective well-being are analyzed. The propositions which are tested were derived from current aging theories. Meta-analysis procedures were employed to synthesize past research findings in gerontology.

The data which were analyzed are those of the Longitudinal Retirement History Study (LRHS), a research project sponsored by the Social Security Administration. The sample consists of 8922 continuers who participated in the 1969, 1971, and 1973 waves of data collection.

Findings from the meta-analysis suggest that the correlation coefficients calculated from the LRHS data on the relationship between subjective well-being and the areas of health resources and social resources are similar to those of other aging studies. The relationship between measures of financial resources and subjective well-being is stronger for the LRHS respondents than that reported in other aging studies.

The results on the analysis of longitudinal change indicate that change in health resources and in financial resources are significant predictors of subjective well-being at a later-pointin-time and of change in subjective well-being. For the present study, change in social resources contributes little to the regression equations.

The three selected approaches to the measurement of change rank individuals similarly on the construct of change. However, 
the use of difference scores, residual change scores, and percentage gain scores does not always result in similar findings when multivariate procedures are used. Residual change scores appear to possess a number of advantages. They tend, however, to be strongly related to the time 2 scores from which they are derived, a phenomenon not emphasized in the measurement of change literature.

Improving the reliability of measures, allowing adequate time for change to occur, and using sample sizes which are large are suggested to maximize the possibility of obtaining correlation coefficients based on change scores which are large and stable. 


\section{ACKNOWLEDGMENTS}

A number of individuals have contributed to my professional and personal growth. I am particularly indebted to my chairperson, Dr. Barbara Stewart, who has been a brillant teacher, an insightful mentor, and a wonderful friend. I am also indebted to the members of my dissertation committee, Drs. Nancy Chapman, Leonard Cain, and James Paulson and wish to acknowledge their guidance, understanding, and support.

I am grateful to Drs. Nohad Toulan and John O'Brien for providing me with opportunities to learn.

I also wish to acknowledge the contributions of William Coshow and Lee Hopper. Both have facilitated the analysis of my data by providing expert programing consultation and unlimited access to the Harris 300. Their patience and understanding far exceeded any reasonable expectations.

Finally, I wish to thank the following individuals for their emotional and instrumental support. Each has contributed in a unique way to the completion of this study. My sincere thanks to Marilyn Petersen, Mary Burki, Karis Swift, Susan Greist, Lisa Chickadonz, Christine Tanner, John Del Togno Armanasco, Mary Sweeney, Margaret Neal, Dawn Kuenle, Carol James, Karen King, Donna Stuteville, Robert McGaughey, and my children Keith and Cheryle walters.

I wish to thank the Multnomah County Fellowship fund for its financial support. 
This project is respectfully dedicated to my mother who has given me unlimited emotional support and who has provided substantial financial backing throughout. 
TABLE OF OONTENTS

PAGE

ACKNONLEDGMENTS................................ ii

LIST OF TABLES..............................

LIST OF FIGURES................................ $x \times i$

CHAPTER

I INTRODUCTION........................... 1

Overview of the Problen.................... I

Theories in Gerontology $\ldots \ldots \ldots \ldots \ldots \ldots \ldots \ldots . . \ldots$

Correlates of Subjective Well-being.......... 5

The Measurement of Change................ 6

Urban Relevance...................... 10

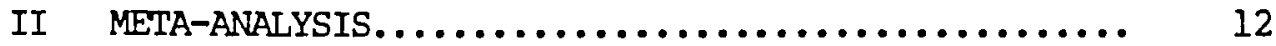

The Technique....................... 12

Methods for the conduct of the Meta-analysis....................... 21

Rules Followed in the Conduct of the Meta-analysis.................... 27

Results of the Meta-Analysis............... 33

The Measurement of Subjective Well-being... 34

Health Resources.................... 39

Clinical Health Indicators.......... 43

Self-perceived Health Indicators...... 44 
Stability over Time.............. 45

Health Status................. 47

Self-perceived Assessment of Health.... 49

Social Resources.................... 53

Size....................... 58

Frequency of Contact.............. 59

Societal Involvement............. 61

Financial Resources.................. 64

Financial Status............... 65

Satisfaction with Financial Status..... 67

Summary of the Studies with Multivariate procedures........................ 69

Summary.......................... 71

III METHODS................................ 74

Research Questions and Hypotheses............. 75

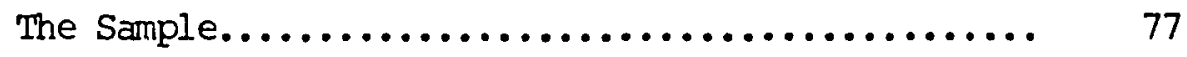

Operationalization of the Dependent and Independent variables.................... 80

Subjective well-being.................... 83

Happiness.......................... 83

outlook on Life...................... 86

Health Resources........................ 86

General Disability................... 87

Overall Disability.................... 87 
vii

Utilization of Health Resources........... 87

Self-perceived Health................. 88

Social Resources.......................... 89

Scope of Immediate Fanily............... 89

Size of Immediate Family................. 90

Frequency of Contact with Members
of the Network...................... 90

Societal Involvement.................. 91

Financial Resources....................... 91

Income.......................... 91

Satisfaction with Standard of Living......... 94

Internal Consistency and Stability............ 95

Descriptive Statistics and Correlations

within a wave......................... 101

The Measurement of Change................. 105

Difference Scores..................... 106

Residual Change Scores.................. 107

Percentage Gain Scores.................. 112

Self-perceived Change................. 114

Data Handling........................... 115

Statistical Analyses...................... 119

IV RESULTS AND DISCUSSION...................... 124

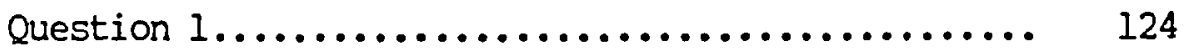

Descriptive Statistics for the Change Measures..... 129

The Happiness Item.................... 129 
viii

Longitudinal Measures of Change........... 135

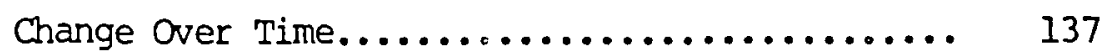

Change in the Rate of Change.............. 143

Difference Scores................. 143

Residual Change Scores............. 145

Percentage Gain Scores............. 146

Stability Coefficients of Change Scores....... 150

Correlation of Change Scores with

One-Point-In-Time Measures.............. 154

Question $2 . \ldots \ldots \ldots \ldots \ldots \ldots \ldots \ldots \ldots \ldots \ldots . \ldots \ldots$

Evidence of Construct Validity: Correlation Among the Three Approaches to the Measurement of Change................. 159

Construct Varidity: Testing Hypotheses....... 164

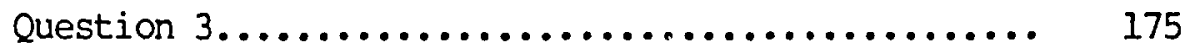

Findings from the Cross-sectional

Analyses........................... 177

The Objective Status Domain........... 177

The Subjective Status Domain........... 179

Findings from the Longitudinal Analysis....... 181

The Objective Status Domain............ 182

The Subjective Status Domain............ 185

Comparison of Cross-sectional and

Longitudinal Findings................ 185 


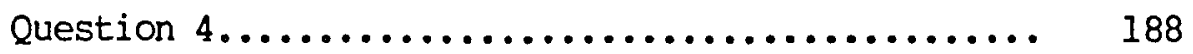

The Objective Status Domain............... 190

Happiness at a Later Point-in-time....... 190

Change in Happiness................. 191

Subjective Domain.................... 193

Happiness at a Later Point-in-time....... 193

Change in Happiness................. 193

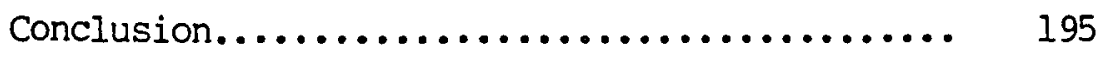

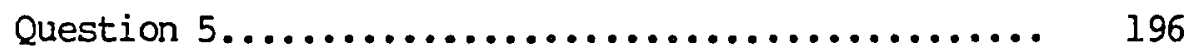

v CONCLUSION................................ 204

Summary of Results........................ 204

Findings from the Univariate Aralyses......... 207

Findings from the Multivariate Analyses....... 209

Findings from the Cross-sectional Analyses..... 211

Findings from the Longitudinal Analyses....... 212

Limitations of the Present Study............. 214

Recommendations for Future Research............ 216

The Use of Meta-analysis................ 218

The Measurement of Change............... 220

Measurement Issues..................... 222

Conclusion............................ 224

BIBLIOGRAPHY............................... 226 
APPENDICES

A SUMMARY OF UNIVARIATE STUDIES............... 231

B SUMMARY OF MULTTVARIATE STUDIES............. 300

C SUPPLEMENTARY TABLES....................... 355

BIBLIOGRAPHY FOR THE META-ANALYSIS $\ldots \ldots \ldots \ldots \ldots \ldots \ldots \ldots \ldots . \ldots . \ldots$ 
LIST OF TABLES

TABLE

PAGE

I Inclusion and Exclusion Status of All the Articles Which were Originally Identified as Relevant to the Meta-analysis.................

II Number of Articles and Number of Effect Sizes for Each Resource Area......................

III Stem-and-leaf Plot of the Correlation Coefficients Between Health Status and Subjective Well-being............................

IV Frequency Distribution of the Correlation Coefficients Between Health Status and Subjective

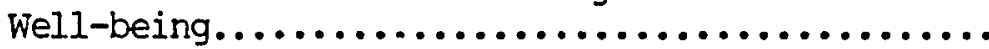

$\mathrm{V}$ Stem-and-leaf Plot of the Correlation Coefficients Between Self-perceived Health and Subjective Well-being....................

VI Frequency Distribution of the Correlation Coefficients Between Self-perceived Health and Subjective Well-being......................

VII Stem-and-leaf Plot of the Correlation Coefficients Between Size of Social Resources and Subjective Well-being.....................

VII Frequency Distribution of the Correlation Coefficients Between Size of Social Resources and Subjective Well-being.....................

IX Stem-and-leaf Plot of the Correlation Coefficients Between Frequency of Contact and Subjective Well-being....................

$X$ Frequency Distribution of the Correlation Coefficients Between Frequency of Contact and Subjective Well-being...................

XI Stem-and-leaf Plot of the Correlation Coefficients Between Societal Involvement and Subjective Well-being.....................

XII Frequency Distribution of the Correlation Coefficients Between Societal Involvement and Subjective well-being.................... 
XIII Stem-and-leaf Plot of the Correlation Coefficients Between Financial Status and Subjective

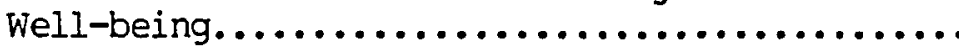

XIV Frequency Distribution of the Correlation Coefficients Between Financial Status and Subjective Well-being...........................

XV Stem-and-leaf Plot of the correlation Coefficients Between Satisfaction with Financial Status and Subjective Well-being...................

XVI Frequency Distribution of the Correlation Coefficients Between Satisfaction with Financial Status and Subjective Well-being..................

XVII Range of the Unstandardized and Standardized Coefficients and their Accompanying Sample Size for the Studies of the Relationship Between Subjective Well-being and the Areas of Health, Social, and Financial Resources..............

XVIII Status of All the Original LRHS

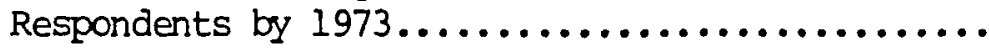

XIX Descriptive Statistics for the Measures of Health, Social, Financial Resources, and Subjective well-being for

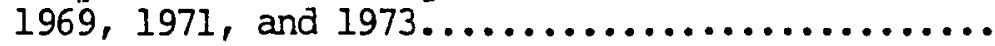

XX Descriptive Statistics for the Items Measuring Health, Financial Resources, and Subjective Well-being for 1969, 1971, and 1973............

XXI Percent Agreement Between Each of the Fourteen Income Categories in 1973 and the Continuous Income Variable Recoded..............

XXII Internal Consistency Coefficients for the Health, Social, Financial, and Subjective Well-being

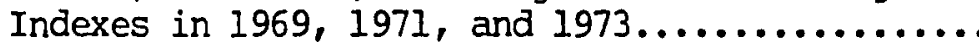

XXIII Two-year and Four-year Stability coefficients for the Indexes Measuring Health, Social, Financial Resources, and Subjective Well-being........... 
XXIV Two-year and Four-year Stability Coefficients for the Items Measuring Health, Financial, and

Subjective Well-being....................

XXV Means, Standard Deviations, and Intercorrelations Among Health, Social, Financial, and Subjective Well-being Measures for the 1969, 1971, and 1973 Waves of Data Collection..............

XXVI Means, Standard Deviations, and Intercorrelations Among Health, Financial, and Subjective Well-being Items for the 1969, 1971, and 1973 Waves of Data Collection...........................

XXVII Reliability of Difference Scores for Varying Degrees of Pre- and Post-Correlation Coefficients and Reliability of Pre- and Post-measures...............

XXVIII Reliability of Residual Change Scores for Varying Degrees of Pre and Post-correlation Coefficients and Reliability of Pre- and Post-measures........

XXIX Correlation Coefficients Between Subjective Well-being and the Areas of Health, Social, and Financial Resources: Summary of the Findings from the Meta-analysis and the

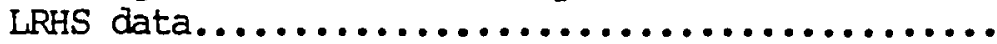

XXX Percentage and Number of Persons Reporting the Same, Less, or More Happiness at Two and FourYear Intervals..........................

XXXI Percentage and Number of Persons Reporting the Same, Less, or More Happiness Over the Four-year Interval..............................

XXXII Significant Differences Between Pairs of Means for the 1969, 1971, and 1973 Items and Indexes and for Difference Scores and Percentage Gain Scores Measuring Health, Social Resources, and Subjective Well-being...........

XXXIII Comparison of Means for the 1969, 1971, and 1973 Items and Indexes and for the Difference Scores and Percentage Gain Scores on the Items and Indexes Measuring Health, Social Resources and Subjective Well-being........... 
XXXIV Significant Differences Between Pairs of Means for the 1969, 1971, and 1973 Items and for Difference Scores and Percentage Gain Scores Measuring Health and Financial Resources, and Subjective Well-being....................

XXXV Comparisons of Means for the 1969, 1971, and 1973 Items and for Difference Scores and Percentage Gain Scores for the Items Measuring Health, Financial Resources, and Subjective Well-being..................

XXXVI Two-year and Four-year Stability Coefficients for the Three Selected Approaches to the Measurement of Change on the Indexes Measuring Health, Social Resources, and

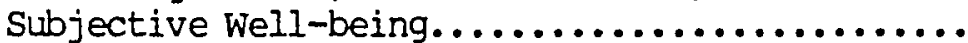

XXXVII Two-year and Four-year Stability Coefficients for the Three Approaches to the Measurement of Change for the Items Measuring Health, Financial Resources, and Subjective Well-being...........

XXXVIII Correlation Coefficients Between One-Point-in-Time Measures and the Three Approaches to the Measurement of Change for the Indexes and Items Measuring Health, Social, and Financial Resources, and Subjective Well-being...........

XXXIX Correlation Coefficients Between one-Point-in-Time Measures and the Three Approaches to the Measurement of Change for the Items Measuring Health, Financial Resources, and Subjective Well-being..................

XI Correlation Coefficients Among the Three Ways of Measuring Change for the Areas of Health, Social, Financial Resources, and Subjective Well-being.............................

XII Correlation Coefficients Among the Three Ways of Measuring Change for the Health and Financial Items in 1969, 1971, and 1973......... 
XLII Means, Standard Deviations, and Intercorrelations Among Change in Health, Social, Financial Resources, and Subjective Well-being as

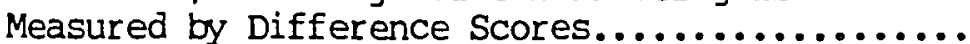

XIIII Means, Standard Deviations, and Intercorrelations Among Change in Health, Social, Financial Resources, and Subjective Well-being as Measured by Residual Change Scores...............

XLIV Means, Standard Deviations, and Intercorrelations Among Change in Health, Social, Financial Resources, and Subjective Well-being as Measured by Percentage Gain Scores.............

XIV Means, Standard Deviations, and Intercorrelations Among Change in Health, Financial, and Happiness Itens as Measured by Difference Scores..................

XIVI Means, Standard Deviations, and Intercorrelations Among Change in Health, Financial, and Happiness Items as Measured by Residual Change Scores.

XLVII Means, Standard Deviations, and Intercorrelations Among Change in Health, Financial, and Happiness Items as Measured by Percentage Gain Scores.....................

XLVIII Multiple Linear Regression for Predicting Subjective Well-being From Health, Social, and Financial Resources in 1969, 1971, and 1973.............

XLIX Multiple Linear Regression for Predicting Subjective Well-being From Health and Financial Items in 1969, 1971, and 1973. 
$x v i$

L Beta Weights for Predicting Subjective Well-being from Change in Health, Social, and Financial Resources for Each of the Three Approaches to the Measurement of Change at Each of the Three Waves of Data Collection................

LI Beta Weights For Predicting Change in Subjective Well-being From Change in Health, Social, and Financial Resources for Each of the Three Approaches to the Measurement of Change at Each of the Three Waves of Data Collection...............

LII Beta Weights for Predicting Subjective Well-being from Change in Health and Financial Items for Each of the Three Approaches to the Measurement of Change at Each of the Three Waves of

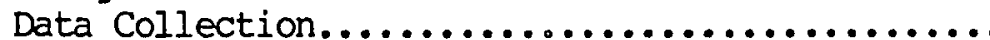

LIII Beta Weights for Predicting Change in Subjective Wellbeing Change in Health and Financial Items for Each of the Three Approaches to the Measurement of Change at Each of the Three Waves of Data Collection.............................

LIV Correlation Coefficients Between Self-perceived Change in Health and Difference Scores, Residual Change Scores, and Percentage Gain Scores for the General Disability Index and the Normative

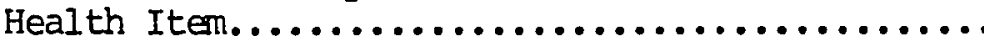

IV Correlation Coefficients of Change in Health Resources and Self-perceived Change in Health With Change Measures in the Areas of Social, Financial Resources, and Subjective Well-being.....................

LVI Descriptive Statistics for the Measures of Change in Health, Social, Financial Resources, and Subjective Well-being as Measured by Difference Scores.........................

LVII Descriptive Statistics for the Measures of Change in Health, Social, Financial Resources, and Subjective Well-being as Measured by Residual Change Scores. 
xvii

LVIII Descriptive Statistics for the Measures of Change in Health, Social, Financial Resources, and Subjective Well-being as Measured by Percentage Gain Scores.....................

LIX Descriptive Statistics for the Change Items in Health, Financial Resources, and Subjective Well-being as Measured by Difference Scores....

LX Descriptive Statistics for the Items Measuring Change in Health, Financial Resources, and Subjective Well-being as Measured by Residual

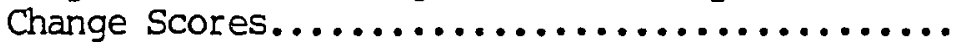

LXI Descriptive Statistics for the Items Measuring Change in Health, Financial Resources, and Subjective Well-being as Measured by Percentage

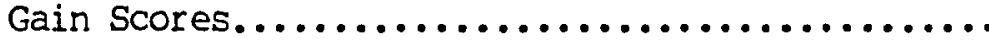

LXII Means, Standard Deviations, and Intercorrelations Among Subjective Well-being, Health, Social, Financial Resources for 1969, 1971, 1973........

LXIII Means, Standard Deviations, and Intercorrelations Among Subjective Well-being, Health, and Financial Items for 1969, 1971, and 1973........

LXIV Multiple Linear Regression for Predicting Subjective Well-being from Change in Health, Social, and Financial Resources as Measured by Difference Scores.

LXV Means, Standard Deviations, and Intercorrelations Among Subjective Well-being and Change in Health, Social, and Financial Resources as Measured by Difference Scores................

LXVI Multiple Linear Regression for Predicting Subjective Well-being from Change in Health, Social, and Financial Resources as Measured by Residual Change Scores....................

LXVII Means, Standard Deviations, and Intercorrelations Among Subjective Well-being and Change in Health, Social, and Financial Resources as Measured by Residual Change Scores.................... 
LXVIII Multiple Linear Regression for Predicting Subjective Well-being from Change in Health, Social, and Financial Resources as Measured by

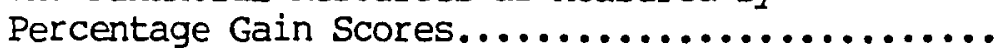

LXIX Means, Standard Deviations, and Intercorrelations Among Subjective Well-being, and Change in Health, Social, and Financial Resources as Measured by Percentage Gain Scores............

LXX Multiple Linear Regression for Predicting Change in Subjective Well-being from Change in Health, Social, and Financial Resources as Measured by Difference Scores.............. 370

LXXI Means, Standard Deviations, and Intercorrelations Among Change in Subjective Well-being, Health, Social, and Financial Resources

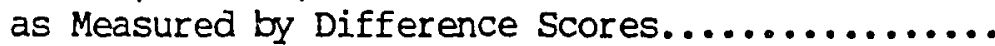

LXXII Multiple Linear Regression for Predicting Change in Subjective Well-being from Change in Health, Social, and Financial Resources as Measured by Residual Change Scores............

LXXIII Means, Standard Deviations, and Intercorrelations Among Change in Subjective Well-being, Health, Social, and Financial Resources as Measured by Residual Change Scores...........

LXXIV Multiple Linear Regression for Predicting Change in Subjective Well-being from Change in Health, Social, and Financial Resources as Measured by Percentage Gain Scores............

LXXV Means, Standard Deviations, and Intercorrelations Among Change in Subjective Well-being Health, Social, and Financial Resources as Measured by Percentage Gain Scores............

LXXVI Multiple Linear Regression for Predicting Subjective well-being from Change in Health and Financial Items as Measured by Difference Scores........... 
$\mathrm{xix}$

LXXVII Means, Standard Deviations, and Intercorrelations Among Subjective Well-being, and Change

in Health, and Financial Items as Measured

by Difference Scores......................

LXXVIII Multiple Linear Regression for Predicting Subjective Well-being from Change in Health and Financial Itens as Measured by Residual Change Scores......

LXXIX Means, Standard Deviations, and Intercorrelations Among Subjective Well-being, and Change in Health, and Financial Items as Measured by Residual Change Scores.............

LXXX Multiple Linear Regression for Predicting Subjective Well-being from Change in Health and Financial Items as Measured by Percentage Gain Scores......

LXXXI Means, Standard Deviations, and Intercorrelations Among Subjective Well-being, and Change in Health, and Financial Items as Measured by Percentage Gain Scores..............

LXXXII Multiple Linear Regression for Predicting Change in Subjective Well-being from Change in Health and Financial Items as Measured by Difference Scores..............

LXXXIII Means, Standard Deviations, and Intercorrelations Among Change in Subjective Well-being, Change in Health, and Change in Financial Items as Measured by Difference Scores..............

LXXXIV Multiple Linear Regression for Predicting Change in Subjective Well-being from Change in Health and Financial Items as Measured by Residual Change Scores.

LXXXV Means, Standard Deviations, and Intercorrelations Among Change in Subjective Well-being, Change in Health, and Change in Financial Items as Measured by Residual Change Scores........... 
LXXXVI Multiple Linear Regression for Predicting Change in Subjective Well-being from Change in Health and Financial Items as Measured by Percentage Gain Scores.......... 386

LXXXVII Means, Standard Deviations, and Intercorrelations Among Change in Subjective Well-being, Change in Health, and Change in Financial Items as Measured by Percentage Gain Scores............ 


\section{LIST OF FIGURES}

FIGURE

PAGE

1. Organizational Scheme for the Conduct of the

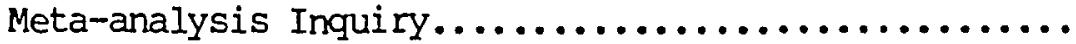

2. Box-and-whisker Plots for the Distributions of the Correlation Coefficients Between Subjective Well-being and the Areas of Health, Social,

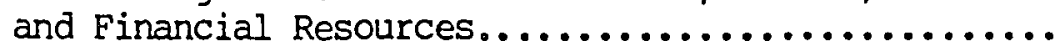

3. Organizational Scheme for the Predictor and Outcome variables........................... 
CHAPTER I

\section{INTRODUCTION}

Overview of the Problem

The link between subjective well-being and the areas of health, social, and financial resources is the central theme of a large body of gerontological literature. Less explored, however, is the relationship between changes in subjective well-being and changes in the areas of health, social, and financial resources. Factors which have served as a deterrent to the exploration of change are twofold. On the one hand, research efforts in gerontology are relatively recent and longitudinal studies are comparatively more costly and more difficult to carry out than cross-sectional ones. On the other hand, the measurement of change is not a straightforward activity because little is known about the relative merits and drawbacks of the different approaches to the measurement of change.

The focus of this dissertation is the measurement of intra-individual change in well-beiag in a sample of randomly selected older persons who were, for the most part, pre-retirees at the time of the first wave of data collection. The outcome measure chosen for this study is 
an item which assesses subjective well-being. The predictor variables were selected from within three areas: health, social, and financial resources. Two major objectives guided the conduct of this study:

1. to use meta-analysis procedures to synthesize research results regarding health, social, and financial correlates of subjective well-being; and

2. to determine if three different approaches to the measurement of change yield different results when the relationship between subjective well-being and the areas of health, social, and financial resources is analyzed for a sample of 8922 respondents who participated in the 1969 , 1971, and 1973 waves of data collection. In the present study, these respondents are referred to as continuers.

The aging theories to be reviewed in the next section were purposely selected on the basis of their common focus on the developmental aspects of aging and adjustment in old age.

Theories in Gerontology

Compared to research in other disciplines, research in gerontology is a comparatively recent phenomenon. Two of the oldest journals in the field, The Gerontologist and the Journal of Gerontology, have been in existence for only 21 and 36 years respectively. However, this field of inquiry has grown at an exponential rate in the last few decades. Many factors could be cited to account for the 
recent growth in aging research. One major factor is the increasing number and proportion of elderly persons in the population which is due, in part, to increased longevity. As a greater number of social scientists are turning their attention to the study of aging, theories are being formulated and tested and a plethora of research findings are accumulating.

One of the most controversial theories in gerontology is that of disengagement. Cumming and Henry (1961) postulated that the aging process is characterized by:

"an inevitable withdrawal or disengagement resulting in decreased interaction between the aging persons and others in the social system he belongs to" (p. 84).

Maladjustment will result, according to the authors, if there is a lack of readiness on the part of the older person to disengage when societal demands require him or her to do so. The basic premise of the inevitability of the process of disengagement, and its corollary of maladjustment if the process is disrupted, gave rise to a substantial debate among gerontologists. In reaction to the disengagement theory, some researchers formulated what has been labeled the activity theory of aging.

Activity theory claims that continued involvement in activities is a prerequisite for psychological well-being in old age (Havighurst, Munnichs, Neugarten, \& Thomae, 1969; Palmore, 1970). The major axiom of this theory is that adjustment, high morale, and/or happiness in old age 
are contingent upon continued engagement. Compensatory activities are needed to fill the void created by cumulative role losses which occur in old age. Activities form the basis for an older person's maintenance of his/her self-concept. Some endorsers of this theoretical perspective advocate organized recreational activities for older persons. Critics of this theory were quick to point out that the nature of the activities may be a contributing factor to successful or unsuccessful aging. They also argued that this theory ignores personality factors, as does disengagement theory.

Continuity theory is yet another theoretical perspective which has guided the inquiry into the developmental process of aging. According to this particular viewpoint, adjustment in old age is dependent on the extent to which an older person is able to maintain the Iifestyle he/she had during the middle years (Maddox, 1968; Williams \& Wirths, 1965).

Researchers in gerontology who endorse a more dynamic view in their interpretation of the aging process have underscored the importance of the interplay of biological, social, and personal changes with personality factors. The developmental approach posits that adjustment to old age is an individualistic process which is dependent on the interface between the personal, social, and environmental changes that accompany old age and an individual's coping 
style or personality (Havighurst, Neugarten, \& Tobin, 1968).

In sum, this review of some of the most current theories in gerontology shows the importance that aging theories have placed on "adjustment" in old age, and the implied emphasis placed on "changes" which accompany old age. The next section discusses briefly the correlates of adjustment or subjective well-being.

Correlates of Subjective Wel l-being

Not surprisingly, because of the emphasis of aging theories on adjustment in old age, numerous research findings deal with the correlates of subjective well-being. The term subjective well-being was chosen here since its general meaning allows for the inclusion of a wide array of indicators of happiness, morale, life satisfaction, and adjustment. Such indicators have one common characteristic; in general, they are based on self-report.

The correlates of subjective well-being which have been repeatedly cited as important are measures of health, social, and financial resources. Larson's (1978) synthesis of the gerontological literature on subjective well-being gives an overview of some of the findings on the relationship between subjective well-being and its correlates. George and Bearon (1980), in an attempt to disentangle the different components of subjective wellbeing, review an impressive number of studies which have 
focused on subjective well-being, health, and financial resources.

The Measurement of Change

As was pointed out previously, current theories in gerontology imply that the process of aging is accompanied by change. Repeatedly, gerontologists have stated that the onset of old age is accompanied by changes in health, changes in social resources such as role losses and losses of social support, and changes in financial and environmental resources. Statements regarding changes in the gerontological literature have been for the most part based on cross-sectional studies which have focused on inter-individual differences. There are numerous ways to assess change. The three approaches which were selected for this study are difference scores, residual change scores, and percentage gain scores. They were chosen based on their particular relevance to the measurement of change in terms of the various aspects of aging.

The controversy surrounding the measurement of change in longitudinal data is primarily centered on two approaches to the evaluation of change or their derivatives, the use of difference scores or raw gain scores and the use of residual change scores or base free measures of change.

Cronbach and Furby (1970) argue that difference scores are "systematically related to any random error of 
measurement" (p. 68). They emphasize the negative psychometric properties of difference scores, including low reliability and negative correlation with time 1 scores, and argue that these factors may lead an investigator to draw faulty conclusions. They recommend the rephrasing of research questions to avoid the problems associated with measuring change or the use of residual change scores which are "primarily a way of singling out individuals who changed more (or less) than expected" (p. 74).

Linn and slinde (1977) illustrate that the reliability of difference scores decreases as the reliability of the two measures decreases and as the stability coefficient between them increases. Thus, the reliability of difference scores decreases as the reliability of the measures used to compute them decreases. Further, as the correlational stability between the two measures increases, the difference scores become increasingly unreliable. An extension of their table is reproduced in Chapter III.

It is not until the 1980's that Rogosa, Brandt, and Zimowski (1982) argued that a difference score "is a natural measure of individual change" (p. 730). They argue that "both statistical and psychometric properties of measures of change are important" (p. 726). They recognize the limitations of difference scores in terms of their psychometric properties but state that these limitations 
are particularly evident with data from two waves only. They argue that:

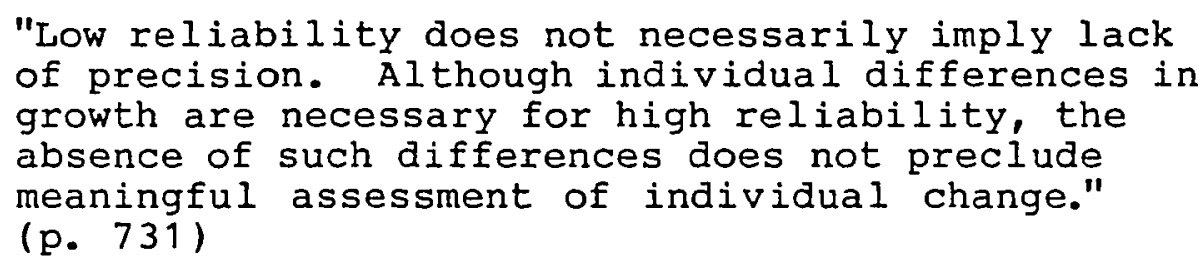

Their individual growth curves illustrate how difference scores can provide a meaningful estimate of intra-individual change. They point out that a large stability coefficient between two measurement points does not confirm that the measures are assessing the same construct on both occasions or that the measures are factorially invariant. They also caution against residual change scores when outliers are present because "atypical data points appear typical (small residuals) and at the same time may yield large residuals for nonoutliers" (p. 739).

Hummel-Rossi and Weinberger (1975) offer some numerical examples which illustrate the use of difference scores and residual change scores in the measurement of intra-individual change when the focus of the research question is varied. No study could be found which compares the results of an analysis when difference scores and residual change scores are employed. The present study is an empirical investigation of the equivalence of three selected approaches to the measurement of longitudinal 
change: difference scores, residual change scores, and percentage gain scores.

The following research questions guided the conduct of the present study:

1. What is the magnitude of the relationship between subjective well-being and the areas of health resources, social resources, and financial resources for the Longitudinal Retirement History study (LRHS) sample? Do these values fall within the range found in the aging literature?

2. Is there evidence which supports the construct validity of change scores? More specifically, do the three selected ways of measuring change in the four areas of health, social, financial resources, and subjective wellbeing result in similar or different orderings of individuals along the continuum of change? Furthermore, do the three selected approaches to the measurement of change produce similar results when hypotheses are tested using univariate statistical procedures?

3. Does change on selected health, social, and financial measures explain a significant amount of variance in subjective well-being and in change in subjective wellbeing? How does this amount of variance compare to that explained by one-point-in-time measures?

4. Do the different ways of measuring change produce significantly different results when the relationship of 
subjective well-being with health, social, and financial resources is analyzed using multiple regression procedures?

5. Is self-perceived change a useful indicator of change and what is its relationship to the three selected approaches to the measurement of change in longitudinal data?

\section{Urban Relevance}

It is common knowledge that the proportion of older persons is steadily increasing. Shortly after the turn of the 21 st century, the baby boom generation will be entering old age. Medical sophistication and improved environmental conditions have contributed to the increase in the average Iife expectancy and are expected to continue to do so. Not all elderly persons are frail and in need of services but for those who need help, early identification of such a need may contribute to their quality of life. If changes in personal and situational conditions are symptomatic of vulnerability, the identification of changes in one or more resource areas may lead to the early detection of needs. Moreover, a reliable and valid way to assess change may help service delivery personnel to set priorities in the delivery of services.

The first objective of this dissertation is to use meta-analysis procedures to summarize the existing literature regarding the correlates of subjective wellbeing. Chapter II contains an overview of the measurement 
of the constructs chosen for this study and the results of the meta-analysis. The use of meta-analysis in the synthesis of the literature is warranted because of the large number of studies which were found on the relationship between subjective well-being and the three selected resource areas. Chapters III through V address the second objective, that of contrasting three methods of measuring intra-individual change. Chapter III describes the research questions, the sample, the operationalization of the dependent and independent variables, the approaches which were chosen for the analysis of change and the statistical analyses which were performed on the data. Chapter IV presents the results and discussion regarding the five research questions for the study. Chapter $V$ contains the conclusions based on the findings of the study and suggestions for future research. 
CHAPTER II

\section{META-ANALYSIS}

The current gerontological literature contains a large number of studies which explore the relationship between subjective well-being and the areas of health resources, social resources, and financial resources. The research synthesis carried out for the present study used meta-analysis procedures to summarize the relevant findings. Meta-analysis is a technique which yields a quantitative synthesis of research studies pertaining to a single area of inquiry. Its purpose is to integrate research findings using statistical analysis to do so.

\section{The Technique}

The conduct of a meta-analysis study is strikingly similar to that of survey research. After the formulation of a research question and the operationalization of the dependent and independent variables, the literature is searched and a pool of studies, which appear to be relevant, is created. The chosen studies are first reviewed, then discarded or retained, based on a set of predetermined selection criteria. Therefore, the final pool is composed of studies which include the dependent and 
the independent variables of interest and which contain statistical information on the findings. This statistical information is either comparable across studies or can be transformed into a statistic which is comparable to that of other studies to be synthesized. Each finding in a study, then, becomes a case or observation. Its value is transformed into a common metric such as an effect size d or a correlation coefficient $\underline{r}$. After the required transformations, the effect sizes are analyzed. Finally, some conclusions are drawn.

There is a variety of approaches to the quantification and analysis of research findings. Three common methods are: the voting method, the combination of probability levels, and the calculation of an average effect size. The voting method of synthesis is primarily concerned with the sorting of research findings into statistically significant (in the positive or negative direction) or non-significant results. A chi-square value is calculated to establish whether or not the observed frequency differs markedly from what is expected by chance. The categorization into significant and non-significant results can be crosstabulated with some other characteristics of the studies. The voting method does not give information on the magnitude of the effect. Furthermore, because the significance level of a finding is tied to the sample size, two studies with an identical effect size (for example, a correlation coefficient of the 
same magnitude) could be tallied into different groups (i.e., one statistically significant, the other not significant) if their respective sample sizes were markedly different.

Several methods have been employed to combine probability levels across studies in order to synthesize a research area (Rosenthal, 1984). As in the voting method of synthesis, the combination of probability leaves unanswered the question of the magnitude of the effect. Rosenthal (1984) advocates its use in conjunction with that of the calculation of an effect size.

Compared to the voting method or to the probability synthesis method, the calculation of an effect size has been advocated as a more powerful and complete way to summarize research findings (Glass, McGaw, \& Smith 1981). The calculation of an effect size in the form of a standardized difference score $\underline{\text { d }}$ is possible when the studies to be summarized compare means between experimental and control groups or among experimental treatment groups in studies with an experimental or quasi-experimental design. Studies of a correlational nature can also be synthesized. The averaging of correlation coefficients gives an estimate of the magnitude and direction of the relationship between two variables.

The appeal of meta-analysis resides in its potential for scientific parsimony, lack of bias, scientific rigor, 
and precision. Its approach to the integration of research studies and to the condensing of scientific information should lead to a deeper understanding of the phenomenon under study and to the identification of gaps in the research domain under scrutiny. The results of a metaanalysis can point to the stability and consistency of research findings which may not be easily detected by the traditional review of the literature. This traditional approach is often referred to as the narrative approach to the synthesis of research findings.

Cooper and Rosenthal (1980) tested the proposition that literature findings may be more consistent than is superficially apparent. The authors chose seven studies on the relationship between gender and persistence. They gave these studies to review to two groups of subjects. One group was instructed to summarize the findings as they would for a journal article. The other group was instructed on how to summarize research results in a metaanalytic way. The authors found that 738 of the subjects in the narrative group as compared to $31 \%$ of those in the meta-analysis group reported no relationship between gender and persistence. Asked to evaluate the magnitude of the relationship, 738 of the subjects in the narrative group as compared to 428 of those in the meta-analysis group labeled the relationship between gender and persistence as very small to non-existent. 
Narrative reviews may enhance, then, the likelihood of retaining information and of reaching conclusions about past research which match one's assumptions or beliefs, not to say prejudices. This may occur because past research contains too much information for the human brain to synthesize without some form of aid. At a minimum, some reviewers may be more enthusiastic advocates of a position than is warranted. Additionally, meta-analysis, because it synthesizes information from a number of research studies on a topic, offers more information than one study, even if the latter has a very large sample size. No single study can give an estimate of the variability of research findings nor can it help in the synthesis of what is already known. Finally, a meta-analysis can help in the identification of methodological factors which may have systematically influenced research findings. With the widespread use of multivariate techniques, design characteristics, reliability, and validity estimates of individual studies can be incorporated into the conduct of a meta-analysis.

The major assumption in a meta-analysis is that the chosen studies are a replication of each other, differing among themselves only in sample size and/or in response format. Each finding is assumed to be an independent observation of the phenomenon under study. Each calculated statistic in a study is a value which belongs to the sampling distribution of that statistic. Instruments are 
assumed to be equivalent in their adequacy to measure the constructs and the relationship under study. In an area of inquiry where tests are standardized and where knowledge of the methodological properties of the instruments have been studied in depth, such assumptions are not unreasonable. However, in areas where such knowledge is scarce, these assumptions are more difficult to make. In summary, the assumption underlying this technique is that findings to be used in the meta-analysis are randomly selected from the same population of findings and that they contain comparable data which can be quantitatively combined.

In the conduct of a meta-analysis inquiry, it is assumed that the universe of studies relevant to the inquiry can be determined and that bias in the selection of studies to be reviewed is at a minimum. How representative are the studies chosen to be included in the analysis? It is often a very difficult question to answer. Reviews which incorporate only published studies may conclude that there is a significant relationship more often than is the case in the population. Selective reporting by authors may also compound the problem. Therefore bias due to the inclusion of some findings and the exclusion of others will result when studies are not easily accessible, when the findings that are significant are the only ones reported, when the findings are reported in ways that cannot be quantified, and when information on 
the conduct of the study and/or the operationalization of the variables has been omitted. A last source of exclusion is tied to the lack of adequate information in the reporting of research findings from multivariate procedures. When such reporting is confined to $\underline{b}$ and beta weights, quantitative synthesis is difficult particularly if variables have a different range and/or the number and type of variables entered in the analysis vary across the studies to be summarized. Strube and Hartman (1983) discuss at length the problems of bias in the creation of the pool of studies as well as possible sources of bias in the conduct of a meta-analysis study.

Glass et al. (1981) cite four major types of criticism levied against the meta-analysis approach to the synthesis of research findings. Some critics state that the meta-analysis approach "mixes apples and oranges" (p. 218). Studies which vary in their instrumentation, in design and sample characteristics, are combined in the quantitative summary. Some critics are bothered by the inclusion of all studies in the analysis, regardless of their quality or worthiness. The bias in published studies toward significant findings has also been cited as a major drawback in the application of meta-analysis procedures. Published studies may on the average tend to reject the null hypothesis more often than is warranted given the population value. The last criticism is that of non- 
independence of two or more results drawn from the same study

Glass et ai. (1981) address each criticism. They argue that the first two are not warranted. Identical studies would give identical results beyond differences which are expected due to sampling error. Findings are the unit of analysis and are analogous to respondents in survey research. They are expected to vary among themselves as people are expected to vary. The source of variation is just another question to be answered as part of the metaanalysis inquiry. As to the imperfections of any one study, the authors argue that every study has some weak and strong points. The strengths and imperfections of studies should be coded and analyzed. Studies should not be thrown out of the analysis based on some judgment of quality. On the question of the bias inherent in published research, Glass et al. (1981) agree with the critics. The "file drawer" approach to the problem developed by Rosenthal (1984) may help in the estimation of that bias. The "file drawer" technique gives an estimate of the number of studies with non-significant results needed to invalidate the conclusion made from the meta-analysis based on published studies only. The authors tend to concede on the issue of the non-independence of results drawn from the same study. They suggest redoing the meta-analysis with multiple findings from one study averaged so that only one finding per study is utilized. A single effect size is 
entered into the meta-analysis as the representative of that study and its sample size is the number of subjects who participated in the study.

A number of decisions have to be made as the metaanalysis is carried out. The selection criteria, and/or the exclusion rules, the decision to include all relevant findings from one study or the choice to include only one finding per study in the analysis to maximize independence of research results will create a lesser or a greater amount of distortion tied to the other methodological properties of the studies under investigation and to the degree of care in the conduct of the meta-analysis itself. The lack of consistency in the coding of research findings and study characteristics, both conceptual and methodological, may pose a threat to the reliability and the validity of the meta-analysis itself. A decision to make statistical corrections is likely to affect the final outcome. Hunter, Schmidt, and Jackson (1982) argue that variability among effect sizes is very often the result of sampling error. They advocate that the variance of effect sizes be corrected for such sampling error, and that the measures be adjusted for restriction of range and/or reliability. They offer formulas to do the corrections they endorse. They offer no solutions for coding or reporting errors. Such errors may be spotted in the frequency distribution of the effect size. It is only 
after all possible corrections have been made, that they recommend the search for moderator variables as an explanation for the variability among study findings. A moderator variable is a conceptual or a methodological factor which mediates the relationship between the variables under study creating heterogeneity among the entire set of effect sizes, in effect then, truly mixing apples and oranges.

In summary, the purpose of a meta-analysis is to give a quantitative summary of research results which answer the same research question. Like any other research endeavor, its value is dependent on its careful execution. By offering mechanisms to probe the relationship between study characteristics and study findings, such an approach not only guides the synthesis of research findings but sheds light on what has been proven giving insights for theory refinement and future research endeavors.

Methods for the Conduct of the Meta-analysis

The purpose of the meta-analysis for this study is primarily descriptive. The summary statistic chosen to measure the magnitude of the effect size is the product moment correlation coefficient. The relationship examined is that between subjective well-being and the areas of health resources, social resources, and financial resources. This section describes the procedures followed in the conduct of the synthesis of the literature. 
Because the findings from cross-sectional studies will be compared to those of the LRHS study, the constructs which were identified as relevant to the metaanalysis were those for which comparable measures were available in the LRHS data set. For the analysis, the area of health resources was subdivided into two sectors: the first group, referred to as health status, encompasses measures of disability, illness, physical health, and clinical assessment; the other group contains measures of self-perceived or global self-assessment of health. The area of social resources was partitioned into three sets, size of social resources, frequency of contact with others, and societal involvement. The area of financial resources was divided into two groups, financial status, and satisfaction with financial status. The organizational scheme of the literature review is summarized in Figure 1. This scheme basically organizes each area along two dimemsions. The first one refers to self-report of a condition or situation that can be observed and the second one taps a more global, evaluative judgment tied to satisfaction. As can be readily noted, the constructs are not evenly distributed across the cells. This unevenness is tied to the necessity of limiting the review to constructs which were measured in the LRHS data set.

The first step in the creation of the pool of articles to be reviewed for the meta-analysis was to 
Construct Areas

\begin{tabular}{|c|c|c|c|c|}
\hline Dimension & Health & Social & Financial & Psychological \\
\hline $\begin{array}{l}\text { report of } \\
\text { a } \\
\text { condition } \\
\text { or } \\
\text { situation } \\
\text { [objective } \\
\text { status] }\end{array}$ & $\begin{array}{l}\text { health } \\
\text { status, } \\
\text { e.g.' } \\
\text { disability, } \\
\text { illness, } \\
\text { clinical } \\
\text { assessment }\end{array}$ & $\begin{array}{l}\text { size, } \\
\text { frequency } \\
\text { of contact, } \\
\text { societal } \\
\text { involvement }\end{array}$ & $\begin{array}{l}\text { financial } \\
\text { status }\end{array}$ & not reviewed \\
\hline $\begin{array}{l}\text { report on } \\
\text { an } \\
\text { affective } \\
\text { state } \\
\text { [subjective } \\
\text { status] }\end{array}$ & $\begin{array}{l}\text { self- } \\
\text { perceived } \\
\text { health }\end{array}$ & $\begin{array}{l}\text { not a } \\
\text { reviewed }\end{array}$ & $\begin{array}{l}\text { satisfaction } \\
\text { with } \\
\text { financial } \\
\text { status }\end{array}$ & happiness \\
\hline
\end{tabular}

Figure 1. Organizational scheme for the conduct of the meta-analysis inquiry.

a

The area was not reviewed because no comparable measure of this construct area was available in the LRHS data. 
compile a list of all the articles having a reference in their title to happiness, life satisfaction, morale, or psychological well-being. In order to do so, a library computer search was commissioned. The search was concentrated in the gerontological literature. Books and unpublished documents were excluded from the pool at the onset.

To complement the computer search, the most wellknown gerontology periodicals were manually reviewed and titles of articles which appeared to be relevant were compiled. The gerontological periodicals surveyed are the Journal of Gerontology from 1946 to the fall of 1984 , the Gerontologist from 1961 to the fall of 1984, Research on Aging from 1979 to the fall of 1984 and the International Journal of Aging and Human Development from 1970 to the fall of 1984. The major publications in the field of gerontology, then, were scanned from the time of their initial publication year.

As the review of each article progressed, the reference 1 ist was inspected and any referenced article not discovered through the computer search or the manual review of the periodicals was added to the pool to be reviewed at a future time period. The articles which constituted the original pool were located by a combination of methods: use of keywords, computer searches, and snowball techniques. The bias associated with a review limited to published studies has been discussed in the previous section. 
Prior to any averaging of research findings, the articles were reviewed and a summary statement was written for each article. This written summary contains information on the author(s) and date of the study, the sample, the sampling techniques, the measurement of the independent and the dependent variables and the magnitude of the effect. The studies were sorted into two sets, those for which data were analyzed with a univariate procedure and those analyzed via a multivariate approach. The summary statement for each study has been included in Appendix A for the studies of a univariate nature and in Appendix $B$ for the studies for which a multivariate procedure was chosen. Both Appendix $A$ and $B$ are organized along the dimensions reported in Figure 1.

Prior to the averaging of research findings within a subset, for example self-perceived health, statistics not reported in the common metric, that of the product moment correlation coefficient, were transformed according to guidelines provided in Glass et al. (1981) and Rosenthal (1984). For example, a phi coefficient can be derived from a chi-square value for a 2 by 2 table. The formula for such a transformation is:

$$
\varphi=\sqrt{\frac{X^{2}}{N}}
$$


For a crosstabulation with more than four cells, the procedure to calculate a correlation coefficient outlined by Walker and Lev (1953) was followed (pp. 278-281).

The correction procedures for restriction of range and reliability advocated by Hunter et al. (1982) were not performed on these data. They require information which, in many instances, is not included in the journal articles which were reviewed. Furthermore, the extreme variability among the studies in terms of instrument selection would have made the task virtually endless.

As a final step, the correlation coefficients were transformed into their Fisher's $z$ equivalent and weighted by their respective sample size minus 3. This transformation prior to averaging is discussed in Downie and Heath (1970). The variability among the correlation coefficients was adjusted for sampling error. The formulas presented in Hunter et al. (1982, pp. 40-45) do not weight the sampling error estimate by the sample size. Paulson (1985) suggested the formulas presented below to estimate true and error variance. These formulas are similar to those presentedin Hunter et al. (1982), but take into account the sample size of individual studies. The formula to estimate the variance of the correlation coefficients is:

$$
\hat{\sigma}_{\zeta}^{2}=\frac{V-(J-1)}{N-3 J-\frac{\sum\left(n_{j}-3\right)^{2}}{N-3 J}}
$$


$\mathrm{n}$ is the sample size for a study;

$N$ is the total number of subjects across all the studies; and

$\mathrm{V}$ is calculated:

$$
V=\sum_{j}\left(n_{j}-3\right) Z_{j}^{2}-(N-3 J) U^{2}
$$

where $U$ is equal to the weighted average correlation coefficient in its Fisher $\mathrm{z}$ form and $\mathrm{z}$ is the Fisher's $\mathrm{z}$ equivalent of each correlation coefficient. The amount of variance after correcting for sampling error is:

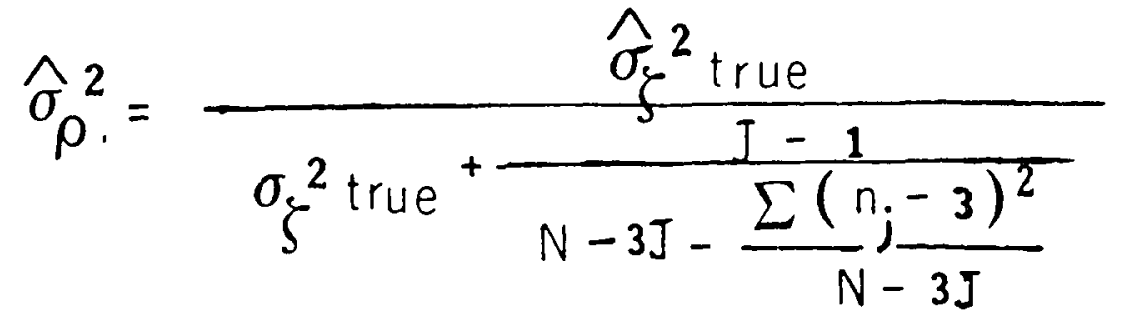

Although Hunter et al. (1982) discuss the role of sampling error, they do not give numeric guidelines for what constitutes homogeneity of findings in terms of the ratio of error to total variance. For the present study, a ratio of 608 or more was selected as the cutoff point.

\section{Rules Fol lowed in the Conduct of the Meta-analysis}

Some specific rules were followed in the conduct of the meta-analysis. The inclusion and exclusion criteria are given first, followed by a description of the rules which were followed in the handing of the effect sizes. 
The first and most important inclusion rule is that studies had to contain information on the relationship between psychological well-being and at least one of the three areas, health, social, and/or financial resources. Studies which contained in their title a reference to subjective well-being but which were not easily accessible or which could not be found were not included. Studies which were investigating the validity of measures were not included in the analysis unless they contained information relevant to the present synthesis. Studies which did not provide enough information on how the constructs were measured could not be classified under a construct and therefore had to be omitted. No effort was made to contact authors of studies to obtain additional information. Studies with indexes measuring a multidimensional construct were not included because they could not be classified. Studies which contained statistical information which could not be converted into the chosen metric, that of the product moment correlation coefficient, had to be rejected. For the studies which relied on multivariate procedures, only those using multiple linear regression are listed in Appendix B. As mentioned earlier, there is no available method of synthesis for studies which report standardized and/or unstandardized regression weights exclusively. For the present analysis, the range of values these weights have taken is presented. 
In order to be included in the synthesis, the studies had to have been conducted on a sample of elderly persons. Because of cases where disability resulted in premature aging or in an elderly-like status, some studies with middle age respondents were retained. For example, the Brown, Perman, and Dobbs' study (1981) of pacemaker recipients was included in the synthesis of health and subjective well-being although the sample is composed of respondents 45 and older. No other inclusion or exclusion rule was applied as it relates to sample characteristics.

Longitudinal studies were excluded unless information of a cross-sectional nature was reported. Information of a correlational nature within a wave of data was therefore included whenever it was provided.

Table I lists the reasons for inclusion and exclusion for the articles which were initially included in the original pool, prior to any review.

The principles which guided the averaging of the effect sizes are described below. All relevant findings from a study were included in the analysis. No studies were eliminated based on quality following the approach advocated by Glass et al. (1981). When more than one variable was employed to measure a construct and findings were reported for each variable, each finding was considered an independent observation. It is plausible, then, that for the same sample, a number of correlation coefficients were reported within an area and across areas. 
TABLE I

INCLUSION AND EXCLUSION STATUS OF ALL THE ARTICLES WHICH WERE ORIGINALLY IDENTIFIED AS RELEVANT TO THE META-ANALYSIS

\begin{tabular}{|c|c|c|}
\hline Status & Number & 8 \\
\hline $\begin{array}{l}\text { Article could not be found or was not } \\
\text { available }\end{array}$ & 7 & 2.7 \\
\hline $\begin{array}{l}\text { Sample was not exclusively composed of } \\
\text { older persons }\end{array}$ & 21 & 8.1 \\
\hline $\begin{array}{l}\text { Not enough information was provided on } \\
\text { the variables or the analysis was not } \\
\text { relevant }\end{array}$ & 71 & 27.4 \\
\hline Article on construct validity only & 25 & 9.7 \\
\hline Multidimensional construct & 2 & 0.8 \\
\hline $\begin{array}{l}\text { Statistic could not be converted into } \\
\text { the common metric }\end{array}$ & 36 & 13.9 \\
\hline $\begin{array}{l}\text { Article contains results identical to } \\
\text { those presented in another article }\end{array}$ & 8 & 3.0 \\
\hline \multirow{2}{*}{$\begin{array}{l}\text { Article was included in the meta- } \\
\text { analysis }\end{array}$} & 89 & 34.4 \\
\hline & 259 & 100.0 \\
\hline
\end{tabular}


It is also possible that some effect sizes are based on the same sample. However, effect sizes which could be identified as redundant information were eliminated from the analysis.

studies not only contain information on the relationship between variables; they also often contain information on subgroups. Whenever the statistic in a study was given for the entire sample as well as for the subgroups, the value reported for the entire sample was used. When the only information reported was on the subgroups, such information was used and was weighted by the subgroup sample size. The non-overlapping nature of the subgroup makes these values independent. However, the restriction of range and sampling error associated with the statistic of a subgroup may have created some distortion in the value of the correlation coefficient.

Table II lists the number of articles included in the analysis for each construct with the number of values which were extracted from these studies. As can readily be observed, the number of values is always larger than the number of articles and the ratio can go as high as 3 to 1. The total number of articles exceeds 89 , the number of articles included in the final pool, because an article may contain information on more than one area.

The lack of statistical independence may be a threat to the validity of the findings from the meta-analysis. Hunter et al. (1982) have discussed at length the problem 
TABLE II

NUMBER OF ARTICLES AND

NUMBER OF EFFECT SIZES FOR EACH RESOURCE AREA

\begin{tabular}{lcc}
\hline Area & $\begin{array}{c}\text { Number } \\
\text { of articles }\end{array}$ & $\begin{array}{c}\text { Number of } \\
\text { effect sizes }\end{array}$ \\
\hline Health Resources & 23 & 35 \\
Health status & 49 & 72 \\
Self-perceived health & & 31 \\
Social Resources & 12 & 57 \\
Size & 31 & \\
Frequency of contact & 37 & 31 \\
Societal involvement & & 25 \\
Financial Resources & 23 & \\
Income & 13 & 350 \\
Satisfaction with & & \\
financial situation & 188 & \\
\cline { 2 - 2 } & &
\end{tabular}


of statistical independence because their primary focus in the conduct of a meta-analysis is that of estimating a population value. They concluded that the inclusion of more than one finding per study may not create a big distortion if the synthesis is based on a relatively large number of studies and if there are relatively few values contributed by any one study. No guidelines related to ratios were given by the authors.

Results of the Meta-analysis

One of the main purposes of the meta-analysis is to estimate the magnitude of the relationship between subjective well-being and the areas of health resources, social resources, and financial resources. Such estimates are to be compared with the values obtained from the analysis of the LRHS data. The findings from the metaanalysis, thus, establish some boundaries within which the calculated statistics from the LRHS data are expected to fall, and provide normative values for comparisons. The remainder of this chapter describes each construct and states the findings of the 7 meta-analyses. For each section, the measurement of the constructs within an area is discussed and some empirical evidence of content and construct validity is presented. This evidence is drawn from past research findings on how measures within an area are interrelated. This account is followed by the description of the results of the meta-analysis for that 
area. The summary of the multivariate studies is then given. The final section discusses the limitations of the meta-analysis and suggests some avenues of inquiry.

The Measurement of Subjective Well-being

Subjective well-being has been used extensively as a criterion since the early 1950's by gerontologists. This author found references to 259 studies on the topic, an average of over 8 articles per year over a 30-year period! Subjective well-being is the rubric under which different measures of life satisfaction, morale, and happiness have been assembled for the meta-analysis.

The construct of subjective well-being refers to a global statement about one's life situation and experience. This statement is, no doubt, influenced by an individual's psychological make-up as well as by the surrounding physical and social environment he/she experiences. It is difficult to araw conceptual boundaries between life satisfaction, morale, and happiness. They share in common a set of conceptual planes or axes along which they vary. These common components are often not explicitly spelled out in the items chosen to measure these constructs. Some dimensions which these components have in common are: the global perspective or lack of specificity they require in the evaluative process; the time perspective they evoke, which can vary from immediate to long term; the mood and the personal predisposition toward life which they inadvertently draw out of the respondent. Measures of 
subjective well-being also imply some degree of comparison, to others, to one's past, or to what is perceived as an ideal state. The basis for comparison is again not always spelled out and left free to vary across respondents in a number of instruments which assess subjective well-being.

Authors have struggled with definitions which discriminate between these concepts (Wilson, 1967; George, 1979). The definitions accentuate the distinctions among these constructs on the dimensions or axes just referred to. Measures of life satisfaction assess present enjoyment of life as well as a sense of contentment with past accomplishments and a sense of optimism about the future. Such measures may force the older respondent into a set of comparisons with others or may set in motion a life review process. Instruments measuring morale, in constrast, put an emphasis on existential outlook on life, enthusiasm, optimism, and an individual's approach to daily living. Happiness items have a more immediate time frame and assess present mood in a more direct way. Wilson (1967) in a lengthy review of the literature on what he calls avowed happiness advances two postulates:

- "prompt satisfaction of needs causes happiness, while the persistence of unfilled needs causes unhappiness; - the degree of fulfillment required to produce satisfaction depends on adaptation or aspiration level, 
which is influenced by past experience, comparisons with others, personal values, and other factors." (p. 302)

Wilson's definition of happiness is more complex than that of mood tone endorsed by George (1979). It overlaps with the one given for life satisfaction and evokes Maslow's hierarchy of needs. It also stirs another controversy. Positive and negative poles of a domain may be conceptually distinct entities. If this is so, the happiness/unhappiness balance may depend on the meshing of a critical mass of conditions related to an individual's personal and environmental resources. This approach would help explain how the same event is handled differently across individuals. It also fits with the postulate that it is not a single event but the combination of events, number and types, which creates an affective state.

Domain specific measures are satisfaction statements about specific areas of life, e.g., marriage, family, friends, work, activities, and standard of living. All measures have overlapping components in that they are tainted by the respondent's mood and general outlook on life.

The instruments which were identified, in the metaanalysis, as outcome measures are listed for each study in Appendices $A$ and $B$ under the column heading of measure of well-being. Across studies, the choice of an outcome ranges from the single global item of happiness to the well-known Life Satisfaction Index (LSI) developed by 
Neugarten, Havighurst, and Tobin (1961). The instruments that were incorporated into the studies differ in terms of their measurement properties. They have a different range. Their variability, internal consistency, and reliability are not equivalent. Some measures are unidimensional and some others are multidimensional. Some variability across these measures can be attributed to random error. Another source of variability is true differences among persons caused by differences in individual characteristics and/or life situations. Some other variability may be due to different frames of reference among respondents, to differences in interpretation, in salience of the issue, and in time span considered. George and Bearon (1980) discuss the conceptual and methodological characteristics of the instruments which have been used extensively in gerontology to measure subjective well-being. The next section describes some of the empirical findings in terms of factor structure and correlations among instruments which assess subjective well-being. These studies are reviewed to show evidence of convergence among different instruments and to justify their inclusion as comparable outcome measures in the metaanalysis.

Adams (1969) in a factor analysis of the ISI items, reported three factors or dimensions of life satisfaction which did not perfectly coincide with the hypothesized 
dimensions of the authors. He named the three factors "congruence between desired and achieved goals", "mood tone", and "zest for life". Hoyt and Creech (1983) identify four factors. Items cluster around "contentment with past life", "present state is happy", "future plans", and "boredom and depression".

some researchers have reported correlation coefficients among measures of subjective well-being. Mason (1954) reports correlation coefficients of .39 and greater between measures of happiness and mood tone. Cutler (1976) calculated a correlation coefficient of .29 between an item measuring happiness and a 4-item index measuring satisfaction with 4 areas of life, e.g., a domain specific measure. Lohmann (1977) examined the relationship among seven instruments and three revised versions of some of the instruments to establish communality among them. She found correlation coefficients between .24 and .98 , median value of .64 . The satisfaction item, because of its restriction of range, has the lowest correlation values with other measures. She does not discuss the possibility that these correlations may reflect response set or even practice effect. Larson (1978) lists instruments which assess subjective well-being. He offers some validity statistics to support Lohmann's findings. Correlations among measures taken two at a time range from .55 to .77 with a median value of .57. Stock and okum (1982) calculated 15 non-redundant coefficients for six measures. 
They report correlation coefficients of .04 to .57 with a median value of .33 for a sample of handicapped persons. The same measures have correlations between .08 and .46 , median value of .31 , in a sample of non-handicapped persons. Carp and Carp (1983) report correlations of .36 to .87 among six scales and their revised versions. The median value for these correlations is .57. As expected, the Bradburn Negative Affect Balance scale correlates negatively with other subjective well-being measures. For the present review, the absolute value of the correlation coefficients was presented because the focus is on the degree of overlap among the measures of subjective wellbeing.

Palmore (1968) finds stability coefficients equal to .65 and greater for the Life Satisfaction Index (LSI) across 4 waves of data collection. Again for the LSI, Palmore and Kivett (1977) report a stability coefficient of .56 between 2 waves of data collection.

The studies discussed above give some evidence that measures of subjective well-being have some degree of communality. They assess to a lesser and greater extent, present, past, and future outlooks, as well as temperament and mood.

Health Resources

The importance of health status as a contributing factor to the overall well-being of older persons has been 
stressed repeatedly in the gerontological literature. Most studies incorporate health status in their design as a control or as a predictor variable. In studies where the criterion is life satisfaction or some other measure of subjective well-being, health status often emerges as the strongest and/or the only significant predictor. The crucial importance of health status is also consistently asserted by older respondents themselves.

No shortage of studies exists which assess the relationship between health status and subjective wellbeing. However, prior to the presentation of the findings for the meta-analysis of health status and subjective wellbeing and of self-perceived health and subjective wellbeing, the relationships among different measures of health are reviewed. This review served as a guide for the grouping of health measures into two subsets, health status and self-perceived health.

The majority of indicators (items or indices) used to measure health status can be sorted into two general groupings as shown in Figure 1 presented earlier. The first one, labeled health status, encompasses measures which assess a condition that could be verified. The second group refers to measures which tap an affective or evaluative component as it pertains to health. Health status measures and self-perceived health measures are described below. 
The construct of health status encompasses clinical health indicators, self-reported health indicators, and functional health indicators. The grouping of clinical health indicators refers to measures which are based on a health rating by at least one health professional (doctor, nurse, pharmacist). In general, this rating is based on a physical examination or on a review of medical charts and records. Self-reported health indicators differ from the first grouping in two major ways. The respondent is the primary source of information and the inventory of health conditions to be reported on is that of chronic illnesses, diseases, and/or symptoms, number of sick days or days in hospitals. Functional health indicators are usually based on self-report but could be assessed by a health professional or a trained interviewer. This grouping is composed of measures which assess the extent to which health is a limiting factor in the respondent's ability to carry out self-care tasks (e. g., bathing, getting dressed, etc.) and/or activities of daily living (e. g., going up and down stairs, cleaning, cooking, shopping, using public transportation, etc.).

The second grouping has been named self-perceived health. Measures which belong to this subset tap a global and subjective assessment of health. This construct reflects a respondent's generalization about his/her health and refers to items which ask the respondent to compare his/her health: a) to others of the same age (i.e., 
normative items) and/or b) to a prior time period in the respondent's life providing a measure of retrospective change (i.e.p ipsative items).

George and Bearon (1980) offer a similar taxonomy. They group health measures into 4 categories, subjective health, iliness and symptoms, functional health, and mental health.

No studies could be found which have used measures from all the subcategories. In general, studies which use indicators from more than one grouping relate health status indicators (clinical health, self-reported health, and/or functional health status) to self-perceived indicators. The consistent finding of such studies is that selfperceived or "subjective" health indicators correlate positively with clinical, self-report, and/or functional health indicators. A meta-analysis on the precise magnitude of this relationship was not within the scope of this study. It is, however, needed and would be particularly informative if it included both conceptual and methodological characteristics of the studies used for the synthesis. The next section narratively reviews the relationships among measures of health. It presents some evidence on the communality among the different measures of health status. It also reviews research findings on the relationship between health status measures and selfperceived health. 
Clinical Health Indicators. Suchman, Phillips, and Streib (1958) report significant differences between a variety of self-report health items and the ratings of a physician recoded as favorable and unfavorable health. Based on the crosstabulations presented in the article, some phi coefficients were calculated. The respective correlations between physician's ratings and self-reported health items are: general health rating (.17), health problems (.14), visit a doctor or hospitalized (.36), and confined to bed for 3 days or more (.31). The sample sizes for these coefficients vary from 996 to 1021.

Suchman et al. (1958) also investigated the relationship between a physician's ratings and functional health indicators. From their tables, a phi coefficient of .27 could be calculated between reduced activities and health ratings of favorable and unfavorable by a physician, and a correlation of .34 between inability to work and the same rating by a physician. Lawton and Brody (1969) report correlation coefficients of .62 between a physician's health ratings and an index measuring self-maintenance ability. They also report a correlation of .40 between the health ratings of a physician and an index measuring ability to perform tasks of daily living.

On the relationship of clinical indicators and selfperceived health, Maddox (1962) found a relationship of .22 (as calculated from the chi-square table) between clinical assessment of functional health and self-perceived health 
for a sample of 251 respondents. LaRue, Bank, Jarvik, and Hetland (1979) report a phi coefficient of .41 between a physician's ratings of health and self-perceived health for a sample of 64 respondents.

Self-Perceived Health Indicators. Information on the relationship between self-peceived health and functional health is presented by Rosencranz and Pihlblad (1970). They developed a health index based on self-report, which is a weighted sum of number and degree of severity of illness, length and type of confinement. They grouped the resulting scores into 5 health classes. Subjects in good health (classes I and II) tend to evaluate their health as good and to report no difficulty in the performance of self-care tasks. For the sample of 1700 respondents, a phi coefficient of .53 between the health index and the selfperceived health item was calculated from the crosstabulation table. Bultena and oyler (1971) report a correlation of $.55(n=300)$ between an 22 -item index of self-reported chronic illnesses and self-perceived health status. Tornstam (1975) sorted 25 different symptoms into a number of categories. For his sample of 469 elderly persons, he reports correlations which range from -.48 to -.38 between self-perceived health and self-reported health indicators such as number of aches, number of serious diseases, visible impairment, and general exhaustedness. He also reports a correlation of .49 between self-perceived 
health and mobility. Auerbach, Gordon, Ullman, and Weisel (1977) report that older persons reporting no or a mild degree of disability also tend to rate their health as excellent or good. Blazer and Houpt (1979) report correlation coefficients of .10 between self-perceived health and a respondent's rating of physical impairment, a correlation of .07 between self-perceived health and number of visits to a doctor, and a correlation of .22 between self-perceived health and number of symptoms for a sample of 719 respondents.

Stability over Time. Information on the stability of physicians' health ratings and of respondents' selfperceived health ratings are provided by Maddox and Douglas (1973). They report stability coefficients for 6 waves of data collection over a 15 year period for a sample of 83 respondents. These coefficients range from .40 to .58 , median value .44 , for health ratings of physicians. For the self-perceived health item, the stability coefficients vary from .32 to .65 , median value of .37 . They report within a wave correlation coefficients between physician's ratings and self-perceived health of .31 to .43 , median value of .34.

In summary, studies on the relationship between selfperceived health and functional health status tend to show a stronger relationship than studies which assess the relationship between physicians' ratings and self-perceived health or functional status. It was pointed out by some 
authors (Larson, 1978; George and Bearon, 1980) that there may not be a direct and/or strong relationship between illness and functional capabilities. In other words, a severe illness is not always accompanied by a high degree of disability. Another explanation can be given for these results. Both self-perceived health and functional health status are based on self-report. Although self-perceived health is a global rating of one's health and ratings of one's functional health status are usually based on ability to perform certain tasks, the degree to which response set and desire to be consistent inflate the magnitude of the relationship is not known. Furthermore, it may be that individuals use functional health status to guide their self-rating of their overall or general health status. Finally, physicians' ratings may be anchored in the severity of the illness while respondents' ratings are focused on disability resulting from the illness.

Based on the literature review just summarized and on the taxonomy 11 lustrated in Figure 1, it was concluded that the area of health resources could justifiably be subdivided into 2 areas, health status and self-perceived health. Appendix A contains a description of the studies which were included in the synthesis of the relationship between the area of health resources and subjective wellbeing. Mental health status was not included in the analysis. As mentioned in the selection criteria for the 
meta-analysis, only studies which measured constructs comparable to those used in the LRHS study were included in the synthesis. Measures of central tendency and variability as well as stem-and-leaf plots (Tukey, 1977) and frequency distributions are presented to summarize the findings. Although the calculation of the effect size was performed with the $z$ transformations, the findings are reported in the original metric because correlation coefficients are more easily grasped.

Health status. Twenty-three studies were identified which contain information on the relationship between disability, illness, functional health status and subjective well-being. A summary statement for each study is given in Appendix A. These studies yielded 35 correlation coefficients. The value of these coefficients range from .02 to .51 with a mode of .20 , a median of .22 , and a mean of .22. The variance of these correlation coefficients is .009. The percent of variability due to sampling error (Paulson, 1985) equals.18. For this resource area, only $18 \%$ of the variability among the correlation coefficients can be attributed to sampling error. The size of the samples for the studies included in the synthesis ranges from 27 to 3199 with a median value of 224. The correlation coefficients for these studies are presented in the stem-and-leaf plot format, Table III, and then grouped in a frequency distribution, Table IV. 
TABLE III

STEM-AND-LEAF PLOT OF THE CORRELATION COEFFICIENTS

BETWEEN HEALTH STATUS AND SUBJECTIVE WELL-BEING

\begin{tabular}{|c|c|}
\hline Stem & Leaf \\
\hline .5 & 1 \\
\hline .4 & 01 \\
\hline .3 & $\begin{array}{lllllll}1 & 1 & 2 & 3 & 6 & 7 & 8\end{array}$ \\
\hline .2 & $\begin{array}{llllllllllll}0 & 0 & 0 & 0 & 2 & 2 & 2 & 3 & 3 & 4 & 7 & 9\end{array}$ \\
\hline .1 & 1134455 \\
\hline .0 & $\begin{array}{llllll}2 & 3 & 6 & 7 & 7 & 8\end{array}$ \\
\hline
\end{tabular}

TABLE IV

FREQUENCY DISTRIBUTION OF THE CORRELATION COEFFICIENTS BETWEEN HEALTH STATUS AND SUBJECTIVE WELL-BEING

\begin{tabular}{ccc}
\hline Range & $\mathrm{N}$ & \& \\
.50 to .59 & 1 & 2.9 \\
.40 to .49 & 2 & 5.7 \\
.30 to .39 & 7 & 20.0 \\
.20 to .29 & 12 & 34.3 \\
.10 to .19 & 7 & 20.0 \\
0 to .09 & 6 & 17.1 \\
& & \\
\hline
\end{tabular}


These correlations have a relatively symmetrical distribution with the mode, median, and mean clustering around the values of .20 and .22. The variance, however, even after correction for sampling error, indicates that these correlation coefficients are not homogeneous. The search for moderator variables of a methodological or conceptual nature is warranted here but was not carried out.

Self-perceived Assessmemt of Health. The second construct in the area of health status is that of selfperceived health, a global rating on health. Items included in this group are ipsative items (one's current health compared to one's past health), normative items (one's health compared to others) or items which do not specify the frame of reference. A typical item with an unstated frame of reference is: "How is your health these days? Would you say it is good, fair, or poor?" The normative version of this item is: "How is your health compared to other people your age? Would you say it is better, the same or worse?". The ipsative item asks respondents to compare their health to that of 2 years ago or some prior time period.

Information on the relationship between self-perceived health and subjective well-being was gathered from 49 studies resulting in 72 correlation coefficients. The range of these coefficients is from -.33 to .62 with a mode of .30 , a median of .35 , and a mean of .34. The 
variance is .01 . Twenty-three percent of the variability in the correlation coefficients can be attributed to sampling error. The sample size for these studies ranges from 30 to 3395 with a median value of 182. Table V gives the stem-and-leaf plot for the correlations which were summarized and Table VI displays the frequency distribution of these correlations.

Part of the lack of homogeneity among the correlation coefficients may be due to the outliers in this distribution. They can easily be identified in the stemand-leaf display of these data (See Table V).

In the two meta-analyses for the area of health resources, it was found that although the measures of central tendency are fairly close together in value, the variability among the correlation coefficients cannot be explained away by sampling error. This indicates a need to search for moderator variables which are of a conceptual and/or a methodological nature. For example, at the construct level, it is possible that measures of health status are assessing different constructs. The variability may also be attributed in part to differences among the criterion measures. They may be assessing different dimensions of subjective well-being which, in turn, have their unique pattern of overlap with health resources. The synthesis needs to be redone grouping the studies into a tighter net at the construct level of both the predictor 


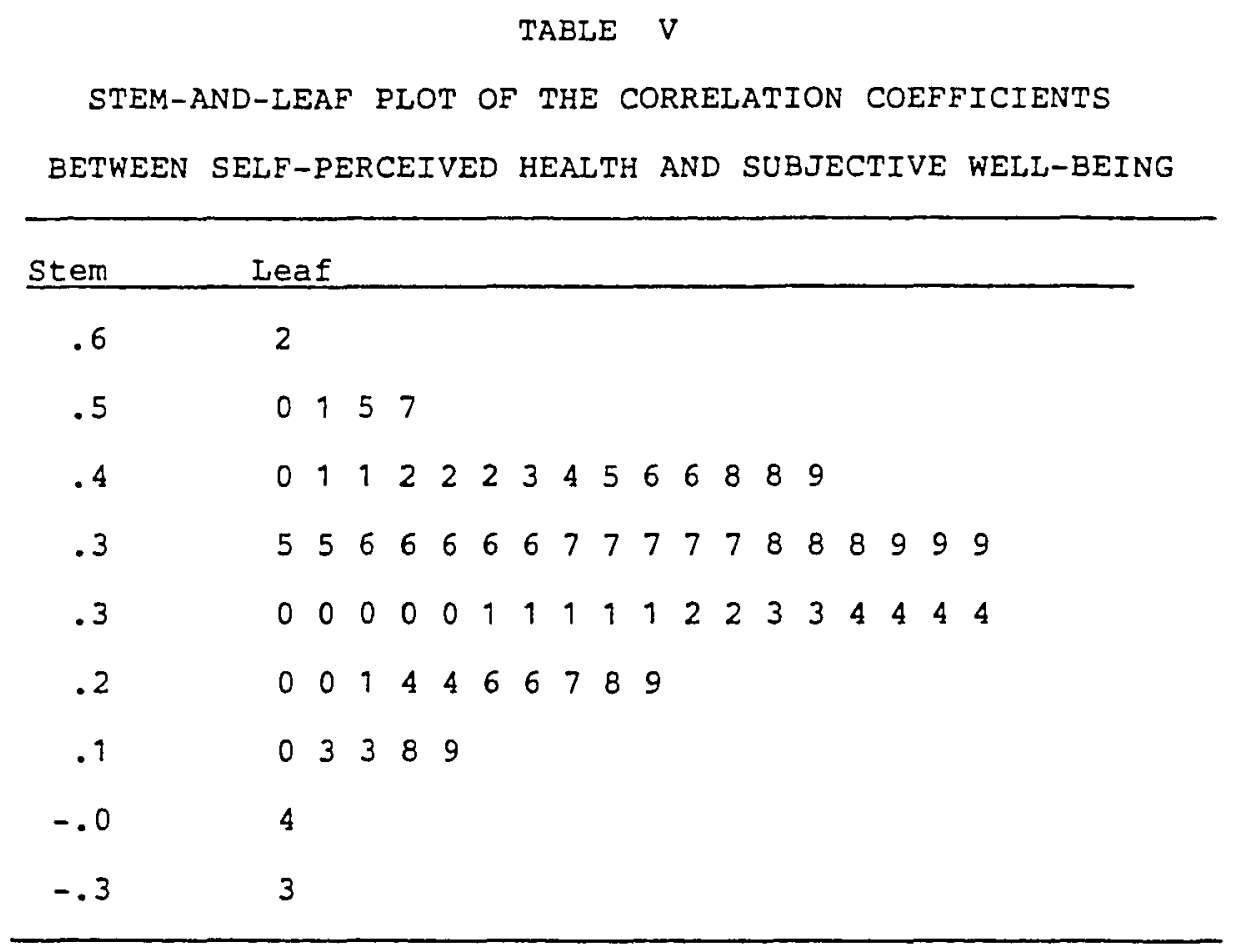

TABLE VI

FREQUENCY DISTRIBUTION OF THE CORRELATION COEFFICIENTS BETWEEN SELF-PERCEIVED HEAITH AND SUBJECTIVE WELL-BEING

\begin{tabular}{lcc} 
Range & $\mathrm{N}$ & 8 \\
.60 to .69 & 1 & 1.4 \\
.50 to .59 & 4 & 5.6 \\
.40 to .49 & 14 & 19.4 \\
.30 to .39 & 36 & 50.0 \\
.20 to .29 & 10 & 13.9 \\
.10 to .19 & 5 & 6.9 \\
.01 to .09 & 0 & 0.0 \\
-.40 to 0 & 2 & 2.8 \\
\hline
\end{tabular}


and criterion variables. A factor analysis approach may be warranted to help in the identification of the components of the domain. At the methodological level, the study characteristics, range of items used in the analysis, reliability of the independent and dependent variables, sample composition should be analyzed within the metaanalytic framework to help in the explanation of heterogeneity of the correlation coefficients.

Larson (1978) estimates the strength of the relationship between health and subjective well-being as ranging from .20 to .40 . Based on the findings from the meta-analysis, the picture is somewhat more complex. The relationship between self-perceived health and subjective well-being is stronger than the relationship of measures of health status to subjective well-being. Moreover, the variability among the correlation coefficients shows that the relationship between measures of health and subjective well-being is not homogeneous. Further analysis to identify conceptual or methodological explanations is warranted. For example, some authors have alluded to the fact that severity of illness is not necessarily linked to severe disability. It may be the case that measures of functional health have a different pattern of overlap with subjective well-being because they are measuring the impact of disability, e.g., change in independence and freedom and change in the composition and function of the network, even changes in financial resources. 
Social Resources

Social resources refers to the composition of an individual's network and to the functions of that network. As gerontologists have become interested in the relationship of social resources to subjective well-being, a number of propositions have been generated. They are summarized below.

The size of the network has been one of the first variables to be linked to subjective well-being. The reasoning behind this approach is that a large network is a potential source of numerous interactions and may not get exhausted during a crisis if a great amount of instrumental and emotional help is needed. Social interactions in themselves are thought to be contributing to subjective well-being for the proponents of activity theory.

To respond to this perspective, Lemon, Bengtson, and Peterson (1972) theorized that it is not so much the number or the frequency of interactions which contribute to wellbeing but the degree of intimacy in the relationship.

If an exchange theory perspective is taken, it could be deduced that a large and diffuse network is costly in terms of time, energy, and emotional resources for the individual. Furthermore, a large network may not get mobilized in times of crisis because the mechanisms for exchange of help and services are not in place. A diffuse and large network may not engender the kind of commitment 
and the sense of obligation that a smaller and closely-knit network may elicit.

The degree of diffusion and the network composition, that is, the types of sectors and the relative density of each sector, are in part a reflection of an individual's lifestyle and life circumstances but also of his/her personality and preferences. Across individuals, the type (sparse or dense), the composition (number of sectors and their density), and function (instrumental help, emotional help, and/or link to formal services) of the network will vary. The stability of its composition and function is also subject to change. There is some evidence presented by Shulman (1975) that the nature of the network varies with stages in the life course.

Within a network, sectors may serve specialized functions. The quality of the interaction, the degree of intimacy, closeness, and trust, the satisfaction with the content of the interaction and exchange, the balance between costs and benefits, and the degree to which expectations are met for emotional and instrumental support, are all factors which will force sectors of the network and members of those sectors into specialized functions. For example, a particular sector (that of family) may provide instrumental help but no emotional help because of non-complementary lifestyles, differences in style of interaction, and/or low degree of intimacy. Following a crisis, some members of that sector could be 
the providers of emotional help because other sectors previously relied upon (e.g., friends) did not fulfill that role and because an external event created the opportunity for them to practice that role. The dynamic quality of the network both in terms of composition and function has not been intensively studied in gerontology. It may be the case that changes in status due to external events reshape the network. This readjustment may have positive or negative consequences. It would then be that during one of the transition phases the network has the potential to become dysfunctional because one or more sectors are not synchronous to others. If this occurred, individual needs would go unmet.

Schulz and Rau (1985) have developed a 2 by 2 classification scheme for events to explain the mediating role of the network on health during a crisis. They classify events on two dimemsions. The first dimension is subdivided into temporally normative or non-normative events and the second dimension is subdivided into statistically normative and non-normative events. Help received following a temporally and statistically normative event (e.g., marriage, widowhood) may have little discernible effect on health due to anticipatory socialization and fulfilled expectations. However, the lack of anticipated support may be detrimental. Individuals who experience statistically non-normative 
events (e.g., widowhood at a young age or rape) may be affected negatively, in regard to health, unless the network acts as a buffer.

studies in gerontology have not investigated in a systematic way the factors associated with social resources. Measures of social resources which have been included in studies are: number of persons in the network, type of relationship in the sectors of the network, distance to members of the network and frequency of interaction with those members (e.g., family, friends, neighbors), type of contact (e.g., in person, by phone, or by letter), who is the initiator of the interaction, presence and number of confidants, number of social roles, number of memberships and involvement in organizations, voting behavior, participation in social and religious activities, and satisfaction with members of the network. Larson (1978) estimates the relationship between informal and formal activities and subjective well-being to be between .10 and .30. Okum, stock, Haring, and witter (1984), in a meta-analysis on the relationship between subjective well-being and social activity, report a mean and a median correlation of .15 , a mode of .12 , and a range of -.42 to .55. They include in their analysis samples of all ages. Their results are based on 107 studies from which they extracted 506 effect sizes.

Chappell (1983) provides information on the relationship among measures of social resources. He finds 
a correlation of .23 between number of close friends and number of neighbors. The relationship of peer interaction in indoor activities and in outdoor type activities with satisfaction has a relatively low degree of association ( $x$ $=.13$ and $r=.14$ respectively). Satisfaction is correlated at the .12 level both with involvement in church related activities and with involvement in politically related activities.

In summary, very little is known about the relationship between type and function of the network and subjective well-being. It is not clear if all the possible patterns which could be generated based on some of the dimensions which were discussed above exist. For example, a network with 3 sectors (family, friends, and neighbors) may be classified in terms of low, medium, or high density. These two dimensions, type of sectors and density, need to be paired with function, (e.g., instrumental, emotional, or linkage-type) which in turn can be categorized as low, medium, or high. Furthermore, it is not known if a relatively dynamic network is more adaptive or if it is more costly and less reliable than more anchored or stable one. The role of different sectors, whether they serve specialized functions or not and the extent to which they are interchangeable is not clear. Finally the type of external event and the level of expectations about the 
proper role of one's network may be related to subjective well-being.

The area of social resources was subdivided into three sections, size of social resources, frequency of contact with others, and societal involvement. As mentioned previously, this grouping is dictated by the content of the items in the LRHS data on this area. However, for this resource area, there is no identical index in the LRHS data which could be constructed to measure frequency of contact across 1969, 1971, and 1973, the three waves of data which are analyzed in the second part of this study. The metaanalysis on the relationship between frequency of contact and subjective well-being was performed because it is a frequently measured aimension of the network in gerontological studies.

Size. The size of social resources refers to the number of persons in the network. This construct has been measured in a number of ways but most often refers to the number of family members, friends, and neighbors the respondent perceives as members of his/her network. The construct can refer to the size of a particular sector in the network, for example, number of friends or number of confidants.

Twelve studies were found which studied the relationship between size of social network and subjective well-being. These studies produced 31 correlation coefficients with a mode of .01 , a median of .05 and a 
mean of .07. The variance of these correlations is .006. The percent of variance which can be attributed to sampling error is 418. Although the variance due to sampling error does not reach the 608 cutoff point chosen at the onset of this study, the variance due to sampling error in this meta-analysis is considerably larger than that found in the area of health resources. The sample size ranges from 54 to 1008 with a median of 137.

The stem-and-leaf display of these correlations, presented in Table VII, emphasizes the skewness of the distribution. This positive skewness is reflected in the value of the mean which is pulled toward a higher value than either the mode or the median. Table VIII contains the frequency distribution for the correlations included in the synthesis of the relationship between size of network and subjective well-being.

Frequency of Contact. Frequency of contact refers to the amount of interaction a respondent typically engages in. It is often the sum of the number of persons in the network weighted by the frequency of in-person contact or some other form of contact, for example by letter or by phone.

Thirty-one studies were found with information on the relationship between frequency of contact and subjective well-being. One hundred correlation coefficients were extracted from these thirty-one studies and were averaged. 


\section{TABLE VII}

STEM-AND-LEAF PLOT OF THE CORRELATION COEFFICIENTS BETWEEN SIZE OF SOCIAL RESOURCES.AND SUBJECTIVE WELL-BEING

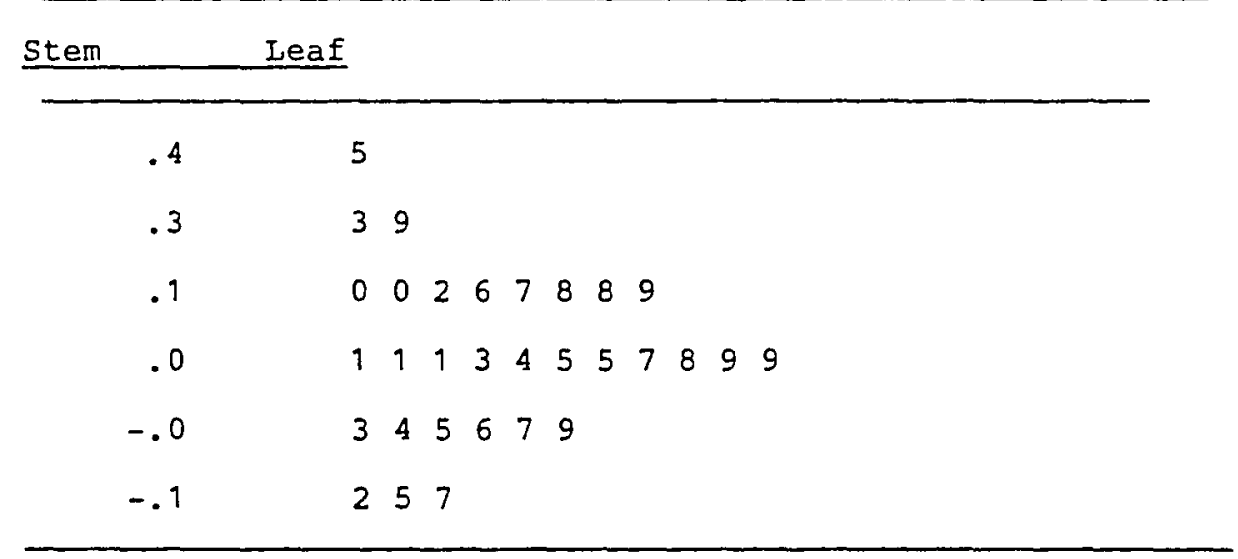

TABLE VIII

FREQUENCY DISTRIBUTION OF THE CORRELATION COEFFICIENTS BETWEEN SIZE OF SOCIAL RESOURCES AND SUBJECTIVE WELI-BEING

\begin{tabular}{lrrr}
\hline Range & & $N$ & 8 \\
\cline { 2 - 4 } .40 to & .49 & 1 & 3.2 \\
.30 to & .39 & 2 & 6.5 \\
.20 to & .29 & 0 & 0.0 \\
.10 to & .19 & 8 & 25.8 \\
0 to & .09 & 11 & 35.5 \\
-.17 to -.01 & 9 & 29.0 \\
\hline
\end{tabular}


The product moment correlation coefficients for these studies range from -.20 to .41 with a mode of .12 , a median of .06, and a mean of .08. The variance of these coefficients is .006 . The percent of variance which can be attributed to sampling error equals $27 \%$. As is the case for size, the distribution of frequency of contact is positively skewed (see Tables IX and $X$ ).

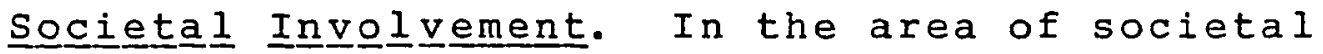
involvement, the findings from 37 studies were compiled. These yielded 57 coefficients with a range of -.01 to .55 , a mode of .16 , a median of .22, and a mean of .23. The distribution of these correlations is not noticeably skewed. The variance among the findings is .014. The percent of variance due to sampling error equals 168. The sample size ranges from 30 to 3395 with a median value of 204 (see Tables XI and XII).

As it is the case for the health resources, two of the three meta-analyses on the relationship between social resources and subjective well-being show that a large percentage of the variability among the findings of the studies cannot be attributed to sampling error. Prior to the search for moderator variables, a regrouping of studies under constructs which have a more restricted domain may be warranted. A closer look at studies with an extremely small or large sample size or with extreme correlation coefficients may also be advisable. Finally a systematic study of the sample characteristics and measurement 
TABLE IX

STEM-AND-LEAF PLOT OF THE CORRELATION COEFFICIENTS BETWEEN FREQUENCY OF CONTACT AND SUBJECTIVE WELL-BEING

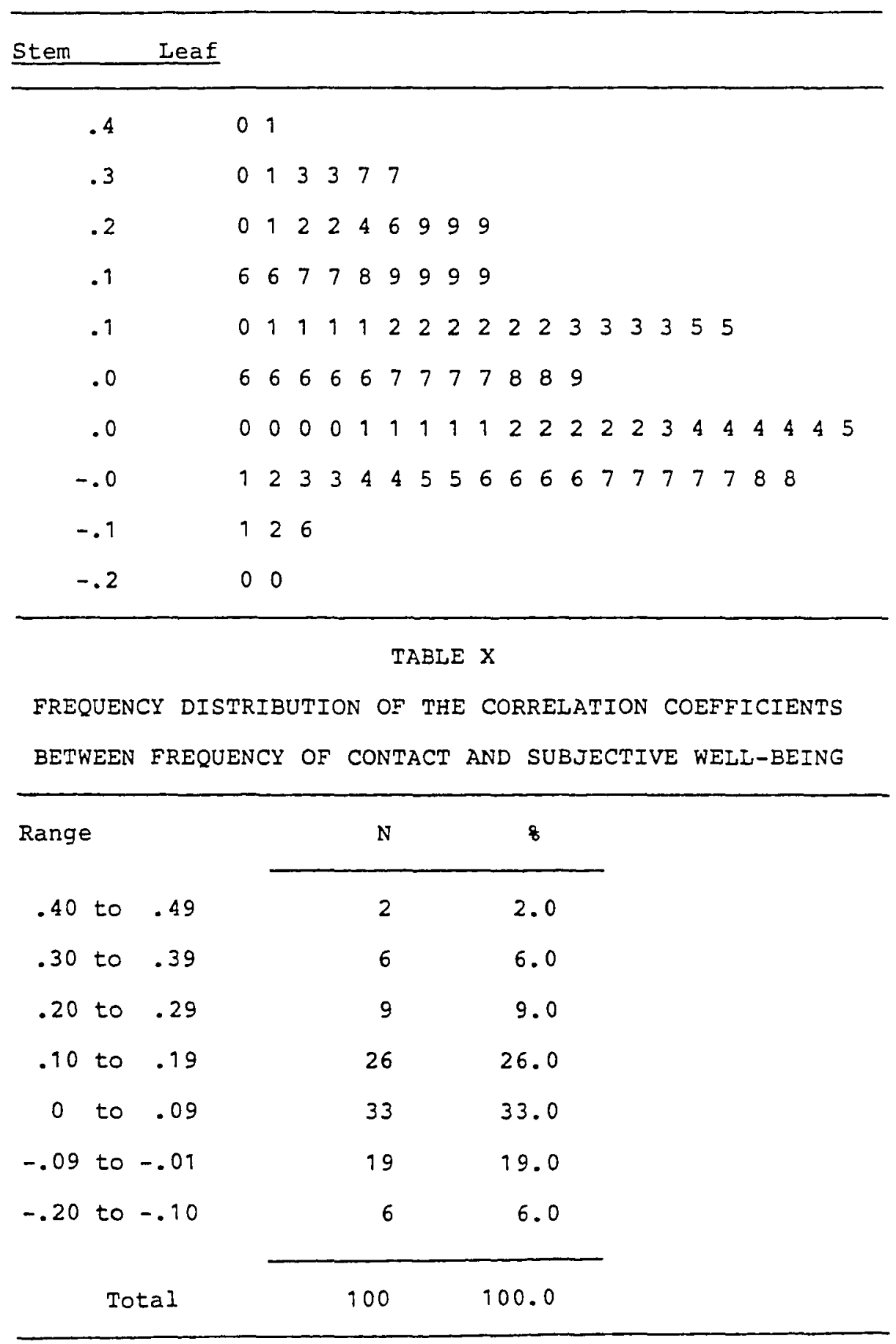


TABLE XI

STEM-AND-LEAF PLOT OF THE CORRELATION COEFFICIENTS

BETWEEN SOCIETAL INVOLVEMENT AND SUBJECTIVE WELL-BEING

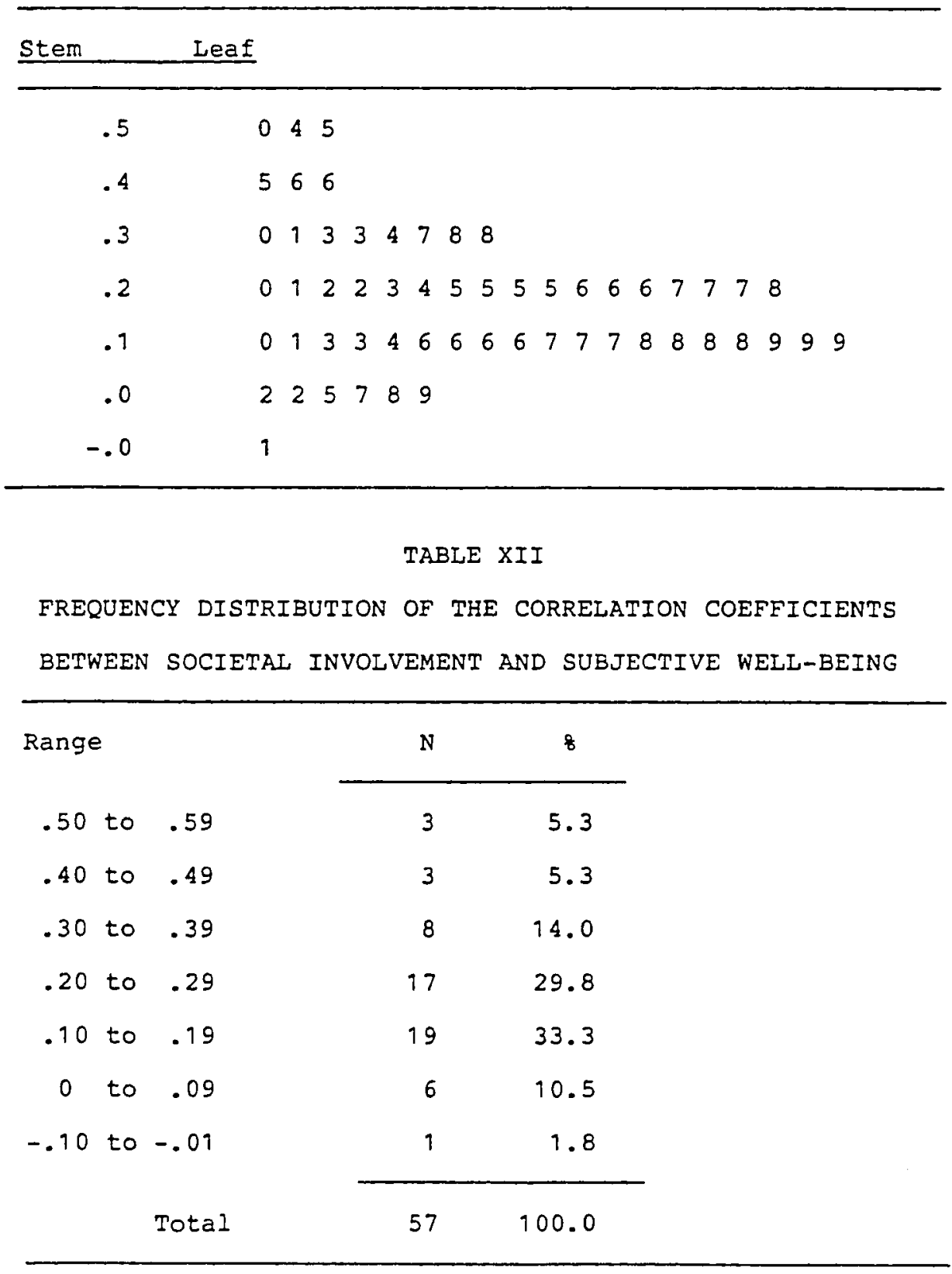


properties of the instruments may provide an explanation for the heterogeneity among these studies. Unfortunately, this type of probing into possible explanations for the variability is beyond the scope of the present study.

Financial Resources

According to George and Bearon (1980) socio-economic status (which is often measured by occupation, education, and incomel, and financial resources contribute to subjective well-being in that financial standing may promote a sense of freedom, independence, security, and/or accomplishment. Socio-economic status, the authors continue, defines an individual's social position and more or less determines his/her life chances. The construct of financial resources is usually measured by an item on individual or household income. More complex instruments are those which measure assets or those which look at net worth. Financial resources can provide access to status symbols. They may have an impact on social resources in that they may determine the size and function of the network. Lack of financial resources may contribute to isolation.

No studies could be found which investigate the relationship among different measures of financial resources. Larson (1978) estimates the magnitude of the relationship between income and subjective well-being to range between .10 and .30 . He points out that this relationship may not be linear but that the line flattens 
after a certain level of subjective well-being is reached. That is to say, beyond a certain level of income, there would be no more increase in well-being. The two metaanalyses which were done for the area of financial resources are: one on financial status and one on satisfaction with financial status.

Financial status. The construct of financial status is commonly assessed by yearly income of the respondent or of the household. This approach, however, is not without its drawbacks. Distortion in respondents' answers may be more or less pronounced depending on their income brackets, their ability to recall accurately, or their willingness to divulge this type of information. As was pointed out by George and Bearon (1980), household income may obscure an individual's financial status.

The synthesis for this construct is based on 23 studies from which 30 correlation coefficients were extracted. The range of these coefficients is from 0 to .35 with a mode of .33 , a median of .21 and a mean of .20 . The distribution has a slight negative skew (see Tables XIII and XIV). The variance equals .006. The percent of variance which can be attributed to sampling error is $87 \%$. A large part of the variability among the findings can be attributed to sampling error. This is expected because most of the studies included in the synthesis use income as a measure of financial status. Therefore, the measures 
TABLE XIII

STEM-AND-LEAF PLOT OF THE CORRELATION COEFFICIENTS

BETWEEN FINANCIAL STATUS AND SUBJECTIVE WELI-BEING

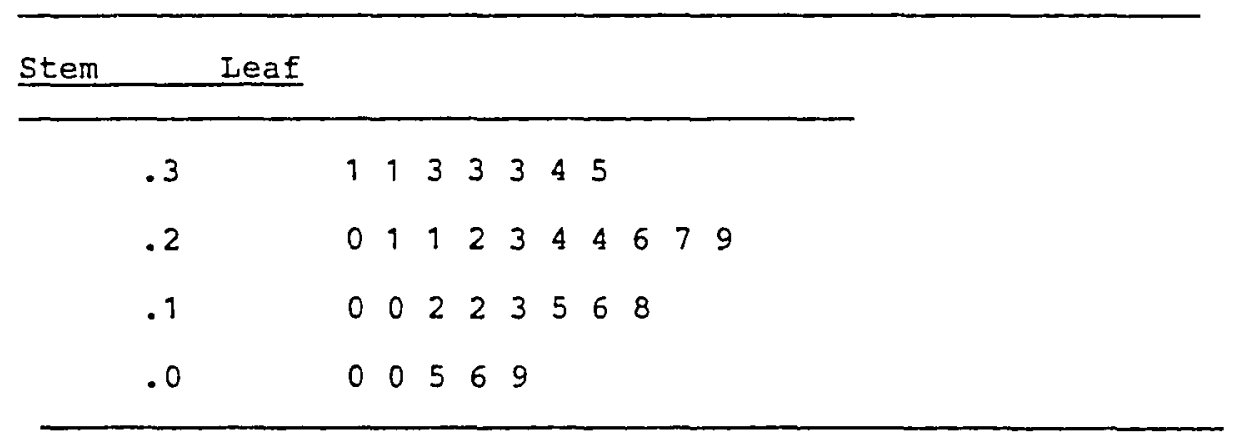

TABLE XIV

FREQUENCY DISTRIBUTION OF THE CORRELATION COEFFICIENTS

BETWEEN FINANCIAL STATUS AND SUBJECTIVE WELL-BEING

\begin{tabular}{|c|c|c|}
\hline Range & $\mathrm{N}$ & 8 \\
\hline .30 to .39 & 7 & 23.3 \\
\hline .20 to .29 & 10 & 33.3 \\
\hline .10 to .19 & 8 & 26.7 \\
\hline 0 to .09 & 5 & 16.7 \\
\hline Total & 30 & 100.0 \\
\hline
\end{tabular}


used to assess financial status have a high degree of similarity. The sample size across these studies varies from 51 to 3395 with a median of 192 .

Satisfaction with Financial Status. Satisfaction with financial status has been measured by a wide array of items. Some items require the respondents to make a global assessment of their satisfaction with their standard of living or with their ability to make ends meet. Some of these items contain no referent; some others instruct the respondents to compare their status to the past (ipsative item) or to others (normative item). No studies were found which give the intercorrelations among differently worded items measuring satisfaction with financial status.

Values for the relationship between satisfaction with financial status and subjective well-being was found in 13 of the studies reviewed. A total of 25 correlation coefficients were combined in the meta-analysis for this construct. These coefficients range in magnitude from .01 to .54 with a mode and a median of .28 , and a mean of .27 (see Tables XV and XVI). The variance is .008. Thirty-one percent of the variance among these findings can be attributed to sampling error. Therefore, in the area of satisfaction with financial status, the greatest part of the variability among findings cannot be attributed to sampling error. The sample size ranges from 30 to 1008 with a median value of 204 . 
Table XV

STEM-AND-LEAF PLOT OF THE CORRELATION COEFFICIENTS BETWEEN SATISFACTION WITH FINANCIAL STATUS AND

SUBJECTIVE WELL-BEING

\begin{tabular}{clllllllll}
\hline Stem & Leaf & & & & & & \\
\hline .5 & 4 & & & & & & \\
.4 & 0 & & & & & & & \\
.3 & 0 & 4 & 5 & 6 & 7 & 8 & 8 & 9 \\
.2 & 2 & 3 & 7 & 7 & 8 & 8 & 8 \\
.1 & 1 & 5 & 6 & 7 & 8 & 8 & & \\
.0 & 1 & 7 & & & & & & \\
\hline
\end{tabular}

TABLE XVI

FREQUENCY DISTRIBUTION OF THE CORRELATION COEFFICIENTS

BETWEEN SATISFACTION WITH FINANCIAL STATUS

AND SUBJECTIVE WELL-BEING

\begin{tabular}{|c|c|c|}
\hline Range & $\mathrm{N}$ & 8 \\
\hline .50 to .59 & 1 & 4.0 \\
\hline .40 to .49 & 1 & 4.0 \\
\hline .30 to .39 & 8 & 32.0 \\
\hline .20 to .29 & 7 & 28.0 \\
\hline .10 to .19 & 6 & 24.0 \\
\hline 0 to .09 & 2 & 8.0 \\
\hline Total & 25 & 100.0 \\
\hline
\end{tabular}


Summary of the Studies With Multivariate Procedures

The studies which were summarized are those which employed multiple linear regression and which reported the $\underline{b}$ and/or the beta weights in the article. As it has been mentioned previously, no real synthesis or calculation of an effect size is possible if $\underline{b}$ and/or beta weights are the reported statistics. Beta weights will vary dependent on the type and number of variables included in the analysis. The $\underline{b}$ weights are comparable across samples but are usually not in the same metric unless the same instruments have been used across studies. Multivariate studies which contain information at the univariate level were included in both analyses. The multivariate studies were summarized as a backdrop for the analyses of the LRHS data (see Table XVII). This summary shows that authors tend to report beta weights and that a small number report both the unstandardized and tli: standardized coefficients. No matter what area is examined, the range of values for the beta weights is around + and - .50 standard deviations, one beta weight exceeeds this value and equals .75 . Therefore, for all the studies reviewed, one standard deviation change on $x$ will not result in more than a half standard deviation change in $y$, holding the other variables entered in the regression analysis constant. The median values of these beta weights range from -.06 to .24. The areas which are based on a report of an affective state le.g., self-perceived health and satisfaction with 
TABLE XVII

RANGE OF THE UNSTANDARDIZED AND STANDARDIZED COEFFICIENTS AND THEIR ACCOMPANYING SAMPLE SIZE FOR THE STUDIES OF THE RELATIONSHIP BETWEEN SUBJECTIVE WELL-BEING AND THE AREAS OF HEAITH, SOCIAL, AND FINANCIAI RESOURCES

\begin{tabular}{|c|c|c|c|c|}
\hline Area & $\begin{array}{l}\text { Number } \\
\text { of } \\
\text { studies }\end{array}$ & $\begin{array}{l}\text { Number } \\
\text { of } \\
\text { effect } \\
\text { sizes }\end{array}$ & $\begin{array}{c}\text { Range of } \\
\text { unstandardized } \\
\text { coefficients }\end{array}$ & $\begin{array}{c}\text { Range of } \\
\text { standardized } \\
\text { coefficients }\end{array}$ \\
\hline \multicolumn{5}{|l|}{ Health Resources } \\
\hline Health status & 21 & 39 & $\begin{array}{c}-6.78 \text { to } 2.22 \\
(n=14)\end{array}$ & $\begin{array}{c}-.44 \text { to } .41 \\
\operatorname{man}=-.06 \\
(n=33)\end{array}$ \\
\hline $\begin{array}{l}\text { Self-perceived } \\
\text { health }\end{array}$ & 35 & 53 & $\begin{array}{c}-1.18 \text { to } 2.99 \\
(n=13)\end{array}$ & $\begin{array}{c}-.40 \text { to } .50 \\
\text { man }=5.24 \\
(n=52)\end{array}$ \\
\hline \multicolumn{5}{|l|}{ Social Resources } \\
\hline Size of network & 9 & 25 & $\begin{array}{c}-0.03 \text { to } 0.21 \\
(n=5)\end{array}$ & $\begin{array}{c}-.09 \text { to } .21 \\
\text { man }=0.07 \\
(n=25)\end{array}$ \\
\hline $\begin{array}{l}\text { Frequency of } \\
\text { contact }\end{array}$ & 13 & 47 & $\begin{array}{c}-0.14 \text { to } 3.54 \\
(n=31)\end{array}$ & $\begin{array}{c}-.21 \text { to } .45 \\
\text { man }=.08 \\
(n=40)\end{array}$ \\
\hline $\begin{array}{l}\text { Societal } \\
\text { involvement }\end{array}$ & 30 & 68 & $\begin{array}{c}-1.88 \text { to } 0.56 \\
(n=28)\end{array}$ & $\begin{array}{c}-.46 \text { to } .75 \\
m d n=.12 \\
(n=58)\end{array}$ \\
\hline \multicolumn{5}{|l|}{ Financial Resources } \\
\hline $\begin{array}{c}\text { Financial } \\
\text { status }\end{array}$ & 16 & 24 & $\begin{array}{c}-0.01 \text { to } 0.79 \\
(n=7)\end{array}$ & $\begin{array}{c}-.09 \text { to } .34 \\
\text { man }=.06 \\
(n=22)\end{array}$ \\
\hline $\begin{array}{l}\text { Satisfaction } \\
\text { with financial } \\
\text { status }\end{array}$ & 16 & 30 & $\begin{array}{c}-1.51 \text { to } 5.78 \\
(n=12)\end{array}$ & $\begin{array}{c}-.18 \text { to } .32 \\
\operatorname{man}=0.18 \\
(n=25)\end{array}$ \\
\hline
\end{tabular}


financial status) have the largest median beta weight values. The lack of standardization and the unsystematic use of multiple linear regression hamper further comments.

\section{Summary}

The most striking finding across all the 7 metaanlyses is the variability among effect sizes within a construct. There is a need to rethink the dimensions of the constructs into smaller subsets for theory formulation. At the methodological level, there is a need to incorporate the methodological characteristics of studies and the measurement properties of the instruments in the metaanalysis to determine their contribution to the variability among findings.

Despite its shortcomings, the meta-analysis has provided some information which refines statements typically made on the relationship of a set of dimensions to subjective well-being. It allows some general but more precise statements about the relationship of subjective well-being and areas of health, social, and financial resources (see Figure 2). As an example, it is well-known among gerontologists that good health contributes to happiness. A look at the findings from the meta-analysis shows that self-perceived health tends to have a stronger relationship with subjective well-being than the more "objective" health measures. Intuitively, this proposition is reasonable because it is likely that a general outlook 


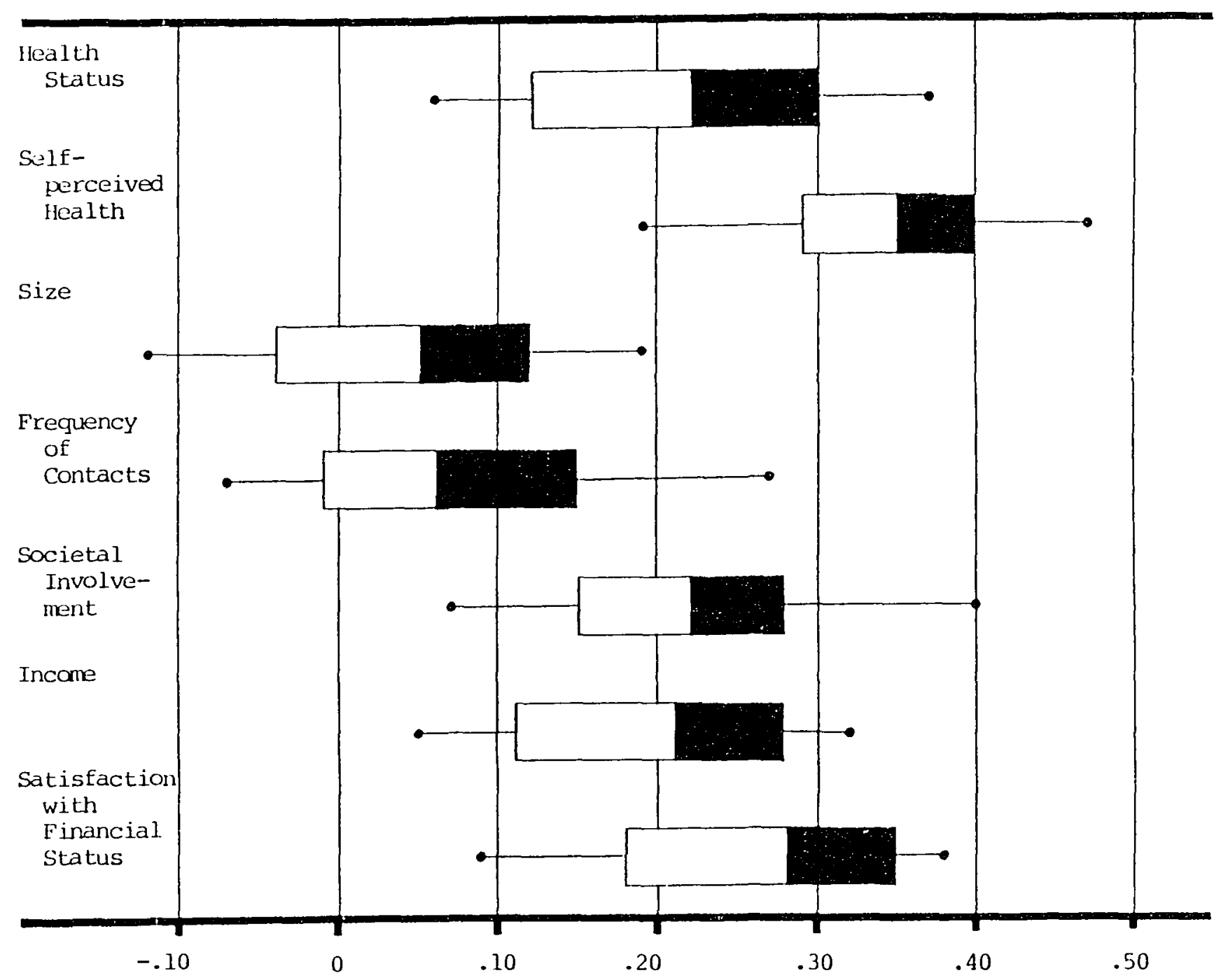

Figure 2. Box-and-whisker Plots for the Distributions of the Correlation coefficients Betwoen Subjective hell-being and the Areas of Health, Social, and Financial Resources. 
on life permeates global statements of satisfaction (Costa, McCrae, \& Norris, 1981). One question which can be asked is: how do older peoplefigure out how happy they are? Is it by summing their standing on domain specific measures, counting their blessings so to speak, or is it that a global outlook taints the domain specific ratings? It may be that there are differences among people on how they arrive at a global rating. If this is the case, is a particular approach to evaluation more beneficial in the context of some events but not in other instances? Which domain specific satisfaction items contribute to the prediction of global ratings? During an interview or within a questionnaire, what is the impact of order of presentation of satisfaction items which are global and domain-specific? Do global items set the mood of the interview and influence the responses of domain specific measures? These and many other questions can be formulated based on the results of the meta-analysis to direct further investigations in the relationship between measures of subjective well-being and measures of health. 
CHAPTER III

METHODS

The primary focus of this study is to determine if different quantitative approaches to the measurement of change yield different results when the relationship between subjective well-being and health, social, and financial resources is analyzed. The basic purpose is the examination of intra-individual change in a random sample of older persons who were, for the most part, pre-retirees at the time of the first wave of data collection in 1969. The analyses for this study were conducted on an existing data set. The secondary data which were analyzed are those of the Longitudinal Retirement History Study (LRHS), a tenyear study of the retirement process sponsored by the Social Security Administration. This chapter states the research questions and the hypotheses which have guided the analysis. It also describes the sample, the dependent and independent variables, and the three methods which were chosen to assess change. Finally, the handling of the data files and the statistical analyses that were used to carry out the data analysis are presented. 
Research Questions and Hypotheses

Five research questions were formulated at the beginning of this study:

1. What is the magnitude of the relationship between subjective well-being and the areas of health, social, and financial resources for the LRHS sample? Do these values fall within the range found in the aging literature?

2. Is there evidence which supports the construct validity of change scores? More specifically, do the three selected ways of measuring change in the four areas of health, social, financial resources, and subjective wellbeing result in similar or different orderings of individuals along the continuum of change? Furthermore, do the three selected approaches to the measurement of change produce similar results when hypotheses are tested using univariate statistical procedures?

3. Does change on selected health, social, and financial measures explain a significant amount of variance in subjective well-being and in change in subjective wellbeing? How does this amount of variance compare to that explained by one-point-in-time measures?

4. Do the different ways of measuring change produce significantly different results when the relationship of subjective well-being with health, social, and financial resources is analyzed using multiple regression procedures?

5. Is self-perceived change a useful indicator of change and what is its relationship to the three selected 
approaches to the measurement of change in longitudinal data?

The first research question above addresses the issue of how representative the results from the LRHS sample are. No hypothesis was formulated to accompany this first research question. The hypotheses corresponding to research questions 2 through 5 are of two kinds. One set of hypotheses was derived from gerontological theories which emphasize that aging is accompanied by changes in health, social, financial resources, and subjective well-being. The literature which was summarized in the meta-analysis section also guided the formulation of this first set of hypotheses. The second set is more methodological and is based on known psychometric properties of change scores. The hypotheses for this study are:

1. increases in disability are related to decreases in income;

2. increases in disability are related to decreases in subjective well-being;

3. increases in financial resources are related to increases in subjective well-being;

4. increases in satisfaction with financial status are related to increases in subjective well-being;

5. increased disability is related to a low rating of one's health compared to two years ago; 
6. positive change in the rating of one's health compared to others is related to a high rating of one's health compared to two years ago;

7. positive change in satisfaction with financial status is related to positive change in one's health compared to others and to a high rating of one's health compared to two years ago;

8. change scores obtained by one approach to the measurement of change in longitudinal data are correlated with change scores obtained by a different approach;

9. in the multiple regression analyses, residual change scores will explain comparatively more variance in subjective well-being and in change in subjective wellbeing than difference scores.

The Sample

The sample of the Longitudinal Retirement History Study (LRHS) includes 11,153 respondents drawn from al 1 fifty states. They were between the ages of 58 and 63 at the time of the first wave of data collection, in 1969. The selected respondents are:

\footnotetext{
"men aged 58-63, regardless of marital status, and women of the same ages who were not, when selected, living with spouses. The respondents were selected by the Bureau of the Census from members of households that had participated in the Current Population Survey." (Irelan, 1976 , p. 4)
}

Members of the sample then are from one birth cohort (19051911). They were interviewed every two years, over a ten- 
year period, starting in 1969 for a total of six waves of data collection. Detailed information on the sampling frame and the standard error is given in Irelan (1976).

The subsample for this study consists of 8922 respondents who participated in the first three waves of data collection, that is, who participated in 1969, 1971, and 1973. These respondents are labeled the continuers. After 4 years, $20 \%$ of the original sample had dropped of $(n=2231)$. Table XVIII lists the reasons for attrition and the number of persons and percent associated with each category.

At the time of the first wave of data collection, the sample of continuers is composed of predominantly white respondents $(898, n=7949)$, males $(728, n=6411)$, between the ages of 58 and 63 (mean age $=60$ ). The majority of the respondents have finished high school (82.68, $n=7365)$, are working (72.88, $n=6493$ ) and are living with a spouse $(63.38, n=6493)$.

There are two important limitations in the choice of continuers from the LRHS for the sample of the current study. It has been suggested that continuers are a selected group of older persons who are not representative of the population (Baltes, Reese, and Nesselroade, 1977). Concerns have also been voiced regarding the generalizability of findings from this 1905-1911 birth cohort that may not be typical of other cohorts of elderly persons (Cain, 1982). No analyses were done to ascertain 
TABLE XVIII

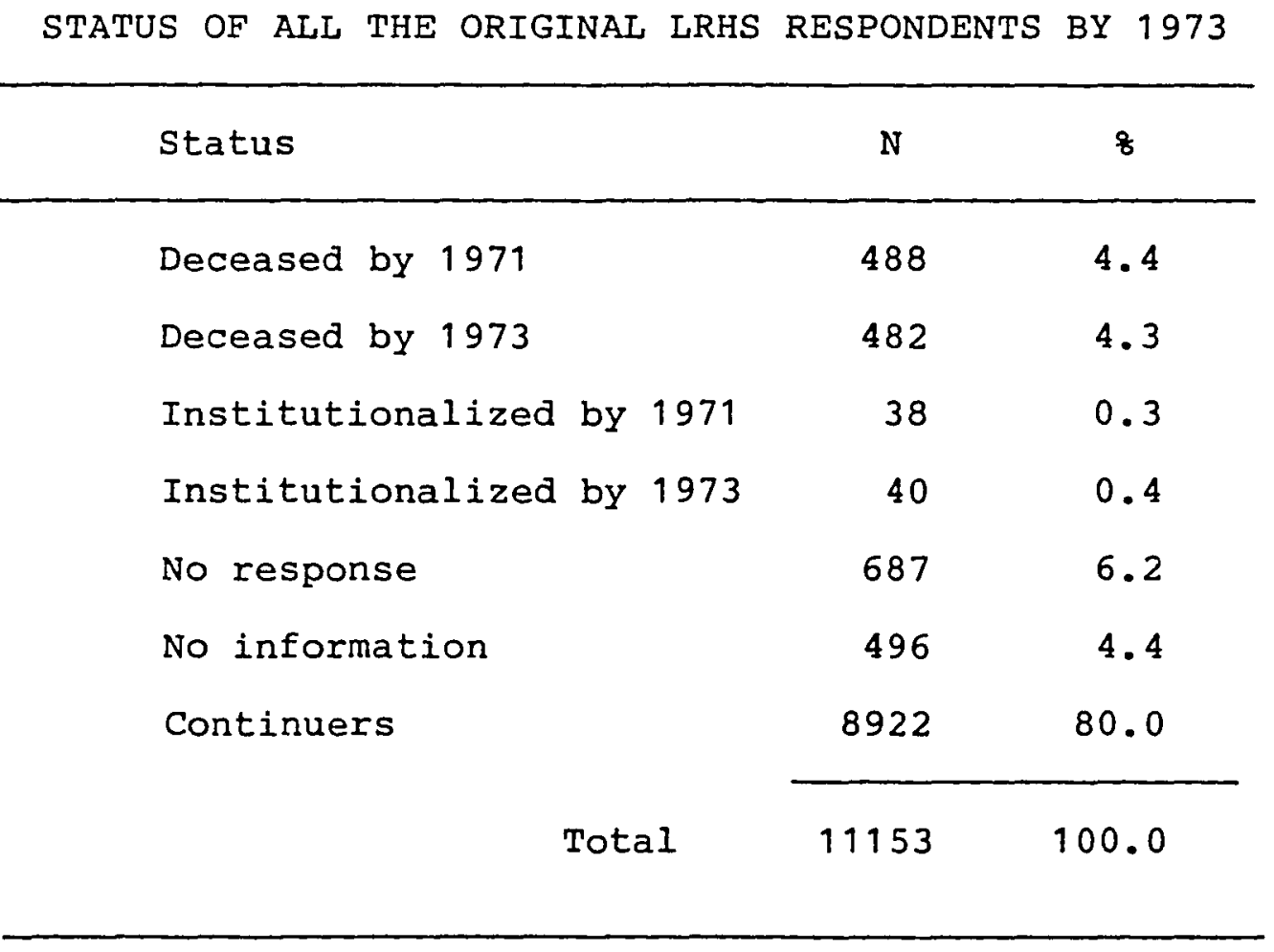


how representative the continuers are with respect to demographic characteristics. A cohort analysis is beyond the scope of this study as well. However, statistical analyses performed on these data to answer the first research question provide indirect evidence regarding the representativeness of the sample, in terms of how similar the correlational results between subjective well-being and the areas of health, social, and financial resources are to results from previous studies.

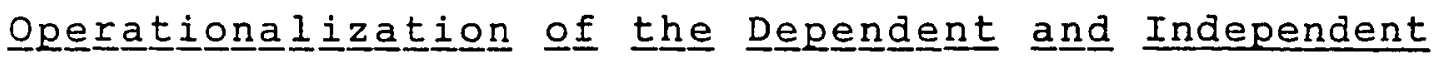
Variables

This section describes the operationalization of the dependent and independent variables. Because this study is based on secondary data, no control could be exercised on the extent to which the four constructs of health, social, and financial resources, and subjective well-being were adequately sampled to represent the domain of the construct. Whenever feasible, indexes rather than items were selected to measure a construct. They were chosen from a set of fifty-four indexes which were initially constructed as part of a funded research project on a random subsample of 973 LRHS respondents (stewart, 1982). The report from the project documents at length the psychometric properties of the indexes, the index construction procedures, and the shortcomings of each index. For the present study, six (6) indexes were chosen 
and the index construction procedures given in the report were replicated. However, for this study, a score was calculated for all the respondents who participated in the first three waves of data collection $(n=8922)$. Permission was obtained from the research team to use the indexes for this study.

Figure 3 is a replica of Figure 1 but contains the names of the indexes and items which were selected to measure the constructs of health, social, and financial resources, and subjective well-being. With the exception of income, objective measures, i.e., those which assess a condition or situation, are indexes. All the subjective measures, i.e., those which tap an affective state, are items with the exception of Outlook on Life. Each measure is described below. A complete discussion of the indexes is available in Methods of assessing well-being and change

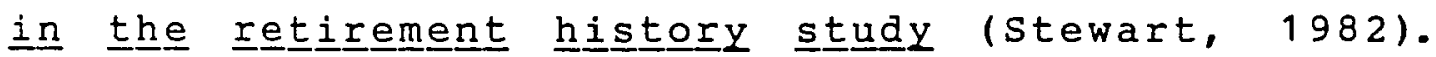
Throughout the description of the measures, the term identical is used. It implies that items, used individually or as components of an index, have identical wording across waves. The term comparable, in contrast, refers to items which were worded in a slightly different way and which may have conveyed a different meaning to the respondents. The term identical does not refer to the order of presentation of the items. This order as well as the total length of each interview questionnaire varies across the three waves of data collection. These variations 


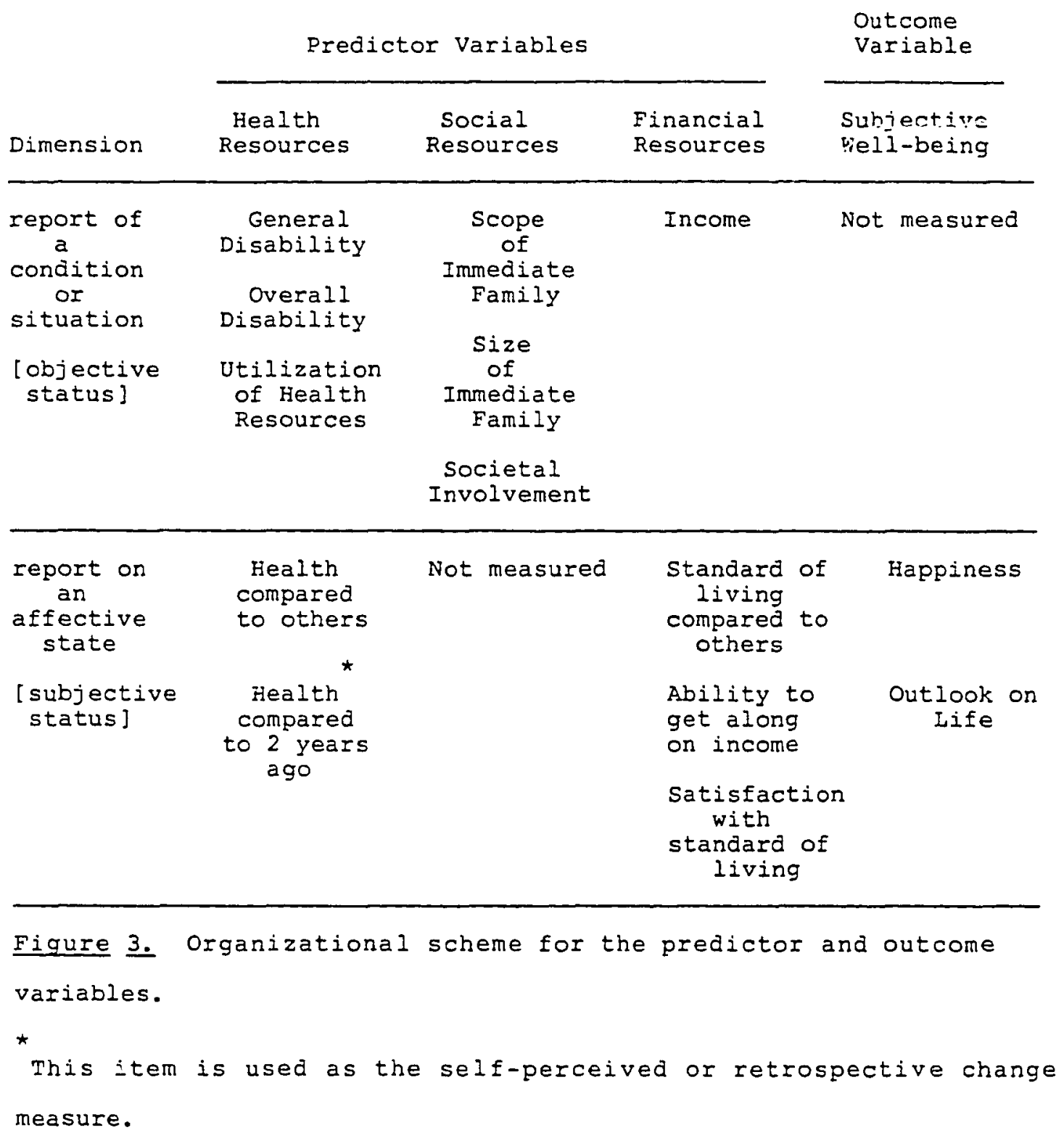


are sources of error which could not be controlled and which may have distorted in a systematic way the results from the change scores.

Descriptive statistics for the indexes measuring objective status are given in Table XIX. Descriptive statistics for the items measuring subjective status are listed in Table Xx. Because the happiness item is used as the outcome measure for all the analyses, it has been included in all the tables for ease of reference.

\section{Subjective Wel l-being}

\section{Happiness}

The outcome or dependent variable for the current study is measured by a single item with a three-point range $(0,1,2)$. When the item has been linearly transformed to the 0 to 10 metric, the three possible scores become 0,5 , and 10. The outcome variable assesses the happiness of the respondents. The precise wording of the item is:

\footnotetext{
"Taking all things together, would you say you're very happy, pretty happy, or not too happy these days?"
}

The item had been included in all three waves (e.g., 1969, 1971, and 1973) and is identical across waves. A high score on this item implies a great degree of happiness. This item or other ones worded similarly have been used in past research studies to obtain a global assessment of a respondent's subjective well-being. 
TABI.E XIX

DESCMIPTIVE STATISTICS FOR TIE MFASIHES OF HFAN,IU, SOCIN,, FINAACIAL, MESOURCES, AND SARSECTIVE WBAL-BE:ING BUA 1969, 1971, AND 1973

\begin{tabular}{|c|c|c|c|c|c|c|c|c|c|c|}
\hline $\begin{array}{l}\text { Resource Ared } \\
\text { Index/Ittem }\end{array}$ & Year & man & Median & mode & $\begin{array}{l}\text { Standard } \\
\text { deviation }\end{array}$ & Min-Max & $\begin{array}{l}\text { Values } \\
\text { In range }\end{array}$ & Skewness & Kurtos18 & $\begin{array}{l}\text { Percent } \\
\text { pulsshing }\end{array}$ \\
\hline $\begin{array}{l}\text { Health Resource } \\
\text { General } \\
\text { Dibabllity }\end{array}$ & $\begin{array}{l}1969 \\
1971 \\
1973\end{array}$ & $\begin{array}{l}2.93 \\
3.16 \\
3.71\end{array}$ & $\begin{array}{l}1.46 \\
1.63 \\
2.14\end{array}$ & $\begin{array}{l}0.00 \\
0.00 \\
0.00\end{array}$ & $\begin{array}{l}4.12 \\
4.21 \\
4.34\end{array}$ & $\begin{array}{l}0.00-10.00 \\
0.00-10.00 \\
0.00-10.00\end{array}$ & $\begin{array}{l}3 \\
3 \\
3\end{array}$ & $\begin{array}{l}0.89 \\
0.78 \\
0.52\end{array}$ & $\begin{array}{l}-0.94 \\
-1.14 \\
-1.47\end{array}$ & $\begin{array}{l}0.1 \\
0.1 \\
0.3\end{array}$ \\
\hline $\begin{array}{l}\text { Overall } \\
\text { Disabllity }\end{array}$ & $\begin{array}{l}1969 \\
1971 \\
1973\end{array}$ & $\begin{array}{l}1.50 \\
1.75 \\
2.24\end{array}$ & $\begin{array}{l}0.10 \\
0.11 \\
0.15\end{array}$ & $\begin{array}{l}0.00 \\
0.00 \\
0.00\end{array}$ & $\begin{array}{l}2.52 \\
2.72 \\
2.96\end{array}$ & $\begin{array}{l}0.00-10.00 \\
0.00=10.00 \\
0.00-10.00\end{array}$ & $\begin{array}{l}16 \\
16 \\
16\end{array}$ & $\begin{array}{l}1.64 \\
1.40 \\
1.00\end{array}$ & $\begin{array}{r}1.81 \\
0.88 \\
-0.20\end{array}$ & $\begin{array}{l}6.0 \\
6.0 \\
5.8\end{array}$ \\
\hline $\begin{array}{l}\text { Utillization } \\
\text { of Health } \\
\text { Resources }\end{array}$ & $\begin{array}{l}1969 \\
1971 \\
1973\end{array}$ & $\begin{array}{l}2.98 \\
3.12 \\
3.28\end{array}$ & $\begin{array}{l}2.84 \\
2.97 \\
3.15\end{array}$ & $\begin{array}{l}3.33 \\
3.30 \\
3.30\end{array}$ & $\begin{array}{l}2.63 \\
2.66 \\
2.62\end{array}$ & $\begin{array}{l}0.00-10.00 \\
0.00-10.00 \\
0.00-10.00\end{array}$ & 4 & $\begin{array}{l}0.53 \\
0.52 \\
0.14\end{array}$ & $\begin{array}{l}-0.33 \\
-0.31 \\
-0.33\end{array}$ & $\begin{array}{l}2.9 \\
0.8 \\
0.9\end{array}$ \\
\hline $\begin{array}{l}\text { Soclal Resource } \\
\text { Scope of } \\
\text { Lapedjate } \\
\text { Fanlly }\end{array}$ & $\begin{array}{l}1969 \\
1971 \\
1973\end{array}$ & $\begin{array}{l}6.27 \\
6.16 \\
6.03\end{array}$ & $\begin{array}{l}6.57 \\
6.17 \\
6.39\end{array}$ & $\begin{array}{l}7.50 \\
7.50 \\
7.50\end{array}$ & $\begin{array}{l}2.21 \\
2.15 \\
2.14\end{array}$ & $\begin{array}{l}0.00-10.00 \\
0.00=10.00 \\
0.00-10.00\end{array}$ & $\begin{array}{l}5 \\
5 \\
5\end{array}$ & $\begin{array}{l}-0.12 \\
-0.45 \\
-0.49\end{array}$ & $\begin{array}{l}-0.16 \\
-0.13 \\
-0.18\end{array}$ & $\begin{array}{l}0.4 \\
2.1 \\
2.3\end{array}$ \\
\hline $\begin{array}{l}\text { Size of } \\
\text { Impediate } \\
\text { Fadly }\end{array}$ & $\begin{array}{l}1969 \\
1971 \\
1973\end{array}$ & $\begin{array}{l}4.97 \\
4.90 \\
4.78\end{array}$ & $\begin{array}{l}5.00 \\
4.88 \\
1.76\end{array}$ & $\begin{array}{l}4.54 \\
1.50 \\
4.50\end{array}$ & $\begin{array}{l}2.11 \\
2.11 \\
2.13\end{array}$ & $\begin{array}{l}0.00-10.00 \\
0.00-10.00 \\
0.00-10.00\end{array}$ & $\begin{array}{l}12 \\
12 \\
12\end{array}$ & $\begin{array}{l}-0.14 \\
-0.12 \\
-0.11\end{array}$ & $\begin{array}{l}-0.63 \\
-0.70 \\
-0.74\end{array}$ & $\begin{array}{l}0.4 \\
2.1 \\
2.3\end{array}$ \\
\hline $\begin{array}{l}\text { Sociletal } \\
\text { Involvement }\end{array}$ & $\begin{array}{l}1969 \\
1971 \\
1973\end{array}$ & $\begin{array}{l}6.89 \\
6.92 \\
5.94\end{array}$ & $\begin{array}{l}7.50 \\
7.64 \\
6.14\end{array}$ & $\begin{array}{r}10.00 \\
10.00 \\
5.00\end{array}$ & $\begin{array}{l}3.16 \\
3.52 \\
3.72\end{array}$ & $\begin{array}{l}0.00-10.00 \\
0.00=10.00 \\
0.00-10.00\end{array}$ & $\begin{array}{l}3 \\
3 \\
3\end{array}$ & $\begin{array}{l}-0.66 \\
-0.70 \\
-0.32\end{array}$ & $\begin{array}{l}-0.72 \\
-0.73 \\
-1.14\end{array}$ & $\begin{array}{l}2.5 \\
1.0 \\
6.1\end{array}$ \\
\hline \multicolumn{11}{|c|}{ PInanclal Rebources } \\
\hline Incume & $\begin{array}{l}1969 \\
1971 \\
1973\end{array}$ & $\begin{array}{l}8.48 \\
8.57 \\
8.63\end{array}$ & $\begin{array}{l}9.66 \\
9.71 \\
9.51\end{array}$ & $\begin{array}{l}12.00 \\
12.00 \\
12.00\end{array}$ & $\begin{array}{l}3.79 \\
3.79 \\
3.50\end{array}$ & $\begin{array}{l}1.00-14.00 \\
1.00=14.00 \\
1.00-14.00\end{array}$ & $\begin{array}{l}14 \\
14 \\
14\end{array}$ & $\begin{array}{l}-0.66 \\
-0.60 \\
-0.52\end{array}$ & $\begin{array}{l}-0.79 \\
-0.88 \\
-0.87\end{array}$ & $\begin{array}{l}3.4 \\
2.6 \\
3.1\end{array}$ \\
\hline $\begin{array}{l}\text { Subjective Hell } \\
\text { thapplnesy }\end{array}$ & $\begin{array}{l}\text {-being } \\
1969 \\
1971 \\
1973\end{array}$ & $\begin{array}{l}5.41 \\
5.69 \\
5.61\end{array}$ & $\begin{array}{l}5.39 \\
5.67 \\
5.61\end{array}$ & $\begin{array}{l}5.00 \\
5.00 \\
5.00\end{array}$ & $\begin{array}{l}3.10 \\
3.11 \\
3.50\end{array}$ & $\begin{array}{l}0.00-10.00 \\
0.00-10.00 \\
0.00-10.00\end{array}$ & $\begin{array}{l}3 \\
3 \\
3\end{array}$ & $\begin{array}{l}-0.10 \\
-0.18 \\
-0.17\end{array}$ & $\begin{array}{l}-0.84 \\
-0.87 \\
-0.96\end{array}$ & $\begin{array}{l}0.9 \\
0.4 \\
0.5\end{array}$ \\
\hline$\underset{\text { Litlook on }}{\text { O.1fe }}$ & $\begin{array}{l}1969 \\
1971 \\
1973\end{array}$ & $\begin{array}{l}5.42 \\
5.57 \\
5.40\end{array}$ & $\begin{array}{l}5.41 \\
5.66 \\
5.38\end{array}$ & $\begin{array}{l}6.94 \\
4.70 \\
1.70\end{array}$ & $\begin{array}{l}2.39 \\
2.28 \\
2.33\end{array}$ & $\begin{array}{l}0.00-10.00 \\
0.00-10.00 \\
0.00-10.00\end{array}$ & $\begin{array}{l}35 \\
35 \\
35\end{array}$ & $\begin{array}{l}-0.36 \\
-0.31 \\
-0.30\end{array}$ & $\begin{array}{l}-0.13 \\
-0.29 \\
-0.13\end{array}$ & $\begin{array}{r}10.7 \\
9.5 \\
11.7\end{array}$ \\
\hline
\end{tabular}

Nate. All the sasures are Identical acrosa the 1969, 1971, and 1973 waves of data collection with the exception of utillzation of Health Resources, Societal Involvement, and Incose. Por these three ocales, it 1s Inspropriate to compare the peans across the three waves of data collection. 
TABLE $\mathrm{XX}$

DESCRIPTIVE STATISTICS FOR THE ITEMS MEASURING HEALTH, FINANCIAL, RESQURCES, ANJ SUBJECTIVE WHZL-BEING FOR 1969, 1971, AND 1973

\begin{tabular}{|c|c|c|c|c|c|c|c|c|c|c|}
\hline $\begin{array}{l}\text { Resource Area } \\
\text { Itern }\end{array}$ & Year & Mean & Median & Mode & $\begin{array}{l}\text { Standard } \\
\text { deviation }\end{array}$ & Min-Max & $\begin{array}{l}\text { Values } \\
\text { in range }\end{array}$ & Skewness & Kurtosis & $\begin{array}{l}\text { Percent } \\
\text { missing }\end{array}$ \\
\hline $\begin{array}{l}\text { Health Resources } \\
\text { Heal th compared } \\
\text { to others }\end{array}$ & $\begin{array}{l}1969 \\
1971 \\
1973\end{array}$ & $\begin{array}{l}1.18 \\
1.14 \\
1.10\end{array}$ & $\begin{array}{l}1.20 \\
1.14 \\
1.11\end{array}$ & $\begin{array}{l}1.00 \\
1.00 \\
1.00\end{array}$ & $\begin{array}{l}0.73 \\
0.70 \\
0.70\end{array}$ & $\begin{array}{l}0.00-2.00 \\
0.00=2.00 \\
0.00-2.00\end{array}$ & $\begin{array}{l}3 \\
3 \\
3\end{array}$ & $\begin{array}{l}-0.28 \\
-0.20 \\
-0.15\end{array}$ & $\begin{array}{l}-1.08 \\
-0.94 \\
-0.98\end{array}$ & $\begin{array}{l}4.0 \\
4.5 \\
4.6\end{array}$ \\
\hline $\begin{array}{l}\text { Health conpared } \\
\text { to } 2 \text { years ago }\end{array}$ & $\begin{array}{l}1969 \\
1971 \\
1973\end{array}$ & $\begin{array}{l}a \\
0.85 \\
0.81\end{array}$ & $\begin{array}{l}a \\
0.88 \\
0.83\end{array}$ & $\begin{array}{l}a \\
1.00 \\
1.00\end{array}$ & $\begin{array}{l}a \\
0.62 \\
0.64\end{array}$ & $\begin{array}{c}a \\
0.00-2.00 \\
0.00-2.00\end{array}$ & $\begin{array}{l}\mathbf{a} \\
3 \\
3\end{array}$ & $\begin{array}{l}a \\
0.11 \\
0.19\end{array}$ & $\begin{array}{c}a \\
-0.49 \\
-0.65\end{array}$ & $\begin{array}{l}a \\
1.5 \\
2.1\end{array}$ \\
\hline $\begin{array}{l}\text { Financial Resources } \\
\text { Standard of } \\
\text { living compared } \\
\text { to others }\end{array}$ & $\begin{array}{l}1959 \\
1971 \\
1973\end{array}$ & $\begin{array}{l}0.95 \\
1.01 \\
0.96\end{array}$ & $\begin{array}{l}0.96 \\
1.01 \\
0.97\end{array}$ & $\begin{array}{l}1.00 \\
1.00 \\
1.00\end{array}$ & $\begin{array}{l}0.54 \\
0.54 \\
0.53\end{array}$ & $\begin{array}{l}0.00-2.00 \\
0.00=2.00 \\
0.00-2.00\end{array}$ & $\begin{array}{l}3 \\
3 \\
3\end{array}$ & $\begin{array}{r}-0.04 \\
0.01 \\
-0.04\end{array}$ & $\begin{array}{l}0.35 \\
0.43 \\
0.48\end{array}$ & $\begin{array}{l}5.1 \\
5.2 \\
7.4\end{array}$ \\
\hline $\begin{array}{l}\text { Ability to } \\
\text { get along on } \\
\text { incame }\end{array}$ & $\begin{array}{l}1969 \\
1971 \\
1973\end{array}$ & $\begin{array}{l}1.47 \\
1.52 \\
1.47\end{array}$ & $\begin{array}{l}1.46 \\
1.51 \\
1.41\end{array}$ & $\begin{array}{l}1.00 \\
1.00 \\
1.00\end{array}$ & $\begin{array}{l}0.95 \\
0.96 \\
0.92\end{array}$ & $\begin{array}{l}0.00-3.00 \\
0.00-3.00 \\
0.00-3.00\end{array}$ & $\begin{array}{l}4 \\
4 \\
4\end{array}$ & $\begin{array}{l}0.03 \\
0.00 \\
0.10\end{array}$ & $\begin{array}{l}-0.91 \\
-0.94 \\
-0.83\end{array}$ & $\begin{array}{l}2.7 \\
0.9 \\
1.2\end{array}$ \\
\hline $\begin{array}{l}\text { Sat Isfaction with } \\
\text { standard of } \\
\text { living }\end{array}$ & $\begin{array}{l}1969 \\
1971 \\
1973\end{array}$ & $\begin{array}{l}1.79 \\
1.81 \\
1.78\end{array}$ & $\begin{array}{l}1.89 \\
1.90 \\
1.86\end{array}$ & $\begin{array}{l}2.00 \\
2.00 \\
2.00\end{array}$ & $\begin{array}{l}0.67 \\
0.71 \\
0.70\end{array}$ & $\begin{array}{l}0.00-3.00 \\
0.00-3.00 \\
0.00-3.00\end{array}$ & $\begin{array}{l}4 \\
4 \\
4\end{array}$ & $\begin{array}{l}-0.82 \\
-0.67 \\
-0.61\end{array}$ & $\begin{array}{l}1.10 \\
0.70 \\
0.57\end{array}$ & $\begin{array}{l}0.7 \\
0.3 \\
0.3\end{array}$ \\
\hline \multicolumn{11}{|c|}{ Subjective Well-being } \\
\hline Happiness ${ }^{b}$ & $\begin{array}{l}1969 \\
1971 \\
1973\end{array}$ & $\begin{array}{l}1.08 \\
1.14 \\
1.12\end{array}$ & $\begin{array}{l}1.08 \\
1.14 \\
1.12\end{array}$ & $\begin{array}{l}1.00 \\
1.00 \\
1.00\end{array}$ & $\begin{array}{l}0.68 \\
0.68 \\
0.70\end{array}$ & $\begin{array}{l}0.00-2.00 \\
0.00-2.00 \\
0.00-2.00\end{array}$ & $\begin{array}{l}3 \\
3 \\
3\end{array}$ & $\begin{array}{l}-0.10 \\
-0.18 \\
-0.17\end{array}$ & $\begin{array}{l}-0.84 \\
-0.87 \\
-0.96\end{array}$ & $\begin{array}{l}0.9 \\
0.4 \\
0.5\end{array}$ \\
\hline
\end{tabular}

Note. All the items are identical across the three waves of data collection.

a This item was not included in the 1969 wave of data collection.

b The happiness item is Identical to the cne presented in Table XIX. The metric presented here 18 the original one after recoding so that a high score means greater happiness. The linear transformation version presented in Table XIX for that item can be obtained by dividing any of the measures of central tendency or variability by 2 and by multiplying the result by 10. The skewness and kurtosis are not affected by the ilnear transformation. Therefore, the values are identical in 


\section{Outlook on Life}

This index was not included throughout the analyses because two of its items on health and financial status overlap with the areas of health and financial resources. Furthermore, the happiness item is one of its components. The Outlook on Life index was used in the present study for the sole purpose of providing preliminary evidence for the construct validity of the measures included in the measurement of change. Because of the overlap, this index was only included in the initial correlation analyses. Outlook on Life is a summative index which assesses the respondents' feelings about their health, their financial status, and their happiness. The index has a 35-point range. A high score on this index implies positive ratings of one's health, financial status, and happiness. It is composed of identical components ( 2 items and one index).

\section{Health Resources}

This area is measured by three indexes (General Disability, Overall Disability, and Utilization of Health Resources) and two items (health compared to others and health compared to 2 years agol. The three indexes were classified as measuring a condition or situation, referred to as objective status, and the two items assess an affective state or subjective status. 
General Disability

General Disability is a summative index composed of 2 items which measure the extent to which health and/or physical disability limit a respondent's ability to work and/or to get around. A high score on this index represents a high degree of disability in terms of mobility and ability to work. This index is composed of identical items across waves and has a 3-point range $(0,5$, and 10).

Overal1 Disability

Overall Disability is an index composed of two other indexes, Work Limitations and Mobility Limitations. A high score on this index represents a high degree of disability. The components of this index are identical across the three waves of data collection. In its range of 0 to 10 are 16 different score values. The index overlaps in its content with the General Disability index because some of the items used to construct its two component indexes were also used to construct the General Disability index.

Utilization of Health Resources

Utilization of Health Resources is a summative index which assesses a respondent's use of medical resources in the last year by seeing a doctor, being hospitalized, and/or receiving medical advice over the telephone. It is composed of items which are comparable across waves. Because this index is not identical across waves it was only included in the initial correlation analyses to give evidence of construct validity for other indexes. 


\section{Self-perceived Health}

Two items were chosen to measure report on an affective state or subjective status for the area of health resources. The first item asks respondents to compare their health to that of others their own age. The item is identical across the three waves of data collection and has a three-point range. A high score on this item implies a positive evaluation of one's health. The precise wording for the item is:

"Is your health better, worse, or the same as that of other people your age?"

It is a normative item which is often used in gerontological research to measure self-perceived health.

The second item was not included in the 1969 wave of data collection. It asks the respondents to compare their health to that of 2 years ago. It has a three-point range and is worded in an identical fashion for the 1971 and 1973 waves of data collection. A high score on this item means that respondents assess their health now as better than it was two years ago. The wording for the item is as follows:

"How would you say your health today compares with your own health two years ago? Is it better, worse, or the same?"

This ipsative item is not as frequently used in the gerontological literature to assess global health as is the normative version of this item. 
Social Resources

The area of social resources is represented by 3 indexes which fall under the dimension of objective status (see Figure 3). No item could be found in the LRHS interview questionnaires which assess feelings about social resources or subjective status. The indexes are briefly described below.

Scope of Immediate Family

This index is composed of 4 items which assess whether or not a respondent has immediate family members in the following four roles: a spouse, a parent, a child, and a sibling. The minimum score on this index is 0 and the maximum score prior to any linear transformation, is 4 . The index has a 5-point range. A person with a high score on this index has a representative in each of the four roles. The index is considered by the research team as identical across waves although some slight variations occurred in wording. The rationale for this reasoning is as follows:

\footnotetext{
"It was assumed by this project's research team that respondents' answers regarding the existence of a family member would be the same regardless of slight variations in question wording." (Stewart, Beaudet, and Petersen, 1982, Chapter 9.1, page 2)
}

This index has limited content validity because its item components refer to the respondent's side of the family only and not to the spouse's or ex-spouse's family. 


\section{Size of Immediate Family}

This index is composed of the same 4 items used to construct the index measuring scope of Immediate Family. In this instance, however, the index is a count of the actual number of persons in each of the roles up to a maximum of four for the number of children and for the number of siblings. For example, married persons get a score of 1 for a 1 ive-in spouse. To that score is added a score of 2 if the respondent has both his/her parents living. The maximum score a respondent can obtain on this index is 11 if he/she is married and lives with his/her spouse, has both parents alive, has four or more children living, and has four or more siblings who are alive. The arbitrary cutoff point of 4 was selected to avoid outliers. The number of score values included in the range of this index is 12. A high score on this index reflects potential links with a large number of immediate family members. The index is identical across waves despite slight variations in wording. The component items of this index overlap with the items used in the construction of the scope of Immediate Family index.

Frequency of Contact with Members of the Network

The LRHS data contain some items which assess the frequency of contact with family members and friends. However, the consistency of these items across waves is lacking so that identical indexes could not be constructed 
for each of the three waves. This construct was not analyzed in the present study to avoid including indexes that are not present at all three waves or indexes which are only comparable to each other across waves. Indexes which are not identical add a potential source of change which cannot be dissociated from actual change.

\section{Societal Invol vement}

Societal Involvement is an index composed of 2 items which measure the extent to which respondents eat away from home and use transportation for trips around town for other than business purposes. This index is comparable across the three waves of data collection and was included in some of the preliminary analyses to provide evidence of construct validity. It has a 3-point range.

As mentioned previously, no LRHS items exist which measure satisfaction with one's network or satisfaction with formal or informal activities.

\section{Financial Resources}

\section{Income}

This area is represented by one item which assesses a respondent's total income based on 14 categories. In 1969, this information was not provided as part of the data. The categorical income question was asked only of the 70 respondents who did not answer all the individual questions on sources of income. In 1971 and in 1973, that question was asked of everyone regardless of how complete 
respondents' answers were on the individual questions on sources of income. To create a categorical income variable for 1969,20 sources of income were summed and the resulting distribution was recoded into 14 categories using the cutoff points listed in the 1971 and 1973 questionnaires. The 1969 indicator is not identical to the 1971 and 1973 item. How a respondent answers individual income questions does not necessarily mirror how he/she will answer a question on total income (Petersen, 1980 ). An initial investigation of this problem could be made. In 1973, the data contain both a continuous summary variable which is the sum of 20 income sources and the categorical income variable. The continuous variable was recoded into 14 categories and a crosstabulation was compiled to estimate how respondents would be classified differently using one or the other source of information to estimate income. The results are presented in Table XXI. The percent of persons identically classified by the two approaches ranges from 508 to 78 \% with a median value of 66\%. This is far from compiete agreement. Persons in the three highest income brackets and those with self-reported incomes between $\$ 1000$ and $\$ 2499$ have the highest percent of agreement between the continous variable and the categorical variable. It is worthy to note however that the highest income brackets have a wider range (\$5000.) than do the lowest income categories (\$500.). The crosstabulation procedure is based on a sample size of 
TABLE XXI

PERCENT AGREEMENT BETWEEN EACH OF THE FOURTEEN

INCOME CATEGORIES IN 1973 AND THE CONTINUOUS INCOME VARIABLE RECODED

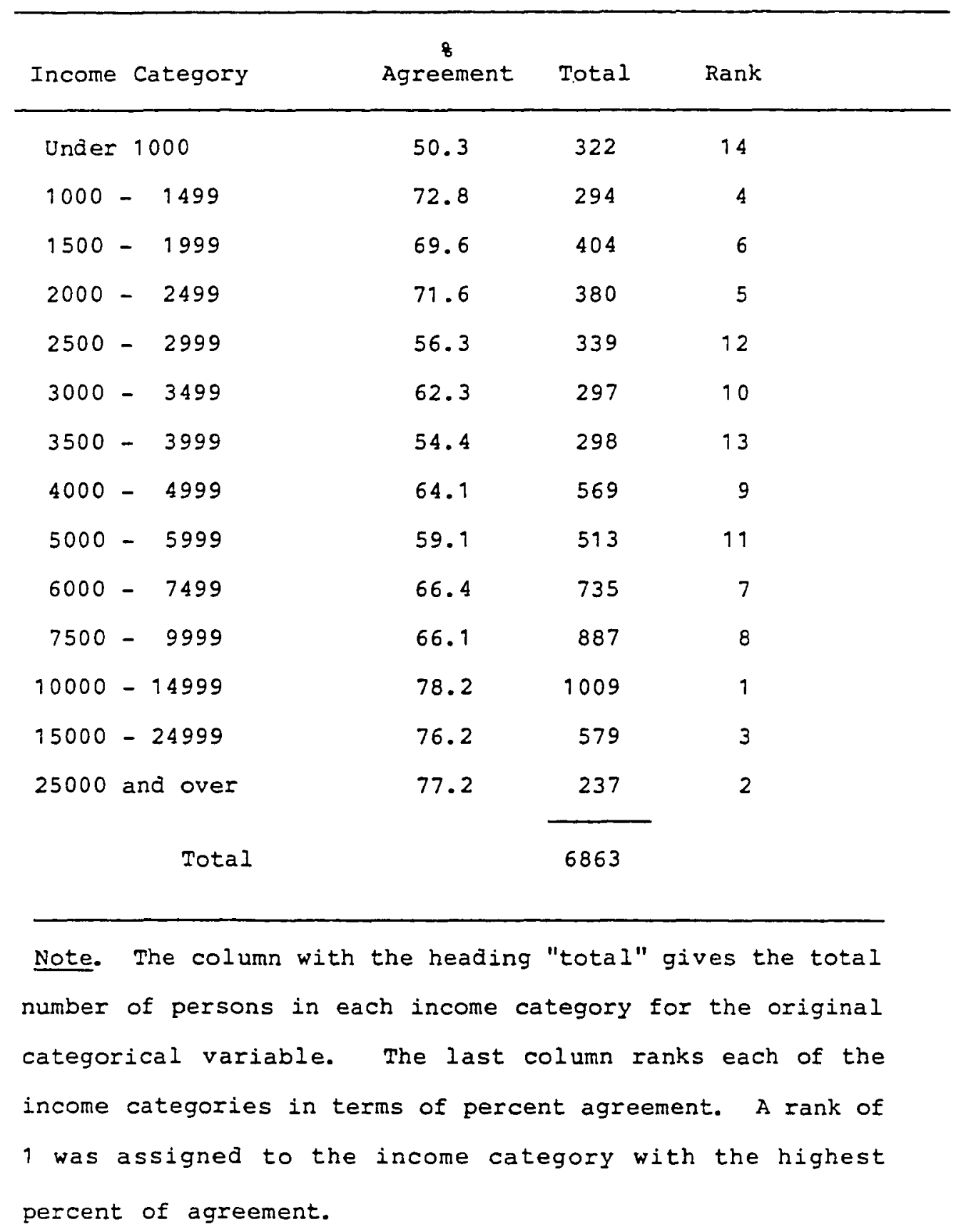


6863, that is, 238 of the respondents have a missing value on one or both variables. The income measure has to be interpreted with extreme caution particularly when difference scores and percentage gain scores are discussed.

\section{Satisfaction with standard of Living}

This area of financial resources is represented by three items. The first item assesses a respondent's feelings about his/her standard of living compared to that of friends or acquaintances. A high score on this item reflects a high degree of satisfaction with one's standard of living. The item has a 3 -point range. It has a normative focus and requires the respondents to compare their way of living to others they know. The item is identical across the three waves of data collection. Its precise wording is:

"Would you say the way you are living is better than, worse than, or about the same as that of most of your friends and acquaintances?"

The second item reflects respondents' ability to meet their needs based on the income they have. The item has a 4point range and a high score reflects that there is always money left over for extras. It is identical across waves. Its wording is:

\footnotetext{
"Which of the following four statements describes your ability to get along on your income? I can't make ends meet; I have just enough, no more; I have enough, with a little extra sometimes; I always have money left over."
}

The last item in this area assesses respondents' satisfaction with their standard of living. The item has a 
4-point range and is identical across the three waves of data collection. - It was recoded so that a high score indicates a high degree of satisfaction. The wording for this item is:

\footnotetext{
"Generally, how satisfied are you with the way you are living now - that is, as far as money and what you are able to have are concerned? Would you say the way you are living is more than satisfactory; satisfactory; unsatisfactory; very unsatisfactory?"
}

Internal Consistency and Stability

The internal consistency for the indexes which measure health resources, social resources, financial resources, and subjective well-being ranges from .22 to .79 with a median value of .42 (see Table XXII). For each index, the pattern of results regarding internal consistency is fairly consistent across the three waves of data collection, with the possible exception of Societal Involvement in 1973. Nunnally (1978) gives some guidelines as to acceptable levels of internal consistency. They are tied to the use to which the index will be put. He suggests a value of .70 or greater for research purposes (pp. 245-246). Some considerations which affect a decision regarding an acceptable level of internal consistency are briefly alluded to below. First, there are instances where a highly internally consistent index is not expected. Indexes assessing behaviors such as the utilization of health resources are not expected to be homogeneous. Such 
TABLE XXII

INIERNA, ONSISTENCY CFFFICIPNTS FOR TIF, HFALTH, SOCIN, FINANCIAL,

AND SURJDCTIVE WEDI $r$ BEING INDEXES IN 1969, 1971, 1973

\begin{tabular}{|c|c|c|c|c|}
\hline $\begin{array}{l}\text { Resource Area } \\
\text { Index/Item }\end{array}$ & $\begin{array}{l}\text { Number } \\
\text { of items/ } \\
\text { Indexes }\end{array}$ & 1969 & 1971 & 1973 \\
\hline $\begin{array}{l}\text { Health Resources } \\
\text { General Disability }\end{array}$ & 2 & $0.79 \quad(n=8916)$ & $0.79(n=8890)$ & $0.78 \quad(n=8899)$ \\
\hline $\begin{array}{l}\text { Overall Disability }{ }^{a} \\
\text { Utilization of Health } \\
\text { Resources }\end{array}$ & 2 & $\begin{array}{ll}0.75 & (n=8399) \\
0.42 & (n=8665)\end{array}$ & $\begin{array}{l}0.74 \quad(n=8407) \\
0.42 \quad(n=8847)\end{array}$ & $\begin{array}{ll}0.72 & (n=8432) \\
0.41 & (n=8846)\end{array}$ \\
\hline $\begin{array}{l}\text { Social Resources } \\
\text { Scope of Immediate } \\
\text { Family }\end{array}$ & 4 & $0.24 \quad(n=8886)$ & $0.23 \quad(n=8734)$ & $0.24(n=8720)$ \\
\hline $\begin{array}{l}\text { Size of Imnediate } \\
\text { Fanily }\end{array}$ & 4 & $0.22(n=8886)$ & $0.21 \quad(\pi=8734)$ & $0.22(n=8720)$ \\
\hline Societal Involvement & 2 & $0.39(n=8703)$ & $0.36(n=8561)$ & $0.26 \quad(n=8375)$ \\
\hline $\begin{array}{l}\text { Financíal Resources } \\
\text { Income }\end{array}$ & 1 & b & b & b \\
\hline $\begin{array}{l}\text { Subjective Well-being } \\
\text { Happiness }\end{array}$ & 1 & b & b & b \\
\hline outlook on Liffe & 3 & $0.61 \quad(n=7968)$ & $0.58 \quad(n=8071)$ & $0.59(n=7877)$ \\
\hline
\end{tabular}

Note. The internal consistency estimates were calculated for the sample of continuers, $n=8922$. The sample size varies due to the listwise deletion of cases with missing values on one or more variables.

a This index is composed of two other indexes, work limitations and mobility limitations.

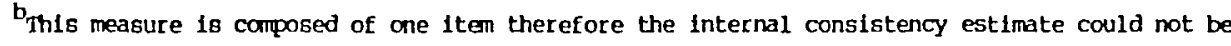
computed.

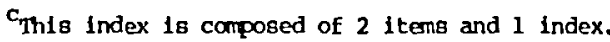


reasoning also holds for the social resources area. secondly, the internal consistency estimate will become progressively larger as items are added to the index if the additional items do not lower the average correlation coefficient. Compared to typical standardized tests in psychology, for example, the indexes constructed for this project have a relatively small number of items. Finally, the internal consistency was calculated for the sample of continuers only. This may have lowered the estimate due to a restriction of range in the sample.

The correlational stability coefficients for the indexes provide preliminary evidence for the construct validity of the measures. As expected the 4-year stability coefficients (last column in Table XXIII) are lower than the 2-year coefficients. Less stability is expected as the length of time between measurement periods increases. Lack of stability may occur because respondents experience real change over time and are therefore ordered differently at the two measurement periods. Lack of stability can also be attributed to various sources of measurement error such as changes in interpretation on the part of the respondents, changes in the salience of the topic, or changes in the willingness of respondents to divulge information in its entirety. The two indexes which measure the composition and number of persons in the immediate family sector of the network have extremely high stability $(r=.88$ to .94). This is expected because change over a 4 -year period in the 
TABLE XXIII

TWO-YEAR AND FOUR-YEAR STABILITY COEFFICIENTS FOR THE INDEXES MEASURING HEALTH, SOCIAL, FINANCIAL RESOURCES, AND SUBJECTTVE WEIL-BEING

\begin{tabular}{|c|c|c|c|}
\hline $\begin{array}{l}\text { Resource Area } \\
\text { Index/Item }\end{array}$ & 1969-1971 & $1971-1973$ & $1969-1973$ \\
\hline $\begin{array}{l}\text { Health Resources } \\
\text { General Disability } \\
\text { Overall Disability } \\
\text { Utilization of } \\
\text { Health Resources }\end{array}$ & $\begin{array}{ll}0.60 & (n=8884) \\
0.68 & (n=7929) \\
0.34 & (n=8592)\end{array}$ & $\begin{array}{ll}0.56 & (n=8867) \\
0.65 & (n=7940) \\
0.33 \quad(n=8773)\end{array}$ & $\begin{array}{ll}0.52 & (n=8893) \\
0.58 & (n=7924) \\
0.28 & (n=8591)\end{array}$ \\
\hline $\begin{array}{l}\text { Social Resources } \\
\text { Scope of Immediate } \\
\text { Family } \\
\text { Size of Immediate } \\
\text { Family } \\
\text { Societal Involvement }\end{array}$ & $\begin{array}{l}0.91 \quad(n=8701) \\
0.94 \quad(n=8701) \\
0.57 \quad(n=8372)\end{array}$ & $\begin{array}{l}0.92 \quad(n=8545) \\
0.94 \quad(n=8545) \\
0.43 \quad(n=8059)\end{array}$ & $\begin{array}{l}0.88 \quad(n=8689) \\
0.93 \quad(n=8689) \\
0.40 \quad(n=8185)\end{array}$ \\
\hline $\begin{array}{l}\text { Financial Resources } \\
\text { Income }\end{array}$ & $0.81 \quad(n=8430)$ & $0.84 \quad(n=8452)$ & $0.76 \quad(n=8363)$ \\
\hline $\begin{array}{l}\text { Subjective Well-being } \\
\text { Happiness } \\
\text { Outlook on Life }\end{array}$ & $\begin{array}{ll}0.42 & (n=8818) \\
0.62 & (n=7318)\end{array}$ & $\begin{array}{ll}0.42 & (n=8847) \\
0.61 & (n=7252)\end{array}$ & $\begin{array}{ll}0.37 \quad(n=8803) \\
0.57 \quad(n=7117)\end{array}$ \\
\hline
\end{tabular}


composition of one's immediate network should not be a normative event especially if the respondents are from the young-old group. The indexes in the area of health, and the index measuring societal involvement show a moderate amount of stability $(r=.40$ to .68$)$. The stability coefficient for the income measure ranges from .76 to .84.

The stability coefficients for the items measuring an affective state have a pattern similar to that of the indexes. Based on a visual inspection of Table XXIV, it appears that the 4-year stability coefficients are lower than the 2-year ones. These stability coefficients range from .28 to .59 with a median value of .43 . If affective states are tied to an individual's personality traits (e.g., optimism), then one would expect self-report items of an evaluative nature to be more stable than measures which assess self-report of a situation or condition. If however, changes in self-report on affective states are symptomatic of changes in other domains and act as a warning sign, then they would tend to reflect more change at an earlier time period than measures of self-report on an objective situation. Finally, if their stability changes at the same rate as that of measures of self-report on objective status, it would imply that affective components are readjusted as external conditions create changes for the individual. For the present study, caution is warranted in the interpretation of the two sets of stability coefficients because of the lack of measures in 
TWO-YEAR AND FOUR-YEAR STABILITY COEFFICIENTS FOR THE TTEMS MEASURING HEALTH, FINANCIAL RESOURCES, AND SUBJECTIVE WEJL-BEING

\begin{tabular}{|c|c|c|c|}
\hline $\begin{array}{l}\text { Resource Area } \\
\text { Item }\end{array}$ & $1969-1971$ & $1971-1973$ & $1969-1973$ \\
\hline \multicolumn{4}{|l|}{ Health Resources } \\
\hline $\begin{array}{l}\text { Heal th compared } \\
\text { to others }\end{array}$ & $0.52(n=8220)$ & $0.50 \quad(n=8168)$ & $0.47(n=8212)$ \\
\hline $\begin{array}{l}\text { Heal th compared } \\
\text { to } 2 \text { years ago }\end{array}$ & $\mathbf{a}$ & $0.28 \quad(n=8597)$ & a \\
\hline \multicolumn{4}{|l|}{ Financial Resources } \\
\hline $\begin{array}{l}\text { Standard of living } \\
\text { compared to others }\end{array}$ & $0.36 \quad(n=8079)$ & $0.33 \quad(n=7898)$ & $0.30 \quad(n=7887)$ \\
\hline $\begin{array}{l}\text { Ability to get along } \\
\text { on income }\end{array}$ & $0.59 \quad(n=8606)$ & $0.58 \quad(n=8735)$ & $0.52(n=8572)$ \\
\hline $\begin{array}{l}\text { Satisfaction with } \\
\text { standard of living }\end{array}$ & $0.44 \quad(n=8838)$ & $0.43(n=8868)$ & $0.36(n=8837)$ \\
\hline $\begin{array}{l}\text { Subjective Well-being } \\
\text { Happiness }\end{array}$ & $0.42 \quad(n=8818)$ & $0.42 \quad(n=8847)$ & ก $37 \quad(n=8803)$ \\
\hline
\end{tabular}

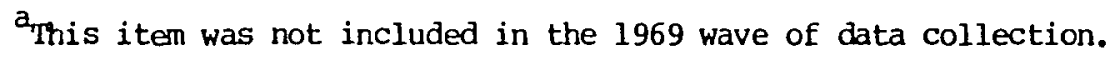


101

some areas (e. g., social resources) and because some indexes are not identical across waves (e.g., income).

\section{Descriptive Statistics and Correlations Within a Wave}

The descriptive statistics for the measures of health, social, financial resources, and subjective well-being offer some preliminary information on the construct validity of the measures used in this study. A one-way repeated measures analysis of variance was done to compare means from identical indexes or items across waves. The results of the analyses are presented in Chapter IV with the discussion for research question 2 on construct validity

The correlation coefficients between the measures of health, social, financial resources, and subjective wellbeing offer some preliminary evidence on the construct validity of the measures. These coefficients are presented in Tables XXV for the indexes and items measuring objective status and in Table XXVI for the items measuring subjective status. As expected, indexes which measure disability are positively correlated with the index which assesses a respondent's Utilization of Health Resources. The indexes measuring disability are not related to size and scope of Immediate Family but are inversely related to the index measuring Societal Involvement. The disability indexes are inversely related to Income and to subjective well-being measures. 
DABLE DON

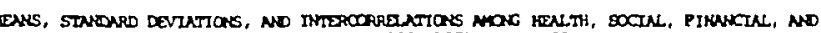

gar.

\begin{tabular}{|c|c|c|c|c|c|c|c|c|c|c|c|}
\hline $\begin{array}{l}\text { Rewautce Aros } \\
\text { Index/Itom }\end{array}$ & & Yoar & (1) & (2) & (3) & (4) & (5) & (6) & (7) & (B) & (9) \\
\hline $\begin{array}{l}\text { Health keouitces } \\
\text { Gorecai } \\
\text { Disability }\end{array}$ & (1) & $\begin{array}{l}1969 \\
1971 \\
1973\end{array}$ & & $\begin{array}{c}0.90 \\
(n-8385) \\
0.90 \\
(\pi-8390) \\
0.91 \\
(n=8405)\end{array}$ & $\begin{array}{c}0.25 \\
(1-8659) \\
0.28 \\
(n-8818) \\
0.26 \\
(n-8825)\end{array}$ & $\begin{array}{l}-0.02 \\
(n-0880) \\
-0.02 \\
(m-6706) \\
0.01 \\
(n-0697)\end{array}$ & $\begin{array}{l}0.05 \\
(n-8880) \\
0.04 \\
(n=8704) \\
0.07 \\
(m-8697)\end{array}$ & $\begin{array}{l}-0.17 \\
(n-8697) \\
-0.14 \\
(m-8533) \\
-0.11 \\
(1 m-10354)\end{array}$ & $\begin{array}{l}-0.28 \\
(1-8610) \\
-0.30 \\
(n-8653) \\
-0.27 \\
(n-2598)\end{array}$ & $\begin{array}{l}-0.25 \\
(n=88441) \\
-0.25 \\
(n-8859) \\
-0.27 \\
(n=8855)\end{array}$ & $\begin{array}{l}-0.50 \\
\{(n=7963) \\
-0.47 \\
(n-8045) \\
-0.45 \\
(n-7860)\end{array}$ \\
\hline $\begin{array}{l}\text { Overail } \\
\text { Dicabllity }\end{array}$ & (2) & $\begin{array}{l}1969 \\
1971 \\
1973\end{array}$ & & & $\begin{array}{c}0.24 \\
(n=28)(5) \\
0.28 \\
(n-8324) \\
0.30 \\
(n-8338)\end{array}$ & $\begin{array}{l}-0.05 \\
(m-8349) \\
-0.04 \\
(1-8220) \\
-0.00 \\
(m-8217)\end{array}$ & $\begin{array}{c}0.03 \\
(n=8349) \\
0.04 \\
(\pi=0220) \\
0.06 \\
(5=8217)\end{array}$ & $\begin{array}{l}-0.23 \\
(\pi-8177) \\
-0.20 \\
(\pi-8052) \\
-0.17 \\
(\text { (20.7894) }\end{array}$ & $\begin{array}{l}-0.35 \\
(n \times 8100) \\
-0.38 \\
(n-1)=164) \\
-0.32 \\
(n-3123)\end{array}$ & $\begin{array}{l}-0.29 \\
(108313) \\
-0.30 \\
(n-8363) \\
-0.30 \\
(n-30365)\end{array}$ & $\begin{array}{l}-0.55 \\
(m-7495) \\
-0.53 \\
(m-7600) \\
-0.54 \\
(n=7430)\end{array}$ \\
\hline $\begin{array}{l}\text { Utill zation of } \\
\text { Health hesources }\end{array}$ & (3) & $\begin{array}{l}1969 \\
1971 \\
1973\end{array}$ & & & & $\begin{array}{c}-0.02 \\
(\mathrm{~m}-8631) \\
-0.01 \\
(\mathrm{n}=8661) \\
0.01 \\
(n+1) 8649)\end{array}$ & $\begin{array}{l}-0.02 \\
(m=8631) \\
-0.01) \\
(\pi=8661) \\
0.01 \\
(\pi-8649)\end{array}$ & $\begin{array}{l}0.04 \\
(288467) \\
0.05 \\
(n-8456) \\
0.02 \\
(1000309)\end{array}$ & $\begin{array}{c}0.02 \\
(n-8379) \\
-0.00 \\
(n-8611) \\
0.02 \\
(n-0547)\end{array}$ & $\begin{array}{l}-0.07 \\
(m-8595) \\
-0.06 \\
(n=8017) \\
-0.08 \\
(m-8802)\end{array}$ & $\begin{array}{l}-0.17 \\
(1.7756) \\
-0.17 \\
(m-8010) \\
-0.19 \\
(\pi=7813)\end{array}$ \\
\hline $\begin{array}{l}\text { Socis] Resources } \\
\text { Scope of } \\
\text { Imdiate Fondly }\end{array}$ & (1) & $\begin{array}{l}2969 \\
1971 \\
2973\end{array}$ & & & & & $\begin{array}{c}0.69 \\
(n=8886) \\
0.69 \\
(n-8734) \\
0.70 \\
(m=8720)\end{array}$ & $\begin{array}{c}0.16 \\
(n-8670) \\
0.15 \\
(n-8390) \\
0.08 \\
(n-6201)\end{array}$ & $\begin{array}{c}0.30 \\
(.08582) \\
0.30 \\
(n-8507) \\
0.31 \\
(n-8437)\end{array}$ & $\begin{array}{c}0.07 \\
(\sin 8612) \\
0.07 \\
(m=8705) \\
0.06 \\
(n=8680)\end{array}$ & $\begin{array}{c}0.06 \\
(n=7938) \\
0.05 \\
(n=7914) \\
0.04 \\
(n=7711)\end{array}$ \\
\hline $\begin{array}{l}\text { S1ze of } \\
\text { Inomdiate Pemilyy }\end{array}$ & (5) & $\begin{array}{l}1969 \\
1971 \\
1973\end{array}$ & & & & & & $\begin{array}{l}-0.02 \\
(\pi-8670) \\
-0.01 \\
(n=8390) \\
-0.02 \\
(\pi-8201)\end{array}$ & $\begin{array}{c}0.06 \\
(108582) \\
0.05 \\
(10-8507) \\
0.06 \\
(1-8137)\end{array}$ & $\begin{array}{l}-0.03 \\
(n=8812) \\
-0.01 \\
(n-8705) \\
-0.02 \\
(1-8600)\end{array}$ & $\begin{array}{l}-0.06 \\
(n=7938) \\
-0.05 \\
(0-7914) \\
-0.05 \\
(\pi 0723)\end{array}$ \\
\hline $\begin{array}{l}\text { social } \\
\text { imvolvasent }\end{array}$ & (6) & $\begin{array}{l}2969 \\
1971 \\
2973\end{array}$ & & & & & & & $\begin{array}{c}0.46 \\
(0-1520) \\
0.46 \\
(n=8369) \\
0.36 \\
(5-6138)\end{array}$ & $\begin{array}{l}0.20 \\
(0-8637) \\
0.16 \\
(m-8540) \\
0.15 \\
(m-8342)\end{array}$ & $\begin{array}{c}0.30 \\
(n=7793) \\
0.26 \\
(m=7788) \\
0.21 \\
(r m-744)\end{array}$ \\
\hline $\begin{array}{l}\text { Punarcial Rewources } \\
\text { Incane }\end{array}$ & (7) & $\begin{array}{l}1969 \\
1971\end{array}$ & & & & & & & & $\begin{array}{c}0.29 \\
(\pi-8556) \\
0.29 \\
(\mathrm{~m}-\mathrm{B} 657) \\
0.27 \\
(\mathrm{~m}-858 \mathrm{~B})\end{array}$ & $\begin{array}{c}0.43 \\
(n=7742) \\
0.44 \\
(n=7894) \\
0.41 \\
(m=7667)\end{array}$ \\
\hline $\begin{array}{l}\text { suejective well teing } \\
\text { Happinews }\end{array}$ & (8) & $\begin{array}{l}2969 \\
2971 \\
2973\end{array}$ & & & & & & & & & $\begin{array}{l}0.77 \\
(n \rightarrow 7968) \\
0.77 \\
(n=8071) \\
0.76 \\
(n=7877)\end{array}$ \\
\hline $\begin{array}{l}\text { artlook } \\
\text { an Life }\end{array}$ & (9) & $\begin{array}{l}1969 \\
197 \\
1973\end{array}$ & & & & & & & & & \\
\hline $\begin{array}{l}\text { Mowi, } \\
\text { othindard deviation, } \\
\text { and arople size }\end{array}$ & & 2969 & $\begin{array}{l}2.93 \\
(4.12) \\
(m 8916)\end{array}$ & $\begin{array}{l}2.50 \\
(2.52) \\
(n=8385)\end{array}$ & $\begin{array}{l}2.98 \\
(2.63) \\
(n=8665)\end{array}$ & $\begin{array}{l}6.27 \\
(2.21) \\
(0=8886)\end{array}$ & $\begin{array}{l}4.97 \\
(2.12) \\
(\pi=8886)\end{array}$ & $\begin{array}{l}6.89 \\
(3.46) \\
(\pi-8703)\end{array}$ & $\begin{array}{l}8.46 \\
(3.79) \\
(n-8616)\end{array}$ & $\begin{array}{l}5.41 \\
(3.40) \\
(n-8846)\end{array}$ & $\begin{array}{l}5.42 \\
(2.39) \\
(n-7968)\end{array}$ \\
\hline & & 1971 & $\begin{array}{l}3.16 \\
(4.21) \\
(m=889)\end{array}$ & $\begin{array}{l}1.75 \\
(2.72) \\
(n=839)\end{array}$ & $\begin{array}{l}3.12 \\
(2.66) \\
(\pi-8847)\end{array}$ & $\begin{array}{l}6.16 \\
(2.15) \\
(n=8736)\end{array}$ & $\begin{array}{l}4.90 \\
(2.11) \\
(n=8734)\end{array}$ & $\begin{array}{l}6.92 \\
(3.52) \\
(n-1) 561)\end{array}$ & $\begin{array}{l}8.57 \\
(3.79) \\
(m-8682)\end{array}$ & $\begin{array}{l}5.69 \\
(3.41) \\
(50890)\end{array}$ & $\begin{array}{l}5.57 \\
(2.28) \\
(1 \mathrm{~m}-8071)\end{array}$ \\
\hline & & 1973 & $\begin{array}{l}3.71 \\
(4.34) \\
(m-8899)\end{array}$ & $\begin{array}{l}2.24 \\
(2.96) \\
(n=8106)\end{array}$ & $\begin{array}{l}3.28 \\
(2.62) \\
(m=8046)\end{array}$ & $\begin{array}{l}6.03 \\
(2.14) \\
(m=8720)\end{array}$ & $\begin{array}{l}4.78 \\
(2.13) \\
(\mathrm{m}=8720)\end{array}$ & $\begin{array}{l}5.91 \\
(3.72) \\
\left(\mathrm{r}^{2} 8375\right)\end{array}$ & $\begin{array}{l}8.63 \\
(3.58) \\
(0=8616)\end{array}$ & $\begin{array}{l}5.61 \\
(3.50) \\
(\mathrm{m} 8078)\end{array}$ & $\begin{array}{l}5.10 \\
(2.331 \\
\text { (507877) }\end{array}$ \\
\hline
\end{tabular}

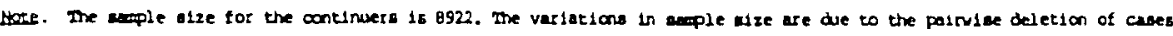
with a nusing value on one $\alpha$ both varlables.

N1 correlations greater then 035 are algolficant at $p \times .001$. 
TPALE XXVI

MEANS, STMNDARD DEVIATIORS, ND INTERCTPRETATIONS WONG HEALTH, FINANCLAL, ND SUBJETTVE WEL-BEINE IT2S FOR THE 1969,1971 , AND 1973 WAVES Of DATA COLDCTION

\begin{tabular}{|c|c|c|c|c|c|c|c|c|}
\hline $\begin{array}{l}\text { Resource Ares } \\
\text { Item. }\end{array}$ & & Year & (1) & (2) & (3) & (4) & (5) & (6) \\
\hline \multirow{4}{*}{$\begin{array}{l}\text { Health Resources } \\
\text { Henl th compared to } \\
\text { others }\end{array}$} & & & & & & & & \\
\hline & (2) & 2969 & & 0 & $\begin{array}{c}0.28 \\
(\mathrm{n}=8199)\end{array}$ & $\begin{array}{l}0.31 \\
(\mathrm{r}=8345)\end{array}$ & $\begin{array}{c}0.30 \\
(n=8519)\end{array}$ & $\begin{array}{c}0.34 \\
(n=8501)\end{array}$ \\
\hline & & 2971 & & $\begin{array}{c}0.38 \\
(n=6399)\end{array}$ & $\begin{array}{c}0.22 \\
(n-8144)\end{array}$ & $\begin{array}{c}0.28 \\
(0-8+48)\end{array}$ & $\begin{array}{c}0.27 \\
(n=8499)\end{array}$ & $\begin{array}{c}0.28 \\
(n=8496)\end{array}$ \\
\hline & & 1973 & & $\begin{array}{l}0.42 \\
(n=8347)\end{array}$ & $\begin{array}{c}0.24 \\
(n-7976)\end{array}$ & $\begin{array}{l}0.28 \\
(n-8420)\end{array}$ & $\begin{array}{c}0.26 \\
(n=8491)\end{array}$ & $\begin{array}{l}0.31 \\
(\pi=8479)\end{array}$ \\
\hline \multirow{3}{*}{$\begin{array}{l}\text { heal th compared } \\
\text { to } 2 \text { years ago }\end{array}$} & (2) & 1969 & & & a & a & a & a \\
\hline & & 2971 & & & $\begin{array}{l}0.14 \\
(n=8336)\end{array}$ & $\begin{array}{l}0.20 \\
(n=8706)\end{array}$ & $\begin{array}{l}0.20 \\
(n=8756)\end{array}$ & $\begin{array}{l}0.21 \\
(n=8752)\end{array}$ \\
\hline & & 2973 & & & $\begin{array}{l}0.16 \\
(n=8106)\end{array}$ & $\begin{array}{c}0.20 \\
(n=8628)\end{array}$ & $\begin{array}{c}0.2) \\
(n=8720)\end{array}$ & $\begin{array}{c}0.24 \\
(n=8692)\end{array}$ \\
\hline \multirow{4}{*}{$\begin{array}{l}\text { Furancial Resources } \\
\text { Standara of living } \\
\text { compared to others }\end{array}$} & & & & & & & & \\
\hline & (3) & 1969 & & & & $\begin{array}{c}0.39 \\
(\mathrm{n}=\mathrm{B} 258)\end{array}$ & $\begin{array}{c}0.47 \\
(n=8451)\end{array}$ & $\begin{array}{c}0.29 \\
(n=8421)\end{array}$ \\
\hline & & 1971 & & & & & & \\
\hline & & 1973 & & & & $\begin{array}{l}0.34 \\
(\mathrm{tm} 8174)\end{array}$ & $\begin{array}{l}0.44 \\
(n=8263)\end{array}$ & $\begin{array}{l}0.30 \\
(n=8247)\end{array}$ \\
\hline \multirow[t]{3}{*}{$\begin{array}{l}\text { Abllity to get } \\
\text { olang on incone }\end{array}$} & (4) & 1969 & & & & & $\begin{array}{c}0.53 \\
(\pi-8646)\end{array}$ & $\begin{array}{c}0.34 \\
(\mathrm{n}=8528)\end{array}$ \\
\hline & & 1971 & & & & & $\begin{array}{c}0.52 \\
(n=8821)\end{array}$ & $\begin{array}{c}0.35 \\
(n=8816)\end{array}$ \\
\hline & & 1973 & & & & & $\begin{array}{c}0.51 \\
(n=8789)\end{array}$ & $\begin{array}{c}0.34 \\
(\mathrm{~m}=8775)\end{array}$ \\
\hline \multirow{3}{*}{$\begin{array}{l}\text { Satisfaction with } \\
\text { stariard of living }\end{array}$} & (5) & 1969 & & & & & & $\begin{array}{l}0.41 \\
(n=8815)\end{array}$ \\
\hline & & 1971 & & & & & & $\begin{array}{c}0.48 \\
(n=8677)\end{array}$ \\
\hline & & 1973 & & & & & & $\begin{array}{l}0.46 \\
(\operatorname{mes871)}\end{array}$ \\
\hline \multirow[t]{3}{*}{$\begin{array}{l}\text { sojective Well-beling } \\
\text { Happlness }\end{array}$} & (6) & 1969 & & & & & & \\
\hline & & 1971 & & & & & & \\
\hline & & 1973 & & & & & & \\
\hline \multirow[t]{3}{*}{$\begin{array}{l}\text { mean, } \\
\text { standard deviation, } \\
\text { and sarople size }\end{array}$} & & 1969 & $\begin{array}{l}1.18 \\
(0.73) \\
(0=8567)\end{array}$ & $\overline{-}$ & $\begin{array}{l}0.95 \\
(0.54) \\
(n=8464)\end{array}$ & $\begin{array}{l}1.47 \\
(0.95) \\
(r=8682)\end{array}$ & $\begin{array}{l}1.79 \\
(0.67) \\
(n=8853)\end{array}$ & $\begin{array}{l}1.08 \\
(0.68) \\
(n=8846)\end{array}$ \\
\hline & & 1971 & $\begin{array}{l}1.14 \\
(0.70) \\
(n-8519)\end{array}$ & $\begin{array}{l}0.85 \\
(0.62) \\
(\pi=8780)\end{array}$ & $\begin{array}{l}1.01 \\
(0.54) \\
(x=8460)\end{array}$ & $\begin{array}{l}2.52 \\
(0.96) \\
(n=8843)\end{array}$ & $\begin{array}{l}1.61 \\
(0.71) \\
(n-8894)\end{array}$ & $\begin{array}{l}1.14 \\
(0.68) \\
(n=8890)\end{array}$ \\
\hline & & 1973 & $\begin{array}{l}1.10 \\
(0.70) \\
(n=8515)\end{array}$ & $\begin{array}{l}0.81 \\
(0.64) \\
(\mathrm{n}=8734)\end{array}$ & $\begin{array}{l}0.96 \\
(0.53) \\
(n=8266)\end{array}$ & $\begin{array}{l}1.47 \\
(0.92) \\
(n+8821)\end{array}$ & $\begin{array}{l}1.78 \\
(0.70) \\
(m-8896)\end{array}$ & $\begin{array}{l}1.12 \\
(0.70) \\
(n=8878)\end{array}$ \\
\hline
\end{tabular}

Nefe. The sample size for the continuers 15 8922 . The variations in sapple size are due to the pairwise deletion of cases with a missing value on one or both varlables.

All correlations greater than .035 are significant at $\mathrm{pr} .001$.

Thes iter was not inciuded in the 1969 wave of date collection. 
Scope of Immediate Family is positively related to Income. This is not the case for the Size of Immediate Family index. Neither Scope nor Size of Immediate Family is associated with happiness. The Societal Involvement index is associated with Income and with happiness but in a fairly weak relationship for the latter variable. Finally, Income is related to happiness in a positive way. The Outlook on Life index replicates the pattern found between the happiness item and the measures of health, social, and financial resources. However, the correlation of that index with other measures is stronger than the corresponding correlation with the happiness item. This is the case because the Outlook on Life index has a wider range and because the content area of some of its component items overlap with the area of health and financial resources.

For the items which assess an affective state, the correlatiors are all above .20 with the exception of the relationship between the ipsative health item and the normative financial satisfaction item which is .14 and .16 for 1971 and 1973 respectively. Moderate correlations exist between the two health items and among the three financial satisfaction items. The correlation of the happiness item with the health and financial satisfaction items is slightly weaker than that found between the health measures or among financial ones. In summary, the items which assess an affective component tend to be associated with each other at a low to moderate level. The 
correlations fluctuate slightly across waves, but no definite trend regarding these difference across waves can be identified.

The Measurement of Change

The primary focus of this study is to compare different ways of measuring change from longitudinal data and to determine if change estimates provide additional information not given by cross-sectional results. As was pointed out earlier, theories in gerontology imply that the process of aging is accompanied by various kinds of change, including changes in health, social, and financial resources. Change that is the result of external events cannot always be isolated from change that is the result of developmental processes. This section outlines the three methods of measuring change which were chosen for this project, their strengths and shortcomings. These methods are the most frequently used techniques in the measurement of change. The section ends with a brief comment on selfperceived change and its relationship to the measurement of change from longitudinal data.

There are numerous mathematical ways to assess change. The approaches discussed below are a subset of these methods. They were chosen based on their particular relevance to aging and because they are methods frequently used to assess change. The approaches to change which are 
compared in this study are: difference scores, residual change scores, and percentage gain scores.

\section{Difference scores}

Probably the most controversial way to assess change is that of using difference scores. Given a score $X$ on an indicator at time 1, and a second score $Y$ on the same indicator at time 2, a difference score $\underline{D}$ is obtained by taking a difference between the two scores,

$$
D=(Y-X)
$$

Psychometricians have devised a formula to get an estimate of the "true" difference score. Such a score is derived by adjusting the raw scores of $X$ and $Y$ by the reliability of the measures and by computing the difference between time 1 and 2 with these adjusted scores. For this study, raw or unadjusted difference scores were calculated.

The characteristics of difference scores have been discussed at length in the change literature. Difference scores are easily understood and provide an estimate of the absolute value of change. However, in most instances, their psychometric properties are not strong. The reliability of difference scores is lower than that of residual change scores. For varying degrees of reliability of the time 1 and time 2 measures and for varying degrees of stability between the time 1 and the time 2 measures, difference scores show lower reliability than the corresponding residual change scores and this is particularly pronounced when both the reliability of the 
time 1 and time 2 measures and the stability of the measures is low (see Tables XXVII and XXVIII). Difference scores correlate negatively with the time 1 measure because they are affected by the well-known phenomenon of regression toward the mean and because they are particularly vulnerable to floor and ceiling effects. Individuals who score in the mid-range of a measure have the potential to go up or down when they are retested. Individuals who score at the extreme end point of the range have the option of going in only one direction. Because it is easier to gain or improve a score when the baseline is low, low scorers often show greater raw gain scores and smaller decline scores than high scorers. Thus difference scores are usually negatively correlated with baseline data or time 1 scores. Finally, difference scores assume invariance of the construct they measure and imply interval level measures. However, a change from midale to low may be qualitatively very different from a change from high to middle.

\section{Residual Change Scores}

Difference scores do not take into account the correlation between $X$ and $Y$, that is the correlation between time 1 and time 2 scores. A procedure advocated by Lord (1963) is that of obtaining a residual score to be used as the measure of change. Such a score is obtained by regressing $Y$ on $X$ and using the deviations from the 
TABLE XXVII

RELIABILITY OF DIFFERENCE SCORES FOR VARYING DEGREES OF PRE- AND POST-CORRETATION WOEFFICILNTS AND RELIABILITY OF PRE- AND POST-MEASURES

\begin{tabular}{l}
$\begin{array}{l}\text { Correlation } \\
\text { Coefficient } \\
\text { Between Pre- } \\
\text { and Post-scores } \\
\text { (Pxy) }\end{array} \begin{array}{c}\text { Reliability of Pre- and Post-scores } \\
\text { (assumed to be equal) } \\
\text { (P) }\end{array}$ \\
\hline
\end{tabular}

\begin{tabular}{llllll}
\hline & .50 & .60 & .70 & .80 & .90 \\
& & & & & \\
\hline 30 & .29 & .43 & .57 & .71 & .86 \\
.40 & .20 & .33 & .50 & .67 & .83 \\
.50 & .00 & .20 & .40 & .60 & .80 \\
.60 & $\mathrm{a}$ & .00 & .02 & .50 & .75 \\
.70 & $\mathrm{a}$ & $\mathrm{a}$ & .00 & .33 & .67 \\
.80 & $\mathrm{a}$ & $\mathrm{a}$ & $\mathrm{a}$ & .00 & .50 \\
.90 & $\mathrm{a}$ & $\mathrm{a}$ & $\mathrm{a}$ & $\mathrm{a}$ & .00 \\
\hline
\end{tabular}

Note. This table is an extension of a table presented in williams and zimmerman,

(1977).

The rellability of the difference scores is computed as follows when the reliability and the standard deviation of the pre- and post-tests are assuned to be equal:

$$
\begin{gathered}
\text { P - Pxy } \\
1-\text { Pxy }
\end{gathered}
$$

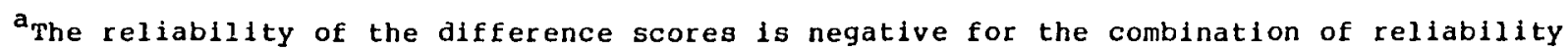


TABLE XXVIII

RELIABILITY OF RESIDUAL CHANGE SCORES FOR VARYING DEGREES OF PRE- AND POST-CORRELATION COEFF KCIENTS AND RELIABILITY OF PRE- AND POST-MEASURES

\begin{tabular}{|c|c|c|c|c|c|}
\hline \multirow[t]{2}{*}{$\begin{array}{l}\text { Correlation } \\
\text { Coefficient } \\
\text { Between Pre- } \\
\text { and Post-scores } \\
(\text { Pxy) }\end{array}$} & \multicolumn{5}{|c|}{$\begin{array}{c}\text { Reliability of Pre- and Post-scores } \\
\text { (assumed to be equal) } \\
\text { (PXX' = PYY') }\end{array}$} \\
\hline & .50 & .60 & .70 & .80 & .90 \\
\hline $\begin{array}{l}.30 \\
.40 \\
.50 \\
.60 \\
.70 \\
.80 \\
.90\end{array}$ & $\begin{array}{l}.45 \\
.31 \\
.17 \\
a \\
a \\
a \\
a\end{array}$ & $\begin{array}{l}.59 \\
.45 \\
.33 \\
.16 \\
\mathrm{a} \\
\mathrm{a} \\
\mathrm{a}\end{array}$ & $\begin{array}{l}.72 \\
.59 \\
.50 \\
.36 \\
.12 \\
a \\
a\end{array}$ & $\begin{array}{l}.85 \\
.72 \\
.67 \\
.58 \\
.42 \\
.09 \\
a\end{array}$ & $\begin{array}{r}.99 \\
.86 \\
.83 \\
.79 \\
.71 \\
.54 \\
.05\end{array}$ \\
\hline
\end{tabular}

Note. This table is an extension of a table presented in Linn and slinde (1977).

The rellability of residual change scores is computed as follows:

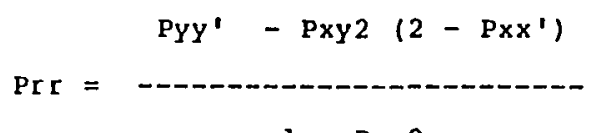

$1-\operatorname{Pxy} 2$

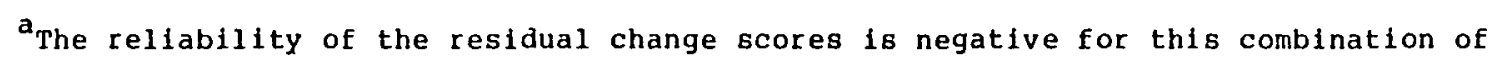
reliability and pre- and post-correlation coefficients. 
regression line, or residuals, as the estimate of the amount of change. Such a method takes the regression toward the mean phenomenon into account in that a person's residual score is based on how different his/her time 2 score is from what one would predict the score would be based on the correlation between $X$ and $Y$. The predicted score is calculated as follows:

$$
Y^{\prime}=b X+a
$$

The residual score is the difference between the actual $Y$ score and the predicted $Y$ score:

$$
\text { res } Y=Y-Y^{\prime}
$$

When the scores are transformed to z-scores, the use of the correlation coefficient between time 1 and 2 becomes evident since the predicted score is obtained as follows:

$$
z^{\prime} y=b z x
$$

where $b$ is the beta weight, which in this instance is equal to the correlation coefficient between $X$ and $Y$. The formula could be rewritten:

$$
\mathrm{Z}^{\prime} \mathrm{y}=\mathrm{r}_{12} \mathrm{Zx}
$$

For this study, the raw scores were not transformed to $z-$ scores and the formulas used to compute the predicted scores and the residual change scores were based on raw $x$ and $y$ scores.

Residual change scores provide an estimate of whether an individual has changed more than what would be expected based on the change which occurs in the entire group. One assumption underlying this approach is that the standard 
error of estimate, which is the standard deviation of the residuals, is presumed to be equal for any given point of x. In actuality, this is rarely the case especially if the distribution of $\mathrm{X}$ or $\mathrm{Y}$ contain outliers. In this instance, the slope of the best fitting line may not be a good estimate of the relationship between $X$ and $Y$ and some distortion is likely to result in the estimate of change (Rogosa et al., 1982).

Cronbach and Furby (1970) have argued that the regression equation used to generate the residual scores should incorporate another factor $W$ which stands for al 1 the other variables (e.g., age) which may be associated with both $X$ and $Y$. The predicted score $Y$ is a Iinear combination of both $\mathrm{X}$ and $\mathrm{W}$ and the residual score is again based on the difference between the actual $Y$ score and the predicted $Y$ score. The residual score, then, is that portion of the actual Y score which cannot be accounted for by the linear combination of $x$ and $w$. The variable $w$ is, of course, a symbol and could stand for more than one variable in a given equation. This approach, then, simply uses multiple linear regression to obtain the predicted $Y$ scores.

In a similar vein, some researchers have advocated the use of analysis of covariance to analyze differences among groups on posttest scores using pretest scores as the covariate. Yet another approach has been suggested, that 
of doing separate analyses of posttest scores for the respondents who have high, middle, and low scores at the pretest. This procedure is referred to as blocking and is useful when the pretest/posttest relationship is nonlinear. Residual change scores allow a somewhat conservative approach to the singling out of individuals who have changed more than would have been predicted given the relationship of time 1 and time 2. It may be a way to separate individual change from developmental change if it can be assumed that change in the group as a whole is a good gauge of developmental change at all levels. For example, individuals with residual scores above +1 standard error of estimate or below -1 standard error of estimate may provide some clues into the correlates of differing rates of change. The most troubling feature of residual change scores is that change is assumed to be equivalent along any point of the continuum of the construct being measured. A change from middle to low, for example, is considered, quantatively at least, equivalent to a change from high to middle. Conceptually, however, such a change may not be equivalent.

\section{Percentage Gain Scores}

Menlo and Johnson (1971) have recommended the use of percentage gain scores as a way to measure intra-individual change. Such an approach takes into account an individual's starting point. A percentage gain score is computed as follows: 


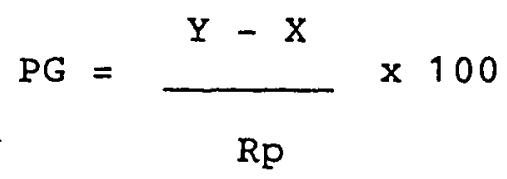

where $\mathrm{Y}$ is the time 2 indicator, $\mathrm{X}$ is the time 1 indicator, and $\mathrm{Rp}$ is the maximum possible gain score. This score is obtained by substracting the time 1 score, $x$, from the highest possible score. Percentage gain scores, then, are a ratio of the difference between the time 2 and the time 1 indicators over the difference between time 1 and the highest possible score which could be obtained. As Menlo and Johnson (1971) point out:

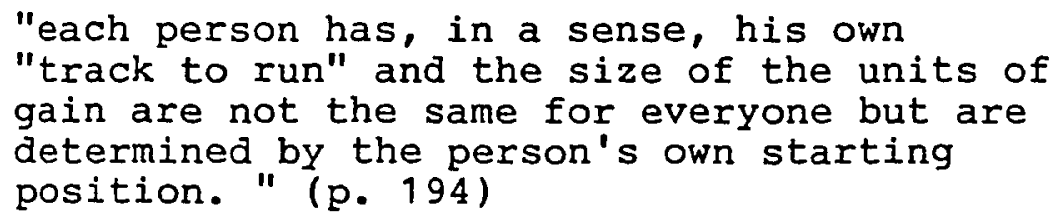

This method assumes that the distance between an individual's starting point and the highest possible score can be covered within the time interval of the data collection wave. It also assumes that intervals along the continuum are equal. Such assumptions may be unrealistic. To continue the analogy of Menlo and Johnson, the last mile may be the most difficult to run. Persons with low scores would be at an advantage in that they may, on the average, cover more distance and show similar or greater amount of gain than persons starting with a high score. Furthermore, the formula presented does not allow for negative percentage gain scores. The following formula (stewart, 
1984) can be used for measuring negative gain or percentage loss (PL):

$$
\mathrm{PL}=\frac{\mathrm{Y}-\mathrm{X}}{\mathrm{X}-\text { Minimum score }}
$$

where $Y$ is the time 2 score, $X$ is the baseline or time 1 score, and the minimum score is the lowest score which can be obtained on the scale, in most instances zero for the current study.

The three approaches to the measurement of change which are to be compared using the LRHS data set have been reviewed. Both difference scores and percentage gain scores are strongly influenced in their approach to measuring change by learning theories. Implicitly they assume that the change will be in the positive direction. Problems of measuring change associated with missing values and with the use of continuers were not addressed since they are beyond the scope of this project. However, these issues are far from trivial and merit in their own right close scrutiny and investigation.

\section{Self-perceived Change}

The last approach to measuring change which has been incorporated in this study is that of self-perceived change or retrospective change. This measure of change is based on an individual's own assessment of change. Typically, a measure based on self-perceived change will contain a time referent. Approaches to the measurement of 
change can be classified on two dimensions, that of the referent or anchor for comparison and whether the change is based on a self-reported individual assessment or whether the measure of change is based on a quantitative approach using longitudinal data.

For the present study, one indicator of self-perceived change was identified in the LRHS data. This item which measures self-perceived changes in health was not included in the 1969 wave of data collection. It is identical in both the 1971 and 1973 waves of data collection. The item has 3 points in its range and its precise wording is:

"How would you say your health today compares with your own health two years ago? Is it better, worse, or the same?"

Data Handling

This first section describes the handling of the data files prior to any data analysis. Such information is provided because examination of the handing of the data gives cues to the integrity of the data base and therefore to the credibility of the findings.

The data analysis for this study was conducted on a Harris 300 located at the Biostatistics Laboratory, Oregon Health Sciences University. The data preparation was done using the statistical Package for the Social sciences (SPSS), version 9.1 or utility subroutines of the Harris computer. The blocked tapes were borrowed from the Institute on Aging at Portland State University. Full 
documentation on these tapes is provided in stewart, 1982. The three data tapes were copied onto disk into three separate data files and the records were unblocked by William Coshow, systems analyst and director of the Biostatistics Laboratory. After the unblocking of the records, an sPSS program was written to define the data files and to determine the location of the alpha characters which were liberally sprinkled among these data. Once the location of the alpha characters was determined, the data files were edited and all alpha characters changed to numeric values. Because the editing process writes values in the data files, the editing was done sequentially and the variables with the largest field or number of columns were edited first. This process preserves the integrity of the record length. For a three column variable, the code of -77 was assigned to the alpha character ONA, a code of -88 was written for the symbol $0 \mathrm{DK}$, and a code of -99 was chosen for the symbol ORA. The symbol ONA or NA means that the item was not answered or is not applicable, the symbol $O D K$ or $D K$ means that the respondent has chosen to answer "don't know", and the symbol ORA or RA means that the respondent refused to answer the question. For two column variables, the codes of $-7,-8$, and -9 were assigned to the symbols NA, DK, and RA respectively. Usually, for one column variable, a code of 7 was assigned for the symbol $A$, a code of 8 for the symbol $k$, and a code of 9 for the 
symbol $R$ unless these values had already been used as valid codes. In this latter case, another value was chosen, usually 0. After this editing process was completed, all blank characters were assigned a value of -999 . At this point the data files were redefined in SPSS and frequency distributions were run for all the variables of interest. These frequencies were compared to the original set to ascertain that no variable had been inadvertently changed during the editing process.

The second step involved the construction of the indexes to be used in the analyses. Each wave of data collection was handled separately. The index construction phase used the programs given in the LRHS report (Stewart, 1982). Minor changes were made to make the programs compatible to the spss version on the Harris. This entailed changing all the names to 6 characters and a redefinition of the missing values which were not identical to those of the original project due to a different process in handling alpha characters. Only indexes in the 0 to 10 metric or the raw metric were replicated. No z-versions or factor score versions of indexes were constructed. The index construction phase was repeated for the 1971 and the 1973 waves of data collection. Frequency distributions were run on all the indexes after the programs had been verified.

After a lengthy process of verification, 3 system files were created, one for each wave of data. These 
system files had uneven sample sizes due to attrition. Fortunately, the LRHS data tapes contain an identification number for each respondent and for each wave of data. In 1969, the identification number ranges from 1 to 11,153 sequentially. The three system files with the newly constructed indexes were broken into three instruction files and three data files using the "write cases" and the "list fileinfo" programs. The 1969 data file was sorted to ascertain that the identification numbers were ordered in a sequential and increasing order. A list of all the identification numbers was printed for 1971. From that list, the missing numbers for the non-continuers could be identified and added to the 1971 data file. Because the identification numbers were the only values added to the data file, for the non-continuers, blank characters were assigned by default to the indexes. These blank characters were later recoded to -999 and provided an easy check on the missing values. The records in the data file were then sorted. This process was repeated for 1973.

The steps just described were needed to allow for the merging of the files across years and for the linkage of the attrition variable with all the data files. After 1969, spouses of original respondents were interviewed if a respondent had died or was institutionalized. For the present analysis, these spouses had to be deleted from the 
data files because a change in respondent would distort the measurement of change.

The attrition variable was added last to the data set after each wave had been reconstructed into a system file. Finally a series of checks were done on the data. First a program was written to verify that across system files, the identification numbers were in an identical position. When this is not the case, the records of the respondents are not matched properly during the merge process. The sex and age of the respondents were checked across the 3 waves and the distribution of the attrition variable was checked to identify possible miscodings. Finally, frequency distributions on some demographic variables were compared to those obtained from the earlier project on index construction (Stewart, 1982). After reasonable certainty was obtained that the data were correct, system files were saved for the continuers $(n=8922)$.

\section{Statistical Analyses}

All analyses were done using the statistical Package for the social sciences (SPSS), version 9.1. The data analysis follows a fairly predictable pattern and was guided by the research questions.

As a first step, frequency distributions and correlation coefficients were computed for each wave of data separately. Subsequently, multiple linear regression programs were run, again within a wave, providing one- 
point-in-time information. The findings from these analyses are compared to the findings of the meta-analysis to answer the first research question.

Prior to the regression analyses, the indexes measuring health and social resources were sorted into two sets. The large sample size of this study permits the inclusion of many predictor variables. However, the large amount of overlap between the indexes within these two resource areas would have only given redundant information. Prior to any sorting, the indexes with non-identical items across waves were eliminated with the exception of Income. That is to say, the indexes of Utilization of Health Resources and Societal Involvement were not considered for any of the analyses after the initial frequency distributions and correlations. For the area of health and social resources, the indexes were matched with other indexes of a similar range. This resulted in two sets of predictor variables, one set composed of the Overall Disability index and the size of Immediate Family index, and the other set composed of the General Disability index and the scope of Immediate Family index. Therefore, two regression analyses were run within a wave with an indicator from each resource area and with the happiness item as the outcome measure. Income was included in both regression analyses to represent the area of financial resources. 
121

The rest of this chapter discusses the computation of the change scores and the analyses which were conducted to answer research questions 2 through 5. The goal was to create three change scores, one for each approach to the measurement of change. Within a given approach to the measurement of change in longitudinal data, (e.g., difference scores), three change scores were calculated, for each of the three waves of data collection, two change measures based on a two-year interval (1969 to 1971 and 1971 to 1973) and one change measure based on a four-year interval (1969 to 1973). A total of 9 change scores, then, were computed for each of the selected measures. The baseline year, referred to as time 1 , and the subsequent wave, labeled time 2 , shift depending on whether change from 1969 to 1971 is considered or change from 1971 to 1973 is the focus. In the case of the 4-year interval, 1969 is the base year or time 1 indicator and 1973 is the time 2 indicator.

For the change estimate based on difference scores, each selected 1969 measure was subtracted from its 1971 identical version yielding a 1971 difference score for that measure. Two difference scores were computed for the 1973 estimate, one as the result of subtracting the 1971 value from the 1973 score and the other from subtracting the 1969 score from the 1973 value. No adjustments were made to account for the reliability of the measures. 
The computations of percentage gain scores followed that of the creation of the difference scores. A positive gain score is obtained if a respondent scores higher at time 2 than he/she did at time 1. A percentage loss occurs for all respondents who score lower at time 2 than they did at time 1. The numerator of the percentage gain score is identical to that of the difference scores. However, this raw difference is adjusted by the maximum amount of change that could have occurred between the two measurement periods. In the presentation of the results, the scores were not transformed to percentages. This can easily be done by multiplying all the values presented by 100 . This Iinear transformation does not in any way change the results.

Residual change scores were computed in three steps. First a regression equation was derived for each measurement period by regressing the time 2 measure on the time 1 version of that measure. Then, the predicted score for each measure was calculated using the $\underline{b}$ weight and the a constant obtained in the regression equation. Finally, a residual score was obtained by substracting the predicted score from the actual time 2 measure. Residual scores have a mean of 0 and it is assumed that, in the population, they are normally distributed around the regression line for any given $x$ value.

The calculation of difference scores, percentage gain scores, and residual change scores was replicated for the 
items which tap the affective component of the areas of health and financial resources, and for the happiness item which measures the outcome of subjective well-being. Descriptive statistics for the change measures are presented in Tables LVI through LVIII of Appendix C for the indexes measuring the objective domain and in Tables LIX through LXI of Appendix $C$ for the items measuring the subjective domain.

The analyses for Research questions 2 through 5 were carried out using multiple linear regression and correlation coefficient procedures. Throughout these analyses, the previously sorted sets of predictor variables for the areas of health and social resources were maintained. Furthermore, all the analyses were replicated for the items measuring subjective status unless stated otherwise. 
CHAPTER IV

RESULTS AND DISCUSSION

Chapter IV describes the findings for this study. It is subdivided into five sections, one for each of the five research questions which were formulated at the beginning of this study.

\section{Question 1}

One important factor which pertains to the generalizability of the findings on the measurement of change is whether or not the LRHS sample is representative of other elderly samples. For the specific purposes of this study, it is important to establish if the magnitude of the relationship found in the LRHS sample of continuers between subjective well-being and the areas of health, social, and financial resources is similar to that reported in past research studies of elderly persons.

The first question was phrased as follows:

$$
\begin{aligned}
& \text { What is the magnitude of the relationship } \\
& \text { between subjective well-being and the } \\
& \text { areas of health, social, and financial } \\
& \text { resources for the LRHS sample? Do these } \\
& \text { values fall within the range found in the } \\
& \text { aging literature? }
\end{aligned}
$$

Pearson correlation coefficients for each of the three waves of data collection were computed for the LRHS sample 
of continuers $(n=8922)$ between the subjective well-being item and the indexes and items chosen to measure the areas of health, social, and financial resources. These correlations were then compared to the results of the metaanalysis presented in Chapter II.

A comparison of the findings from the LRHS data with those obtained from the meta-analysis can be readily made using Table XXIX. The first two columns of the table give the means and standard deviations of the correlation coefficients between subjective well-being and the selected measures of health, social, and financial resources. These statistics are based on the results of the meta-analysis for each resource area. Column 3 contains the values of the 25 th and the 75 th percentile for the distributions of these correlation coefficients. The last three columns Iist the correlation coefficients calculated for the LRHS sample on each of the selected measures.

The majority of the correlation coefficients computed for the LRHS sample fall within + and - one standard deviation of the calculated mean correlation of the metaanalysis. Futhermore, for the areas of disability, selfperceived health, and societal involvement, 7 out of a possible 9 LRHS coefficients fall within $1 / 2$ a standard deviation of the mean correlation for that area. However, for the area of inancial resources, 5 out of 6 correlation coefficients calculated for the LRHS sample fall above the 
CORRETATION OOEFFICIENTS BEIWEEN SUBJECTTVE WEIL,-BEING AND THE AREAS OF HEALTH, SOCIAL,, AND FINANCIAL RESQURCES: SUMMARY OF THE FINDINGS FROM THE MET'A-ANALYSIS AND THE LRHS DATA

\begin{tabular}{|c|c|c|c|c|c|c|c|}
\hline \multirow[b]{2}{*}{ Resource Area } & \multicolumn{4}{|c|}{ Results from the Meta-analysis } & \multicolumn{3}{|c|}{ Results from the LRHS data } \\
\hline & $\begin{array}{l}\text { Average } \\
\text { correlation } \\
\text { coefficient }\end{array}$ & $\begin{array}{l}\text { Standard } \\
\text { deviation }\end{array}$ & $\begin{array}{l}25 \text { th } \\
\text { percentile }\end{array}$ & $\begin{array}{l}\text { 75th } \\
\text { percentile }\end{array}$ & 1969 & 1971 & 1973 \\
\hline \multicolumn{8}{|l|}{ Health Resources } \\
\hline Disability & .22 & .10 & .12 & .30 & .25 & .25 & .27 \\
\hline Self-perceived health & .34 & .10 & .29 & .40 & .34 & .28 & .31 \\
\hline \multicolumn{8}{|l|}{ Social Resources } \\
\hline $\begin{array}{l}\text { Size of immediate } \\
\text { family network }\end{array}$ & .07 & .08 & -.04 & .12 & -.03 & -.01 & -.02 \\
\hline $\begin{array}{l}\text { Frequency of } \\
\text { social contacts }\end{array}$ & .08 & .08 & -.01 & .15 & a & a & $\mathbf{a}$ \\
\hline Societal involvement & .23 & .12 & .15 & .28 & .20 & .18 & .15 \\
\hline \multicolumn{8}{|l|}{ Financtal Resources } \\
\hline Income & .20 & .08 & .11 & .28 & .29 & .29 & .27 \\
\hline $\begin{array}{l}\text { Satisfaction with } \\
\text { standard of living }\end{array}$ & .27 & .09 & .18 & .35 & .41 & .48 & .46 \\
\hline
\end{tabular}

a Because no Identical itens could be found in the LRHS data set which measure this construct, the relationship between frequency of social contacts and subjective well-being could not be calculated for the LRHS sample. 
boundary of the first standard deviation established in the meta-analysis.

A similar pattern of results is observed when LRHS correlations are compared to percentile rank bands based on the meta-analysis (see Figure 2 in Chapter II). In the areas of health and social resources, all the calculated correlations for the LRHS sample fall between the 10 th and the goth percentiles of the distributions of the correlation coefficients from the meta-analysis. In fact, with very few exceptions, the coefficients in these two areas fall between the 25 th and the 75 th percentile of their respective distribution.

The correlation coefficients between subjective wellbeing and the measures for the area of financial resources have a different pattern from the one observed for the areas of health and social resources. The calculated correlation between subjective well-being and satisfaction with standard of living falls beyond the 90 th percentile at each of the three waves of data collection. The magnitude of the relationship between this affective item and subjective well-being is stronger than what, on the average, is reported in other aging studies. Although the calculated correlation coefficient between income and subjective well-being falls within the 75 th percentile in 1973, it falls beyond the 75th percentile for the 1969 and the 1971 waves of data collection. 
In summary, the majority of the correlation coefficients calculated from the LRHS data to estimate the relationship between subjective well-being and the areas of health and social resources fall within + and - one standard deviation from the mean established in the metaanalysis. To answer the first research question, the data suggest that the LRHS sample of continuers, at least with regard to the correlation of health and social resources with subjective well-being, is fairly typical of other elderly samples.

The discrepancy in the area of financial resources may be due to a combination of factors. The LRHS sample is comparatively young, and is approaching retirement or has just retired. The salience of financial resources may be heightened during this life cycle stage. Furthermore, in general, the samples which were part of the meta-analysis tend to have subjects who are older. They also tend to have a higher percentage of female respondents. Such samples, which are older and predominantly female, may have a smaller range on income than the LRHS sample.

Another explanation for the comparatively high magnitude of the correlation coefficients obtained may be found in the particular nature of the variables used to measure this domain. For example, the income variable has a range which is comparatively larger than most income measures used in the studies which were part of the metaanalysis. As for the item measuring satisfaction with 
standard of living, which exhibits the strongest degree of relationship with subjective well-being, the item is placed next to the subjective well-being measure (i.e., the happiness item) in the 1971 and in the 1973 LRHS questionnaires. This placement may have contributed to the comparatively large degree of correlation between the two measures. Finally, the results of the two meta-analyses for the area of financial resources are based on a relatively small number of effect sizes. Therefore the resulting distributions may not be good estimates of the sampling distributions of the correlation coefficients between measures of financial resources and subjective well-being.

\section{Descriptive Statistics for the Change Measures}

Prior to addressing research questions 2 through 5, a brief description of change over time in the happiness item is presented as well as an overview of the descriptive statistics for the difference scores, residual change scores, and percentage gain scores for both the happiness item and the independent variables used in subsequent analyses.

\section{The Happiness Item}

A classification based on the happiness item was devised as follows. Persons answering that they are "very happy" were sorted into the group labeled high (Hi), persons answering that they are "somewhat happy" were 
tallied into the medium group (Med), and persons who report that they are "not too happy" were assigned to the low group (LO). It is possible to crosstabulate the answers of the respondents in 1969 with their answer in 1971, and to repeat the process, this time crosstabulating answers in 1971 with those in 1973. It is also possible to crosstabulate the answers in 1969 with those in 1973 providing a 4-year estimate of change. The results of these crosstabulations are presented in Table XXX.

Over half of the continuers report the same amount of happiness when two waves of data collection are paired. of those, around 30 report a medium amount of happiness and less than 108 report a low degree of happiness while around 15 o report that they are "very happy" at the 2-year and 4year intervals.

Approximately 208 of the sample report a lesser degree of happiness over time and the percentage among this group are fairly constant whether a 2-year or a 4-year interval is examined. The majority of those who report less happiness over time (around 108 of the entire sample) belong to the high-medium (HiMed) group. These individuals report that they are "somewhat happy" but had chosen the "very happy" option at the previous wave of data collection. Another 7 to 88 of the respondents end up in the "not too happy" group having belonged to the "somewhat happy" group at the previous wave (the MedLo group). Very 
TABLE XXX

PERCENIAGE AND MUMBER OF PERSONS REPORTTING THE SAME, LESS,

OR MORE HAPPINESS AT TWO- AND FOUR-YEAK INIERVALS

\begin{tabular}{llllll}
\hline & $1969-1971$ & $1971-1973$ & $1969-1973$ \\
Group & & 8 & $N$ & $N$ & 8 \\
\hline
\end{tabular}

Same degree of happiness over time

\section{LOLO}

Medmed

HiHi

A lesser degree of happiness over time

$\begin{array}{lrr}\text { Medlo } & 7.0 & 6 \\ \text { HiMed } & 10.6 & 931 \\ \text { HiLo } & 1.5 & 135\end{array}$

A greater degree of happiness over time

$\begin{array}{rr}8.8 & 778 \\ 32.3 & 2852 \\ 15.4 & 1359\end{array}$

778
2852

$\begin{array}{rr}8.5 & 754 \\ 30.6 & 2704 \\ 17.1 & 1513\end{array}$

$\begin{array}{rrr}754 & 8.6 & 758 \\ 2704 & 30.4 & 2671 \\ 1513 & 14.7 & 1296\end{array}$

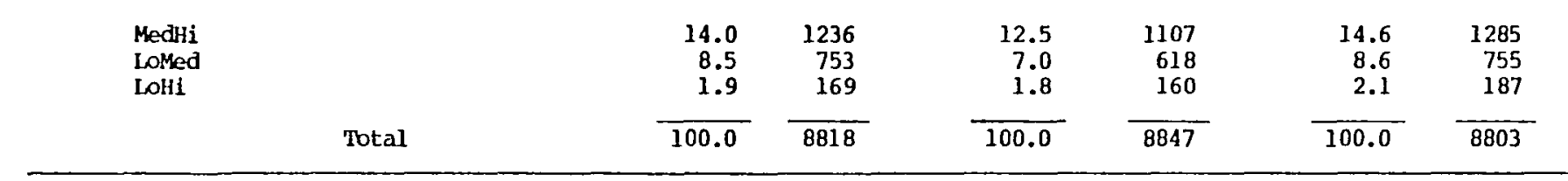

Note. The sample size for the continuers is 8922 . It varies due to the exclusion of cases with missing value on the happiness item. 
few respondents $(1.5$ to 2.48 of the entire sample) report that they are "not too happy" after having endorsed the "very happy" category at a previous wave.

Between 20 and 258 of the respondents report a greater amount of happiness over time. Their pattern of response is similar to the one observed for the repondents who report less happiness over time. The majority of the respondents reporting greater happiness over time move from the midale category, "the somewhat happy" group, to the "very happy" group. Between 7 and 8.68 of the sample report that they are "somewhat happy" after having chosen the low group option at a previous wave. Finally very few respondents, around 28 of the sample, report being "very happy" after having started in the "not too happy" group.

Table XXXI is the result of a three-way crosstabulation between the 1971 and the 1973 wave of data collection for each of the three options of the 1969 wave. The sample of continuers is almost evenly distributed across the three options of same, less, or more happiness over time. Over a third $(36.18)$ of the respondents report the same degree of happiness at all three points in time. of those, the majority $(56.48)$ reports that they are "somewhat happy".

Around 318 of the respondents report a lesser degree of happiness over time. Sorted in this group are people who experience a down trend, for example the HiMedLo group, and persons with a mixed pattern of ups and downs but who 


\section{TADLE XXXI}

PERCENTAGE AND NUMBER OF PERSONS REPORTING TIIE SAME, LESS OR MORE HAPPINESS OWER THE FCUR-YEAR INTYTNAL

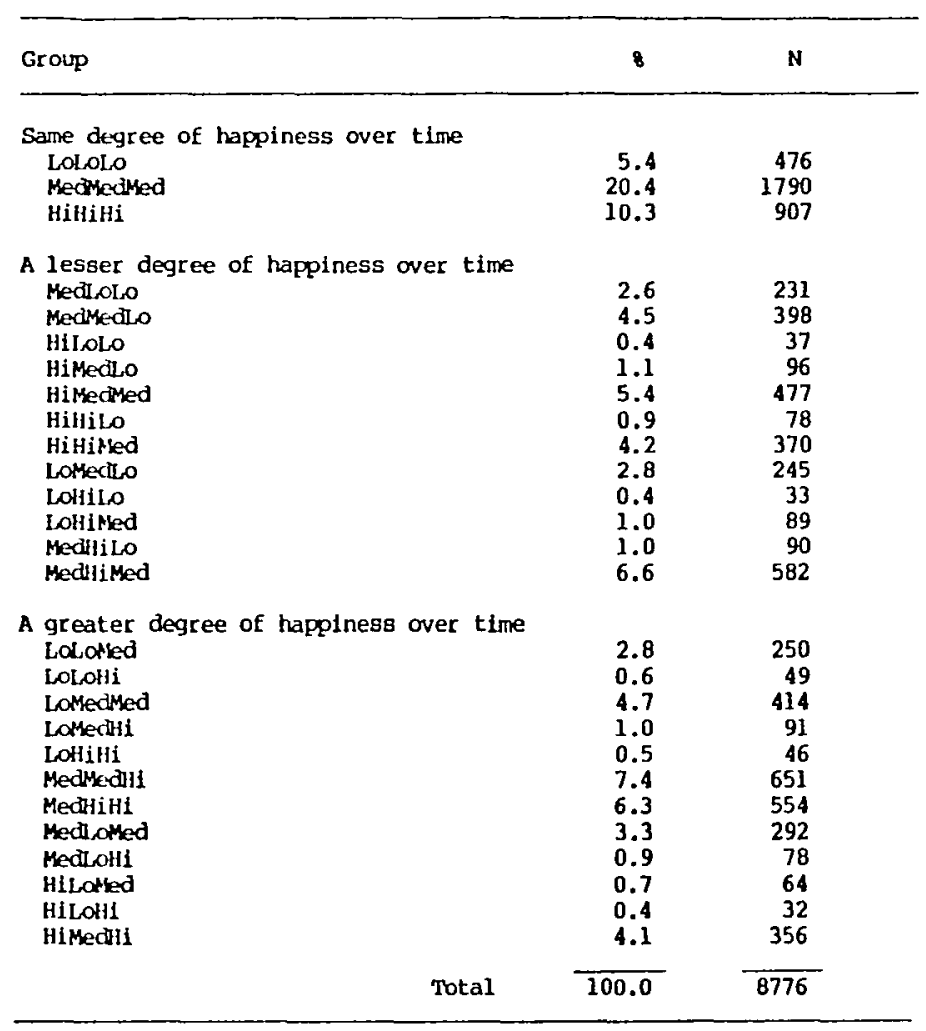

Note. The sample size for the continuers 18 8922. It varles due to the

exclusion of cases with missing value on the happiness item at one or more of

the waves of data collection. 
express less happiness in 1973 than they did in 1971. The most frequent pattern, approximately 528 of those who report less happiness over time, is that of ending in the "somewhat happy" group after having belonged to the "very happy" group, i.e., the MedHiHi, MedMedHi, and HiMedHi group. This pattern is experienced by 16.28 of the entire sample.

Around $33 \%$ of the respondents report a greater degree of happiness over time. People classified in this category are respondents who experience an upward trend, for example the LoMedHi group, and persons with a mixed pattern of ups and downs but who express more happiness in 1973 than they did in 1971. The majority of this grouping (approximately 548 ) is composed of respondents who move between the medium and high category, i.e., the HiMedmed, HiHimed, and the MedHiMed groupings. This pattern is reported by $17.8 \%$ of the entire sample.

In general, the continuers tend to report a fair amount of happiness over time and a substantial percentage are stable across the first three waves of data collection. The majority (64.78) stay within the high or medium category at all three points in time and of those (478), report the same amount of happiness from one wave of data collection to the next. When change occurs, it is usually a change to the next closest category. Very few repondents move from the low to the high category 1 1.58 of the entire 
sample) or from the high to the low grouping (1.78 of the entire sample).

The patterns shown in these data indicate that around the time of retirement, individuals tend to report a fair amount of happiness. Factors which may have contributed to these patterns are: a large proportion of the sample is composed of married males and the item which measures happiness has only a three-point range. Furthermore the response options offered to the respondents may have evoked some response set pattern, may have permitted easy recall, or may have triggered in some respondents a desire to appear in a positive light to the interviewer. It may also be the case that, faced with the wording of the three options for that item, the respondents concluded that, all things considered, they could experience more unhappiness than they presently do.

\section{Longitudinal Measures of Change}

The focus of question 2 is on a comparison of the three approaches to the measurement of change which were selected for this study. Prior to doing such a comparison, however, it is important to gather some preliminary evidence on the construct validity of the measures used in this study and on the construct validity of the change scores for these measures. As mentioned previously, gerontological theories emphasize that aging is accompanied by changes in the areas of health, social, financial resources, and subjective well-being. As respondents get 
older, then, change on the measures for these resource areas should be detected.

To seek information on the construct validity of the measures analyzed in this study and on the construct validity of the change scores, a series of repeated measures analysis of variance (ANOVA) were computed on the absolute scores and on the change scores of the indexes and items chosen to assess the areas of health, social, financial resources, and subjective well-being. Two sets of analyses were carried out. The first set of analyses focuses on whether or not change occurred from 1969 to 1971, from 1971 to 1973, and from 1969 to 1973. The second set of analyses compares the rate of change. The purpose of this second set is to determine if the rate of change from 1971 to 1973 is larger than the rate of change between 1969 and 1971. These analyses also give information on whether or not change during the 4-year interval, from 1969 to 1973, is greater than change which occurs during a 2-year interval, from 1969 to 1971 or from 1971 to 1973. Comparisons, then, are made between the 1969-1971 change scores and the 1971-1973 scores yielding 2-year interval comparisons. Comparisons are also made between the 19691973 change scores and the 1969-1971 and the 1971-1973 change scores providing information on the 4-year versus 2year rate of change. 
The findings from the repeated measures analysis of variance (ANOVA) are summarized in Table XXXII for the indexes and items which measure the objective domain, and in Table XXXIV for the items which assess the subjective domain. The descriptive statistics for the 1969, 1971, and 1973 waves of data collection were presented in Chapter III, Tables XIX and XX. The descriptive statistics for the Change measures are presented in Appendix $C$, Tables IVI through LXI. Tables XXXIII and XXXV contain the means, standard deviations, $F$ values, and critical differences which were computed in the repeated measures ANOVA. The critical difference is based on a Tukey test for means 3 steps apart and with a p value of .01. The ANOVA was computed only for measures that are identical across waves. Because the mean of residual change scores is 0 , no ANOVA was calculated for this approach to the measurement of change.

\section{Change Over Time.}

For the objective domain, fifteen comparisons were made on the measures assessing health, social resources, and subjective well-being to determine if the means are significantly different among the three waves of data collection. Fourteen of the fifteen comparisons were significant at $p=.01$ (See upper section of Tables XXXII and XXXIV). Across the four years spanning this study, respondents, on the average, report a greater amount of disability and a shrinkage in the scope and size of their 
TRLE XOXII

SIONIFICANT DIPPERDNCES BETWEEN PAIRS OF MEANS FOR THE 1969, 1971, MNO 1973 ITDMS

ND INDEXES NI FOR DIFTERENCE SOORES NO PERCEMAGE GAIN SOORES MEASURINC

HENTY, SOCIAL RESOURCE, AND SUBJETIVE WDIFBEINC

\begin{tabular}{|c|c|c|c|}
\hline $\begin{array}{l}\text { Resource Area } \\
\text { Index/Item }\end{array}$ & $2969-1971$ & $1971-1973$ & $1969-1973$ \\
\hline \multicolumn{4}{|l|}{ Health Resources } \\
\hline $\begin{array}{l}\text { General Disability } \\
\text { Qverall Disability }\end{array}$ & $\ddot{*}$ & $\because$ & $\because$ \\
\hline \multicolumn{4}{|l|}{ Social Resources } \\
\hline Scope of Irmediate Fanfly & $*$ & "* & * \\
\hline Size of Imediate Fonlly & $\bullet$ & $m$ & $*$ \\
\hline \multicolumn{4}{|l|}{ Subjective Well-being } \\
\hline Happiness & $*$ & NS & ** \\
\hline Difference Scores & $1969-1971 / 1971-1973$ & $1971-1973 / 1969-1973$ & $1969-1971 / 1969-1973$ \\
\hline \multicolumn{4}{|l|}{ Health Resources } \\
\hline General Disability & $*$ & $\ddot{m}$ & $\because$ \\
\hline Overali Digabliti & $* *$ & $*$ & "* \\
\hline \multicolumn{4}{|l|}{ Social Resources } \\
\hline Scope of Indediate Fandy & ns & $\because$ & $\because$ \\
\hline Size of Immediate Fambly & NS & $*$ & 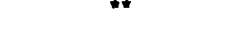 \\
\hline $\begin{array}{l}\text { abjective Hell-being } \\
\text { Bappiness }\end{array}$ & $\bullet$ & $\because$ & ks \\
\hline
\end{tabular}

\begin{tabular}{|c|c|c|c|}
\hline Percentage Gain Scares & $1969-1971 / 1971-1973$ & $2971-1973 / 1969-1973$ & $1969-1971 / 1969-1973$ \\
\hline $\begin{array}{l}\text { Bealth Resources } \\
\text { General Disability } \\
\text { Overall Disability }\end{array}$ & $N$ & kS & 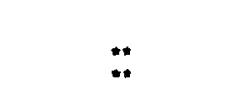 \\
\hline $\begin{array}{l}\text { Social Resources } \\
\text { Scope of Irmediate Fondly } \\
\text { Size of Impdace Fondly }\end{array}$ & $\begin{array}{l}\text { NS } \\
\text { NS }\end{array}$ & $\because$ & $\because$ \\
\hline $\begin{array}{l}\text { Sutjective well-belng } \\
\text { Happiness }\end{array}$ & $*$ & $*$ & Ns \\
\hline
\end{tabular}

Nete. Camparibons beween mans over time were anly made far indexes and items which are 1dentical across waves of data collection. The repeated measures analysis of variance could not be conputed for the residual change ecores because the moan of residuals is 0 .

The " Indicates that the peans are significantly different froc ench other at the $p=.01$ level. The Bymbol "NS" indicates that the means are not signtficantly different from ooch other at the $p=.01$ level. 
TABLE XXXIII

\begin{tabular}{|c|c|c|c|c|c|}
\hline $\begin{array}{l}\text { Resource Ares } \\
\text { Index/Item }\end{array}$ & 1969 & 1971 & 1973 & $\mathbf{F}$ & $\begin{array}{l}\text { critical } \\
\text { difference }\end{array}$ \\
\hline $\begin{array}{l}\text { Bealth Resources } \\
\text { Gerera! Disability } \\
\text { overall Disability }\end{array}$ & $\begin{array}{l}2.94(4.22) \\
1.45(2.50)\end{array}$ & $\begin{array}{l}3.17(4.21) \\
1.70(2.70)\end{array}$ & $\begin{array}{l}3.71(4.34) \\
2.16(2.94)\end{array}$ & $\begin{array}{l}276.29 \\
360.26\end{array}$ & $\begin{array}{l}.122 B \\
.0776\end{array}$ \\
\hline $\begin{array}{l}\text { Social Resources } \\
\text { Scope of Imnediate } \\
\text { Fandly } \\
\text { Size of Impediate } \\
\text { Fanily }\end{array}$ & $\begin{array}{l}6.30(2.20) \\
5.00(2.10)\end{array}$ & $\begin{array}{l}6.17(2.15) \\
4.91(2.11)\end{array}$ & $\begin{array}{l}6.06(2.13) \\
4.80(2.12)\end{array}$ & $\begin{array}{l}272.71 \\
310.38\end{array}$ & $\begin{array}{l}.0305 \\
.0237\end{array}$ \\
\hline $\begin{array}{l}\text { Subjective Well-being } \\
\text { Happiness }\end{array}$ & $5.41(3.40)$ & $5.71(3.41)$ & $5.62(3.51)$ & 28.20 & .1167 \\
\hline & $1969-2971$ & $1971-1973$ & $1969-1973$ & $\mathbf{P}$ & $\begin{array}{l}\text { critical } \\
\text { difference }\end{array}$ \\
\hline \multicolumn{6}{|l|}{ Difference Scores } \\
\hline $\begin{array}{l}\text { Bealth Resources } \\
\text { General Disabil1ty } \\
\text { Orerall Disability }\end{array}$ & $\begin{array}{ll}0.23 & (3.73) \\
0.24 & (2.07)\end{array}$ & $\begin{array}{ll}0.54 & (4.00) \\
0.46 & (2.34)\end{array}$ & $\begin{array}{l}0.77(4.16) \\
0.70(2.49)\end{array}$ & $\begin{array}{r}53.86 \\
102.84\end{array}$ & $\begin{array}{l}.1521 \\
.0934\end{array}$ \\
\hline $\begin{array}{l}\text { Soclal Reacurces } \\
\text { Scope of Immediate } \\
\text { Panlly }\end{array}$ & $-0.13(0.92)$ & $-0.21(0.88)$ & $-0: 24(1.09)$ & 71.38 & .0348 \\
\hline $\begin{array}{l}\text { Size of Inmediate } \\
\text { Fondly }\end{array}$ & $-0.09(0.73)$ & $-0.21(0.70)$ & $-0.20(0.81)$ & 74.15 & .0283 \\
\hline $\begin{array}{l}\text { Subjective Well-being } \\
\text { Bappiness }\end{array}$ & $0.29(3.65)$ & $-0.09(3.74)$ & $0.20(3.86)$ & 31.78 & .1471 \\
\hline \multicolumn{6}{|l|}{ Percentage cain Scores } \\
\hline $\begin{array}{l}\text { Heal th Resources } \\
\text { Genero? Disability } \\
\text { Querall Disabulity }\end{array}$ & $\begin{array}{rr}0.02 & (0.46) \\
-0.02 & (0.36)\end{array}$ & $\begin{array}{ll}0.05 & (0.49) \\
0.01 & (0.38)\end{array}$ & $\begin{array}{ll}0.08 & (0.51) \\
0.04 & (0.38)\end{array}$ & $\begin{array}{l}47.09 \\
62.12\end{array}$ & $\begin{array}{l}.0601 \\
.0152\end{array}$ \\
\hline $\begin{array}{l}\text { Soclal Resources } \\
\text { Scope of Inmediate } \\
\text { Fomily }\end{array}$ & $-0.01(0.15)$ & $-0.01 \quad(0.15)$ & $-0.03(0.17)$ & 40.32 & .0057 \\
\hline $\begin{array}{l}\text { Size of Intediote } \\
\text { Fonily }\end{array}$ & $-0.02(0.16)$ & $-0.03(0.15)$ & $-0.05(0.17)$ & 88.85 & .0054 \\
\hline $\begin{array}{l}\text { Subjective Well-being } \\
\text { Happiness }\end{array}$ & $0.06(0.54)$ & $0.01 \quad(0.54)$ & $0.05(0.56)$ & 29.52 & .0212 \\
\hline
\end{tabular}

Hore. The means are presented as the first nember of the pair and the atandard deviations are in parentheses. The values of the means and otandard devlations my vary bilightly from those presented In the descriptive atatiatics tables de to the llstwise deletion of cases with mising values.

The baple sizes associated with each index or 1 tee starting with the General Dibability index are $8861,7517,8515,8515$, and 8776 .

The critical difference was computed as follaws:

$$
\text { critical difference } * \frac{\text { MS res }}{n} \times \text { eritical value }
$$

where the critical value is equal to 4.12 for a Tukey test with mans three steps opart and $p=.01$.

No repeated messures analysis of varlance can be computed for the residual change ocores because their means 160 . 
TABLE XOXIV

SIONIFICANT DIFFEREXCAS BETWEDN PAIRS OF MENNS FOR THE 1969, 1971, ND 1973 TTDMS

AND TOR DIFFERDACE SCORES MND PERCDNTAGE GANN SOORES MEASURING HEALTH,

FINANCIAL RESOIRCES, ND SUEJECTIVE WELI-BEINE

\begin{tabular}{|c|c|c|c|}
\hline $\begin{array}{l}\text { Resource Ares } \\
\text { Iter. }\end{array}$ & $1969-1971$ & $1971-1973$ & $1969-1973$ \\
\hline $\begin{array}{l}\text { Heal th Resources } \\
\text { Bealth compared to others } \\
\text { Health compared to } 2 \text { years ago }\end{array}$ & * & $\ddot{*}$ & $\ddot{m}$ \\
\hline $\begin{array}{l}\text { Financial Resources } \\
\text { Standard of living compared to others } \\
\text { Ability to get along on incone } \\
\text { Satisfactior. with standard of llving }\end{array}$ & $\ddot{*}$ & $\because$ & $\begin{array}{l}\text { NS } \\
\text { NS } \\
\text { NS }\end{array}$ \\
\hline $\begin{array}{l}\text { Subjective Well-being } \\
\text { Happiness }\end{array}$ & $*$ & NS & $*$ \\
\hline Difference Scores & $1969-1971 / 2971-1973$ & $1971-1973 / 1969-1973$ & $1969-1971 / 1969-1973$ \\
\hline $\begin{array}{l}\text { Bealth Resources } \\
\text { Beal th. corpered to others } \\
\text { bealth. campared to } 2 \text { years ago }\end{array}$ & as & $\ddot{a}$ & $\ddot{*}$ \\
\hline $\begin{array}{l}\text { Financial Resources } \\
\text { Standard of living coupared to others } \\
\text { Ability to get lang or. income } \\
\text { Satiofactian with otandard of living }\end{array}$ & $\because$ & $\because$ & $\because$ \\
\hline $\begin{array}{l}\text { Subjective Well-being } \\
\text { gappiness }\end{array}$ & $*$ & $*$ & NS \\
\hline Percentage Gain Scores & $1969-1971 / 1971-1973$ & $1971-1973 / 1969-1973$ & $1969-1971 / 1969-1973$ \\
\hline $\begin{array}{l}\text { Bealth Resources } \\
\text { Beal th carpared to others } \\
\text { Health campered to } 2 \text { years ago }\end{array}$ & NS & 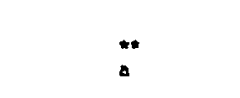 & $\ddot{*}$ \\
\hline $\begin{array}{l}\text { Financial Resources } \\
\text { Standard of living compared to others } \\
\text { Ability to get atong on incane : } \\
\text { Satisfaction vith standard of living }\end{array}$ & $\because$ & $\ddot{*}$ & $\because$ \\
\hline $\begin{array}{l}\text { Subjective Hell-being } \\
\text { Bappiness }\end{array}$ & $*$ & 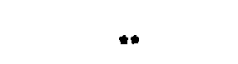 & NS \\
\hline
\end{tabular}

Note. Comparisons betreen means over time were only made for ltems which are identical across waves of dats collection. The repeated measures analysis of variance could not be corputed for the residual change bcores because the mean mean of residual change bcores is 0 .

The " Indicates that the means are significantly different from oach other at the $p=.01$ level. The cymbol "NS" indicates that the means are not Blgnificantly different from each other at the $p=.01$ level.

The comparisons for the happiness item are repeated in this table for case of reference.

This ited was not included in the 1969 questionsaire. 
COMPARISONS OF MENS FOR THE 1969, 1971, ND 1973 ITEXS ND FOR DYFFEREYCE SOORES AND PERCDNTAGE GAIN SOORES FOR THE ITPMS KEASURTNC HEALTY, FIHUCIAL RESOURCES, ANO SUBJECTIVE WELITIEING

\begin{tabular}{|c|c|c|c|c|c|}
\hline $\begin{array}{l}\text { Resource Area } \\
\text { Iten }\end{array}$ & 1969 & 1971 & 1973 & $\mathbf{F}$ & $\begin{array}{l}\text { critical } \\
\text { difference }\end{array}$ \\
\hline \multicolumn{6}{|l|}{ Hesil th Hesources } \\
\hline $\begin{array}{l}\text { Heal th compared } \\
\text { to other } 5\end{array}$ & $1.19(0.72)$ & $1.26(0.70)$ & $1.12(0.70)$ & 45.72 & .0231 \\
\hline $\begin{array}{l}\text { Heal th compared } \\
\text { to } 2 \text { yesrs ago }\end{array}$ & $a$ & $0.85(0.62)$ & $0.81 \quad(0.64)$ & 19.44 & .0238 \\
\hline \multirow{4}{*}{$\begin{array}{l}\text { Panancial Resources } \\
\text { Standard of living } \\
\text { compared to others } \\
\text { Noility to get alang } \\
\text { on income } \\
\text { Satisfied with } \\
\text { scandard of living }\end{array}$} & & & & & \\
\hline & $0.95(0.54)$ & $1.02(0.54)$ & $0.96(0.53)$ & 43.69 & .0207 \\
\hline & $1.17(0.95)$ & $1.53(0.96)$ & $1.47(0.92)$ & 23.43 & .0277 \\
\hline & $1.79(0.67)$ & $1.81(0.70)$ & $1.78(0.70)$ & 9.63 & .0232 \\
\hline \multirow{3}{*}{$\begin{array}{l}\text { Subjective Well-being } \\
\text { Happineas }\end{array}$} & & & & & \\
\hline & $1.08(0.68)$ & $2.14(0.68)$ & $1.12(0.70)$ & 28.20 & .0233 \\
\hline & $2969-1972$ & $1971-1973$ & $2969-1973$ & $\mathbf{F}$ & $\begin{array}{l}\text { critical } \\
\text { difference }\end{array}$ \\
\hline \multicolumn{6}{|l|}{ Difference Scoreb } \\
\hline \multirow{2}{*}{\multicolumn{6}{|c|}{$\begin{array}{l}\text { Heal th Resources } \\
\text { bealts, compared } \\
\text { to others } \\
\text { Heal th compered } \\
\text { to } 2 \text { years ago }\end{array}$}} \\
\hline & & & & & \\
\hline \multirow{3}{*}{$\begin{array}{l}\text { Financial Resources } \\
\text { Standard of living } \\
\text { conpared to others } \\
\text { Nbility to get alang } \\
\text { on incoose } \\
\text { satidfied with } \\
\text { standard of living }\end{array}$} & $0.06(0.61)$ & $-0.05 \quad(0.62)$ & $0.01 \quad(0.63)$ & 79.30 & .0262 \\
\hline & $0.06(0.86)$ & $-0.06(0.86)$ & $-0.00(0.92)$ & 45.38 & .0345 \\
\hline & $0.02(0.73)$ & $-0.04(0.75)$ & $-0.02(0.77)$ & 25.23 & .0293 \\
\hline $\begin{array}{l}\text { Bujective Hell-being } \\
\text { soppiness }\end{array}$ & $0.06 \quad(0.73)$ & $-0.02(0.75)$ & $0.04(0.77)$ & 31.78 & .0294 \\
\hline \multicolumn{6}{|l|}{ Percentage Gain scores } \\
\hline $\begin{array}{l}\text { Heal th Rescurces } \\
\text { Bealthi coopared } \\
\text { to others } \\
\text { bedth comared } \\
\text { to } 2 \text { years ago }\end{array}$ & $\begin{array}{c}0.01 \quad(0.49) \\
\end{array}$ & $\begin{array}{c}0.00(0.50) \\
\end{array}$ & $\begin{array}{c}-0.02(0.51) \\
a\end{array}$ & 9.94 & .0201 \\
\hline \multirow{3}{*}{$\begin{array}{l}\text { Finsucial Reoources } \\
\text { Standard of living } \\
\text { compared to cthers } \\
\text { Ability to get along } \\
\text { on incalk } \\
\text { Satiafied with } \\
\text { seandard of living }\end{array}$} & $0.05(0.45)$ & $-0.04(0.45)$ & $0.00 \quad(0.46)$ & 79.44 & .0291 \\
\hline & $0.03(0.48)$ & $-0.03(0.46)$ & $-0.00(0.49)$ & 36.20 & .0187 \\
\hline & $0.04(0.42)$ & $0.01 \quad(0.41)$ & $0.02(0.43)$ & 24.51 & .0162 \\
\hline $\begin{array}{l}\text { Subjective Well-being } \\
\text { Happiness }\end{array}$ & $0.06(0.5 d)$ & $0.01(0.54)$ & $0.05(0.56)$ & 29.52 & .0212 \\
\hline
\end{tabular}

Note. Tre mans are presented an the $115 \mathrm{st}$ menber of the pair and the standard deviations are in parentheses. The values of the mears and atandard deviatlans may vary slightly from those presented in the descripeive otntistics tables due to the listrige deletion of cases with nising volues.

The crjtical difference was computed as follows:

$$
\text { critical difference = }
$$

where the critical value 15 egual to 4.12 for a Tukey test for means three steps apart and $p=.01$.

No repeated ansures analysis of varlance can be computed for the residual change scores because their weans 150 .

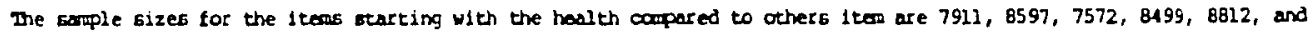
B776.

The information on the happiness 1 teo is repeated in the table for cose of reference.

This itere was not included in the 1969 wave of dats collection. 
immediate family. They report more happiness in 1971 and in 1973 than they do in 1969. The means on the happiness item for the 1971 and 1973 waves are not significantly different from each other leading to the conclusion that on the average, the respondents do not report a different amount of happiness in 1971 and in 1973.

The comparisons for the two health indexes offer redundant information because the indexes have overlapping component items. The same is true for the two social indexes. These indexes, however, are used later on in separate sets of analyses and evidence on the construct validity of all the measures analyzed in this study is being sought.

For the subjective domain, 13 comparisons, excluding those for the happiness item, were computed and 9 are significant at $\mathrm{p}=.01$. On the average, the respondents rate their health status as worse over time. The pattern of response for the satisfaction with financial status items follows that of the happiness item. The respondents give the highest ratings on items of that domain in 1971. The 1971 mean for each of these three items is significantly different from the 1973 mean. It is also significantly different from the 1969 mean for two of the three items. No differences exist between the 1969 means and the 1973 means of the three financial satisfaction items. 
The next section is a brief discussion on how to interpret the measures of central tendency for each the three selected approaches to the measurement of change in longitudinal data. It also summarizes the comparisons of means for the difference scores and percentage gain scores.

Change in the Rate of Change

Evidence of construct validity for the measures of change can be provided by the examination of the rate of change from 1969 to 1971 and from 1971 to 1973 , the 2-year interval data. Comparisons between the 2-year-interval data and the 4-year-interval data also furnish information on the construct validity of the measures. The next section highlights the findings from the repeated measures ANOVA for the difference scores and the percentage gain scores.

Difference scores. Difference scores are obtained by subtracting a time 1 measure from the same measure at time 2. A positive sign, then, denotes an increase between time 1 and time 2 on the selected measure and a negative sign denotes a decrease over time.

The results of the comparisons of means for difference scores indicate that, on the average, the rate of change in disability is greater between 1971 and 1973 than between 1969 and 1971. Furthermore, respondents' change scores on disability for the 4-year interval are, on the average, larger than for either one of the 2-year intervals. In the area of social resources, no difference exists between the 
2-year interval means. Comparisons between the 2-yearinterval data and the 4-year-interval data indicate that, on the average, the shrinkage in the scope and size of the immediate family is larger from 1969 to 1973 than it is between 1969 to 1971 or between 1971 to 1973. Finally, the mean difference on the happiness item from 1971 to 1973 is significantly smaller than that of the 1969-1971 interval and than that of the 1969-1973 interval. For the happiness item, the change from 1969 to 1971 is not significantly different from the change between 1969 and 1973. With very few exceptions (see descriptive statistics of Appendix C), the modal category of difference scores is 0 , indicating that for the largest number of continuers, no change has occurred between any two measurement points. The variability of the change scores appears to be larger for the 4-year interval suggesting that the processes associated with aging do not have a uniform impact on the respondents. As mentioned previously, no comments can be made for the area of financial resources, because income is measured by an item which is not identical across the three waves of data collection.

For the items which assess the more subjective aspect of the health and financial resource areas, the absolute value of the mean difference between two points in time is never greater than .08 . Of the 12 comparisons which were made, excluding the happiness item, 10 are significant at 
the .01 level. No difference between the 2-year interval means was found on the normative health item. However, on the average, the respondents rate their decline in health as significantly larger across the 4 -year interval than across the 1969-1971 or the 1971-1973 interval.

For the satisfaction with financial resources items, the respondents report the highest degree of satisfaction in 1971 creating positive change from 1969 to 1971 and negative change from 1971 to 1973. By 1973, the respondents do not rate their satisfaction with their financial situation differently from that of 1969. The absolute value of the average change from 1969 to 1973 is not greater than .02. The absolute difference in the amount of change in the means for the 1969-1971 period is close to that of the 1971-1973 period. However, the change is in the opposite direction creating significant differences between these two periods and between the 2-year change and the 4-year change with one exception the comparison of 1971-1973 with 1969-1973 for the satisfaction with standard of living item. As shown in Appendix C, Table LIX, the mode of difference scores for all the measures in this domain is 0 , denoting no change for the greatest number of respondents.

Residiual Change scoores. As it was explained previously, a residual change score indicates whether or not a respondent has changed more than what could be predicted based on the correlation coefficient between two 
points in time, i.e., the stability coefficient for the measure of interest. The larger the correlation between time 1 and time 2 , or the greater the stability, the less the change and the smaller the residual change scores. A residual change score, then, assesses whether or not an individual has changed more than what would be expected based on the stability coefficients obtained for the entire sample. Residual change scores always have a mean of 0 . A positive sign indicates that the actual score is greater than what would have been predicted and a negative sign denotes that the actual score is smaller than what would have been predicted based on the correlation of time 1 and time 2 for that measure. The descriptive statistics for the residual change scores are presented in Appendix C, Tables LVII and LX. As mentioned above, no comparisons of means could be done because residual change scores always have a mean of 0 .

Percentage Gain Score. As mentioned in Chapter III, percentage gain scores are difference scores adjusted for the initial starting point of the respondents. They are the result of the ratio of the time 2 minus the time 1 measure over the difference between the starting point, or time 1 score, and the end point on the scale. The pattern of significant results for the percentage gain scores are almost the same as those of the difference scores on the measures assessing the objective domain. Of the 15 
comparisons made, 10 are significant at $p=.01$ compared to 12 significant results for difference scores. Contrary to difference scores which exhibited 3 significant pairwise differences for the General Disability index, there was only one significant difference on the General Disability index for percentage gain scores. The rate of change from 1969 to 1971 is smaller than the rate of change from 1969 to 1973. The mode for most of the measures assessing an objective situation is 0 , denoting no change.

For the items measuring the more affective component of the areas of health and financial resources, the patterns of significant comparisons obtained with the difference scores are replicated exactly by the percentage gain scores. Furthermore, as with the difference scores, the mode of the percentage gain scores for these items is 0. In general, the absolute mean values of the pecentage gain scores for all of the measures tend to be relatively small, ranging from 1 to 8 .

In summary, comparisons of the means across the three waves of data collection reveal that the measures of health and social resources of the objective domain are detecting change. On the average, respondents report more disability and less social resources as they age. Comparisons between the 2-year-interval data yield greater change from 1971 to 1973 than from 1969 to 1971 for the health resources measures only. In both the health and social resource 
areas for these measures, the 4-year rate of change is larger than the 2-year rate.

In the subjective domain, the findings are not as clear cut. On the average, respondents rate their health more negatively as time passes. The comparisons for the 2year-interval data showed no significant difference for that item but both means for the 2-year-interval data are significantly different from the mean of the 4-yearinterval data.

For the satisfaction with financial resources items and the happiness item, the most positive ratings occur in 1971, creating positive change from 1969 to 1971 and negative change from 1971 to 1973. The value of the means in 1973 are close to those of 1969 and no significant differences are found on the means of the financial items between the 1969 and 1973 waves of data collection. There is positive change from 1969 to 1971 and negative change from 1971 to 1973 on the financial and the happiness items. With two exceptions, significant differences occur on the rate of change between the 1969-1971 and the 1971-1973 intervals and between the 2-year-interval data and the 4year-interval data. However, for these items, the rate of change for the 2 -year interval is larger than for the 4year interval.

In conclusion, the comparisons of means on the measures and on the change scores for the measures provide some initial documentation of their construct validity. 
Change over time was detected and, in many instances for the measures of the objective domain, the change from 1971 to 1973 is larger than the change from 1969 to 1971 and change over the 4 -year interval is usually larger than change over each of the 2-year intervals. For the measures of the subjective domain, the patterns are not that of a progressive decline over time. Many explanations can be generated to explain this phenomenon. A negative evaluation on domain specific and global measures may not be tied with aging. Mood may play a large role in these ratings creating a halo effect across the domain specific ratings and the happiness item. The happiness item is asked early in the interview in all three waves and in 1971 and 1973 is followed by one satisfaction with financial status item. Societal changes in 1971 may have made respondents particularly optimistic or for a large number of respondents, their financial situation and their happiness increased at that point in time. The 1971 time period may have coincided for many with that of the preretirement years which are usually high income years. Finally, the subjective domain is measured by items which tend to be less reliable than indexes. As illustrated in Chapter III, Table XXVII, the reliability of difference scores is particularly low when the reliability of the preand posttest measures is low and the stability coefficients are low. 
Stability Coefficients of Change Scores

This section discusses briefly the stability coefficients of change scores. They are presented in Table XXXVI for the measures which assess the objective status domain and in Table XXXVII for the measures which assess the subjective status. The theoretical formulas predict that if the time 1, time 2 , and time 3 measures have a 0 correlation with one another, the correlation coefficient between difference scores based on time 2 minus time 1 and the difference scores based on time 3 minus time 2 is -.50 . Even if the time 1, time 2, and time 3 measures are positively correlated, a negative correlation is to be expected (Paulson, 1975). Likewise, the theoretical formulas predict that residual change scores based on time 1 and time 2 will have a negative correlation with the residual change scores based on time 2 and time 3.

As expected, the stability coefficients between 19691971 change scores are negatively correlated with the 19711973 change scores. Respondents who experience change from 1969 to 1971 change comparatively less from 1971 to 1973 and respondents who experience relatively less change from 1969 to 1971 change comparatively more from 1971 to 1973. This negative correlation is partly due to floor and ceiling effects and to regression toward the mean phenomenon. However, from a developmental perspective it would be predicted that change accompanies aging but that it occurs at a different rate among individuals. Therefore 
TABLE XXOVI

TWO-YEAR AND FOUR-YEAR STABIIITY COEFFICIENIS FOR THE THREE SEIUCTED APPPDACHES TO THE MEASURPMEN OF OHANGE ON THE INDEXES MEASURING HEALTH, SOCIAL RESOURCES, AND SUBJDCIVE WEIL-BEING

\begin{tabular}{|c|c|c|c|}
\hline $\begin{array}{l}\text { Resource Ares } \\
\text { Index/Item }\end{array}$ & $1969-1972 / 1971-1973$ & $1971-1973 / 1969-1973$ & $1969-1971 / 1969-1973$ \\
\hline \multicolumn{4}{|l|}{ Difference Scores } \\
\hline $\begin{array}{l}\text { Bealth Resources } \\
\text { General Disability } \\
\text { Overall Disability }\end{array}$ & $\begin{array}{l}-0.42 \\
-0.37\end{array}$ & $\begin{array}{l}0.58 \\
0.63\end{array}$ & $\begin{array}{l}0.49 \\
0.48\end{array}$ \\
\hline $\begin{array}{l}\text { Social Resources } \\
\text { Scope of Imnediate } \\
\text { Fanily } \\
\text { Size of Immediate } \\
\text { Fanily }\end{array}$ & $\begin{array}{l}-0.26 \\
-0.35\end{array}$ & $\begin{array}{l}0.58 \\
0.55\end{array}$ & $\begin{array}{l}0.63 \\
0.59\end{array}$ \\
\hline $\begin{array}{l}\text { Financial Resources } \\
\text { Income }\end{array}$ & -0.32 & 0.53 & 0.63 \\
\hline $\begin{array}{l}\text { Subjective Well-being } \\
\text { Happiness }\end{array}$ & -0.45 & 0.54 & 0.50 \\
\hline \multicolumn{4}{|l|}{ Residual Change Scores } \\
\hline $\begin{array}{l}\text { Eealth Resources } \\
\text { General Disability } \\
\text { Overall Disability }\end{array}$ & $\begin{array}{l}-0.16 \\
-0.17\end{array}$ & $\begin{array}{l}0.84 \\
0.80\end{array}$ & $\begin{array}{l}0.37 \\
0.43\end{array}$ \\
\hline $\begin{array}{l}\text { Social Resources } \\
\text { Soope of Immediate } \\
\text { Fanily } \\
\text { Size of Imediate } \\
\text { Family }\end{array}$ & $\begin{array}{l}-0.22 \\
-0.32\end{array}$ & $\begin{array}{l}0.65 \\
0.59\end{array}$ & 0.57 \\
\hline $\begin{array}{l}\text { Financial Resources } \\
\text { Incone }\end{array}$ & -0.20 & 0.68 & 0.58 \\
\hline $\begin{array}{l}\text { Subjective Well-being } \\
\text { Bappiness }\end{array}$ & -0.10 & 0.89 & 0.30 \\
\hline \multicolumn{4}{|l|}{ Percentage Gain Scores } \\
\hline $\begin{array}{l}\text { Bealth Resources } \\
\text { General Disability } \\
\text { overall Disability }\end{array}$ & $\begin{array}{l}-0.37 \\
-0.28\end{array}$ & $\begin{array}{l}0.58 \\
0.59\end{array}$ & $\begin{array}{l}0.44 \\
0.44\end{array}$ \\
\hline $\begin{array}{l}\text { Social Resources } \\
\text { Scope of Imnediate } \\
\text { Fanily } \\
\text { Size of Imnediate } \\
\text { Fanily }\end{array}$ & $\begin{array}{l}-0.24 \\
-0.22\end{array}$ & $\begin{array}{l}0.57 \\
0.63\end{array}$ & $\begin{array}{l}0.60 \\
0.56\end{array}$ \\
\hline $\begin{array}{l}\text { Financial Resources } \\
\text { Incame }\end{array}$ & -0.21 & 0.63 & 0.50 \\
\hline $\begin{array}{l}\text { Subjective Well-being } \\
\text { Eappiness }\end{array}$ & -0.38 & 0.62 & 0.40 \\
\hline
\end{tabular}

Note. The sample size associated with each index or item starting with the General Disability inde: is $8861,7517,8515,8515,8223$, and 8776 . 
TABLE XXXVII

TWO-YEAR AND FOUR-YEAR STABIITY COEFFICIENSS FOR THE THREE APPROACHES

TO THE MEASUREMENT $C F$ CFANGE FOR THE ITEMS MEASURINC HEALTH,

FINANCLAL RESOURCES, AND SUBJECTIVE WEILBEING

\begin{tabular}{|c|c|c|c|}
\hline $\begin{array}{l}\text { Resource Area } \\
\text { Iten }\end{array}$ & $1969-1971 / 1971-1973$ & $1971-1973 / 1969-1973$ & 1969-1971/1969-1973 \\
\hline \multicolumn{4}{|l|}{ Difference Scores } \\
\hline & -0.44 & 0.53 & 0.52 \\
\hline $\begin{array}{l}\text { Heal th campared } \\
\text { to } 2 \text { years ago }\end{array}$ & a & a. & a \\
\hline & -0.46 & 0.53 & 0.51 \\
\hline $\begin{array}{l}\text { Ability to get along } \\
\text { on income }\end{array}$ & -0.43 & 0.53 & 0.53 \\
\hline $\begin{array}{l}\text { Satisfied with } \\
\text { standard of living }\end{array}$ & -0.45 & 0.55 & 0.50 \\
\hline $\begin{array}{l}\text { Subjective well-being } \\
\text { Happiness }\end{array}$ & -0.45 & 0.54 & 0.50 \\
\hline \multicolumn{4}{|l|}{ Residual Conge Scores } \\
\hline $\begin{array}{l}\text { Health Resources } \\
\text { Heal th campared }\end{array}$ & -0.14 & 0.85 & 0.34 \\
\hline $\begin{array}{l}\text { Benith campared } \\
\text { to } 2 \text { years ago }\end{array}$ & a & $\mathbf{a}$ & a \\
\hline $\begin{array}{l}\text { Financial Resources } \\
\text { Standard of living } \\
\text { conpar ed to others }\end{array}$ & -0.07 & 0.93 & 0.25 \\
\hline $\begin{array}{l}\text { Ability to get along } \\
\text { on income }\end{array}$ & -0.16 & 0.82 & 0.40 \\
\hline $\begin{array}{l}\text { Satisfied with } \\
\text { standard of living }\end{array}$ & -0.09 & 0.90 & 0.32 \\
\hline $\begin{array}{l}\text { Subjective Well-being } \\
\text { Happiness }\end{array}$ & -0.10 & 0.89 & 0.30 \\
\hline \multicolumn{4}{|l|}{ Percentage Gain Scores } \\
\hline \multirow{2}{*}{$\begin{array}{l}\text { Bealth Rescurces } \\
\text { Beal th compared } \\
\text { to others } \\
\text { Heal th compared } \\
\text { to } 2 \text { years ago }\end{array}$} & -0.38 & 0.56 & 0.45 \\
\hline & a & a & a \\
\hline \multirow{3}{*}{$\begin{array}{l}\text { Financial Resources } \\
\text { Standard of living } \\
\text { campared to others } \\
\text { ability to get along } \\
\text { on lncame } \\
\text { Satisfied with } \\
\text { standard of living }\end{array}$} & -0.39 & 0.64 & 0.35 \\
\hline & -0.33 & 0.60 & 0.42 \\
\hline & -0.36 & 0.64 & 0.37 \\
\hline $\begin{array}{l}\text { Subjective Well-being } \\
\text { Happiness }\end{array}$ & -0.38 & 0.61 & 0.40 \\
\hline
\end{tabular}

Nore. The respective sample size for each item is 7911, 7572, 8499, 8812, and 8776 .

Information on the happiness iten is repeated here for ease of reference.

This item was not included in the 1969 wave of data collection. 
respondents who show marked change in one measurement period should not show as much change in the following measurement period as individuals who did not change originally. It would also be predicted that developmental change will occur as a result of normative life events but that change due to non-normative life events will create variability in the rate of change among respondents.

The stability coefficients for residual change scores between the 1969-1971 and the 1971-1973 change scores are negative but smaller than the corresponding ones for difference scores and percentage gain scores. The residual change scores are the least affected by floor and ceiling effects or by regression toward the mean and the difference between residual scores and difference scores is particularly marked if the reliability of the measures and the stability coefficient between time 1 and time 2 are low. Examples of the reliability of difference scores and residual scores for varying degrees of reliability and stability are presented in Chapter III, Tables XXVII and XVIII.

The stability coefficients between change in a 2 -year interval and change in a 4-year interval are more difficult to interpret because the time 1 measurement or the time 2 measurement is shared by the 2-year and the 4-year measures of change. The patterns of difference scores and percentage gain scores are more similar to each other than 
those of residual change scores. The stability of residual scores is lower when the time 1 and time 2 stability coefficients are high. The stability coefficients of residual scores are also higher when the 2-year and 4-year interval share the same time 2 measure. Therefore the stability coefficients for residual scores are higher between the 1971-1973 and the 1969-1973 time period than between the 1969-1971 and the 1969-1973 time period.

Correlation of Change Scores with one-Point-in-Time

\section{Measures}

The correlation coefficients of difference scores, residual scores, and percentage gain scores presented in Tables XXXVIII and XXXIX illustrate that the three selected approaches to the measurement of change in longitudinal data tend to correlate positively with the time 2 measures and also illustrate that this pattern is particularly pronounced when change is measured with residual scores. The theoretical correlation of residual change scores with the time 2 measure used to construct that residual score is:

$$
\rho_{x y}=\sqrt{1-\rho_{12}^{2}}
$$

That is, as the stability coefficient decreases, the formula predicts a larger correlation of the residual change score with the time 2 measures. In other words, the more the stability between time 1 and time 2 the less the residual scores are correlated with the time 2 measures. As 
TAM.E Xxxvi11

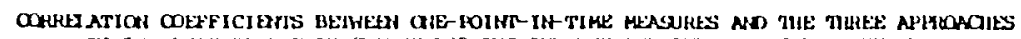

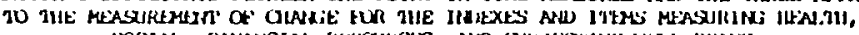
SOCIN., EIHANCIAL, HESGUICES, NDO SULNECHIVE HLA.-LEINX

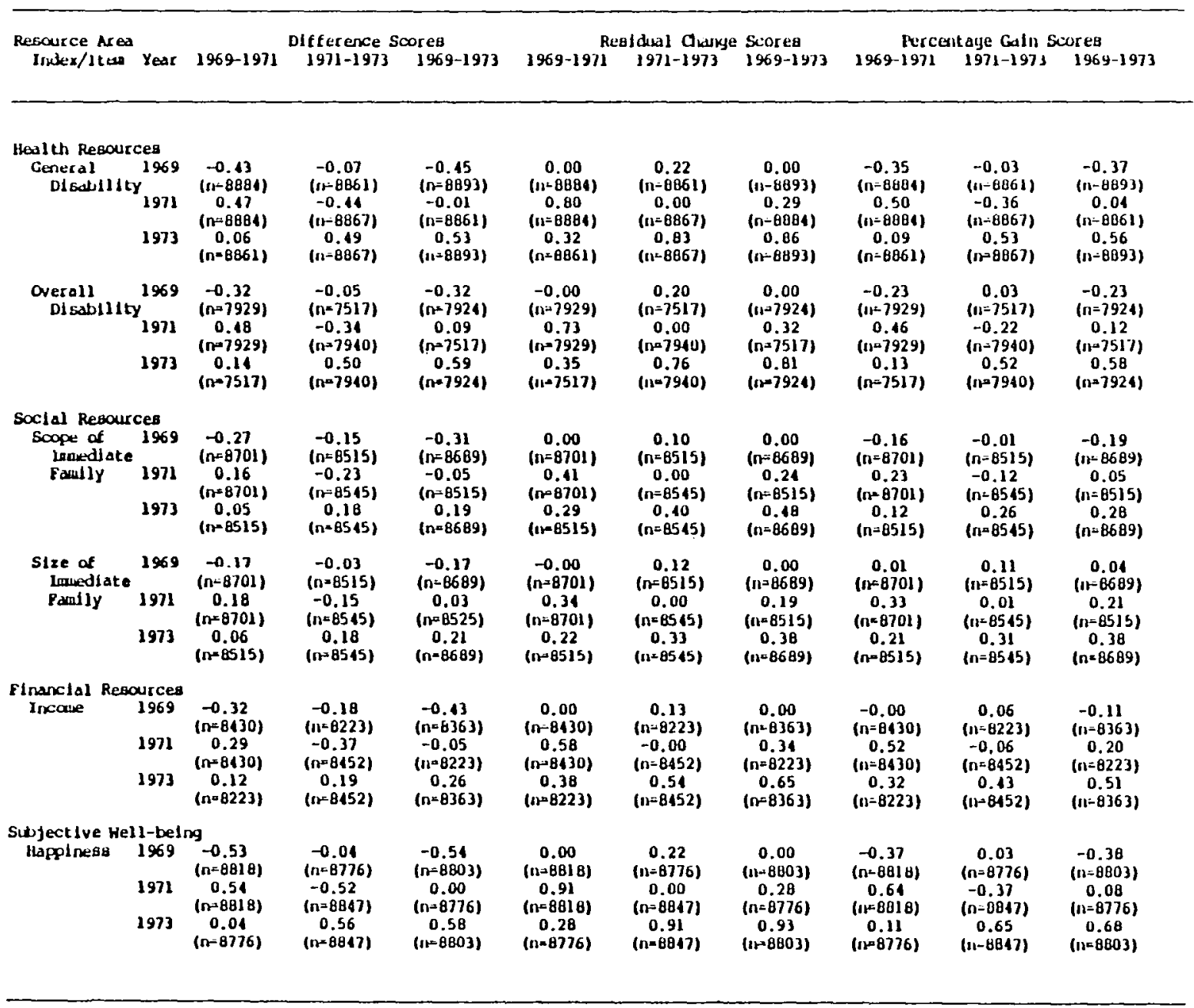


TASLE XXXIX

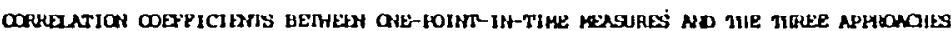

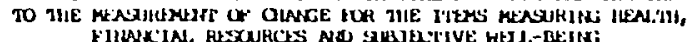

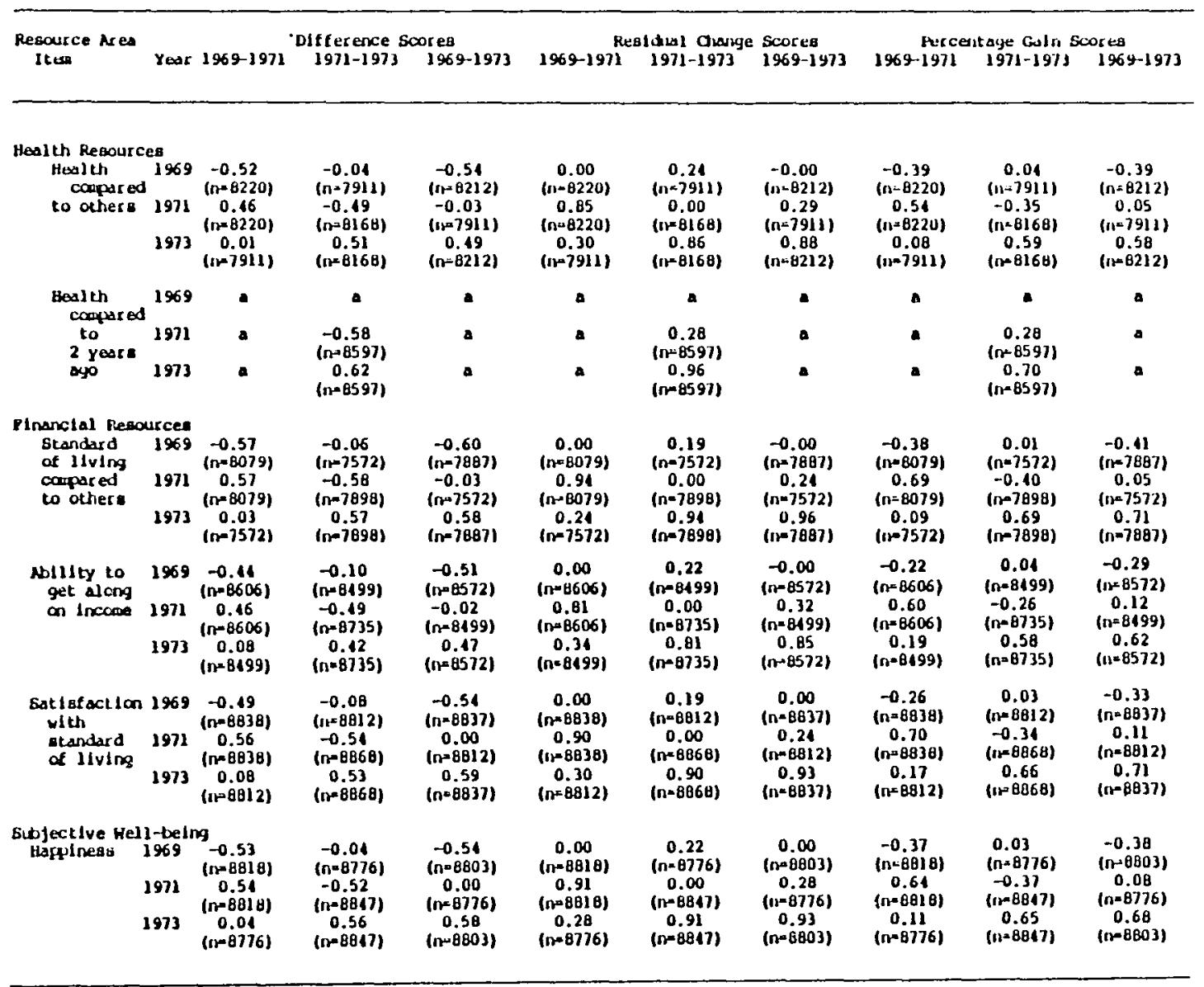

Hote. Inforwstion on the happlinesa iteo is repested for ease of reference.

Mhls ites was not included In the 1969 questlonsalce. 
expected, difference scores are negatively correlated with time 1 scores and residual scores have a 0 correlation with time 1 scores.

Percentage gain scores generally seem to hold a middle ground between residual change scores and difference scores. The negative correlation between percentage gain scores and time 1 scores is not as pronounced as for difference scores but is also not .00 as for residual change scores. Similarly the positive correlation between percentage gain scores and time 2 scores is not as great as for residual change scores but is greater than that for difference scores.

\section{Question $\underline{2}$}

The focus of question 2 is on the gathering of evidence which supports the construct validity of the change scores used in this study. First, construct validity of a measure can be demonstrated if the measure correlates highly with another measure of the same construct. It is expected, then, that change scores for a given variable obtained by one approach to the measurement of change in longitudinal data are comparable to those obtained by a different approach. Second, the testing of hypotheses derived from gerontological theories should also provide evidence on the construct validity of a measure. The change scores in this study should correlate in 
predictable ways with measures of other constructs as hypothesized on a thecretical basis.

Question 2 was phrased as follows:

Is there evidence which supports the construct validity of change scores? More specifically, do the three selected ways of measuring change in the four areas of health, social, financial resources, and subjective well-being result in similar or different orderings of individuals along the continuum of change? Furthermore, do the three selected approaches to the measurement of change produce similar results when hypotheses are tested using univariate statistical procedures?

Question 2 addresses a basic issue in the measurement of change, that of determining whether the three selected approaches to the measurement of change in longitudinal data produce comparable results. Two validation strategies, both based on correlation coefficients, were employed to answer this question. First, correlation coefficients for a given variable were computed between the three different versions of the change scores taken two at a time. For example, change scores on the disability index based on difference scores were correlated with residual change scores and with percentage gain scores obtained on that index. Second, change scores based on one approach to the measurement of change for the areas of health, social, and financial resources, and subjective well-being were correlated among themselves. For example, difference scores on the disability index were correlated with difference scores on the subjective well-being item. The hypotheses which guided the analyses of these data are 
presented with the section which discusses the results of the second validation strategy. The next section reviews the findings of the first validation strategy, that is, the correlation coefficients among the three approaches to the measurement of change in longitudinal data.

Evidence of Construct Validity: Correlation Among the Three Approaches to the Measurement of Change.

An examination of Tables XI and XII reveals that there is considerable overlap among the three approaches to the measurement of change, irrespective of the measures employed. Results pertaining to the variables used to assess objective status are discussed first. These results are presented in Table $\mathrm{XL}$.

Among the variables which assess the objective status of the resource areas, the range of the correlation coefficients is .84 to .99 with a median value of .90 . For a given index or item, the magnitude of the correlation between any two approaches to the measurement of change across a 2-year or a 4-year time span does not vary by more than .02. One exception to this generalization can be found. The correlation coefficient on income between difference scores and residual change scores for the 19691971 interval is .05 larger than for the 1969-1973 interval. The high degree of overlap among the three approaches to the measurement of change for all of the measures is, in part, attributable to the fact that each of 
TABLE XL

CORRETATION COEFFICIENIS AMONG THE THREE WAYS OF MEASURING CHANGE FOR THE AREAS OF HEALTH, SOCIAL, FINANCIAL RESOURCE'S, AND SUBJECTIVE WELL-BEING

\begin{tabular}{|c|c|c|c|c|}
\hline $\begin{array}{l}\text { Resource Area } \\
\text { Index/Item }\end{array}$ & Year & $\begin{array}{l}\text { Difference } \\
\text { Score With } \\
\text { Residual } \\
\text { Change Score }\end{array}$ & $\begin{array}{l}\text { Difference } \\
\text { Score With } \\
\text { Percentage } \\
\text { Gain Score }\end{array}$ & $\begin{array}{l}\text { Residual Change } \\
\text { Score With } \\
\text { Percentage } \\
\text { Gain Score }\end{array}$ \\
\hline $\begin{array}{l}\text { Health Resources } \\
\text { General Disability }\end{array}$ & $\begin{array}{l}69-71 \\
71-73 \\
69-73\end{array}$ & $\begin{array}{l}.90 \quad(n=8884) \\
.90 \quad(n=8867) \\
.89 \quad(n=8893)\end{array}$ & $\begin{array}{ll}.95 & (n=8884) \\
.95 & (n=8867) \\
.95 & (n=8893)\end{array}$ & $\begin{array}{l}.89(n=8884) \\
.88(n=8867) \\
.88 \quad(n=8893)\end{array}$ \\
\hline Overall Disability & $\begin{array}{l}69-71 \\
71-73 \\
69-73\end{array}$ & $\begin{array}{ll}.95 & (n=7929) \\
.94 & (n=7940) \\
.95 & (n=7924)\end{array}$ & $\begin{array}{ll}.88 & (n=7929) \\
.88 & (n=7940) \\
.90 & (n=7924)\end{array}$ & $\begin{array}{l}.85(n=7929) \\
.86 \quad(n=7940) \\
.87 \quad(n=7924)\end{array}$ \\
\hline $\begin{array}{l}\text { Social Resources } \\
\text { Scope of Imnediate } \\
\text { Family }\end{array}$ & $\begin{array}{l}69-71 \\
71-73 \\
69-73\end{array}$ & $\begin{array}{l}.96 \quad(n=8701) \\
.97 \quad(n=8545) \\
.95 \quad(n=8689)\end{array}$ & $\begin{array}{l}.92(n=8701) \\
.93(n=8545) \\
.93(n=8689)\end{array}$ & $\begin{array}{ll}.92 & (n=8701) \\
.92 & (n=8545) \\
.92 & (n=8689)\end{array}$ \\
\hline $\begin{array}{l}\text { Size of Inmediate } \\
\text { Earnily }\end{array}$ & $\begin{array}{l}69-71 \\
71-73 \\
69-73\end{array}$ & $\begin{array}{ll}.99 & (n=8701) \\
.99 & (n=8545) \\
.98 & (n=8689)\end{array}$ & $\begin{array}{l}.91 \quad(n=8701) \\
.90 \quad(n=8545) \\
.90 \quad(n=8689)\end{array}$ & $\begin{array}{ll}.92 & (n=8701) \\
.91 & (n=8545) \\
.92 & (n=8689)\end{array}$ \\
\hline $\begin{array}{l}\text { Financial Resources } \\
\text { Income }\end{array}$ & $\begin{array}{l}69-71 \\
71-73 \\
69-73\end{array}$ & $\begin{array}{l}.95(n=8430) \\
.93(n=8452) \\
.90 \quad(n=8363)\end{array}$ & $\begin{array}{l}.84(n=8430) \\
.85(n=8452) \\
.86(n=8363)\end{array}$ & $\begin{array}{l}.89(n=8430) \\
.89(n=8452) \\
.90(n=8363)\end{array}$ \\
\hline $\begin{array}{l}\text { Subjective Well-being } \\
\text { Happiness }\end{array}$ & $\begin{array}{l}69-71 \\
71-73 \\
69-73\end{array}$ & $\begin{array}{l}.85(n=8818) \\
.85(n=8847) \\
.84(n=8803)\end{array}$ & $\begin{array}{l}.94 \quad(n=8818) \\
.94 \quad(n=8847) \\
.94 \quad(n=8803)\end{array}$ & $\begin{array}{l}.88 \quad(n=8818) \\
.88 \quad(n=8847) \\
.88 \quad(n=8803)\end{array}$ \\
\hline
\end{tabular}


CORREIATION OOFFFICIFNTS AMONG THE THIREE WAYS OF MFASURING GHANGE FOR THE HEALTH AND FINANCIAL ITEMS IN 1969, 1971, AND 1973

\begin{tabular}{|c|c|c|c|c|}
\hline $\begin{array}{l}\text { Resource Area } \\
\text { Item }\end{array}$ & Year & $\begin{array}{l}\text { Difference } \\
\text { Score With } \\
\text { Residual } \\
\text { Change Score }\end{array}$ & $\begin{array}{l}\text { Difference } \\
\text { Score With } \\
\text { Percentage } \\
\text { Gain Score }\end{array}$ & $\begin{array}{l}\text { Residual Change } \\
\text { Score With } \\
\text { Percentage } \\
\text { Gain Score }\end{array}$ \\
\hline $\begin{array}{l}\text { Health Resources } \\
\text { Heal th compared to } \\
\text { others }\end{array}$ & $\begin{array}{l}69-71 \\
71-73 \\
69-73\end{array}$ & $\begin{array}{ll}.85 & (n=8220) \\
.87 & (n=8168) \\
.84 & (n=8212)\end{array}$ & $\begin{array}{l}.94 \quad(n=8220) \\
.94 \quad(n=8168) \\
.94 \quad(n=8212)\end{array}$ & $\begin{array}{l}.87(n=8220) \\
.89(n=8168) \\
.87(n=8212)\end{array}$ \\
\hline $\begin{array}{l}\text { Health compared to } \\
2 \text { years ago }\end{array}$ & $\begin{array}{l}69-71 \\
71-73 \\
69-73\end{array}$ & $.81 \stackrel{a}{a}{ }_{a}^{(n=8597)}$ & $.94 \begin{array}{l}a \\
a \\
a\end{array}$ & $.85 \begin{array}{l}a \\
(n=8597) \\
a\end{array}$ \\
\hline $\begin{array}{l}\text { Financial Resources } \\
\text { Standard of living } \\
\text { compared to others }\end{array}$ & $\begin{array}{l}69-71 \\
71-73 \\
69-73\end{array}$ & $\begin{array}{l}.82(n=8079) \\
.81 \quad(n=7898) \\
.80 \quad(n=7887)\end{array}$ & $\begin{array}{ll}.94 & (n=8079) \\
.94 & (n=7898) \\
.94 & (n=7887)\end{array}$ & $\begin{array}{ll}.88 & (n=8079) \\
.87 & (n=7898) \\
.87 & (n=7887)\end{array}$ \\
\hline $\begin{array}{l}\text { Ability to get along } \\
\text { on incane }\end{array}$ & $\begin{array}{l}69-71 \\
71-73 \\
69-73\end{array}$ & $\begin{array}{l}.90 \quad(n=8606) \\
.87(n=8735) \\
.86(n=8572)\end{array}$ & $\begin{array}{l}.92 \quad(n=8606) \\
.91 \quad(n=8735) \\
.92 \quad(n=8572)\end{array}$ & $\begin{array}{ll}.91 & (n=8606) \\
.90 & (n=8735) \\
.90 & (n=8572)\end{array}$ \\
\hline $\begin{array}{l}\text { Satisfaction with } \\
\text { standard of living }\end{array}$ & $\begin{array}{l}69-71 \\
71-73 \\
69-73\end{array}$ & $\begin{array}{ll}.87 & (n=8838) \\
.84 & (n=8868) \\
.84 & (n=8837)\end{array}$ & $\begin{array}{l}.92(n=8838) \\
.93(n=8868) \\
.93(n=8837)\end{array}$ & $\begin{array}{l}.91 \quad(n=8838) \\
.89(n=8868) \\
.89(n=8837)\end{array}$ \\
\hline $\begin{array}{l}\text { Subjective Well-being } \\
\text { Happiness }\end{array}$ & $\begin{array}{l}69-71 \\
71-73 \\
69-73\end{array}$ & $\begin{array}{l}.85 \quad(n=8818) \\
.85 \quad(n=8847) \\
.84 \quad(n=8803)\end{array}$ & $\begin{array}{l}.94 \quad(n=8818) \\
.94(n=8847) \\
.94(n=8893)\end{array}$ & $\begin{array}{l}.88 \quad(n=8818) \\
.88 \quad(n=8847) \\
.88 \quad(n=8803)\end{array}$ \\
\hline
\end{tabular}

This item was not included in the 1969 wave of data collection. 
the three types of change measures use the same 1969, 1971, and 1973 scores in their calculation.

Correlation coefficients between difference scores and residual change scores tend to be higher when the range of difference scores and of residual change scores is larger. For example, the coefficients for Overall Disability, Size of Immediate Family, and Income are greater than those for the General Disability and Happiness measures. In contrast, the correlation coefficients between difference scores and percentage gain scores tend to be stronger when the range of the measures is comparatively low.

The apparent role of the range does not seem to replicate when residual change scores are correlated with percentage gain scores. The magnitude of the correlation coefficients is slightly smaller than that found for the corresponding correlations between difference scores and residual change scores. Exceptions to this comment are for the income measure for the 1969-1973 wave and the happiness item for both the 2-year and 4-year time span. No distinctive trend can be observed for the correlation between residual change scores and percentage gain scores when compared to that of difference scores with percentage gain scores. The magnitude of the correlation coefficients is lower in the areas of health and subjective well-being, virtually identical for the area of social resources, and slightly stronger for the income variable. 
Correlation coefficients for the three approaches to the measurement of change for the items which assess the more subjective or affective aspect of the resource areas are presented in Table XII. These coefficients range from .80 to .94 with a median of .89. In general, the correlations between difference scores and percentage gain scores which range from .91 to .94 are greater than the correlations of difference scores with residual change scores and those of residual change scores with percentage gain scores. Among correlation coefficients between difference scores and residual change scores, items with the lowest stability coefficients, namely the ipsative health item and the item on standard of living compared to others, tend to produce low correlation coefficients among these two approaches. No such pattern can be detected when the correlation coefficients between difference scores and percentage gain scores are examined or when coefficients between residual change scores and percentage gain scores are reviewed. Finally, the magnitude of the correlation coefficients between residual change scores and percentage gain scores is greater than the corresponding magnitude for residual change scores and difference scores.

In summary, the correlation coefficients among the three approaches to the measurement of change in longitudinal data provide evidence on the construct validity of the measures used for this study. There is a considerable amount of agreement among the three methods in 
terms of ranking individuals on the construct of change in the areas of health, social, financial resources, and subjective well-being. Patterns found within measures representing the objective domain are not identical to those observed for the items measuring the subjective domain. In general, difference scores and residual change scores seem to be more highly correlated when the range of the measures is large whereas difference scores and percentage gain scores are more highly correlated when the range of the measures is small.

\section{Construct Validity: Testing Hypotheses}

Evidence of construct validity for the change measures in the areas of health, social, financial resources, and subjective well-being can be provided by the testing of hypotheses which are derived from gerontological theories. As mentioned previously, construct validity of a measure can be demonstrated if the measure is related to other measures as was predicted based on a theoretical perspective. The hypotheses which were formulated for this study are derived from the gerontological theories which postulate that aging is accompanied by change. The specific hypotheses which were tested are:

1) increases in disability are related to decreases in income;

2) increases in disability are related to decreases in subjective well-being; 
3) increases in financial resources are related to increases in subjective well-being; and

4) increases in satisfaction with financial status are related to increases in subjective well-being.

No hypotheses were formulated on the relationships between the area of social resources and the areas of health, financial resources, and subjective well-being. The hypotheses were originally listed with question 2 in Chapter III.

The focus of this section, then, is on the demonstration of construct validity via hypothesis testing. This section also discusses whether or not there is similarity among the three selected approaches to the measurement of change in longitudinal data. The correlation coefficients which were employed to test the hypotheses are presented in Tables XLII through XLIV for the items and indexes measuring the objective status and in Tables XLV through XLVII for the items measuring the affective status of the selected resource areas.

An examination of Tables XIII, XIIII and XIIV shows that there is complete agreement among the three selected approaches to the measurement of change in terms of the direction of the relationship between any two measures. For all three approaches, as hypothesized, changes in disability are negatively correlated to changes in financial resources and subjective well-being ( $<.001)$, but are not significantly related to changes in social 
MEANS, STANDARD DEVIATIONS, AND INTEROORRETATIONS AMONG CILANGE IN HENLTY, SOCTAL,

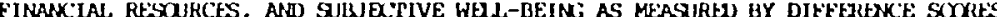

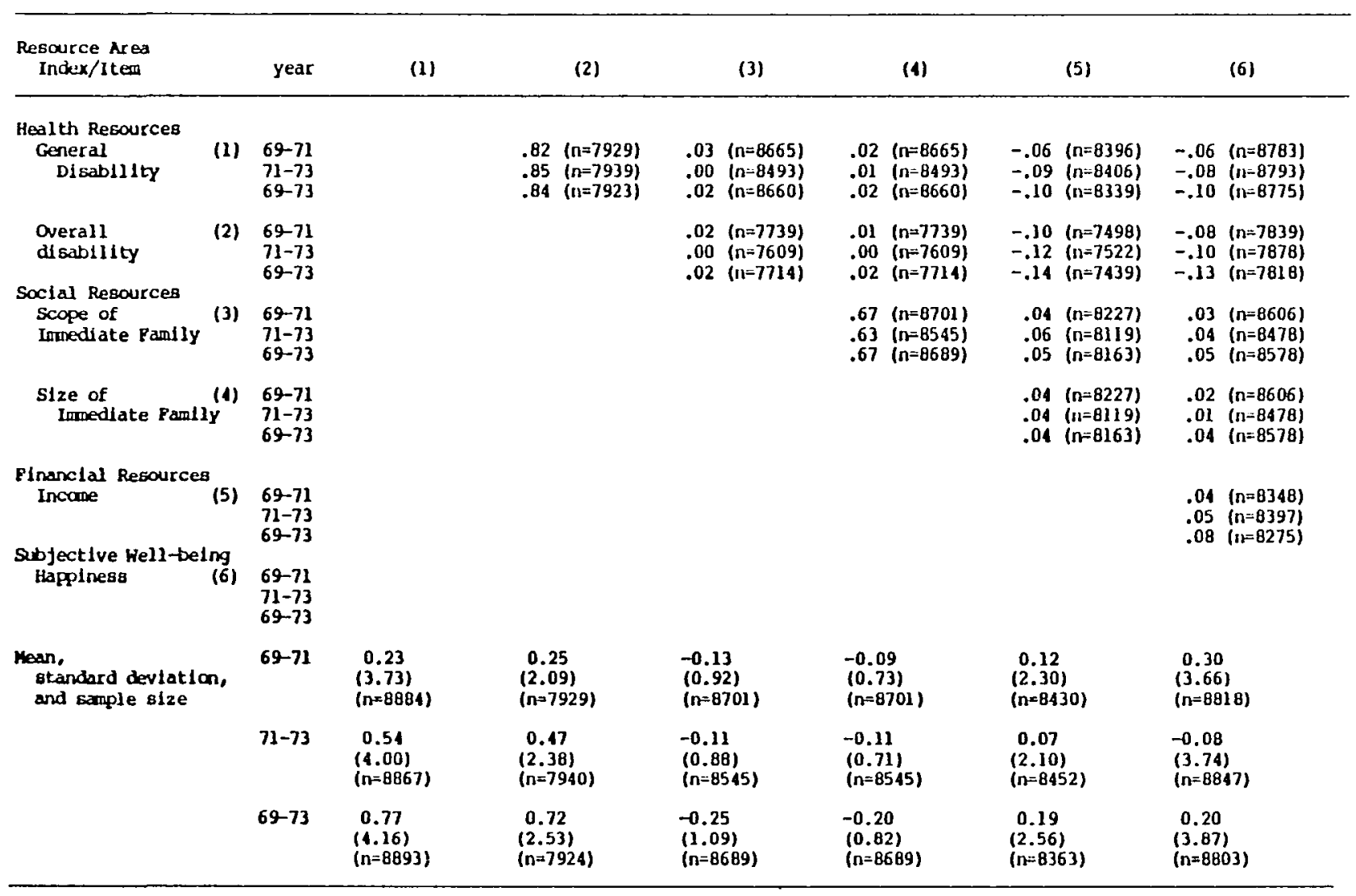

Note. The sample size for the continuers is 8922. The varlations in sample slze are due to the palrwise deletlon of cases with a missing value on one or both varlables.

All correlations greater than .035 are significant at $p<.001$. 
TABLE XLIII

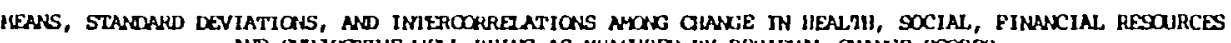

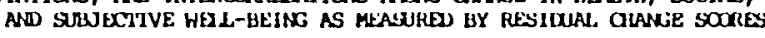

\begin{tabular}{|c|c|c|c|c|c|c|c|}
\hline $\begin{array}{l}\text { Resource Ares } \\
\text { Index/Item }\end{array}$ & year & (1) & (2) & (3) & (4) & (5) & (6) \\
\hline $\begin{array}{l}\text { Health Resources } \\
\text { General } \\
\text { Dlsabllity }\end{array}$ & $\begin{array}{l}69-71 \\
71-73 \\
69-73\end{array}$ & & $\begin{array}{l}.84(n=7929) \\
.87(n=7939) \\
.87(n=7923)\end{array}$ & $\begin{array}{l}.02(n=8665) \\
.01 \quad(n=8493) \\
.02 \\
(n=8660)\end{array}$ & $\begin{array}{l}.02(n=8665) \\
.02(n=8493) \\
.02(n=8660)\end{array}$ & $\begin{array}{l}-.12(n=8395) \\
-.11(n=8406) \\
-.14(n=0339)\end{array}$ & $\begin{array}{l}-.12 \quad(n=8783) \\
-.15 \quad(n=8793) \\
-.17 \\
(n=8775)\end{array}$ \\
\hline$\underset{\text { Disability }}{\text { Overall }}$ & $\begin{array}{l}69-71 \\
71-73 \\
69-73\end{array}$ & & & $\begin{array}{ll}.02 & (n-7739) \\
.01 & (n=7609) \\
.02 & (n=7714)\end{array}$ & $\begin{array}{ll}.01 & (n=7739) \\
.01 & (n=7609) \\
.02 & (n=7714)\end{array}$ & $\begin{array}{l}-.16(n=7498) \\
-.12(n=7522) \\
-.18 \quad(n-7439)\end{array}$ & $\begin{array}{ll}-.15 & (n=7839) \\
-.16 & (n=7878) \\
-.20 & (n=7818)\end{array}$ \\
\hline $\begin{array}{l}\text { Social Resources } \\
\text { Scope of } \\
\text { Lumedlate Paolly }\end{array}$ & $\begin{array}{l}69-71 \\
71-73 \\
69-73\end{array}$ & & & & $\begin{array}{l}.66(n=8701) \\
.64(n-8545) \\
.66(n=8689)\end{array}$ & $\begin{array}{ll}.06 & (n=8227) \\
.08 & (1-8119) \\
.08(n=8163)\end{array}$ & $\begin{array}{l}.05(n=8606) \\
.06 \quad(n=8478) \\
.06 \quad(n=8578)\end{array}$ \\
\hline $\begin{array}{l}\text { Size of } \\
\text { Immedlate Pondly }\end{array}$ & $\begin{array}{l}69-71 \\
71-73 \\
69-73\end{array}$ & & & & & $\begin{array}{l}.03(n=8227) \\
.05(n=119) \\
.04(n=0163)\end{array}$ & $\begin{array}{l}.03(n=8606) \\
.02(n=8478) \\
.01(n=8578)\end{array}$ \\
\hline $\begin{array}{l}\text { Pinancial Resources } \\
\text { Incone }\end{array}$ & $\begin{array}{l}69-71 \\
71-73 \\
69-73\end{array}$ & & & & & & $\begin{array}{l}.10(n=8348) \\
.10(n=8397) \\
.13(n=8275)\end{array}$ \\
\hline $\begin{array}{l}\text { Subjective Hell-being } \\
\text { Happlisess }\end{array}$ & $\begin{array}{l}69-71 \\
71-73 \\
69-73\end{array}$ & & & & & & \\
\hline \multirow[t]{3}{*}{$\begin{array}{l}\text { Man, } \\
\text { standard deviation, } \\
\text { and sample size }\end{array}$} & $69-71$ & $\begin{array}{l}0.00 \\
(3.37) \\
(n=8884)\end{array}$ & $\begin{array}{l}0.00 \\
(1.98) \\
(n=7929)\end{array}$ & $\begin{array}{l}0.00 \\
(0.89) \\
(n-8701)\end{array}$ & $\begin{array}{l}0.00 \\
(0.72) \\
(12-8701)\end{array}$ & $\begin{array}{l}0.00 \\
(2.18) \\
(n=8430)\end{array}$ & $\begin{array}{l}0.00 \\
(3.09) \\
(n=8818)\end{array}$ \\
\hline & $71-73$ & $\begin{array}{l}0.00 \\
(3.59) \\
(n=8867)\end{array}$ & $\begin{array}{l}0.00 \\
(2.21) \\
(n=7940)\end{array}$ & $\begin{array}{l}0.00 \\
(0.85) \\
(n=8545)\end{array}$ & $\begin{array}{l}0.00 \\
(0.70) \\
(n=8545)\end{array}$ & $\begin{array}{l}0.00 \\
(1.95) \\
(n=0452)\end{array}$ & $\begin{array}{l}0.00 \\
(3.19) \\
(n=8047)\end{array}$ \\
\hline & $69-73$ & $\begin{array}{l}0.00 \\
(3.71) \\
(n=8093)\end{array}$ & $\begin{array}{l}0.00 \\
(2.40) \\
(n=7924)\end{array}$ & $\begin{array}{l}0.00 \\
(1.04) \\
(n=8689)\end{array}$ & $\begin{array}{l}0.00 \\
(0.81) \\
(n=0689)\end{array}$ & $\begin{array}{l}0.00 \\
(2.31) \\
(n=8363)\end{array}$ & $\begin{array}{l}0.00 \\
(3.25) \\
(n=8803)\end{array}$ \\
\hline
\end{tabular}

Hote. The sapple size for the continuers 18 8922. The variations in sample size are due to the pairuise deletion of cases with o pissing value on one or both variables.

All correlations greater than .035 are signiflcant at pe .001. 
TABLE XI.IV

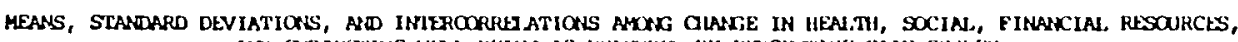

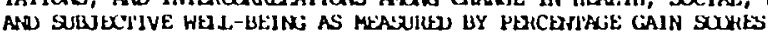

\begin{tabular}{|c|c|c|c|c|c|c|c|}
\hline $\begin{array}{l}\text { Resource Area } \\
\text { Index/Item }\end{array}$ & year & (1) & (2) & (3) & (4) & (5) & (6) \\
\hline $\begin{array}{l}\text { Heal th Resources } \\
\text { General } \\
\text { Disabllity }\end{array}$ & $\begin{array}{l}69-71 \\
71-73 \\
69-73\end{array}$ & & $\begin{array}{l}.82(n=7929) \\
.82(n)=7939) \\
.82(n=7923)\end{array}$ & $\begin{array}{l}.02(n=8665) \\
.00(n-893) \\
.02(n-8660)\end{array}$ & $\begin{array}{ll}.02 & (n=8665) \\
.01 & (n-8493) \\
.02 & (n=8660)\end{array}$ & $\begin{array}{l}-.04(n=8396) \\
-.07(n=8406) \\
-.08 \quad(n=8339)\end{array}$ & $\begin{array}{l}-.04(n=8783) \\
-.07(n=8793) \\
-.10(n=8775)\end{array}$ \\
\hline$\underset{\text { Disabllity }}{\text { Overall }}$ & $\begin{array}{l}69-71 \\
71-73 \\
69-73\end{array}$ & & & $\begin{array}{l}.03(n=7739) \\
.00(n \rightarrow 709) \\
.03(n=7714)\end{array}$ & $\begin{array}{ll}.02 & (n=7739) \\
.02 & (n=7609) \\
.03 & (11-7714)\end{array}$ & $\begin{array}{l}-.07 \quad(n-7498) \\
-.08(n-7522) \\
-.12 \quad(n-7139)\end{array}$ & $\begin{array}{ll}-.06 & (n=7839) \\
-.08 & (n=7878) \\
-.12 & (n=7818)\end{array}$ \\
\hline $\begin{array}{l}\text { Social Resources } \\
\text { Scope of } \\
\text { Inmediate Family }\end{array}$ & $\begin{array}{l}69-71 \\
71-73 \\
69-73\end{array}$ & & & & $\begin{array}{l}.69(n=8701) \\
.67(n-8545) \\
.70(n-8689)\end{array}$ & $\begin{array}{ll}.05 & (n=8227) \\
.06 & (n=819) \\
.05 & (11=8163)\end{array}$ & $\begin{array}{ll}.03 & (n=8606) \\
.04 & (n=8478) \\
.05 & (n=8578)\end{array}$ \\
\hline $\begin{array}{l}\text { Size of } \\
\text { Inmedlate Pamlly }\end{array}$ & $\begin{array}{l}69-71 \\
71-73 \\
69-73\end{array}$ & & & & & $\begin{array}{l}.05(n=8227) \\
.05(1,=8119) \\
.04(n=8163)\end{array}$ & $\begin{array}{ll}.03 & (n=8606) \\
.02 & (n=8478) \\
.04 & (n=8578)\end{array}$ \\
\hline $\begin{array}{l}\text { Firanclal Resources } \\
\text { Incone }\end{array}$ & $\begin{array}{l}69-71 \\
71-73 \\
69-73\end{array}$ & & & & & & $\begin{array}{l}.05(n=8348) \\
.06(n=8397) \\
.08 \quad(n=8275)\end{array}$ \\
\hline $\begin{array}{l}\text { Subjective well-beiny } \\
\text { Happinesi }\end{array}$ & $\begin{array}{l}69-71 \\
71-73 \\
69-73\end{array}$ & & & & & & \\
\hline $\begin{array}{l}\text { Moan, } \\
\text { standard devlation, } \\
\text { and sample bize }\end{array}$ & $69-71$ & $\begin{array}{l}0.02 \\
(0.46) \\
(n=8884)\end{array}$ & $\begin{array}{l}-0.02 \\
(0.36) \\
(n=7929)\end{array}$ & $\begin{array}{l}-0.01 \\
(0.15) \\
(n=8701)\end{array}$ & $\begin{array}{l}-0.02 \\
(0.11) \\
(11=0701)\end{array}$ & $\begin{array}{l}0.03 \\
(0.33) \\
(n-8430)\end{array}$ & $\begin{array}{l}0.06 \\
(0.54) \\
(n=8818)\end{array}$ \\
\hline & $71-73$ & $\begin{array}{l}0.05 \\
(0.49) \\
(n=8867)\end{array}$ & $\begin{array}{l}0.01 \\
(0.38) \\
(n=7940)\end{array}$ & $\begin{array}{l}-0.01 \\
(0.15) \\
(n=8545)\end{array}$ & $\begin{array}{l}-0.03 \\
(0.15) \\
(n=8545)\end{array}$ & $\begin{array}{l}0.04 \\
(0.31) \\
(n=8452)\end{array}$ & $\begin{array}{l}0.01 \\
(0.54) \\
(n=8847)\end{array}$ \\
\hline & $69-73$ & $\begin{array}{l}0.08 \\
(0.50) \\
(n=8993)\end{array}$ & $\begin{array}{l}0.04 \\
(0.391 \\
(n=7924)\end{array}$ & $\begin{array}{l}-0.03 \\
(0.18) \\
(n=8689)\end{array}$ & $\begin{array}{l}-0.05 \\
(0.17) \\
(n=8689)\end{array}$ & $\begin{array}{l}0.06 \\
(0.35) \\
(n=8363)\end{array}$ & $\begin{array}{l}0.05 \\
(0.56) \\
(n=8003)\end{array}$ \\
\hline
\end{tabular}

Nete. The sample alze for the continuers is 8922. The variations In sample slze are die to the pairwise deletion of cases with a sisaing value on ane or both variables. 
resources. The sign of these coefficients indicates that as individuals report a change toward more disability, they also report a decrease in financial resources and in happiness. Decreases in the scope and size of one's immediate family are related to decreases in financial resources implying that a negative change in social resources is associated with a decrease in income. This relationship, however, was not hypothesized. Finally, changes in financial resources are associated with changes in subjective well-being, indicating that an increase in income is related to an increase in happiness.

For all three approaches to the measurement of change, correlations between disability and financial resources, disability and subjective well-being, and financial resources and subjective well-being are larger when they are based on 4-year-interval change scores than on the 2year-interval change scores. Furthermore, for these measures, the residual change scores tend to produce larger correlations than either the difference scores or the percentage gain scores. Measures of change in health and subjective well-being tend to show the largest degree of relationship. Change in income is also positively related to change in subjective well-being, but the magnitude of the relationship tends to be smaller than that between disability and happiness. 
In summary, similar patterns were discovered among the three approaches to the measurement of change for the variables measuring objective status. These patterns offer some evidence of construct validity because they operate in predictable ways. For example, change in scope and size of immediate family has a weak relationship to change in happiness and increased disability is related to decreased happiness. Both the direction and the magnitude of the correlation coefficients tend to be replicated for the 2year and 4-year interval and the relationships across the 4-year interval tend to be stronger than those at the 2year interval for the hypothesized relationships. Residual change scores tend to yield larger correlation coefficients than difference scores and percentage gain scores do when the variance explained is 18 or greater.

As hypothesized, all the measures which assess subjective status within a given approach to the measurement of change in longitudinal data are positively correlated with each other (see Tables XLV, XLVI, and XLVII). A positive change in the normative health item is associated with a positive change in the ipsative health item, in the satisfaction with the financial resources items, and in the happiness item. Likewise, a positive change in one of the items measuring affect toward financial resources is associated with a positive change in the other financial items and in the happiness item. 
TABLE X.V

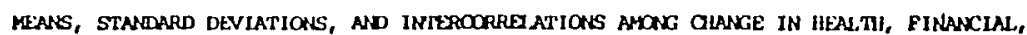

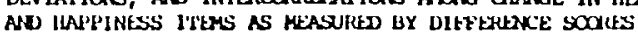

\begin{tabular}{|c|c|c|c|c|c|c|c|}
\hline $\begin{array}{l}\text { Resource Area } \\
\text { Item }\end{array}$ & year & (1) & (2) & (3) & (1) & (5) & (6) \\
\hline $\begin{array}{l}\text { Health Resources } \\
\text { Health capared (1) } \\
\text { to others }\end{array}$ & $\begin{array}{l}69-71 \\
71-73 \\
69-73\end{array}$ & & $.26 \underset{\substack{(n=7896) \\
a}}{a}$ & $\begin{array}{l}.10(n=7590) \\
.08(n-7406) \\
.13(n=7421)\end{array}$ & $\begin{array}{ll}.06 & (\mathrm{n}=7944) \\
.10 & (\mathrm{n}=8012) \\
.12 & (\mathrm{n}=7913)\end{array}$ & $\begin{array}{l}.09(n=8158) \\
.09(n)-8125) \\
.09(n=8142)\end{array}$ & $\begin{array}{l}.10(n=8138) \\
.10(n=811) \\
.14(n=8115)\end{array}$ \\
\hline $\begin{array}{l}\text { Health campared (2) } \\
\text { to } 2 \text { years ago }\end{array}$ & $\begin{array}{l}69-71 \\
71-73 \\
69-73\end{array}$ & & & $.06 \underset{\substack{a \\
a}}{a}$ & $.06 \underset{\substack{a \\
a}}{a}$ & $.07 \underset{\substack{a \\
a}}{a}=0550)$ & $\underset{a}{a} .10(n-B 528)$ \\
\hline $\begin{array}{l}\text { Financial Resources } \\
\text { Standard of } \\
\text { living compared } \\
\text { to others }\end{array}$ & $\begin{array}{l}69-71 \\
71-73 \\
69-73\end{array}$ & & & & $\begin{array}{l}.14(n=7830) \\
.13(n \rightarrow 756) \\
.19(n-7603)\end{array}$ & $\begin{array}{l}.25(n=8060) \\
.25(n=7809) \\
.31(n=7871)\end{array}$ & $\begin{array}{l}.11(n=8031) \\
.12(n)=786) \\
.15 \quad(n=7832)\end{array}$ \\
\hline $\begin{array}{l}\text { Abillty to get (1) } \\
\text { allong an } \\
\text { Incume }\end{array}$ & $\begin{array}{l}69-71 \\
71-73 \\
69-73\end{array}$ & & & & & $\begin{array}{l}.23 \quad(n-8552) \\
.21 \quad(n=8691) \\
.26(n=8517)\end{array}$ & $\begin{array}{l}.10(n=8531) \\
.10(n=8673) \\
.11 \quad(n=8485)\end{array}$ \\
\hline $\begin{array}{l}\text { Satiofaction } \\
\text { vith standard } \\
\text { of llving }\end{array}$ & $\begin{array}{l}69-71 \\
71-73 \\
69-73\end{array}$ & & & & & & $\begin{array}{ll}.21 & (n=8777) \\
.24 & (n=8427) \\
.24 & (n=8765)\end{array}$ \\
\hline $\begin{array}{l}\text { Sabjective Hell-being } \\
\text { Happiness }\end{array}$ & $\begin{array}{l}69-71 \\
71-73 \\
69-73\end{array}$ & & & & & & \\
\hline \multirow[t]{3}{*}{$\begin{array}{l}\text { Mean, } \\
\text { standard deviation, } \\
\text { and sample alze }\end{array}$} & $69-71$ & $\begin{array}{l}-0.04 \\
(0.70) \\
(n=8220)\end{array}$ & : & $\begin{array}{l}0.06 \\
(0.61) \\
(n=8079)\end{array}$ & $\begin{array}{l}0.05 \\
(0.86) \\
(n=8606)\end{array}$ & $\begin{array}{l}0.02 \\
(0.73) \\
(n=8038)\end{array}$ & $\begin{array}{l}0.06 \\
(0.73) \\
(n=8818)\end{array}$ \\
\hline & $71-73$ & $\begin{array}{l}-0.04 \\
(0.70) \\
(n=8168)\end{array}$ & $\begin{array}{l}-0.04 \\
(0.76) \\
(n=8597)\end{array}$ & $\begin{array}{l}-0.05 \\
(0.62) \\
(n=7898)\end{array}$ & $\begin{array}{l}-0.05 \\
(0.86) \\
(n=8735)\end{array}$ & $\begin{array}{l}-0.03 \\
(0.75) \\
(11=8868)\end{array}$ & $\begin{array}{l}-0.02 \\
(0.75) \\
(n=8847)\end{array}$ \\
\hline & $69-73$ & $\begin{array}{l}-0.08 \\
(0.73) \\
\left(n^{2}=0212\right)\end{array}$ & $\begin{array}{l}a \\
a \\
a\end{array}$ & $\begin{array}{l}0.01 \\
(0.64) \\
(n=7887)\end{array}$ & $\begin{array}{l}0.00 \\
(0.92) \\
(n=8572)\end{array}$ & $\begin{array}{l}-0.02 \\
(0.27) \\
(n=8837)\end{array}$ & $\begin{array}{l}0.04 \\
(0.77) \\
(n=8803)\end{array}$ \\
\hline
\end{tabular}

Note. The saple elze for the continuera 18 8922. The variations in sample glze are due to the paliwlse deletion of cases with a solssing value $c$ one or both varlables.

All correlations greater than .035 are significant at $p \times .001$.

athis Item was not included in the 1969 wave of data collection. 


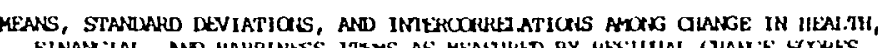

\begin{tabular}{|c|c|c|c|c|c|c|c|c|}
\hline $\begin{array}{l}\text { Resource Ared } \\
\text { Item }\end{array}$ & & year & (1) & (2) & (3) & (4) & (5) & (6) \\
\hline $\begin{array}{l}\text { Health Resources } \\
\text { Health coupar ed } \\
\text { to others }\end{array}$ & (1) & $\begin{array}{l}69-71 \\
71-73 \\
69-73\end{array}$ & & $\underset{\substack{a \\
a}}{a}$ & $\begin{array}{l}.13(n=7590) \\
.14(n=7406) \\
.16(n=7421)\end{array}$ & $\begin{array}{ll}.11 & (n=7944) \\
.15 & (n=8012) \\
.16 & (n=7913)\end{array}$ & $\begin{array}{l}.14 \quad(n=8158) \\
.15(n=8125) \\
.15 \quad(1-8112)\end{array}$ & $\begin{array}{ll}.15 & (n-8138) \\
.18 & (n-8111) \\
.20 & (n-8115)\end{array}$ \\
\hline $\begin{array}{l}\text { Heal th compared } \\
\text { to } 2 \text { years ago }\end{array}$ & (2) & $\begin{array}{l}69-71 \\
71-73 \\
69-73\end{array}$ & & & $.12 \underset{\left(n^{2} 7636\right)}{a}$ & $.11 \underset{\substack{a \\
a}}{a}$ & $.14 \underset{\substack{a \\
a}}{a}$ & $.18 \underset{\substack{a \\
a}}{a}(0528)$ \\
\hline $\begin{array}{l}\text { Financial Resources } \\
\text { Standard of living } \\
\text { canpared to others }\end{array}$ & (3) & $\begin{array}{l}69-71 \\
71-73 \\
69-73\end{array}$ & & & & $\begin{array}{r}.19 \\
.20 \\
.20=7830) \\
.24=7756) \\
(n=7603)\end{array}$ & $\begin{array}{r}.32(n=8060) \\
.34(n=7889) \\
.37(n=7871)\end{array}$ & $\begin{array}{ll}.18 & (n=8031) \\
.21 & (n-7866) \\
.23 & (n=7832)\end{array}$ \\
\hline $\begin{array}{l}\text { Ability to get } \\
\text { along on } \\
\text { incone }\end{array}$ & (1) & $\begin{array}{l}69-71 \\
71-73 \\
69-73\end{array}$ & & & & & $\begin{array}{l}.32(n=8552) \\
.30(n=8691) \\
.35 \\
(n=8517)\end{array}$ & $\begin{array}{l}.19(n=8531) \\
.17(n=8673) \\
.19(n-8485)\end{array}$ \\
\hline $\begin{array}{l}\text { Satisfaction } \\
\text { ulth standard } \\
\text { of living }\end{array}$ & (5) & $\begin{array}{l}69-71 \\
71-73 \\
69-73\end{array}$ & & & & & & $\begin{array}{l}.34(n=8777) \\
.33 \\
.35=8827) \\
.35=8765)\end{array}$ \\
\hline $\begin{array}{l}\text { sobjective Well-being } \\
\text { Happlness }\end{array}$ & (6) & $\begin{array}{l}69-71 \\
71-73 \\
69-73\end{array}$ & & & & & & \\
\hline \multirow{3}{*}{\multicolumn{2}{|c|}{$\begin{array}{l}\text { Mean, } \\
\text { standard deviation, } \\
\text { and bample size }\end{array}$}} & $69-71$ & $\begin{array}{l}0.00 \\
(0.60) \\
(n=8220)\end{array}$ & : & $\begin{array}{l}0.00 \\
(0.50) \\
(n=8079)\end{array}$ & $\begin{array}{l}0.00 \\
(0.77) \\
(n=8606)\end{array}$ & $\begin{array}{l}0.00 \\
(0.63) \\
(n=8838)\end{array}$ & $\begin{array}{l}0.00 \\
(0.62) \\
(n=8018)\end{array}$ \\
\hline & & $71-73$ & $\begin{array}{l}0.00 \\
(0.61) \\
(n=8168)\end{array}$ & $\begin{array}{l}0.00 \\
(0.62) \\
(11=8597)\end{array}$ & $\begin{array}{l}0.00 \\
(0.50) \\
(n=7898)\end{array}$ & $\begin{array}{l}0.00 \\
(0.75) \\
(n=8735)\end{array}$ & $\begin{array}{l}0.00 \\
(0.63) \\
(n-8868)\end{array}$ & $\begin{array}{l}0.00 \\
(0.64) \\
(n=8047)\end{array}$ \\
\hline & & $69-73$ & $\begin{array}{l}0.00 \\
(0.62) \\
(n=0212)\end{array}$ & $a$ & $\begin{array}{l}0.00 \\
(0.51) \\
(n=7887)\end{array}$ & $\begin{array}{l}0.00 \\
(0.79) \\
(n=8572)\end{array}$ & $\begin{array}{c}0.00 \\
(0.65) \\
(n=8837)\end{array}$ & $\begin{array}{l}0.00 \\
(0.65) \\
(n=8803)\end{array}$ \\
\hline
\end{tabular}

Note. The sample size for the contlnuers 1s 8922. The varlations In sample size are de to the palrulise deletion of cases with a sibsing value on one or both varlables.

All correlations greater than .035 are glgnificant at $p \times .001$.

Mis ites was not included in the 1969 wave of data collection. 


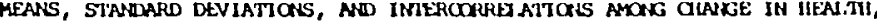

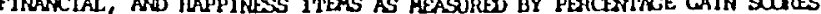

\begin{tabular}{|c|c|c|c|c|c|c|c|c|}
\hline $\begin{array}{l}\text { Resource Area } \\
\text { Item }\end{array}$ & & year & (1) & (2) & (3) & (4) & (5) & (6) \\
\hline $\begin{array}{l}\text { Heal th Resources } \\
\text { Hedlth caupared } \\
\text { to others }\end{array}$ & (1) & $\begin{array}{l}69-71 \\
71-73 \\
69-73\end{array}$ & & $.26 \underset{\substack{a \\
(n=7896)}}{a}$ & $\begin{array}{l}.08(n=7590) \\
.07(11=706) \\
.11 \quad(1-7421)\end{array}$ & $\begin{array}{l}.05(n=7944) \\
.10(n)=8012) \\
.11(n=7913)\end{array}$ & $\begin{array}{l}.08(n=8158) \\
.09(n=8125) \\
.09(n=8112)\end{array}$ & $\begin{array}{l}.08(n=8138) \\
.11(n=8111) \\
.14(n=8115)\end{array}$ \\
\hline $\begin{array}{l}\text { Hool th cunpared } \\
\text { to } 2 \text { years ago }\end{array}$ & (2) & $\begin{array}{l}69-71 \\
71-73 \\
69-73\end{array}$ & & & $.06 \underset{\substack{a \\
(n=7636)}}{a}$ & $.07 \underset{\substack{a \\
a}}{a}$ & $.08 \underset{\substack{n \\
(n=8550) \\
a}}{a}$ & $.10 \underset{\substack{a \\
a}}{a}$ \\
\hline $\begin{array}{l}\text { Financial Resources } \\
\text { Stanulard of living } \\
\text { coupared to } \\
\text { others }\end{array}$ & (3) & $\begin{array}{l}69-71 \\
71-73 \\
69-73\end{array}$ & & & & $\begin{array}{l}.13\left(n^{2} 7830\right) \\
.13 \quad(n=7756) \\
.18 \quad(1=7603)\end{array}$ & $\begin{array}{l}.23(n-8060) \\
.24(n-7889) \\
.29(n=7871)\end{array}$ & $\begin{array}{l}.10(n=8031) \\
.12(n-7866) \\
.14(n=7832)\end{array}$ \\
\hline $\begin{array}{l}\text { Abllity to get } \\
\text { along on lnccose }\end{array}$ & (4) & $\begin{array}{l}69-71 \\
71-73 \\
69-73\end{array}$ & & & & & $\begin{array}{l}.23(n=8552) \\
.19(n=8691) \\
.25(n=8517)\end{array}$ & $\begin{array}{ll}.10 & (n=8531) \\
.11 & (n-8673) \\
.11 & (n=8485)\end{array}$ \\
\hline $\begin{array}{l}\text { Sat isfaction with } \\
\text { otandard of } 1 \text { lving }\end{array}$ & (5) & $\begin{array}{l}69-71 \\
71-73 \\
69-73\end{array}$ & & & & & & $\begin{array}{ll}.21 & (n=8777) \\
.23 & (n=8027) \\
.23 & (n=8765)\end{array}$ \\
\hline $\begin{array}{l}\text { subjective Well-belng } \\
\text { Happliness }\end{array}$ & (6) & $\begin{array}{l}69-71 \\
71-73 \\
69-73\end{array}$ & & & & & & \\
\hline \multirow{3}{*}{\multicolumn{2}{|c|}{$\begin{array}{l}\text { Maan, } \\
\text { standard devlation, } \\
\text { and sample blze }\end{array}$}} & $69-71$ & $\begin{array}{l}0.01 \\
(0.49) \\
(n=0220)\end{array}$ & $\begin{array}{l}a \\
a \\
a\end{array}$ & $\begin{array}{l}0.04 \\
(0.45) \\
(n-8079)\end{array}$ & $\begin{array}{l}0.03 \\
(0.48) \\
(n=8606)\end{array}$ & $\begin{array}{l}0.04 \\
(0.42) \\
(n=8838)\end{array}$ & $\begin{array}{l}0.06 \\
(0.54) \\
(n=8818)\end{array}$ \\
\hline & & 21-73 & $\begin{array}{l}0.00 \\
(0.50) \\
(n=8168)\end{array}$ & $\begin{array}{l}-0.05 \\
(0.53) \\
(n=8597)\end{array}$ & $\begin{array}{l}-0.04 \\
(0.15) \\
(n=7898)\end{array}$ & $\begin{array}{l}-0.03 \\
(0.46) \\
(n-8735)\end{array}$ & $\begin{array}{l}0.01 \\
(0.41) \\
(n=8868)\end{array}$ & $\begin{array}{l}0.01 \\
(0.54) \\
(n=884)\end{array}$ \\
\hline & & $69-73$ & $\begin{array}{l}-0.02 \\
(0.51) \\
(n=8212)\end{array}$ & a & $\begin{array}{l}0.00 \\
(0.17) \\
(n-7487)\end{array}$ & $\begin{array}{l}-0.00 \\
(0.49) \\
(n=8572)\end{array}$ & $\begin{array}{l}0.02 \\
(0.13) \\
(n-8837)\end{array}$ & $\begin{array}{l}0.05 \\
(0.56) \\
(n=8803)\end{array}$ \\
\hline
\end{tabular}

Note. The saple size for the continuers is 8922. The varlations in sample gize are due to the polrwise deletian of cases with a plesing value on one ar both variables.

Nl correlations grester than .035 are significant at $p . .001$.

athla ftem was not Included in the 1969 wave of data collection. 
For all of the approaches to the measurement of change, the coefficients for the 4-year interval are equal to or greater than the corresponding ones for a 2-year interval among the items assessing subjective status. In general, the correlation coefficients for the residual change scores are larger than those for the difference scores and for those of the percentage gain scores. The correlation coefficients based on difference scores are equal to or slightly larger that the corresponding ones for the percentage gain scores.

In conclusion, it can be stated that the analyses have provided evidence of construct validity for the change measures. The different approaches to the measurement of change in longitudinal data rank people similarly on measures assessing objective status and subjective status. In general, high correlation coefficients were obtained for a given variable between the three selected approaches to the measurement of change. Furthermore, support for the hypothesized direction among the change measures for the areas of health, social, financial resources, and subjective well-being was found. The correlations among the 4-year-interval data tend to be larger than those for the 2-year-intarval data as hypothesized. However, although change scores in health and financial resources are significantly related to change scores in subjective well-being, the absolute value of the correlation coefficients is never greater than . 35 . 
If a) one approach to the measurement of change is to be selected, b) the focus is on correlating a change measure with some criterion, and c) the measures to be used have psychometric properties similar to those of the measures for this study, residual change scores tend to yield larger correlation coefficients for the hypothesized relationships. When a relationship does not seen to be present, the residual change scores yield correlation coefficients which are close to 0 just as difference scores and percentage gain scores do. Finally, the relationship between residual change scores and difference scores tends to be the greatest when the range of the measures is wider. This may occur because the ceiling effects associated with difference scores have less of a chance to operate when this condition is present.

\section{Question $\underline{3}$}

knowledge in gerontology is almost exclusively derived from cross-sectional studies. It is important to seek evidence on the contributions of longitudinal analysis toward the refinement of gerontological theories and policy development. Results of the analyses guided by question 3 offer preliminary evidence on the usefulness of longitudinal analysis. Question 3 was worded as follows:

Does change on selected health, social, and financial measures explain a significant amount of variance in subjective well-being and in change in subjective well-being? How does this 
amount of variance compare to that explained by one-point-in-time measures?

A series of multiple linear regression procedures was computed to address these issues. First, cross-sectional regression analyses were performed for both the objective and subjective domain for each of the three waves of data collection. Second, longitudinally derived predictors were used in two sets of regression analyses, the first set with happiness as the outcome measure and the second set with change in happiness as the outcome measure. The regression analyses were repeated for each of the three sets of longitudinally derived predictors, the change scores from 1969 to 1971 , the change scores from 1971 to 1973 , and the change score from 1969 to 1973. Because three approaches to the measurement of change in longitudinal data had originally been selected, the analyses for the 2-year and 4-year intervals were carried out for each approach separately. Finally, for the objective domain, the sorting of the predictor variables for the areas of health and social resources into two groups was maintained and the analyses were done separately for Overall Disability, Size of Immediate Family, and Income as one group of predictors and General Disability, scope of Immediate Family, and Income as the other group. The cross-sectional analyses for the measures of the objective domain and for the measures of the subjective domain are discussed first, 
followed by the findings from the longitudinal analyses for each domain.

\section{Findings From the Cross-sectional Analyses}

The Objective Status Domain. Cross-sectional analyses were performed for the 1969, 1971, and 1973 wave of data collection with the happiness item from that wave as the outcome measure and with three predictor variables, one from each resource area. Within the objective domain, two regressions were computed per wave to maintain the two groupings of the independent variables used previously. Therefore, within a wave, one regression was computed with Overall Disability, Size of Immediate Family, and Income as the predictor variables. Another regression was computed with General Disability, scope of Immediate Family, and Income as the predictor variables. This sorting of one indicator per area for health and social resources was done to minimize the amount of duplication among the predictor variables while matching the variables on their range.

The results from the cross-sectional analyses are presented in Table XLVIII (the means, standard deviations, and correlation coefficients for these analyses are presented in Appendix C, Table LXII). For both sets of predictor variables, the amount of variance explained in happiness is fairly constant across waves, ranging from 118 to $13 \%$. Furthermore, the order of entry of the first two predictor variables is replicated across waves within a set of predictor variables. For the first set of predictor 
TABLE XLVIII

MULTIPLE LINEAR REGRFSSION FOR PREDICTING SUBJECTTVE WET, -BEING FROM HEALTH, SOCIAL, AND FINANCIAL, RESOURCES IN 1969, 1971, AND 1973

\begin{tabular}{|c|c|c|c|c|c|c|c|c|c|c|c|c|}
\hline \multirow[b]{2}{*}{ Index/Iten } & \multicolumn{4}{|c|}{1969} & \multicolumn{4}{|c|}{1971} & \multicolumn{4}{|c|}{1973} \\
\hline & $\begin{array}{l}\text { Order of } \\
\text { entry }\end{array}$ & $\mathbf{b}$ & beta & $\Delta \mathrm{R} 2$ & $\begin{array}{l}\text { Order of } \\
\text { entry }\end{array}$ & $\mathrm{b}$ & beta & $\triangle \mathrm{R} 2$ & $\begin{array}{l}\text { Order of } \\
\text { entry }\end{array}$ & b & beta & $\Delta R 2$ \\
\hline $\begin{array}{l}\text { Overall } \\
\text { Disability }\end{array}$ & 1 & -0.30 & -0.22 & 0.09 & 1 & -0.27 & -0.21 & 0.08 & 1 & -0.29 & -0.24 & 0.09 \\
\hline $\begin{array}{l}\text { Size of } \\
\text { Immediate Family }\end{array}$ & 3 & -0.06 & -0.04 & 0.00 & - & - & - & - & - & - & - & - \\
\hline \multirow[t]{2}{*}{ Income } & 2 & 0.19 & 0.21 & 0.04 & 2 & 0.19 & 0.21 & 0.04 & 2 & 0.19 & 0.19 & 0.04 \\
\hline & Total & $\mathrm{R} 2=0.13$ & \multicolumn{2}{|c|}{$\mathbb{N}=8010$} & Total & $\mathrm{R} 2=0.12$ & \multicolumn{2}{|c|}{$\mathrm{N}=7986$} & Total & $\mathrm{R} 2=0.13$ & \multicolumn{2}{|c|}{$N=7927$} \\
\hline \multirow{4}{*}{$\begin{array}{l}\text { General } \\
\text { Disability } \\
\text { Scope of } \\
\text { Immediate Eamily } \\
\text { Incone }\end{array}$} & 2 & -0.15 & -0.18 & 0.03 & 2 & -0.14 & -0.17 & 0.03 & 2 & -0.17 & -0.21 & 0.04 \\
\hline & - & - & - & - & - & - & - & - & - & - & - & - \\
\hline & 1 & 0.21 & 0.24 & 0.08 & 1 & 0.21 & 0.23 & 0.08 & 1 & 0.21 & 0.21 & 0.07 \\
\hline & Total & $\mathrm{R} 2=0.11$ & $\mathbf{N}=$ & 8518 & Total & $\mathrm{R} 2=0.11$ & $\mathbf{N}=$ & 8456 & Total & $\mathrm{R} 2=0.11$ & $\mathbf{N}=$ & 8388 \\
\hline
\end{tabular}

Note. The dash $(-)$ indicates that the variable did not reach the level of statistical significance (p $<.05)$ necessary to be entered into the regression analysis. 
variables, the $b$ weights range from -.27 to -.30 for the Overall Disability index and equal .19 at all three points in time for the income variable. For the second set of predictors, the b weights equal .21 for the Income variable, and range from -.14 to -.17 for the General Disability index. The most interesting occurrence may be that the order of entry across the two sets of predictor variables is reversed with the health index explaining more variance when its range is larger. In both sets and across all three waves, the measures of social resources do not contribute to the regression equation.

The Subjective status Domain. The results of the multiple linear regressions for the cross-sectional analysis of the subjective status domain are presented in Table XIIX (the means, standard deviations, and correlation coefficients for these analyses are presented in Appendix C, Table LXIII). The percent of variance explained by the linear combination of the predictor variables is between 23 and 268 and the order of entry of the first three variables is identical across the three waves. As shown in Table XLIX, the satisfaction with standard of living item is entered first, followed by the normative health item and by the ability to get along on income item. However, the variables across waves do not explain an identical amount of variance and their respective $b$ and beta weights are not identical. The pattern of the amount of variance explained 
TABLE XLIX

MULTIPLE LINEAR REGRESSION FOR PREDTCTING SUBJECTIVE WEIL-BEING FROM HEALTH AND FINANCIAL ITEMS IN 1969, 1971, AND 1973

\begin{tabular}{|c|c|c|c|c|c|c|c|c|c|c|c|c|}
\hline \multirow[b]{2}{*}{ Item } & \multicolumn{4}{|c|}{1969} & \multicolumn{4}{|c|}{1971} & \multicolumn{4}{|c|}{1973} \\
\hline & $\begin{array}{l}\text { Order of } \\
\text { entry }\end{array}$ & b & beta & $\Delta \mathrm{R} 2$ & $\begin{array}{l}\text { Order of } \\
\text { entry }\end{array}$ & b & beta & $\triangle \mathrm{R} 2$ & $\begin{array}{l}\text { Order of } \\
\text { entry }\end{array}$ & b & beta & $\Delta \mathrm{R} 2$ \\
\hline $\begin{array}{l}\text { Health compared } \\
\text { to others }\end{array}$ & 2 & 0.19 & 0.20 & 0.05 & 2 & 0.12 & 0.12 & 0.03 & 2 & 0.14 & 0.14 & 0.04 \\
\hline $\begin{array}{l}\text { Health compared } \\
\text { to } 2 \text { years ago }\end{array}$ & $a$ & $a$ & a & $a$ & 4 & 0.07 & 0.07 & 0.00 & 4 & 0.09 & 0.08 & 0.00 \\
\hline $\begin{array}{l}\text { Standard of living } \\
\text { compared to others }\end{array}$ & 4 & 0.09 & 0.07 & 0.00 & 5 & 0.07 & 0.06 & 0.00 & 5 & 0.10 & 0.08 & 0.00 \\
\hline $\begin{array}{l}\text { Ability to get along } \\
\text { on income }\end{array}$ & 3 & 0.08 & 0.12 & 0.01 & 3 & 0.07 & 0.10 & 0.01 & 3 & 0.07 & 0.09 & 0.01 \\
\hline \multirow[t]{2}{*}{$\begin{array}{l}\text { Satisfaction with } \\
\text { standard of living }\end{array}$} & 1 & 0.26 & 0.25 & 0.17 & 1 & 0.33 & 0.34 & 0.22 & 1 & 0.32 & 0.32 & 0.21 \\
\hline & Total & $\mathrm{R} 2=0.23$ & \multicolumn{2}{|c|}{$N=7956$} & Total & $\mathrm{R} 2=0.26$ & \multicolumn{2}{|c|}{$\mathbf{N}=7957$} & Total & $R 2=0.26$ & \multicolumn{2}{|c|}{$\mathbf{N}=7728$} \\
\hline
\end{tabular}

This item was not Included in the 1969 wave of data collection. 
by each predictor variable in the 1971 analysis is closer to the pattern in the 1973 analysis than to the pattern in the 1969 analysis. In 1969, the satisfaction with standard of living item explains comparatively less variance and the health item explains comparatively more variance than in the 1971 and 1973 analysis. The relative magnitude of the beta weights across waves for a variable underlines this pattern. In the 1969 analysis, the beta weight for the satisfaction with standard of living item equals .25, and for the normative health item it is equal to .20 . In 1971, the corresponding beta weights are .34 and .12 and in the 1973 analysis, the corresponding values are .32 and .14 . A beta weight indicates the amount of change in standard deviation units in the dependent variable for one standard deviation change in an independent variable with all the other predictor variables held constant. In 1969 , the difference in the predicted happiness item in standard deviation units is .20 for a standard deviation difference in the health item. It is only .12 and .14 in the 1971 and 1973 analysis. The $b$ weights range from .26 to .33 for the satisfaction with standard of living item, from .12 to .19 for the normative health item and from .07 to .08 for the ability to get along on one's income item.

Findings From the Longitudinal Analysis

The second phase of the analysis for question 3 involved computing regression procedures for the happiness 
item and for change in the happiness item using one change measure from each of the three resource areas as predictor variables. As stated previously, three change scores were computed for all the variables, a difference score, a residual change score, and a percentage gain score. Within each approach to the measurement of change in longitudinal data, a change measure was computed between 1969 and 1971, between 1971 and 1973, and between 1969 and 1973. Finally, for the objective status domain, the sorting of the predictor variables into two sets was maintained. One regression analysis was carried out with overall Disability, Size of Immediate Family, and Income as predictor variables, and another analysis was done with General Disability, Scope of Immediate Family, and Income as predictor variables. For the objective status domain, then, a total of 36 regression analyses were computed and for the subjective status domain, 18 regression analyses were done.

The objective status Domain. The results for the objective status domain are presented in Table L and LI. The happiness item is the outcome measure in the first table and change in the happiness item is the outcome measure in the second table. For question 3 , the variations found among the three selected approaches to the measurement of change in longitudinal data are ignored because they are the focus of question 4 . 
BETA WETGRTS FOR PPEDICTING SUBJECTTVE WELL-BETNG FPOM OHANGE IN HEALTH, SOCIAL, AND FINANCIAL RESOURCES FOR EACH $O$ F THE THREE APPPOACHES TO THE MEASURDMENT OF CHANGE AT EACH OF THE THREE WAVES OF DATA COLLCTION

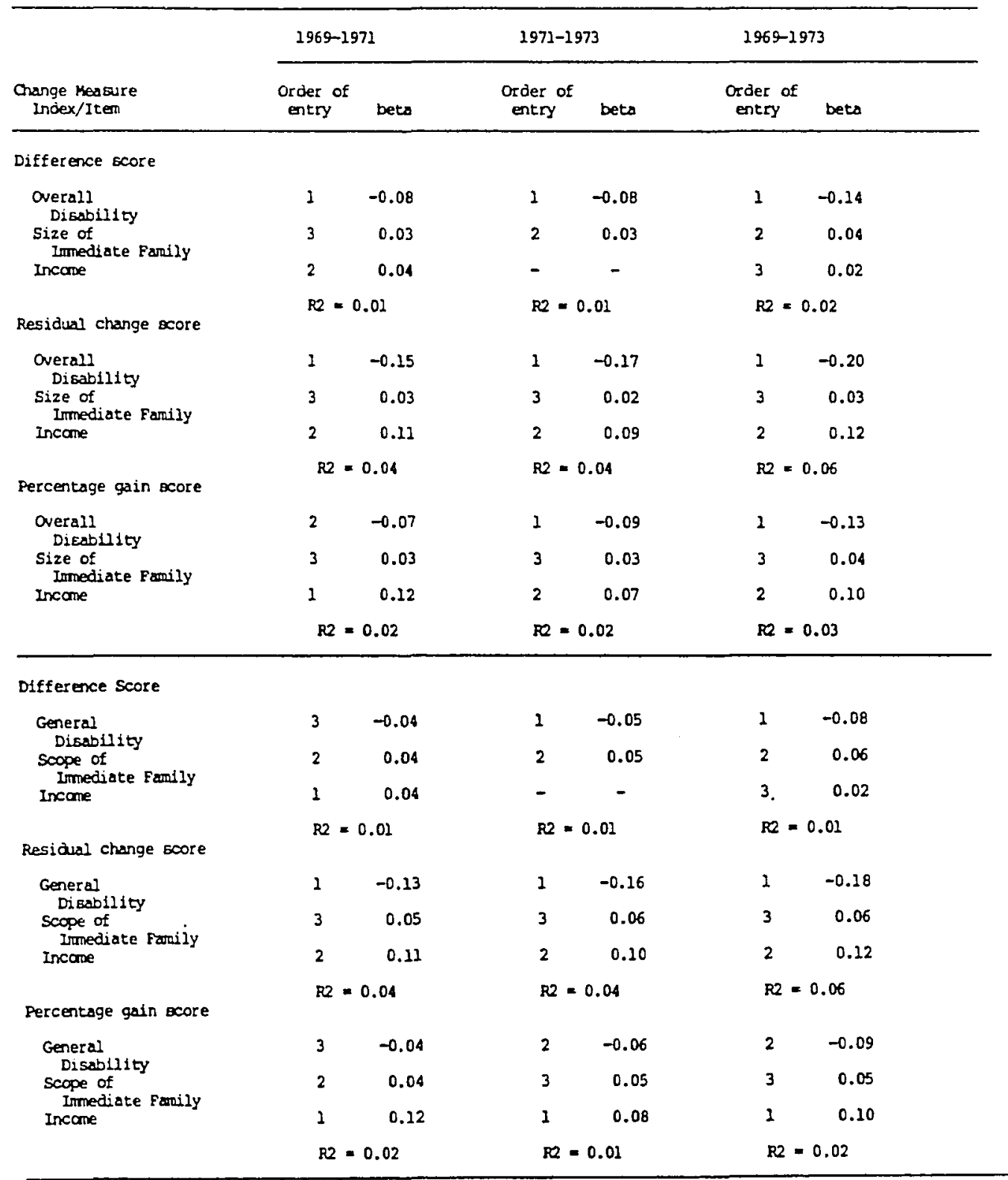

Note. The outcame in the 1969-1971 analysis is the happiness iten in 1971. Likewise, the outcome tn the 1971-1973 and in the 1969-1973 analyses is the happiness fter in 1973.

The dash (-) indicates that the variable did not reach the level of statistical significance (pK.05) necessary to be entered into the regression anslysis.

The sample sizes for the regression analyses with overall Disability, Size of Immediate Family, and Income as the independent variables are 7303 for the 1969-1971 wave of data collection, 7207 for the 1971-1973 wave, and 7233 for the 1969-1973 wave. The smple sizes for the regression analyses with Generar Disability, Scope of Immediate Fandly, and Income are 8172, 8044, and 8108 for the 1969-1971, 1971-1973, and 1969-1973 waves of data collection. 
TARLE LI

BETA WEIGTSS FOR PREDICTING GHANGE IN SUBJECTVE WDI-BEING FROM OHANGE IN REALTH, SOCIAL, AND FINANCIAL RESOURCES FOR EACH OF THE TIREE APPROACHES TO THE KEASUREMENT

OF OUANGE FI EACH OF THE TMRRE WAVES OF DATA COLIDCTION

\begin{tabular}{|c|c|c|c|c|c|c|}
\hline \multirow{2}{*}{$\begin{array}{l}\text { Crange Mesoure } \\
\text { Index/Itex }\end{array}$} & \multicolumn{2}{|c|}{$1969-1971$} & \multicolumn{2}{|c|}{$1971-1973$} & \multicolumn{2}{|c|}{$1969-1973$} \\
\hline & $\begin{array}{l}\text { Order of } \\
\text { entry }\end{array}$ & bets & $\begin{array}{l}\text { Order of } \\
\text { entry }\end{array}$ & bete & $\begin{array}{l}\text { Order of } \\
\text { entry }\end{array}$ & bets \\
\hline \multicolumn{7}{|l|}{ Difference boore } \\
\hline $\begin{array}{l}\text { Overall } \\
\text { Disability } \\
\text { Size of } \\
\text { Imnediate Fandly } \\
\text { Incame }\end{array}$ & 3 & -0.08 & - & -0.10 & 3 & $\begin{array}{l}0.04 \\
0.06\end{array}$ \\
\hline Residual change score & \multicolumn{2}{|c|}{$R 2=0.01$} & \multicolumn{2}{|c|}{$202=0.01$} & \multicolumn{2}{|c|}{$R 2=0.02$} \\
\hline $\begin{array}{l}\text { Overall } \\
\text { Disability } \\
\text { Size of } \\
\text { Inmediate Fonily } \\
\text { Incoree }\end{array}$ & 2 & -0.13 & 2 & -0.16 & 2 & -0.19 \\
\hline \multirow[b]{2}{*}{$\begin{array}{l}\text { Percentage gain acore } \\
\text { Overall } \\
\text { Disabillity } \\
\text { Size of } \\
\text { Imediate Fonily } \\
\text { Income }\end{array}$} & \multicolumn{2}{|c|}{$P 2=0.03$} & \multicolumn{2}{|c|}{$\mathrm{PQ}=0.03$} & \multicolumn{2}{|c|}{$R 2=0.05$} \\
\hline & ${ }^{3}$ & $0.0 i^{0.05}$ & $\stackrel{2}{R 2}=0$ & $\begin{array}{r}-0.08 \\
0.02\end{array}$ & ${ }_{\mathrm{R} 2}^{2}=$ & $\begin{array}{r}0.04 \\
0.07\end{array}$ \\
\hline \multicolumn{7}{|l|}{ DLfference soare } \\
\hline $\begin{array}{l}\text { General } \\
\text { Disablility } \\
\text { Socope of } \\
\text { Inmediate Fonily } \\
\text { Incone }\end{array}$ & $\begin{array}{l}1 \\
3 \\
2\end{array}$ & $\begin{array}{r}-0.06 \\
0.03\end{array}$ & $\begin{array}{l}1 \\
3\end{array}$ & $\begin{array}{r}-0.08 \\
0.03\end{array}$ & $\begin{array}{l}1 \\
3\end{array}$ & $\begin{array}{r}-0.10 \\
0.04\end{array}$ \\
\hline & \multicolumn{2}{|c|}{$R 2=0.01$} & \multicolumn{2}{|c|}{$82=0.01$} & \multicolumn{2}{|c|}{$R 2=0.02$} \\
\hline $\begin{array}{l}\text { Residial change score } \\
\text { General } \\
\text { Dibsbillty } \\
\text { Scope of } \\
\text { Inmediate ganily } \\
\text { Income }\end{array}$ & $\begin{array}{l}1 \\
3\end{array}$ & -0.11 & $\begin{array}{l}3 \\
2\end{array}$ & -0.14 & $\begin{array}{l}3 \\
2\end{array}$ & $\begin{array}{l}0.06 \\
0.10\end{array}$ \\
\hline Percentage gain Bcore & \multicolumn{2}{|c|}{$\mathrm{P} 2=0.02$} & \multicolumn{2}{|c|}{$\mathrm{P} 2=0.03$} & \multicolumn{2}{|c|}{$R 2=0.04$} \\
\hline \multirow[t]{2}{*}{$\begin{array}{l}\text { Goneral } \\
\text { Disability } \\
\text { Scope of } \\
\text { Inmediate Panlly } \\
\text { Incame }\end{array}$} & $\begin{array}{l}2 \\
3 \\
1\end{array}$ & $\begin{array}{r}-0.04 \\
0.03 \\
0.05\end{array}$ & $\begin{array}{l}1 \\
3 \\
2\end{array}$ & $\begin{array}{r}-0.07 \\
0.03\end{array}$ & $\begin{array}{l}1 \\
3 \\
2\end{array}$ & -0.10 \\
\hline & \multicolumn{2}{|c|}{$R 2=0.00$} & \multicolumn{2}{|c|}{$F 2=0.01$} & \multicolumn{2}{|c|}{$R 2=0.02$} \\
\hline
\end{tabular}

Note. The ourcane in the 1969-1971 analysis is the change in happlness from 1969 to 1971. Likewloe, the outcome in the 1971-1973 and in the 1969-1973 analyses is the chame in happiness from 1971 to 1973 and from 1969 to 1973 respectively.

The dash (-) Indicates that the variable did not reach the level of statistical significance (p<.05) necessary to be entered into the regression analysis.

The somple sizes for the regression analyses with overall Diabbility, Size of Inmediate Fandly, and Incame as the independent varlables are 7255 for the 1959-1971 wave of dato collection, 7190 for the 1971-1973 wave, and 7183 for the 1969-1973 wave. The Bample sizes for the regression anslyseg with General Disabllity, Scope of Immediate Fandly, and Incone are 8120, 8023, and 8055 for the 1969-1971, 1971-1973, and 1969-1973 waves of dats collection. 
The range of the variance explained in happiness by using one change measure from each resource area as a predictor variable is between 1 and 38 for difference scores and percentage gain scores and between 4 and 68 for residual change scores for both sets of predictor variables (see Table $L$ ). When change in happiness is the outcome measure (see Table LI), the variance explained is between 0 and 28 for difference scores and percentage gain scores, and between 2 and 5 f for residual change scores.

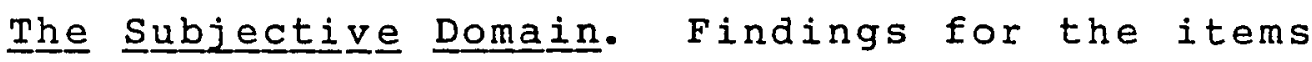
measuring the subjective status domain are presented in Table LII for the happiness item and in Table LIII for the change in happiness outcome. For difference scores, the variance explained is between 2 and 38 when happiness at a later-point-in-time is the outcome; it is between 16 and 188 for residual change scores, and between 6 and 78 for percentage gain scores. When the outcome is change in happiness, the difference scores and percentage gain scores explain between 5 and $7 \%$ of the variance and the residual change scores explain between 12 and $15 \%$ of the variance.

Comparis으므 으 Cross-sectional and Longitudinal Findings

In general, the cross-sectional analyses for the objective and subjective domains explain more variance in the happiness outcome than the longitudinal analyses. In the cross-sectional analyses for the objective domain, the R2 ranges from .11 to .13 with a median value of .11. For 
TABLE LII

BETA WEIGTIS FOR FREDICTING SUBJDCTIVE WILL-BETNG FTOM CHANGE IN HEALTH AND FINANCIAL ITEYS FOR EACH $O F$ THE THREE APPROACHES TO THE MEASUREMENT OF GHANGE AT EACH OF TRE THREE WAVES OF DATA COLECTION

\begin{tabular}{|c|c|c|c|c|c|c|}
\hline \multirow[b]{2}{*}{$\begin{array}{l}\text { Measure of change } \\
\text { Itero }\end{array}$} & \multicolumn{2}{|c|}{$1969-1971$} & \multicolumn{2}{|c|}{$1971-1973$} & \multicolumn{2}{|c|}{$1969-1973$} \\
\hline & $\begin{array}{l}\text { Ozder of } \\
\text { entry }\end{array}$ & beta & $\begin{array}{l}\text { Order of } \\
\text { entry }\end{array}$ & bete & $\begin{array}{l}\text { Order of } \\
\text { entry }\end{array}$ & beta \\
\hline \multicolumn{7}{|l|}{ Difference score } \\
\hline $\begin{array}{l}\text { Bealth compared } \\
\text { to others }\end{array}$ & - & - & - & - & - & - \\
\hline $\begin{array}{l}\text { Bealth campar ed } \\
\text { to } 2 \text { years ago }\end{array}$ & $\mathbf{a}$ & $\mathbf{a}$ & 3 & 0.05 & a & $\mathbf{a}$ \\
\hline $\begin{array}{l}\text { Standard of living } \\
\text { compared to others }\end{array}$ & - & - & 2 & 0.05 & 2 & 0.04 \\
\hline $\begin{array}{l}\text { Abilicy to get along } \\
\text { an income }\end{array}$ & 2 & 0.03 & - & - & - & - \\
\hline $\begin{array}{l}\text { Satisfaction with } \\
\text { standard of living }\end{array}$ & 1 & 0.16 & 1 & 0.09 & 1 & 0.15 \\
\hline Residual change ecore & \multicolumn{2}{|c|}{$\mathrm{PQ}=0.03$} & \multicolumn{2}{|c|}{$R 2=0.02$} & \multicolumn{2}{|c|}{$\mathrm{RO}=0.03$} \\
\hline $\begin{array}{l}\text { Beslth compared } \\
\text { to others }\end{array}$ & 2 & 0.11 & 4 & 0.10 & 2 & 0.14 \\
\hline $\begin{array}{l}\text { Bealth compared } \\
\text { to } 2 \text { years ago }\end{array}$ & $\mathbf{a}$ & $\mathbf{a}$ & 2 & 0.11 & $\mathbf{a}$ & $\mathbf{a}$ \\
\hline $\begin{array}{l}\text { Standard of living } \\
\text { compared to others }\end{array}$ & 4 & 0.08 & 3 & 0.11 & 3 & 0.11 \\
\hline $\begin{array}{l}\text { Noility to get along } \\
\text { on incane }\end{array}$ & 3 & 0.10 & 5 & 0.07 & 4 & 0.07 \\
\hline $\begin{array}{l}\text { Satibfaction with } \\
\text { standard of living }\end{array}$ & 1 & 0.29 & 1 & 0.25 & 1 & 0.29 \\
\hline Percentage gain acore & \multicolumn{2}{|c|}{$R 2=0.16$} & \multicolumn{2}{|c|}{$R 2=0.17$} & \multicolumn{2}{|c|}{$R 2=0.18$} \\
\hline $\begin{array}{l}\text { Bealth campared } \\
\text { to other } 5\end{array}$ & 4 & 0.03 & 5 & 0.05 & 3 & 0.05 \\
\hline $\begin{array}{l}\text { Bealth compared } \\
\text { to } 2 \text { years ago }\end{array}$ & a & $\mathbf{a}$ & 3 & 0.06 & a & a \\
\hline $\begin{array}{l}\text { Standard of living } \\
\text { compared to others }\end{array}$ & 3 & 0.03 & 2 & 0.08 & 2 & 0.07 \\
\hline $\begin{array}{l}\text { Ability to get alang } \\
\text { on income }\end{array}$ & 2 & 0.08 & 4 & 0.05 & 4 & 0.05 \\
\hline \multirow{2}{*}{$\begin{array}{l}\text { Satisfaction with } \\
\text { standard of living }\end{array}$} & 1 & 0.23 & 2 & 0.16 & 1 & 0.21 \\
\hline & \multicolumn{2}{|c|}{$R 2=0.07$} & \multicolumn{2}{|c|}{$R 2=0.06$} & \multicolumn{2}{|c|}{$R 2=0.07$} \\
\hline
\end{tabular}

Note. The outcome in the 1969-1971 andysis is the happlness 1tem in 1971. Likewise, the outcare in the 1971-1973 and in the 1969-1973 analyses is the happiness 1tem in 1973.

The dash (-) indicates that the variable did not reach the level of statistical significance (pr.05) necessary to be entered into the regression analysis.

The sample size for the regression analysis is 7329 for the $1969-1971$ wave of data collection, 7026 for the 1971-1973 wave, and 7132 for the 1969-1973 wave.

This iten was not included in the 1969 wave of data collection. 
TABLE LIII

\begin{tabular}{|c|c|c|c|c|c|c|}
\hline \multirow[b]{2}{*}{$\begin{array}{l}\text { Measure of change } \\
\text { Item }\end{array}$} & \multicolumn{2}{|c|}{$1969-1971$} & \multicolumn{2}{|c|}{$1971-1973$} & \multicolumn{2}{|c|}{$1969-1973$} \\
\hline & $\begin{array}{l}\text { Order of } \\
\text { entry }\end{array}$ & beta & $\begin{array}{l}\text { Order of } \\
\text { entry }\end{array}$ & beta & $\begin{array}{l}\text { Order of } \\
\text { entry }\end{array}$ & bets \\
\hline \multicolumn{7}{|l|}{ Difference score } \\
\hline $\begin{array}{l}\text { Heal th compared } \\
\text { to others }\end{array}$ & 2 & 0.08 & 4 & 0.05 & 2 & 0.11 \\
\hline $\begin{array}{l}\text { Health compared } \\
\text { to } 2 \text { years ago }\end{array}$ & a & a & 2 & 0.06 & a & a \\
\hline $\begin{array}{l}\text { Standard of living } \\
\text { campared to others }\end{array}$ & 3 & 0.04 & 3 & 0.05 & 3 & 0.07 \\
\hline $\begin{array}{l}\text { Ability to get alang } \\
\text { on income }\end{array}$ & 4 & 0.04 & 5 & 0.04 & 4 & 0.03 \\
\hline $\begin{array}{l}\text { Satisfaction with } \\
\text { standard of living }\end{array}$ & 1 & 0.17 & 2 & 0.20 & 1 & 0.18 \\
\hline Residual change score & \multicolumn{2}{|c|}{$R_{2}=0.05$} & \multicolumn{2}{|c|}{$R 2=0.07$} & \multicolumn{2}{|c|}{$R 2=0.07$} \\
\hline $\begin{array}{l}\text { Health compared } \\
\text { to others }\end{array}$ & 2 & 0.10 & 3 & 0.09 & 2 & 0.13 \\
\hline $\begin{array}{l}\text { Health compared } \\
\text { to } 2 \text { years ago }\end{array}$ & a & a & 2 & 0.10 & a & $\Delta$ \\
\hline $\begin{array}{l}\text { Standard of living } \\
\text { compared to others }\end{array}$ & 4 & 0.06 & 4 & 0.08 & 3 & 0.10 \\
\hline $\begin{array}{l}\text { Abllity to get along } \\
\text { on income }\end{array}$ & 3 & 0.07 & 5 & 0.05 & 4 & 0.05 \\
\hline $\begin{array}{l}\text { Satisfaction with } \\
\text { standard of living }\end{array}$ & 1 & 0.27 & 1 & 0.25 & 1 & 0.27 \\
\hline Percentage gain score & \multicolumn{2}{|c|}{$R 2=0.12$} & \multicolumn{2}{|c|}{$R 2=0.14$} & \multicolumn{2}{|c|}{$\mathrm{R} 2=0.15$} \\
\hline $\begin{array}{l}\text { Heal th compared } \\
\text { to others }\end{array}$ & 2 & 0.07 & 2 & 0.07 & 2 & 0.10 \\
\hline $\begin{array}{l}\text { Health corpared } \\
\text { to } 2 \text { years ago }\end{array}$ & $\mathbf{a}$ & a & 4 & 0.06 & a & a \\
\hline $\begin{array}{l}\text { Standard of living } \\
\text { compared to others }\end{array}$ & 4 & 0.04 & 3 & 0.06 & 3 & 0.07 \\
\hline $\begin{array}{l}\text { Ability to get along } \\
\text { on incame }\end{array}$ & 3 & 0.04 & 5 & 0.06 & 4 & 0.04 \\
\hline \multirow[t]{2}{*}{$\begin{array}{l}\text { Satisfaction with } \\
\text { standard of living }\end{array}$} & 1 & 0.17 & 1 & 0.18 & 1 & 0.18 \\
\hline & \multicolumn{2}{|c|}{$R_{2}=0.05$} & \multicolumn{2}{|c|}{$R 2=0.07$} & \multicolumn{2}{|c|}{$R 2=0.07$} \\
\hline
\end{tabular}

Note. The outcome in the 1969-1971 anslysis is the change in happiness from 1969 to 1971. L1kewise, the outcome in the 1971-1973 and in the 1969-1973 analyses is the change in happiness fran 1971 to 1973 and fram 1969 to 1973 respectively.

The sample size for the regression analysis is 7301 for the $1969-1971$ wave of data collection, 7017 for the 1971-1973 wave, and 7103 for the $1965-1973$ wave.

This Item was not included in the 1969 wave of data collection. 
the subjective domain, the $R 2$ ranges from .23 to .26 with a median value of .25 . For the longitudinal analyses with measures from the objective domain, the R2 ranges from .01 to .06 when happiness is the outcome measure and from .00 to .05 when change in happiness is the outcome measure. For both analyses, the median 22 is .02. For the measures assessing the subjective domain, the $\mathrm{R} 2$ ranges from .02 to .18 with a median value of .07 for the analysis with happiness as the outcome measure and the $\mathrm{R} 2$ ranges from .05 to .15 with a median value of .07 for the analysis with change in happiness as the outcome measure. Worthy of attention is that more variance is explained when measures of the subjective domain are analyzed, where change in a global assessment of a domain seems to be tied to both the report of happiness at a later-point-in-time and to change in happiness.

\section{Question $\underline{4}$}

After providing preliminary evidence on the nature of the results obtained from cross-sectional versus longitudinal analysis, the question still remains as to the relative merits of the different approaches to the measurement of change. Question 4 addresses this issue:

Do the different ways of measuring change produce significantly different results when the relationship of subjective well-being with health, social, and financial resources is analyzed using multiple regression procedures? 
The results pertaining to this question are presented in Tables $L$ and II for the objective status domain and in Tables LII and LIII for the subjective status domain. These tables were presented with question 3 and their organization will not be reviewed here. Complete documentation on the regression analyses are presented in Tables LXIV through IXXV of Appendix C for the objective domain and in Tables LXXVI through LXXXVII of Appendix C for the subjective domain. The first set of 6 tables contains information on the analyses of difference scores, residual change scores, and percentage gain scores with the happiness item as the outcome measure. The second set of six tables presents information on the analyses when change in happiness is the outcome measure. Within each set, the first table contains the results of the regression analysis and the second table contains the means, standard deviations, and correlation coefficients for the analysis. The same organization is used for the analyses of the subjective domain.

Because the three selected approaches to the measurement of change in longitudinal data may operate differently when the outcome is happiness at a later-pointin-time and when the outcome is change in happiness, the presentation of the results for question 4 is subdivided into two parts, one for each version of the outcome measure. As was the case throughout this study, findings 
for measures of the objective status domain are presented first.

The Objective Status Domain

Happiness at a Laterer-Point-in-Time. With one exception, the 1971-1973 analysis for percentage gain scores, the amount of variance explained in the analysis of the 2 -year interval data is replicated within a given approach to the measurement of change (See Table L). For both sets of predictor variables, difference scores explain 18 of the variance in the happiness item for the 1969-1971 and for the 1971-1973 analysis, residual change scores explain 48 of the variance and percentage gain scores explain between 1 and 28. For the 1969-1973 analysis, the residual change scores explain 68 of the variance with either set of predictor variables, but difference scores and percentage gain scores explain more variance in happiness (an additional 1\%) when the first set of predictor variables is utilized. The range of the first set of predictor variables, Overall Disability and Size of Immediate Family, is wider than the range of the corresponding measures for the second set, General Disability and Scope of Immediate Family.

For residual change scores, the order of entry of predictors for all 6 regression analyses is identical. This order of entry is changes in health followed by changes in income and by changes in social resources. For the 6 regression analyses for percentage gain scores, 3 
different orders of entry of predictors occur and for the 6 regression analyșes for difference scores, 4 different orders of entry occur.

Change in Happiness. As in the case of the analyses regarding happiness at a later-point-in-time, the amount of variance explained by changes in the predictor variables is smaller at the 2-year interval than at the 4-year interval (See Table LI). For change in happiness, the amount of its variance explained by change in the predictor variables for difference scores and percentage gain scores is 18 , with one exception being the 1969-1971 analysis for percentage gain scores where the variance explained is less than 18. The variance explained for these two approaches to the measurement of change in longitudinal data at the 4-year interval is 28. For residual change scores, the variance explained amounts to 38 at the 2 -year interval and to 58 at the 4-year interval for the predictor variables of the first set, that is those with a comparatively wider range. With the second set of predictor variables, the variance explained by the residual change scores is 2 to 38 for the 2-year interval and 48 for the 4-year interval. The residual change scores explain a larger amount of variance in change in happiness than do difference scores and percentage gain scores but the results are also affected by the range of scores in the predictor variables. 
The dominant pattern for the order of entry of the predictor variables is change in health as the first predictor, change in income as the second predictor, followed by change in a social resources measure. This pattern, which occurs 15 out of 18 times for the change in happiness outcome, was also the modal pattern of entry in the previous analyses when happiness at a later-point-intime was the outcome measure (see Table L). The three analyses which do not follow this pattern are the analysis of the percentage gain scores in 1969-1971, where Income is entered as the first predictor, and the 1971-1973 analysis for difference scores and residual change scores, where Size of Immediate Family does not reach the level of significance necessary to be entered as the third predictor.

In summary, for the objective status domain, the residual change scores explain more variance in both happiness at a later-point-in-time and in change in happiness than do difference scores or percentage gain scores. Moreover, for this approach to the measurement of change, the order of entry of the predictor variables can be replicated for both versions of the outcome measure and with both sets of predictor variables which vary in terms of range of scores. Residual change scores explain more variance in the analysis of 4-year-interval data than they do in the analysis of 2-year-interval data. Finally, residual change scores explain less variance (between 1 and 
28 less) in the change in happiness outcome than they do in the happiness at a later-point-in-time outcome.

\section{Subjective Domain}

Happiness at a Later-Point-in-Time. In the subjective domain, the residual change scores explain between 16 and 188 of the variance in happiness, the percentage gain scores explain between 6 and 78 , and the difference scores explain between 2 and 38 (See Table LII).

The dominant pattern in terms of order of entry of the variables is difficult to determine because one of the health items was not included in the 1969 questionnaire. For all the analyses, 9 out of 9, the first predictor is the satisfaction with standard of living item. For the second predictor, the difference scores and percentage gain scores have the same pattern in the 1969-1971 analysis where ability to get along on one's income is entered and in the 1971-1973 and 1969-1973 analysis where standard of living compared to others is entered. For residual change scores, a health item is entered before any other financial item as the second predictor. Therefore, for residual change scores, an item from the health resource area seems to take precedence over a satisfaction with financial status item as the second predictor.

Change in Happiness. The percent of variance explained in the outcome by difference scores is identical to that of percentage gain scores for their corresponding 
waves. It ranges from 5 to $7 \%$. For residual change scores, the variance explained in change in happiness ranges from 12 to 158 (See Table LIII).

The predictor entered first for all the analyses is the satisfaction with standard of living item. The second predictor for all the analyses of the 2-year-interval data, that is, the 1969-1971 waves and the 1971-1973 waves, is the normative health item. When the ipsative health item is present, that is in the 1971-1973 analysis, it is entered as the second predictor for the difference scores and the residual change scores. The third predictor in the analysis of difference scores is the normative standard of living item. This item is also entered as the third predictor in two of the three analyses of the percentage gain scores, the 1971-1973 and the 1969-1973 analyses and in the analysis of the 1969-1973 residual change scores. In the analysis of residual change scores, there is no consistent pattern in the order of entry of the variables beyond the second predictor.

In summary, for the subjective domain, there is less of a consistent pattern in terms of the order of entry of the predictor variables than was occurring for the objective domain beyond the first predictor. This first predictor is the satisfaction with standard of living item. Change in one of the health items seems to play a larger role in the analysis of the happiness at a later-point-intime outcome with the residual change scores as predictor 
variables than it does with difference scores or percentage gain scores. However, in the analysis of change in happiness, the normative health item is entered as second predictor in 7 out of the 9 analyses. Finally, the pattern of order of entry for the predictor variables is replicated for both the happiness and the change in happiness outcomes within the 1969-1971 wave and within the 1969-1973 wave when residual change scores are used as predictor variables. For the predictor variables of the subjective domain, a different decision would be made on the degree of importance of a particular resource area depending on the choice of the approach to the measurement of change and on the choice of the outcome measure.

\section{Conclusion}

When the approach to the measurement of change is varied, different results are obtained within a domain area, both in terms of the amount of variance explained and in terms of the relative importance of a resource area for predicting happiness and change in happiness. Regardless of the approach to the measurement of change, less variance is explained by variables from the objective status domain than from the subjective domain. In general, residual change scores explain more variance in the outcome than do difference scores and percentage gain scores. Furthermore, residual change scores explain more variance in the outcome when the 4-year-interval rather than the 2-year-interval 
data are analyzed. They also explain more variance in the happiness at a later-point-in-time outcome than in the change in happiness outcome. In contrast, difference scores and percentage gain scores explain more variance in the change in happiness outcome than they do in the happiness at a later-point-in-time outcome when predictor variables from the subjective domain are used. A greater amount of consistency was obtained with residual change scores in the order of entry of the predictor variables. The dominant pattern of entry is change in health, financial, and social resources for the objective domain, and change in standard of $l i v i n g$ and in the normative health item for the subjective domain.

Question 5

Information on the relationship between self-perceived change and the different approaches to the measurement of change in longitudinal data sheds some light on the relative usefulness of the former approach as a measure of change and provides evidence on the construct validity of change scores for the measures analyzed in this study. The correspondence between self-perceived change and difference scores, residual change scores, and percentage gain scores is the focus of question 5. It is expected that selfperceived change is correlated with each of the three selected approaches to the measurement of longitudinal change. Question 5 was stated as follows: 
Is self-perceived change a useful indicator of change and what is its relationship to the three selected approaches to the measurement of change in longitudinal data?

The self-perceived measure of change or retrospective change item which was found in the LRHS data is a one item measure which requires the respondents to compare their health to that of 2 years ago and which has been referred to as the ipsative health item. The response options are "worse", "same", or "better" which are coded 0, 1, and 2 respectively. The item was not included in the 1969 wave of data collection but was asked in the 1971 and 1973 questionnaires. To answer question 5, comparisons are made between the self-perceived health item and change in the General Disability index and change in the item measuring health compared to others, referred to as the normative health item.

The hypotheses which have guided this set of analyses are:

1) increased disability is related to a low rating of one's health compared to two years ago;

2) positive change in the rating of one's health comparea to others is related to a high rating of one's health compared to two years ago;

3) positive change in income is related to positive change in one's health compared to others, to a high rating of one's health compared to two years ago, and to decreased disability; 
4) increase in satisfaction with financial status and in subjective well-being is related to positve change in one's health, to a high rating of one's health compared to two years ago, and to decreased disability.

Evidence of construct validity comes from two sets of analyses and is based exclusively on correlation coefficients. The first set examines the relationship between the self-perceived change item and changes in the General Disability index and in the normative health item as measured by difference scores, residual change scores, and percentage gain scores. The second set examines the relationship between self-perceived change in health and change in measures from the areas of social and financial resources and subjective well-being. These correlation coefficients are compared to those obtained when difference scores, residual change scores, and percentage gain scores in the disability index and in the normative health item are correlated with the same measures.

Table IIV contains information on the correlation between self-perceived change in health and the three selected approaches to the measurement of change for the General Disability index and for the normative health item. The purpose of the analysis is to determine the amount of correspondence between a retrospective measure of change and change measures based on longitudinal data.

There is complete agreement in regard to the direction of the relationship among the three approaches to the 
TABLE LIV

CORRET.ATION COEFFICIENIS BETWEEN SET,F-PERCEIVED CHANGE IN HEALTH AND DIFFERENCE SOORES, RESIDUAL CHANGE SOORES, AND PERCENTAGE GAIN SOORES FOR THE GENERAL DISABILITY INDEX AND THE NORMATIVE HEALTH ITTEM

\begin{tabular}{lllll}
\hline $\begin{array}{l}\text { Change Measure } \\
\text { Index/Item }\end{array}$ & Year & $\begin{array}{l}\text { Self-Perceived } \\
\text { Change With } \\
\text { Difference } \\
\text { Score }\end{array}$ & $\begin{array}{l}\text { Self-Perceived } \\
\text { Change With } \\
\text { Residual } \\
\text { Change Score }\end{array}$ & $\begin{array}{l}\text { Self-Perceived } \\
\text { Change With } \\
\text { Percentage } \\
\text { Gain Score }\end{array}$ \\
\hline General Disability & $69-71$ & $-.13(n=8745)$ & $-.23 \quad(n=8745)$ & $-.13(n=8745)$ \\
& $71-73$ & $-.19(n=8684)$ & $-.29(n=8684)$ & $-.20(n=8684)$ \\
Health compared to & $69-71$ & $.16(n=8106)$ & $.32 \quad(n=8106)$ & $.20 \quad(n=8106)$ \\
others & $71-73$ & $.20 \quad(n=8006)$ & $.35 \quad(n=8006)$ & $.24 \quad(n=8006)$ \\
& $69-73$ & $.21 \quad(n=8053)$ & $.37(n=8053)$ & $.25 \quad(n=8053)$ \\
\hline
\end{tabular}

Note. The 1969-1971 change measures were correlated with the 1971 item measuring self-perceived change in health in the last two years. The 1971-1973 change measures were correlated with the itern on self-perceived change in health from the 1973 questionnaire. 
measurement of change in longitudinal data and selfperceived change in health (see Table LIV). Persons who experience increased disability tend to rate their health compared to two years ago in a negative way. Persons who have a positive change in the ratings of their health compared to others tend to rate their health compared to two years ago in a positive way. In terms of the magnitude of the relationship, residual change scores produce larger correlation coefficients than difference scores and percentage gain scores do. As mentioned previously, this can be attributed in part to the larger range of residual scores, to their greater reliability as compared to difference scores, and to a lesser role of floor and ceiling effects. The change scores from 1971 to 1973 produce larger correlations with self-perceived change in health than the change scores from 1969 to 1971 . This is probably due to increased variability among the respondents and argues for construct validity. As respondents age, they should experience change at a different rate, creating variability among them. Finally change in health compared to others is more closely related to self-perceived change in health than changes in disability. The larger correlations may be due to the fact that ratings on the normative and the ipsative health items measure domainspecific satisfaction. These two items also measure a respondent's outlook on life. Moreover, the 2 items follow each other in the 1971 and in the 1973 questionnaires. 
The second set of analyses focuses on testing hypotheses which were derived from theories in gerontology. Table LV contains the results of these analyses. AlI the correlation coefficients are in the predicted direction. As expected, there is virtually no relationship between changes in Scope and size of Immediate Family and changes in General Disability, changes in ratings of health compared to others and ratings of health compared to two years ago. Positive changes in income are related to a change toward less disability, to a positive change in health compared to others, and to a positive rating of one's health compared to two years ago. Finally, positive changes in the satisfaction with financial status items and the happiness items are related to a change toward less disability, to positive changes in ratings of one's health compared to others, and to positive ratings of one's health compared to two years ago.

For the hypothesized relationships, the correlation coefficients based on residual change scores are higher than those based on difference scores and percentage gain scores. The self-perceived health item correlates more highly with measures based on residual change scores than with measures based on difference scores or percentage gain scores. Furthermore, the self-perceived change in health item correlates more closely with measures based on 
TARLE LV

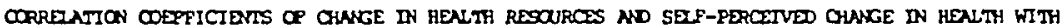
CHANGE MENSURES DN THE AREAS OF SOCLN, PINANCINL RESOURCES, ND SUBJECITVE WELI-BEING

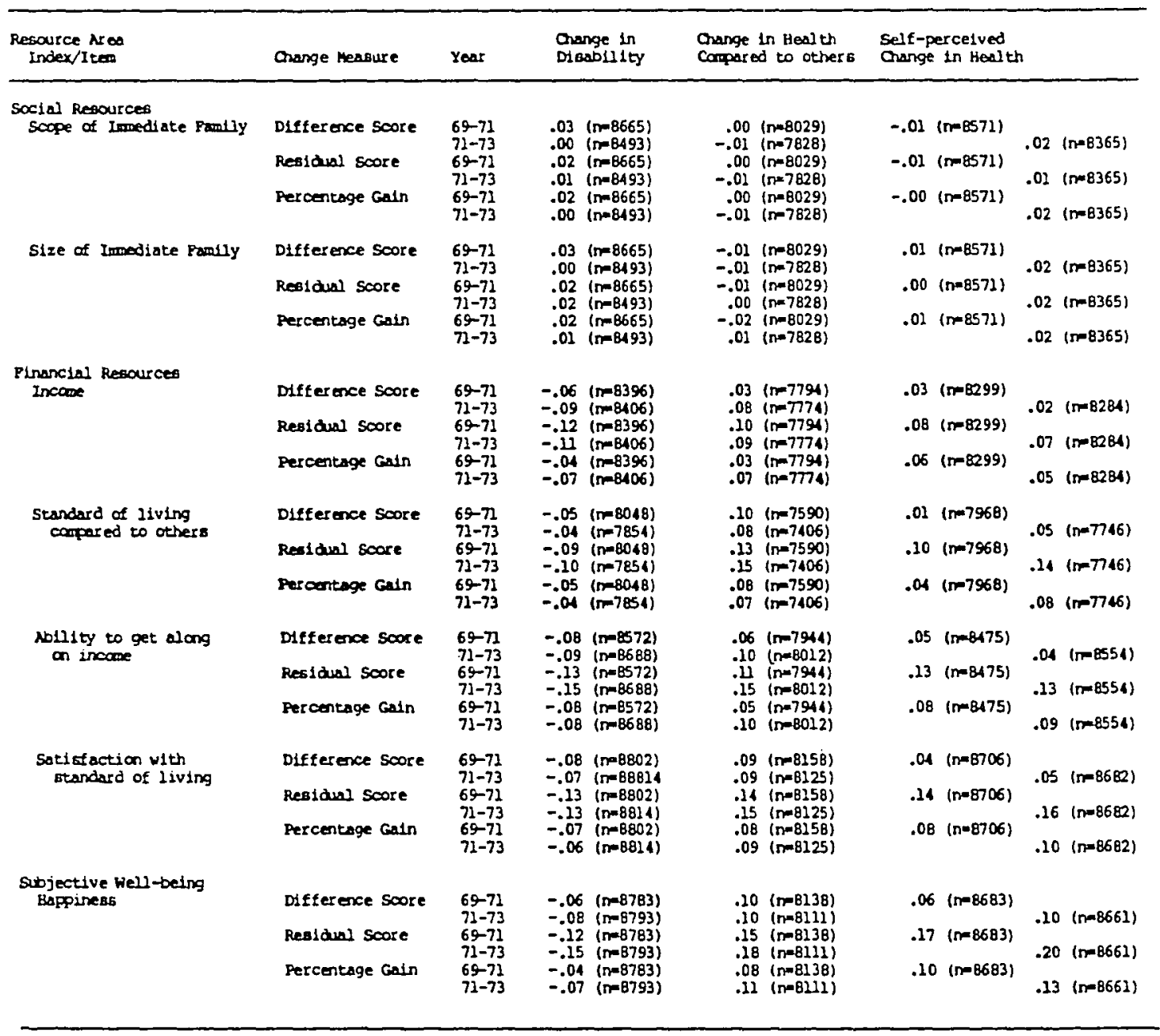

Note. The correlation coefficients are couputed within an apposch to the neasurement of change, e.g., difference exores for the General Disability Index are correlated with difference scares for the scope of Imediate Fanlly Index and residual change scores for these bro indexes are correlated together. The 1969-1971 change seocures for the ceneral Disabllity Index and the Bealth coupared to others 1teo vere correlated with the 1969-1971 change moseure. Inewise the 1971-1973 charge peacures for the General Dibabjlity Index and the band th compared to others ltem vere correlated with the 1971-1973 change mensures for the

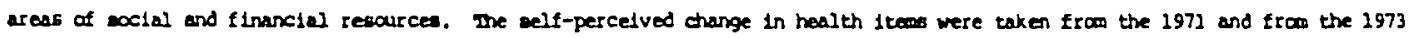
questionaires. They are correlated with the change moares for their respective vave. 
percentage gain scores than with measures based on difference scores. Retrospective ratings or self-perceived change may be measuring not only a respondent's basic outlook but also his/her expectations making the ratings somewhat more similar to percentage gain scores than to difference scores.

In summary, measures of change based on longitudinal data are related to retrospective change. The relationship is not so strong as to argue for the use of retrospective change as a substitute for longitudinal change, however, without further systematic testing. The correspondence which seems to exist between the health item measuring retrospective assessment of change and measures of changes in longitudinal data is due in part to the fact that most of the correlation coefficients for these data are based on single items which belong to the subjective status domain. Ratings on items of that domain are all based on a respondent's evaluation of his/her life circumstances but also on a basic outlook, a comparison of self to others, to the past, and to one's expectations. Initial evidence was found to suggest that retrospective change is related to measures based on percentage gain scores suggesting that retrospective change incorporates one's expectations. 


\section{CHAPTER V}

\section{CONCLUSION}

This study had two main objectives. The first one was to establish whether or not cross-sectional findings from other aging studies could be replicated using data from the LRHS sample. The second objective was to determine the extent to which three selected approaches to the measurement of longitudinal change produce similar results when the relationship between subjective well-being and measures from the areas of health, social, and financial resources are analyzed.

This chapter summarizes the results and outlines the limits of the present study. It also suggests directions for future research in gerontology.

\section{Summary of Results}

The meta-analysis conducted to fulfill the first objective revealed that there is a comparatively large number of studies which focus on the relationship between subjective well-being and the areas of health, social, and financial resources. The application of this technique to the synthesis of research results yielded some estimates of the magnitude of the relationship between subjective well- 
being and the three selected resource areas. Furthermore, the analysis revealed that,

- contrary to expectations, a relatively small proportion of the variability among the correlational findings which were summarized for the meta-analysis can be attributed to sampling error. This finding underscores the importance of examining generalizations which are commonplace regarding the relationship between health resources, social resources, financial resources, and subjective well-being. The variability among the correlational findings also suggests that a search for methodological and conceptual moderator variables is warranted.

A comparison of the findings from the meta-analysis and those based on data from the LRHS study revealed that:

- the magnitude of the relationship between subjective well-being and measures of health and social resources in the LRHS data is within the boundaries established by the meta-analysis of past aging studies for these resource areas;

- the relationship between financial resources and subjective well-being is stronger for the LRHS sample than that reported in other aging studies.

Despite the stronger than average relationship between financial resources and subjective well-being for the LRHS sample, it was concluded that the LRHS data can be used for preliminary work in the area of measuring longitudinal 
change. The findings on the measurement of longitudinal change are the focus of the remalnder of this section.

Findings from published studies in social gerontology are primarily based on cross-sectional analyses. There are relatively few longitudinal studies which document change that accompany aging. A literature search for studies with a longitudinal component uncovered 50 published articles from 1960 to the present. Over half of these studies (578) have a sample size between 100 and 500. An examination of their approach to the measurement of longitudinal change highlights the relatively unexplored nature of the study of longitudinal and retrospective change in gerontology. Thirty-two percent of the studies predict a time 2 outcome using time 1 predictors; $28 \%$ of the studies assess change with residual change scores and 5 영 rely on difference scores to do so. Nine percent of the studies which were reviewed create a measure of change based on the joint distribution of the respondents' standing on a variable measured at time 1 and at time 2. Twenty-six percent of the studies analyze change with paired t-tests or repeated measures analysis of variance. Only one study briefly discusses the relative merits of residual change scores (Palmore and Kivett, 1977, p. 314 ).

Although the focus of the majority of the longitudinal studies in social gerontology is on change, there is relatively little emphasis on the extent of change or on 
the relative strengths and weaknesses of the different approaches to the measurement of change. The present study is an empirical investigation of three approaches to the measurement of longitudinal change. Furthermore, the analyses are based on a national representative sample. The present study also documents changes which accompany aging around the retirement years. Because three waves of data are analyzed, the findings from the present study have the advantages associated with repeated measurements. On that topic, Palmore (1968) states:

"This (advantage of repeated measurements) is the ability to use consistency as a test of reliable and significant change when one has three or more repeated measurements on the same sample. When a change is observed between two points in time, there is always the possibility that this change might be due to temporary or chance fluctuations. But when the same change is observed between the second and third points in time, our confidence in the reliability and significance of this change can be greatly increased because the probability of two such changes occurring by chance is much smaller". (p. 259-260)

The findings related to the comparison of the three approaches to the measurement of change are presented first. They are followed by the findings on the amount of change and its correlates in the LRHS data.

Findings from the Univariate Analyses

- the three selected approaches to the measurement of change rank individuals similarly on the construct of change in the areas of health, social, financial resources, and subjective well-being. In general, difference scores 
and residual change scores seem to be more highly correlated when the range of the measures is large whereas difference scores and percentage gain scores are more highly correlated when the range of the measures is comparatively small.

- as expected, similar patterns of correlation were observed for the three selected approaches to the measurement of change when changes in health, social, financial resources and subjective well-being are correlated with one another. The correlations for the 4year-interval data are larger than those of the 2-yearinterval data for the hypothesized relationships. Residual change scores tend to produce larger correlation coefficients that difference scores or percentage gain scores do for the hypothesized relationships.

- as expected, the stability coefficients for the measures of change across consecutive 2 -year periods are negatively correlated. These negative stability coefficients are smaller for residual change scores than for difference scores and percentage gain scores and may occur because residual change scores are less affected by floor and ceiling effects and by regression toward the mean;

- as expected, difference scores are negatively correlated with time 1 scores and residual change scores have a correlation of .00 with time 1 scores. Percentage 
gain scores hold a middle ground between the two other approaches to the measurement of longitudinal change.

- the change scores based on the three approaches to the measurement of longitudinal change correlate positively with time 2 measures. This pattern is stronger for residual change scores and is more pronounced if the stability coefficient between time 1 and time 2 is low.

Findings from the Multivariate Analyses

- the findings from the multivariate analyses vary as a function of the selected approach to the measurement of change both in terms of the amount of variance explained and in terms of the order of entry of the predictor variables in the analysis of the happiness and the change in happiness outcomes.

- change measures from the objective domain explain comparatively less variance in the happiness outcome and in the change in the happiness outcome than the change measures from the subjective domain do;

- residual change scores explain more variance in both the happiness at one-point-in-time outcome and the change in happiness outcome than difference scores and percentage gain scores do;

- residual change scores show more consistency than difference scores or percentage gain scores do in the order of entry of the predictor variables;

- residual change scores explain more variance in the outcome measures when the 4-year-interval data are analyzed 
than when the 2-year-interval data are analyzed. This pattern is not as pronounced or consistent with difference scores and percentage gain scores.

- some preliminary evidence was found which indicates that self-perceived change in health is related to change based on longitudinal data;

- the magnitude of the relationship between selfperceived change in health and longitudinally derived change scores does not warrant the use of self-perceived change as the sole measure of longitudinal change without further testing.

In sum, preliminary empirical work on a comparison of three approaches to the measurement of longitudinal change revealed that the three approaches rank individuals similarly on the construct of change. Furthermore, residual change scores seem to possess some desirable psychometric properties which are not always shared by difference scores or percentage gain scores. However, residual change scores are more strongly correlated with the time 2 measure than either difference scores or percentage gain scores. This correlation becomes stronger as the stability coefficient decreases, i.e., as more change occurs. The analyses in this study indicate that the three selected approaches to the measurement of longitudinal change are complementary. However, more systematic empirical work needs to be carried out to 
compare these approaches. Likewise, the measurement of retrospective change and its relationship to the measurement of longitudinal change needs further probing.

The empirical work of the present study provides some preliminary evidence that changes occur around the retirement years. It also presents evidence on the construct validity of the measures which were used to measure longitudinal change. Findings from the multivariate cross-sectional analyses are presented first. They are followed by the findings which related to change and its correlates.

\section{Findings from the Cross-sectional Analyses}

- the cross-sectional analyses using one-point-intime measures of health, social, and financial resources explain between 11 and 138 of the variance in the happiness outcome. For these analyses, measures of social resources do not explain a significant amount of variance in happiness;

- the cross-sectional findings were replicated at each of the three waves of data collection both in terms of the amount of variance explained in happiness and in the order of entry of the predictor variables;

- in the cross-sectional analyses, the order of entry of the predictor variables is tied to the range of the measures when indexes measuring the objective domain of health resources are analyzed; 
- the cross-sectional analyses explain more variance in the happiness item than longitudinal analyses do;

Findings from the Longitudinal Analyses

- a large percentage of LRHS respondents (64.7\%) indicate moderate to high levels of subjective well-being as measured by the happiness item. Of those, almost half (478), report the same amount of happiness from one wave of data collection to the next;

- as expected, on the average, the LRHS continuers report increased disability and a shrinkage in the scope and size of their immediate family over time. On the average, over time, they also assess their health in a more negative way than they did 2 years earlier;

- contrary to expectations, the reported satisfaction of IRHS respondents with their financial status and their reported happiness does not decline over time but increases from 1969 to 1971 and then returns to the 1969 level in 1973;

- as expected, the rate of change in disability is greater from 1971 to 1973 than from 1969 to 1971. However, this pattern does not occur for the measures of social resources;

- as expected, the 4-year rate of change is larger than the 2 -year rate of change for the measures which assess the objective domain for the areas of health and social resources, and for the normative health item; 
- the dominant pattern of entry for the objective domain is that of changes in health, followed by changes in income. In the present study, change in the measures of social resources contribute relatively little to the regression equations;

- in the subjective domain, change in satisfaction with one's standard of living and change in the assessment of one's health compared to others are the two items which explain the greatest amount of variance in the happiness and in the change in happiness outcomes.

In conclusion, it was found that the findings from one analysis can often be replicated across the three waves of data collection. The findings also suggest that the psychometric properties of the measures used (i.e., the range, the reliability, and the stability of the measures), the focus of the measures (assessment of the objective or the subjective domain), and the particular approach to the measurement of change create variability in the results which, in certain instances, would lead to different conclusions on the relative importance of a resource area. The patterns among the findings suggest future research topics which are discussed in the last section of this chapter. The next section discusses the limitations of the present study. 
Limitations of the Present Study

The limitations of the present study stem from two main sources. One source is tied to the decisions which were made at the onset of the study to exclude certain topics or avenues of inquiry. The other source is tied to the selection of the LRHS data.

The present study did not concern itself with the issues of selective sampling, selective survival, and selective arop-outs. Selective sampling refers to the original selection process of the respondents. Although the response rate for these data is 88.98 (Irelan, 1976), the bias created by the refusal on the part of some randomly selected respondents to participate in the initial wave of data collection is not known. Furthermore, with each subsequent wave, attrition resulted from deaths, institutionalizations, refusals, and non-reachables. As a result, the sample of continuers which was employed in the analyses of this study may not be representative of elderly persons of the 58-63 age group. The sample of continuers may contain an overrepresentation of healthy, wealthy, and happy older persons than would be found in the population. Moreover, the possible impact of repeated testing was not evaluated.

Although these factors cannot be ignored, their anticipated impact on the findings of the present study is that the rate of change for the continuers may be slower than that of the non-continuers, yielding findings of 
greater stability than may be the case for elderly persons of that age group.

In the realm of measuring change, three methods of measuring change were selected among a wide range of options. These measures, however, were selected on the basis of their widespread use, their relevance to the study of aging, and because of their psychometric properties.

The limitations of this study also stem from the choice of using secondary data. The choice of a design based on one birth cohort with no cross-sectional control was implicit in the choice of the LRHS data.

The measures which were analyzed have some drawbacks as wel1. First, measures could not be found to match all the cells of the organizational scheme (see Figure 1). For example, no measure of the subjective domain in the area of social resources could be found. The measures which were analyzed are ordinal in nature. Many items in the questionnaires were not worded in an identical fashion across waves and therefore could not be considered for inclusion in this study. Of the measures which were selected, their order of presentation within an interview schedule was not identical across the three waves of data, creating a source of variation which could not be controlled. It was not possible to systematically vary the psychometric properties of the measures which were analyzed in this study. Not enough measures could be found within a 
resource area to yield information on the systematic role of the range, the internal consistency, and the stability of the measures in the assessment of longitudinal change. Finally, no analysis of the impact of the missing values was carried out. The extent of missing data was assumed to be random. Such an assumption may not be tenable.

The limits of this study were reviewed to put in context the generalizability of the findings. They also suggest future research topics. The last section of this chapter, then, focuses on the research implications of this study.

Recommendations for Future Research

The findings suggest that each of the three selected approaches to the measurement of longitudinal change produce change scores which have different patterns of strengths and weaknesses. Difference scores provide an immediate and easily understood measure of change and may be most useful in instances where a quick decision has to be made and when the measurement can be done with relative precision. For example, changes in body temperature, in number of days spent in bed, or in number of activities engaged in may be particularly amenable to the use of difference scores. In contrast, percentage gain scores provide a measure of change adjusted for the total amount of change which could occur given the instrument utilized. This approach to change may be particularly helpful in 
measuring the impact of intervention strategies. Finally, residual change scores, by taking into account the stability experienced by all the individuals in the sample, provide an estimate of how much more individuals have changed than would be predicted based on their initial score on the measure under study. They incorporate a developmental aspect to change which is not provided by the other two approaches. Residual change scores also tend to be more reliable than difference scores. However, residual change scores are more highly correlated with the time 2 score from which they are derived than either difference scores or percentage gain scores.

The use of the three selected approaches to the measurement of longitudinal change in concert can lead to the identification of individuals who experience some changes and the amount of change can be gauged within the context of how much change could occur and of how much change has occurred compared to the amount that would be predicted. This approach may then lead to the identification of subgroups which are benefiting from a particular intervention or to the identification of individuals who are particularly frail or in need of immediate intervention.

The present study can easily serve as the backdrop for a Iifelong agenda of research. Some of the recommendations which follow can be implemented with relatively limited 
resources while some others require the unfolding of full blown research projects.

The Use of Meta-analysis

The findings from the meta-analysis can be viewed as the beginning of the ordered classification of some of the knowledge which is available in gerontology. The variability among the findings from the meta-analysis suggest that the constructs which were identified need to be partitioned into subsets. In other words, the data indicate that the domain of the constructs which were examined could be reorganized into components. For example, in the areas of health, a redefinition of the health status domain into clinical indicators and functional health indicators may be warranted. Furthermore, moderator variables of a conceptual nature and of a methodological nature can be sought. For example, design and instrument characteristics could be incorporated in the meta-analysis.

A meta-analysis on the relationships among the components of a resource area may contribute to the refinement of gerontological theories. Within a given resource area, it may be possible to rank the components of the domain along the continuum of objectivity. For example, in the area of health, clinical health indicators based on chart review would receive a high score on objectivity. In contrast, a global rating of health based on self-report would be the anchor point for the subjective 
pole. Self-reports of health behaviors may be rated with a moderate score on objectivity. A look at the results of the meta-analysis when such a factor is incorporated in the analysis may provide at the very least knowledge of the foundations of our statement that health is related to happiness. It may also provide some clarification on the contribution of health to subjective well-being. Finally, it may help identify areas of research which are relatively uninvestigated.

The use of meta-analysis for the summary of the aging literature highlights the fact that a large portion of the findings in aging research are based on self-report. There is a need to evaluate the relative impact of reliance on self-report. For example, the use of self-report may be more appropriate for some resource areas than for others because the topic area is less threatening, or because it allows for easy recall or reconstruction. However, it cannot be assumed that the bias created by self-report is random or that it has a uniform impact on subgroups or subsamples. For example, early retirees may report more disability than others of the same age groups because they are more disabled or because they feel inclined to justify their early retirement status.

The degree of bias which may be introduced by the extent of missing values also needs investigation and can be carried out within the framework of the meta-analysis. 
Missing values are usually assumed to be random. Missing values may create a restriction of range and may lead to the underestimation of the magnitude of the relationship. Moreover, if missing values are concentrated in one resource area such as financial resources, this restriction of range may lead to a systematic underestimation of the role of financial resources in subjective well-being.

The Measurement of Change

In order to document further the construct validity of the measures of change used for this study, it is possible to identify groups based on age, gender, marital status, retirement status, and even future outcome (i.e, death, institutionalization) and to explore the amount and the rate of change in the areas of health, social, financial resources, and subjective well-being.

The present study provided some preliminary evidence that the indexes constructed as part of an earlier project (Stewart, 1982) are sensitive to change. The analyses on the amount and the rate of change could be replicated with the 1975, 1977, and 1979 waves of data collection. This investigation would provide further information on the processes associated with aging. It may also be possible to create other identical indexes in the subsequent waves to broaden the measurement of the resource areas which were analyzed for this study.

It is sometimes assumed that changes in one component of a domain result in changes in all the other components 
of that domain. For example, it is assumed that input from the environment, e.g., a doctor's negative evaluation of one's health, leads to a change in an individual's evaluation of his/her health status. However, it may be the case that changes in global health ratings occur only when there is a concurrent restriction of one's independence or functional ability or when the disease is associated with pain and discomfort or when the change is greater than expected. It could also be the case that the reevaluation of one's health following a doctor's report is a function of the perceived seriousness of the ailment, fear, amount of visible symptoms, reaction of immediate or significant others. Finally, the reevaluation of one's health following a doctor's report may occur for some individuals and not for others. The rate and the amount of change, as well as the uniformity of change between domain specific and global ratings need further clarification.

Further probing into other approaches to the measurement of longitudinal change is warranted. of possible usefulness may be an exploration of the role of retrospective measures of change when their degree of required objectivity is systematically varied. For example, the retrospective global evaluation of one's health may be tainted by mood, by an individual's outlook on life, or by one's temporal circumstances. However, a retrospective evaluation which relies more heavily on 
recall than on one's subjective assessment may operate in a different fashion.

A study of the circumstances which surround intraindividual change may lead to the identification of coping styles. The amount of stability and change which is experienced and which is reported may be a function of a set of factors which included basic outlook, access to resources, expectations, present situation, long term and short term anticipated consequences, life cycle stage, past experience, and degree of physical and emotional frailty. Very little information exists on the relative interchangeability of resource areas or on the mediating influence of perceptions on the evaluation of one's subjective well-being as changes are experienced. This study offers preliminary evidence that change in the areas of health and financial resources is associated with change in happiness. Further clarification is needed on the mediating influences of perceptions, expectations, and on the relative interchangeability of resource areas as shock absorbers of the impact of life cycle transitions.

\section{Measurement Issues}

The findings from the present study give some clues that research results are closely tied to the content of the measures but also to their psychometric properties. For example, as expected, changes in health are the strongest predictor of subjective well-being. However, when the range of the disability index is smaller than that 
of the income measure, the latter explains more variance in the outcome measure than the former. The well-known finding in gerontology that health is related to happiness may in part be a function of the relative emphasis that aging studies have placed on developing measures of health which have sound psychometric properties. In the same vein, the systematic investigation of the role of the focus of the measures (i.e., global versus specific), of selfreport, of the reactivity of the topic area, and of the relative impact of the order of presentation of the questions during an interview session is also warranted. The sorting and systematic rating of the psychometric properties of measures which are used in aging studies may lead to the disentanglement of the conceptual and methodological bases of research findings.

The longitudinal analyses of the present study have provided some preliminary evidence that aging is accompanied by changes. Aging theories imply change but relatively little empirical documentation of this assumption has been done. As mentioned previously, the majority of the findings in gerontology are based on crosssectional studies. It is recommended that more empirical work on the comparability of approaches to the measurement of change be carried out.

In the present study, although changes in health and financial resources are significantly related to changes in 
subjective well-being, the magnitude of the correlation coefficients is not large, i.e., it is never greater than .35. Because correlations based on change scores tend not to be large, longitudinal research in gerontology should rely on measures as reliable as possible and should not use single item measures. Longitudinal studies should also allow adequate time for change to occur. Such practices would improve the reliability and range of change scores and thus increase the possibility of obtaining relatively large correlations based on change scores. Furthermore, because correlations based on change scores tend to be low, it becomes more imperative to use large sample sizes so that the correlational results are stable, 1.e., they have a small standard error. Finally, in the present study, it was not always possible to systematically and independently vary the range, stability, and the focus of the measures of each resource area. Further empirical work on the role of these factors and their contribution to findings in gerontology is certainly warranted.

\section{Conclusion}

This study lays the ground work for the understanding of the processes which accompany aging. Further work is needed in the measurement of change to foster greater knowledge of these processes. Moreover, there is some indication that what we know may be more closely tied to how we measure a phenomenon than is acknowledged. It is 
common knowledge that complexity was added to research design and data analysis with the advent of multivariate procedures and the use of computers. Further probing into the relative role of the "what" versus the "how" of our measures will at the very least clarify what we know. It may not be possible for aging research to rely exclusively on unobtrusive methods. It is possible, however, to study systematically the contributions of our methods to our study results. 


\section{BIBLIOGRAPHY}

Adams, D. (1969). Analysis of a life satisfaction index. Journal of Gerontology, 24 (4), 470-474.

Auerbach, M. I., Gordon, D. W., Ullmann, A., \& Weisel, M. J. (1977). Health care in a selected urban elderly population: Utilization patterns and perceived needs. Gerontologist, 17 (4), 341-346.

Baltes, P. B., Reese, H. W. , \& Nesselroade, J. R. (1977). Life-span developmental psychology: Introduction to research methods. Monterey, California: Brooks/Cole Publishing Company.

Blazer, D. G., \& Houpt, J. L. (1979). Perception of poor health in the healthy older adult. Journal of the American Geriatrics Society, 27 (7), 330-334.

Brown, J. S., Perman, B. S., \& Dobbs, J. L. (1981). The will-to-live. Research in Aging, 3 (2), 182-201.

Bultena, G. L. \& Oyler, R. (1971). Effects of health on disengagement and morale. Aging and Human Development, $2(2)$, $142-148$.

Cain, L. D, Personal communication, November 19, 1982.

Carp, F. M. \& Carp, A. (1983). Structural stability of well-being factors across age and gender, and development of scales of well-being unbiased for age and gender. Journal of Gerontology, $38(5), 572-581$.

Cascio, W. F., \& Kurtines, W. M. (1977). A practical method for identifying significant change scores. Educational and Esychological Measurement, 37, 889-895.

Chappell, N. L. (1983). Informal support networks among the elderly . Research on Aging, 5 (1), 77-99.

Cooper, H. M., \& Rosenthal, R. (1980). Statistical versus traditional procedures for summarizing research findings. Esychological Bulletin, 87 (3), 442-449.

Costa, P. T., McCrae, R. R., \& Norris, H. H. (1981). Personal adjustment to aging: Longitudinal prediction from neuroticism and extraversion. Journal of Gerontology, 36 (1), 78-85.

Cronbach, L. J., \& Furby, L. (1970). How we sould measure "change" or should we? Rsycholegical Bulletin, 74, 68-80. 
Cumming E., \& Henry, W. E. (1961). Growing old: the process of disengagement. New York: Basic Books, Inc.

Cutler, S. J., (1976). Membership in different types of voluntary associations and psychological well-being. Gerontologist, $16(4), 335-339$.

Downie, N. M., \& Heath, R. W. (1970). Basic statistical methods (3rd ed.). New York: Harper and Row Publishers.

George, L. K. (1979). The happiness syndrome: Methodological and substantive issues in the study of social psychological wellbeing in adulthood. Gerontologist, 19 (2), 210-216.

George, L. K., \& Bearon, L. B. (1980). Quality of life in older persons, meaning and measurement. New York: Human Sciences Press.

Glass, G. V., McGaw, B., \& Smith, M. L. (1981). Meta-analysis in social research. Beverly Hills: Sage Publications.

Havighurst, R. J., Neugarten, B., \& Tobin, S.S. (1968). Disengagement and patterns of aging. In B. L. Neugarten (Ed.), Middle age and aging. Chicago: University of Chicago Press.

Havighurst, R. J., Munnichs, J. M.A., Neugarten, B., \& Thomae, H. (1969). Adjustment to retirement. Assen, The Netherlandds: Van Gorcum and Company.

Hoyt, D. R., \& Creech, J. C. (1983). The life satisfaction index: A methodological and theoretical critique. Journal of Gerontology, 38 (1), 111-116.

Hummel-Rossi, B., \& Weinberg, S. L. (1975). Practical guidelines in applying current theories to the measurement of change (Part 1 and 2). JSAS Cataleg of selected documents in psychology, 5, 226, (MS No. 916).

Hunter, J. E., Schmidt, F. L., \& Jackson, G. B. (1982) . Metaanalysis, cumulating research findings across studies. Studying organizations: Innovations in Methodology Series, No. 4. Beverly Hills: Sage Publications.

Irelan, L. (1976). Retirement history study: Introduction. In L. M. Irelan, D. R. Motley, R. Schwab, S. R. Sherman, \& J. Murray (Eds.). Almest 65: baseline data from the retirement history study. (U.S. Department of Health, Education, and Welfare, Social Security Administration, Office of Research and Statistics Publication No. SSA 76-11806). Washington, DC: U.S. Government Printing Office. 
Larson, R. (1978). Thirty years of research on the subjective wellbeing of older Americans. Journal of Gerontology, 33 (1), 109125.

LaRue, A., Bank, L., Jarvik, L., \& Hetland, M. (1979). Health in old age. How do physicians' ratings and self-ratings compare? Journal of Gerontology, 34 (5), 687-691.

Lawton, M. P., \& Brody, E. M. (1969). Assessment of older people: Self-maintaining and instrumental activities of daily living. Gerontologist, 2 (3), Part 1, 179-186.

Lemon, B. W. , Bengtson, V. L., \& Peterson, J. A. (1972). An exploration of the activity theory of aging: Activity types and life satisfaction among in-movers to a retirement comunity. Journal of Gerontology, 27 (4), 511-523.

Linn, R. L. \& Slinde, J. A. (1977). The determination of the significance of chnage between pre- and posttesting periods. Review of Educational Researche 47 (1), 121-150.

Lohmann, N. (1977). Correlates of life satisfaction, morale, and adjustment measures. Journal of Gerontology, 32(1), 73-75.

Lord, F. M. (1963). Elementary models for measuring change. In C. W. Harris (Ed.), Problems in measuring change. Madison: University of Chicago Press.

Maddox G. L. (1962). Some correlates of differences in self-assessment of health status among the elderly. Journal of Gerontology, 17 (2), 180-185.

Maddox, G. L. (1968). Persistence of life style among the elderly: A longitudinal study of patterns of social activity in relation to life satisfaction. In B. L. Neugarten (Ed.), Middle age and aging. Chicago: University of Chicago Press.

Maddox, G. L., \& Douglas, E. B. (1973). Self-assessment of health: A longitudianl study of elderly subjects. Journal of Health and Social Behavior, 14, 87-93.

Mason E. P. (1954). Some correlates of self-judgments of the aged. Journal of Gerontology, 2 (3), 324-338.

Menlo, A., \& Johnson, M. C. (1971). The use of percentage gain as a means toward the assessment of individual achievement. California Journal of Educational Research, 22 (5), 193-201. 
Neugarten, B. L., Havighurst, R. J., \& Tobin, S. S. (1961). Measurement of life satisfaction. Journal of Gerontology, 16 (2), 134-143.

Nie, N. H., Hull, C. H., Jenkins, J. G., Steinbrenner, K., \& Bent, D. H. (1975). Statistical Package for the Social Sciences, SPSS, (2nd ed.), New York: MoGraw Hill.

Nunnally, J. C. (1978). Psychometric Theory (2nd ed.). New York: MoGraw Hill.

Okum, M. A., Stock, W. A., Haring, M. J., \& Witter, R. A. (1984). The social activity/subjective well-being relation. Research on Aging, 6 (1), 45-65.

Palmore, E. B. (1968). The effects of aging on activities and attitudes. Gerontologist, 8 (4), 259-263.

Palmore, E. (Ed.) . (1970). Normal Aging (2 vols.). Durham, NC: Duke University Press.

Palmore, E. \& Rivett, V. (1977). Change in life satisfaction: A longitudinal study of persons aged 46-70. Journal of Gerontology, 32(3), 311-316.

Paulson, J. Personal communication, April 8, 1985.

Petersen, M. D., Personal communication, November 19, 1980.

Pierce, R. C., \& Clark, M. (1973). Measurement of morale in the elderly. International Journal of Aging and Human Development, 4 (2), 83-101.

Rogosa, D. , Brandt, D., \& Zimowski, M. (1982). A growth curve approach to the measurement of change. Psychological Bulletin, 22 (3), 726-746.

Rosencranz, H. A., \& Pihlblad, C. T. (1970). Measuring the health of the elderly. Journal of Gerontology, 25 (2), 129-133.

Rosenthal, R. (1984). Meta-analytic procedures for social research. Applied Research Methods Series, No. 6, Beverly Hills: Sage Publications.

Schulz, R., \& Rau, M. T. (1985). Social support through the life course. In S. Cohen \& L. Syme (Eds.), Social suppert and health. New York: Academic Press.

Shulman, N. (1975). Life-cycle variations in patterns of close relationships. Journal of marriage and the family, 37, 813821 . 
Stewart, B. J. (Ed.), (1982). Methods of assessing well-being and change in the Retirement History study. Final report to the Social Security Administration, Institute on Aging, Portand State University.

Stewart, B. J., Personal communication, September 8, 1984.

Stewart, B. J., Beaudet, M., \& Petersen, M. D. (1982). Social indexes. In B. J. Stewart (Ed.), Methods of assessing wellbeing and change in the Retirement History Study. Final report to the Social Security Administration, Institute on Aging, Portland State University.

Stock, W. A., \& Okum, M. A. (1982). The construct validity of life satisfaction among the elderly. Journal of Gerontology, 37 (5), 625-627.

Strube, M. J. \& Hartmann, D. P. (1983). Meta-analysis: Techniques, applications, and functions. Journal of Consulting and Clinical Psychology, 51 (1), 14-27.

Suchman, E. A., Phillips, B.S., \& Streib, G. F. (1958). An analysis of the validity of health questionnaires. Social Forces, 36, 223232.

Tissue, R., \& Stewart, B. J. (1979, November). An analysis of environmental, social and personal dimensions and their relationship to psychological well-being in late life. Paper presented at the meeting of the Gerontological society, Washington, DC.

Tornstam, L. (1975). Health and self-perception: A system's theoretical approach, Gerontologist, 15 (3), 264-270.

Tukey, M. C. (1977). Exploratory data analysis. Reading Mass.: Addison-Wesley.

Walker, H. M. , \& Lev, J. (1953). Statistical inference. New York: Holt, Rinehart, \& Winston.

Williams, R. H., \& Wirths, C. G. (1965). Lives through the years. New York: Atherton Press.

Williams, R. H. \& Zimmerman, D. W. (1977). The reliability of difference scores when errors are correlated. Educational and Psychological Measurement, 37, 679-689.

Wilson, W. (1967) . Correlates of avowed happiness. Psychological Bulletin, 67, 294-306. 
APPENDIX A

SUMMARY OF UNIARIATE STUDIES 
APPENDIX A

STUDIES OF THE REIATIONSHIP BETWEEN HEALTH STATUS AND SUBJECTIVE WELL-BEING

\begin{tabular}{|c|c|c|c|c|c|}
\hline $\begin{array}{l}\text { NUTHOR (S) } \\
\text { AND DATE }\end{array}$ & SAMPLE & MEASURE OF HEALTH & $\begin{array}{l}\text { MEASURE OF } \\
\text { WEIL-BEING }\end{array}$ & $\begin{array}{l}\text { TYPE OF } \\
\text { ANALYSIS }\end{array}$ & RESULTS \\
\hline $\begin{array}{l}\text { Chapman and } \\
\text { Beaudet } \\
\text { (1983) }\end{array}$ & $\begin{array}{l}65 \text { and older } \\
\text { at-risk of } \\
\text { institutionalization } \\
\text { ( } 768 \text { female) } \\
\text { average age: } 78 \\
\text { stratified random } \\
\text { sample } \\
\text { ( } n=397 \text {, wave } 1 \text { ) } \\
\text { analysis on } \\
\text { continuers only } \\
\text { ( } n=224)\end{array}$ & $\begin{array}{l}\text { 6-item index } \\
\text { measuring lack of } \\
\text { disability } \\
\text { and illness } \\
\text { (alpha= .54) }\end{array}$ & $\begin{array}{l}\text { 14-item index } \\
\text { modified LSIA } \\
\text { (alpha }=.85 \text { ) }\end{array}$ & univarlate & $r=.37 k k *$ \\
\hline $\begin{array}{l}\text { Deimling, } \\
\text { Harel, and } \\
\text { Noelker } \\
\text { (1983) }\end{array}$ & $\begin{array}{l}\text { elderly living in a } \\
\text { housing site with } \\
\text { some age-integrated } \\
\text { and some age- } \\
\text { segregated buildings } \\
\text { predominantly poor } \\
\text { average age: } 73 \\
\text { (788 female) } \\
\text { ( } 568 \text { minority) } \\
\text { surveyed all older } \\
\text { residents } \\
\text { (728 response rate) } \\
\text { ( } n=326)\end{array}$ & $\begin{array}{l}\text { one item measuring } \\
\text { physical functioning }\end{array}$ & LSI & univariate & $\begin{array}{l}\text { r not reported } \\
\text { for the entire } \\
\text { sample } \\
r=.15 \\
\text { (White } \\
\text { subsample) } \\
r=.14 \\
\text { (Black } \\
\text { subsample) } \\
r \text { not reported } \\
\text { for the entire } \\
\text { sample } \\
r \text { not reported } \\
\text { for White } \\
\text { subsanple } \\
r=.20 \\
\text { (Black } \\
\text { subsample) }\end{array}$ \\
\hline
\end{tabular}




\begin{tabular}{|c|c|c|c|c|c|}
\hline $\begin{array}{l}\text { Ory and } \\
\text { Goldberg } \\
\text { (1983) }\end{array}$ & $\begin{array}{l}65 \text { and older } \\
\text { noninstitutionalized } \\
\text { residents of } \\
\text { Washington county, } \\
\text { Maryland, } \\
\text { age range: } 65 \text { to } 75 \\
\text { (1008 white married } \\
\text { women) } \\
\text { sampled all who met } \\
\text { eligibility criteria } \\
\text { described above } \\
\text { (718 response rate) } \\
\text { (n=1073) }\end{array}$ & $\begin{array}{l}\text { one item measuring } \\
\text { degree of mobility } \\
\text { (range: } 1 \text { to } 5 \text { ) } \\
\text { one item measuring } \\
\text { number of } 111 \text { nesses }\end{array}$ & $\begin{array}{l}\text { one item measuring } \\
\text { happiness } \\
\text { (range: } 1 \text { to } 3 \text { ) }\end{array}$ & univariate & $r=-.14 \star^{7}$ \\
\hline $\begin{array}{l}\text { Ziegler and } \\
\text { Reid } \\
\text { (1983) }\end{array}$ & $\begin{array}{l}\text { elderly in need } \\
\text { of services } \\
\text { living in an } \\
\text { apartment complex } \\
\text { for the elderly } \\
\text { in Toronto } \\
\text { average age: } 78 \\
\text { (B2\% female) } \\
\text { ( } n=79 \text { wave } 1 \text { ) } \\
\text { ( } n=66 \text { wave } 2 \text { ) } \\
\text { ( } n=52 \text { wave } 3 \text { ) }\end{array}$ & $\begin{array}{l}\text { 10-item index } \\
\text { measuring lack of } \\
\text { disability and } \\
\text { illness } \\
\text { (alpha }=.78 \text { wave } 2 \text { ) } \\
\text { (alpha }=.58 \text { wave } 3 \text { ) }\end{array}$ & $\begin{array}{l}\text { 13-item index } \\
\text { LSIz } \\
\text { (alpha }=.80 \text { wave } 2 \text { ) } \\
\text { (alpha } .75 \text { wave } 3 \text { ) }\end{array}$ & univariate & $\begin{array}{l}\mathrm{r} \text { not reported } \\
\text { (wave } 1 \text { ) } \\
r=.31^{*} \\
\text { (wave 2) } \\
r=.40^{\star} \\
\text { (wave } 3 \text { ) }\end{array}$ \\
\hline $\begin{array}{l}\text { Fengler and } \\
\text { Danigelis } \\
\text { (1982) }\end{array}$ & $\begin{array}{l}65 \text { and older } \\
\text { residents of } 4 \\
\text { counties in } \\
\text { northwestern vermont } \\
\text { median age: } 72 \\
\text { ( } 618 \text { female) } \\
\text { subsample of } \\
\text { female widows } \\
\text { systematic selection } \\
\text { ( } \mathrm{n}=326)\end{array}$ & $\begin{array}{l}\text { 12-item index } \\
\text { measuring } \\
\text { disability } \\
\text { number of sick days }\end{array}$ & $\begin{array}{l}\text { 3-item index } \\
\text { measuring } \\
\text { life satisfaction }\end{array}$ & univariate & $\begin{array}{l}r=-.23 \star^{7} \\
r=-.22 \star^{7}\end{array}$ \\
\hline $\begin{array}{l}\text { Harel and } \\
\text { Noelker } \\
\text { (1982) }\end{array}$ & $\begin{array}{l}54 \text { and older } \\
\text { institutionalized } \\
\text { elderly from the } \\
\text { cleveland } \\
\text { metropolitan area } \\
\text { average age: } 81 \\
\text { (age range: } 54 \text { to } 97 \text { ) } \\
\text { (668 fomale) } \\
\text { nonprobability sample } \\
\text { (n=125) }\end{array}$ & $\begin{array}{l}\text { one item measuring } \\
\text { mobility status }\end{array}$ & $\begin{array}{l}\text { Philadelphia } \\
\text { Geriatric Center } \\
\text { morale scale } \\
\text { one item measuring } \\
\text { life satisfaction }\end{array}$ & univarlate & $\mathrm{r}=. .1 \mathrm{i}$ \\
\hline
\end{tabular}




\begin{tabular}{|c|c|c|c|c|c|}
\hline $\begin{array}{l}\text { Harel, } \\
\text { Sollod, } \\
\text { and Bognar } \\
(1982)\end{array}$ & $\begin{array}{l}60 \text { and older } \\
\text { noninstitutionalized } \\
\text { residents of Greene } \\
\text { county, Ohio } \\
\text { living in semi-rural } \\
\text { areas } \\
\text { ( } 608 \text { female) } \\
\text { systematic random } \\
\text { sample } \\
\text { ( } 888 \text { response rate) } \\
\text { ( } n=1008)\end{array}$ & $\begin{array}{l}\text { number of } \\
\text { physical } \\
\text { disabilities } \\
\text { (items from the onRS } \\
\text { questionnaire) } \\
\text { physical health } \\
\text { (ratings by } \\
\text { interviewers) }\end{array}$ & $\begin{array}{l}\text { one item measuring } \\
\text { mental and emotional } \\
\text { health }\end{array}$ & univariate & $r=.36^{\star \star \star \star}$ \\
\hline $\begin{array}{l}\text { Snow and } \\
\text { Crapo } \\
\text { (1982) }\end{array}$ & $\begin{array}{l}65 \text { and older } \\
\text { noninstitutionalized } \\
\text { outpatients of a } \\
\text { Veterans } \\
\text { Administration } \\
\text { medical clinic } \\
\text { mean age: } 71 \\
\text { (age range: } 65 \text { to } 98 \text { ) } \\
\text { (1008 male) } \\
\text { convenience sample } \\
\text { ( } n=205 \text { ) }\end{array}$ & $\begin{array}{l}\text { one item measuring } \\
\text { health status based } \\
\text { on a rating by a } \\
\text { physician } \\
\text { (range: } 0 \text { to } 10 \text { ) }\end{array}$ & $\begin{array}{l}\text { 18-item index } \\
\text { LSIA } \\
\text { (range: } 0 \text { to } 36 \text { ) } \\
\text { Affect Balance } \\
\text { scale } \\
\text { (range: } 0 \text { to } 10 \text { ) }\end{array}$ & univariate & $\begin{array}{l}r=.24^{\star \star} \\
r=.15\end{array}$ \\
\hline $\begin{array}{l}\text { Strain and } \\
\text { Chappell } \\
\text { (1982) }\end{array}$ & $\begin{array}{l}65 \text { and older } \\
\text { noninstitutionalized } \\
\text { residents of } \\
\text { Winnipeg, Manitoba } \\
\text { subsample of } \\
\text { nonusers of home } \\
\text { care services } \\
\text { ( } 518 \text { female) } \\
\text { stratified random } \\
\text { sample } \\
348 \text { refusal rate } \\
(n=400)\end{array}$ & $\begin{array}{l}\text { number of } \\
\text { chronic illness }\end{array}$ & LSIA & univarlate & $r=.08$ \\
\hline
\end{tabular}




\begin{tabular}{|c|c|c|c|c|c|}
\hline \multirow[b]{2}{*}{$\begin{array}{l}\text { Reid and } \\
\text { ziegler } \\
(1980)\end{array}$} & \multirow[b]{2}{*}{$\begin{array}{l}\text { study } 1 \text { and } 2: \\
\text { institutionalized and } \\
\text { noninstitutionalized } \\
\text { subjects who could } \\
\text { be contacted for } \\
\text { a one-year follow- } \\
\text { up interview } \\
\text { (898 fenale) } \\
\text { average age: } 77 \\
\text { convenience sample } \\
578 \text { attrition rate } \\
(n=27)\end{array}$} & \multirow[b]{2}{*}{$\begin{array}{l}\text { 40-iten index } \\
\text { measuring disability } \\
\text { and illness, e.g.' } \\
\text { the extent to which } \\
\text { a set of } 26 \text { illnesses } \\
\text { interfere with daily } \\
\text { activities and } \\
\text { another set of } 14 \\
\text { items measuring } \\
\text { the extent to which } \\
\text { subjects reported } \\
\text { using medical } \\
\text { services and the } \\
\text { anount of time } \\
\text { reported as sick time } \\
\text { (alpha=.49) }\end{array}$} & \multirow[b]{2}{*}{$\begin{array}{l}\text { LSIz } \\
\text { (alpha }=.67)\end{array}$} & \multirow{2}{*}{ univarlate } & \multirow{2}{*}{$r=-.51 * \star^{7}$} \\
\hline & & & & & \\
\hline & $\begin{array}{l}\text { study } 3 \text { and } 4: \\
\text { institutionalized and } \\
\text { noninstitutionalized } \\
\text { subjects who could } \\
\text { be contacted a } \\
\text { year later for a } \\
\text { follow-up interview } \\
\text { average age: } 78 \\
\text { convenience sample } \\
178 \text { attrition rate } \\
(n=52)\end{array}$ & $\begin{array}{l}\text { same as above } \\
(\text { alpha }=.60)\end{array}$ & $\begin{array}{l}\text { LSIZ } \\
\text { (alpha }=.68 \text { ) }\end{array}$ & univarlate & $r=-.38 * \star$ \\
\hline $\begin{array}{l}\text { Jackson, } \\
\text { Bacon, and } \\
\text { Peterson } \\
\text { (1978) }\end{array}$ & $\begin{array}{l}54 \text { years and older } \\
\text { noninstitutionalized } \\
\text { elderly living in } \\
\text { the Detroit area } \\
\text { (1008 retired Blacks) } \\
\text { predominantly poor } \\
\text { average age: } 70 \\
\text { (age range: } 54 \text { to } 83 \text { ) } \\
\text { (728 female) } \\
\text { sample purposely } \\
\text { selected from Black } \\
\text { older adult center } \\
\text { participants } \\
(58 \text { refusal rate) } \\
\text { (n=102) }\end{array}$ & $\begin{array}{l}\text { one item measuring } \\
\text { whether the } \\
\text { respondent has been } \\
\text { hospitalized for an } \\
\text { illness he/she } \\
\text { considers serious } \\
\text { (range: } 0 \text { to 1) }\end{array}$ & LSIA & univariate & $r=.03$ \\
\hline
\end{tabular}




\begin{tabular}{|c|c|c|c|c|c|}
\hline $\begin{array}{l}\text { Mles } \\
(1978)\end{array}$ & $\begin{array}{l}65 \text { and older } \\
\text { sample from the } \\
\text { province of Manitoba } \\
128 \text { of sample } \\
\text { institutionalized } \\
\text { stratified random } \\
\text { sample } \\
\text { ( } n=3851 \text { but } n=3632 \\
\text { for analysis due to } \\
\text { missing data; } \\
n=3199 \text {, group 1; } \\
n=433 \text {, group 2) }\end{array}$ & $\begin{array}{l}\text { 4-item index } \\
\text { measuring disability } \\
\text { and illness }\end{array}$ & LSIA & univariate & $\begin{array}{l}r=-.27 \\
\text { (group } 1 \text { ) } \\
r=-.22 \\
\text { (group 2) }\end{array}$ \\
\hline $\begin{array}{l}\text { Sauer } \\
\text { (1977) }\end{array}$ & $\begin{array}{l}65 \text { and older } \\
\text { noninstitutionalized } \\
\text { elderly from the low } \\
\text { socioeconomic areas } \\
\text { of Philadelphia } \\
\text { ( } 568 \text { female) } \\
\text { ( } 778 \text { Black elderly) } \\
\text { stratified random } \\
\text { sample ( } n=1022 \\
\text { but } n=932 \text { for } \\
\text { analysis due to } \\
\text { missing data) }\end{array}$ & $\begin{array}{l}\text { 3-1tem index } \\
\text { measuring functional } \\
\text { health } \\
\text { (range: } 0 \text { to } 3 \text { ) }\end{array}$ & $\begin{array}{l}\text { 17-item index } \\
\text { modified version of } \\
\text { the Philadelhia } \\
\text { Geriatric Center } \\
\text { morale scale } \\
\text { (range: } 0 \text { to 17) } \\
\text { (alpha= .82) }\end{array}$ & univariate & \begin{tabular}{l}
$r=.41^{\star}$ \\
(entire \\
sample) \\
$r=.42^{\star}$ \\
(Black \\
subsample) \\
$r=.35^{\star}$ \\
(White \\
subsample) \\
\multicolumn{7}{r}{}
\end{tabular} \\
\hline $\begin{array}{l}\text { Toseland } \\
\text { and Sykes } \\
\text { (1977) }\end{array}$ & $\begin{array}{l}55 \text { and older } \\
\text { noninstitutionalized } \\
\text { living in suburban } \\
\text { and rural areas near } \\
\text { Madison, Wisconsin } \\
\text { ( } 318 \text { female) } \\
\text { systematic random } \\
\text { selection from a } 1 \text { ist } \\
\text { of participants and } \\
\text { non-participants } \\
\text { at a senior center } \\
\text { ( } 348 \text { response rate) } \\
\text { (n=137) }\end{array}$ & $\begin{array}{l}\text { one item measuring } \\
\text { chronic health } \\
\text { problems }\end{array}$ & $\begin{array}{l}\text { 13-item LSIZ } \\
\text { (range: } 0 \text { to 26) }\end{array}$ & univariate & $\mathrm{r}=-.02$ \\
\hline
\end{tabular}




\begin{tabular}{|c|c|c|c|c|c|}
\hline $\begin{array}{l}\text { Fine } \\
\text { (1975) }\end{array}$ & $\begin{array}{l}65 \text { and older } \\
\text { noninstitut:ionalized } \\
\text { living in the Bronx } \\
\text { users and potential } \\
\text { users of Dial-A-Ride } \\
\text { program } \\
\text { average age: } 73 \\
\text { (age range: } 65 \text { to } 89 \text { ) } \\
\text { (758 female) } \\
\text { stratified random } \\
\text { sample } \\
\text { (n=169) }\end{array}$ & $\begin{array}{l}\text { one item measuring } \\
\text { ability to go outdoor } \\
\text { without difficulty } \\
\text { one item measuring } \\
\text { ability to go up and } \\
\text { down stairs without } \\
\text { difficulty }\end{array}$ & $\begin{array}{l}\text { 7-item index } \\
\text { measuring life } \\
\text { satisfaction } \\
\text { (index based on a } \\
\text { factor analysis of } \\
\text { LSI, locus of } \\
\text { control, and } \\
\text { autonomy scale } \\
\text { items) }\end{array}$ & univariate & $r=.20$ \\
\hline $\begin{array}{l}\text { Lawton, } \\
\text { Nahemow, } \\
\text { and Teaff } \\
\text { (1975) }\end{array}$ & $\begin{array}{l}\text { elderly living in } \\
\text { HuD public housing } \\
\text { projects } \\
\text { in-depth personal } \\
\text { interviews conducted } \\
\text { with approximately } \\
20 \text { tenants at each } \\
\text { of the } 154 \text { selected } \\
\text { sites } \\
\text { national probability } \\
\text { sample } \\
\text { ( } 898 \text { response rate) } \\
\text { ( } n=2457 \text { due to } \\
\text { missing data) }\end{array}$ & $\begin{array}{l}\text { 2-item index } \\
\text { measuring mobility } \\
\text { e.g., frequency of } \\
\text { going outside the } \\
\text { building and } \\
\text { outside the } \\
\text { neighborhood }\end{array}$ & $\begin{array}{l}\text { 2-item index } \\
\text { measuring morale }\end{array}$ & univariate & $r=.22$ \\
\hline $\begin{array}{l}\text { Sinith and } \\
\text { Brand } \\
\text { (1975) }\end{array}$ & $\begin{array}{l}\text { elderly persons } \\
\text { institutionalized } \\
\text { residents of } \\
\text { Halifax, Nova scotia, } \\
\text { ( } 638 \text { female) } \\
\text { surveyed all persons } \\
\text { who could be } \\
\text { interviewed } \\
\text { ( }=75)\end{array}$ & $\begin{array}{l}\text { one item measuring } \\
\text { disability recoded } \\
\text { into } 2 \text { groups }\end{array}$ & $\begin{array}{l}\text { 12-item index } \\
\text { modified LSI } \\
\text { (range: } 0 \text { to } 12 \\
\text { recoded into } 2 \\
\text { groups) }\end{array}$ & univariate & $r=.32$ \\
\hline $\begin{array}{l}\text { Brand and } \\
\text { Smith } \\
\text { (1974) }\end{array}$ & $\begin{array}{l}65 \text { and older } \\
\text { ( } 658 \text { female) } \\
\text { approximately half } \\
\text { the sample was } \\
\text { selected from tenants } \\
\text { living in low cost } \\
\text { housing ( } n=68 \text { ) } \\
\text { and the other half } \\
\text { from the conmunity } \\
\text { ( } n=69 \text { ) all subjects } \\
\text { volunteered for a } \\
\text { health screening } \\
\text { examination } \\
\text { ( } n=137)\end{array}$ & $\begin{array}{l}\text { number of chronic } \\
\text { conditions recorded } \\
\text { in health } \\
\text { examination } \\
\text { (range recoded into } \\
2 \text { groups) }\end{array}$ & $\begin{array}{l}\text { 12-item Index } \\
\text { modified LSI scale } \\
\text { (range: } 0 \text { to } 12 \\
\text { recoded into } 2 \\
\text { groups) }\end{array}$ & univarlate & $r=.20$ \\
\hline
\end{tabular}




\begin{tabular}{|c|c|c|c|c|c|}
\hline $\begin{array}{l}\text { Edwards and } \\
\text { Rlenmack } \\
\text { (1973) }\end{array}$ & $\begin{array}{l}45 \text { and older } \\
\text { residents of four } \\
\text { counties in virginia } \\
\text { ( } 548 \text { female) } \\
\text { quota sample for } \\
\text { proportionate } \\
\text { representation of } \\
\text { those below and above } \\
65 \text { years } \\
\text { ( } n=507)\end{array}$ & $\begin{array}{l}\text { one item measuring } \\
\text { number of ailments } \\
\text { in the last month } \\
\text { one item measuring } \\
\text { number of ailments } \\
\text { in the last year }\end{array}$ & $\begin{array}{l}\text { 10-item index } \\
\text { modified LSIA } \\
(\text { alpha }=.90)\end{array}$ & univariate & $\begin{array}{l}r=-.06^{\prime} \\
r=-.07^{7}\end{array}$ \\
\hline $\begin{array}{l}\text { Thompson } \\
\text { (1973) }\end{array}$ & $\begin{array}{l}65 \text { and older } \\
\text { noninstitutionalized } \\
\text { multi-stage } \\
\text { probability sample } \\
\text { in U. S. } \\
\text { ( } n=3996 \text { ) } \\
\text { subsample of males } \\
\text { only } \\
\text { (age range: } 65 \text { to } 98 \text { ) } \\
\text { average age: } 73 \\
\text { median age: } 71 \\
\text { ( } n=1589 \text { ) }\end{array}$ & $\begin{array}{l}\text { 8-item index } \\
\text { measuring } \\
\text { disability, e.g., } \\
\text { extent to which } \\
\text { respondent has } \\
\text { difficulty } \\
\text { performing certain } \\
\text { tasks } \\
\text { (range recoded into } \\
3 \text { groups) }\end{array}$ & $\begin{array}{l}\text { 8-item index } \\
\text { measuring morale } \\
\text { (recoded into } \\
3 \text { groups) }\end{array}$ & univariate & $\mathrm{r}=-.20$ \\
\hline $\begin{array}{l}\text { Palmore } \\
\text { and Luikart } \\
\text { (1972) }\end{array}$ & $\begin{array}{l}46 \text { and older } \\
\text { noninstitutionalized } \\
\text { residents of Durham, } \\
\text { North Carolina } \\
\text { average age: } 59 \\
\text { age range: } 46 \text { to } 71 \\
\text { respondents } \\
\text { tend to be well off } \\
\text { (488 female) } \\
\text { random sample from a } \\
\text { member ship list of a } \\
\text { major health } \\
\text { insurance company } \\
\text { (528 refusal rate) } \\
\text { longitudinal data } \\
\text { wave I data only } \\
\text { (n=502) }\end{array}$ & $\begin{array}{l}\text { one item measuring } \\
\text { health status } \\
\text { based on a rating } \\
\text { by a physician } \\
\text { (range: } 4 \text { to } 10 \text { ) }\end{array}$ & $\begin{array}{l}\text { one item measuring } \\
\text { happiness } \\
\text { Cantril ladder } \\
\text { (range: } 0 \text { to } 9 \text { ) }\end{array}$ & univariate & $\begin{array}{l}r=.11 \\
\text { (entire } \\
\text { sample) } \\
r=.09 \\
\text { (males) } \\
r \text { not reported } \\
\text { (females) }\end{array}$ \\
\hline
\end{tabular}




\begin{tabular}{|c|c|}
\hline $\begin{array}{l}\text { Bultena } \\
\text { and OYler } \\
\text { (1971) }\end{array}$ & $\begin{array}{l}65 \text { and older } \\
\text { residents of } \\
\text { Wisconsin } \\
\text { median age: } 73 \\
\text { (age range: } 65 \text { to } 91 \text { ) } \\
158 \text { random sample } \\
(\mathrm{n}=300)\end{array}$ \\
\hline $\begin{array}{l}\text { Streib } \\
\text { (1956) }\end{array}$ & $\begin{array}{l}60 \text { and older } \\
\text { residents of } 37 \\
\text { urban areas of the } \\
\mathrm{U} . \mathrm{S} \text {. } \\
\text { national probability } \\
\text { sample } \\
\text { (male subsample only) } \\
\text { ( } \mathrm{n}=936)\end{array}$ \\
\hline
\end{tabular}

22-1tem index 13-item index

measur ing number of

chronic conditions (range: 0 to 13 ,

(range recoded into recoded into 3

4 groups)

$$
\text { groups) }
$$

\section{3-item index}

measuring $d$

and illness

3-item index

measuring adjustment

Guttman scale

univariate

(range dichotomized)

univariate

(range dichotomized) $\mathbf{r}=-. .31$

(male subsample only)

$(n=936)$ 
STUDIES OF THE RELATIONSHIP BETWEEN SELF-PERCEIVED HEALTH MND SUBJECTIVE WELL-BEING

\begin{tabular}{|c|c|c|c|c|c|}
\hline $\begin{array}{l}\text { AUTIOR (S) } \\
\text { AND DATE }\end{array}$ & SAMPLE & MENSURE OF HEALTY & $\begin{array}{l}\text { MENSURE OF } \\
\text { WELL-BEING }\end{array}$ & $\begin{array}{l}\text { TYPE OF } \\
\text { ANALYSIS }\end{array}$ & RESULTS \\
\hline $\begin{array}{l}\text { Hooker and } \\
\text { Ventis } \\
\text { (1984) }\end{array}$ & $\begin{array}{l}53 \text { and older } \\
\text { residents of } \\
\text { southeastern and } \\
\text { central Virginia } \\
\text { middle class } \\
\text { background } \\
\text { average age: } 70 \\
\text { (age range: } 53 \text { to } 88 \text { ) } \\
\text { ( } 558 \text { female) } \\
\text { convenience sample } \\
\text { of volunteers } \\
\text { recruited from } \\
\text { national associations } \\
\text { of retired persons } \\
(688 \text { response rate) } \\
\text { ( } n=76 \text { ) }\end{array}$ & $\begin{array}{l}\text { one item measuring } \\
\text { self-perceived } \\
\text { health } \\
\text { (range: } 1 \text { to } 4 \text { ) }\end{array}$ & $\begin{array}{l}\text { LSIA } \\
\text { (alpha }=.73)\end{array}$ & univariate & $r=.39 * \star \star$ \\
\hline $\begin{array}{l}\text { Baur } \\
\text { and Okun } \\
\text { (I983) }\end{array}$ & $\begin{array}{l}66 \text { and older } \\
\text { apartment dwellers } \\
\text { of a retirement } \\
\text { community in Phoenix, } \\
\text { Arizona, who could } \\
\text { be reinterviewed } \\
3 \text { years after the } \\
\text { first wave of data } \\
\text { collection } \\
\text { (age range: } 66 \text { to } 94) \\
\text { (808 female) } \\
\text { stratified random } \\
\text { sample } \\
\text { (178 attrition rate) } \\
\text { ( } n=87)\end{array}$ & $\begin{array}{l}\text { one item measuring } \\
\text { self-perceived } \\
\text { health } \\
\text { (range: } 1 \text { to } 9 \text { ) }\end{array}$ & $\begin{array}{l}\text { LSIB } \\
\text { (alpha }=.69, \text { wave } 1 \text { ) } \\
\text { LSIB } \\
\text { (alpha }=.73 \text {, wave } 2 \text { ) }\end{array}$ & univarlate & $\begin{array}{l}r=.37^{\star \star \star *} \\
r=.34^{\star \star \star}\end{array}$ \\
\hline
\end{tabular}




\begin{tabular}{|c|c|c|}
\hline $\begin{array}{l}\text { Deimling, } \\
\text { Harel, } \\
\text { and Noelker } \\
\text { (1983) }\end{array}$ & $\begin{array}{l}\text { elderly living in a } \\
\text { housing site with } \\
\text { some age-integrated } \\
\text { and some age- } \\
\text { segiegated buildings } \\
\text { predominantly poor } \\
\text { average age: } 73 \\
\text { ( } 788 \text { female) } \\
\text { ( } 568 \text { minority) } \\
\text { surveyed all older } \\
\text { residents } \\
\text { ( } 728 \text { response rate) } \\
(n=326)\end{array}$ & $\begin{array}{l}\text { one item measuring } \\
\text { self-perceived } \\
\text { health }\end{array}$ \\
\hline $\begin{array}{l}\text { Kozma and } \\
\text { Stones } \\
\text { (1983) }\end{array}$ & $\begin{array}{l}65 \text { and older } \\
\text { urban, rural, and } \\
\text { institutionalized } \\
\text { residents of } \\
\text { Newfoundland } \\
\text { random selection } \\
\text { ( } n=600) \\
\text { rural ( } n=200 \text { ) group } 1 \\
\text { urban ( } n=200 \text { ) group } 2 \\
\text { institutional ized } \\
\text { ( } n=200) \text { group } 3\end{array}$ & $\begin{array}{l}\text { one item measuring } \\
\text { self-perceived } \\
\text { health } \\
\text { (range: } 1 \text { to } 7 \text { ) }\end{array}$ \\
\hline $\begin{array}{l}\text { Ory and } \\
\text { Goldberg } \\
(1983)\end{array}$ & $\begin{array}{l}65 \text { and older } \\
\text { noninstitutionalized } \\
\text { living in Washington } \\
\text { county, Maryland } \\
1008 \text { white, married } \\
\text { women } \\
\text { (age range: } 65 \text { to } 75 \text { ) } \\
\text { sampled all who met } \\
\text { eligibility criteria } \\
\text { described above } \\
\text { (n=1073) }\end{array}$ & $\begin{array}{l}\text { one item measuring } \\
\text { self-perceived } \\
\text { health } \\
\text { (range: } 1 \text { to } 5 \text { ) }\end{array}$ \\
\hline
\end{tabular}

LSIA

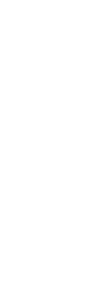

$r=.32 \star \star \star$
(entire
sample)
$r=.37 \star \star$
(group 1)
$r=.39 \star *$
(group 2)
$r=.25 \star \star$
(group 3)
$r=.31 * \star$ $r=.32 \star \star \star$
(entire
sample)
$r=.37 \star *$
(group 1)
$r=.39 * *$
(group 2)
$r=.25 *$
(group 3 )
$r=.31 * \star$

$r=.32^{\star \star \star}$
(entire
sample)
$r=.37^{\star \star}$
(group 1)
$r=.39 \star \star$
(group 2)
$r=.25^{\star \star}$
(group 3)
$r=.31^{\star \star}$

$r=.32 \star \star \star$
(entire
sample)
$r=.37^{\star \star}$
(group 1)
$r=.39 \star \star$
(group 2)
$r=.25 *$
(group 3 )
$r=.31 * \star$

$r=.32^{\star \star \star}$
(entire
sample)
$r=.37^{\star \star}$
(group 1)
$r=.39 \star \star$
(group 2)
$r=.25^{\star \star}$
(group 3)
$r=.31^{\star \star}$

$r=.32 \star \star \star$
(entire
sample)
$r=.37 \star *$
(group 1)
$r=.39 * *$
(group 2)
$r=.25 *$
(group 3 )
$r=.31 * \star$

$r=.32 \star \star \star$
(entire
sample)
$r=.37 \star *$
(group 1)
$r=.39 * *$
(group 2)
$r=.25 *$
(group 3 )
$r=.31 * \star$

$r=.32 \star \star \star$
(entire
sample)
$r=.37 \star *$
(group 1)
$r=.39 * *$
(group 2)
$r=.25 *$
(group 3 )
$r=.31 * \star$

$r=.32 \star \star \star$
(entire
sample)
$r=.37 \star \star$
(group 1)
$r=.39 \star \star$
(group 2)
$r=.25 * \star$
(group 3)
$r=.31 * \star$

(entire

sample)

$r=.30$

subsample)

r not reported

for Black
subsample) 


\begin{tabular}{|c|c|c|c|c|c|}
\hline $\begin{array}{l}\text { Fengler and } \\
\text { Danigelis } \\
\text { (1982) }\end{array}$ & $\begin{array}{l}65 \text { and older } \\
\text { residents of } 4 \\
\text { counties in } \\
\text { northwestern vermont } \\
\text { median age: } 72 \\
\text { ( } 618 \text { female) } \\
\text { subsample of female } \\
\text { widows } \\
\text { systematic selection } \\
\text { ( } \mathrm{n}=326)\end{array}$ & $\begin{array}{l}\text { one item measuring } \\
\text { self-perceived } \\
\text { health } \\
\text { (normative item) }\end{array}$ & $\begin{array}{l}\text { 3-item index } \\
\text { measuring } \\
\text { life satisfaction }\end{array}$ & univariate & $\mathrm{r}=.21 *$ \\
\hline $\begin{array}{l}\text { Harel and } \\
\text { Noelker } \\
(1982)\end{array}$ & $\begin{array}{l}54 \text { and older } \\
\text { institutionalized } \\
\text { residents of the } \\
\text { Cleveland } \\
\text { metropolitan area } \\
\text { (668 female) } \\
\text { average age: } 81 \\
\text { (age range: } 54 \text { to } 97 \text { ) } \\
\text { nonprobability } \\
\text { sample } \\
\text { (n=125) }\end{array}$ & $\begin{array}{l}\text { one item measuring } \\
\text { self-perceived } \\
\text { health }\end{array}$ & $\begin{array}{l}\text { Philadelphia } \\
\text { Geriatric Center } \\
\text { morale scale } \\
\text { one item measuring } \\
\text { life satisfaction }\end{array}$ & univariate & $\begin{array}{l}r=.36 \star \star \star \\
r=.24 \star \star\end{array}$ \\
\hline $\begin{array}{l}\text { Harel, } \\
\text { Sollod, } \\
\text { and Bognar } \\
(1982)\end{array}$ & $\begin{array}{l}60 \text { and older } \\
\text { noninstitutionalized } \\
\text { residents of Greene } \\
\text { county, Ohio } \\
\text { living in semi-rural } \\
\text { areas } \\
\text { ( } 608 \text { female) } \\
\text { systematic random } \\
\text { sample } \\
\text { ( } 888 \text { response rate) } \\
\text { ( } n=1008 \text { ) }\end{array}$ & $\begin{array}{l}\text { one item measuring } \\
\text { self-perceived } \\
\text { health }\end{array}$ & $\begin{array}{l}\text { one itern measuring } \\
\text { mental and } \\
\text { emot lonal health } \\
\text { (range: } 0 \text { to } 3 \text { ) }\end{array}$ & univariate & $r=.57 * \pi \star$ \\
\hline
\end{tabular}




\begin{tabular}{|c|c|c|c|c|c|}
\hline $\begin{array}{l}\text { Seleen } \\
(1982)\end{array}$ & $\begin{array}{l}55 \text { and older } \\
\text { noninstitutionalized } \\
\text { residents of Rhode } \\
\text { Island } \\
\text { ( } 568 \text { female) } \\
\text { random selection of } \\
6 \text { senior centers in } \\
\text { the state } \\
\text { surveyed persons } \\
\text { attending the noon } \\
\text { meal } \\
(n=205)\end{array}$ & $\begin{array}{l}\text { one item measuring } \\
\text { self-perceived } \\
\text { health }\end{array}$ & $\begin{array}{l}\text { LSIA } \\
\text { Cantril ladder }\end{array}$ & univariate & $\begin{array}{l}r=.30 \star \star \star \\
r=.29 * k *\end{array}$ \\
\hline $\begin{array}{l}\text { Snow and } \\
\text { Crapo } \\
\text { (1982) }\end{array}$ & $\begin{array}{l}65 \text { and older } \\
\text { noninstitutionalized } \\
\text { outpatients of a } \\
\text { Veterans } \\
\text { Adninistration } \\
\text { medical clinic } \\
\text { mean age: } 71 \\
\text { (age range: } 65 \text { to } 98 \text { ) } \\
\text { (1008 male) } \\
\text { convenience sample } \\
\text { ( }=205 \text { ) }\end{array}$ & $\begin{array}{l}\text { one item measuring } \\
\text { self-percelved } \\
\text { health } \\
\text { (range: } 0 \text { to } 10 \text { ) }\end{array}$ & $\begin{array}{l}\text { 18-item index } \\
\text { LSIA } \\
\text { (range: } 0 \text { to } 36 \text { ) } \\
\text { Affect Balance } \\
\text { Scale } \\
\text { (range: } 0 \text { to } 10 \text { ) }\end{array}$ & univar late & $\begin{array}{l}r=.50 * \star * \\
r=.38 * \star \star\end{array}$ \\
\hline $\begin{array}{l}\text { Brown, } \\
\text { Perman, } \\
\text { and Dobbss } \\
\text { (1981) }\end{array}$ & $\begin{array}{l}45 \text { and older } \\
\text { noninstitutionalized } \\
\text { working class } \\
\text { background } \\
\text { predominantly poor } \\
\text { and unemployed } \\
\text { pacemaker recipients } \\
\text { (818 male) } \\
\text { average age: } 69 \\
\text { (age range: } 45 \text { to } 85 \text { ) } \\
\text { convenience sample } \\
\text { (n=100) }\end{array}$ & $\begin{array}{l}\text { one item measuring } \\
\text { self-perceived } \\
\text { health } \\
\text { (range: } 0 \text { to } 10 \text { ) }\end{array}$ & $\begin{array}{l}7-1 \text { tem index } \\
\text { measuring } \\
\text { despair and } \\
\text { hopelessness } \\
\text { (alpha }=.79 \text { ) } \\
\text { (range: } 0 \text { to 28) }\end{array}$ & univarlate & $r=.31^{*}$ \\
\hline
\end{tabular}




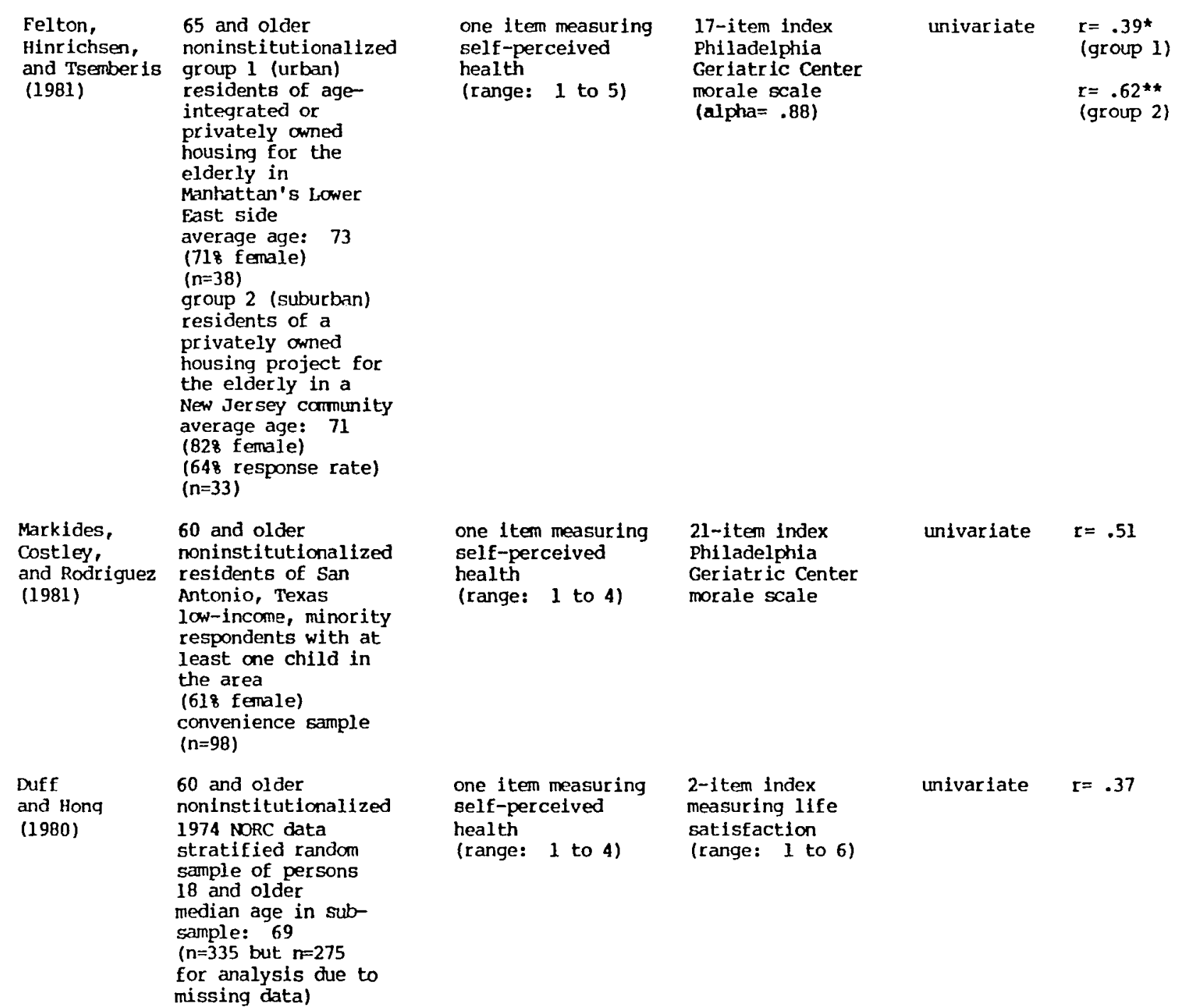

\section{Felton,}

Hinrichsen,

and Ts

65 and older

noninstitutionalized

group 1 (urban)

residents of age-
integrated or

privately owned

elderly in

Manhattan's Lower

East side

average age: 73

( 718 female)

$(n=38)$

group 2 (suburban)

residents of $a$

privately owned

the elderly in a

New Jersey cormunity

average age:

(628 female)

$(n=33)$

Markides,

60 and older

noninstitutionalized

and Rodriquez residents of San

(1981)

Antonio, Texas

low-income, minority

respondents with at

the area

the area

convenience sample$$
\text { ( } \mathrm{n}=98 \text { ) }
$$

Duff

and Honq

60 and older

noninstitutionalized

1974 NORC data

stratified random

sample of persons

18 and older

median age in sub-

sample: 69

$(n=335$ but $n=275$

for analysis due to

missing data)

one item measuring 17-item index

self-perceived

Philadelphia

Geriatric Center

(range: 1 to 5 )

(alpha $=.88$ )

univariate

$r=.39 \star$

(group I)

$r=.62 \star \star$

(group 2)

one item measuring self-perceived

health

(range: 1 to 4 )

21-item index

philadelphia

Geriatric Center

$\begin{array}{ll}\text { one item measuring } & \text { 2-item index } \\ \text { self-percelved } & \text { measuring life } \\ \text { health } & \text { satisfaction } \\ \text { (range: 1 to 4) } & \text { (range: 1 to 6) }\end{array}$

univariate

$r=.51$

univariate

$\mathrm{r}=.37$ 


\begin{tabular}{|c|c|c|c|c|c|}
\hline $\begin{array}{l}\text { Fawcett, } \\
\text { stonner, } \\
\text { and zepelin } \\
(1980)\end{array}$ & $\begin{array}{l}65 \text { and older } \\
\text { institutionalized } \\
\text { average age: } 80 \\
\text { (age range: } 67 \text { to 95) } \\
\text { (1008 female) } \\
\text { convenience sample } \\
(n=56)\end{array}$ & $\begin{array}{l}\text { one item measuring } \\
\text { self-perceived } \\
\text { health } \\
\text { (range: } 1 \text { to } 3 \text { ) }\end{array}$ & $\begin{array}{l}\text { 18-item index } \\
\text { LSIz }\end{array}$ & univar iate & $r=.37 * \star \star$ \\
\hline $\begin{array}{l}\text { Lee and } \\
\text { Ellithorpe } \\
\text { (1980) }\end{array}$ & $\begin{array}{l}60 \text { and older } \\
\text { noninstitutionalized } \\
\text { residents of } \\
\text { Washington state } \\
\text { ( } 498 \text { female) } \\
\text { average age: } 68 \\
\text { two-stage probability } \\
\text { sample } \\
\text { ( } 758 \text { response rate) } \\
\text { subsample of elderly } \\
\text { with children but } \\
\text { living in separate } \\
\text { residences from them } \\
\text { ( } n=578 \text { but n=403 for } \\
\text { analysis due to } \\
\text { missing data) }\end{array}$ & $\begin{array}{l}\text { one item measuring } \\
\text { self-perceived } \\
\text { health } \\
\text { (range: } 1 \text { to } 5 \text { ) }\end{array}$ & $\begin{array}{l}\text { 6-item index } \\
\text { measuring life } \\
\text { satisfaction } \\
\text { (alpha }=.85 \text { males) } \\
\text { (alpha }=.87 \text { females) }\end{array}$ & univariate & $\begin{array}{l}r=.37 \\
\text { (males) } \\
r=.24 \\
\text { (females) }\end{array}$ \\
\hline $\begin{array}{l}\text { Lee and } \\
\text { Ihinger- } \\
\text { Tallman } \\
(1980)\end{array}$ & $\begin{array}{l}60 \text { and older } \\
\text { survey in Washington } \\
\text { state, two-stage } \\
\text { probability sample } \\
\text { ( } 758 \text { response rate) } \\
\text { ( } \mathrm{n}=870 \text { but } n=554 \\
\text { in analysis due to } \\
\text { missing data } \\
267 \text { males and } \\
287 \text { females) }\end{array}$ & $\begin{array}{l}\text { one 1tem measuring } \\
\text { self-reported health } \\
\text { dichotomized into } \\
\text { poor and good } \\
\text { (range: 0 to } 1 \text { ) }\end{array}$ & $\begin{array}{l}6 \text {-item Index } \\
\text { measuring life } \\
\text { satisfaction } \\
\text { (range: 1 to } 24 \\
\text { recoded into } 3 \\
\text { groups) } \\
\text { (alpha }=.85 \text { males) } \\
\text { (alpha }=.87 \text { females) }\end{array}$ & univarlate & $\begin{array}{l}r=.30 \\
\text { (males) } \\
r=.33 \\
\text { (females) }\end{array}$ \\
\hline
\end{tabular}




\begin{tabular}{|c|c|c|c|c|c|}
\hline $\begin{array}{l}\text { Mancini, } \\
\text { Quinn, } \\
\text { Gavigan, } \\
\text { and Franklin } \\
(1980)\end{array}$ & $\begin{array}{l}\text { elderly persons, } \\
\text { residents of two } \\
\text { high-rise public } \\
\text { housing apartment } \\
\text { ( } 758 \text { female) } \\
\text { average age: } 70 \\
\text { simple random } \\
\text { sample } \\
(718 \text { response rate) } \\
(n=74)\end{array}$ & $\begin{array}{l}\text { one item measuring } \\
\text { self-perceived } \\
\text { health } \\
\text { (range: o to 9) } \\
\text { complexes }\end{array}$ & $\begin{array}{l}\text { Cantril ladder } \\
\text { (range: } 0 \text { to } 9 \text { ) }\end{array}$ & univariate & $r=.33 * *$ \\
\hline $\begin{array}{l}\text { Mediey } \\
(1980)\end{array}$ & $\begin{array}{l}65 \text { and older } \\
\text { noninstitutionalized } \\
\text { (648 female) } \\
\text { national probability } \\
\text { sample } \\
\text { ( } n=301,192 \text { fenales } \\
\text { and } 109 \text { males) }\end{array}$ & $\begin{array}{l}\text { one item measuring } \\
\text { satisfaction with } \\
\text { health status } \\
\text { (range: } 1 \text { to } 7 \text { ) }\end{array}$ & $\begin{array}{l}\text { 9-1tem index } \\
\text { measuring life } \\
\text { satisfaction } \\
\text { (range: } 21 \text { to 147) }\end{array}$ & univariate & $\begin{array}{l}r=.36^{\star} \\
\text { (males) } \\
r=.38^{\star} \\
\text { (females) }\end{array}$ \\
\hline $\begin{array}{l}\text { Spreitzer } \\
\text { and Snyder } \\
(1980)\end{array}$ & $\begin{array}{l}65 \text { and older } \\
\text { NORC data, (1972, } \\
1973 \text {, and } 1974 \\
\text { yearly survey } \\
\text { combined for the } \\
\text { analysis) } \\
\text { national probability } \\
\text { sample } \\
(n=756)\end{array}$ & $\begin{array}{l}\text { one item measuring } \\
\text { self-perceived } \\
\text { health } \\
\text { (range: } 1 \text { to } 3 \text { ) }\end{array}$ & $\begin{array}{l}\text { one item measuring } \\
\text { happiness } \\
\text { (range: I to } 3 \text { ) }\end{array}$ & unfvariate & $\mathrm{r}=.26^{1,6}$ \\
\hline $\begin{array}{l}\text { Lee } \\
\text { (1979) }\end{array}$ & $\begin{array}{l}60 \text { and older } \\
\text { survey in Washington } \\
\text { state, two-stage } \\
\text { probability sample } \\
\text { ( } 758 \text { response rate) } \\
\text { subsample of married } \\
\text { persons only } \\
\text { ( } 418 \text { female) } \\
\text { ( } n=588 \text { but } n=388 \\
\text { for analysis due to } \\
\text { missing data) }\end{array}$ & $\begin{array}{l}\text { one item measuring } \\
\text { self-perceived } \\
\text { health } \\
\text { (range: } 1 \text { to } 5 \text { ) }\end{array}$ & $\begin{array}{l}\text { 6-item index } \\
\text { measuring life } \\
\text { satisfaction } \\
\text { (range: } 6 \text { to 24) } \\
\text { (alpha }=.85 \text { males) } \\
\text { (alpha }=.87 \text { females) }\end{array}$ & univariate & $\begin{array}{l}r=.31 \\
\text { (males) } \\
r=.34 \\
\text { (females) }\end{array}$ \\
\hline
\end{tabular}




\begin{tabular}{|c|c|c|c|c|c|}
\hline $\begin{array}{l}\text { Markides } \\
\text { and Martin } \\
\text { (1979) }\end{array}$ & $\begin{array}{l}60 \text { and older } \\
\text { predominantly poor } \\
\text { ( } 648 \text { female) } \\
\text { white subsample only } \\
\text { data collected in } \\
\text { four low-income } \\
\text { census tracts of } \\
\text { San Antonio, Texas } \\
\text { ( } n=141)\end{array}$ & $\begin{array}{l}\text { one item measuring } \\
\text { self-perceived } \\
\text { health } \\
\text { (range: } 1 \text { to } 4 \text { ) }\end{array}$ & $\begin{array}{l}\text { 13-item index } \\
\text { LSI }\end{array}$ & univariate & $\begin{array}{l}r=.42 \\
\text { (males) } \\
r=.49 \\
\text { (females) }\end{array}$ \\
\hline $\begin{array}{l}\text { Spakes } \\
\text { (1979) }\end{array}$ & $\begin{array}{l}55 \text { and older } \\
\text { noninstitutionalized } \\
\text { comparatively well } \\
\text { off } \\
\text { stratified national } \\
\text { sample } \\
\text { elderly subsample only } \\
(n=873)\end{array}$ & $\begin{array}{l}\text { one item measuring } \\
\text { self-perceived } \\
\text { health }\end{array}$ & $\begin{array}{l}\text { one item measuring } \\
\text { life satisfaction } \\
\text { (range: } 1 \text { to } 7 \text { ) }\end{array}$ & univariate & $r=.32$ \\
\hline $\begin{array}{l}\text { Ward } \\
(1979)\end{array}$ & $\begin{array}{l}50 \text { and older } \\
\text { noninstitutionalized } \\
\text { NORC surveys } \\
\text { combined for the } 1972 \\
\text { through } 1977 \text { years } \\
\text { national probability } \\
\text { sample ( }=3557 \text {, } \\
58 \text { ( }=162) \text { never } \\
\text { married). }\end{array}$ & $\begin{array}{l}\text { one item measuring } \\
\text { self-perceived } \\
\text { health }\end{array}$ & $\begin{array}{l}\text { one item measuring } \\
\text { happiness } \\
\text { (range: } 1 \text { to } 3 \text { ) }\end{array}$ & univariate & $\begin{array}{l}r=.27^{\star t} \\
\text { (married) } \\
r=.40^{\star} \\
\text { (never } \\
\text { married) }\end{array}$ \\
\hline $\begin{array}{l}\text { Jackson, } \\
\text { Bacon, } \\
\text { and Peterson } \\
\text { (1978) }\end{array}$ & $\begin{array}{l}54 \text { years and older } \\
\text { noninstitutionalized } \\
\text { elderly living in } \\
\text { the Detroit area } \\
\text { (1008 retired Blacks) } \\
\text { predominantly poor } \\
\text { average age: } 70 \\
\text { (age range: } 54 \text { to } 83 \text { ) } \\
\text { (728 female) } \\
\text { sample purposely } \\
\text { selected from Black } \\
\text { older adult center } \\
\text { participants } \\
\text { (58 refusal rate) } \\
\text { (n=102) }\end{array}$ & $\begin{array}{l}\text { one item measuring } \\
\text { self-perceived } \\
\text { health } \\
\text { (range: } 0 \text { to } 1 \text { ) }\end{array}$ & LSIA & univariate & $\mathrm{r}=-.44 * \star$ \\
\hline
\end{tabular}




\begin{tabular}{|c|c|c|c|c|c|}
\hline $\begin{array}{l}\text { Lee } \\
\text { (1978) }\end{array}$ & $\begin{array}{l}60 \text { and older } \\
\text { survey in washington } \\
\text { state, two-stage } \\
\text { probability sample } \\
\text { ( } 758 \text { response rate) } \\
\text { subsample of married } \\
\text { persons only } \\
\text { ( } 398 \text { female) } \\
\text { ( } n=588 \text { but } n=439 \text { for } \\
\text { analysis due to } \\
\text { missing data) }\end{array}$ & $\begin{array}{l}\text { one item measuring } \\
\text { self-perceived } \\
\text { health } \\
\text { (range: } 1 \text { to } 5 \text { ) }\end{array}$ & $\begin{array}{l}\text { 6-item index } \\
\text { measuring life } \\
\text { satisfaction } \\
\text { (range: } 6 \text { to } 24 \text { ) } \\
\text { (alpha }=.85 \text { males) } \\
\text { (alpha }=.87 \text { females) }\end{array}$ & univariate & $\begin{array}{l}r=.37 \star{ }^{4} \\
\text { (males) } \\
r=.35^{\star \star} \\
\text { (females) }\end{array}$ \\
\hline $\begin{array}{l}\text { Myles } \\
\text { (1978) }\end{array}$ & $\begin{array}{l}65 \text { and older } \\
\text { sample from the } \\
\text { province of Manitoba } \\
\text { 128 of sample is } \\
\text { institutionalized } \\
\text { stratified random } \\
\text { sample } \\
\text { ( } n=3851 \text { but } n=3632 \\
\text { for analysis due to } \\
\text { missing data; } \\
\text { group } 1, \text { conmunity } \\
\text { residents, n=3199; } \\
\text { group } 2, \text { institution- } \\
\text { alized, n=433) }\end{array}$ & $\begin{array}{l}\text { one item measuring } \\
\text { self-perceived } \\
\text { health } \\
\text { (range: } 1 \text { to } 5 \text { ) }\end{array}$ & LSIA & univariate & $\begin{array}{l}{ }^{7} \\
\text { (group } 1 \text { ) } \\
7=-.34 \\
\text { (group 2) }\end{array}$ \\
\hline $\begin{array}{l}\text { Fox } \\
\text { (1977) }\end{array}$ & $\begin{array}{l}48 \text { and older } \\
\text { middle class, } \\
\text { financially well off } \\
\text { white women of the } \\
\text { Durham, North } \\
\text { Carolina area } \\
\text { participants in the } \\
\text { second Duke } \\
\text { Longitudinal study of } \\
\text { Aging } \\
\text { average age: } 61 \\
\text { (n= } 212 \text {, subdivided } \\
\text { into retirees (n=56), } \\
\text { workers }(n=87), \text { and } \\
\text { housewives }(n=69))\end{array}$ & $\begin{array}{l}\text { one item measuring } \\
\text { self-perceived } \\
\text { health } \\
\text { (range: } 0 \text { to } 9 \text { ) }\end{array}$ & $\begin{array}{l}\text { 9-item index } \\
\text { Affect Balance } \\
\text { Scale }\end{array}$ & univariate & $\begin{array}{l}r=.31^{\star \star} \\
\text { (retirees) } \\
r=.30^{\star} \\
\text { (workers) } \\
r=.18 \\
\text { (houscwives) }\end{array}$ \\
\hline
\end{tabular}




$\begin{array}{ll}\text { Palmore and } & 46 \text { and older } \\ \text { Kivett } & \text { longitudinal study } \\ \text { (1977) } & \text { of middle and upper } \\ \text { middle class persons } & \text { from the Durham, } \\ \text { North Carolina area } & \text { stratified random } \\ \text { sample of members of } & \text { a local health } \\ \text { insurance association } & 3 \text { waves of data } \\ \text { collection over a } & \text { six-year period } \\ \text { continuers tend to be } & \text { better off in all } \\ \text { domains } & \text { (258 attrition) } \\ \text { (488 female at } \\ \text { wave } 3 \text { ) (n=378) } \\ \text { 55 and older } \\ \text { noninstitutionalized } \\ \text { living in suburban } \\ \text { and rural areas near } \\ \text { Madison, Wisconsin } \\ \text { and Sykes } \\ \text { (1977) } \\ \text { (318 female) } \\ \text { systematic random } \\ \text { selection from a 1ist } \\ \text { of participants and } \\ \text { non-participants } \\ \text { at a senior center } \\ \text { (348 response rate) } \\ \text { (n=137) }\end{array}$

one item measuring

self-perceived

th (wave 1)

(range: 0 to 9 )

one item measuring

self-perceived

health
Cantril ladder

(range: 0 to 9 )

univariate

(wave 1 LSI)

13-item LSIZ

(range: 0 to 26 )

univariate 6,7 


\begin{tabular}{|c|c|c|c|c|c|}
\hline $\begin{array}{l}\text { Bild and } \\
\text { Havighurst } \\
\text { (1976) }\end{array}$ & $\begin{array}{l}60 \text { and older } \\
\text { noninstitutionalized } \\
\text { residents of Chicago } \\
\text { ( } 538 \text { women) } \\
\text { sample drawn to be } \\
\text { representative of } 7 \\
\text { groups of elderly in } \\
\text { the city } \\
(n=570)\end{array}$ & $\begin{array}{l}\text { one item measuring } \\
\text { self-perceived } \\
\text { health } \\
\text { (range: } 1 \text { to } 5 \text { ) }\end{array}$ & $\begin{array}{l}\text { 18-item index } \\
\text { LSI }\end{array}$ & univariate & $r=.55$ \\
\hline $\begin{array}{l}\text { Medley } \\
(1976)\end{array}$ & $\begin{array}{l}65 \text { and older } \\
\text { noninstitutionalized } \\
\text { national probability } \\
\text { sample of persons } \\
18 \text { and older }(n=2164) \\
178 \text { elderly }(n=362) \\
\text { median age: } 71 \\
\text { ( } 648 \text { female) } \\
\text { ( } n=301 \text { for analysis } \\
\text { due to missing data) }\end{array}$ & $\begin{array}{l}\text { one item measuring } \\
\text { satisfaction with } \\
\text { health } \\
\text { (range: } 1 \text { to } 7 \text { ) }\end{array}$ & $\begin{array}{l}\text { 9-item index } \\
\text { measuring global } \\
\text { life satisfaction } \\
\text { (range: } 21 \text { to } 147 \text { ) }\end{array}$ & univarlate & $\begin{array}{l}r=.36 \\
\text { (males) } \\
r=.38 \\
\text { (females) }\end{array}$ \\
\hline $\begin{array}{l}\text { Sauer, } \\
\text { Shehan, } \\
\text { and Boymel } \\
(1976)\end{array}$ & $\begin{array}{l}60 \text { and older } \\
\text { noninstitutionalized } \\
\text { elderly } \\
\text { subsample of the } \\
1973 \text { NORC data } \\
\text { national probability } \\
\text { sample of persons } \\
18 \text { and older (n=1504) } \\
\text { ( } n=324 \text { for analysis) }\end{array}$ & $\begin{array}{l}\text { one item measuring } \\
\text { self-perceived } \\
\text { health } \\
\text { (range: } 0 \text { to } 3 \text { ) }\end{array}$ & $\begin{array}{l}\text { 6-item index } \\
\text { measuring } \\
\text { satisfaction with } \\
\text { income, community, } \\
\text { hobbies, family, } \\
\text { friends, and global } \\
\text { happiness } \\
\text { (alpha= .68) }\end{array}$ & univarlate & $r=.35^{\star}$ \\
\hline
\end{tabular}




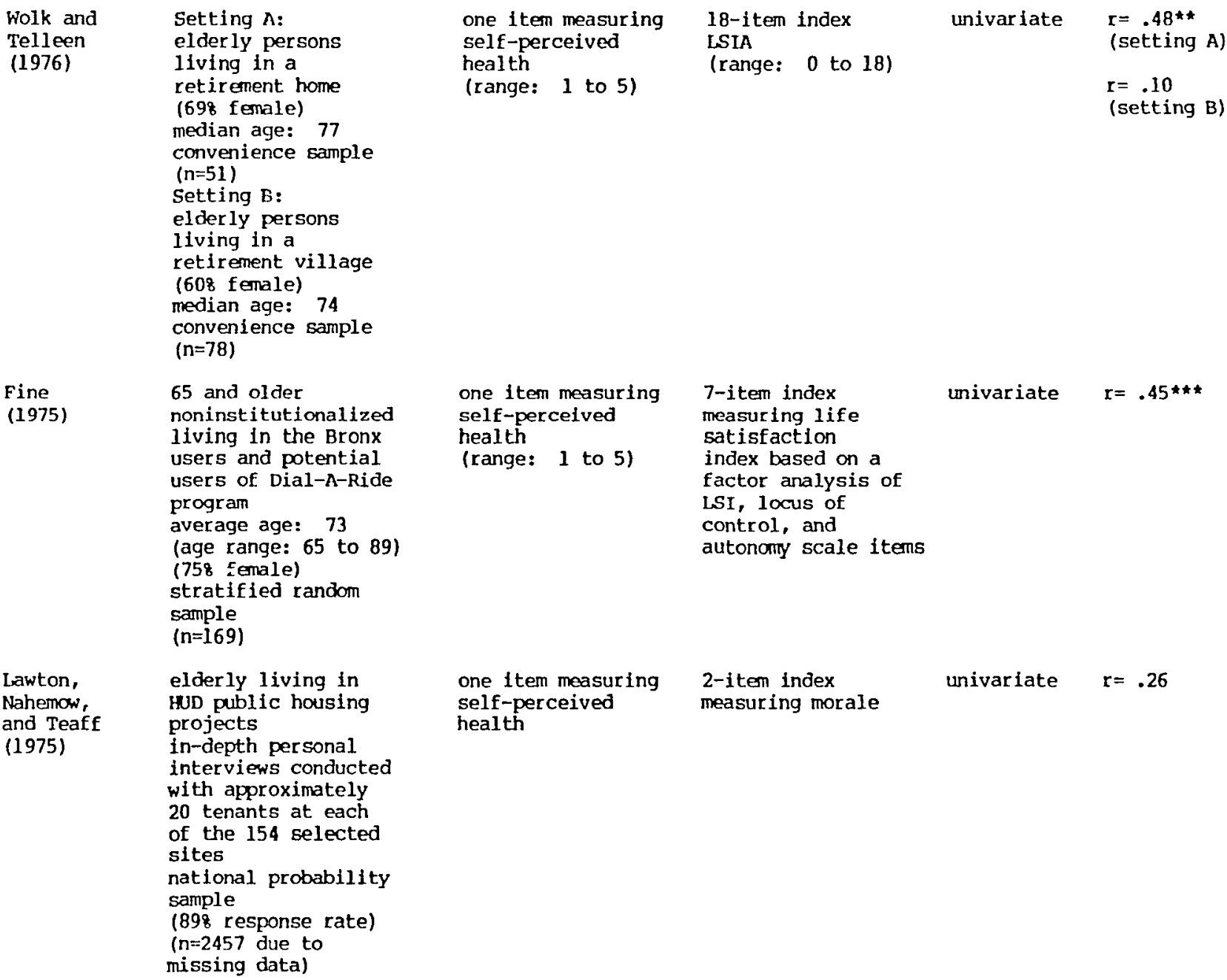

Lawton,

and Teaff

HUD public housing

projects

in-depth personal

interviews conducted

with approximately

20 tenants at each

of the 154 selected

sites

national probability

sample

(898 response rate)

$(n=2457$ due to

missing data)

univariate 


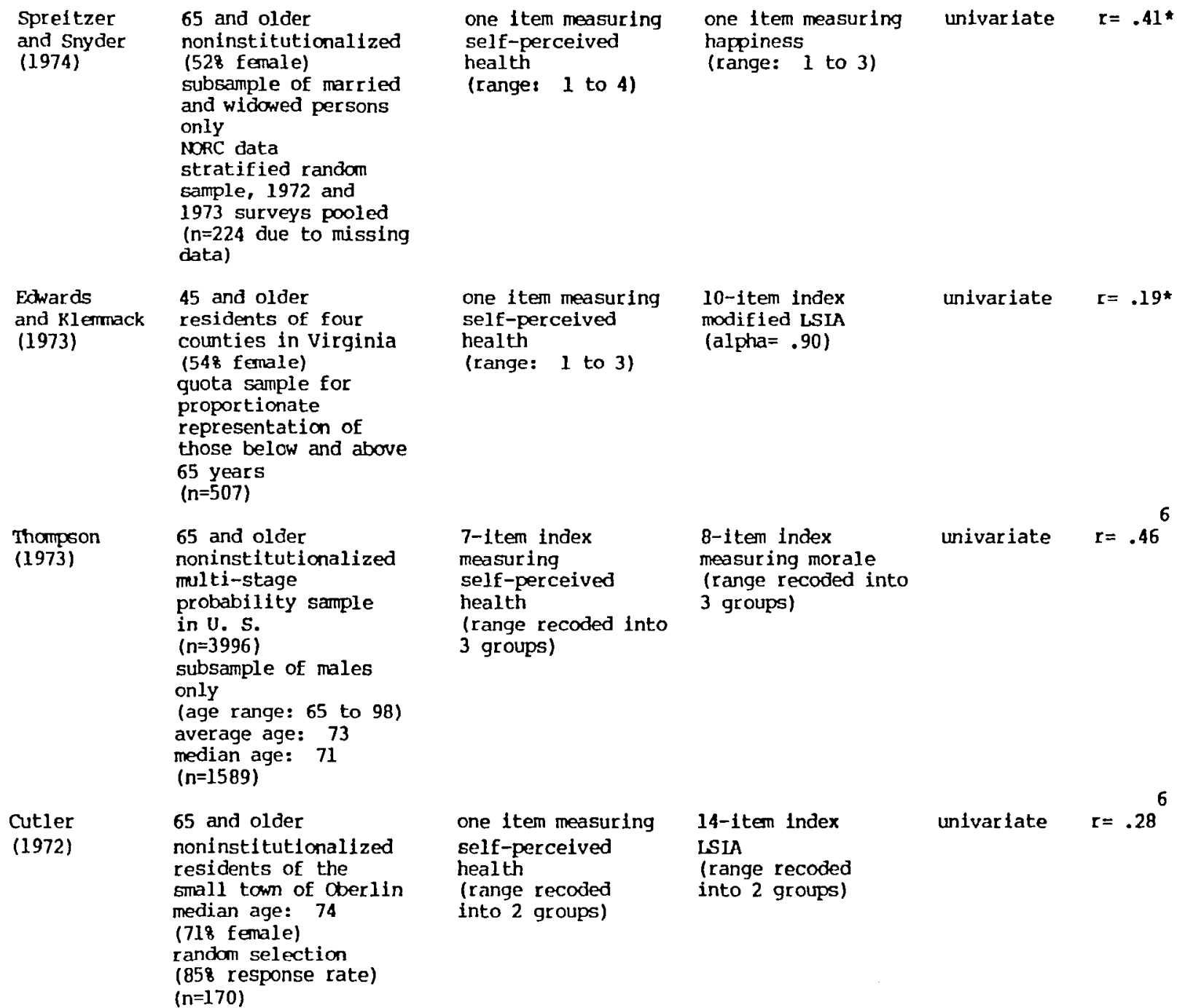

Spreitzer and Snyder (1974)

65 and older

noninst itutionalized

(528 female)

subsample of married and widowed persons

NORC data

stratified randon sample, 1972 and

1973 surveys pooled

( $n=224$ due to missing

data)

Edwards

and klemmack

(1973)

45 and older

residents of four

counties in virginia

(548 female)

quota sample for

proportionate

representation of

those below and above

65 years
$(n=507)$

Thompson

65 and older

noninstitutionalized

multi-stage

probability sample

in U. 5 .

( $n=3996$ ) of males

only

(age range: 65 to 98 )

(age range: 65 to 98 )

average age: 73

$(n=1589)$

Cutler

65 and olde

noninstitutionalized

residents of the

small town of Oberin

median age: 7

(718 female)

random selection

(858 response rate)

$(n=170)$

one item measuring

self-perceived

health

(range: 1 to 4 )

one item measuring

happiness

(range: 1 to 3 )

univar late

$r=.41^{\star}$

one item measuring

self-perceived

health

(range: 1 to 3 )

10-item index

modified LSIA

(alpha $=.90)$

univariate

$L=.19 \star$

7-item index

measuring

self-perceived

health

(range recoded into

3 groups)

one item measuring

self-perceived

health

(r ange recoded

into 2 groups)

14-item index

LSIA

(range recoded

into 2 groups)

8-item index

3 groups)

univariate

$r=.46^{6}$

univarlate

$r=.28^{6}$ 
Palmore and Luikart

(1972)

\begin{tabular}{|c|c|}
\hline & $\begin{array}{l}\text { North Carolina } \\
\text { average age: } 59 \\
\text { age range: } 46 \text { to } 71 \\
\text { respondents } \\
\text { tend to be well off } \\
\text { ( } 488 \text { female) } \\
\text { random sample from a } \\
\text { menbership list of a } \\
\text { major health } \\
\text { insurance conpany } \\
\text { (refusal rate: } 528 \text { ) } \\
\text { longitudinal data } \\
\text { wave } 1 \text { data only } \\
\text { ( } n=502 \text { ) }\end{array}$ \\
\hline $\begin{array}{l}\text { Bultena } \\
\text { and Oyler } \\
\text { (1971) }\end{array}$ & $\begin{array}{l}65 \text { and older } \\
\text { residents of } \\
\text { Wisconsin } \\
\text { median age: } 73 \\
\text { (age range: } 65 \text { to } 91) \\
158 \text { random sample } \\
(n=300)\end{array}$ \\
\hline $\begin{array}{l}\text { Gubrium } \\
\text { (1970) }\end{array}$ & $\begin{array}{l}60 \text { and older } \\
\text { noninstitutionalized } \\
\text { residents of the } \\
\text { Detroit area } \\
\text { (age range: } 60 \text { to 94) } \\
\text { stratified random } \\
\text { sample } \\
\text { (n=210) }\end{array}$ \\
\hline
\end{tabular}

one item measuring

self-perceived

health

(range: 1 to 9)

one item measuring

self-perceived

health

(range: 1 to 5

(range: 1 to

groups )

one item measuring

self-perceived

health

(range recoded into

3 groups) one item measuring

happiness

Cantril ladder

(range: 0 to 9 )

univariate

$r=.43$

(entire

$r=44$

$r=.44$

(males)

$r=.42$

(fernales)

13-iten index

modif ied LSI

(range: 0 to 13

recoded into 3

groups)

univariate

$I=.30$

7-item index

(scale of Kutner

et al.)

(range recoded into

3 groups)

univariate

$r=.46^{6}$ 


\begin{tabular}{|c|c|c|c|c|}
\hline $\begin{array}{l}\text { Bultena } \\
\text { (1969) }\end{array}$ & $\begin{array}{l}63 \text { and older } \\
\text { residents of } 3 \\
\text { communities in } \\
\text { Wisconsin } \\
\text { (1008 retired males) } \\
\text { median age: } 74 \\
\text { (age rarge: } 63 \text { to 99) } \\
\text { sample drawn by an } \\
\text { area probability } \\
\text { technique and by } \\
\text { random selection } \\
\text { ( } \mathrm{n}=284 \text { ) }\end{array}$ & $\begin{array}{l}\text { one } 1 \text { tem measuring } \\
\text { perceived change in } \\
\text { health } \\
\text { (range: } 1 \text { to } 4 \text { ) }\end{array}$ & $\begin{array}{l}\text { 13-item index } \\
\text { modified LSI } \\
\text { (range: } 0 \text { to } 26, \\
\text { recoded into } 3 \\
\text { groups) }\end{array}$ & $\tau=.32$ \\
\hline $\begin{array}{c}\text { Messer } \\
(1968)\end{array}$ & $\begin{array}{l}62 \text { and older } \\
\text { noninstitutionalized } \\
10 \text { income, residents } \\
\text { of public housing in } \\
\text { Chicago } \\
1008 \text { retired } \\
\text { ( } 688 \text { fenale) } \\
\text { (age range: } 62 \text { to } 90 \text { ) } \\
\text { stratified } \\
\text { probability sample } \\
\text { (response rate: 848) } \\
\text { (n=243) }\end{array}$ & $\begin{array}{l}\text { Index measuring } \\
\text { self-percelved } \\
\text { health } \\
\text { (range: } 0 \text { to } 8 \\
\text { recoded into } \\
2 \text { groups) } \\
\text { groups) }\end{array}$ & $\begin{array}{l}7 \text {-item index } \\
\text { measuring life } \\
\text { satisfaction } \\
\text { scale of Kutner } \\
\text { et al. } \\
\text { (range: } 0 \text { to } 7 \\
\text { recoded into } 3\end{array}$ & $r=.20$ \\
\hline $\begin{array}{c}\text { Maddox } \\
(1963)\end{array}$ & $\begin{array}{l}60 \text { and older } \\
\text { noninstitutionalized } \\
\text { residents of Durham, } \\
\text { North Corolina, } \\
\text { median age: } 70 \\
\text { (age range: } 60 \text { to } 94 \text { ) } \\
\text { volunteers selected } \\
\text { to participated in } \\
\text { the Duke } \\
\text { Longitudinal Study } \\
\text { of Aging } \\
278 \text { attrition rate } \\
\text { wave } 1: n=250 ; \\
\text { wave } 2: n=182 \\
\text { analyses done on } \\
\text { continuers only } \\
\text { (n=182) }\end{array}$ & $\begin{array}{l}\text { one item measuring } \\
\text { self-perceived } \\
\text { health } \\
\text { (range dichotomized) }\end{array}$ & $\begin{array}{l}\text { 56-1tem lndex univariate } \\
\text { measuring satisfaction } \\
\text { with } 8 \text { areas of one's } \\
\text { life (scale of } \\
\text { Cavan et al.) } \\
\text { (range dichotomized) }\end{array}$ & $\begin{array}{l}r=.34 \\
\text { (wave } 1 \text { ) } \\
6=.42 \\
r=.42 \\
\text { (wave 2) }\end{array}$ \\
\hline
\end{tabular}




\begin{tabular}{|c|c|}
\hline $\begin{array}{l}\text { Maddox and } \\
\text { Eisdorfer } \\
(1962)\end{array}$ & $\begin{array}{l}60 \text { and older } \\
\text { noninstitutionalized } \\
\text { residents of Durham, } \\
\text { North Corolina, } \\
\text { median age: } 70 \\
\text { (age range: } 60 \text { to } 94 \text { ) } \\
\text { volunteers selected } \\
\text { to participate in } \\
\text { the Duke } \\
\text { Longitudinal Study } \\
\text { of nging } \\
(n=250)\end{array}$ \\
\hline $\begin{array}{l}\text { Lepkowski } \\
\text { (1956) }\end{array}$ & $\begin{array}{l}\text { Group 1: } \\
65 \text { and older } \\
\text { institutionalized } \\
\text { average age: } 77 \\
\text { (age range: } 65 \text { to } 95 \text { ) } \\
\text { of the } 298 \text { residents } \\
\text { only } 93 \text { were } \\
\text { available for the } \\
\text { study } \\
\text { ( } n=93 \text { but } n=32 \text { for } \\
\text { analysis) } \\
\text { Group 2: } \\
60 \text { and older } \\
\text { noninstitutionalized } \\
\text { residents of New York } \\
\text { city, } \\
\text { average age: } 69 \\
\text { (age range: } 60 \text { to } 84 \text { ) } \\
\text { sample is composed of } \\
\text { regular menbers of a } \\
\text { catholic club for } \\
\text { elderly persons } \\
\text { ( } n=32 \text { ) }\end{array}$ \\
\hline
\end{tabular}

one item measuring self-perceived

health

(range dichotomized)

satisfaction with

iffe

(range dichotomized,

median split)

7-item index

measuring self

perceived health

(modified Cavan

inventory)

7-1tem index

measuring happines

(modified Cavan

univariate

inventory)

univariat

$r=.31^{6}$
$=.36 *$

(group 1)

$r=.48 * \star$

(group 2) 


\begin{tabular}{|c|c|c|c|c|}
\hline $\begin{array}{l}\text { Mason } \\
\text { (1954) }\end{array}$ & $\begin{array}{l}\text { elderly persons } \\
\text { residents of the } \\
\text { St. Louis area } \\
\text { sample broken into } \\
2 \text { groups } \\
\text { Group } 1 \text { : } \\
55 \text { and older } \\
\text { institutionalized } \\
10 \text { income } \\
\text { ( } n=60 \text { ) } \\
\text { Group } 2 \text { : } \\
60 \text { and older } \\
\text { noninstitutionalized } \\
\text { middle class } \\
\text { sample drawn from } \\
\text { individuals receiving } \\
\text { a routine checkup } \\
\text { from a physician } \\
\text { specializing in } \\
\text { geriatric medicine } \\
\text { (n=30) }\end{array}$ & $\begin{array}{l}\text { one item measuring } \\
\text { self-perceived } \\
\text { health } \\
\text { one item measuring } \\
\text { self-perceived } \\
\text { health, iten } \\
\text { from the Chicago } \\
\text { Attitude Scale } \\
\text { (range: I to 6) }\end{array}$ & $\begin{array}{l}\text { one item measuring } \\
\text { general mood } \\
\text { one item measuring } \\
\text { present mood }\end{array}$ & $\begin{array}{l}r=.13 \\
\text { (group 1) } \\
r=-.04 \\
\text { (group 2) } \\
r=.30^{\star} \\
\text { (group 1) } \\
r=.13 \\
\text { (group 2) } \\
r=.39 \star \star \\
\text { (group 1) } \\
r=-.33 \\
\text { (group 2) }\end{array}$ \\
\hline
\end{tabular}


STUDIES OF THE RELATIONSIIP BETWEEN SIZE OF NETWORK AND SURJECTIVE WEUL-BEING

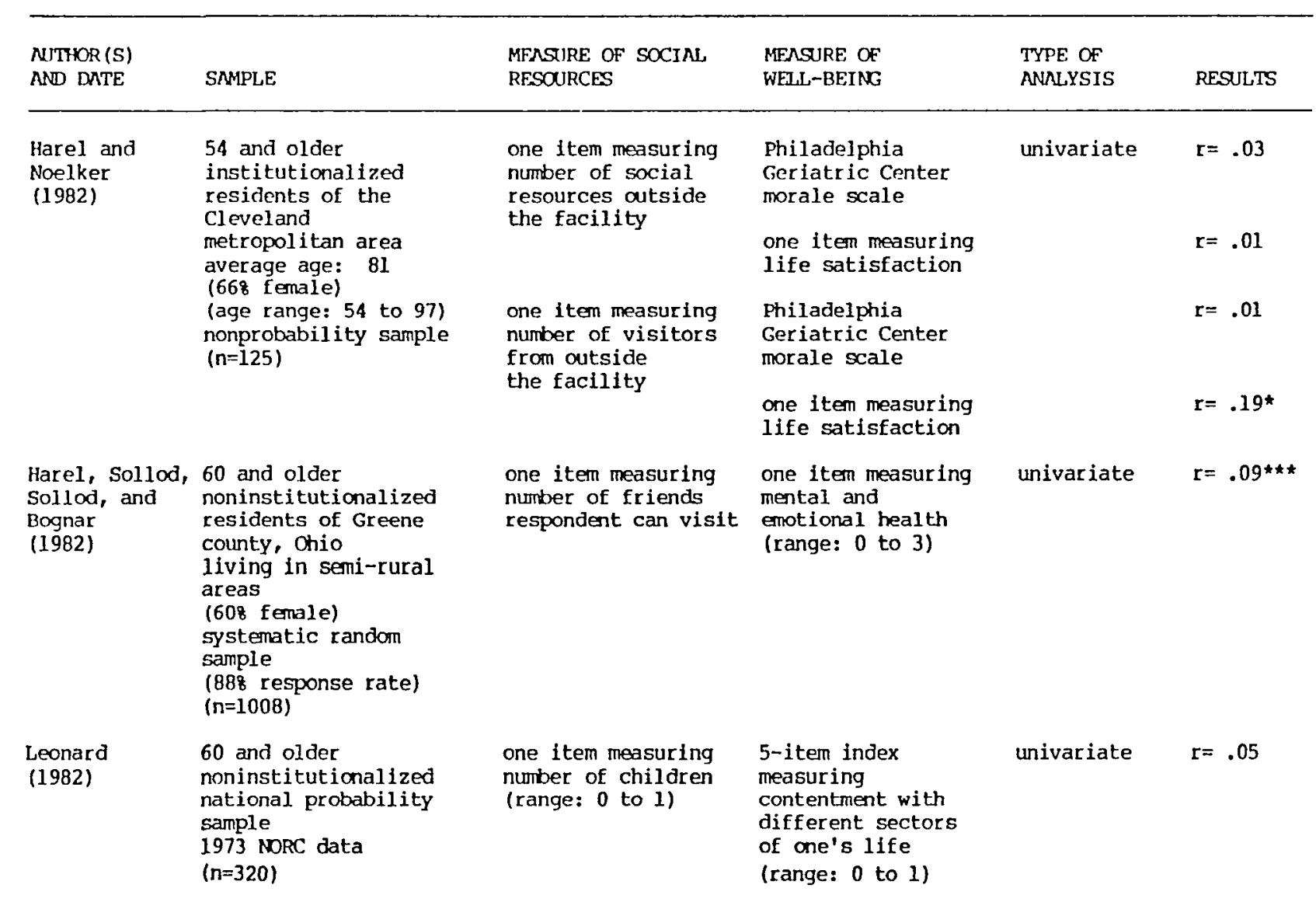


Tesch,

institutionalized

and Nehrke

(1981)

2 and older

veterans, residents

of Bath, New York

(1008 male)

average age: 70

(age range: 52 to 90 )

convenience sample

orawn from one

self-care floor of

the residential

facility

(238 refusal rate)

$(\mathrm{n}=54)$

Lee and

Ellithorpe

60 and older

noninstitutionalized

residents of

Washington state

(498 female)

average age: 68

two-stage probability

sample

(758 response rate)

subsample of children

with independent

residences

$(n=578$ but $n=403$ for

analysis due to

missing data) one item measuring 17-1tem index

number of friends

within the facility

Philadelphia

Geriatric Center

and number of times morale ocale

respondent is named (range: 0 to 17 )

as a friend by others univariate

$r=.01$ one item measuring

number of children

6-itern index

measuring life

satisfaction

(alpha $=.85$ males)

(alpha $=.87$ females) univariate

$\mathrm{r}=-.03$

(males)

$r=.05$ 


\begin{tabular}{|c|c|c|c|c|c|}
\hline \multirow[t]{4}{*}{$\begin{array}{l}\text { Conner, } \\
\text { Powers, } \\
\text { Bultena } \\
(1979)\end{array}$} & \multirow[t]{4}{*}{$\begin{array}{l}70 \text { and oider } \\
\text { noninstitutionalized } \\
\text { residents of Iowa } \\
\text { ( } 708 \text { fenale) } \\
\text { respondents were } \\
\text { selected from five } \\
\text { counties to be } \\
\text { representative of } \\
\text { the elderly in the } \\
\text { state of Iowa } \\
(n=218)\end{array}$} & $\begin{array}{l}\text { number of } \\
\text { immediate family } \\
\text { members in the } \\
\text { network } \\
\text { (range: } 0 \text { to } 8 \text { ) } \\
\text { number of siblings } \\
\text { and other relatives } \\
\text { in the network } \\
\text { (range: } 0 \text { to 9) }\end{array}$ & $\begin{array}{l}\text { 13-item index } \\
\text { LSIz } \\
\text { (range: } 13 \text { to } 39 \text { ) } \\
\text { (alpha }=.93 \text { ) }\end{array}$ & univariate & $r=.08$ \\
\hline & & $\begin{array}{l}\text { number of friends } \\
\text { and neighbors in the } \\
\text { network } \\
\text { (range: } 0 \text { to } 9 \text { ) }\end{array}$ & & & $r=.07$ \\
\hline & & $\begin{array}{l}\text { number of confidants } \\
\text { (range: } 0 \text { to } 2 \text { ) }\end{array}$ & & & $r=-.07$ \\
\hline & & $\begin{array}{l}\text { total number of person } \\
\text { in the network } \\
\text { ( } \mathrm{range}: 0 \text { to } 16 \text { ) }\end{array}$ & & & $\mathrm{r}=.16^{\star}$ \\
\hline $\begin{array}{l}\text { Lee } \\
\text { (1979) }\end{array}$ & $\begin{array}{l}60 \text { and older } \\
\text { survey in Washington } \\
\text { state, two-stage } \\
\text { probability sample } \\
\text { ( } 758 \text { response rate) } \\
\text { subsample of married } \\
\text { persons only } \\
\text { ( } 418 \text { female) } \\
\text { ( } n=588 \text { but } n=388 \\
\text { for analysis due to } \\
\text { missing data) }\end{array}$ & $\begin{array}{l}\text { one 1tem measuring } \\
\text { number of children }\end{array}$ & $\begin{array}{l}\text { 6-item Index } \\
\text { measuring life } \\
\text { satisfaction } \\
\text { (range: } 6 \text { to } 24 \text { ) } \\
\text { (alpha }=.85 \text { males) } \\
\text { (alpha }=.87 \text { females) }\end{array}$ & univariate & $\begin{array}{l}r=-.09 \\
\text { (males) } \\
r=-.12 \\
\text { (females) }\end{array}$ \\
\hline $\begin{array}{l}\text { Spakes } \\
(1979)\end{array}$ & $\begin{array}{l}55 \text { and older } \\
\text { noninstitutionalized } \\
\text { high socio-economic } \\
\text { status } \\
\text { stratified national } \\
\text { sample, elderly } \\
\text { subsample only } \\
\text { (n=873) }\end{array}$ & $\begin{array}{l}\text { one item measuring } \\
\text { number of close } \\
\text { friends living in } \\
\text { the cormunity }\end{array}$ & $\begin{array}{l}\text { one item } \\
\text { measuring Iffe } \\
\text { satisfaction } \\
\text { (range: } 1 \text { to } 7 \text { ) }\end{array}$ & univariate & $r=.18 k k k$ \\
\hline
\end{tabular}




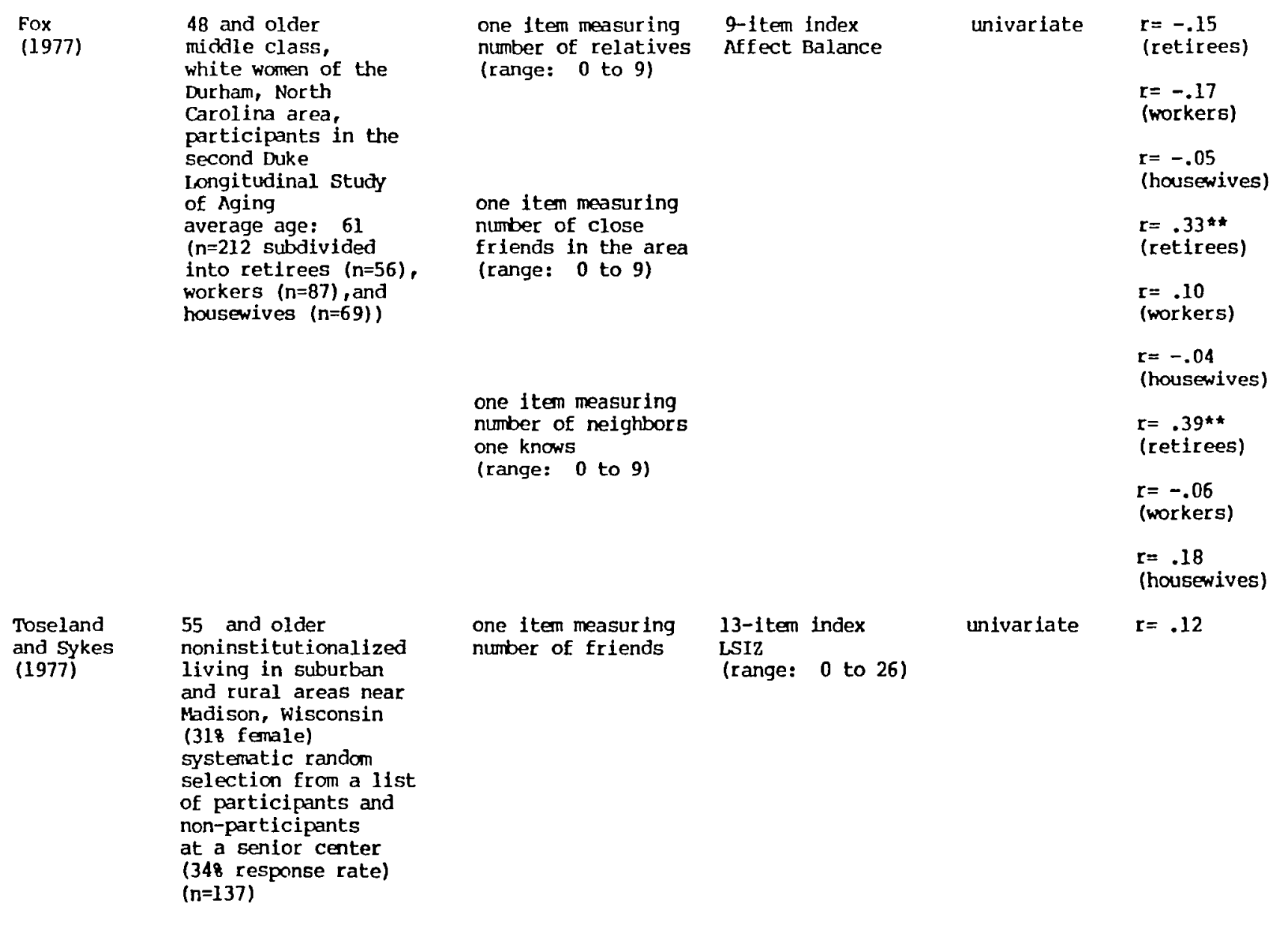




\begin{tabular}{|c|c|c|c|c|c|}
\hline $\begin{array}{l}\text { Edwards and } \\
\text { Klemmack } \\
\text { (1973) }\end{array}$ & $\begin{array}{l}45 \text { and older } \\
\text { residents of four } \\
\text { counties in virginia } \\
\text { ( } 548 \text { female) } \\
\text { quota sample for } \\
\text { proportionate } \\
\text { representation of } \\
\text { those below and above } \\
65 \text { years } \\
(n=507)\end{array}$ & $\begin{array}{l}\text { one item measuring } \\
\text { number of friends } \\
\text { one item measuring } \\
\text { number of neighbors } \\
\text { knowil to respondent } \\
\text { one item measuring } \\
\text { number of relatives } \\
\text { living in the } \\
\text { household }\end{array}$ & $\begin{array}{l}\text { 10-item index } \\
\text { modif ied ISSIA } \\
\text { (alpha }=.90 \text { ) }\end{array}$ & univariate & $\begin{array}{l}r=.04 \\
r=.09 * \\
r=.10 *\end{array}$ \\
\hline $\begin{array}{l}\text { Moriwaki } \\
\text { (1973) }\end{array}$ & $\begin{array}{l}60 \text { and older } \\
\text { resident of Los } \\
\text { Angeles county } \\
\text { median age: } 70 \\
\text { (age range: } 60 \text { to } 84 \text { ) } \\
\text { ( } 518 \text { female) } \\
\text { sample tend to be } \\
\text { healthier than } \\
\text { elderly In general } \\
\text { sample drawn from } \\
\text { two major } \\
\text { metropolitan health } \\
\text { plans } \\
\text { ( } n=71 \text { ) }\end{array}$ & $\begin{array}{l}\text { one item measuring } \\
\text { number of } \\
\text { significant others }\end{array}$ & $\begin{array}{l}\text { 10-item index } \\
\text { Bradburn Affect } \\
\text { Balance scale } \\
\text { (range: } 0 \text { to } 10 \text { ) }\end{array}$ & univariate & $r=.45^{\star \star}$ \\
\hline
\end{tabular}


STUDIES OF THE RELATIONSHIP BETWEEN FREQUENCY OF OONTACTS AND SUBJECTIVE WELL-BEING

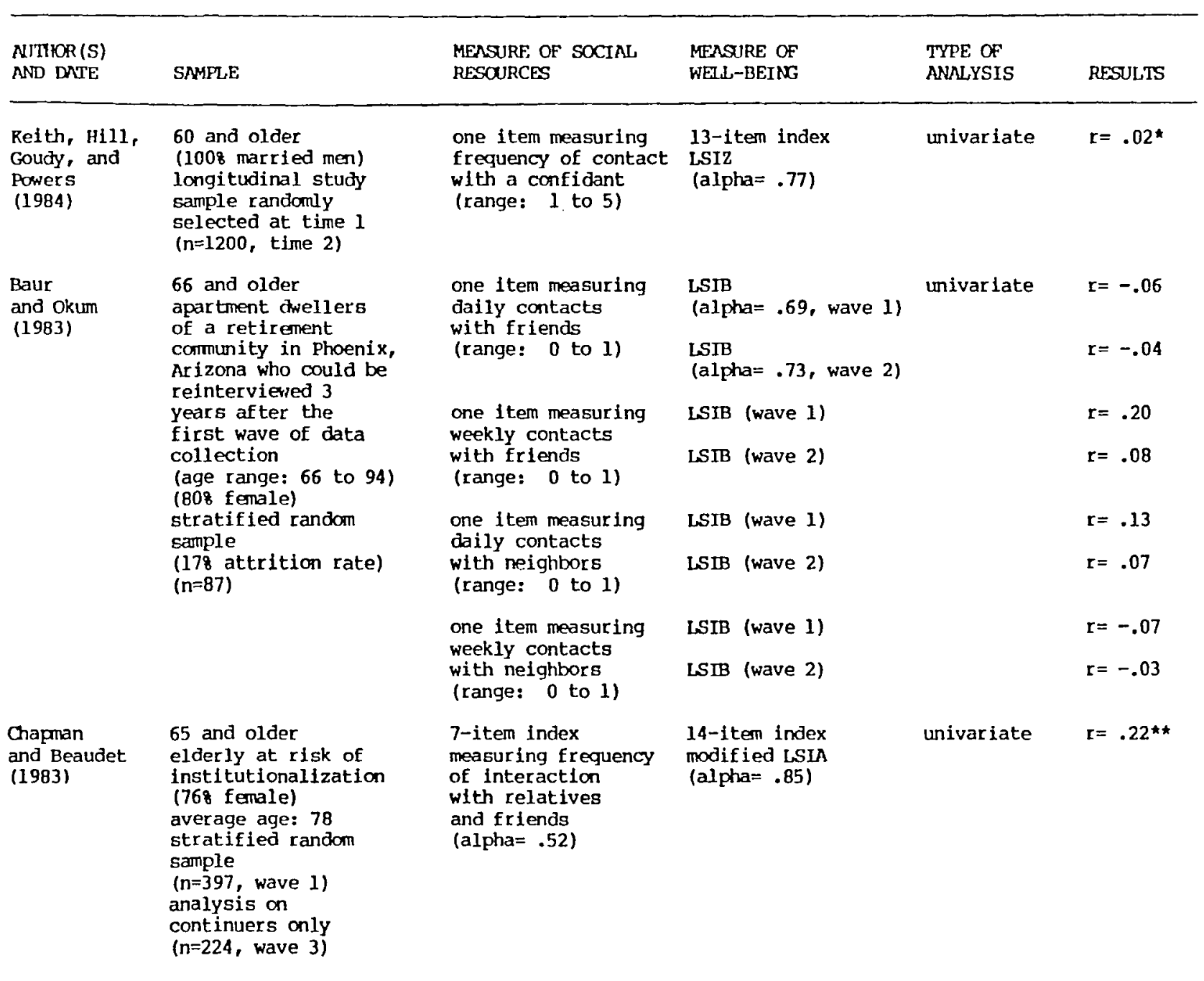




\begin{tabular}{|c|c|c|c|}
\hline $\begin{array}{l}\text { Deiml ing, } \\
\text { Harel, } \\
\text { and Noelker } \\
\text { (1983) }\end{array}$ & $\begin{array}{l}\text { elderly living in } \\
\text { a housing site with } \\
\text { some age-integrated } \\
\text { and some age- } \\
\text { segregated buildings } \\
\text { predominantly poor } \\
\text { average age: } 73 \\
\text { ( } 788 \text { female) } \\
\text { (568 minority) } \\
\text { surveyed all older } \\
\text { residents } \\
(728 \text { response rate) } \\
\text { ( } n=326)\end{array}$ & $\begin{array}{l}\text { one index measuring } \\
\text { number of relatives } \\
\text { and friends in the } \\
\text { network, their } \\
\text { proximity, and } \\
\text { the frequency of } \\
\text { contact with the } \\
\text { respondent }\end{array}$ & LSIA \\
\hline $\begin{array}{l}\text { Ory and } \\
\text { Goldberg } \\
(1983)\end{array}$ & $\begin{array}{l}65 \text { and older } \\
\text { noninstitutionalized } \\
\text { living in } \\
\text { Washington county, } \\
\text { Maryland } \\
\text { (age range: } 65 \text { to } 75 \text { ) } \\
\text { (n=1073) } \\
1008 \text { white, married } \\
\text { women } \\
\text { sampled all who met } \\
\text { eligibility criteria } \\
\text { described above } \\
\text { (718 response rate) } \\
(n=1073)\end{array}$ & $\begin{array}{l}\text { number of persons } \\
\text { (relatives and } \\
\text { friends) respondent } \\
\text { has regular contacts } \\
\text { with } \\
\text { number of relatives } \\
\text { respondent has } \\
\text { regular contacts with } \\
\text { number of friends } \\
\text { respondent has } \\
\text { regular contacts with } \\
\text { number of confidants } \\
\text { respondent has } \\
\text { regular contacts with }\end{array}$ & $\begin{array}{l}\text { one item measuring } \\
\text { happiness } \\
\text { (range: } 1 \text { to } 3 \text { ) }\end{array}$ \\
\hline $\begin{array}{l}\text { Ward and } \\
\text { Kilburn } \\
\text { (1983) }\end{array}$ & $\begin{array}{l}65 \text { and older } \\
\text { subsample of } 1974 \text { NORC } \\
\text { data, random sample } \\
\text { of persons } 18 \text { and } \\
\text { over ( } n=5000) \\
\text { ( } n=2723 \text { for } \\
\text { analysis) }\end{array}$ & $\begin{array}{l}\text { one item measuring } \\
\text { most recent contact } \\
\text { with children } \\
\text { (range: } 1 \text { to 6) } \\
\text { one item measuring } \\
\text { most recent contact } \\
\text { with close friend } \\
\text { (range: } 1 \text { to 6) } \\
\text { one item measuring } \\
\text { most recent } \\
\text { contact w1th } \\
\text { neighbors } \\
\text { (range: } 1 \text { to 6) }\end{array}$ & $\begin{array}{l}\text { 18-item index } \\
\text { LSI } \\
\text { (range: } 1 \text { to } 36 \text { ) }\end{array}$ \\
\hline
\end{tabular}

$\begin{array}{ll}\mathrm{r}=.15 \\ \text { univariate } & \text { (entire } \\ \text { sample) }\end{array}$

$r=.11$
White

subsample)

$r=.05$

subsample)

univariate

$r=.01$

$r=-.07$ *

$r=.07 \star$

$r=.12^{\star \star}$

univariate

$r=.05^{\star}$

$r=.17 *$

$r=.19 \star$ 


\begin{tabular}{|c|c|c|c|c|c|}
\hline $\begin{array}{l}\text { Harel } \\
\text { and Noelker } \\
\text { (1982) }\end{array}$ & $\begin{array}{l}54 \text { and older } \\
\text { institutionalized } \\
\text { residents of the } \\
\text { Cleveland } \\
\text { metropolitan area } \\
\text { average age: } 81 \\
\text { (668 female) } \\
\text { (age range: } 54 \text { to } 97 \text { ) } \\
\text { nonprobability sample } \\
\text { (n=125) }\end{array}$ & $\begin{array}{l}\text { one item measuring } \\
\text { number of visitors } \\
\text { from outside } \\
\text { the facility }\end{array}$ & $\begin{array}{l}\text { Philadelphia } \\
\text { Geriatric Center } \\
\text { morale scale } \\
\text { one item measuring } \\
\text { life satisfaction }\end{array}$ & univariate & $r=.19 *$ \\
\hline $\begin{array}{l}\text { Harel, } \\
\text { Sollod, } \\
\text { and Bognar } \\
(1982)\end{array}$ & $\begin{array}{l}60 \text { and older } \\
\text { noninstitutionalized } \\
\text { residents of Greene } \\
\text { county, Ohio } \\
\text { living in semi-rural } \\
\text { areas } \\
\text { ( } 608 \text { female) } \\
\text { systematic random } \\
\text { sample } \\
\text { ( } 888 \text { response rate) } \\
\text { ( } n=1008)\end{array}$ & $\begin{array}{l}\text { one item measuring } \\
\text { frequency of } \\
\text { talking to others } \\
\text { one item measuring } \\
\text { frequency of } \\
\text { in-person contact }\end{array}$ & $\begin{array}{l}\text { one item measuring } \\
\text { mental and } \\
\text { emotional health } \\
\text { (range: } 0 \text { to } 3 \text { ) }\end{array}$ & univar iate & $\begin{array}{l}\mathrm{r}=.16^{\star \star \star} \\
\mathrm{r}=.18^{\star \star \star}\end{array}$ \\
\hline
\end{tabular}




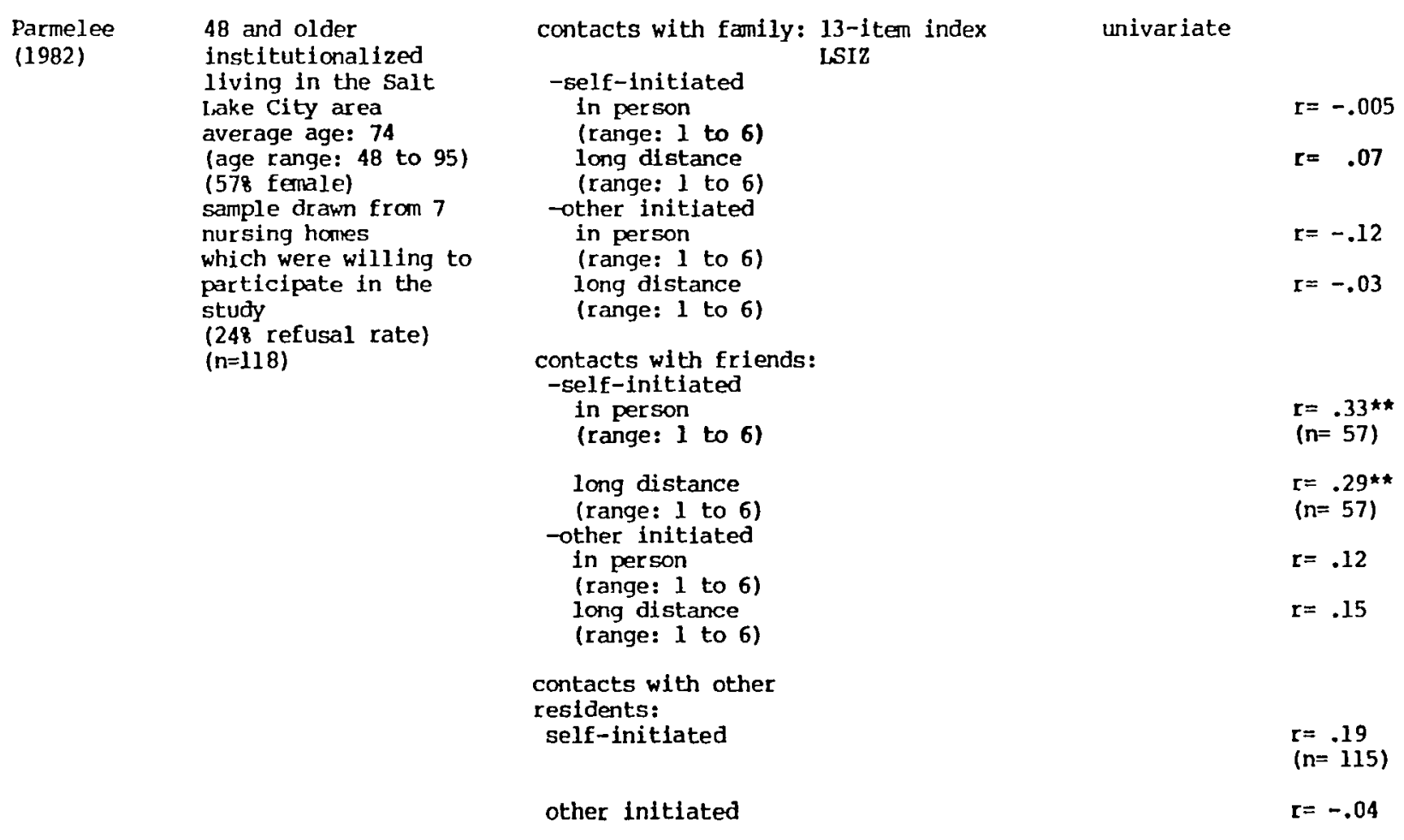




\begin{tabular}{|c|c|c|c|c|c|}
\hline $\begin{array}{l}\text { Felton, } \\
\text { Hinrichsen, } \\
\text { and T'sember is } \\
\text { (1981) }\end{array}$ & $\begin{array}{l}65 \text { and older } \\
\text { noninstitutionalized } \\
\text { group } 1 \text { (urban) } \\
\text { residents of age- } \\
\text { integrated or } \\
\text { privately owned } \\
\text { housing for the } \\
\text { elderly in } \\
\text { Manhattan's Lower } \\
\text { East side } \\
\text { average age: } 73 \\
\text { ( } 718 \text { female) } \\
\text { (n=38) } \\
\text { group } 2 \text { (suburban) } \\
\text { residents of a } \\
\text { privately owned } \\
\text { housing project for } \\
\text { the elderly in a } \\
\text { New Jersey cómunity } \\
\text { average age: } 71 \\
\text { (828 female) } \\
\text { (648 response rate) } \\
\text { ( } n=33 \text { ) }\end{array}$ & $\begin{array}{l}\text { Index measuring } \\
\text { frequency of } \\
\text { visiting with } \\
\text { friends }\end{array}$ & $\begin{array}{l}\text { 17-item index } \\
\text { Philadelphia } \\
\text { Geriatric Center } \\
\text { morale scale } \\
\text { (alpha }=\text {.88) }\end{array}$ & univariate & $\begin{array}{l}r=.22 \\
\text { (group 1) } \\
r=.40^{\star} \\
\text { (group 2) }\end{array}$ \\
\hline $\begin{array}{l}\text { Tesch, } \\
\text { Whi tbourne, } \\
\text { and Nehrke } \\
\text { (1981) }\end{array}$ & $\begin{array}{l}52 \text { and older } \\
\text { institutionalized } \\
\text { veterans, residents } \\
\text { of Bath, New York } \\
\text { (1008 male) } \\
\text { average age: } 70 \\
\text { (age range: } 52 \text { to } 90 \text { ) } \\
\text { convenience sample } \\
\text { drawn from one } \\
\text { self-care floor of } \\
\text { the residential } \\
\text { facility } \\
(238 \text { refusal rate) } \\
(n=54)\end{array}$ & $\begin{array}{l}\text { index measuring } \\
\text { frequency of } \\
\text { contacts with family } \\
\text { and friends } \\
\text { (range: } 0 \text { to 13) }\end{array}$ & $\begin{array}{l}\text { 17-item Index } \\
\text { Philadelphia } \\
\text { Geriatric Center } \\
\text { morale scale } \\
\text { (range: } 0 \text { to 17) }\end{array}$ & univariate & $I=.26 \star$ \\
\hline
\end{tabular}




\begin{tabular}{|c|c|c|c|c|c|}
\hline $\begin{array}{l}\text { Duff } \\
\text { and Hong } \\
(1980)\end{array}$ & $\begin{array}{l}60 \text { and older } \\
\text { noninstitutionalized } \\
1974 \text { NORC data } \\
\text { stratified random } \\
\text { sample of persons } \\
18 \text { and older } \\
\text { median age in sub- } \\
\text { sample: } 69 \\
\text { ( } \mathrm{n}=335 \text { but } \mathrm{n}=275 \\
\text { for analysis due to } \\
\text { missing data) }\end{array}$ & $\begin{array}{l}\text { one item measuring } \\
\text { frequency of } \\
\text { in-person contact } \\
\text { with relatives } \\
\text { (range: } 1 \text { to } 7 \text { ) } \\
\text { one item measuring } \\
\text { frequency of } \\
\text { in-person contact } \\
\text { with friends } \\
\text { (range: } 1 \text { to } 7 \text { ) }\end{array}$ & $\begin{array}{l}\text { 2-item index } \\
\text { measuring life } \\
\text { satisfaction } \\
\text { (range: } 1 \text { to } 6 \text { ) }\end{array}$ & univariate & $r=.12$ \\
\hline & & $\begin{array}{l}\text { one iten measuring } \\
\text { frequency of } \\
\text { in-person contact } \\
\text { with neighbors } \\
\text { (range: } 1 \text { to } 7 \text { ) }\end{array}$ & & & $\mathbf{r}=.11$ \\
\hline $\begin{array}{l}\text { Lee and } \\
\text { Ihinger- } \\
\text { Tallman } \\
(1980)\end{array}$ & $\begin{array}{l}60 \text { and older } \\
\text { survey in Washington } \\
\text { state, two-stage } \\
\text { probability sample } \\
\text { ( } 758 \text { response rate) } \\
\text { ( } \mathrm{n}=870 \text { and } n=651 \\
\text { for analysis due to } \\
\text { missing data } \\
315 \text { males and } \\
336 \text { females) }\end{array}$ & $\begin{array}{l}\text { one item measuring } \\
\text { amount of interaction } \\
\text { with siblings } \\
\text { (range: } 0 \text { to 2) }\end{array}$ & $\begin{array}{l}6 \text {-1tem index } \\
\text { measuring Iffe } \\
\text { satisfaction } \\
\text { (range: } 1 \text { to } 24 \\
\text { recoded into } 3 \\
\text { groups) } \\
\text { (alpha }=.85 \text { males) } \\
\text { (alpha }=.87 \text { females) }\end{array}$ & univariate & $\begin{array}{l}r=.02 \\
\text { (males) } \\
1,6 \\
r=.04 \\
\text { (females) }\end{array}$ \\
\hline \multirow[t]{3}{*}{$\begin{array}{l}\text { Mancini } \\
(1980)\end{array}$} & $\begin{array}{l}65 \text { and older } \\
\text { noninstitutionalized } \\
\text { of high socio- } \\
\text { economic status } \\
\text { ( } 548 \text { female) } \\
\text { average age: } 72 \\
\text { ciuster sampling } \\
\text { (n=104, } 56 \text { females } \\
\text { and } 48 \text { males) }\end{array}$ & $\begin{array}{l}\text { one item measuring } \\
\text { in-person contact } \\
\text { with friends } \\
\text { (range: } 1 \text { to } 4 \text { ) }\end{array}$ & $\begin{array}{l}\text { 17-item index } \\
\text { Geriatric Center } \\
\text { morale scale }\end{array}$ & univariate & $\begin{array}{l}r=.17^{\star} \\
\text { (entire sample) } \\
r=.23 \\
\text { (males) } \\
r=.12 \\
\text { (females) }\end{array}$ \\
\hline & & $\begin{array}{l}\text { one item measuring } \\
\text { frequency of } \\
\text { teleptone contact } \\
\text { with friends } \\
\text { (range: } 1 \text { to 4) }\end{array}$ & & & $\begin{array}{l}r=-.08 \\
\text { (entire sample) } \\
r=.14 \\
\text { (males) }\end{array}$ \\
\hline & & & & & $\begin{array}{l}r=-.17 \\
\text { (females) }\end{array}$ \\
\hline
\end{tabular}




$\begin{array}{ll}\text { Mancini, } & \text { elderly persons, } \\ \text { Quinn, } & \text { residents of two } \\ \text { Gavigan, } & \text { high-rise } \\ \text { and Franklin } & \text { public housing } \\ \text { (1980) } & \text { apartment complexes } \\ & \text { (758 female) } \\ & \text { average age: 70 } \\ & \text { simple random } \\ & \text { sample } \\ & (718 \text { response rate) } \\ & (n=74)\end{array}$

one item measuring frequency of

in-person contacts

wth:

relatives

friends

neighbors

confidant
children

one item measuring

frequency of

telephone contacts with:

other relatives

friends

neighbors

neighbors

children
Cantril ladder

(range: 0 to 9)

$r=.03$

$1=.13$

$r=.04$

$\mathbf{r}=.04$
$\mathbf{r}=.06$

$r=.13$

$r=.12$

$r=-.12$

$r=-.07$ 


\begin{tabular}{|c|c|c|c|c|c|}
\hline \multirow[t]{4}{*}{$\begin{array}{l}\text { Conner, } \\
\text { Powers, } \\
\text { and Bultena } \\
(1979)\end{array}$} & \multirow[t]{4}{*}{$\begin{array}{l}70 \text { and older } \\
\text { noninstitutionalized } \\
\text { residents of lowa } \\
\text { (708 female) } \\
\text { respondents were } \\
\text { celected from five } \\
\text { counties to be } \\
\text { representative of } \\
\text { the elderly in the } \\
\text { state of Iowa } \\
\text { (n=218) }\end{array}$} & $\begin{array}{l}\text { frequency of } \\
\text { face-to-face } \\
\text { contacts with } \\
\text { immediate family } \\
\text { members } \\
\text { (range: } 0 \text { to 16) } \\
\text { frequency of } \\
\text { face-to-face } \\
\text { contacts with } \\
\text { siblings and } \\
\text { other relatives } \\
\text { (range: } 0 \text { to 1877) }\end{array}$ & $\begin{array}{l}\text { 13-iten index } \\
\text { LSIz } \\
\text { (range: } 13 \text { to 39) } \\
\text { (alpha }=.93 \text { ) }\end{array}$ & univariate & $r=.08$ \\
\hline & & $\begin{array}{l}\text { frequency of } \\
\text { face-to-face } \\
\text { contacts with } \\
\text { friends and } \\
\text { neighbors } \\
\text { (range: } 0 \text { to 2555) }\end{array}$ & & & $r=.06$ \\
\hline & & $\begin{array}{l}\text { frequency of } \\
\text { face-to-face } \\
\text { contacts with } \\
\text { confidants } \\
\text { (range: } 0 \text { to } 730 \text { ) }\end{array}$ & & & $\mathrm{r}=-.05$ \\
\hline & & $\begin{array}{l}\text { frequency of } \\
\text { face-to-face } \\
\text { contacts with all } \\
\text { the members of the } \\
\text { network } \\
\text { (range: } 0 \text { to } 3674 \text { ) }\end{array}$ & & & $r=.07$ \\
\hline
\end{tabular}




\begin{tabular}{|c|c|c|c|c|c|}
\hline $\begin{array}{l}\text { Lee } \\
\text { (1979) }\end{array}$ & $\begin{array}{l}60 \text { and older } \\
\text { survey in washington } \\
\text { state, two-stage } \\
\text { probability sample } \\
\text { ( } 758 \text { response rate) } \\
\text { subsample of married } \\
\text { persons only } \\
\text { ( } 418 \text { female) } \\
\text { ( } n=588 \text { but n=388 } \\
\text { for analysis due to } \\
\text { missing data) }\end{array}$ & $\begin{array}{l}\text { one item measuring } \\
\text { number of visits } \\
\text { with children in } \\
\text { the last month } \\
\text { one item measuring } \\
\text { number of telephone } \\
\text { calls from children } \\
\text { in the last month }\end{array}$ & $\begin{array}{l}6 \text {-item index } \\
\text { measuring life } \\
\text { satisfaction } \\
\text { (range: } 6 \text { to 24) } \\
\text { (alpha }=.85 \text { males) } \\
\text { (alpha }=.87 \text { females) }\end{array}$ & univariate & $\begin{array}{l}r=-.06 \\
\text { (males) } \\
r=-.07 \\
\text { (females) } \\
r=-.05 \\
\text { (males) } \\
r=-.20 \\
\text { (females) }\end{array}$ \\
\hline & & $\begin{array}{l}\text { one item measuring } \\
\text { number of letters } \\
\text { from children } \\
\text { in the last month }\end{array}$ & & & $\begin{array}{l}r=.005 \\
\text { (males) } \\
r=.02 \\
\text { (females) }\end{array}$ \\
\hline & & $\begin{array}{l}\text { one item measuring } \\
\text { frequency of } \\
\text { interaction } \\
\text { with child seen } \\
\text { most often } \\
\text { (range: } 1 \text { to } 7 \text { ) }\end{array}$ & & & $\begin{array}{l}r=-.11 \\
\text { (males) } \\
r=-.16 \\
\text { (females) }\end{array}$ \\
\hline $\begin{array}{l}\text { Ward } \\
(1979)\end{array}$ & $\begin{array}{l}50 \text { and older } \\
\text { noninstitutionalized } \\
\text { NORC surveys combined } \\
\text { for the } 1972 \text { through } \\
\text { the } 1977 \text { years } \\
\text { national probability } \\
\text { sample ( } n=3557 \text {, } \\
58 \text { ( }=162 \text { ) never } \\
\text { married) }\end{array}$ & $\begin{array}{l}\text { one item measuring } \\
\text { frequency of } \\
\text { contacts with } \\
\text { relatives } \\
\text { one item measuring } \\
\text { frequency of } \\
\text { contacts with } \\
\text { neighbors } \\
\text { (range: } 1 \text { to } 3 \text { ) } \\
\text { one iten measuring } \\
\text { frequency of } \\
\text { contacts with } \\
\text { friends } \\
\text { (range: } 1 \text { to 3) }\end{array}$ & $\begin{array}{l}\text { one item measuring } \\
\text { happiness }\end{array}$ & univariate & $\begin{array}{l}r=.06^{*} \\
\text { (married) } \\
r=.04 \\
\text { (never } \\
\text { married) } \\
r=.06^{*} \\
\text { (married) } \\
r=.10 \\
\text { (never } \\
\text { married) } \\
r=.11 \\
\text { (married) } \\
r=.29 * \\
\text { (never } \\
\text { married) }\end{array}$ \\
\hline
\end{tabular}




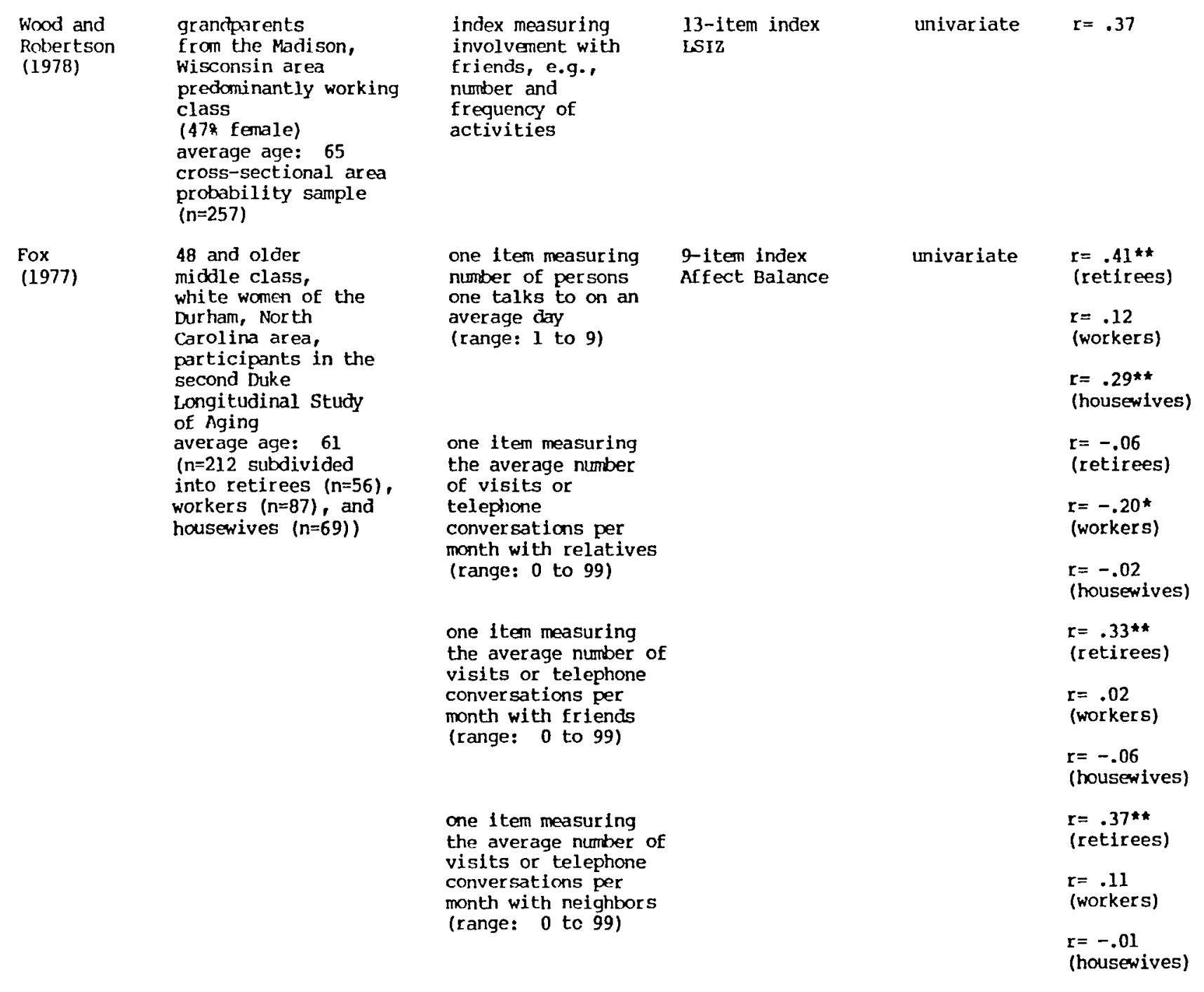




\begin{tabular}{|c|c|c|c|c|c|}
\hline $\begin{array}{l}\text { Palmore } \\
\text { and Kivett } \\
\text { (1977) }\end{array}$ & $\begin{array}{l}46 \text { and older } \\
\text { longitudinal study } \\
\text { of middle and upper } \\
\text { middle class persons } \\
\text { from the Durham, } \\
\text { North Carolina area, } \\
\text { stratified randor } \\
\text { sample of mentbers of } \\
\text { a local heal th } \\
\text { insurance company } \\
\text { ( } n=502) \\
3 \text { waves of data } \\
\text { collection over a } \\
\text { six-year period } \\
\text { continuers tend to } \\
\text { be better off in all } \\
\text { domains } \\
(258 \text { attrition) } \\
\text { ( } 488 \text { female at wave } 3 \text { ) } \\
\text { ( } n=378 \text { ) }\end{array}$ & $\begin{array}{l}\text { total number of } \\
\text { hours spent in a } \\
\text { typical week with } \\
\text { relatives and } \\
\text { friends and/or } \\
\text { involved in } \\
\text { social activities } \\
\text { (wave } 1 \text { data) }\end{array}$ & $\begin{array}{l}\text { Cantril ladder } \\
\text { (range: } 0 \text { to } 9 \text { ) }\end{array}$ & univariate & $\begin{array}{l}t=.11^{\star} \\
\text { (wave } 1 \text { LSI) }\end{array}$ \\
\hline \multirow[t]{3}{*}{$\begin{array}{l}\text { Sauer } \\
\text { (1977) }\end{array}$} & $\begin{array}{l}65 \text { and older } \\
\text { noninstitutionalized } \\
\text { elderly from the low } \\
\text { socioeconomic areas } \\
\text { of Philadelphia } \\
\text { ( } 568 \text { female) } \\
\text { ( } 778 \text { Black elderly) } \\
\text { stratified random } \\
\text { sample } \\
\text { ( } n=1022 \text { but } \\
n=932 \text { for analysis } \\
\text { due to missing data) }\end{array}$ & $\begin{array}{l}\text { one item measuring } \\
\text { frequency of } \\
\text { interaction with } \\
\text { family }\end{array}$ & $\begin{array}{l}\text { 17-item index } \\
\text { modified version } \\
\text { of the Philadelphia } \\
\text { Geriatric Center } \\
\text { morale scale } \\
\text { (range: } 0 \text { to } 17 \text { ) } \\
\text { (alpha= .82) }\end{array}$ & univariate & $\begin{array}{l}r=.09^{\star} \\
\text { (entire } \\
\text { sample) } \\
r=.05 \\
\text { (Black } \\
\text { subsample) } \\
r=.22^{\star} \\
\text { (White } \\
\text { Eubsample) }\end{array}$ \\
\hline & & $\begin{array}{l}\text { one item measuring } \\
\text { frequency of } \\
\text { interaction with } \\
\text { friends }\end{array}$ & & & $\begin{array}{l}r=-.08 * \\
\text { (entire } \\
\text { sample) } \\
r=-.09 \\
\text { (Black } \\
\text { subsample) }\end{array}$ \\
\hline & & & & & $\begin{array}{l}r=-.01 \\
\text { (White } \\
\text { subsarple) }\end{array}$ \\
\hline
\end{tabular}




\begin{tabular}{|c|c|c|c|c|c|}
\hline $\begin{array}{l}\text { Conner } \\
\text { and Powers } \\
\text { (1975) }\end{array}$ & $\begin{array}{l}70 \text { and older } \\
\text { noninstitutionalized } \\
\text { residents of } 5 \\
\text { counties in a mid- } \\
\text { western state } \\
\text { cross-sectional } \\
\text { representative } \\
\text { sample } \\
\text { (n=185) }\end{array}$ & $\begin{array}{l}\text { 6-item index } \\
\text { measuring frequency } \\
\text { of interaction with } \\
\text { family, frlends, and } \\
\text { neighbors } \\
\text { (range: } 0 \text { to } 3130 \text { ) }\end{array}$ & LSIZ & univar iate & $r=.01$ \\
\hline $\begin{array}{l}\text { Sinith } \\
\text { and Brand } \\
\text { (1975) }\end{array}$ & $\begin{array}{l}\text { elderly persons } \\
\text { institutionalized } \\
\text { residents of } \\
\text { Halifax, Nova Scotia, } \\
\text { ( } 638 \text { female) } \\
\text { surveyed all persons } \\
\text { who could be } \\
\text { interviewed } \\
\text { ( }=75)\end{array}$ & $\begin{array}{l}\text { one item measuring } \\
\text { frequency of contact } \\
\text { with family and } \\
\text { friends recoded into } \\
2 \text { groups }\end{array}$ & $\begin{array}{l}\text { 12-item index } \\
\text { modified LSI } \\
\text { (range: 0 to } 12 \\
\text { recoded into } 2 \\
\text { groups) }\end{array}$ & univariate & $\mathbf{r}=.31$ \\
\hline $\begin{array}{l}\text { Fine } \\
\text { (1975) }\end{array}$ & $\begin{array}{l}65 \text { and older } \\
\text { noninstitutionalized } \\
\text { living in the Bronx } \\
\text { users and potential } \\
\text { users of Dial-A-Ride } \\
\text { program } \\
\text { average age: } 73 \\
\text { (age range: } 65 \text { to } 89 \text { ) } \\
\text { (758 female) } \\
\text { stratified random } \\
\text { sample } \\
\text { (n= 169) }\end{array}$ & $\begin{array}{l}\text { set of Items combined } \\
\text { into an index to } \\
\text { measure mobility and } \\
\text { which incorporate } \\
\text { frequency of contact } \\
\text { and distance to } \\
\text { children, relatives, } \\
\text { friends, and } 17 \\
\text { kinds of places } \\
\text { (e.g., doctor, bank, } \\
\text { etc...) }\end{array}$ & $\begin{array}{l}\text { 7-item index } \\
\text { measuring life } \\
\text { satisfaction } \\
\text { index based on a } \\
\text { factor analysis of } \\
\text { LSI, locus of } \\
\text { control, and } \\
\text { autonomy scale } \\
\text { items }\end{array}$ & univarlate & $r=.30 \star \star \star$ \\
\hline $\begin{array}{l}\text { Lawton, } \\
\text { Nahemow, } \\
\text { and Teaff } \\
(1975)\end{array}$ & $\begin{array}{l}\text { elderly living in } \\
\text { HDD public housing } \\
\text { projects } \\
\text { in-depth personal } \\
\text { interviews conducted } \\
\text { with approximately } \\
20 \text { tenants at each } \\
\text { of the } 154 \text { selected } \\
\text { sites } \\
\text { national probability } \\
\text { sample } \\
\text { ( } 898 \text { response rate) } \\
\text { ( }=2457 \text { due to } \\
\text { missing data) }\end{array}$ & $\begin{array}{l}2 \text {-item index } \\
\text { measuring number of } \\
\text { friends and number } \\
\text { of visits with } \\
\text { friends in the last } \\
\text { week } \\
\text { one item measuring } \\
\text { freguency of contact } \\
\text { with the relative } \\
\text { seen most of ten }\end{array}$ & $\begin{array}{l}\text { 2-iten index } \\
\text { measuring morale }\end{array}$ & univarlate & $r=.00$ \\
\hline
\end{tabular}




\begin{tabular}{|c|c|c|c|c|c|}
\hline $\begin{array}{l}\text { Curry } \\
\text { and Ratliff } \\
\text { (1973) }\end{array}$ & $\begin{array}{l}60 \text { and older } \\
\text { institutionalized } \\
\text { living in one } \\
\text { county in ohio } \\
\text { Aid for the Aged } \\
\text { recipients } \\
\text { low income, } \\
\text { ( } 648 \text { female) } \\
\text { average age: } 75 \\
\text { stratified random } \\
\text { sample by size of } \\
\text { home } \\
(n=200)\end{array}$ & $\begin{array}{l}\text { index measuring } \\
\text { total number of } \\
\text { contacts with } \\
\text { relatives and } \\
\text { friends }\end{array}$ & $\begin{array}{l}20 \text {-item index } \\
\text { LSI } \\
\text { (range: } 0 \text { to } 60, \\
\text { recoded into three } \\
\text { categories) }\end{array}$ & univariate & $\mathrm{r}=.24$ \\
\hline \multirow[t]{3}{*}{$\begin{array}{l}\text { Edwards } \\
\text { and Klemmack } \\
\text { (1973) }\end{array}$} & $\begin{array}{l}45 \text { and older } \\
\text { residents of four } \\
\text { counties in virginia } \\
\text { ( } 548 \text { female) } \\
\text { quota sample for } \\
\text { proportionate } \\
\text { representation of } \\
\text { those below and above } \\
65 \text { years } \\
\text { (n=507) }\end{array}$ & $\begin{array}{l}\text { one item measuring } \\
\text { frequency of } \\
\text { in-person contact } \\
\text { with children } \\
\text { one item measuring } \\
\text { frequency of } \\
\text { in-person contact } \\
\text { with relatives }\end{array}$ & $\begin{array}{l}\text { 10-item index } \\
\text { modified LSIA } \\
\text { (alpha= .90) }\end{array}$ & univariate & $r=.06$ \\
\hline & & $\begin{array}{l}\text { one item measuring } \\
\text { frequency of in- } \\
\text { person contact with } \\
\text { neighbors }\end{array}$ & & & $r=.16 *$ \\
\hline & & $\begin{array}{l}\text { one item measuring } \\
\text { frequency of } \\
\text { contact by phone } \\
\text { with relatives, } \\
\text { neighbors, and } \\
\text { friends }\end{array}$ & & & $r=.13^{*}$ \\
\hline $\begin{array}{c}\text { Martin } \\
(1973)\end{array}$ & $\begin{array}{l}52 \text { and older } \\
\text { 1n-movers into an } \\
\text { age-segregated } \\
\text { retirement community } \\
\text { in Southern } \\
\text { California } \\
\text { high socio-economic } \\
\text { status } \\
\text { median age: } 67 \\
\text { ( } 558 \text { female) } \\
\text { random sanple } \\
\text { (658 response rate) } \\
\text { ( } n=411)\end{array}$ & $\begin{array}{l}\text { index measuring } \\
\text { extent of family } \\
\text { interaction } \\
\text { (range: } 0 \text { to } 38 \text { ) }\end{array}$ & $\begin{array}{l}\text { 13-item index } \\
\text { LSTB } \\
\text { (range: } 13 \text { to } 38 \text { ) }\end{array}$ & univariate & $r=-.07$ \\
\hline
\end{tabular}




\begin{tabular}{|c|c|c|c|c|c|}
\hline $\begin{array}{l}\text { Palmore } \\
\text { and Luikart } \\
\text { (1972) }\end{array}$ & $\begin{array}{l}46 \text { and older } \\
\text { noninstitutionalized } \\
\text { residents of Durham, } \\
\text { North Carolina } \\
\text { average age: } 59 \\
\text { age range: } 46 \text { to } 71 \\
\text { respondents } \\
\text { tend to be well off } \\
\text { ( } 488 \text { female) } \\
\text { random sample from a } \\
\text { member ship list of a } \\
\text { major health } \\
\text { insurance company } \\
\text { (refusal rate: } 528 \text { ) } \\
\text { longitudinal data } \\
\text { wave } 1 \text { data only } \\
\text { ( } n=502 \text { ) }\end{array}$ & $\begin{array}{l}\text { one item measuring } \\
\text { number of contacts } \\
\text { with relatives, } \\
\text { friends, and } \\
\text { neighbors on a } \\
\text { monthly basis } \\
\text { (range: } 1 \text { to } 306 \text { ) }\end{array}$ & $\begin{array}{l}\text { one } 1 \text { tem measuring } \\
\text { happiness } \\
\text { Cantril ladder } \\
\text { (range: } 0 \text { to } 9 \text { ) }\end{array}$ & univariate & $\begin{array}{l}r=.01 \\
\text { (entire } \\
\text { sample) }\end{array}$ \\
\hline $\begin{array}{l}\text { Bultena } \\
\text { and Oyler } \\
\text { (1971) }\end{array}$ & $\begin{array}{l}65 \text { and older } \\
\text { residents of } \\
\text { Wisconsin } \\
\text { median age: } 73 \\
\text { (age range: } 65 \text { to 91) } \\
158 \text { randorn sample } \\
(n=300)\end{array}$ & $\begin{array}{l}\text { 6-item Index } \\
\text { measuring frequency } \\
\text { of in-person contacts } \\
\text { with family and } \\
\text { friends } \\
\text { (range: o to } 283 \\
\text { recoded into } 3 \\
\text { groups) }\end{array}$ & $\begin{array}{l}\text { 13-item index } \\
\text { modified LSIA }\end{array}$ & univariate & $\mathrm{r}=.21$ \\
\hline
\end{tabular}


STUDIES OF THE RELATIONSHIP BETWEEN SOCIETAL INVOLVEMENT AND SUBJECTIVE WELL-BEING

\begin{tabular}{|c|c|c|c|c|c|}
\hline $\begin{array}{l}\text { NJTHFOR (S) } \\
\text { AND DATE }\end{array}$ & SNMPLE & $\begin{array}{l}\text { MENSURE OF SOCIETAL } \\
\text { INVOLVEMENT }\end{array}$ & $\begin{array}{l}\text { MENSURE OF } \\
\text { WEIL-BEING }\end{array}$ & $\begin{array}{l}\text { TYPE OF } \\
\text { ANALYSIS }\end{array}$ & RESULTS \\
\hline $\begin{array}{l}\text { Hooker } \\
\text { and ventis } \\
(1984)\end{array}$ & $\begin{array}{l}53 \text { and older } \\
\text { residents of } \\
\text { southeastern and } \\
\text { central Virginia } \\
\text { Middle class } \\
\text { background } \\
\text { average age: } 70 \\
\text { (age range: } 53 \text { to } 88 \text { ) } \\
\text { ( } 558 \text { female) } \\
\text { convenience sample } \\
\text { of volunteers } \\
\text { recruited from } \\
\text { national associations } \\
\text { of retired persons } \\
\text { ( } 688 \text { response rate) } \\
\text { ( } n=76 \text { ) }\end{array}$ & $\begin{array}{l}\text { one 1tem measuring } \\
\text { mean number of } \\
\text { activities } \\
\text { engaged in on a } \\
\text { daily basis } \\
\text { (range: } 1 \text { to } 11 \text { ) }\end{array}$ & $\begin{array}{l}\text { LSIn } \\
\text { (alpha }=.73)\end{array}$ & univariate & $\mathrm{r}=.20^{\star}$ \\
\hline $\begin{array}{l}\text { Deimling, } \\
\text { Harel, } \\
\text { and Noelker } \\
\text { (1983) }\end{array}$ & $\begin{array}{l}\text { elderly living in } \\
\text { a housing site with } \\
\text { some age-integrated } \\
\text { and some age- } \\
\text { segregated buildings } \\
\text { predominantly poor } \\
\text { average age: } 73 \\
\text { ( } 788 \text { female) } \\
\text { (568 minority) } \\
\text { surveyed all older } \\
\text { residents } \\
\text { ( } 728 \text { response rate) } \\
\text { ( } n=326)\end{array}$ & $\begin{array}{l}\text { one index measuring } \\
\text { frequency of } \\
\text { participation, on a } \\
\text { weekly basis, in } \\
\text { recreational, social, } \\
\text { or cultural } \\
\text { activities }\end{array}$ & LSIA & univarlate & $\begin{array}{l}r=.18 \\
\text { (entire } \\
\text { sample) } \\
r=.12 \\
\text { (White } \\
\text { subsample) } \\
r=.21 \\
\text { (Black } \\
\text { subsample) }\end{array}$ \\
\hline
\end{tabular}




\begin{tabular}{|c|c|c|c|c|c|}
\hline $\begin{array}{l}\text { Kozma } \\
\text { and Stones } \\
\text { (1983) }\end{array}$ & $\begin{array}{l}65 \text { and older } \\
\text { urban, rural, and } \\
\text { institutionalized } \\
\text { residents of } \\
\text { Newfoundland } \\
\text { random selection } \\
\text { ( } n=600) \\
\text { rural ( } n=200) \text { group } 1 \\
\text { urban ( } n=200) \text { group } 2 \\
\text { institutionalized } \\
\text { ( } n=200) \text { group } 3\end{array}$ & $\begin{array}{l}\text { 37-item index } \\
\text { measuring } \\
\text { activities }\end{array}$ & $\begin{array}{l}24-i \text { tem Index } \\
\text { measuring happiness }\end{array}$ & univariate & $\begin{array}{l}r=.25^{\star \star} \\
\text { (entire sample) } \\
r=.20^{\star \star} \\
\text { (group } 1 \text { ) } \\
r=.29 \star \star \\
\text { (group 2) } \\
r=.22^{\star \star} \\
\text { (group 3) }\end{array}$ \\
\hline $\begin{array}{l}\text { Ory and } \\
\text { Goldberg } \\
\text { (1983) }\end{array}$ & $\begin{array}{l}65 \text { and older } \\
\text { noninstitutionalized } \\
\text { living in } \\
\text { Washington county, } \\
\text { Maryland, } \\
1008 \text { white, married } \\
\text { women } \\
\text { (age range: } 65 \text { to } 75 \text { ) } \\
\text { sampled all who met } \\
\text { the eligibility } \\
\text { criteria described } \\
\text { above } \\
\text { (718 response rate) } \\
\text { (n=1073) }\end{array}$ & $\begin{array}{l}\text { number of } \\
\text { organizations } \\
\text { respondent belongs } \\
\text { to }\end{array}$ & $\begin{array}{l}\text { one item measuring } \\
\text { happiness } \\
\text { (range: } 1 \text { to } 3 \text { ) }\end{array}$ & univariate & $r=.16^{\star \star}$ \\
\hline $\begin{array}{l}\text { Ward and } \\
\text { Kilburn } \\
\text { (1983) }\end{array}$ & $\begin{array}{l}65 \text { and older } \\
\text { subsample of } 1974 \\
\text { NoRC data, random } \\
\text { sample of persons } \\
18 \text { and older }(n=5000) \\
\text { ( } n=2723 \text { for } \\
\text { analysis) }\end{array}$ & $\begin{array}{l}\text { 9-item index } \\
\text { measuring community } \\
\text { mobility, e.g. } \\
\text { how recently the } \\
\text { respondent has gone } \\
\text { to } 9 \text { community } \\
\text { places } \\
\text { (range: } 9 \text { to } 54 \text { ) }\end{array}$ & $\begin{array}{l}\text { 18-item index } \\
\text { LSI } \\
\text { (range: } 1 \text { to } 36 \text { ) }\end{array}$ & univariate & $I=.38^{\star}$ \\
\hline $\begin{array}{l}\text { ziegler } \\
\text { and Reid } \\
(1983)\end{array}$ & $\begin{array}{l}\text { elderly in need } \\
\text { of services } \\
\text { living in an } \\
\text { apartment complex } \\
\text { for the elderly } \\
\text { in Toronto } \\
\text { average age: } 78 \\
\text { (828 female) } \\
\text { (n=79 wave 1) }\end{array}$ & $\begin{array}{l}\text { 21-item index } \\
\text { measuring frequency } \\
\text { of participation } \\
\text { in various types } \\
\text { of activities } \\
\text { (alpha }=.63 \text { wave 1) }\end{array}$ & $\begin{array}{l}\text { 13-item index } \\
\text { LSIZ } \\
\text { (alpha= } .65 \text { wave 1) }\end{array}$ & univariate & $\begin{array}{l}r=.37 * * * \\
\text { (wave 1) }\end{array}$ \\
\hline
\end{tabular}




\begin{tabular}{|c|c|c|c|c|c|}
\hline $\begin{array}{l}\text { Fengler and } \\
\text { Danigelis } \\
\text { (1982) }\end{array}$ & $\begin{array}{l}65 \text { and older } \\
\text { residents of } 4 \\
\text { counties in } \\
\text { northwestern vermont } \\
\text { median age: } 72 \\
\text { ( } 618 \text { female) } \\
\text { subsample of female } \\
\text { widows only } \\
\text { systematic selection } \\
(n=326)\end{array}$ & $\begin{array}{l}\text { 3-item index } \\
\text { measuring } \\
\text { participation in } \\
\text { social and religious } \\
\text { activities }\end{array}$ & $\begin{array}{l}\text { 3-item index } \\
\text { measuring } \\
\text { life satisfaction }\end{array}$ & univariate & $r=.19^{\star}$ \\
\hline $\begin{array}{l}\text { Harel and } \\
\text { Noelker } \\
(1982)\end{array}$ & $\begin{array}{l}54 \text { and older } \\
\text { institutionalized } \\
\text { elderly from the } \\
\text { Cleveland } \\
\text { metropolitan area } \\
\text { average age: } 81 \\
\text { (age range: } 54 \text { to } 97 \text { ) } \\
\text { (668 female) } \\
\text { nonprobability sample } \\
\text { ( } n=125 \text { ) }\end{array}$ & $\begin{array}{l}\text { frequency of } \\
\text { participation in } \\
\text { social activities }\end{array}$ & $\begin{array}{l}\text { Philadelphia } \\
\text { Geriatric Center } \\
\text { morale scale } \\
\text { one item measuring } \\
\text { life satisfaction }\end{array}$ & univariate & $\begin{array}{l}r=.26 * \star \\
r=.17\end{array}$ \\
\hline $\begin{array}{l}\text { Harel, } \\
\text { Sollod, } \\
\text { and Bognar } \\
(1982)\end{array}$ & $\begin{array}{l}60 \text { and older } \\
\text { noninstitutionallzed } \\
\text { residents of Greene } \\
\text { county, ohio } \\
\text { living in semi-rural } \\
\text { areas } \\
\text { ( } 608 \text { female) } \\
\text { systematic random } \\
\text { sample } \\
(888 \text { response rate) } \\
(n=1008)\end{array}$ & $\begin{array}{l}\text { one item measuring } \\
\text { participation } \\
\text { in activities }\end{array}$ & $\begin{array}{l}\text { one item measuring } \\
\text { mental and } \\
\text { emotional health } \\
\text { (range: } 0 \text { to } 3 \text { ) }\end{array}$ & univarfate & $r=.25^{\star k \star}$ \\
\hline $\begin{array}{l}\text { Brown, } \\
\text { Perman, } \\
\text { and Dobbs } \\
(1981)\end{array}$ & $\begin{array}{l}45 \text { and older } \\
\text { noninstitutionalized } \\
\text { working class, } \\
\text { predominantly poor, } \\
\text { and unemployed } \\
\text { pacemaker recipients } \\
\text { ( } 818 \text { male) } \\
\text { average age: } 69 \\
\text { (age range: } 45 \text { to } 85 \text { ) } \\
\text { convenience sample } \\
\text { (n=100) }\end{array}$ & $\begin{array}{l}\text { 3-item index } \\
\text { measuring } \\
\text { participation in } \\
\text { formal and } \\
\text { informal } \\
\text { activities } \\
\text { (range: } 3 \text { to } 8 \text { ) }\end{array}$ & $\begin{array}{l}\text { 7-item index } \\
\text { measuring } \\
\text { despair and } \\
\text { hopelessness } \\
\text { (alpha: } .79 \text { ) } \\
\text { (range: } 0 \text { to 28) }\end{array}$ & univariate & $\mathrm{r}=-.22^{\star}$ \\
\hline
\end{tabular}




\begin{tabular}{|c|c|c|c|c|c|}
\hline $\begin{array}{l}\text { Markides, } \\
\text { Costley, } \\
\text { and Rodriguez } \\
(1981)\end{array}$ & $\begin{array}{l}60 \text { and older } \\
\text { noninstitutionalized } \\
\text { residents of San } \\
\text { Antonio, Texas } \\
\text { low-income, minority } \\
\text { respondents with at } \\
\text { least one child in } \\
\text { the area } \\
\text { ( } 618 \text { female) } \\
\text { convenience sample } \\
\text { (n=98) }\end{array}$ & $\begin{array}{l}\text { 7-item index } \\
\text { measuring } \\
\text { participation in } \\
\text { social and religious } \\
\text { activities and } \\
\text { memberships in formal } \\
\text { associations } \\
\text { (range: } 0 \text { to } 16 \text { ) }\end{array}$ & $\begin{array}{l}\text { 21-item index } \\
\text { philadelphia } \\
\text { Geriatric Center } \\
\text { morale scale }\end{array}$ & univariate & $r=.30$ \\
\hline $\begin{array}{l}\text { Duff and Hong } \\
(1980)\end{array}$ & $\begin{array}{l}60 \text { and older } \\
\text { noninstitutionalized } \\
\text { subsample of NORC } \\
\text { data, stratified } \\
\text { random sample of } \\
\text { persons } 18 \text { and older } \\
\text { median age in sub- } \\
\text { sample: } 69 \\
\text { ( } n=335 \text { but n=275 } \\
\text { for analysis due to } \\
\text { missing data) }\end{array}$ & $\begin{array}{l}\text { one item measuring } \\
\text { frequency of } \\
\text { church attendance }\end{array}$ & $\begin{array}{l}\text { 2-item index } \\
\text { measuring life } \\
\text { satisfaction } \\
\text { (range: } 1 \text { to } 6 \text { ) }\end{array}$ & univariate & $\mathrm{r}=.23$ \\
\hline $\begin{array}{l}\text { Markides } \\
\text { and Martin } \\
\text { (1979) }\end{array}$ & $\begin{array}{l}60 \text { and older } \\
\text { predominantly poor } \\
\text { (648 female) } \\
\text { White subsample only } \\
\text { data collected in } \\
\text { four low-income } \\
\text { census tracts of } \\
\text { San Antonio, Texas } \\
(n=141)\end{array}$ & $\begin{array}{l}\text { weighted score } \\
\text { measuring } \\
\text { participation } \\
\text { in formal and } \\
\text { informal activities } \\
\text { (range: } 0 \text { to } 21 \text { ) }\end{array}$ & $\begin{array}{l}\text { 13-item index } \\
\text { LSIZ }\end{array}$ & univariate & $\begin{array}{l}r=.55 \\
\text { (males) } \\
r=.45 \\
\text { (females) }\end{array}$ \\
\hline $\begin{array}{l}\text { Spakes } \\
\text { (1979) }\end{array}$ & $\begin{array}{l}55 \text { and older } \\
\text { noninstitutionalized } \\
\text { hygh socio-economic } \\
\text { status } \\
\text { stratified national } \\
\text { sample, elderly } \\
\text { subsample only } \\
\text { ( } \mathrm{n}=873 \text { ) }\end{array}$ & $\begin{array}{l}\text { degree of commity } \\
\text { involvement, e.g., } \\
\text { total number of } \\
\text { formal and } \\
\text { recreational } \\
\text { activities involved } \\
\text { in } \\
\text { (range: } 0 \text { to } 31 \text { ) }\end{array}$ & $\begin{array}{l}\text { one item measuring } \\
\text { life satisfaction } \\
\text { (range: } 1 \text { to } 7 \text { ) }\end{array}$ & univariate & $r=.11$ \\
\hline
\end{tabular}




\begin{tabular}{|c|c|c|c|c|c|}
\hline $\begin{array}{l}\text { Ward } \\
\text { (1979) }\end{array}$ & $\begin{array}{l}60 \text { and older } \\
\text { noninstitutionalized } \\
\text { elderly } \\
\text { average age: } 74 \\
\text { ( } 568 \text { female) } \\
\text { high socio-economic } \\
\text { status } \\
\text { purposive sample } \\
\text { (808 response rate) } \\
\text { ( } \mathrm{n}=323 \text { ) }\end{array}$ & $\begin{array}{l}\text { number of } \\
\text { associations } \\
\text { respondent } \\
\text { participates in } \\
\text { frequency of } \\
\text { participation in } \\
\text { association } \\
\text { activities } \\
\text { degree of } \\
\text { involvenent in } \\
\text { associations } \\
\text { (range: 0 to 3) }\end{array}$ & $\begin{array}{l}\text { 13-item index } \\
\text { LSIz } \\
\text { (range: } 13 \text { to } 52 \text { ) } \\
\text { (alpha } .79 \text { ) }\end{array}$ & univariate & $\begin{array}{l}r=.17 \\
\text { ( } n=208 \text { due } \\
\text { to missing } \\
\text { values) }\end{array}$ \\
\hline $\begin{array}{l}\text { Ward } \\
\text { (1979) }\end{array}$ & $\begin{array}{l}50 \text { and older } \\
\text { noninstitutionalized } \\
\text { NORC surveys combined } \\
\text { for the } 1972 \text { through } \\
\text { the } 1977 \text { years } \\
\text { national probability } \\
\text { sample (n=3557, } \\
58 \text { ( } n=162) \text { never } \\
\text { married) }\end{array}$ & $\begin{array}{l}\text { number of } \\
\text { associations } \\
\text { respondent } \\
\text { belongs to }\end{array}$ & $\begin{array}{l}\text { one iten measuring } \\
\text { happiness } \\
\text { (range: } 1 \text { to } 3 \text { ) }\end{array}$ & univariate & $\begin{array}{l}r=.08^{3} \\
\text { (married) } \\
r=.26 \star^{3} \\
\text { (never } \\
\text { married) }\end{array}$ \\
\hline $\begin{array}{c}\text { George } \\
(1978)\end{array}$ & $\begin{array}{l}50 \text { and older } \\
\text { middle class, } \\
\text { healthy, and } \\
\text { financially } \\
\text { confortable } \\
\text { respondents, } \\
\text { originally selected } \\
\text { from a list of } \\
\text { participants in a } \\
\text { local health } \\
\text { insurance program } \\
\text { volunteers in the } \\
\text { Duke Longitudinal } \\
\text { Study of nging } \\
\text { third wave of data } \\
\text { collection } \\
\text { ( } 488 \text { female) } \\
\text { age range: } 50 \text { to } 76 \\
\text { (n=380) }\end{array}$ & $\begin{array}{l}\text { one index measuring } \\
\text { time spent, on a } \\
\text { weekly basis, in } \\
\text { social activities } \\
\text { e.g., church } \\
\text { attendance, religlous, } \\
\text { clubs or voluntary } \\
\text { organizational } \\
\text { activities, volunteer } \\
\text { work, and time spent } \\
\text { in informal } \\
\text { socializing } \\
\text { (range: 0 to 42) } \\
\text { (alpha = .78) }\end{array}$ & $\begin{array}{l}\text { Affect Balance } \\
\text { Scale } \\
\text { (range: } 0 \text { to } 31 \text { ) }\end{array}$ & univariate & $I=.18$ \\
\hline
\end{tabular}




\begin{tabular}{|c|c|c|c|c|c|}
\hline $\begin{array}{l}\text { Jackson, } \\
\text { Bacon, and } \\
\text { Peterson } \\
(1978)\end{array}$ & $\begin{array}{l}54 \text { and older } \\
\text { noninstitutionalized } \\
\text { elderly living in } \\
\text { the Detroit area } \\
\text { (1008 retired Blacks) } \\
\text { predominantly poor } \\
\text { average age: } 70 \\
\text { (age range: } 54 \text { to } 83 \text { ) } \\
\text { (728 female) } \\
\text { sample purposely } \\
\text { selected from Black } \\
\text { older adult center } \\
\text { participants } \\
\text { (58 refusal rate) } \\
\text { ( } n=102)\end{array}$ & $\begin{array}{l}\text { index measuring } \\
\text { number of } \\
\text { organizations, } \\
\text { length of tenure, } \\
\text { and amount of } \\
\text { participation in } \\
\text { organizational } \\
\text { activities } \\
\text { index measuring } \\
\text { involvement in } \\
\text { electoral politics }\end{array}$ & LSIA & univariate & $r=.19 *$ \\
\hline $\begin{array}{l}\text { Fox } \\
\text { (1977) }\end{array}$ & $\begin{array}{l}48 \text { and older } \\
\text { middle class, } \\
\text { financially well off } \\
\text { white women of the } \\
\text { Durham, North } \\
\text { Carolina area } \\
\text { participants in the } \\
\text { second Duke } \\
\text { Longitudinal study } \\
\text { of Aging } \\
\text { average age: } 61 \\
\text { (n= } 212 \text { subdivided } \\
\text { into retirees ( } n=56) \text {, } \\
\text { workers (n=87),and } \\
\text { housewives }(n=69) \text { ) }\end{array}$ & $\begin{array}{l}\text { one item measuring } \\
\text { the average number } \\
\text { of times in a month } \\
\text { one attends non- } \\
\text { religious } \\
\text { association } \\
\text { meetings } 0 \text { to 9) } \\
\text { (range: } 0 \text { to }\end{array}$ & $\begin{array}{l}\text { 9-item index } \\
\text { Affect Balance } \\
\text { scale }\end{array}$ & univariate & $\begin{array}{l}r=.27^{\star \star} \\
\text { (retirees) } \\
r=.25 \star \\
\text { (workers) } \\
r=.02 \\
\text { (housewives) }\end{array}$ \\
\hline $\begin{array}{l}\text { Sauer } \\
\text { (1977) }\end{array}$ & $\begin{array}{l}65 \text { and older } \\
\text { noninstitutionalized } \\
\text { elderly from the low } \\
\text { socioeconomic areas } \\
\text { of philadelphia } \\
\text { ( } 568 \text { female) } \\
\text { ( } 778 \text { Black elderly) } \\
\text { stratified random } \\
\text { sample } \\
\text { ( } n=1022 \text { but } \\
n=932 \text { for analysis } \\
\text { due to missing data) }\end{array}$ & $\begin{array}{l}\text { one item measuring } \\
\text { nimber of } \\
\text { memberships } \\
\text { in voluntary } \\
\text { associations }\end{array}$ & $\begin{array}{l}\text { 17-item index } \\
\text { modified version } \\
\text { of the philadelphia } \\
\text { Geriatric Center } \\
\text { morale scale } \\
\text { (range: } 0 \text { to 17) } \\
\text { (alpha }=.82 \text { ) }\end{array}$ & univariate & $\begin{array}{l}r=.13^{\star} \\
\text { (entire } \\
\text { sample) } \\
r=.14^{\star} \\
\text { (Black } \\
\text { subsample) } \\
r=.05 \\
\text { (White } \\
\text { subsample) }\end{array}$ \\
\hline
\end{tabular}




\begin{tabular}{|c|c|c|c|c|c|}
\hline $\begin{array}{l}\text { Toseland } \\
\text { and Sykes } \\
(1977)\end{array}$ & $\begin{array}{l}55 \text { and older } \\
\text { noninstitutionalized } \\
\text { living in suburban } \\
\text { and rural areas near } \\
\text { Madison, Wisconsin } \\
\text { ( } 318 \text { female) } \\
\text { systematic random } \\
\text { selection from a list } \\
\text { of participants and } \\
\text { non-participants } \\
\text { at a senior center } \\
\text { (348 response rate) } \\
\text { ( } n=137)\end{array}$ & $\begin{array}{l}\text { one item measuring } \\
\text { activity level } \\
\text { (range: 0 to 26) }\end{array}$ & $\begin{array}{l}\text { I3-item index } \\
\text { LSIZ }\end{array}$ & univariate & $r=-.46^{7}$ \\
\hline $\begin{array}{l}\text { Sauer, } \\
\text { Shehan, } \\
\text { and Boyme1 } \\
(1976)\end{array}$ & $\begin{array}{l}60 \text { and older } \\
\text { noninstitutionalized } \\
\text { subsample of } \\
1973 \text { NoRC data, } \\
\text { national probability } \\
\text { sample of persons } \\
18 \text { and older ( } n=1504) \\
\text { ( } n=324 \text { for analysis) }\end{array}$ & $\begin{array}{l}\text { one item measuring } \\
\text { frequency of } \\
\text { attendance at } \\
\text { religious services } \\
\text { one item measuring } \\
\text { political } \\
\text { participation e.g., } \\
\text { whether the } \\
\text { respondent voted in } \\
\text { 1972 national } \\
\text { election } \\
\text { (range: } 0 \text { to } 1 \text { ) }\end{array}$ & $\begin{array}{l}\text { 6-item index } \\
\text { measuring } \\
\text { satisfaction } \\
\text { with income, } \\
\text { commutty, } \\
\text { hobbies, family, } \\
\text { friends, and } \\
\text { global happiness } \\
\text { (alpha = .68) }\end{array}$ & univariate & $\begin{array}{l}\mathrm{r}=.13^{*} \\
\mathrm{r}=.21 *\end{array}$ \\
\hline $\begin{array}{l}\text { Wolk and } \\
\text { Telleen } \\
\text { (1976) }\end{array}$ & $\begin{array}{l}\text { Setting A: } \\
\text { elderly per sons } \\
\text { living in a } \\
\text { retirement home } \\
\text { ( } 698 \text { female) } \\
\text { median age: } 77 \\
\text { convenience sample } \\
\text { ( } n=51 \text { ) } \\
\text { Setting B: } \\
\text { elderly persons } \\
\text { living in a } \\
\text { retirement village } \\
\text { ( } 608 \text { female) } \\
\text { median age: } 74 \\
\text { convenience sample } \\
\text { (n=78) }\end{array}$ & $\begin{array}{l}\text { 40-item index } \\
\text { measuring } \\
\text { frequency of } \\
\text { participation in } \\
\text { both formal and } \\
\text { informal activities } \\
\text { (range: } 0 \text { to } 80 \text { ) }\end{array}$ & $\begin{array}{l}\text { 18-item index } \\
\text { LSIA } \\
\text { (range: } 0 \text { to } 18 \text { ) }\end{array}$ & univariate & $\begin{array}{l}r=.33^{\star} \\
\text { (setting A) } \\
r=.16 \\
\text { (setting B) }\end{array}$ \\
\hline
\end{tabular}




\begin{tabular}{|c|c|c|c|c|c|}
\hline $\begin{array}{l}\text { Fine } \\
\text { (1975) }\end{array}$ & $\begin{array}{l}65 \text { and older } \\
\text { noninstitutionalized } \\
\text { living in the Bronx } \\
\text { users and potential } \\
\text { users of Dial-A-Ride } \\
\text { program } \\
\text { average age: } 73 \\
\text { (age range: } 65 \text { to } 89 \text { ) } \\
\text { (758 female) } \\
\text { stratified random } \\
\text { sample } \\
(n=169)\end{array}$ & $\begin{array}{l}\text { Gat of items combined } \\
\text { into an index to } \\
\text { measure number of } \\
\text { trips last week to } \\
\text { visit children, } \\
\text { relatives, and } \\
\text { friends and number of } \\
\text { trips to } 17 \text { kinds of } \\
\text { places (e. g.,' } \\
\text { doctor, bank, etc.) }\end{array}$ & $\begin{array}{l}7 \text {-item index } \\
\text { measur ing 1ife } \\
\text { satisf action } \\
\text { index based on a } \\
\text { factor analysis of } \\
\text { LSI, locus of } \\
\text { control, and } \\
\text { autonomy scale } \\
\text { items }\end{array}$ & univariate & $r=.07$ \\
\hline $\begin{array}{l}\text { Lawton, } \\
\text { Nahemow, } \\
\text { and TeafE } \\
(1975)\end{array}$ & $\begin{array}{l}\text { elderly living in } \\
\text { HuD public housing } \\
\text { projects } \\
\text { in-depth personal } \\
\text { interview conducted } \\
\text { with approximately } \\
20 \text { tenants at each } \\
\text { of the } 154 \text { selected } \\
\text { sites } \\
\text { national probability } \\
\text { sample } \\
\text { ( } 898 \text { response rate) } \\
\text { ( } n=2457 \text { due to } \\
\text { missing data) }\end{array}$ & $\begin{array}{l}\text { number of on-site } \\
\text { activities 1nvolved } \\
\text { in during the year }\end{array}$ & $\begin{array}{l}\text { 2-item index } \\
\text { measuring morale }\end{array}$ & univarlate & $r=.16$ \\
\hline $\begin{array}{l}\text { Sherman } \\
\text { (1974) }\end{array}$ & $\begin{array}{l}\text { elderly persons } \\
\text { Iiving in six } \\
\text { different retirement } \\
\text { housing sites in the } \\
\text { Los Angeles area } \\
\text { matched with controls } \\
\text { living in } \\
\text { conventional } \\
\text { dispersed housing } \\
\text { (638 female) } \\
\text { average age: } 73 \\
\text { convenience sample } \\
\text { ( } 328 \text { attrition rate) } \\
\text { (n=600 but n=389 for } \\
\text { analysis due to } \\
\text { missing data) }\end{array}$ & $\begin{array}{l}\text { 12-item index } \\
\text { measuring frequency } \\
\text { of participation in } \\
\text { a given list of } \\
\text { activities } \\
\text { (range: 0 to 16) } \\
\text { Neugarten's scale) }\end{array}$ & $\begin{array}{l}\text { 6-item index } \\
\text { measuring life } \\
\text { satisfaction } \\
\text { (items selected from } \\
\text { from Cavan's scale, } \\
\text { Kutner's scale, and }\end{array}$ & univariate & $I=.25$ \\
\hline
\end{tabular}




\begin{tabular}{|c|c|c|c|c|c|}
\hline $\begin{array}{l}\text { Spreitzer } \\
\text { and Snyder } \\
(1974)\end{array}$ & $\begin{array}{l}65 \text { and older } \\
\text { noninstitutionalized } \\
\text { ( } 528 \text { female) } \\
\text { subsample of married } \\
\text { and widowed persons } \\
\text { only (n=952) } \\
\text { NORC data } \\
\text { stratified random } \\
\text { sample, } 1972 \text { and } \\
1973 \text { surveys pooled } \\
\text { ( }=224 \text { due to } \\
\text { missing data) }\end{array}$ & $\begin{array}{l}\text { one } 1 \text { tem measuring } \\
\text { frequency of church } \\
\text { attendance } \\
\text { (range: } 1 \text { to } 9 \text { ) }\end{array}$ & $\begin{array}{l}\text { one item measuring } \\
\text { happiness } \\
\text { (range: } 1 \text { to } 3 \text { ) }\end{array}$ & univariate & $r=-.01$ \\
\hline \multirow[t]{3}{*}{$\begin{array}{l}\text { Edwards and } \\
\text { Klemmack } \\
\text { (1973) }\end{array}$} & \multirow{3}{*}{$\begin{array}{l}45 \text { and older } \\
\text { residents of four } \\
\text { counties in virginia } \\
\text { ( } 548 \text { female) } \\
\text { quota sample for } \\
\text { proportionate } \\
\text { representation of } \\
\text { those below and above } \\
65 \text { years } \\
(n=507)\end{array}$} & $\begin{array}{l}\text { one item measuring } \\
\text { whether or not } \\
\text { respondent has } \\
\text { voted in the last } \\
\text { national elections }\end{array}$ & \multirow[t]{3}{*}{$\begin{array}{l}\text { 10-item index } \\
\text { modified LSIA } \\
\text { (alpha }=.90)\end{array}$} & \multirow[t]{3}{*}{ univariate } & $r=.05$ \\
\hline & & $\begin{array}{l}\text { index measuring } \\
\text { extent and intensity } \\
\text { of participation } \\
\text { in formal voluntary } \\
\text { associations } \\
\text { (Chapin's scale) }\end{array}$ & & & $\mathrm{r}=.24^{\star}$ \\
\hline & & $\begin{array}{l}\text { degree of involvement } \\
\text { in church related } \\
\text { organizations }\end{array}$ & & & $r=.19 *$ \\
\hline $\begin{array}{l}\text { Martin } \\
(1973)\end{array}$ & $\begin{array}{l}52 \text { and older } \\
\text { in-movers into an } \\
\text { age-segregated } \\
\text { retirement commity } \\
\text { in Southern } \\
\text { California } \\
\text { respondents well to } \\
\text { do } \\
\text { median age: } 67 \\
\text { ( } 558 \text { female) } \\
\text { random sample } \\
\text { ( } 658 \text { response rate) } \\
\text { ( } n=411)\end{array}$ & $\begin{array}{l}\text { index measuring } \\
\text { degree of involvement } \\
\text { with family, friends, } \\
\text { neighbors, and with } \\
\text { religious and non- } \\
\text { religious } \\
\text { organizations } \\
\text { (range: } 0 \text { to } 78 \text { ) }\end{array}$ & $\begin{array}{l}\text { 13-item index } \\
\text { LSIB } \\
\text { (range: } 13 \text { to } 58 \text { ) }\end{array}$ & univariate & $r=.16$ \\
\hline
\end{tabular}




\begin{tabular}{|c|c|c|c|c|c|}
\hline $\begin{array}{l}\text { Palmore and } \\
\text { Luikart } \\
\text { (1972) }\end{array}$ & $\begin{array}{l}46 \text { and older } \\
\text { noninstitutionalized } \\
\text { residents of Durham, } \\
\text { North Carolina } \\
\text { average age: } 59 \\
\text { (age range: } 46 \text { to } 71 \text { ) } \\
\text { respondents } \\
\text { tend to be well off } \\
\text { ( } 488 \text { female) } \\
\text { randam sample from a } \\
\text { membership list of a } \\
\text { major health } \\
\text { insurance company } \\
\text { (refusal rate: 528) } \\
\text { longitudinal data } \\
\text { wave 1 data only } \\
\text { (n=502) }\end{array}$ & $\begin{array}{l}\text { one item measuring } \\
\text { number of religious } \\
\text { and non-rel igious } \\
\text { meetings respondent } \\
\text { attends on a } \\
\text { monthly basis } \\
\text { (range: } 0 \text { to 18) } \\
\text { one item measuring } \\
\text { total number of } \\
\text { hours on a weekly } \\
\text { basis spent in } \\
\text { social activities } \\
\text { (range: } 0 \text { to } 34 \text { ) }\end{array}$ & $\begin{array}{l}\text { one item measuring } \\
\text { happiness } \\
\text { Cantril ladder } \\
\text { (range: } 0 \text { to } 9 \text { ) }\end{array}$ & univariate & $\begin{array}{l}r=.18 \\
\text { ientire sample) } \\
r=.18 \\
\text { (males) } \\
r=.19 \\
\text { (females) } \\
r=.09 \\
\text { (entire } \\
\text { sample) } \\
r \text { not } \\
\text { reported } \\
\text { (males) } \\
r \text { not } \\
\text { reported } \\
\text { (females) }\end{array}$ \\
\hline $\begin{array}{l}\text { Wylie } \\
\text { (1970) }\end{array}$ & $\begin{array}{l}65 \text { and older } \\
\text { noninstitutionalized } \\
\text { residents of a rural } \\
\text { town in Ransas } \\
\text { potential participants } \\
\text { in a demonstration } \\
\text { program } \\
\text { ( } 468 \text { response rate) } \\
\text { ( } n=281 \text { at wave } 1 \text { ' } \\
n=131 \text { continuers at } \\
\text { wave } 2,2.5 \text { years } \\
\text { later) }\end{array}$ & $\begin{array}{l}\text { index measuring } \\
\text { social participation } \\
\text { (range: } 0 \text { to } 6 \text { ) }\end{array}$ & $\begin{array}{l}\text { 13-item index } \\
\text { LSIz } \\
\text { (range: } 0 \text { to } 26 \text { ) }\end{array}$ & $\begin{array}{l}\text { univariate } \\
\text { (wave 2) }\end{array}$ & $\begin{array}{l}r=.27^{\star \star} \\
(\text { wave } 1) \\
r=.38^{\star \star}\end{array}$ \\
\hline $\begin{array}{l}\text { Bultena } \\
\text { (1969) }\end{array}$ & $\begin{array}{l}63 \text { and older } \\
\text { residents of } 3 \\
\text { communities in } \\
\text { Wisconsin } \\
\text { (1008 retired males) } \\
\text { median age: } 74 \\
\text { (age range: } 63 \text { to 99) } \\
\text { sample drawn by an } \\
\text { area probability } \\
\text { technique and by } \\
\text { random selection } \\
\text { (n=284) }\end{array}$ & $\begin{array}{l}\text { one item measuring } \\
\text { perceived change in } \\
\text { organizational } \\
\text { participation } \\
\text { (range: } 1 \text { to 4) }\end{array}$ & $\begin{array}{l}\text { 13-item index } \\
\text { modified LSI } \\
\text { (range: } 0 \text { to } 26, \\
\text { recoded into } 3 \\
\text { groups) }\end{array}$ & univariate & $r=.50$ \\
\hline
\end{tabular}




\begin{tabular}{|c|c|c|c|c|}
\hline $\begin{array}{l}\text { Carp } \\
(1968)\end{array}$ & $\begin{array}{l}\text { elderly persons } \\
\text { noninstitutionalized } \\
\text { residents of San } \\
\text { Antonio, Texas } \\
\text { in-movers into } \\
\text { Victoria plaza } \\
\text { median age: } 72 \\
\text { (B08 female) } \\
\text { convenience sample } \\
\text { ( } n=204) \\
\text { (range dichotomized) }\end{array}$ & $\begin{array}{l}\text { index measuring } \\
\text { number of activities } \\
\text { engaged in and } \\
\text { whether each } \\
\text { activity is a } \\
\text { solitary one or not } \\
\text { one item measuring } \\
\text { involvement in } \\
\text { volunteer work }\end{array}$ & $\begin{array}{l}\text { index measuring } \\
\text { happiness } \\
\text { (scale of Burgess } \\
\text { et al.) }\end{array}$ & $r=.17^{\star}$ \\
\hline $\begin{array}{l}\text { Palmore } \\
(1968)\end{array}$ & $\begin{array}{l}70 \text { and older } \\
\text { noninstitutionalized } \\
\text { residents of Durham, } \\
\text { Nor th Carolina } \\
\text { mean age: } 78 \\
\text { (age range: } 70 \text { to } 93 \text { ) } \\
\text { (608 female) } \\
\text { original panel } \\
\text { selected from a list } \\
\text { of menbers of a } \\
\text { health insurance } \\
\text { company ( }=256 \text { ) } \\
(508 \text { attrition rate) } \\
\text { (n=127, wave } 4 \text { ) }\end{array}$ & $\begin{array}{l}\text { 4-item index } \\
\text { measuring change } \\
\text { from time } 1 \text { to time } 4 \\
\text { time } 4 \text { in social, } \\
\text { cultural, and } \\
\text { leisure } \\
\text { activities }\end{array}$ & $\begin{array}{l}56 \text {-item index univariate } \\
\text { measuring change } \\
\text { fram time } 1 \text { to time } 4 \\
\text { in satisfaction with } \\
8 \text { areas of life, e.g., } \\
\text { health, friends, } \\
\text { work, economic } \\
\text { security, relligion, } \\
\text { usefulness, family, } \\
\text { and general } \\
\text { happiness }\end{array}$ & $\begin{array}{l}r=.22 \\
\text { (males) } \\
r=.10 \\
\text { (females) }\end{array}$ \\
\hline $\begin{array}{l}\text { Maddox } \\
(1963)\end{array}$ & $\begin{array}{l}60 \text { and older } \\
\text { noninstitutionalized } \\
\text { residents of Durham, } \\
\text { North Corolina } \\
\text { median age: } 70 \\
\text { (age range: } 60 \text { to 94) } \\
\text { volunteers selected } \\
\text { to participated in } \\
\text { the Duke Longitudinal } \\
\text { Study of Aging } \\
\text { (278 attrition rate) } \\
\text { wave } 1: n=250 ; \\
\text { wave } 2: n=182 \\
\text { analyses done on } \\
\text { continuers only } \\
\text { ( } n=182 \text { ) }\end{array}$ & $\begin{array}{l}\text { set of items } \\
\text { measuring involvenent } \\
\text { in social activities } \\
\text { which result in } \\
\text { social interaction } \\
\text { (range dichotomized, } \\
\text { median split) } \\
\text { set of 1tems } \\
\text { measuring } \\
\text { involvement in } \\
\text { social activities } \\
\text { which do not } \\
\text { necessarily involve } \\
\text { social interaction } \\
\text { (range dichotomized, } \\
\text { median split) }\end{array}$ & $\begin{array}{l}56 \text {-item index } \\
\text { measuring } \\
\text { satisfaction with } \\
8 \text { areas of one's } \\
\text { life (scale of } \\
\text { Cavan et al.) } \\
\text { (range dichotomized) }\end{array}$ & $\begin{array}{l}r=.46 \\
\text { (wave } 1 \text { ) } \\
6 \\
r=.26 \\
\text { (wave 2) } \\
\\
\begin{array}{c}r=.34 \\
\text { (wave } 1 \text { ) }\end{array} \\
\begin{array}{c}6 \\
r=.31 \\
\text { (wave } 2 \text { ) }\end{array}\end{array}$ \\
\hline
\end{tabular}




\begin{tabular}{|c|c|c|c|c|c|}
\hline $\begin{array}{l}\text { Jeffers and } \\
\text { Nichols } \\
\text { (1961) }\end{array}$ & $\begin{array}{l}60 \text { and older } \\
\text { noninstitutionalized } \\
\text { volunteers, residents } \\
\text { of Piedmont, North } \\
\text { Carolina } \\
\text { high socio-economic } \\
\text { status } \\
\text { median age: } 70 \\
\text { (age range: } 60 \text { to 94) } \\
\text { (59\% women) } \\
\text { snowball technique } \\
\text { (n=245) }\end{array}$ & $\begin{array}{l}\text { 20-item Index } \\
\text { measuring social } \\
\text { activities } \\
\text { (scale of Cavan } \\
\text { et al.) }\end{array}$ & $\begin{array}{l}56-\text { item index } \\
\text { measuring } \\
\text { satisfaction with } \\
8 \text { areas of one's } \\
\text { life } \\
\text { (scale of Cavan } \\
\text { et al.) }\end{array}$ & univariate & $I=.54 \star \star \star$ \\
\hline $\begin{array}{l}\text { Mason } \\
(1954)\end{array}$ & $\begin{array}{l}\text { elderly persons } \\
\text { residents of the } \\
\text { st. Louis area } \\
\text { sample broken into } \\
2 \text { groups } \\
\text { Group } 1 \text { : } \\
55 \text { and older } \\
\text { institutionalized } \\
10 \text { income } \\
\text { (n= 60) } \\
\text { Group } 2 \text { : } \\
60 \text { and older } \\
\text { noninstitutionalized } \\
\text { middle class } \\
\text { sample drawn from } \\
\text { individuals receiving } \\
\text { a routine checkup } \\
\text { from a physician } \\
\text { specializing in } \\
\text { geriatric medicine } \\
\text { (n=30) }\end{array}$ & $\begin{array}{l}\text { one item measuring } \\
\text { number of activities }\end{array}$ & $\begin{array}{l}\text { one item measuring } \\
\text { happiness } \\
\text { (range: } 1 \text { to } 6 \text { ) }\end{array}$ & univariate & $\begin{array}{l}r=.02 \\
\text { (group 1) } \\
r=.28 \\
\text { (group 2) }\end{array}$ \\
\hline
\end{tabular}


STUDIES OF THE REIATIONSHIP BETWEEN FINANCIAL STATUS AND SUBJECTIVE WEIL-BEING

\begin{tabular}{|c|c|c|c|c|c|}
\hline $\begin{array}{l}\text { NUTHOR (S) } \\
\text { AND DATE }\end{array}$ & SNMPLE & $\begin{array}{l}\text { MEASURE OF FINANCTAL } \\
\text { RESOURCES }\end{array}$ & $\begin{array}{l}\text { MEASURE OF } \\
\text { WELL-BEING }\end{array}$ & $\begin{array}{l}\text { TYPE OF } \\
\text { ANALYSIS }\end{array}$ & RESULTS \\
\hline $\begin{array}{l}\text { Fengler and } \\
\text { Danigelis } \\
\text { (1982) }\end{array}$ & $\begin{array}{l}65 \text { and older } \\
\text { residents of } 4 \\
\text { counties in } \\
\text { northwestern vermont } \\
\text { median age: } 72 \\
(618 \text { female) } \\
\text { subsample of } \\
\text { female widows } \\
\text { systematic selection } \\
\text { (n=326) }\end{array}$ & Incone & $\begin{array}{l}\text { 3-item index } \\
\text { measuring } \\
\text { life satisfaction }\end{array}$ & univariate & $r=.10^{*}$ \\
\hline $\begin{array}{l}\text { Harel, } \\
\text { Sollod, } \\
\text { and Bognar } \\
(1982)\end{array}$ & $\begin{array}{l}60 \text { and older } \\
\text { noninstitutionalized } \\
\text { elderly from the } \\
\text { Cleveland } \\
\text { metropolitan area } \\
\text { average age: } 81 \\
\text { (age range: } 54 \text { to } 97 \text { ) } \\
\text { (668 female) } \\
\text { nonprobability sample } \\
\text { ( } \mathrm{n}=125 \text { ) }\end{array}$ & $\begin{array}{l}\text { one item measuring } \\
\text { financtal status }\end{array}$ & $\begin{array}{l}\text { one item measuring } \\
\text { mental and } \\
\text { emotional health } \\
\text { (range: } 0 \text { to } 3 \text { ) }\end{array}$ & univariate & $r=.23 * \star *$ \\
\hline $\begin{array}{l}\text { Leonard } \\
\text { (1982) }\end{array}$ & $\begin{array}{l}60 \text { and older } \\
\text { noninstitutionalized } \\
1973 \text { NORC data } \\
\text { national } \\
\text { probability sample } \\
(n=320)\end{array}$ & $\begin{array}{l}\text { income } \\
\text { (range: } 0 \text { to } 1 \text { ) }\end{array}$ & $\begin{array}{l}\text { 5-item index } \\
\text { measuring } \\
\text { contentment with } \\
\text { different sectors } \\
\text { of one's life } \\
\text { (range: } 0 \text { to } 1 \text { ) }\end{array}$ & univariate & $r=.27$ \\
\hline $\begin{array}{l}\text { Snow and } \\
\text { Crapo } \\
\text { (1982) }\end{array}$ & $\begin{array}{l}65 \text { and older } \\
\text { outpatients of } \\
\text { a veterans } \\
\text { Administration } \\
\text { medical clinic } \\
\text { (1008 male) } \\
\text { average age: } 71 \\
\text { (age range: } 65 \text { to } 98 \text { ) } \\
\text { convenience sample } \\
\text { ( } n=205 \text { ) }\end{array}$ & $\begin{array}{l}\text { income } \\
\text { (range: } 0 \text { to } 13 \text { ) }\end{array}$ & $\begin{array}{l}\text { 18-1tem index } \\
\text { LSIA } \\
\text { (range: } 0 \text { to } 36 \text { ) } \\
\text { Af fect Balance } \\
\text { Scale } \\
\text { (range: } 0 \text { to } 10 \text { ) }\end{array}$ & univariate & $\begin{array}{l}r=.05 \\
r=.06\end{array}$ \\
\hline
\end{tabular}




\begin{tabular}{|c|c|c|c|c|c|}
\hline $\begin{array}{l}\text { Markides, } \\
\text { Costley, } \\
\text { and Rodriguez } \\
\text { (1981) }\end{array}$ & $\begin{array}{l}60 \text { and older } \\
\text { noninstitutionalized } \\
\text { residents of San } \\
\text { Antonio, Texas } \\
\text { low-income, minority } \\
\text { respondents with at } \\
\text { least one child in } \\
\text { the area } \\
\text { ( } 618 \text { female) } \\
\text { convenience sample } \\
\text { (n=98) }\end{array}$ & $\begin{array}{l}\text { income } \\
\text { (range: } 1 \text { to } 6 \text { ) }\end{array}$ & $\begin{array}{l}\text { 21-iten index } \\
\text { Philadelphia } \\
\text { Geriatric Center } \\
\text { morale scale }\end{array}$ & univariate & $r=.26$ \\
\hline $\begin{array}{l}\text { Duff } \\
\text { and Hong } \\
(1980)\end{array}$ & $\begin{array}{l}60 \text { and older } \\
\text { noninstitutionalized } \\
1974 \text { NORC data } \\
\text { stratified random } \\
\text { sample of persons } \\
18 \text { and older } \\
\text { median age in sub- } \\
\text { sample: } 69 \\
\text { ( } n=335 \text { but n=275 } \\
\text { for analysis due to } \\
\text { missing data) }\end{array}$ & $\begin{array}{l}\text { one itern measuring } \\
\text { family income }\end{array}$ & $\begin{array}{l}\text { 2-1tem Index } \\
\text { measuring life } \\
\text { satisfaction } \\
\text { (range: } 1 \text { to } 6 \text { ) }\end{array}$ & univariate & $r=.29$ \\
\hline $\begin{array}{l}\text { Medley } \\
(1980)\end{array}$ & $\begin{array}{l}65 \text { and older } \\
\text { noninstitutionalized } \\
\text { ( } 648 \text { female) } \\
\text { national probability } \\
\text { sample } \\
\text { ( } \mathrm{n}=301 \text {, } \\
192 \text { females and } \\
109 \text { males) }\end{array}$ & $\begin{array}{l}\text { yearly income } \\
\text { (range: } 0 \text { to } 17 \text { ) }\end{array}$ & $\begin{array}{l}\text { 9-item index } \\
\text { measuring life } \\
\text { satisfaction } \\
\text { (range: } 21 \text { to } 147 \text { ) }\end{array}$ & univariate & $\begin{array}{l}r=.31^{\star} \\
\text { (males) } \\
r=.00 \\
\text { (females) }\end{array}$ \\
\hline $\begin{array}{l}\text { Markides } \\
\text { and Martin } \\
(1979)\end{array}$ & $\begin{array}{l}60 \text { and older } \\
\text { predominantly poor } \\
\text { ( } 648 \text { female) } \\
\text { white subsample only } \\
\text { data collected in } \\
\text { four low-income } \\
\text { census tracts of } \\
\text { San Antonio, } \\
\text { Texas } \\
\text { ( } n=141)\end{array}$ & $\begin{array}{l}\text { one item measuring } \\
\text { monthly income } \\
\text { (range: } 1 \text { to } 6 \text { ) }\end{array}$ & $\begin{array}{l}\text { 13-item index } \\
\text { LSIZ }\end{array}$ & univariate & $\begin{array}{l}r=.33 \\
\text { (males) } \\
r=.34 \\
\text { (females) }\end{array}$ \\
\hline
\end{tabular}




\begin{tabular}{|c|c|c|c|c|c|}
\hline $\begin{array}{l}\text { Ward } \\
\text { (1979) }\end{array}$ & $\begin{array}{l}50 \text { and older } \\
\text { noninstitutionalized } \\
\text { NORC surveys combined } \\
\text { for the } 1972 \text { through } \\
\text { the } 1977 \text { years } \\
\text { probability sample } \\
\text { ( } n=3557,58 \text { ( }=162) \\
\text { never married) }\end{array}$ & income & $\begin{array}{l}\text { one item measuring } \\
\text { happiness }\end{array}$ & univariate & $\begin{array}{l}r=.12^{\star} \\
\text { (married) } \\
r=.21^{\star} \\
\text { (never } \\
\text { married) }\end{array}$ \\
\hline $\begin{array}{l}\text { Jackson, } \\
\text { Bacon, } \\
\text { and Peterson } \\
(1978)\end{array}$ & $\begin{array}{l}54 \text { and older } \\
\text { noninstitutionalized } \\
\text { elderly living in } \\
\text { the Detroit area } \\
\text { (1008 retired Blacks) } \\
\text { predominantly poor } \\
\text { average age: } 70 \\
\text { (age range: } 54 \text { to } 83 \text { ) } \\
\text { ( } 728 \text { female) } \\
\text { sample purposely } \\
\text { selected from Black } \\
\text { older adult center } \\
\text { participants } \\
\text { (58 refusal rate) } \\
\text { (n=102) }\end{array}$ & income & LSIA & univariate & $r=.20 *$ \\
\hline $\begin{array}{l}\text { Mancini } \\
\text { (1978) }\end{array}$ & $\begin{array}{l}\text { older persons } \\
\text { living in two } \\
\text { high-rise, public } \\
\text { housing projects for } \\
\text { the elderly in } \\
\text { Greensboro, } \\
\text { North Carolina } \\
\text { average age: } 70 \\
\text { (758 female) } \\
258 \text { simple random } \\
\text { sample } \\
(718 \text { response rate) } \\
(n=74)\end{array}$ & income & $\begin{array}{l}\text { Cantril ladder } \\
\text { (range: } 0 \text { to 9) }\end{array}$ & univariate & $r=.18$ \\
\hline
\end{tabular}




\begin{tabular}{|c|c|c|c|c|c|}
\hline $\begin{array}{l}\text { Fox } \\
(1977)\end{array}$ & $\begin{array}{l}48 \text { and older } \\
\text { middlle class, } \\
\text { financially well off } \\
\text { white wanen of the } \\
\text { Durham, North } \\
\text { Carolina area } \\
\text { participants in the } \\
\text { second Duke } \\
\text { Longitudinal study } \\
\text { of Aging } \\
\text { average age: } 61 \\
\text { (n=212 subdivided } \\
\text { into retirees (n=56), } \\
\text { workers (n=87), and } \\
\text { housewives }(n=69))\end{array}$ & income & $\begin{array}{l}\text { 9-item index } \\
\text { Affect Balance } \\
\text { Scale }\end{array}$ & univariate & $\begin{array}{l}r=.13 \\
\text { (retirees) } \\
r=.15 \\
\text { (workers) } \\
r=.24 * * \\
\text { (housewives) }\end{array}$ \\
\hline $\begin{array}{l}\text { Sauer } \\
(1977)\end{array}$ & $\begin{array}{l}65 \text { and older } \\
\text { noninstitutionalized } \\
\text { elderly from the low } \\
\text { socioeconomic areas } \\
\text { of philadelphia } \\
\text { ( } 568 \text { female) } \\
\text { ( } 778 \text { Black elderly) } \\
\text { stratified random } \\
\text { sample } \\
\text { ( } n=1022 \text { but n=932 } \\
\text { for analysis due to } \\
\text { missing data) }\end{array}$ & Income & $\begin{array}{l}\text { 17-item index } \\
\text { modified version of } \\
\text { the Philadelphia } \\
\text { Geriatric Center } \\
\text { morale scale } \\
\text { (range: } 0 \text { to } 17 \text { ) } \\
\text { (alpha }=.82 \text { ) }\end{array}$ & univariate & $\begin{array}{l}r=.12^{\star} \\
\text { (entire } \\
\text { sample) } \\
r=.14 \\
\text { (Black } \\
\text { subsample) } \\
r=.07 \\
\text { (White } \\
\text { subsample) } \\
6.7\end{array}$ \\
\hline $\begin{array}{l}\text { Toseland } \\
\text { and Sykes } \\
\text { (1977) }\end{array}$ & $\begin{array}{l}55 \text { and older } \\
\text { noninstitutionalized } \\
\text { living in suburban } \\
\text { and rural areas near } \\
\text { Madison, Wisconsin } \\
\text { ( } 318 \text { female) } \\
\text { systematic random } \\
\text { selection from a list } \\
\text { of participants and } \\
\text { non-participants } \\
\text { at a senior center } \\
\text { ( } 348 \text { response rate) } \\
\text { ( } n=137)\end{array}$ & $\begin{array}{l}\text { one item measuring } \\
\text { financial status }\end{array}$ & $\begin{array}{l}\text { 13-item index } \\
\text { LSIz } \\
\text { (range: } 0 \text { to 26) }\end{array}$ & univariate & $r=-.24$ \\
\hline
\end{tabular}




\begin{tabular}{|c|c|c|c|c|c|}
\hline $\begin{array}{l}\text { Bild and } \\
\text { Havighurst } \\
\text { (1976) }\end{array}$ & $\begin{array}{l}60 \text { and older } \\
\text { noninstitutionalized } \\
\text { residents of Chicago } \\
\text { ( } 538 \text { women) } \\
\text { sample drawn to be } \\
\text { representative of } \\
7 \text { groups of elderly } \\
\text { in the city } \\
(n=570)\end{array}$ & income & $\begin{array}{l}\text { 18-item index } \\
\text { LSI }\end{array}$ & univariate & $\mathrm{r}=.22$ \\
\hline $\begin{array}{l}\text { Medley } \\
(1976)\end{array}$ & $\begin{array}{l}65 \text { and older } \\
\text { noninstitutionalized } \\
\text { national probability } \\
\text { sample of persons } \\
18 \text { and older ( } n=2164) \\
178 \text { elderly } \\
\text { median age of persons } \\
\text { in subsample: } 71 \\
\text { ( } 648 \text { female) } \\
\text { ( } n=362 \text {, but } \\
n=301 \text { for analysis } \\
\text { due to missing data) }\end{array}$ & $\begin{array}{l}\text { income } \\
\text { (range: } 0 \text { to } 17 \text { ) }\end{array}$ & $\begin{array}{l}\text { 9-item index } \\
\text { measuring global } \\
\text { life satisfaction } \\
\text { (range: } 21 \text { to } 147 \text { ) }\end{array}$ & univariate & $\begin{array}{l}r=.31 \\
\text { (males) } \\
r=-.00 \\
\text { (females) }\end{array}$ \\
\hline $\begin{array}{l}\text { Sauer, } \\
\text { Shehan, } \\
\text { and Boymel } \\
(1976)\end{array}$ & $\begin{array}{l}60 \text { and older } \\
\text { noninstitutionalized } \\
\text { subsample of } \\
1973 \text { NORC data } \\
\text { national probability } \\
\text { sample of persons } \\
18 \text { and older ( } n=1504) \\
\text { ( } n=324 \text { for analysis) }\end{array}$ & income & $\begin{array}{l}\text { 6-item index } \\
\text { measuring } \\
\text { satisfaction } \\
\text { with income, } \\
\text { community, hobbies, } \\
\text { family, friends, and } \\
\text { global happiness } \\
\text { (alpha= .68) }\end{array}$ & univariate & $r=.33^{\star}$ \\
\hline $\begin{array}{l}\text { Fine } \\
(1975)\end{array}$ & $\begin{array}{l}65 \text { and older } \\
\text { noninstitutionalized } \\
\text { living in the Bronx } \\
\text { users and potential } \\
\text { users of Dial-A-Ride } \\
\text { program } \\
\text { average age: } 73 \\
\text { (age range: } 65 \text { to } 89 \text { ) } \\
\text { (758 female) } \\
\text { stratified random } \\
\text { sample } \\
\text { (n=169) }\end{array}$ & income & $\begin{array}{l}\text { 7-item index } \\
\text { measuring life } \\
\text { satisfaction } \\
\text { index based on a } \\
\text { factor analysis of } \\
\text { LSI, locus of } \\
\text { control, and } \\
\text { autonomy scale items }\end{array}$ & univariate & $r=.35 * \star \star$ \\
\hline
\end{tabular}




\begin{tabular}{|c|c|c|c|c|c|}
\hline $\begin{array}{l}\text { Hutchinson } \\
\text { (1975) }\end{array}$ & $\begin{array}{l}60 \text { and older } \\
\text { low income elderly } \\
\text { residents of } 3 \\
\text { predominantly urban } \\
\text { counties in Florida } \\
\text { stratified random } \\
\text { sample (n=1657) } \\
\text { for this analysis, } \\
\text { whites only, married } \\
\text { at least once, } \\
\text { ( } 658 \text { female) } \\
\text { ( } n=893 \text { ) }\end{array}$ & $\begin{array}{l}\text { income } \\
\text { (range dichotomized) }\end{array}$ & $\begin{array}{l}\text { one item measuring } \\
\text { happiness } \\
\text { (range: } 1 \text { to } 3 \text { ) }\end{array}$ & univariate & $r=.09$ \\
\hline $\begin{array}{l}\text { Spreitzer } \\
\text { and Snyder } \\
\text { (1974) }\end{array}$ & $\begin{array}{l}65 \text { and older } \\
\text { noninstitutionalized } \\
\text { ( } 528 \text { female) } \\
\text { subsample of married } \\
\text { and widowed persons } \\
\text { only } \\
\text { NORC data } \\
\text { stratified random } \\
\text { sample, } 1972 \text { and } 1973 \\
\text { surveys pooled } \\
\text { ( } n=224 \text { due to missing } \\
\text { data) }\end{array}$ & $\begin{array}{l}\text { income } \\
\text { (range: } 1 \text { to } 12 \text { ) }\end{array}$ & $\begin{array}{l}\text { one item measuring } \\
\text { happiness } \\
\text { (range: } 1 \text { to } 3 \text { ) }\end{array}$ & univarlate & $r=.16$ \\
\hline $\begin{array}{l}\text { Edwards and } \\
\text { Klemmack } \\
\text { (1973) }\end{array}$ & $\begin{array}{l}45 \text { and older } \\
\text { residents of four } \\
\text { counties in virginia } \\
\text { ( } 548 \text { female) } \\
\text { quota sample for } \\
\text { proportionate } \\
\text { representation of } \\
\text { those below and above } \\
65 \text { years } \\
\text { ( }=507)\end{array}$ & income & $\begin{array}{l}\text { 10-item index } \\
\text { modified LSIA } \\
\text { (alpha }=.90 \text { ) }\end{array}$ & univariate & $r=.33^{*}$ \\
\hline
\end{tabular}




\begin{tabular}{|c|c|c|c|c|c|}
\hline $\begin{array}{l}\text { Thormpson } \\
\text { (1973) }\end{array}$ & $\begin{array}{l}65 \text { and older } \\
\text { noninstitutionalized } \\
\text { multi-stage } \\
\text { probability sample } \\
\text { in } U \text {. S. } \\
\text { ( } n=3996 \text { ) } \\
\text { subsample of males } \\
\text { only } \\
\text { (age range: } 65 \text { to } 98 \text { ) } \\
\text { average age: } 73 \\
\text { median age: } 71 \\
\text { ( } n=1589 \text { ) }\end{array}$ & $\begin{array}{l}\text { one item measuring } \\
\text { income } \\
\text { (range recoded into } \\
3 \text { groups) }\end{array}$ & $\begin{array}{l}\text { 8-item index } \\
\text { measuring morale } \\
\text { (range recoded into } \\
3 \text { groups) }\end{array}$ & univariate & $\mathrm{r}=.2 \mathrm{I}$ \\
\hline $\begin{array}{l}\text { Palmore and } \\
\text { Luikart } \\
\text { (1972) }\end{array}$ & $\begin{array}{l}46 \text { and older } \\
\text { noninstitutionalized } \\
\text { residents of Durham, } \\
\text { North Carolina } \\
\text { average age: } 59 \\
\text { age range: } 46 \text { to } 71 \\
\text { respondents } \\
\text { tend to be well off } \\
\text { ( } 488 \text { female) } \\
\text { random sample from a } \\
\text { menbership I ist of a } \\
\text { major health } \\
\text { insurance company } \\
\text { (528 refusal rate) } \\
\text { longitudinal data } \\
\text { wave 1 data only } \\
\text { (n=502) }\end{array}$ & $\begin{array}{l}\text { income } \\
\text { (range: } 0 \text { to } 15)\end{array}$ & $\begin{array}{l}\text { one item measuring } \\
\text { happiness } \\
\text { Cantril ladder } \\
\text { (range: } 0 \text { to } 9 \text { ) }\end{array}$ & univariate & $\begin{array}{l}r=.10 \\
\text { (entire } \\
\text { sample) }\end{array}$ \\
\hline
\end{tabular}


STUDIES OF THE RELATIONSHIP BETWEEN SATISFACTION WITH FINANCIAL STATUS AND SUBJECTTVE WEIL-BEING

\begin{tabular}{|c|c|c|c|c|c|}
\hline $\begin{array}{l}\text { AUTHOR (S) } \\
\text { AND DATE }\end{array}$ & SAMPLE & $\begin{array}{l}\text { MFNSURE OF FINANCIAL } \\
\text { RFSOURCES }\end{array}$ & $\begin{array}{l}\text { MEASURE OF } \\
\text { WEIL-BEING }\end{array}$ & $\begin{array}{l}\text { TYPE OF } \\
\text { ANALYSIS }\end{array}$ & RESULTS \\
\hline $\begin{array}{l}\text { Baur } \\
\text { and Okun } \\
(1983)\end{array}$ & $\begin{array}{l}66 \text { and older } \\
\text { apartment dwellers } \\
\text { of a retirement } \\
\text { commity in Phoenix, } \\
\text { Arizona who could be } \\
\text { reinterviewed } 3 \\
\text { years after the } \\
\text { first wave of data } \\
\text { collection } \\
\text { (age range: } 66 \text { to } 94) \\
\text { (808 female) } \\
\text { stratified random } \\
\text { sample } \\
\text { (178 attrition rate) } \\
\text { (n=87) }\end{array}$ & $\begin{array}{l}\text { one item measuring } \\
\text { perceived adequacy } \\
\text { of income } \\
\text { (range: } 0 \text { to } 1 \text { ) }\end{array}$ & $\begin{array}{l}\text { LSIB } \\
\text { (alpha }=.69, \text { wave } 1) \\
\text { LSIB } \\
\text { (alpha }=.73, \text { wave } 2)\end{array}$ & univariate & $\begin{array}{l}r=.07 \\
r=.11\end{array}$ \\
\hline $\begin{array}{l}\text { Kozma and } \\
\text { Stones } \\
(1983)\end{array}$ & $\begin{array}{l}65 \text { and older } \\
\text { urban, rural, and } \\
\text { institutionalized } \\
\text { residents of } \\
\text { Newfoundland } \\
\text { random selection } \\
\text { ( } n=600) \\
\text { rural }(n=200) \text { group } 1 \\
\text { urban ( } n=200) \text { group } 2 \\
\text { institutionalized } \\
(n=200) \text { group } 3\end{array}$ & $\begin{array}{l}\text { one item measuring } \\
\text { financial } \\
\text { satisfaction }\end{array}$ & $\begin{array}{l}\text { 24-iten index } \\
\text { measuring happiness }\end{array}$ & univariate & $\begin{array}{l}r=.18^{\star \star} \\
\text { (entire sample) } \\
r=.14^{\star} \\
\text { (group 1) } \\
\text { not reported } \\
\text { (group 2) } \\
\text { not reported } \\
\text { (group 3) }\end{array}$ \\
\hline $\begin{array}{l}\text { Fengler and } \\
\text { Danigelis } \\
\text { (1982) }\end{array}$ & $\begin{array}{l}65 \text { and older } \\
\text { residents of } 4 \\
\text { counties in } \\
\text { northwestern vermont } \\
\text { median age: } 72 \\
\text { ( } 618 \text { female) } \\
\text { subsample of } \\
\text { female widows } \\
\text { systematic selection } \\
\text { ( } n=326)\end{array}$ & $\begin{array}{l}\text { one item measuring } \\
\text { how well money meets } \\
\text { one's needs } \\
\text { one item measuring } \\
\text { the respondent's } \\
\text { financial position } \\
\text { compared to that of } \\
\text { others }\end{array}$ & $\begin{array}{l}\text { 3-item index } \\
\text { measuring } \\
\text { life satisfaction }\end{array}$ & univariate & $\begin{array}{l}r=.38^{\star} \\
r=.15^{\star}\end{array}$ \\
\hline
\end{tabular}




\begin{tabular}{|c|c|c|c|c|c|}
\hline $\begin{array}{l}\text { Harel, Sollod, } \\
\text { and Bognar } \\
\text { (1982) }\end{array}$ & $\begin{array}{l}60 \text { and ol der } \\
\text { noninstitutionalized } \\
\text { residents of Greene } \\
\text { county, Ohio } \\
\text { living in semi-rural } \\
\text { areas } \\
\text { (608 female) } \\
\text { systematic random } \\
\text { sample } \\
(888 \text { response rate) } \\
(n=1008)\end{array}$ & $\begin{array}{l}\text { one item measuring } \\
\text { how well money meets } \\
\text { one's needs } \\
\text { one item measuring } \\
\text { whether respondent } \\
\text { has extra money } \\
\text { one item measuring } \\
\text { whether respondent } \\
\text { has enough money for } \\
\text { emergencies }\end{array}$ & $\begin{array}{l}\text { one item measuring } \\
\text { mental and } \\
\text { emotional health } \\
\text { (range: } 0 \text { to } 3 \text { ) }\end{array}$ & univariate & $\mathrm{r}=.17 \star \star \star$ \\
\hline $\begin{array}{l}\text { Seleen } \\
\text { (1982) }\end{array}$ & $\begin{array}{l}55 \text { and older } \\
\text { noninstitutionalized } \\
\text { residents of Rhode } \\
\text { Island } \\
\text { ( } 568 \text { female) } \\
\text { random selection of } \\
6 \text { senior centers in } \\
\text { the state } \\
\text { surveyed all persons } \\
\text { attending the noon } \\
\text { meal } \\
(n=205)\end{array}$ & $\begin{array}{l}\text { one item measuring } \\
\text { financial } \\
\text { satisfaction }\end{array}$ & $\begin{array}{l}\text { LSIA } \\
\text { Cantril ladder }\end{array}$ & univarlate & $\begin{array}{l}\mathrm{r}=.28 * k \hbar \\
\mathrm{r}=.30 * k \star\end{array}$ \\
\hline $\begin{array}{l}\text { Spreitzer } \\
\text { and Snyder } \\
(1980)\end{array}$ & $\begin{array}{l}65 \text { and older } \\
\text { NORC data } \\
(1972,1973 \text {, and } \\
1974 \text { yearly survey } \\
\text { combined for } \\
\text { analysis) national } \\
\text { probability sample } \\
\text { ( } n=756)\end{array}$ & $\begin{array}{l}\text { one Item measuring } \\
\text { satisfaction with } \\
\text { financial situation } \\
\text { (range: } 1 \text { to } 3 \text { ) }\end{array}$ & $\begin{array}{l}\text { one item measuring } \\
\text { happiness } \\
\text { (range: } 1 \text { to } 3 \text { ) }\end{array}$ & univariate & $\mathrm{r}=.16$ \\
\hline $\begin{array}{l}\text { Lee } \\
\text { (1979) }\end{array}$ & $\begin{array}{l}60 \text { and older } \\
\text { survey in Washington } \\
\text { state, two-stage } \\
\text { probability sample } \\
\text { ( } 758 \text { response rate) } \\
\text { subsample of married } \\
\text { persons only } \\
\text { ( } 418 \text { female) } \\
\text { (n=588 but n=388 } \\
\text { for analysis due to } \\
\text { missing data) }\end{array}$ & $\begin{array}{l}\text { one item measuring } \\
\text { satisfaction with } \\
\text { standard of living } \\
\text { (range: } 1 \text { to } 5 \text { ) }\end{array}$ & $\begin{array}{l}\text { 6-item index } \\
\text { measuring life } \\
\text { satisfaction } \\
\text { (range: } 6 \text { to 24) } \\
\text { (alpha }=.85 \text { males) } \\
\text { (alpha }=.87 \text { females) }\end{array}$ & univariate & $\begin{array}{l}r=.36 \\
\text { (males) } \\
r=.28 \\
\text { (females) }\end{array}$ \\
\hline
\end{tabular}

one item measuring
how well money meet

health

whether respondent

one item measuring

nancial

residents of Rhod

nding the noon

$(n=205)$

e Item measurin

setisfaction with

range: 1 to 3 )

(alpha $=.87$ females) $r=.28$

males)

missing data) 


\begin{tabular}{|c|c|c|c|c|c|}
\hline $\begin{array}{l}\text { Lee } \\
\text { (1978) }\end{array}$ & $\begin{array}{l}60 \text { and older } \\
\text { survey in washington } \\
\text { state, two-stage } \\
\text { probability sample } \\
\text { ( } 758 \text { response rate) } \\
\text { subsample of married } \\
\text { persons } \\
\text { ( } 398 \text { female) } \\
\text { ( } n=588 \text { but } n=439 \\
\text { for analysis due to } \\
\text { missing data) }\end{array}$ & $\begin{array}{l}\text { one item measuring } \\
\text { satisfaction with } \\
\text { standard of living } \\
\text { (range: } 1 \text { to } 5 \text { ) }\end{array}$ & $\begin{array}{l}\text { 6-iten index } \\
\text { measuring life } \\
\text { satisfaction } \\
\text { (range: } 6 \text { to } 24 \text { ) } \\
\text { (alpha }=.85 \text { males) } \\
\text { (alpha }=.87 \text { females) }\end{array}$ & univariate & $\begin{array}{l}\mathrm{r}=.38^{\star \star} \\
\text { (males) } \\
\mathrm{r}=.34 \star \star \\
\text { (fomales) }\end{array}$ \\
\hline $\begin{array}{l}\text { Medley } \\
(1976)\end{array}$ & $\begin{array}{l}65 \text { and older } \\
\text { noninstitutionalized } \\
\text { national probability } \\
\text { sample of persons } \\
18 \text { and older ( } n=2164) \\
178 \text { elderly } \\
\text { median age of persons } \\
\text { in subsample: } 71 \\
(648 \text { female) } \\
\text { ( } n=362 \text { but } n=301 \text { for } \\
\text { analysis due to } \\
\text { missing data) }\end{array}$ & $\begin{array}{l}\text { one item measuring } \\
\text { satisfaction with } \\
\text { standard of living } \\
\text { (range: } 1 \text { to } 7 \text { ) }\end{array}$ & $\begin{array}{l}\text { 9-item index } \\
\text { measuring global } \\
\text { life satisfaction } \\
\text { (range: } 21 \text { to } 147 \text { ) }\end{array}$ & univariate & $\begin{array}{l}r=.39 \\
\text { (males) } \\
r=.54 \\
\text { (females) }\end{array}$ \\
\hline $\begin{array}{l}\text { Spreitzer } \\
\text { and Snyder } \\
\text { (1974) }\end{array}$ & $\begin{array}{l}65 \text { and older } \\
\text { noninstitutionalized } \\
\text { ( } 528 \text { female) } \\
\text { subsample of married } \\
\text { and widowed persons } \\
\text { only } \\
\text { NORC data } \\
\text { stratified random } \\
\text { sample, } 1972 \text { and } 1973 \\
\text { surveys pooled } \\
(\mathrm{n}=224 \text { due to missing } \\
\text { data) }\end{array}$ & $\begin{array}{l}\text { one item measuring } \\
\text { satisfaction with } \\
\text { standard of living } \\
\text { (range: } 1 \text { to } 3 \text { ) }\end{array}$ & $\begin{array}{l}\text { one item measuring } \\
\text { happiness } \\
\text { (range: } 1 \text { to } 3 \text { ) }\end{array}$ & univariate & $r=.40^{\star}$ \\
\hline $\begin{array}{l}\text { Gubrium } \\
\text { (1970) }\end{array}$ & $\begin{array}{l}60 \text { and older } \\
\text { noninstitutionalized } \\
\text { residents of the } \\
\text { Detroit area } \\
\text { (age range: } 60 \text { to } 94 \text { ) } \\
\text { stratifled random } \\
\text { sample } \\
(n=210)\end{array}$ & $\begin{array}{l}\text { one item measuring } \\
\text { financial situation } \\
\text { (range: 1 to } 5 \\
\text { recoded into } 2 \\
\text { groups) }\end{array}$ & $\begin{array}{l}\text { 7-item index } \\
\text { (scale of Kutner } \\
\text { et al.) }\end{array}$ & univariate & $r=.27^{\circ}$ \\
\hline
\end{tabular}




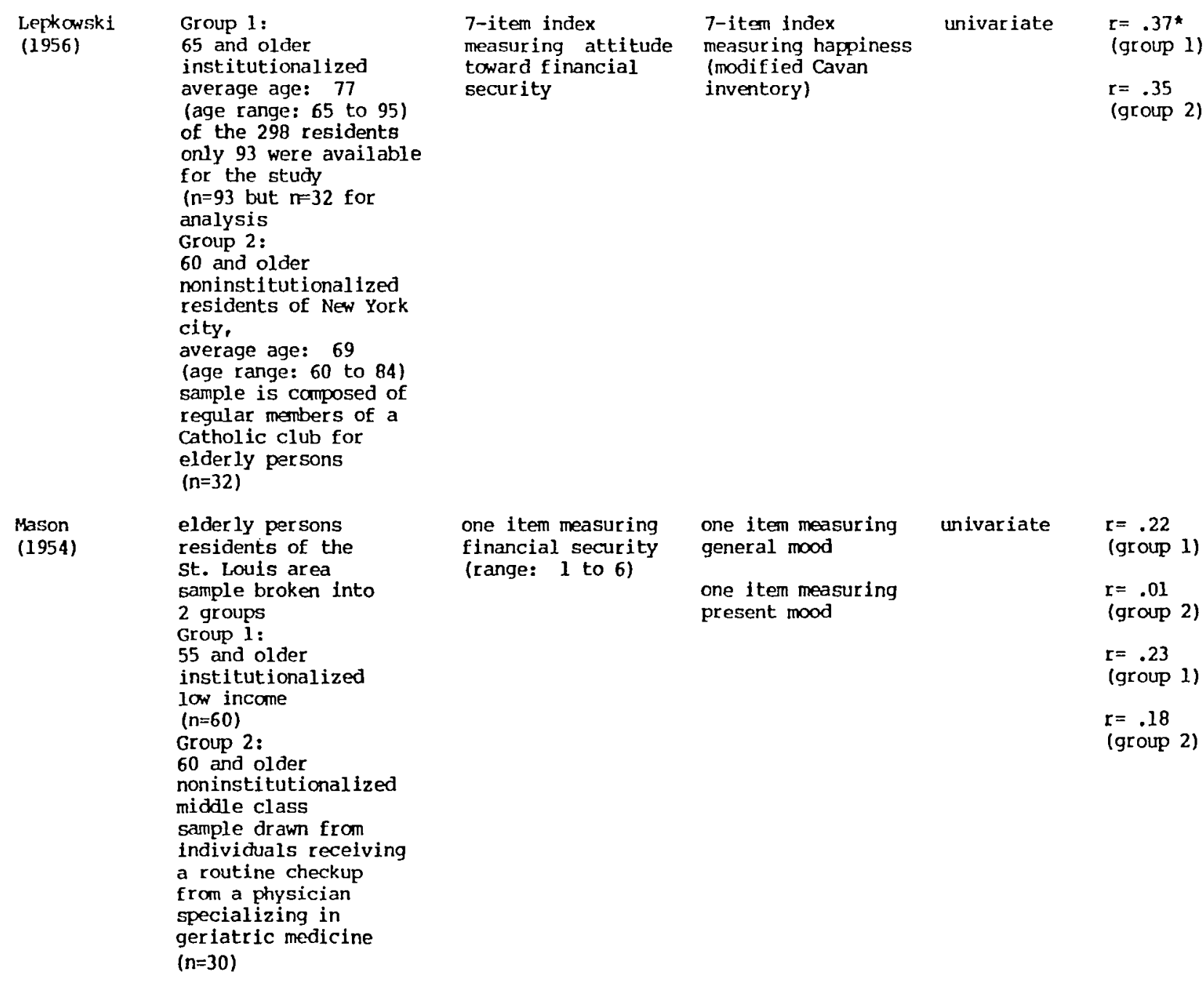

7-item index

measuring attitude

toward financial

7-itsm index

measuring happiness

(modified Cavan

univar iate

$r=.37^{*}$

security

inventory)

$r=.35$

(group 2)

one item measuring

financial security

one item measuring

general mood

univariate

$\mathrm{r}=.22$

(range: 1 to 6 )

one item measuring present mood

(group 1)

$r=.01$

(group 2)

$\mathrm{r}=.23$

(group 1)

$r=.18$

(group 2) 
1. The masure of association has been calculated from the contingency tables.

2. The size of each group is estimated based on information given in the text.

3. The sample size for the statistics is not reported.

4. Values differ sightly from those presented in another article due to missing values which resulted in differences in the composition of the sample across analyses.

5. The procectures for sample selection were not given in the article. The sample was assumed to be a convenience sample.

6. Because the author (s) do(es) not report how the construct was measured, it has been assumed that a single iten was used.

7. The sign of the correlation coefficlent was reversed prior to the inclusion of the correlation coefficient in the meta-analysis. 
APPENDIX B

SUMMARY OF MULTVARIATE STUDIES 
APPENDIX B

STUDIES OF THE REIATTONSHIP BETWEFN HENLTH STATUS AND SUBJECTTVE WEJ-BEING

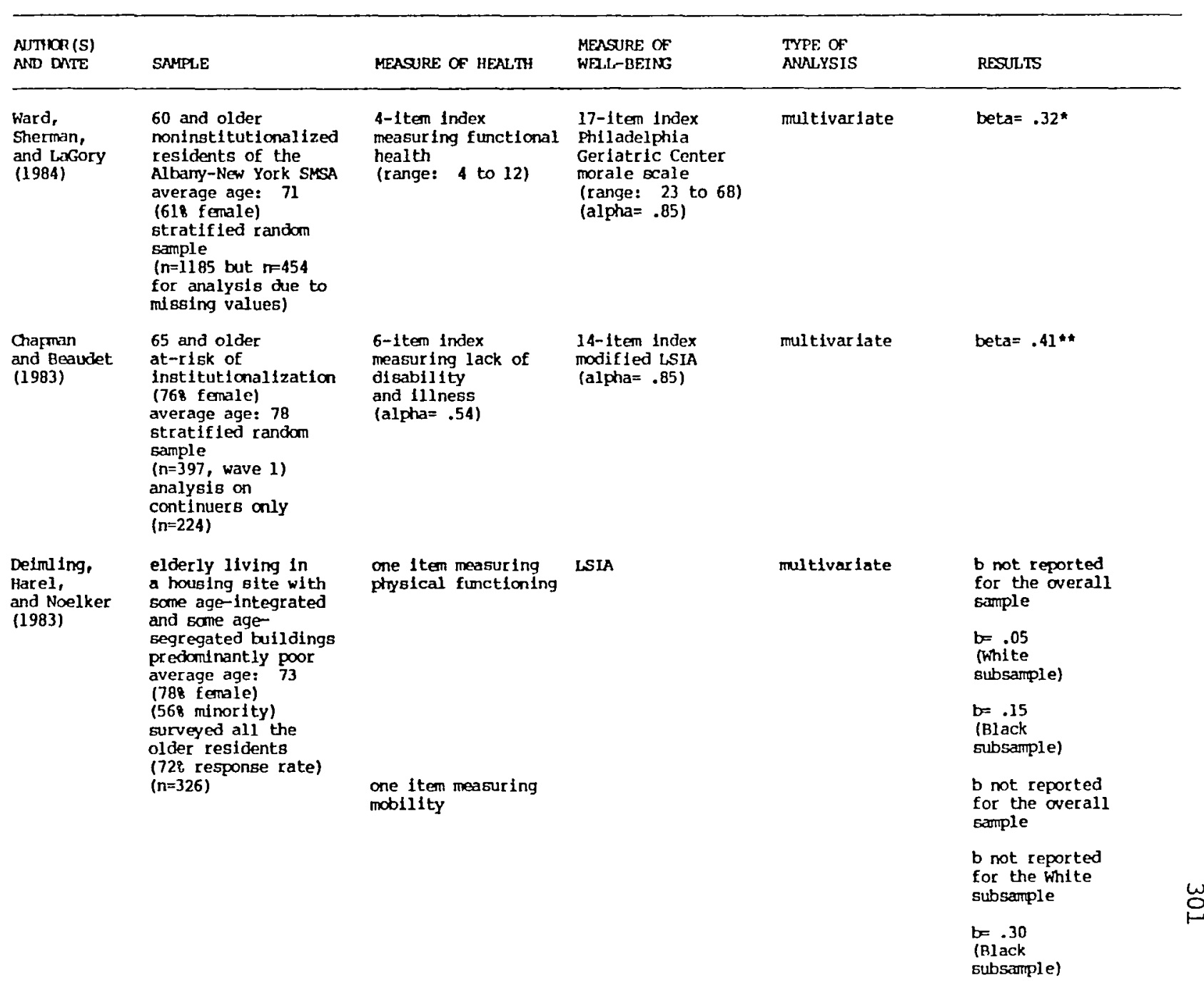




\begin{tabular}{|c|c|c|c|c|c|}
\hline \multirow[t]{4}{*}{$\begin{array}{l}\text { Liang } \\
\text { and War fel } \\
\text { (1983) }\end{array}$} & $\begin{array}{l}65 \text { and older } \\
\text { predominantly poor } \\
\text { (628 female) } \\
\text { state survey in } \\
\text { North Carolina } \\
\text { stratified random } \\
\text { sample } \\
\text { ( } n=961)\end{array}$ & $\begin{array}{l}\text { 17-item index } \\
\text { measuring functional } \\
\text { and self-perceived } \\
\text { health } \\
\text { (alpha }=.88 \text { ) }\end{array}$ & $\begin{array}{l}\text { 8-item index } \\
\text { measuring } 11 \text { fe } \\
\text { sat1sfaction } \\
\text { (alpha= .77) }\end{array}$ & multivariate & beta $=.11 * * *$ \\
\hline & $\begin{array}{l}65 \text { and older } \\
\text { predominantly poor } \\
\text { (588 female) } \\
\text { state survey in } \\
\text { Wisconsin } \\
\text { stratified multi- } \\
\text { stage cluster sample } \\
\text { (n=2000) }\end{array}$ & $\begin{array}{l}\text { 20-1tem index } \\
\text { measur ing functional } \\
\text { and self-perceived } \\
\text { health } \\
\text { (alpha= .85) }\end{array}$ & $\begin{array}{l}\text { 8-item Index } \\
\text { measuring life } \\
\text { satisfaction } \\
\text { (alpha= .61) }\end{array}$ & & beta $=.10^{* * \star}$ \\
\hline & $\begin{array}{l}65 \text { and older } \\
\text { predominantly poor } \\
\text { (608 female) } \\
\text { state survey in } \\
\text { Minnesota } \\
\text { stratifled multi- } \\
\text { stage cluster sample } \\
\text { ( } n=1500)\end{array}$ & $\begin{array}{l}\text { 20-item index } \\
\text { measuring functional } \\
\text { and self-percelved } \\
\text { health } \\
\text { (alpha = .85) }\end{array}$ & $\begin{array}{l}\text { 8-item Index } \\
\text { measuring 11fe } \\
\text { satisfaction } \\
\text { (alpha =.62) }\end{array}$ & & beta $=.08^{* * *}$ \\
\hline & $\begin{array}{l}65 \text { and older } \\
\text { predominantly poor } \\
\text { (618 female) } \\
\text { national survey } \\
(n=3996)\end{array}$ & $\begin{array}{l}\text { index measuring } \\
\text { functional and } \\
\text { self-perceived } \\
\text { health }\end{array}$ & $\begin{array}{l}\text { 16-iten Index } \\
\text { modified version } \\
\text { of the Philadelphia } \\
\text { Geriatric Center } \\
\text { morale scale }\end{array}$ & & beta $=.29 * * \star$ \\
\hline $\begin{array}{l}\text { Ory and } \\
\text { Goldberg } \\
\text { (1983) }\end{array}$ & $\begin{array}{l}65 \text { and older } \\
\text { moninstitutionalized } \\
\text { resident of } \\
\text { Washington county, } \\
\text { Maryland } \\
\text { (age range: } 65 \text { to } 75) \\
\text { (1008 white, married } \\
\text { women) } \\
\text { sampled all who met } \\
\text { eligibility criteria } \\
\text { described above } \\
\text { (718 response rate) } \\
\text { (n=1073) }\end{array}$ & $\begin{array}{l}\text { one item measuring } \\
\text { degree of mobliity } \\
\text { (range: } 1 \text { to } 5 \text { ) }\end{array}$ & $\begin{array}{l}\text { one } 1 \text { term measuring } \\
\text { happiness } \\
\text { (range: } 1 \text { to } 3 \text { ) }\end{array}$ & multivariate & beta $=.16$ \\
\hline
\end{tabular}




\begin{tabular}{|c|c|c|c|c|c|}
\hline $\begin{array}{l}\text { Usut, Rell, } \\
\text { and phillips } \\
\text { (1983) }\end{array}$ & $\begin{array}{l}60 \text { and older } \\
\text { noninstitutionalized } \\
\text { residents of a county } \\
\text { in Kentucky } \\
338 \text { Blacks ( } n=219 \text { ) } \\
\text { convenience sample } \\
\text { ( } n=704 \text { but } n=657 \\
\text { for analysis due to } \\
\text { missing data) }\end{array}$ & $\begin{array}{l}\text { 11-item index } \\
\text { measuring } \\
\text { disability } \\
\text { (range: 0 to } 11 \text { ) }\end{array}$ & $\begin{array}{l}\text { 13-item index } \\
\text { LSIZ } \\
\text { (range: } 0 \text { to 13) }\end{array}$ & multivarlate & $\begin{array}{l}b=-.14^{*} \\
\text { (White } \\
\text { subsample) } \\
b=.40^{* \star} \\
\text { (Black } \\
\text { subsample) }\end{array}$ \\
\hline $\begin{array}{l}\text { Beckman } \\
\text { and Houser } \\
(1982)\end{array}$ & $\begin{array}{l}60 \text { and older } \\
\text { noninstitutionalized } \\
\text { residents of Los } \\
\text { Angeles county } \\
\text { (1008 female) } \\
\text { average age: } 68 \\
\text { (age range: } 60 \text { to } 75 \text { ) } \\
\text { sample selected by a } \\
\text { combination of random } \\
\text { and snowball } \\
\text { techniques } \\
\text { ( } n=719 \text { but n=563 } \\
\text { for analysis due to } \\
\text { missing data) } \\
\text { childless married } \\
\text { (n=156, group 1) } \\
\text { childless widowed } \\
\text { ( } n=114 \text {, group 2) } \\
\text { parent married } \\
\text { (n=155, group 3) } \\
\text { parent widowed } \\
\text { ( } n=138, \text { group 4) }\end{array}$ & $\begin{array}{l}\text { One item measuring } \\
\text { presence or absence } \\
\text { of a serious } 111 \text { ness } \\
\text { in the past year }\end{array}$ & $\begin{array}{l}\text { index composed of } \\
\text { items measuring } \\
\text { dissatisfaction, } \\
\text { unhappiness, } \\
\text { and loneliness }\end{array}$ & multivarlate & 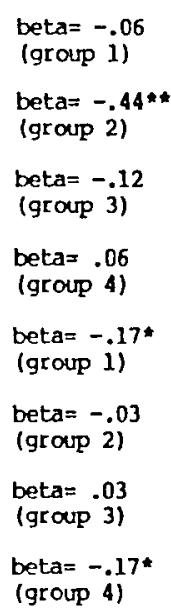 \\
\hline $\begin{array}{l}\text { Fenglet and } \\
\text { Danigelis } \\
\text { (1982) }\end{array}$ & $\begin{array}{l}65 \text { and older } \\
\text { residents of } 4 \\
\text { counties in } \\
\text { nothwestern vemont } \\
\text { median age: } 72 \\
\text { (618 female) } \\
\text { subsample of } \\
\text { female widows } \\
\text { systematic selection } \\
\text { (n=326) }\end{array}$ & $\begin{array}{l}\text { 12-1tem Index } \\
\text { measuring } \\
\text { disability }\end{array}$ & $\begin{array}{l}\text { 3-item index } \\
\text { measuring } \\
\text { l1fe satisfaction }\end{array}$ & mutivariate & beta $=-.20$ \\
\hline
\end{tabular}




\begin{tabular}{|c|c|c|c|c|c|}
\hline $\begin{array}{l}\text { Harel and } \\
\text { Noelker } \\
(1982)\end{array}$ & $\begin{array}{l}54 \text { and older } \\
\text { institutionalized } \\
\text { elderly fram the } \\
\text { Cleveland } \\
\text { metropolitan area } \\
\text { average age: } 81 \\
\text { (age range: } 54 \text { to } 97 \text { ) } \\
\text { (668 female) } \\
\text { nonprobability sample } \\
\text { ( } n=125 \text { ) }\end{array}$ & $\begin{array}{l}\text { one item measuring } \\
\text { mobility status }\end{array}$ & $\begin{array}{l}\text { Philadelphia } \\
\text { Geriatric Center } \\
\text { morale scale }\end{array}$ & multivariate & beta $=.13$ \\
\hline $\begin{array}{l}\text { MoClell and } \\
\text { (1982) }\end{array}$ & $\begin{array}{l}65 \text { and older } \\
\text { subsample of } 1974 \\
\text { NoRC data, sample of } \\
\text { persons 18 and older } \\
\text { (n=4254) subsample } \\
\text { subdivided into } \\
\text { two groups, those who } \\
\text { pref et to interact } \\
\text { with people of all } \\
\text { ages (sample I, } \\
\text { n=1414) and those } \\
\text { who prefer to } \\
\text { interact with people } \\
\text { their own age } \\
\text { (sample } 2, n=477 \text { ) }\end{array}$ & $\begin{array}{l}\text { one item masuring } \\
\text { whether or not } \\
\text { liealth is a problem }\end{array}$ & $\begin{array}{l}\text { 4-item index } \\
\text { measuring } \\
\text { life satisfaction }\end{array}$ & multivariate & $\begin{array}{l}\text { beta }=-.15^{\star *} \\
\text { (sample } 1) \\
\text { beta }=-.26^{\star \star} \\
(\text { sample } 2)\end{array}$ \\
\hline $\begin{array}{l}\text { Strain and } \\
\text { Chappell } \\
\text { (1982) }\end{array}$ & $\begin{array}{l}65 \text { and older } \\
\text { noninstitutionallzed } \\
\text { residents of } \\
\text { Winnipeg, Manitoba } \\
\text { subsample of } \\
\text { nonusers of home } \\
\text { care services } \\
\text { (158 fenale) } \\
\text { stratified random } \\
\text { sample } \\
\text { (348 refusal rate) } \\
\text { (n=400) }\end{array}$ & $\begin{array}{l}\text { number of } \\
\text { chronic tllnesses }\end{array}$ & $\begin{array}{l}\text { LSIA } \\
\text { one Item measuring } \\
\text { happiness } \\
\text { (range: 1 to 5) }\end{array}$ & multivarlate & $\begin{array}{l}\text { beta }=-.26 \\
b=-6.78 \\
b e t a=-.14 \\
b=-.72\end{array}$ \\
\hline $\begin{array}{l}\text { Mutran and } \\
\text { Reitzes } \\
\text { (1981) }\end{array}$ & $\begin{array}{l}55 \text { and older } \\
\text { noninstitutionalized } \\
\text { average age: } 71 \\
\text { (age range: } 55 \text { to 96) } \\
\text { (1008 male) } \\
\text { 1974 NCA data } \\
\text { national probability } \\
\text { sample } \\
(n=1055)\end{array}$ & $\begin{array}{l}\text { one item measuring } \\
\text { health as a serious } \\
\text { problem } \\
\text { (range: 1 to } 3 \text { ) }\end{array}$ & $\begin{array}{l}\text { 10-iter Index } \\
\text { Affect Balance } \\
\text { scale } \\
\text { (alpha }=.60 \text { ) } \\
\text { (range: }-5 \text { to }+5 \text { ) }\end{array}$ & multivarlate & $\begin{array}{l}b=-.35 \\
b e t a=-.29 *\end{array}$ \\
\hline
\end{tabular}




\begin{tabular}{|c|c|c|c|c|c|}
\hline $\begin{array}{l}\text { George } \\
(1978)\end{array}$ & $\begin{array}{l}50 \text { and older } \\
\text { representative of } \\
\text { the middle class, } \\
\text { healthy, and } \\
\text { financlally } \\
\text { conf ortable } \\
\text { respondents } \\
\text { originally selected } \\
\text { from a list of } \\
\text { participants in a } \\
\text { local health } \\
\text { tnsurance program } \\
\text { volunteers in the } \\
\text { Duke Longitudinal } \\
\text { Study of nging } \\
\text { 3rd wave of data } \\
\text { collection } \\
\text { (488 female) } \\
\text { (age range: } 50 \text { to 76) } \\
\text { (n=360) }\end{array}$ & $\begin{array}{l}\text { one } 1 \text { tem measuring } \\
\text { health impairment } \\
\text { as assessed by a } \\
\text { clinician }\end{array}$ & $\begin{array}{l}\text { Affect Balance } \\
\text { scale }\end{array}$ & multivariate & $\begin{array}{l}b=-.21 * k \\
b e t a=-.13 *\end{array}$ \\
\hline $\begin{array}{l}\text { Jackson, } \\
\text { Bacon, } \\
\text { and Peter son } \\
\text { (1978) }\end{array}$ & $\begin{array}{l}54 \text { and older } \\
\text { noninstitutionallized } \\
\text { elderly living in } \\
\text { the Detroit area } \\
\text { (1008 retired Blacks) } \\
\text { predominantly poor } \\
\text { average age: } 70 \\
\text { (age range: } 54 \text { to } 83 \text { ) } \\
\text { (728 female) } \\
\text { sample purposely } \\
\text { selected from Black } \\
\text { older adult center } \\
\text { participants } \\
\text { (58 refusal rate) } \\
\text { (n=102) }\end{array}$ & $\begin{array}{l}\text { one item measuring } \\
\text { whether the } \\
\text { respondent has been } \\
\text { hospltallzed for } \\
\text { an Illness he/she } \\
\text { considers ser lous } \\
\text { (range: } 0 \text { to } 1 \text { ) }\end{array}$ & LSIA & multivar iate & beta $=-.04$ \\
\hline $\begin{array}{l}\text { Myles } \\
\text { (1978) }\end{array}$ & $\begin{array}{l}65 \text { and older } \\
\text { sample from the } \\
\text { province of Manitoba } \\
128 \text { sample } 18 \\
\text { institutionalized } \\
\text { stratified random } \\
\text { sample } \\
\text { ( }=3851 \text {, but } \\
\text { in } 3632 \text { for analysis } \\
\text { due to mi solng data) }\end{array}$ & $\begin{array}{l}\text { 1-1tem Index } \\
\text { measuring disability } \\
\text { and 11lness }\end{array}$ & ISIA & multivariate & $\begin{array}{l}b=-.68 \\
\text { beta }=-.12 \\
\text { (cominity } \\
\text { residing, } \\
n=3199 \text { ) } \\
b=-.23 \\
\text { beta }=-.10 \\
\text { (institution- } \\
\text { alized, } n=433 \text { ) }\end{array}$ \\
\hline
\end{tabular}




\begin{tabular}{|c|c|c|c|c|c|}
\hline $\begin{array}{l}\text { Noelker } \\
\text { and Harel } \\
\text { (1978) }\end{array}$ & $\begin{array}{l}54 \text { and older } \\
\text { institutionalized } \\
\text { elderly } \\
\text { average age: } 81 \\
\text { (age range: } 54 \text { to } 97 \text { ) } \\
\text { (668 fenlale) } \\
\text { systematic selection } \\
\text { of } 14 \text { nursing homes } \\
\text { and systematic randon } \\
\text { sample of residents } \\
\text { from the self-care } \\
\text { floors } \\
\text { (n=125) }\end{array}$ & $\begin{array}{l}\text { one item measuring } \\
\text { need for mobility } \\
\text { assistance }\end{array}$ & $\begin{array}{l}\text { Philadelphia } \\
\text { Geriatric Center } \\
\text { morale ocale }\end{array}$ & multivar late & beta $=-.35$ \\
\hline $\begin{array}{l}\text { Sauer } \\
\text { (1977) }\end{array}$ & $\begin{array}{l}65 \text { and older } \\
\text { noninstitutional lzed } \\
\text { elderly from the low } \\
\text { socioeconomic areas } \\
\text { of philadelphia } \\
\text { (568 female) } \\
\text { (77 Black elder ly) } \\
\text { stratified random } \\
\text { Bample (n=1022 } \\
\text { but n=932 for } \\
\text { analysis due to } \\
\text { missing data) }\end{array}$ & $\begin{array}{l}\text { 3-1tern index } \\
\text { measuring functional } \\
\text { health } 0 \text { to } 3 \text { ) } \\
\text { (range: o to }\end{array}$ & $\begin{array}{l}\text { 17-iter 1ndex } \\
\text { modified version of } \\
\text { the Philadelphia } \\
\text { Geriatric Center } \\
\text { morale scale } \\
\text { (range: o to 17) } \\
\text { (alpha=.82) }\end{array}$ & multivariate & $\begin{array}{l}\text { betas .35** } \\
\text { (entire sample) } \\
\text { beta }=.37 * * \\
\text { (Black } \\
\text { subsample) } \\
\text { betas .23** } \\
\text { (White } \\
\text { subsample) }\end{array}$ \\
\hline $\begin{array}{l}\text { Toseland } \\
\text { and sykes } \\
\text { (1977) }\end{array}$ & $\begin{array}{l}55 \text { and older } \\
\text { noninstitutionalized } \\
\text { living in suburban } \\
\text { and rural areas near } \\
\text { Madison, wiscons in } \\
\text { (318 fenale) } \\
\text { systematic random } \\
\text { selection from a list } \\
\text { of participants and } \\
\text { non-participants } \\
\text { at a senior center } \\
\text { (34 response rate) } \\
\text { (n=137) }\end{array}$ & $\begin{array}{l}\text { one item measuring } \\
\text { chronic health } \\
\text { problems }\end{array}$ & $\begin{array}{l}\text { 13-1tera LSI2 } \\
\text { (range: } 0 \text { to 26) }\end{array}$ & multivarlate & $b=2.22$ \\
\hline
\end{tabular}




\begin{tabular}{|c|c|c|c|c|c|}
\hline $\begin{array}{l}\text { Rnapp } \\
\text { (1976) }\end{array}$ & $\begin{array}{l}62 \text { and ol der } \\
\text { noninstitutionalized } \\
\text { residents of a } \\
\text { coastal resort in } \\
\text { sovthern England } \\
\text { (558 fomale) } \\
\text { average age: } 76 \\
\text { (age range: } 62 \text { to } 86) \\
\text { convenience sample } \\
\text { (n=51) }\end{array}$ & $\begin{array}{l}\text { one Item measuring } \\
\text { immobility as rated } \\
\text { by the interviewer } \\
\text { (range: I to } 5 \text { ) }\end{array}$ & $\begin{array}{l}\text { 6-1tem 1ndex from } \\
\text { the ISIA scale } \\
\text { which measure zest } \\
\text { for life } \\
\text { (range: } 5 \text { to 12) } \\
\text { 3-1tem index from } \\
\text { the ISIn scale } \\
\text { which measure } \\
\text { congruence } \\
\text { (range: } 2 \text { to 6) }\end{array}$ & multivariate & $\begin{array}{l}b=-.41 \\
b e t a=-.38\end{array}$ \\
\hline $\begin{array}{l}\text { Edvards and } \\
\text { Rlemmack } \\
\text { (1973) }\end{array}$ & $\begin{array}{l}45 \text { and older } \\
\text { residents of four } \\
\text { countles in Virginia } \\
\text { (548 female) } \\
\text { quota sample for } \\
\text { proportionate } \\
\text { representation of } \\
\text { those below and above } \\
65 \text { years } \\
\text { ( }=507)\end{array}$ & $\begin{array}{l}\text { one 1tem measuring } \\
\text { number of allments } \\
\text { in the last month } \\
\text { one 1tem measuring } \\
\text { number of allments } \\
\text { in the last year }\end{array}$ & $\begin{array}{l}\text { 10-item index } \\
\text { modified LSIA } \\
\text { (alpha }=.90)\end{array}$ & multivariate & $\begin{array}{l}\text { beta }=.04 \\
\text { beta }=.01\end{array}$ \\
\hline $\begin{array}{l}\text { Palmore and } \\
\text { Luikart } \\
\text { (1972) }\end{array}$ & $\begin{array}{l}46 \text { and older } \\
\text { noninstitutionalized } \\
\text { residents of Durham, } \\
\text { North Carol Ina } \\
\text { average age: } 59 \\
\text { age range: } 46 \text { to } 71 \\
\text { respondents } \\
\text { tend to be well off } \\
\text { (488 female) } \\
\text { random sample from a } \\
\text { mentership } 11 \text { ist of a } \\
\text { major health } \\
\text { insurance compary } \\
\text { (528 refusal rate) } \\
\text { longltudinal data } \\
\text { wave } 1 \text { data only } \\
\text { (n=502) }\end{array}$ & $\begin{array}{l}\text { one Item measuring } \\
\text { health status } \\
\text { based on a rating } \\
\text { by a physiclan } \\
\text { (range: \& to } 10 \text { ) }\end{array}$ & $\begin{array}{l}\text { one item measuring } \\
\text { happiness } \\
\text { Cantril ladder } \\
\text { (range: } 0 \text { to } 9 \text { ) }\end{array}$ & multivariate & $\begin{array}{l}\text { beta }=.25 \\
\text { (entire sample) } \\
\text { beta }=.28 \\
\text { (males) } \\
\text { beta not } \\
\text { reported } \\
\text { (females) }\end{array}$ \\
\hline
\end{tabular}


STUDIES OF THE REIATIONSHIP BETWEFN SELF-PERCEIVED HENLTH ND SUBUECTIVE FEבL-BEINO

\begin{tabular}{|c|c|c|c|c|c|}
\hline $\begin{array}{l}\text { NITHOR (S) } \\
\text { NDD DNTE }\end{array}$ & SNMPLE & MEASURE OF HEALTH & $\begin{array}{l}\text { MFASURE OF } \\
\text { WETL-BEING }\end{array}$ & $\begin{array}{l}\text { TYPF OF } \\
\text { ANALYSIS }\end{array}$ & RESURTS \\
\hline $\begin{array}{l}\text { Collette } \\
\text { (1984) }\end{array}$ & $\begin{array}{l}60 \text { and older } \\
\text { noninstitutionalized } \\
\text { residents of Sidney, } \\
\text { Mustralia } \\
\text { (648 fenale) } \\
\text { cluster samping } \\
\text { age stratified } \\
(n=1048 \text { ) }\end{array}$ & $\begin{array}{l}\text { one item measuring } \\
\text { self-perceived } \\
\text { health }\end{array}$ & $\begin{array}{l}\text { 14-item index } \\
\text { modified version of } \\
\text { Philadelphia } \\
\text { Geriatric Center } \\
\text { morale gcale }\end{array}$ & multivar late & $\begin{array}{l}b=.17 \\
b e t a=.19 * \text { ** } \\
\text { (females) } \\
b=.16 \\
\text { beta=.16** } \\
\text { (males) }\end{array}$ \\
\hline $\begin{array}{l}\text { Hooker } \\
\text { and Vent is } \\
\text { (1984) }\end{array}$ & $\begin{array}{l}53 \text { and older } \\
\text { residents of } \\
\text { southeastern and } \\
\text { central virginia } \\
\text { middle class } \\
\text { background } \\
\text { average age: } 70 \\
\text { (age range: } 53 \text { to } 88 \text { ) } \\
\text { ( } 558 \text { female) } \\
\text { convenience sample } \\
\text { of volunteers } \\
\text { recruited from } \\
\text { nat ional associatlons } \\
\text { of retired persons } \\
\text { (688 response rate) } \\
\text { (n=76 but rn } 57 \text { for } \\
\text { analysis due to } \\
\text { missing data) }\end{array}$ & $\begin{array}{l}\text { one Item measuring } \\
\text { self-perceived } \\
\text { health } \\
\text { (range: } 1 \text { to } 4 \text { ) }\end{array}$ & $\begin{array}{l}\text { LSIA } \\
\text { (alpha = .73) }\end{array}$ & multivarlate & $\begin{array}{l}\mathrm{b}=1.88 \\
\mathrm{bet} a=.50 * *\end{array}$ \\
\hline $\begin{array}{l}\text { Baur } \\
\text { and Okun } \\
\text { (1983) }\end{array}$ & $\begin{array}{l}66 \text { and older } \\
\text { apartment dwellers } \\
\text { of a retirement } \\
\text { community in Phoenix, } \\
\text { Arizona, who could } \\
\text { be reinterviewed } \\
3 \text { years af ter the } \\
\text { f1rst wave of data } \\
\text { collection } \\
\text { (age range: } 66 \text { to } 94) \\
\text { (808 fenale) } \\
\text { stratified random } \\
\text { sample } \\
\text { (178 attrition rate) } \\
\text { (n=87) }\end{array}$ & $\begin{array}{l}\text { one item measuring } \\
\text { self-perceived } \\
\text { heal th } \\
\text { (range: } 1 \text { to } 9 \text { ) }\end{array}$ & $\begin{array}{l}\text { LSIB } \\
\text { (alpha }=.69, \text { wave } 1 \text { ) }\end{array}$ & multivariate & $\begin{array}{l}\mathrm{b}=.94 * k \\
\text { beta }=.32 * k\end{array}$ \\
\hline
\end{tabular}




\begin{tabular}{|c|c|c|c|c|c|}
\hline $\begin{array}{l}\text { Deiml Ing, } \\
\text { Harel, } \\
\text { and Noelker } \\
\text { (1983) }\end{array}$ & $\begin{array}{l}\text { elderly living in a } \\
\text { housing site with } \\
\text { some age- integrated } \\
\text { and come age- } \\
\text { segregated buildings } \\
\text { predoninantly poor } \\
\text { average age: } 73 \\
\text { (788 female) } \\
\text { (568 minority) } \\
\text { surveyed all older } \\
\text { residents } \\
\text { (728 response rate) } \\
(n=326)\end{array}$ & $\begin{array}{l}\text { one item measuring } \\
\text { self-perceived } \\
\text { health }\end{array}$ & LSI & multivar iate & $\begin{array}{l}b=.18 \\
\text { (entire sample) } \\
b=.24 \\
\text { (White } \\
\text { subsample) } \\
\text { b not reported } \\
\text { for Black } \\
\text { subsample }\end{array}$ \\
\hline $\begin{array}{l}\text { Rozma and } \\
\text { Stones } \\
(1983)\end{array}$ & $\begin{array}{l}65 \text { and older } \\
\text { urban, rural, and } \\
\text { institutionalized } \\
\text { residents of } \\
\text { Newfoundland } \\
\text { random selection } \\
\text { (n=600) } \\
\text { rural (n=200) group } 1 \\
\text { urban (n=200) group } 2 \\
\text { institutionalized } \\
\text { (n=200) group 3 }\end{array}$ & $\begin{array}{l}\text { one item measuring } \\
\text { self-perceived } \\
\text { health } \\
\text { (range: } 1 \text { to } 7 \text { ) }\end{array}$ & $\begin{array}{l}\text { 24-item index } \\
\text { measuring happiness }\end{array}$ & multivariate & $\begin{array}{l}\text { beta }=.25 \\
\text { (entire sample) } \\
\text { beta }=.33 \\
\text { (group 1) } \\
\text { beta }=.31 \\
\text { (group 2) } \\
\text { beta= } .14 \\
\text { (group 3) }\end{array}$ \\
\hline $\begin{array}{l}\text { Ory and } \\
\text { Goldberg } \\
\text { (1983) }\end{array}$ & $\begin{array}{l}65 \text { and ol der } \\
\text { noninstitutionalized } \\
\text { residents of } \\
\text { ashington county, } \\
\text { Maryland } \\
\text { (age range: } 65 \text { to } 75 \text { ) } \\
\text { (1008 white married } \\
\text { women) } \\
\text { sampled all who met } \\
\text { eligibility criteria } \\
\text { described above } \\
\text { (718 response rate) } \\
\text { (n=1073) }\end{array}$ & $\begin{array}{l}\text { one Iten measuring } \\
\text { self-perceived } \\
\text { health } \\
\text { (range: } 1 \text { to } 5 \text { ) }\end{array}$ & $\begin{array}{l}\text { one iten measuring } \\
\text { happiness } \\
\text { (range: } 1 \text { to } 3 \text { ) }\end{array}$ & multivariate & beta $=.13$ \\
\hline
\end{tabular}




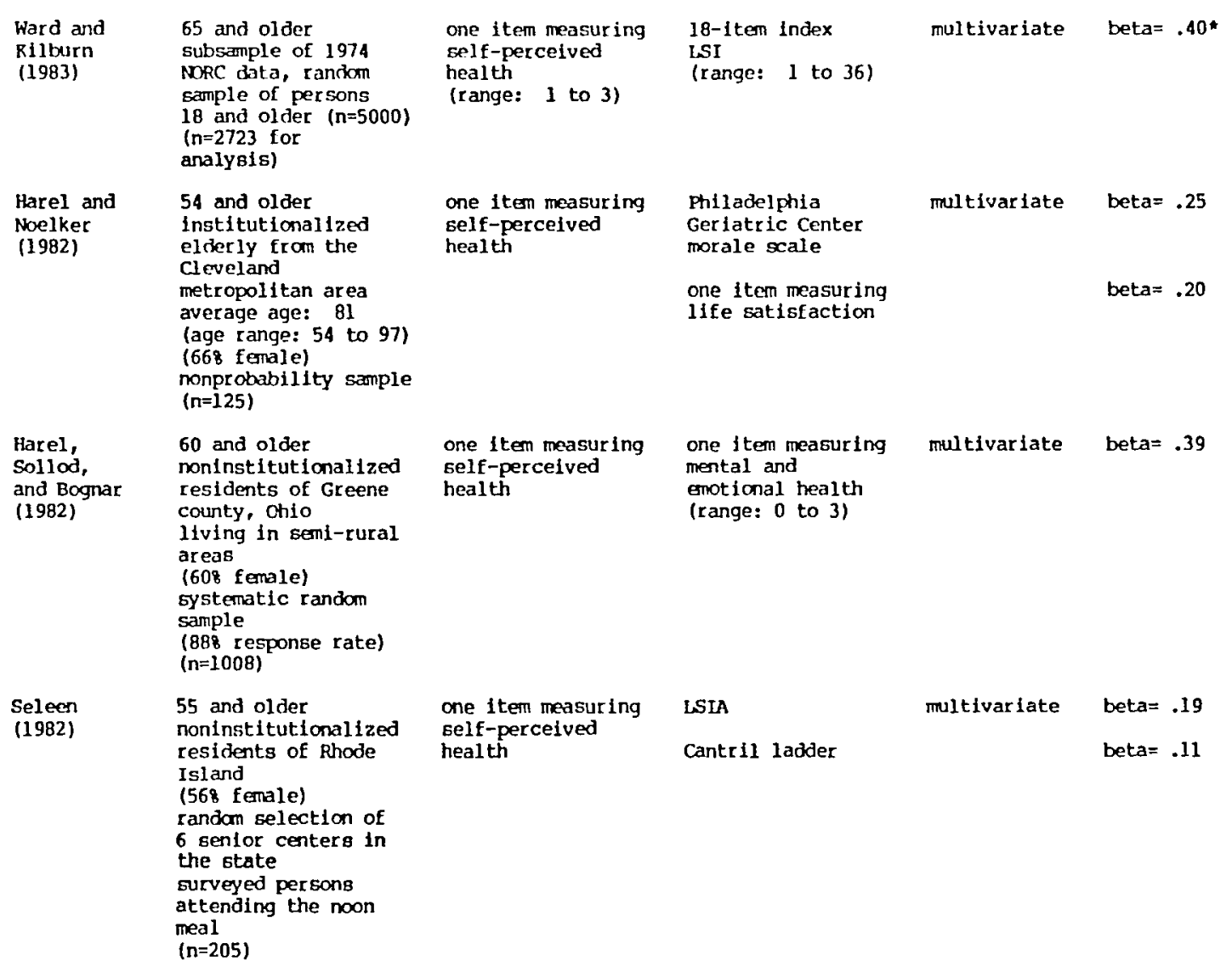




\begin{tabular}{|c|c|c|c|c|c|}
\hline $\begin{array}{l}\text { Srow and } \\
\text { Crapo } \\
\text { (1982) }\end{array}$ & $\begin{array}{l}65 \text { and older } \\
\text { noninstitutionalized } \\
\text { outpatients of a } \\
\text { Veterans } \\
\text { Adninistration } \\
\text { medical clinic } \\
\text { mean age: } 71 \\
\text { (age range: } 65 \text { to 98) } \\
\text { (1008 male) } \\
\text { convenience sample } \\
\text { (n=205) }\end{array}$ & $\begin{array}{l}\text { one item measuring } \\
\text { self-percelved } \\
\text { health } \\
\text { (range: } 0 \text { to } 10 \text { ) }\end{array}$ & $\begin{array}{l}\text { 18-item index } \\
\text { LSIA } \\
\text { (range: } 0 \text { to } 36 \text { ) } \\
\text { Af fect Balance } \\
\text { Scale } \\
\text { (range: } 0 \text { to } 10 \text { ) }\end{array}$ & multivar late & beta $=.27$ \\
\hline $\begin{array}{l}\text { Brown, } \\
\text { Perman, } \\
\text { and Dobbs } \\
(1981)\end{array}$ & $\begin{array}{l}45 \text { and older } \\
\text { noninstitutionalized } \\
\text { working class } \\
\text { background } \\
\text { predkminantly poor } \\
\text { and unemployed } \\
\text { pacemaker recipients } \\
\text { (ave male) } \\
\text { average age: } 69 \\
\text { (age range: } 45 \text { to } 85 \text { ) } \\
\text { convenience sample } \\
\text { (n=100) }\end{array}$ & $\begin{array}{l}\text { one Item measuring } \\
\text { self-perceived } \\
\text { health } \\
\text { (range: } 0 \text { to } 10 \text { ) }\end{array}$ & $\begin{array}{l}\text { 7-item index } \\
\text { measuring } \\
\text { despair and } \\
\text { hopelessness } \\
\text { (alpha= } .^{79)} \\
\text { (range: } 0_{\text {to }} \text { 28) }\end{array}$ & multivariate & beta $=-.20$ \\
\hline $\begin{array}{l}\text { Elwell } \\
\text { and Maltbie- } \\
\text { Crannell } \\
(1981)\end{array}$ & $\begin{array}{l}50 \text { years and older } \\
\text { noninstitutionalized } \\
\text { (538 female) } \\
\text { average age: } 63 \\
\text { NoRC data } \\
\text { stratified random } \\
\text { sample, } 1974,1975 \text {, } \\
\text { and } 1977 \\
\text { surveys poled } \\
\text { (n=1660 but } n=1413 \\
\text { for analysis due to } \\
\text { missing data) }\end{array}$ & $\begin{array}{l}\text { one iten measuring } \\
\text { self-percelved } \\
\text { health }\end{array}$ & $\begin{array}{l}\text { 5-item index } \\
\text { measuring } \\
\text { satisfaction with } \\
\text { selected aspects } \\
\text { of one's life }\end{array}$ & multivar late & $\begin{array}{l}\text { beta }=.39 * \\
b=2.00 \\
\text { (males) } \\
\text { beta }=.36 * \\
b=1.83 \\
\text { (fomales) }\end{array}$ \\
\hline
\end{tabular}




\begin{tabular}{|c|c|c|c|c|c|}
\hline $\begin{array}{l}\text { Felton, } \\
\text { lint ichsen, } \\
\text { and Tsamber is } \\
\text { (1981) }\end{array}$ & $\begin{array}{l}65 \text { and older } \\
\text { noninstitutionalized } \\
\text { group } 1 \text { (urban) } \\
\text { residents of age- } \\
\text { integrated or } \\
\text { privately owned } \\
\text { housing for the } \\
\text { elderly in } \\
\text { Manhattan's Lower } \\
\text { East side } \\
\text { aver age age: } 73 \\
\text { (718 female) } \\
\text { ( } n=38 \text { but } n=30 \text { for } \\
\text { analysis due to } \\
\text { missing data) } \\
\text { group } 2 \text { (suburban) } \\
\text { residents of a } \\
\text { privately owned } \\
\text { housing project for } \\
\text { the elderly in a } \\
\text { New Jersey cormunity } \\
\text { average age: } 71 \\
\text { (828 female) } \\
\text { (648 response rate) } \\
\text { (n=33 but } n=32 \text { for } \\
\text { analysis due to } \\
\text { missing data) }\end{array}$ & $\begin{array}{l}\text { One } 1 \text { tem measuring } \\
\text { self-perceived } \\
\text { health } \\
\text { (range: } 1 \text { to } 5 \text { ) }\end{array}$ & $\begin{array}{l}\text { 17-item index } \\
\text { Philadel phia } \\
\text { Ger latric Center } \\
\text { morale scale } \\
\text { (alpha }=.88 \text { ) }\end{array}$ & mult tivar iate & $\begin{array}{l}\text { beta }=.06 \\
\text { (group 1) } \\
\text { beta }=.47 \\
\text { (group 2) }\end{array}$ \\
\hline $\begin{array}{l}\text { Fengler } \\
\text { and Jensen } \\
\text { (1981) }\end{array}$ & $\begin{array}{l}65 \text { and older } \\
\text { median age: } 72 \\
\text { ( } 618 \text { female) } \\
\text { survey of four } \\
\text { counties in Norttwest } \\
\text { Vermont } \\
\text { random sample } \\
\text { ( } n=1400 \text {, analysis } \\
\text { based on } n=1077 \text { ) }\end{array}$ & $\begin{array}{l}\text { one item measuring } \\
\text { self-perceived } \\
\text { health }\end{array}$ & $\begin{array}{l}\text { 3-item index } \\
\text { measuring } \\
\text { umhappiness, } \\
\text { boredom, and } \\
\text { loneliness } \\
\text { (range: } 0 \text { to 3) }\end{array}$ & multivariate & beta $=.16$ \\
\hline
\end{tabular}




\begin{tabular}{|c|c|c|c|c|c|}
\hline $\begin{array}{l}\text { Markides, } \\
\text { Costley, } \\
\text { and } \\
\text { Rodriguez } \\
\text { (1981) }\end{array}$ & $\begin{array}{l}60 \text { and older } \\
\text { noninstitutionalized } \\
\text { residents of San } \\
\text { Antonin, Texas } \\
\text { low-Income, minority } \\
\text { respondents, with at } \\
\text { least one child in } \\
\text { the area } \\
\text { (618 female) } \\
\text { convenience sample } \\
(n=98)\end{array}$ & $\begin{array}{l}\text { one item measuring } \\
\text { self-perceived } \\
\text { health } \\
\text { (range: I to } 4 \text { ) }\end{array}$ & $\begin{array}{l}\text { 21-1tem index } \\
\text { Philadelphia } \\
\text { Geriatric Center } \\
\text { morale scale }\end{array}$ & multivariate & beta $=.39 *$ \\
\hline $\begin{array}{l}\text { Duff } \\
\text { and Hong } \\
(1980)\end{array}$ & $\begin{array}{l}60 \text { and older } \\
\text { noninstitutionalized } \\
1974 \text { NOPC data } \\
\text { stratified random } \\
\text { gample of persons } \\
18 \text { and older } \\
\text { median age In sub- } \\
\text { gample: } 69 \\
\text { (n=335 but }=275 \\
\text { for analysis due to } \\
\text { mlssing data) }\end{array}$ & $\begin{array}{l}\text { one } 1 \text { tem measuring } \\
\text { self-percelved } \\
\text { health } \\
\text { (range: } 1 \text { to } 4 \text { ) }\end{array}$ & $\begin{array}{l}\text { 2-1tem Index } \\
\text { measuring 11fe } \\
\text { satisfaction } \\
\text { (range: } 1 \text { to 6) }\end{array}$ & multivariate & beta $=.21$ \\
\hline
\end{tabular}




\begin{tabular}{|c|c|c|c|c|c|}
\hline $\begin{array}{l}\text { Fengler, } \\
\text { Danigelis, } \\
\text { and Grams } \\
(1980)\end{array}$ & $\begin{array}{l}65 \text { and older } \\
\text { noninstitutionalized } \\
\text { residents of four } \\
\text { counties in Northwest } \\
\text { Vermont } \\
\text { median age: } 72 \\
\text { (618 female) } \\
\text { random sample } \\
\text { (n=1400 but } n=1036 \\
\text { for analysis due to } \\
\text { missing data) } \\
\text { ample subdivided } \\
\text { into: } \\
\text { married (n=508 } \\
\text { group 1), } \\
\text { living with others } \\
\text { (n=246, group 2), } \\
\text { living alone } \\
\text { (n=282, group 3) }\end{array}$ & $\begin{array}{l}\text { one tem measuring } \\
\text { self-percelved } \\
\text { health } \\
\text { (normative item) }\end{array}$ & $\begin{array}{l}\text { 3-1tem index } \\
\text { measuring } \\
\text { unhappiness, } \\
\text { boredom, and } \\
\text { lonellness } \\
\text { (range: 0 to 3) }\end{array}$ & multivariate & $\begin{array}{l}\text { beta }=.21 * * \\
\text { (group 1) } \\
\text { beta=.16** } \\
\text { (group 2) } \\
\text { beta not } \\
\text { reported } \\
\text { (group 3) }\end{array}$ \\
\hline $\begin{array}{l}\text { Hoyt, Raiser, } \\
\text { Peters, and } \\
\text { Babchuk } \\
(1980)\end{array}$ & $\begin{array}{l}65 \text { and older } \\
\text { noninstitutionalized } \\
\text { residents of a mid- } \\
\text { western city } \\
\text { average age: } 75 \\
\text { (608 fenale) } \\
\text { random sample } \\
\text { (718 response rate) } \\
\text { (n=124 but rizi22 } \\
\text { for analysis due to } \\
\text { missing data) }\end{array}$ & $\begin{array}{l}\text { 2-item index } \\
\text { measuring self- } \\
\text { perceived health } \\
\text { (range: } 0 \text { to } 6 \text { ) }\end{array}$ & $\begin{array}{l}\text { I8-item Index } \\
\text { LSIA }\end{array}$ & mantivariate & beta $=.22^{\star}$ \\
\hline
\end{tabular}




\begin{tabular}{|c|c|c|c|c|c|}
\hline $\begin{array}{l}\text { Lee and } \\
\text { El11thorpe } \\
(1980)\end{array}$ & $\begin{array}{l}60 \text { and older } \\
\text { moninstitutionalized } \\
\text { residents of } \\
\text { Washington state } \\
\text { ( } 498 \text { fomale) } \\
\text { average age: } 68 \\
\text { two-stage probability } \\
\text { sample } \\
\text { ( } 758 \text { response rate) } \\
\text { subsample of children } \\
\text { with independent } \\
\text { residences } \\
\text { (n=578 but } n=403 \text { for } \\
\text { analysis due to } \\
\text { missing data) }\end{array}$ & $\begin{array}{l}\text { one item measuring } \\
\text { self-perceived } \\
\text { health } \\
\text { (range: } 1 \text { to } 5 \text { ) }\end{array}$ & $\begin{array}{l}\text { 6-item index } \\
\text { measuring life } \\
\text { satisfaction } \\
\text { (alpha }=.85 \text { males) } \\
\text { (alpha }=.87 \text { females) }\end{array}$ & multivariate & $\begin{array}{l}\text { beta }=.32 \\
\text { (males) } \\
\text { beta }=.22 \\
\text { (females) }\end{array}$ \\
\hline $\begin{array}{l}\text { Medley } \\
(1980)\end{array}$ & $\begin{array}{l}65 \text { and older } \\
\text { noninstitutionallzed } \\
\text { ( } 648 \text { female) } \\
\text { national probability } \\
\text { sample } \\
\text { ( } n=301,192 \text { females } \\
\text { and } 109 \text { males) }\end{array}$ & $\begin{array}{l}\text { one Item measuring } \\
\text { satisfaction with } \\
\text { health status } \\
\text { (range: i to } 7 \text { ) }\end{array}$ & $\begin{array}{l}\text { 9-item index } \\
\text { measuring life } \\
\text { satisfaction } \\
\text { (range: } 21 \text { to 147) }\end{array}$ & multivariate & $\begin{array}{l}\text { beta }=.18 \\
\text { (females) } \\
\text { beta }=.24 \\
\text { (males) }\end{array}$ \\
\hline $\begin{array}{l}\text { Lee } \\
\text { (1979) }\end{array}$ & $\begin{array}{l}60 \text { and older } \\
\text { survey in Washington } \\
\text { state, two-stage } \\
\text { probability sample } \\
\text { ( } 758 \text { response rate) } \\
\text { subsample of married } \\
\text { persons only } \\
(418 \text { female }) \\
\text { (n=588 but } n=388 \\
\text { for analysis due to } \\
\text { missing data) }\end{array}$ & $\begin{array}{l}\text { one } 1 \text { tem measuring } \\
\text { self-perceived } \\
\text { health } \\
\text { (range: } 1 \text { to } 5 \text { ) }\end{array}$ & $\begin{array}{l}\text { 6-1tem index } \\
\text { measuring life } \\
\text { satisfaction } \\
\text { (range: } 6 \text { to 24) } \\
\text { (alpha= } .85 \text { males) } \\
\text { (alpha }=.87 \text { females) }\end{array}$ & mul tivar fate & $\begin{array}{l}b=.60 \\
\text { betal }=.23 \\
\text { (males) } \\
b=.82 * \\
\text { beta }=.26 \\
\text { (females) }\end{array}$ \\
\hline
\end{tabular}




\begin{tabular}{|c|c|c|c|c|c|}
\hline $\begin{array}{l}\text { Markides } \\
\text { and Martin } \\
(1979)\end{array}$ & $\begin{array}{l}60 \text { and older } \\
\text { predominantly poor } \\
\text { (648 fenale) } \\
\text { white subsample only } \\
\text { data collected in } \\
\text { four low-incme } \\
\text { census tracts of } \\
\text { San Antonio, Texas } \\
\text { ( } n=141)\end{array}$ & $\begin{array}{l}\text { one item measuring } \\
\text { self-perceived } \\
\text { health } \\
\text { (range: } 1 \text { to } 4 \text { ) }\end{array}$ & $\begin{array}{l}\text { 13-item index } \\
\text { LSI2 }\end{array}$ & multivariate & $\begin{array}{l}\text { beta }=.30 \\
\text { (males) } \\
\text { beta }=.37 \\
\text { (f emales) }\end{array}$ \\
\hline $\begin{array}{l}\text { Jackson, Bacon, } \\
\text { and Peterson } \\
(1978)\end{array}$ & $\begin{array}{l}\text { 'ron-institutionalized } \\
\text { elderly living in } \\
\text { the Detroit area } \\
\text { (1008 retired Blacks) } \\
\text { predominantly poor } \\
\text { average age: } 70 \\
\text { (age range: } 54 \text { to } 83 \text { ) } \\
\text { (728 fenale) } \\
\text { sample purposely } \\
\text { selected from Black } \\
\text { older adult center } \\
\text { participants } \\
\text { (58 refusal rate) } \\
\text { (n=102) }\end{array}$ & $\begin{array}{l}54 \text { years and ol der } \\
\text { self-percelved } \\
\text { health } \\
\text { (range: } 0 \text { to } 1 \text { ) }\end{array}$ & one Item measuring & LSIA & multivariate beta $=-.40^{\star \star}$ \\
\hline $\begin{array}{l}\text { Lee } \\
\text { (1978) }\end{array}$ & $\begin{array}{l}60 \text { and older } \\
\text { survey In Washington } \\
\text { state, two-stage } \\
\text { probability sample } \\
\text { ( } 758 \text { response rate) } \\
\text { subsample of married } \\
\text { persons only } \\
\text { (398 female) } \\
\text { (n=588 but } n=439 \\
\text { for analysis die to } \\
\text { missing data) }\end{array}$ & $\begin{array}{l}\text { one item measuring } \\
\text { self-percelved } \\
\text { health } \\
\text { (range: } 1 \text { to } 5 \text { ) }\end{array}$ & $\begin{array}{l}\text { 6-item Index } \\
\text { measuring life } \\
\text { satisfaction } \\
\text { (range: } 6 \text { to 24) } \\
\text { (alpha= .85 males) } \\
\text { (alpha= } .87 \text { females) }\end{array}$ & multivariate & $\begin{array}{l}\text { beta }=.27 \\
\text { (males) } \\
\text { beta }=.23 \\
\text { (females) }\end{array}$ \\
\hline
\end{tabular}


Myleg
(1978)

65 and older
cample from the

province of Manitob

128 of sample 16

institutionallzed

stratified random

sample

( $n=3851$ but $n=3632$

for analysis due to

missing data;

group 1 , cormunity

residents, $n=3199 ;$
group 2 , institution

group 2, institut

Noelker and Harel

54 and older

institutional 1zed

elderly

average age:

(668 female)

systernatic selection

of 14 nursing homes

and systematic randon

sample of residento

belf-care

$(n=125)$ one item measuring ISIA

self-perceived

(range: 1 to 5 )

(1)

1 to 5

.

mult tuar iate

beta= -.27

$\mathrm{b}=-1.18$

beta $=-.23$
(group 2)

a
one item measuring self-perceived

(range: 1 to 3 )

Botwinick's

multivariate

beta $=.17$

Philadelphia

Geriatric Center

morale scale

beta $=.22$ 


\begin{tabular}{|c|c|c|c|c|c|}
\hline $\begin{array}{l}\text { Palmore } \\
\text { and Rivett } \\
\text { (1977) }\end{array}$ & $\begin{array}{l}46 \text { and older } \\
\text { longitudinal study } \\
\text { of middle and upper } \\
\text { middle class persons } \\
\text { from the Durham, } \\
\text { North Carolina area } \\
\text { stratif led randan } \\
\text { sample of member } 8 \text { of } \\
\text { a local health } \\
\text { insurance company } \\
\text { (n=502) } \\
3 \text { waves of data } \\
\text { collection over a } \\
\text { six-year per iod } \\
\text { continuers tend to be } \\
\text { better off in all } \\
\text { domaing } \\
\text { (258 attrition) } \\
\text { (488 female at wave 3) } \\
\text { (n=378) }\end{array}$ & $\begin{array}{l}\text { one Item measuring } \\
\text { self-perceived } \\
\text { health } \\
\text { (range: } 0 \text { to } 9 \text { ) }\end{array}$ & $\begin{array}{l}\text { Cantrill ladder } \\
\text { (range: } 0 \text { to } 9 \text { ) }\end{array}$ & multivariate & $\begin{array}{l}\text { beta }=.39 \\
\text { (wave } 11 \\
\text { beta }=.27 \\
\text { (wave } 2 \mathrm{~L} \\
\text { beta= } .25 \\
\text { (wave } 3 \mathrm{~L}\end{array}$ \\
\hline $\begin{array}{l}\text { Toseland } \\
\text { and Sykes } \\
\text { (1977) }\end{array}$ & $\begin{array}{l}55 \text { and older } \\
\text { noninstitutionalized } \\
\text { living in suburban } \\
\text { and rural areas near } \\
\text { Madison, wisconsin } \\
\text { (318 forale) } \\
\text { systematic random } \\
\text { selection from a list } \\
\text { of participants and } \\
\text { non-participants } \\
\text { at a senior center } \\
\text { (348 response rate) } \\
\text { (n=137) }\end{array}$ & $\begin{array}{l}\text { one iten measuring } \\
\text { self-perceived } \\
\text { health }\end{array}$ & $\begin{array}{l}\text { 13-1tem ISIZ } \\
\text { (range: } 0 \text { to 26) }\end{array}$ & multivariate & $b=2.07$ \\
\hline
\end{tabular}




\begin{tabular}{|c|c|c|c|c|c|}
\hline $\begin{array}{l}\text { Sauer, } \\
\text { Shehan, } \\
\text { and Boymel } \\
\text { (1976) }\end{array}$ & $\begin{array}{l}60 \text { and older } \\
\text { noninstitutionallzed } \\
\text { subsample of } 1973 \\
\text { MoRC data, national } \\
\text { probability sample } \\
\text { of per sons } 18 \text { and } \\
\text { older (n=1504) } \\
\text { ( } n=304 \text { for analysis) }\end{array}$ & $\begin{array}{l}\text { one item measur ing } \\
\text { self-perceived } \\
\text { health } \\
\text { (range: } 0 \text { to } 3 \text { ) }\end{array}$ & $\begin{array}{l}\text { 6-item index } \\
\text { measur ing } \\
\text { satisfaction with } \\
\text { income, cormunity, } \\
\text { hohbies, family, } \\
\text { friends, and global } \\
\text { happiness } \\
\text { (alphas .68) }\end{array}$ & multivariate & beta $=.25 * *$ \\
\hline $\begin{array}{l}\text { Medley } \\
(1976)\end{array}$ & $\begin{array}{l}65 \text { and older } \\
\text { noninstitutionalized } \\
\text { national probability } \\
\text { sample of persons } \\
\text { i8 and older ( } n=2164) \\
178 \text { elderly } \\
\text { median age of persons } \\
\text { in subsample: } 71 \\
\text { ( } 648 \text { female) } \\
\text { (n=362 but } n=301 \\
\text { for analysis } \\
\text { due to missing data) }\end{array}$ & $\begin{array}{l}\text { one item measuring } \\
\text { watisfaction with } \\
\text { health } \\
\text { (range: } 1 \text { to } 7)\end{array}$ & $\begin{array}{l}\text { 9-1tem index } \\
\text { measur ing global } \\
\text { life satisfaction } \\
\text { (range: } 21 \text { to } 147 \text { ) }\end{array}$ & multivariate & $\begin{array}{l}b=2.99 * \\
\text { beta= }=24 \\
\text { (males) } \\
b=2.50^{*} \\
\text { beta =.18 } \\
\text { (females) }\end{array}$ \\
\hline $\begin{array}{l}\text { Wolk and } \\
\text { Telleen } \\
\text { (1976) }\end{array}$ & $\begin{array}{l}\text { Setting A: } \\
\text { elderly persons } \\
\text { living in a } \\
\text { retirement home } \\
\text { (698 female) } \\
\text { median age: } 77 \\
\text { convenience sample } \\
\text { (n=51) } \\
\text { Setting B: } \\
\text { elderly persons } \\
\text { living in a } \\
\text { retirement village } \\
\text { (608 fenale) } \\
\text { median age: } 74 \\
\text { convenlence sample } \\
\text { (n=78) }\end{array}$ & $\begin{array}{l}\text { one Item measuring } \\
\text { self-perceived } \\
\text { health } \\
\text { (range: } 1 \text { to } 5 \text { ) }\end{array}$ & $\begin{array}{l}\text { 18-item Index } \\
\text { LSIA } \\
\text { (range: } 0 \text { to } 18 \text { ) }\end{array}$ & multivariate & $\begin{array}{l}\text { beta }=.28 \\
\text { (setting A) } \\
\text { beta }=.10 \\
\text { (setting B) }\end{array}$ \\
\hline $\begin{array}{l}\text { Tornstam } \\
\text { (1975) }\end{array}$ & $\begin{array}{l}45 \text { and older } \\
\text { moninstitutionallzed } \\
\text { residents of a } \\
\text { Swedish town } \\
\text { (age range: } 45 \text { to } 75 \text { ) } \\
\text { random sample } \\
\text { (n=469) }\end{array}$ & $\begin{array}{l}\text { one item measuring } \\
\text { satisfaction with } \\
\text { health } \\
\text { (range: } 1 \text { to } 5 \text { ) }\end{array}$ & $\begin{array}{l}\text { set of items } \\
\text { merged into an } \\
\text { index measuring } \\
\text { general satisfaction }\end{array}$ & multivariate & beta $=.24$ \\
\hline
\end{tabular}




\begin{tabular}{|c|c|c|c|c|c|}
\hline $\begin{array}{l}\text { Spreitzer } \\
\text { and Srryder } \\
\text { (1974) }\end{array}$ & $\begin{array}{l}65 \text { and older } \\
\text { noninstitutionalized } \\
\text { ( } 528 \text { fomale) } \\
\text { married and widowed } \\
\text { persons only } \\
\text { Norc data } \\
\text { stratified random } \\
\text { sample, } 1972 \text { and } 1973 \\
\text { surveys pooled } \\
\text { (n=224 due to missing } \\
\text { data) }\end{array}$ & $\begin{array}{l}\text { one item measuring } \\
\text { self-perceived health } \\
\text { (range: I to 4) }\end{array}$ & $\begin{array}{l}\text { one item measuring } \\
\text { happiness } \\
\text { (range: } 1 \text { to } 3 \text { ) }\end{array}$ & multivariate & beta $=.30$ \\
\hline $\begin{array}{l}\text { Edwards and } \\
\text { klemmack } \\
(1973)\end{array}$ & $\begin{array}{l}45 \text { and older } \\
\text { residents of four } \\
\text { counties in virginia } \\
\text { (548 female) } \\
\text { guota sample for } \\
\text { proportionate } \\
\text { representation of } \\
\text { those below and above } \\
65 \text { years } \\
\text { (n=507) }\end{array}$ & $\begin{array}{l}\text { one 1tem measuring } \\
\text { self-perceived } \\
\text { health } \\
\text { (range: I to } 3 \text { ) }\end{array}$ & $\begin{array}{l}\text { 10-item Index } \\
\text { modif led LsiA } \\
\text { (alpha=.90) }\end{array}$ & multivariate & beta $=.16^{*}$ \\
\hline $\begin{array}{l}\text { Palmore and } \\
\text { Lulkart } \\
\text { (1972) }\end{array}$ & $\begin{array}{l}46 \text { and older } \\
\text { noninstitutional ized } \\
\text { residents of Durham, } \\
\text { North Carolina } \\
\text { average age: } 59 \\
\text { age range: } 46 \text { to } 71 \\
\text { respondents } \\
\text { tend to be well off } \\
\text { (488 female) } \\
\text { randam sample from a } \\
\text { membership list of a } \\
\text { major health } \\
\text { insurance company } \\
\text { (refusal rate: 528) } \\
\text { lonaitudinal data } \\
\text { wave } 1 \text { data only } \\
\text { (n=502) }\end{array}$ & $\begin{array}{l}\text { one item measuring } \\
\text { self-perceived } \\
\text { health } \\
\text { (range: } 1 \text { to } 9 \text { ) }\end{array}$ & $\begin{array}{l}\text { one item measuring } \\
\text { happiness } \\
\text { Cantr11 ladder } \\
\text { (range: } 0 \text { to } 9 \text { ) }\end{array}$ & mul tivariate & $\begin{array}{l}\text { beta }=.44 \\
\text { (entire sample) } \\
\text { beta }=.46 \\
\text { (males) } \\
\text { beta }=.40 \\
\text { (females) }\end{array}$ \\
\hline
\end{tabular}


STUDIES OF THE RETATIONSHIP BETWEEN SIZE OF NETWORK AND SUBJECTIVE WELL-BEING

\begin{tabular}{|c|c|c|c|c|c|}
\hline $\begin{array}{l}\text { NUTHOR (S) } \\
\text { AND DATE }\end{array}$ & SMPPLE & $\begin{array}{l}\text { MFNSURE OF SOCIAL } \\
\text { RESOURCES }\end{array}$ & $\begin{array}{l}\text { MENSIRE OF } \\
\text { WELL-BEING }\end{array}$ & $\begin{array}{l}\text { TYPE OF } \\
\text { ANNYYSIS }\end{array}$ & RESULTS \\
\hline $\begin{array}{l}\text { Collette } \\
\text { (1984) }\end{array}$ & $\begin{array}{l}60 \text { and older } \\
\text { noninstitutionalized } \\
\text { residents of } \\
\text { Sichey, Australla } \\
\text { (648 female) } \\
\text { cluster sampling } \\
\text { age stratified } \\
\text { (n=1048) }\end{array}$ & $\begin{array}{l}\text { one item measuring } \\
\text { number of persons in } \\
\text { the network }\end{array}$ & $\begin{array}{l}\text { 14-1tem index } \\
\text { modified version of } \\
\text { the Philadelphia } \\
\text { Geriatric Center } \\
\text { morale cale }\end{array}$ & multivar late & $\begin{array}{l}\text { beta }=.03 \\
b=.10 \\
\text { (females) } \\
\text { beta }=.07 \star \\
b=.21 * \\
\text { (males) }\end{array}$ \\
\hline $\begin{array}{l}\text { Ward, Sherman, } \\
\text { and LaGory } \\
\text { (1984) }\end{array}$ & $\begin{array}{l}60 \text { and older } \\
\text { noninstitutionalized } \\
\text { residents of the } \\
\text { Albany, New York } \\
\text { SHSA } \\
\text { average age: } 71 \\
\text { (618 female) } \\
\text { stratified random } \\
\text { gample } \\
\text { (n=1185 but n=454 } \\
\text { for analysis due to } \\
\text { missing data) }\end{array}$ & $\begin{array}{l}\text { number of } \\
\text { instrumental } \\
\text { helpers in the } \\
\text { neighborhood } \\
\text { number of confidants } \\
\text { number of relatives } \\
\text { seen regularly } \\
\text { number of friends } \\
\text { in the area }\end{array}$ & $\begin{array}{l}\text { 17-ftem index } \\
\text { Philadelphia } \\
\text { Ger latric Center } \\
\text { morale scale } \\
\text { (range: } 23 \text { to 68) } \\
\text { (alpha }=.85 \text { ) }\end{array}$ & multivariate & $\begin{array}{l}\text { beta }=-.03 \\
\text { beta }=-.03 \\
\text { beta }=.07\end{array}$ \\
\hline $\begin{array}{l}\text { Ory and } \\
\text { Goldberg } \\
(1983)\end{array}$ & $\begin{array}{l}65 \text { and older } \\
\text { noninstitutionalized } \\
\text { residents of } \\
\text { Washington county, } \\
\text { Maryland } \\
\text { (age range: } 65 \text { to } 75 \text { ) } \\
\text { (1008 white, married } \\
\text { wamen) } \\
\text { sampled all who met } \\
\text { eligiblilty criteria } \\
\text { described above } \\
\text { (718 response rate) } \\
\text { (n=1073) }\end{array}$ & $\begin{array}{l}\text { number of persons } \\
\text { (relatives and } \\
\text { friends) respondent } \\
\text { has regular contacts } \\
\text { w1th } \\
\text { number of conf } 1 \text { dants } \\
\text { respondent has } \\
\text { regular contacts } \\
\text { with }\end{array}$ & $\begin{array}{l}\text { one item measuring } \\
\text { happiness } \\
\text { (range: } 1 \text { to } 3 \text { ) }\end{array}$ & multivariate & beta $=.07$ \\
\hline
\end{tabular}




\begin{tabular}{|c|c|c|c|c|c|}
\hline $\begin{array}{l}\text { Beckman } \\
\text { and Houser } \\
\text { (1982) }\end{array}$ & $\begin{array}{l}60 \text { and older } \\
\text { noninstitutionalized } \\
\text { residents of Los } \\
\text { Angeles cointy } \\
\text { (1008 female) } \\
\text { average age: } 68 \\
\text { (age range: } 60 \text { to } 75) \\
\text { sample selected by a } \\
\text { combination of random } \\
\text { and snowball } \\
\text { techniques } \\
\text { (n=719 but } n=563 \\
\text { for analysis due to } \\
\text { missing data) } \\
\text { childless married } \\
\text { (n=156, group 1) } \\
\text { childless widowed } \\
\text { (n=114, group 2) } \\
\text { parent married } \\
\text { (n=155, group 3) } \\
\text { parent widowed } \\
\text { (n=138, group 4) }\end{array}$ & $\begin{array}{l}\text { one } 1 \text { tem measuring } \\
\text { number of } \\
\text { conf idants } \\
\text { one iten measur ing } \\
\text { number of persons } \\
\text { respondent feels } \\
\text { she can always count } \\
\text { on }\end{array}$ & $\begin{array}{l}\text { index camposed } \\
\text { of Items measuring } \\
\text { dissatisf action, } \\
\text { unhappiness, } \\
\text { and loneliness }\end{array}$ & miltivariate & $\begin{array}{l}\text { beta }=.13 \\
\text { (group 1) } \\
\text { beta= } .08 \\
\text { (group 2) } \\
\text { beta }=.10 \\
\text { (group 3) } \\
\text { beta }=.11 \\
\text { (group 4) } \\
\text { beta= } .16 \\
\text { (group 1) } \\
\text { beta = .15 } \\
\text { (group 2) } \\
\text { beta= .05 } \\
\text { (group 3) } \\
\text { beta }=-.0 \\
\text { (group 4) }\end{array}$ \\
\hline $\begin{array}{l}\text { Harel and } \\
\text { Noelker } \\
\text { (1982) }\end{array}$ & $\begin{array}{l}54 \text { and older } \\
\text { institutionallzed } \\
\text { elderly from the } \\
\text { Cleveland } \\
\text { metropolitan area } \\
\text { average age: } 81 \\
\text { (age range: } 54 \text { to 97) } \\
\text { (668 female) } \\
\text { nonprobability sample } \\
\text { (n=125) }\end{array}$ & $\begin{array}{l}\text { one item measuring } \\
\text { number of } \\
\text { "pref er red" } \\
\text { visitors }\end{array}$ & $\begin{array}{l}\text { Philadelphia } \\
\text { Geriatric Center } \\
\text { morale scale } \\
\text { one 1tem measuring } \\
\text { life satisfaction }\end{array}$ & multivariate & beta $=.21$ \\
\hline $\begin{array}{l}\text { Strain and } \\
\text { Chappell } \\
(1982)\end{array}$ & $\begin{array}{l}65 \text { and older } \\
\text { noninstitutionalized } \\
\text { residents of } \\
\text { Winnipeg, Manitobs } \\
\text { subsample of } \\
\text { nonusers of home } \\
\text { care services } \\
\text { (518 female) } \\
\text { stratified random } \\
\text { sample } \\
\text { ( } 348 \text { refusal rate) } \\
\text { ( } n=400)\end{array}$ & $\begin{array}{l}\text { one item measuring } \\
\text { number of } \\
\text { conf Idants }\end{array}$ & LSIA & multivariate & $\begin{array}{l}b=.16 \\
\text { beta }=.14\end{array}$ \\
\hline
\end{tabular}




\begin{tabular}{|c|c|c|c|c|c|}
\hline $\begin{array}{l}\text { Lee } \\
\text { (1979) }\end{array}$ & $\begin{array}{l}60 \text { and older } \\
\text { survey in washington } \\
\text { state, two-stage } \\
\text { probabllity sample } \\
\text { ( } 758 \text { response rate) } \\
\text { subsample of married } \\
\text { persons only } \\
\text { (418 female) } \\
\text { ( } \mathrm{n}=508 \text { but } n=388 \\
\text { for analysis due to } \\
\text { missing data) }\end{array}$ & $\begin{array}{l}\text { one item measuring } \\
\text { number of children }\end{array}$ & $\begin{array}{l}\text { 6-item Index } \\
\text { measuring life } \\
\text { satisfaction } \\
\text { (range: } 6 \text { to } 24) \\
\text { (alpha= } .85 \text { males) } \\
\text { (alpha }=.87 \text { females) }\end{array}$ & multivarlate & $\begin{array}{l}b=-.03 \\
\text { beta= }-.02 \\
\text { (males) } \\
b=.10 \\
\text { beta= .07 } \\
\text { (females) }\end{array}$ \\
\hline $\begin{array}{l}\text { Spakes } \\
\text { (1979) }\end{array}$ & $\begin{array}{l}55 \text { and ol der } \\
\text { noninstitutionalized } \\
\text { high socio-economic } \\
\text { status } \\
\text { stratifled national } \\
\text { sample, elderly } \\
\text { subsample only } \\
(n=873)\end{array}$ & $\begin{array}{l}\text { number of close } \\
\text { friends living in } \\
\text { the community }\end{array}$ & $\begin{array}{l}\text { one item } \\
\text { measuring life } \\
\text { satisfaction } \\
\text { (range: } 1 \text { to } 7 \text { ) }\end{array}$ & multival iate & beta $=.09$ \\
\hline $\begin{array}{l}\text { Edwards and } \\
\text { Rlestmack } \\
\text { (1973) }\end{array}$ & $\begin{array}{l}45 \text { and older } \\
\text { residents of four } \\
\text { counties in Virginia } \\
\text { (548 female) } \\
\text { quota sample for } \\
\text { proportionate } \\
\text { representation of } \\
\text { those below and above } \\
65 \text { years } \\
\text { (n=507) }\end{array}$ & $\begin{array}{l}\text { one item measuring } \\
\text { number of friends } \\
\text { one item measuring } \\
\text { number of neighbors } \\
\text { known to respondent } \\
\text { one item measuring } \\
\text { number of relatives } \\
\text { living in the } \\
\text { household }\end{array}$ & $\begin{array}{l}\text { 10-item index } \\
\text { modif ied LSIA } \\
\text { (alpha }=.90)\end{array}$ & multivar late & $\begin{array}{l}\text { beta }=-.01 \\
\text { beta }=.11 *\end{array}$ \\
\hline
\end{tabular}


STUDIES OF THE RELATIONSHIP BETWEEN INFORMAL CONTACTS ND SURJECTIVE WEHL-BEING

\begin{tabular}{|c|c|c|c|c|c|}
\hline $\begin{array}{l}\text { NUTIOR (S) } \\
\text { NND DNTE }\end{array}$ & SMMRE & $\begin{array}{l}\text { MFASIRE OF SOCIAL } \\
\text { RESOURCES }\end{array}$ & $\begin{array}{l}\text { MENSIRE OF } \\
\text { WFIJ-BEING }\end{array}$ & $\begin{array}{l}\text { TYPE. OF } \\
\text { NNNLYSIS }\end{array}$ & RESIRTS \\
\hline $\begin{array}{l}\text { Ward, Sherman, } \\
\text { and Ifacory } \\
\text { (1984) }\end{array}$ & $\begin{array}{l}60 \text { and older } \\
\text { moninstitutionalized } \\
\text { residents of the } \\
\text { Albany-New York } \\
\text { SMSA } \\
\text { average age: } 71 \\
\text { (618 female) } \\
\text { stratifled random } \\
\text { sample } \\
\text { (n=1185 but n= } 454 \\
\text { for analysis due to } \\
\text { missing data) }\end{array}$ & $\begin{array}{l}\text { frequency of } \\
\text { contact with } \\
\text { a confidant } \\
\text { (range: 1 to 5) } \\
\text { frequency of } \\
\text { interaction with } \\
\text { children } \\
\text { (range: } 1 \text { to } 4 \text { ) } \\
\text { frequency of } \\
\text { interaction with } \\
\text { neighbors }\end{array}$ & $\begin{array}{l}\text { 17-item index } \\
\text { Philadelphia } \\
\text { Ger iatric Center } \\
\text { morale scale } \\
\text { (range: } 23 \text { to 68) } \\
\text { (alpha= .85) }\end{array}$ & multivariate & beta $=-.01$ \\
\hline \multirow[t]{4}{*}{$\begin{array}{l}\text { Baur and Okun } \\
\text { (1983) }\end{array}$} & \multirow{4}{*}{$\begin{array}{l}66 \text { and older } \\
\text { apartment dwellers } \\
\text { of a retirement } \\
\text { community in Phoenix, } \\
\text { Arizona, who could } \\
\text { be reinterviewed } \\
3 \text { years after the } \\
\text { first wave of data } \\
\text { collection } \\
\text { (age range: } 66 \text { to } 94 \text { ) } \\
\text { (808 female) } \\
\text { stratified random } \\
\text { sample } \\
\text { (178 attrition rate) } \\
\text { (n=87) }\end{array}$} & $\begin{array}{l}\text { one item measuring } \\
\text { daily contacts } \\
\text { with frtends } \\
\text { (range: } 0 \text { to } 1 \text { ) }\end{array}$ & $\begin{array}{l}\text { LSIB } \\
\text { (alpha }=.69, \text { wave 1) } \\
\text { (alpha }=.73, \text { wave 2) }\end{array}$ & multivar late & $\begin{array}{l}b=1.02 \\
\text { beta }=.14\end{array}$ \\
\hline & & $\begin{array}{l}\text { one item measuring } \\
\text { weekly contacts } \\
\text { with friends } \\
\text { (range: } 0 \text { to } 1 \text { ) }\end{array}$ & LSIB (wave 1) & & $\begin{array}{l}b=1.64 \\
\text { beta }=.20\end{array}$ \\
\hline & & $\begin{array}{l}\text { one item measuring } \\
\text { daily contacts } \\
\text { with neighbors } \\
\text { (range: } 0 \text { to } 1 \text { ) }\end{array}$ & LSIB (wave 1) & & $\begin{array}{l}b=3.54 \\
\text { beta }=.33\end{array}$ \\
\hline & & $\begin{array}{l}\text { one item measuring } \\
\text { weekly contacts } \\
\text { with neighbor } 8 \\
\text { (ranges } 0 \text { to } 1 \text { ) }\end{array}$ & LSIB (wave 1) & & $\begin{array}{l}b=2.86 \\
\text { beta }=.23\end{array}$ \\
\hline
\end{tabular}




\begin{tabular}{|c|c|c|c|c|c|}
\hline $\begin{array}{l}\text { Deiml ing, } \\
\text { Harel, and } \\
\text { Noelker } \\
\text { (1983) }\end{array}$ & $\begin{array}{l}\text { elderly Ilving in } \\
\text { a housing site with } \\
\text { some age-integrated } \\
\text { and some age- } \\
\text { segregated builidings } \\
\text { predominantly poor } \\
\text { average age: } 73 \\
\text { (78z fenale) } \\
\text { (568 minority) } \\
\text { surveyed all older } \\
\text { residents } \\
\text { (728 response rate) } \\
\text { (n=326) }\end{array}$ & $\begin{array}{l}\text { one index measuring } \\
\text { number of relatives } \\
\text { and friends in the } \\
\text { network, their } \\
\text { proximity, and } \\
\text { the frequency of } \\
\text { contact with the } \\
\text { respondent }\end{array}$ & LSIA & multivariate & $\begin{array}{l}b=.07 \\
\text { (entire } \\
\text { sample) } \\
b=.05 \\
\text { (white } \\
\text { subsample) } \\
b=.04 \\
\text { (Black } \\
\text { Eubsample) }\end{array}$ \\
\hline \multirow[t]{5}{*}{$\begin{array}{l}\text { Usui, Rell, } \\
\text { and Phillipe } \\
\text { (1983) }\end{array}$} & \multirow{5}{*}{$\begin{array}{l}60 \text { and older } \\
\text { noninstitutionalized } \\
\text { residents of a county } \\
\text { in Rentucky } \\
338 \text { Blacks ( } n=219) \\
\text { conventence sample } \\
\text { ( } n=704 \text { but } n=657 \\
\text { for analysis due to } \\
\text { missing data) }\end{array}$} & $\begin{array}{l}\text { frequency of contact } \\
\text { with closest relative } \\
\text { (range: } 1 \text { to } 8 \text { ) }\end{array}$ & $\begin{array}{l}\text { 13-1tem index } \\
\text { LSIz }\end{array}$ & multivar late & $\begin{array}{l}b=.18 * * \\
\text { (White } \\
\text { subsample) } \\
b=.14 \\
\text { (Black } \\
\text { subsample) }\end{array}$ \\
\hline & & \multirow[t]{2}{*}{$\begin{array}{l}\text { frequency of contact } \\
\text { with closest friend } \\
\text { (range: } 1 \text { to } 8 \text { ) }\end{array}$} & & & $\begin{array}{l}\text { be .13* } \\
\text { (White } \\
\text { subsample) }\end{array}$ \\
\hline & & & & & $\begin{array}{l}\mathrm{b}=.13 \\
\text { (Black } \\
\text { subsarmple) }\end{array}$ \\
\hline & & \multirow[t]{2}{*}{$\begin{array}{l}\text { frequency of contact } \\
\text { with closest neighbor } \\
\text { (range: I to 8) }\end{array}$} & & & $\begin{array}{l}\mathrm{b}=.14^{\star \star} \\
\text { (White } \\
\text { subsample) }\end{array}$ \\
\hline & & & & & $\begin{array}{l}\mathrm{b}=.06 \\
\text { (Black } \\
\text { subsample) }\end{array}$ \\
\hline
\end{tabular}




\begin{tabular}{|c|c|c|c|c|c|}
\hline $\begin{array}{l}\text { Ward and } \\
\text { Rilburn } \\
(1983)\end{array}$ & $\begin{array}{l}65 \text { and older } \\
\text { subsample of } 1974 \\
\text { NORC cata random } \\
\text { sample of persons } \\
18 \text { and over ( } n=5000) \\
\text { (n=2723 for } \\
\text { analygis) }\end{array}$ & $\begin{array}{l}\text { one item measuring } \\
\text { most recent contact } \\
\text { with children } \\
\text { (range: } 1 \text { to } 6 \text { ) } \\
\text { one Iten measuring } \\
\text { most recent contact } \\
\text { with close frlend } \\
\text { (range: } 1 \text { to } 6 \text { ) }\end{array}$ & $\begin{array}{l}\text { 18-item index } \\
\text { LSI } \\
\text { (range: } 1 \text { to } 36 \text { ) }\end{array}$ & multivariate & beta $=.08 *$ \\
\hline & & $\begin{array}{l}\text { one item measuring } \\
\text { most recent } \\
\text { contact with } \\
\text { neighbor } \\
\text { (range: } 1 \text { to } 6 \text { ) }\end{array}$ & & & beta $=.05 *$ \\
\hline $\begin{array}{l}\text { Beckman } \\
\text { and Houser } \\
\text { (1982) }\end{array}$ & $\begin{array}{l}60 \text { and older } \\
\text { noninstitutionalized } \\
\text { residents of Los } \\
\text { Angeles county } \\
\text { (1008 female) } \\
\text { average age: } 68 \\
\text { (age range: } 60 \text { to } 75) \\
\text { sample selected by a } \\
\text { combination of random } \\
\text { and mowball } \\
\text { techniques } \\
\text { ( } n=719 \text { but } n=563 \\
\text { for analysis due to } \\
\text { missing data) } \\
\text { childless married } \\
\text { ( } n=156, \text { group 1) } \\
\text { chldaless widowed } \\
\text { (n=114, group 2) } \\
\text { parent married } \\
\text { (n=155, group 3) } \\
\text { parent widowed } \\
\text { (n=138, group 4) }\end{array}$ & $\begin{array}{l}\text { 6-item index } \\
\text { measuring } \\
\text { frequency of } \\
\text { interaction with } \\
\text { relatives, friends, } \\
\text { and neighbors }\end{array}$ & $\begin{array}{l}\text { 1ndex camposed } \\
\text { of itens measur ing } \\
\text { dissatisfaction, } \\
\text { unhappincss, } \\
\text { and loneliness }\end{array}$ & muitivar late & $\begin{array}{l}\text { beta }=.04 \\
\text { (group 1) } \\
\text { beta }=.06 \\
\text { (group 2) } \\
\text { beta }=.12 \\
\text { (group 3) } \\
\text { beta=.08 } \\
\text { (group 4) }\end{array}$ \\
\hline
\end{tabular}




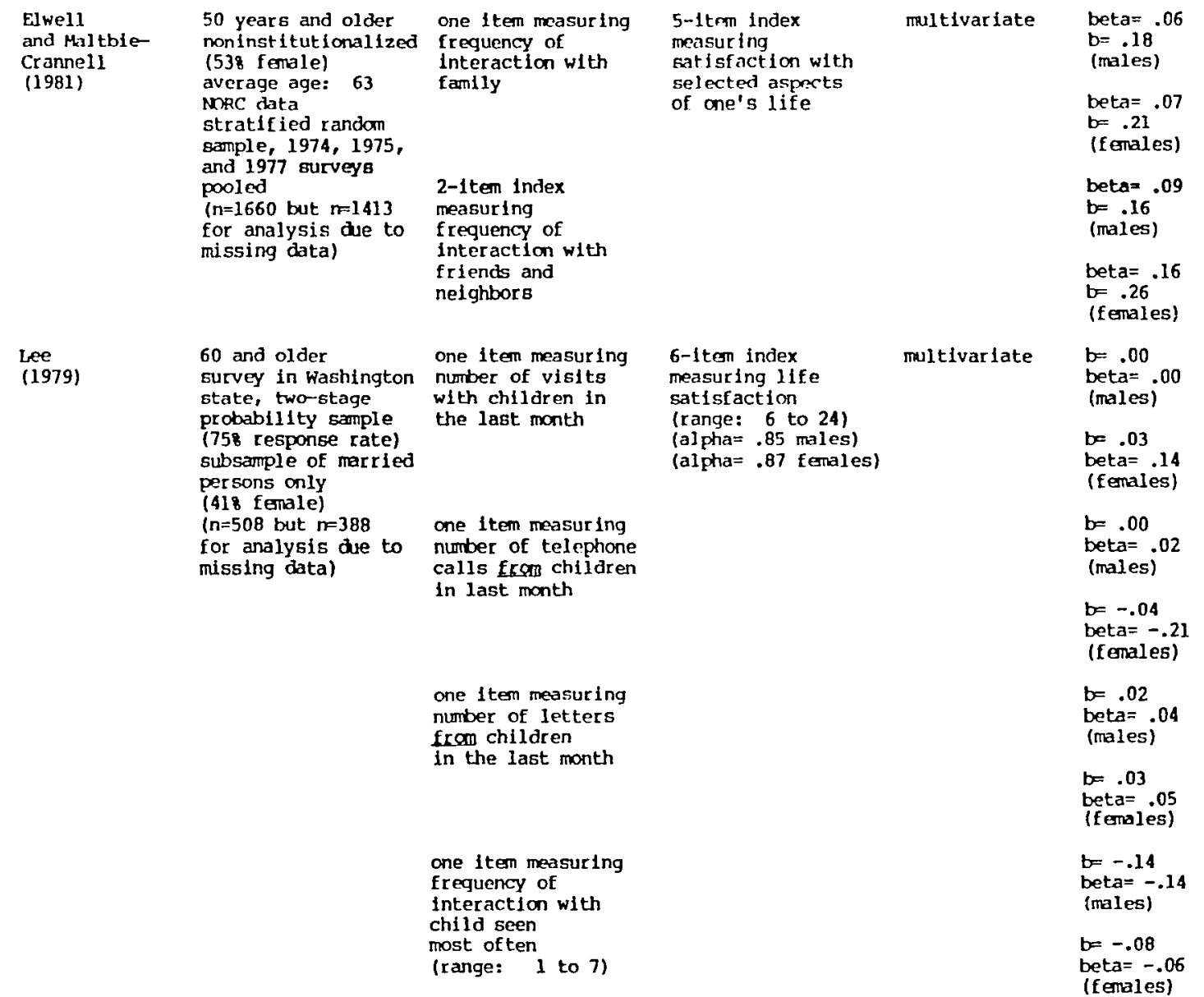




\begin{tabular}{|c|c|c|c|c|c|}
\hline \multirow[t]{2}{*}{$\begin{array}{l}\text { Wood and } \\
\text { Robertson } \\
(1978)\end{array}$} & \multirow[t]{2}{*}{$\begin{array}{l}\text { grandparents from } \\
\text { Madison, wisconsin } \\
\text { arca predominantly } \\
\text { working class } \\
\text { (478 female) } \\
\text { average age: } 65 \\
\text { cross-sectional area } \\
\text { probability sample } \\
\text { (n=257) }\end{array}$} & $\begin{array}{l}\text { index measuring } \\
\text { involvement with } \\
\text { friends, e.g., } \\
\text { number and } \\
\text { frequency of } \\
\text { activities with } \\
\text { friends }\end{array}$ & \multirow[t]{2}{*}{$\begin{array}{l}\text { 13-1 item index } \\
\text { LSI2 }\end{array}$} & \multirow[t]{2}{*}{ multivariate } & $\begin{array}{l}b=.11 \\
\text { beta= } .33\end{array}$ \\
\hline & & $\begin{array}{l}\text { Index measuring } \\
\text { involvenent with } \\
\text { grandchildren, e.g., } \\
\text { number and frequency } \\
\text { of activitipg } \\
\text { with grandchildren }\end{array}$ & & & $\begin{array}{l}b=.07 \\
\text { beta }=.16\end{array}$ \\
\hline \multirow[t]{2}{*}{$\begin{array}{l}\text { Rnapp } \\
\text { (1977) }\end{array}$} & \multirow{2}{*}{$\begin{array}{l}62 \text { and older } \\
\text { primar ily manual } \\
\text { workers } \\
\text { (558 fenale) } \\
\text { average age: } 76 \\
\text { (age range: } 62 \text { to } 86 \text { ) } \\
\text { converience sample } \\
\text { (n=51) }\end{array}$} & $\begin{array}{l}\text { number of hours } \\
\text { on a weekly tasis } \\
\text { spent with family and } \\
\text { friends }\end{array}$ & $\begin{array}{l}4 \text {-item Index } \\
\text { from the LSI scale } \\
\text { measur ing } \\
\text { contentment } \\
\text { (range: } 0 \text { to } 8 \text { ) }\end{array}$ & \multirow[t]{2}{*}{ multivariate } & $\begin{array}{l}b=.09 \\
\text { beta }=.18\end{array}$ \\
\hline & & & $\begin{array}{l}\text { 4-1tem index from } \\
\text { the LSI scale } \\
\text { measuring achievement } \\
\text { (range: } 0 \text { to } 8 \text { ) }\end{array}$ & & $\begin{array}{l}b=.13 \\
\text { beta= } .27\end{array}$ \\
\hline \multirow[t]{6}{*}{$\begin{array}{l}\text { Saver } \\
\text { (1977) }\end{array}$} & \multirow{6}{*}{$\begin{array}{l}65 \text { and older } \\
\text { noninstitutionalized } \\
\text { elderly from the low } \\
\text { socioeconomic areas } \\
\text { of Philadelphia } \\
\text { (568 female) } \\
\text { (778 Black elderly) } \\
\text { stratified randiam } \\
\text { sample } \\
\text { (n=1022 but } \\
n=932 \text { for analysis } \\
\text { due to missing data) }\end{array}$} & $\begin{array}{l}\text { one } 1 \text { tesm measuring } \\
\text { frequency of } \\
\text { interaction with } \\
\text { family }\end{array}$ & \multirow{6}{*}{$\begin{array}{l}\text { 17-1tem index } \\
\text { modified version } \\
\text { of the Philadelphia } \\
\text { Ger iatric Center } \\
\text { morale scale } \\
\text { (range: } 0 \text { to } 17 \text { ) } \\
\text { (alphas .82) }\end{array}$} & \multirow[t]{6}{*}{ multivariate } & $\begin{array}{l}\text { beta }=.10 \\
\text { (entire } \\
\text { sample) }\end{array}$ \\
\hline & & & & & $\begin{array}{l}\text { beta }=.08 \\
\text { (Black } \\
\text { cubsample) }\end{array}$ \\
\hline & & & & & $\begin{array}{l}\text { beta }=.18^{* *} \\
\text { (White } \\
\text { subsomple) }\end{array}$ \\
\hline & & \multirow[t]{3}{*}{$\begin{array}{l}\text { one item measuring } \\
\text { frequency of } \\
\text { interaction with } \\
\text { friends }\end{array}$} & & & $\begin{array}{l}\text { beta= -.02 } \\
\text { (entire } \\
\text { sample) }\end{array}$ \\
\hline & & & & & $\begin{array}{l}\text { beta }=-.05 \\
\text { (Black } \\
\text { subsample) }\end{array}$ \\
\hline & & & & & $\begin{array}{l}\text { beta }=.11 \\
\text { (White } \\
\text { subsample) }\end{array}$ \\
\hline
\end{tabular}




\begin{tabular}{|c|c|c|c|c|c|}
\hline \multirow[t]{4}{*}{$\begin{array}{l}\text { Rnapp } \\
\text { (1976) }\end{array}$} & \multirow{4}{*}{$\begin{array}{l}62 \text { and older } \\
\text { noninst itutionalized } \\
\text { residents of a } \\
\text { crastal resort } \\
\text { in Scuthern Pngland } \\
\text { ( } 558 \text { fenale) } \\
\text { average age: } 76 \\
\text { (age range: } 62 \text { to } 86 \text { ) } \\
\text { convenience sample } \\
\text { (n=51) }\end{array}$} & \multirow{4}{*}{$\begin{array}{l}\text { number of hours } \\
\text { on a weekly basis } \\
\text { spent with family } \\
\text { and friends }\end{array}$} & $\begin{array}{l}6 \text {-itrm index } \\
\text { from the LSIA } \\
\text { scale which measures } \\
\text { mood tone } \\
\text { (range: } 2 \text { to 12) }\end{array}$ & multivariate & $\begin{array}{l}b=.19^{5} \\
\text { beta }=.45\end{array}$ \\
\hline & & & $\begin{array}{l}\text { 6-1tem index from } \\
\text { the ISIA scale } \\
\text { which measures zest } \\
\text { for life } \\
\text { (range: } 5 \text { to 12) }\end{array}$ & & $\begin{array}{l}b=.19 \\
\text { beta }=.39\end{array}$ \\
\hline & & & $\begin{array}{l}\text { 3-1tem Index from } \\
\text { the LSIA scale } \\
\text { which measures } \\
\text { congruence } \\
\text { (range: } 2 \text { to } 6 \text { ) }\end{array}$ & & $\begin{array}{l}b=.10 \\
b e t a=.36\end{array}$ \\
\hline & & & $\begin{array}{l}\text { 3-1tem index from } \\
\text { the isIA scale } \\
\text { which measure } 8 \\
\text { resolution } \\
\text { (range: } 0 \text { to } 6 \text { ) }\end{array}$ & & $\begin{array}{l}b=.10 \\
\text { beta }=.22\end{array}$ \\
\hline \multirow[t]{3}{*}{$\begin{array}{l}\text { Edwards and } \\
\text { Re enmack } \\
\text { (1973) }\end{array}$} & \multirow[t]{3}{*}{$\begin{array}{l}45 \text { and older } \\
\text { residents of four } \\
\text { counties in Virginia } \\
\text { (548 fenale) } \\
\text { quota sample for } \\
\text { proportionate } \\
\text { representation of } \\
\text { those below and above } \\
65 \text { years } \\
\text { ( } n=507)\end{array}$} & $\begin{array}{l}\text { one iten measuring } \\
\text { frequency of } \\
\text { in-person contact } \\
\text { with children } \\
\text { one item measuring } \\
\text { frequency of } \\
\text { in-person contact } \\
\text { with relatives }\end{array}$ & $\begin{array}{l}\text { 10-item index } \\
\text { modified LSIA } \\
\text { (alpha }=.90)\end{array}$ & multivariate & beta $=.02$ \\
\hline & & $\begin{array}{l}\text { one item measuring } \\
\text { frequency of in- } \\
\text { person contact with } \\
\text { nelghbor } 8\end{array}$ & & & beta $=.14 *$ \\
\hline & & $\begin{array}{l}\text { one item measuring } \\
\text { frequency of } \\
\text { contact by phone } \\
\text { with relatives, } \\
\text { neighbors, and } \\
\text { friends }\end{array}$ & & & beta $=.11 *$ \\
\hline
\end{tabular}


STUDIES OF THE REJATIONSHIP BETWEEN SOCIETAL INNOLVEMENT ND SUBJECTIVE WELL-BEING

\begin{tabular}{|c|c|c|c|c|c|}
\hline $\begin{array}{l}\text { NTTYOR(S) } \\
\text { NND DNTE }\end{array}$ & SAMPLE & $\begin{array}{l}\text { MFASURE OF SOCIAL } \\
\text { INVOLVEMEAT }\end{array}$ & $\begin{array}{l}\text { MEASURE OF } \\
\text { WEII BEING }\end{array}$ & $\begin{array}{l}\text { TYPF, } \boldsymbol{O F} \\
\text { NNRYSIS }\end{array}$ & RESULTS \\
\hline $\begin{array}{l}\text { Hooker and } \\
\text { Vent 1s } \\
(1984)\end{array}$ & $\begin{array}{l}53 \text { and older } \\
\text { residents of } \\
\text { southeastern and } \\
\text { central virginia } \\
\text { middle class } \\
\text { background } \\
\text { average age: } 70 \\
\text { (age range: } 53 \text { to } 88 \text { ) } \\
\text { (558 female) } \\
\text { convenience sample } \\
\text { of volunteers } \\
\text { recruited from } \\
\text { national associations } \\
\text { of retired persons } \\
\text { (688 response rate) } \\
\text { (n=76 but m=57 for } \\
\text { analysis due to } \\
\text { missing data) }\end{array}$ & $\begin{array}{l}\text { one item measuring } \\
\text { mean number of } \\
\text { activities } \\
\text { engaged in on a } \\
\text { daily basis } \\
\text { (range: } 1 \text { to } 11 \text { ) } \\
\end{array}$ & $\begin{array}{l}\text { LSIN } \\
\text { (alpha = .73) }\end{array}$ & multivariate & $\begin{array}{l}b=-.02 \\
\text { beta }=.16\end{array}$ \\
\hline $\begin{array}{l}\text { Deimling, } \\
\text { Harel, and } \\
\text { Noelker } \\
\text { (1983) }\end{array}$ & $\begin{array}{l}\text { elderly living in } \\
\text { a housing site with } \\
\text { some age-1ntegrated } \\
\text { and sone age- } \\
\text { segregated buildings } \\
\text { predoninantly poor } \\
\text { average age: } 73 \\
\text { (788 female) } \\
\text { (568 minority) } \\
\text { surveyed all older } \\
\text { residents } \\
\text { (728 response rate) } \\
(n=326)\end{array}$ & $\begin{array}{l}\text { one index measuring } \\
\text { frequency of } \\
\text { participation, on a } \\
\text { weekly basiz, in } \\
\text { recreational, social, } \\
\text { or cultural } \\
\text { activities }\end{array}$ & LSIA & multivariate & $\begin{array}{l}\mathrm{b}=.10 \\
\text { (entire } \\
\text { sample) } \\
\mathrm{b}=.10 \\
\text { (White } \\
\text { subsample) } \\
\mathrm{b}=.21 \\
\text { (Black } \\
\text { subsample) }\end{array}$ \\
\hline
\end{tabular}




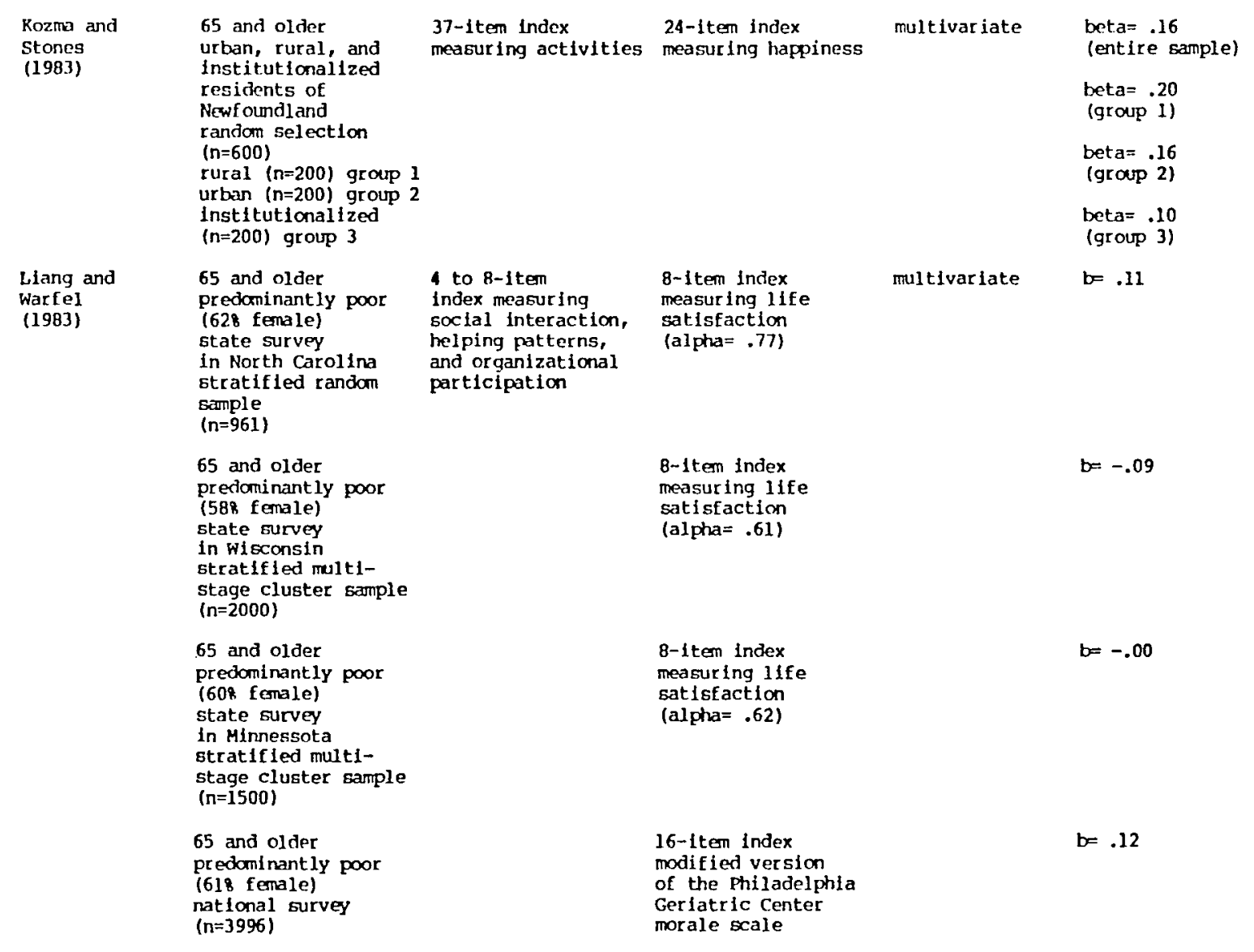




\begin{tabular}{|c|c|c|c|c|c|}
\hline $\begin{array}{l}\text { Ory and } \\
\text { Goldberg } \\
\text { (1983) }\end{array}$ & $\begin{array}{l}65 \text { and older } \\
\text { noninstitutionalized } \\
\text { residents of } \\
\text { Washington county, } \\
\text { Maryland } \\
\text { (age range: } 65 \text { to } 75) \\
\text { (1008 white, married } \\
\text { women) } \\
\text { sampled all who met } \\
\text { el lgibility criteria } \\
\text { described above } \\
\text { (718 response rate) } \\
\text { (n=1073) }\end{array}$ & $\begin{array}{l}\text { number of } \\
\text { organizations } \\
\text { respondent belongs } \\
\text { to }\end{array}$ & $\begin{array}{l}\text { one item measuring } \\
\text { happiness } \\
\text { (range: } 1 \text { to } 3 \text { ) }\end{array}$ & multivariate & beta $=.08$ \\
\hline $\begin{array}{l}\text { Usui, Refl, } \\
\text { and Phillips } \\
\text { (1983) }\end{array}$ & $\begin{array}{l}60 \text { and older } \\
\text { noninstitutionalized } \\
\text { residents of a county } \\
\text { in Rentirky } \\
338 \text { Blacks ( } n=219) \\
\text { convenience sample } \\
\text { (n=704 but } n=657 \\
\text { for analysis due to } \\
\text { missing data) }\end{array}$ & $\begin{array}{l}\text { one } 1 \text { tem measuring } \\
\text { number of } \\
\text { member ships in } \\
\text { voluntary } \\
\text { associations }\end{array}$ & $\begin{array}{l}\text { 13-iter index } \\
\text { LSIz } \\
\text { (range: } 0 \text { to 13) }\end{array}$ & multivar iate & $\begin{array}{l}b=.33 * \\
\text { (thite } \\
\text { subsample) } \\
b=.45^{*} \\
\text { (Black } \\
\text { subsample) } \\
b=.09 \\
\text { (White } \\
\text { subsample) } \\
b=.01 \\
\text { (Black } \\
\text { subsample) }\end{array}$ \\
\hline $\begin{array}{l}\text { Ward and } \\
\text { Rilburn } \\
\text { (1983) }\end{array}$ & $\begin{array}{l}65 \text { and older } \\
\text { subsample of } 1974 \\
\text { RoRC data, random } \\
\text { sample of persons } 18 \\
\text { and over ( }=5000) \\
(\mathrm{n}=2723 \text { for } \\
\text { analysis) }\end{array}$ & $\begin{array}{l}\text { 9-item index } \\
\text { measuring how } \\
\text { recently a respondent } \\
\text { has gone to } 9 \\
\text { cormunity places } \\
\text { (range: g to 54) }\end{array}$ & $\begin{array}{l}\text { 18-item Index } \\
\text { LSI } \\
\text { (range: } 1 \text { to } 36 \text { ) }\end{array}$ & multivariate & beta $=.12^{\star}$ \\
\hline $\begin{array}{l}\text { Harel and } \\
\text { Noelker } \\
(1982)\end{array}$ & $\begin{array}{l}54 \text { and older } \\
\text { 1nstitutionalized } \\
\text { elderly from the } \\
\text { Cleveland } \\
\text { metropolitan area } \\
\text { average age: } 81 \\
\text { (age range: } 57 \text { to 97) } \\
\text { (668 female) } \\
\text { nonprobability sample } \\
\text { ( } n=125 \text { ) }\end{array}$ & $\begin{array}{l}\text { one Item measuring } \\
\text { frequency of } \\
\text { participation in } \\
\text { social activities }\end{array}$ & $\begin{array}{l}\text { Philladelphia } \\
\text { Gerfatric Center } \\
\text { morale scale }\end{array}$ & multivariate & bet $a=.13$ \\
\hline
\end{tabular}




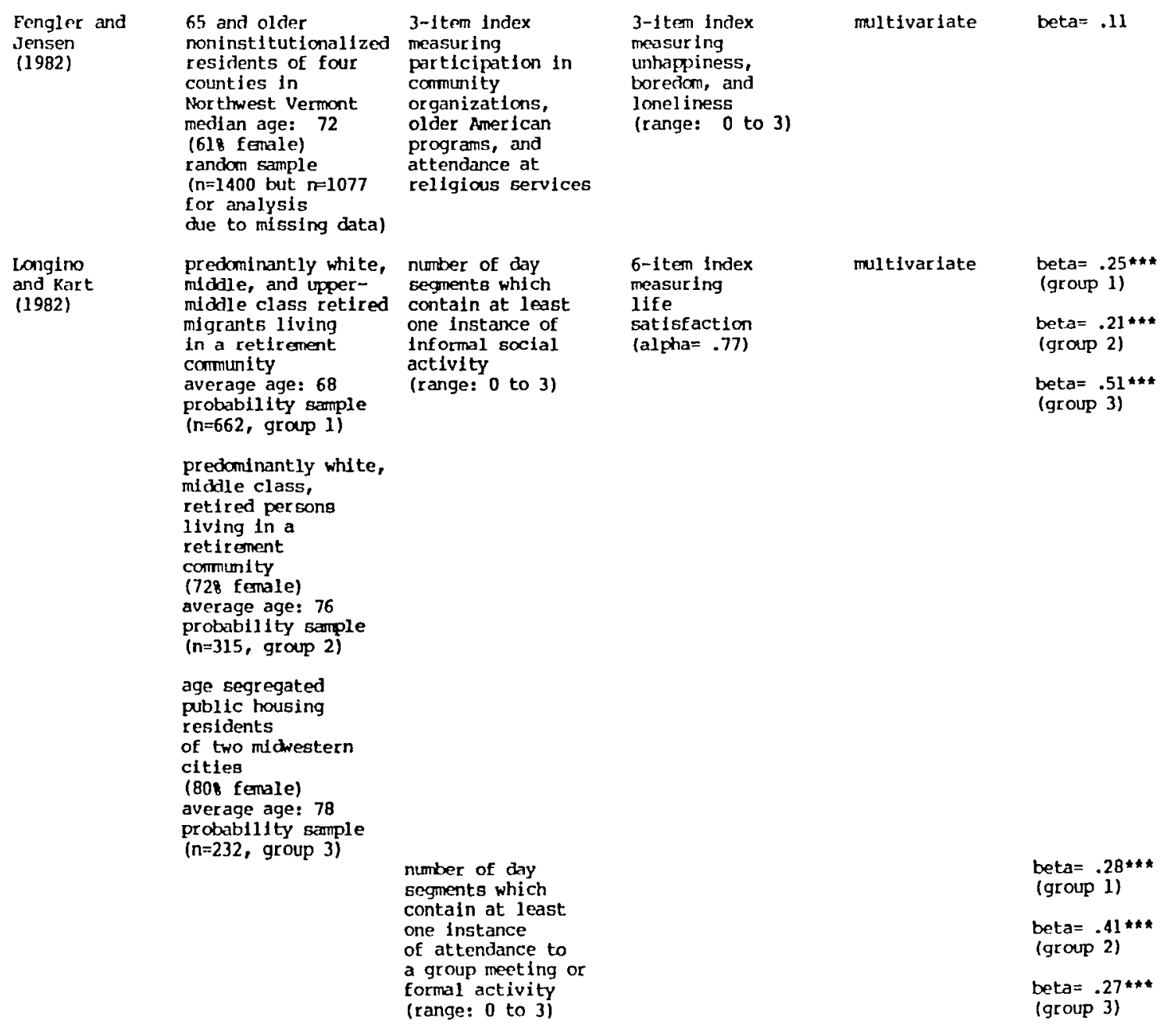




\begin{tabular}{|c|c|c|c|c|c|}
\hline $\begin{array}{l}\text { MoClelland } \\
(1982)\end{array}$ & $\begin{array}{l}65 \text { and older } \\
\text { subdsample of } 1974 \\
\text { NORC data, sample of } \\
\text { per sons } 18 \text { and over } \\
\text { (n-4254) subsample } \\
\text { suludivided into two } \\
\text { groups, those who } \\
\text { pref er to interact } \\
\text { with people of all } \\
\text { ages (sample } 1 \text {, } \\
n=1414 \text { ) and those } \\
\text { who prefer to } \\
\text { interact with people } \\
\text { their Own age } \\
\text { (sample 2, } n=477 \text { ) }\end{array}$ & $\begin{array}{l}\text { 4-item index } \\
\text { measuring } \\
\text { participation in } \\
\text { formal and } \\
\text { informal social } \\
\text { activities }\end{array}$ & $\begin{array}{l}\text { 4-item index } \\
\text { measuring } \\
\text { life satisfaction }\end{array}$ & multivariate & $\begin{array}{l}\text { beta }=.04 \\
\text { (sample 1) } \\
\text { beta }=.20 \star \star \\
\text { (sample 2) }\end{array}$ \\
\hline $\begin{array}{l}\text { Brown, } \\
\text { Perman, } \\
\text { and Dobbs } \\
\text { (1981) }\end{array}$ & $\begin{array}{l}45 \text { and older } \\
\text { noninstitutionalized } \\
\text { working class } \\
\text { background } \\
\text { predominantly poor } \\
\text { and unemployed } \\
\text { pacemaker recipients } \\
\text { (818 male) } \\
\text { average age: } 69 \\
\text { (age range: } 45 \text { to } 85 \text { ) } \\
\text { convenience sample } \\
\text { (n=100) }\end{array}$ & $\begin{array}{l}\text { 3-item index } \\
\text { measuring } \\
\text { participation in } \\
\text { formal and } \\
\text { informal activities } \\
\text { (range: } 3 \text { to 8) }\end{array}$ & $\begin{array}{l}\text { 7-item Index } \\
\text { measuring } \\
\text { despair and } \\
\text { hopelessness } \\
\text { (alpha= .79) } \\
\text { (range: i to 28) }\end{array}$ & multivariate & beta $=.13$ \\
\hline $\begin{array}{l}\text { Elwell } \\
\text { and Maltbie- } \\
\text { Crannell } \\
\text { (1981) }\end{array}$ & $\begin{array}{l}50 \text { years and older } \\
\text { noninstitutionalized } \\
\text { (538 f emale) } \\
\text { average age: } 63 \\
\text { MORC data } \\
\text { strat if ied random } \\
\text { Eample, 1974, 1975, } \\
\text { and } 1977 \text { surveys } \\
\text { pooled } \\
\text { (n=1660 but n=1413 } \\
\text { for analysis due to } \\
\text { missing data) }\end{array}$ & $\begin{array}{l}\text { number of } \\
\text { memberships in } \\
\text { organizations }\end{array}$ & $\begin{array}{l}5 \text {-item Index } \\
\text { measuring } \\
\text { satisfaction with } \\
\text { selected aspects } \\
\text { on one's life }\end{array}$ & multivar iate & $\begin{array}{l}\text { beta }=.10 \\
b=.23 \\
\text { (males) } \\
\text { beta }=.15 \\
b=.40 \\
\text { (females) }\end{array}$ \\
\hline
\end{tabular}




\begin{tabular}{|c|c|c|c|c|c|c|}
\hline $\begin{array}{l}\text { Markides, } \\
\text { Costley, } \\
\text { and } \\
\text { Rodriguez } \\
(1981)\end{array}$ & $\begin{array}{l}60 \text { and older } \\
\text { noninstitutionalized } \\
\text { residents of San } \\
\text { Antonio, Texas } \\
\text { low-income, minority } \\
\text { respondents with at } \\
\text { least one child in } \\
\text { the area } \\
\text { ( } 618 \text { fenale) } \\
\text { convenience sample } \\
\text { (n=98) }\end{array}$ & $\begin{array}{l}\text { 7-1tem Index } \\
\text { measuring } \\
\text { participation in } \\
\text { social and religious } \\
\text { activities and } \\
\text { menberships in } \\
\text { fomal associations } \\
\text { (range: 0 to 16) }\end{array}$ & $\begin{array}{l}\text { 21-item index } \\
\text { Philadelphia } \\
\text { Ger latric Center } \\
\text { morale scale }\end{array}$ & multivariate & beta $=$ & .09 \\
\hline $\begin{array}{l}\text { Duff and Hong } \\
(1980)\end{array}$ & $\begin{array}{l}60 \text { and older } \\
\text { noninstitutionallzed } \\
1974 \text { NORC data } \\
\text { stratif ied random } \\
\text { sample of persons } \\
18 \text { and older } \\
\text { median age in sub- } \\
\text { sample: } 69 \\
\text { (n=335 but } n=275 \\
\text { for analysis due to } \\
\text { missing data) }\end{array}$ & $\begin{array}{l}\text { one item measuring } \\
\text { frequency of } \\
\text { church attendance }\end{array}$ & $\begin{array}{l}\text { 2-item Index } \\
\text { measuring life } \\
\text { satisfaction } \\
\text { (range: } 1 \text { to } 6 \text { ) }\end{array}$ & multivariate & beta $=$ & .13 \\
\hline $\begin{array}{l}\text { Hoyt, Raiser, } \\
\text { Peter s, and } \\
\text { Babchuk } \\
(1980)\end{array}$ & $\begin{array}{l}65 \text { and older } \\
\text { noninstitutionalized } \\
\text { residents of a mid- } \\
\text { western city } \\
\text { average age: } 75 \\
\text { ( } 608 \text { f } \text { emale) } \\
\text { random Eample } \\
\text { ( } 718 \text { response rate) } \\
\text { ( } \mathrm{n}=124 \text { but } n=122 \\
\text { for analysis die to } \\
\text { missing data) }\end{array}$ & $\begin{array}{l}\text { one Item measuring } \\
\text { number of } \\
\text { associations the } \\
\text { respondent belongs } \\
\text { to }\end{array}$ & $\begin{array}{l}\text { 18-1tem index } \\
\text { LSIA }\end{array}$ & multivariate & beta $=$ & $.17 *$ \\
\hline
\end{tabular}




\begin{tabular}{|c|c|c|c|c|c|}
\hline \multirow[t]{4}{*}{$\begin{array}{l}\text { Liang, Duorkin, } \\
\text { Rahana, and } \\
\text { Mazian } \\
(1980)\end{array}$} & $\begin{array}{l}65 \text { and older } \\
\text { predoxinantly poor } \\
\text { (628 female) } \\
\text { state gurvey in } \\
\text { North Carol ina } \\
\text { stratified randam } \\
\text { sample } \\
(n=961)\end{array}$ & $\begin{array}{l}\text { 7-item index } \\
\text { measuring amount of } \\
\text { social contacts, } \\
\text { organizational } \\
\text { participatim, and } \\
\text { helping patterns } \\
\text { (alpha }=.53 \text { ) }\end{array}$ & $\begin{array}{l}\text { 8-item index } \\
\text { measuring life } \\
\text { sat isfaction } \\
\text { (alpha= .77) }\end{array}$ & multivar late & beta $=.09$ * \\
\hline & $\begin{array}{l}65 \text { and older } \\
\text { predominantly poor } \\
\text { (588 female) } \\
\text { state survey in } \\
\text { Wisconsin } \\
\text { stratified multi- } \\
\text { stage cluster sample } \\
(n=2000)\end{array}$ & $\begin{array}{l}\text { 4-item Index } \\
\text { measuring amount of } \\
\text { social contacts, } \\
\text { organizational } \\
\text { participation, and } \\
\text { helping patterns } \\
\text { (alpha }=.52 \text { ) }\end{array}$ & $\begin{array}{l}\text { 8-item Index } \\
\text { measur ing life } \\
\text { sat isfaction } \\
\text { (alpha= .61) }\end{array}$ & & beta $=.01$ \\
\hline & $\begin{array}{l}65 \text { and older } \\
\text { predominantly poor } \\
\text { (608 female) } \\
\text { state survey in } \\
\text { Minnesota } \\
\text { stratified multi- } \\
\text { stage cluster sample } \\
\text { (n=1500) }\end{array}$ & $\begin{array}{l}\text { 4-item Index } \\
\text { measuring } \\
\text { social contacts, } \\
\text { organizational } \\
\text { participation, and } \\
\text { helping patterns } \\
\text { (alpha = .57) }\end{array}$ & $\begin{array}{l}\text { 8-1tem index } \\
\text { measuring IIfe } \\
\text { satisfaction } \\
\text { (alpha= .62) }\end{array}$ & & beta $=.00$ \\
\hline & $\begin{array}{l}65 \text { and older } \\
\text { white, urban elderly, } \\
\text { predominantly poor } \\
\text { (568 female) } \\
\text { convenience sample } \\
\text { from the Detrolt } \\
\text { area } \\
(n=402)\end{array}$ & $\begin{array}{l}\text { 8-item index } \\
\text { measuring } \\
\text { social contacts, } \\
\text { organizational } \\
\text { participation, and } \\
\text { helping patterns } \\
\text { (alpha= .60) }\end{array}$ & $\begin{array}{l}\text { 16-item Index } \\
\text { modified version of } \\
\text { the Philadelphia } \\
\text { Ger iatric Center } \\
\text { morale scale } \\
\text { (alpha }=.81 \text { ) }\end{array}$ & & beta $=.03$ \\
\hline $\begin{array}{l}\text { Markides and } \\
\text { Martin } \\
\text { (1979) }\end{array}$ & $\begin{array}{l}60 \text { and older } \\
\text { predominantly poor } \\
\text { (648 female) } \\
\text { White subsample only } \\
\text { data collected in } \\
\text { four low-income } \\
\text { census tracts of } \\
\text { San } A \text { intonlo, Texas } \\
\text { ( } n=141)\end{array}$ & $\begin{array}{l}\text { welghted score } \\
\text { measuring } \\
\text { particlpation } \\
\text { in formal and } \\
\text { informal activities } \\
\text { (range: } 0 \text { to 21) }\end{array}$ & $\begin{array}{l}\text { 13-1tem index } \\
\text { LSIz }\end{array}$ & multivarlate & $\begin{array}{l}\text { beta }=.38 \\
\text { (males) } \\
\text { beta }=.33 \\
\text { (fomales) }\end{array}$ \\
\hline
\end{tabular}




\begin{tabular}{|c|c|c|c|c|c|}
\hline $\begin{array}{l}\text { Spakes } \\
\text { (1979) }\end{array}$ & $\begin{array}{l}55 \text { and older } \\
\text { noninstitutionalized } \\
\text { high socio-economic } \\
\text { status } \\
\text { stratified national } \\
\text { scomple, elderly } \\
\text { subsample only } \\
(n=873)\end{array}$ & $\begin{array}{l}\text { degree of conmunity } \\
\text { involvement, e.g.. } \\
\text { total number of } \\
\text { formal and } \\
\text { recreational } \\
\text { activities involved } \\
\text { in } \\
\text { (range: } 0 \text { to } 31 \text { ) }\end{array}$ & $\begin{array}{l}\text { one item measuring } \\
\text { life satisfaction } \\
\text { (range: I to } 7 \text { ) }\end{array}$ & multivariate & beta: .11 \\
\hline \multirow[t]{2}{*}{$\begin{array}{l}\text { Jacksor, } \\
\text { Bacon, and } \\
\text { Peterson } \\
\text { (1978) }\end{array}$} & $\begin{array}{l}54 \text { and older } \\
\text { noninstitutionalized } \\
\text { elderiy living in } \\
\text { the Detrot area } \\
\text { (1008 retired Blacks) } \\
\text { predominantly poor } \\
\text { average age: } 70 \\
\text { (age range: } 54 \text { to } 83 \text { ) } \\
\text { (72 female) }\end{array}$ & $\begin{array}{l}\text { Index measuring } \\
\text { number of } \\
\text { organizations, length } \\
\text { of tenure, and } \\
\text { amount of } \\
\text { participation in } \\
\text { organizational } \\
\text { activities }\end{array}$ & LSIA & multivariate & beta $=-.03$ \\
\hline & $\begin{array}{l}\text { sample purposely } \\
\text { selected from Black } \\
\text { older adult center } \\
\text { participants } \\
(58 \text { refusal rate) } \\
(\text { (n=102) }\end{array}$ & $\begin{array}{l}\text { Index measur Ing } \\
\text { imvolvement in } \\
\text { electoral politics }\end{array}$ & & & beta $=.12$ \\
\hline $\begin{array}{l}\text { Wood and } \\
\text { Rober tson } \\
(1978)\end{array}$ & $\begin{array}{l}\text { grandparents from the } \\
\text { Madison, wisconsin } \\
\text { area, predominantly } \\
\text { working class } \\
\text { (478 fenale) } \\
\text { average age: } 65 \\
\text { cross-sectional area } \\
\text { probabil1ty sample } \\
\text { (n=257) }\end{array}$ & $\begin{array}{l}\text { index measuring } \\
\text { organizational } \\
\text { involvement e.g., } \\
\text { number of } \\
\text { organizations } \\
\text { participated in } \\
\text { and length of } \\
\text { menbership }\end{array}$ & $\begin{array}{l}\text { 13-1tem index } \\
\text { ISIz }\end{array}$ & multivar iate & $\begin{array}{l}b=.07 \\
b e t a=.06\end{array}$ \\
\hline
\end{tabular}




\begin{tabular}{|c|c|c|c|c|}
\hline \multirow[t]{5}{*}{$\begin{array}{l}\text { Rnapp } \\
\text { (1977) }\end{array}$} & \multirow[t]{5}{*}{$\begin{array}{l}62 \text { and older } \\
\text { primarily manual } \\
\text { workers } \\
\text { (558 female) } \\
\text { average age: } 76 \\
\text { (age range: } 62 \text { to } 86 \text { ) } \\
\text { convenience sample } \\
\text { (n=51) }\end{array}$} & $\begin{array}{l}\text { number of hours on a } \\
\text { weekly basis spent } \\
\text { 1n organizational } \\
\text { activities }\end{array}$ & $\begin{array}{l}\text { 4-item index from } \\
\text { the IsI scale } \\
\text { masuring } \\
\text { contentment } \\
\text { (range: 0 to 8) } \\
\text { 4-item index from } \\
\text { the LSI scale } \\
\text { measuring } \\
\text { achievement } \\
\text { (range: 0 to 8) }\end{array}$ & $\begin{array}{l}b=.14 \\
b e t a=.23\end{array}$ \\
\hline & & $\begin{array}{l}\text { number of hours } \\
\text { on a weekly basis } \\
\text { spent in social } \\
\text { activities }\end{array}$ & $\begin{array}{l}\text { 4-1tem index from } \\
\text { the ISI scale } \\
\text { measuring contentment } \\
\text { (range: } 0 \text { to } 8 \text { ) }\end{array}$ & $\begin{array}{l}b=.13 \\
b e t a=.22\end{array}$ \\
\hline & & & $\begin{array}{l}\text { 4-item index } \\
\text { from the LSI scale } \\
\text { measur ing achievement } \\
\text { (range: } 0 \text { to } 8 \text { ) }\end{array}$ & $\begin{array}{l}b=.12 \\
b e t a=.20\end{array}$ \\
\hline & & $\begin{array}{l}\text { number of hours on a } \\
\text { weekly basis spent } \\
\text { shopping }\end{array}$ & $\begin{array}{l}\text { 4-item Index from } \\
\text { the isI scale } \\
\text { measuring } \\
\text { contentment } \\
\text { (range: } 0 \text { to } 8 \text { ) }\end{array}$ & $\begin{array}{l}b=-.33 \\
\text { beta }=-.33\end{array}$ \\
\hline & & & $\begin{array}{l}4 \text {-item index from } \\
\text { the } 1 . S I \text { scale } \\
\text { measuring } \\
\text { achievenent } \\
\text { (range: } 0 \text { to } 8 \text { ) }\end{array}$ & $\begin{array}{l}b=.07 \\
\text { beta }=.07\end{array}$ \\
\hline
\end{tabular}




\begin{tabular}{|c|c|c|c|c|c|}
\hline $\begin{array}{l}\text { Paimore and } \\
\text { Kivett } \\
\text { (1977) }\end{array}$ & $\begin{array}{l}46 \text { and older } \\
\text { longitudinal study } \\
\text { of middle, and } \\
\text { upper-middle } \\
\text { class persons from } \\
\text { the Durham, North } \\
\text { Carolina area, } \\
\text { stratified random } \\
\text { sample of menbers of } \\
\text { a local heal th } \\
\text { insurance company } \\
\text { ( } n=502) \\
3 \text { waves of data } \\
\text { collection over a } \\
\text { six-year period } \\
\text { continuers tend to } \\
\text { be better off in all } \\
\text { domains } \\
\text { (258 attrition) } \\
\text { (488 fenale at wave 3) } \\
\text { (n=378) }\end{array}$ & $\begin{array}{l}\text { total number of } \\
\text { religious services } \\
\text { and of other group } \\
\text { meet Ings respondent } \\
\text { usually attends } \\
\text { in a month } \\
\text { (wave 1) } \\
\text { (range: o to 18) } \\
\end{array}$ & $\begin{array}{l}\text { Cantril ladder } \\
\text { (range: } 0 \text { to } 9 \text { ) }\end{array}$ & muitivariate & $\begin{array}{l}\text { beta }=.15 * * \\
\text { (wave } 1 \text { ISI) } \\
\text { beta }=.04 \\
\text { (wave } 2 \text { LSI) } \\
\text { beta }=.06 \\
\text { (wave } 3 \text { LSI) }\end{array}$ \\
\hline $\begin{array}{l}\text { Sauer } \\
\text { (1977) }\end{array}$ & $\begin{array}{l}65 \text { and older } \\
\text { noninstitutionalized } \\
\text { elderly from the low } \\
\text { socioeconomic areas } \\
\text { of Philadel phia } \\
\text { (568 female) } \\
\text { ( } 778 \text { black elderly) } \\
\text { stratifled random } \\
\text { sample } \\
\text { (n=1022 but } \\
n=932 \text { for analysis } \\
\text { due to missing data) }\end{array}$ & $\begin{array}{l}\text { one item measuring } \\
\text { number of } \\
\text { membershipe in } \\
\text { voluntary } \\
\text { associations }\end{array}$ & $\begin{array}{l}\text { 17-1tem index } \\
\text { modified version } \\
\text { of the phi ladelphia } \\
\text { Geriatric Center } \\
\text { morale scale } \\
\text { (range: .0 to 17) } \\
\text { (alpha= .82) }\end{array}$ & multivariate & $\begin{array}{l}\text { beta= } .04 \\
\text { (entice sample) } \\
\text { beta }=.07 \\
\text { (Black } \\
\text { subsample) } \\
\text { beta }=-.04 \\
\text { (White } \\
\text { subsample) }\end{array}$ \\
\hline $\begin{array}{l}\text { Toseland } \\
\text { and Sykes } \\
\text { (1977) }\end{array}$ & $\begin{array}{l}55 \text { and older } \\
\text { noninstitutionalized } \\
\text { living in suburban } \\
\text { and rural areas near } \\
\text { Madison, Wisconsin } \\
\text { ( } 318 \text { fenale) } \\
\text { systematic random } \\
\text { selection from a } 11 \text { st } \\
\text { of participants and } \\
\text { non-participants } \\
\text { at a senior center } \\
(348 \text { response rate) } \\
\text { (n=137) }\end{array}$ & $\begin{array}{l}\text { one item measuring } \\
\text { activity level }\end{array}$ & $\begin{array}{l}\text { 13-item index } \\
\text { LSIz } \\
\text { (range: } 0 \text { to 26) }\end{array}$ & multivariate & $b=-1.88$ \\
\hline
\end{tabular}




\begin{tabular}{|c|c|c|c|c|}
\hline \multirow[t]{5}{*}{$\begin{array}{l}\text { Knapp } \\
(1976)\end{array}$} & \multirow[t]{5}{*}{$\begin{array}{l}62 \text { and older } \\
\text { noninstitutionalized } \\
\text { residents of a } \\
\text { coastal resort in } \\
\text { Southern England } \\
\text { ( } 558 \text { f emale) } \\
\text { average age: } 76 \\
\text { (age range: } 62 \text { to } 86 \text { ) } \\
\text { convenlence sample } \\
\text { ( } n=51)\end{array}$} & $\begin{array}{l}\text { number of hours } \\
\text { on a weekly basis } \\
\text { spent in formal } \\
\text { associations and } \\
\text { organizational } \\
\text { activities }\end{array}$ & $\begin{array}{l}\text { 6-item Index } \\
\text { from the LSIn } \\
\text { scale which measures } \\
\text { mood tone } \\
\text { (range: } 2 \text { to } 12 \\
\text { 3-item index from } \\
\text { the LSIA scale } \\
\text { which mrasures } \\
\text { congruence } \\
\text { (range: } 2 \text { to } 6 \text { ) }\end{array}$ & $\begin{array}{l}b=.56 \\
\text { beta }=.75\end{array}$ \\
\hline & & $\begin{array}{l}\text { number of hours on a } \\
\text { weekly basis spent } \\
\text { in social activities }\end{array}$ & $\begin{array}{l}\text { 6-item Index from } \\
\text { the l.sin scale which } \\
\text { which measures mood } \\
\text { tone } \\
\text { (range: } 2 \text { to 12) }\end{array}$ & $\begin{array}{l}b=.44 \\
b e t a=.51\end{array}$ \\
\hline & & $\begin{array}{l}\text { number of hours on a } \\
\text { weekly basis spent } \\
\text { shopping }\end{array}$ & $\begin{array}{l}\text { 6-1tem Index from } \\
\text { the LSIA scale which } \\
\text { measures mood tone } \\
\text { (range: } 2 \text { to 12) }\end{array}$ & $\begin{array}{l}b=-.29 \\
b e t a=-.20\end{array}$ \\
\hline & & & $\begin{array}{l}\text { 6-1tem index from } \\
\text { the LSIA scale which } \\
\text { measures zest for life } \\
\text { (range: } 5 \text { to 12) }\end{array}$ & $\begin{array}{l}b=.29 \\
b e t a=.29\end{array}$ \\
\hline & & & $\begin{array}{l}\text { 3-1tem Index from } \\
\text { the LSIA scale } \\
\text { which measurea } \\
\text { congruence } \\
\text { (range: } 2 \text { to 6) }\end{array}$ & $\begin{array}{l}b=.27 \\
b e t a=.44\end{array}$ \\
\hline $\begin{array}{l}\text { Sauer, Shehan, } \\
\text { and Boymel } \\
(1976)\end{array}$ & $\begin{array}{l}60 \text { and older } \\
\text { noninstitutionalized } \\
\text { Eubsample of } 1973 \\
\text { NoRC data, national } \\
\text { probabllity sample } \\
\text { of persons } 18 \text { and } \\
\text { older (n=1504) } \\
\text { ( } n=324 \text { for } \\
\text { analysis) } \\
\end{array}$ & $\begin{array}{l}\text { one item measuring } \\
\text { frequency of } \\
\text { attendance at } \\
\text { religious services } \\
\text { one item measuring } \\
\text { political } \\
\text { participation e.g., } \\
\text { whether the } \\
\text { respondent voted in } \\
\text { 1972 national } \\
\text { election } \\
\text { (range: 0 to 1) }\end{array}$ & $\begin{array}{l}\text { 6-item index } \\
\text { measuring } \\
\text { satisfaction } \\
\text { with lncome, } \\
\text { cormunity, } \\
\text { hobles, fantly, } \\
\text { friends, and } \\
\text { glohal happiness } \\
\text { (alpha= .68) }\end{array}$ & beta $=.08$ \\
\hline
\end{tabular}




\begin{tabular}{|c|c|c|c|c|c|}
\hline $\begin{array}{l}\text { Wolk and } \\
\text { Telleen } \\
(1976)\end{array}$ & $\begin{array}{l}\text { Setting A: } \\
\text { elderly persons } \\
\text { living in a } \\
\text { retirement home } \\
\text { ( } 698 \text { female) } \\
\text { median age: } 77 \\
\text { convenience sample } \\
\text { (n=51) } \\
\text { Setting B: } \\
\text { elderly persong } \\
\text { living in a } \\
\text { retirement village } \\
\text { (608 fenale) } \\
\text { median age: } 74 \\
\text { convenience sample } \\
\text { (n=78) }\end{array}$ & $\begin{array}{l}\text { 40-item index } \\
\text { measuring } \\
\text { frequency of } \\
\text { participation in } \\
\text { both formal and } \\
\text { informal activities } \\
\text { (range: } 0 \text { to 80) }\end{array}$ & $\begin{array}{l}\text { 18-1tam index } \\
\text { LSIA } \\
\text { (range: } 0 \text { to } 18 \text { ) }\end{array}$ & multivariate & $\begin{array}{l}\text { beta }=.30 \\
\text { (setting A) } \\
\text { beta }=.13 \\
\text { (setting B) }\end{array}$ \\
\hline $\begin{array}{l}\text { Spreitzer } \\
\text { and Srryder } \\
\text { (1974) }\end{array}$ & $\begin{array}{l}65 \text { and older } \\
\text { noninstitutionalized } \\
(528 \text { female) } \\
\text { subsample of } \\
\text { married and widowed } \\
\text { persons only } \\
\text { inRC data } \\
\text { stratified randam } \\
\text { sample, } 1972 \text { and } \\
1973 \text { surveys pooled } \\
\text { (n=224 due to } \\
\text { missing data) }\end{array}$ & $\begin{array}{l}\text { one } 1 \text { tem measuring } \\
\text { frequency of church } \\
\text { attendance } \\
\text { (range: } 1 \text { to } 9 \text { ) }\end{array}$ & $\begin{array}{l}\text { one item measuring } \\
\text { happiness } \\
\text { (range: } 1 \text { to } 3 \text { ) }\end{array}$ & multivariate & beta $=.01$ \\
\hline \multirow[t]{3}{*}{$\begin{array}{l}\text { Edwards and } \\
\text { Kl Emmack } \\
\text { (1973) }\end{array}$} & \multirow{3}{*}{$\begin{array}{l}45 \text { and older } \\
\text { residents of four } \\
\text { counties in virginia } \\
\text { ( } 548 \text { female) } \\
\text { quota sample for } \\
\text { proportionate } \\
\text { representation of } \\
\text { those below and above } \\
65 \text { years } \\
\text { ( } n=507)\end{array}$} & $\begin{array}{l}\text { one iten measuring } \\
\text { whether or not } \\
\text { respondent has } \\
\text { voted in the last } \\
\text { national elections }\end{array}$ & \multirow[t]{3}{*}{$\begin{array}{l}\text { 10-item Index } \\
\text { modified LSIA } \\
\text { (alpha }=.90)\end{array}$} & \multirow[t]{3}{*}{ multivariate } & beta $=-.14^{*}$ \\
\hline & & $\begin{array}{l}\text { Index measuring } \\
\text { extent and intensity } \\
\text { of participation } \\
\text { in formal volumtary } \\
\text { associations } \\
\text { (chapin's scale) }\end{array}$ & & & beta $=.09$ \\
\hline & & $\begin{array}{l}\text { degree of involvement } \\
\text { in church-related } \\
\text { organizations }\end{array}$ & & & beta $=.14 *$ \\
\hline
\end{tabular}


Palmore and Luikart

46 and older

esidents of Durham, number of religious

North Carolina

average age: 59

age range: 46 to 7

respondents

tend to be well off

(488 female)

from a one item moasuring

mamber ship 1

insurance company

(refusal rate: 528)

longitudinal data

wave 1 data only

$(n=502)$ one item measuring multivariate

happiness

Cantril ladder

(range: 0 to 9 )

attends on a

monthly basis
(range: 0 to 18 )

total number of
hours on a weekly

social activities
(range: 0 to 34) beta $=.05$

(entire sample)

beta $=.04$
(males)

beta $=.06$

(females)

beta not

(entire sample)

beta $=.03$

(males)

beta not

reported 
SIUDIES OF THE REZATIONSHIP BETHEEN FINANCIAL, STATUS ND SUBJECTTVE WEIL-BEINO

\begin{tabular}{|c|c|c|c|c|c|}
\hline $\begin{array}{l}\text { NTTHOR (S) } \\
\text { ND DNTE }\end{array}$ & SMMLE & $\begin{array}{l}\text { MEASURE OF FINMACIN, } \\
\text { RESOURCES }\end{array}$ & $\begin{array}{l}\text { MFASURE OF } \\
\text { WE,L-BEING }\end{array}$ & $\begin{array}{l}\text { TYPE OF } \\
\text { NNRYSIS }\end{array}$ & RESIITS \\
\hline $\begin{array}{l}\text { Usul, Rell, } \\
\text { and Phill1pe } \\
\text { (1983) }\end{array}$ & $\begin{array}{l}60 \text { and older } \\
\text { noninstitutionalized } \\
\text { residents of a county } \\
\text { in Kentucky } \\
338 \text { Blacks }(n=219) \\
\text { convenlence sample } \\
\text { ( } n=704 \text { but n }=657 \text { for } \\
\text { analysis due to } \\
\text { missing data) }\end{array}$ & $\begin{array}{l}\text { income } \\
\text { (range: } 1 \text { to } 12 \text { ) }\end{array}$ & $\begin{array}{l}\text { 13-1tem index } \\
\text { LSIz } \\
\text { (range: } 0 \text { to 13) }\end{array}$ & multivar iate & $\begin{array}{l}\mathrm{b}=.29 * \text { } \\
\text { (White } \\
\text { subsample) } \\
\mathrm{b}=.08 \\
\text { (Black } \\
\text { subsample) }\end{array}$ \\
\hline $\begin{array}{l}\text { Ward and } \\
\text { Kilburn } \\
\text { (1983) }\end{array}$ & $\begin{array}{l}65 \text { and older } \\
\text { subsample of } 1974 \\
\text { NORC data, random } \\
\text { sample of persons } \\
18 \text { and older ( } n=5000) \\
\text { ( } n=2723 \text { for } \\
\text { analysis) }\end{array}$ & Income & $\begin{array}{l}\text { 18-1tem index } \\
\text { LSI } \\
\text { (range: } 1 \text { to } 36 \text { ) }\end{array}$ & multivariate & beta $=.07 *$ \\
\hline $\begin{array}{l}\text { Beckman } \\
\text { and Houser } \\
\text { (1982) }\end{array}$ & $\begin{array}{l}60 \text { and older } \\
\text { noninstitutionalized } \\
\text { residents of Los } \\
\text { Angeles county } \\
\text { (1008 female) } \\
\text { average age: } 68 \\
\text { (age range: } 60 \text { to } 75) \\
\text { sample selected by a } \\
\text { combination of random } \\
\text { and snowball } \\
\text { techniques } \\
\text { ( } n=719 \text { but } n=563 \\
\text { for analysis due to } \\
\text { miseing data) } \\
\text { childless married } \\
\text { ( } n=156, \text { group } 1) \\
\text { childless widowed } \\
\text { ( } n=114, \text { group 2) } \\
\text { parent married } \\
\text { ( } n=155 \text {, group 3) } \\
\text { parent widowed } \\
\text { ( } n=138, \text { group 4) }\end{array}$ & income & $\begin{array}{l}\text { index composed } \\
\text { of items } \\
\text { measur ing } \\
\text { dissatisfaction, } \\
\text { unhappiness, } \\
\text { and lonel iness }\end{array}$ & mult tvar late & $\begin{array}{l}\text { beta }=.05 \\
\text { (group 1) } \\
\text { beta= } .14 \\
\text { (group 2) } \\
\text { beta= } .06 \\
\text { (group 3) } \\
\text { beta=.09 } \\
\text { (group 4) }\end{array}$ \\
\hline
\end{tabular}




\begin{tabular}{|c|c|c|c|c|c|}
\hline $\begin{array}{l}\text { Elwell } \\
\text { and Maltble- } \\
\text { Crannell } \\
\text { (1981) }\end{array}$ & $\begin{array}{l}50 \text { years and older } \\
\text { noninstitutional ized } \\
\text { (538 female) } \\
\text { average age: } 63 \\
\text { NORC data } \\
\text { stratif } \\
\text { sample, } 1974,1975, \\
\text { and } 1977 \text { surveys } \\
\text { pooled } \\
\text { (n=1660 but n=1413 } \\
\text { for analysis due to } \\
\text { missing data) }\end{array}$ & Income & $\begin{array}{l}\text { 5-1tem index } \\
\text { monsur ing } \\
\text { ratisfaction with } \\
\text { selected aspects } \\
\text { of one's life }\end{array}$ & multivarlate & $\begin{array}{l}\text { heta }=.10^{*} \\
b=.16 \\
\text { (males) } \\
\text { beta }=-.002 \\
b=-.003 \\
\text { (females) }\end{array}$ \\
\hline $\begin{array}{l}\text { Markides, } \\
\text { Costley, } \\
\text { and } \\
\text { Rodriguez } \\
\text { (1981) }\end{array}$ & $\begin{array}{l}60 \text { and older } \\
\text { noninstitutionalized } \\
\text { residents of San } \\
\text { Antonio, Texas } \\
\text { low-1nccme, minority } \\
\text { respondents with at } \\
\text { least one child in } \\
\text { the area } \\
\text { ( } 618 \text { female) } \\
\text { convenience sample } \\
\text { (n=98) }\end{array}$ & $\begin{array}{l}\text { income } \\
\text { (range: } 1 \text { to } 6 \text { ) }\end{array}$ & $\begin{array}{l}\text { 21-1tem Index } \\
\text { Philadelphia } \\
\text { Geriatric Center } \\
\text { morale ocale }\end{array}$ & multivariate & beta $=.12$ \\
\hline $\begin{array}{l}\text { Mutran and } \\
\text { Reitzes } \\
\text { (1981) }\end{array}$ & $\begin{array}{l}55 \text { and older } \\
\text { noninstitutionalized } \\
\text { average age: } 71 \\
\text { (age range: } 55 \text { to } 96 \text { ) } \\
\text { (1008 male) } \\
\text { i974 } \mathrm{NCA} \text { data } \\
\text { national probability } \\
\text { 6ample } \\
\text { (n=1055) }\end{array}$ & $\begin{array}{l}\text { incotie } \\
\text { (range: } 1 \text { to } 11 \text { ) }\end{array}$ & $\begin{array}{l}\text { 10-item Index } \\
\text { Af fect Balance } \\
\text { scale } \\
\text { (alpha= } .6 n \text { ) } \\
\text { (range: }-5 \text { to }+5 \text { ) }\end{array}$ & multivardate & $\begin{array}{l}b=-.01 \\
b e t a=-.01\end{array}$ \\
\hline $\begin{array}{l}\text { Duff and liong } \\
\text { (1980) }\end{array}$ & $\begin{array}{l}60 \text { and older } \\
\text { noninst1tutional1zed } \\
1974 \text { NORC nata } \\
\text { stratifled random } \\
\text { sample of per sons } \\
18 \text { and older } \\
\text { median age in sub- } \\
\text { sample: } 69 \\
\text { (n=335 but n=275 } \\
\text { for analysis due to } \\
\text { missing data) }\end{array}$ & $\begin{array}{l}\text { one item measuring } \\
\text { famlly income }\end{array}$ & $\begin{array}{l}\text { 2-item index } \\
\text { measuring life } \\
\text { satisfaction } \\
\text { (range: } 1 \text { to } 6 \text { ) }\end{array}$ & multivariate & beta $=.16$ \\
\hline
\end{tabular}




\begin{tabular}{|c|c|c|c|c|c|}
\hline $\begin{array}{l}\text { Medlcy } \\
(1980)\end{array}$ & $\begin{array}{l}65 \text { and older } \\
\text { noninstitutionalized } \\
\text { (648 female) } \\
\text { national probability } \\
\text { sample } \\
\text { (n=301, } 192 \text { females } \\
\text { and } 109 \text { males) }\end{array}$ & $\begin{array}{l}\text { Incone } \\
\text { (range: } 0 \text { to } 17 \text { ) }\end{array}$ & $\begin{array}{l}\text { 9-1tem Index } \\
\text { measuring J ife } \\
\text { satisfaction } \\
\text { (range: } 21 \text { to } 147 \text { ) }\end{array}$ & multivariate & $\begin{array}{l}\text { beta }=.12 \\
\text { (males) } \\
\text { beta }=-.09 \\
\text { (fenales) }\end{array}$ \\
\hline $\begin{array}{l}\text { Markides and } \\
\text { Martin } \\
(1979)\end{array}$ & $\begin{array}{l}60 \text { and older } \\
\text { predonil nantly poor } \\
\text { (648 fenale) } \\
\text { white subsample only } \\
\text { data collected in } \\
\text { four low-income } \\
\text { census tracts of } \\
\text { San Antonio, } \\
\text { Texas } \\
\text { ( } n=141)\end{array}$ & $\begin{array}{l}\text { one item measuring } \\
\text { monthly income } \\
\text { (range: } 1 \text { to } 6 \text { ) }\end{array}$ & $\begin{array}{l}\text { 13-1tem index } \\
\text { LSIZ }\end{array}$ & multivar late & $\begin{array}{l}\text { beta }=-.06 \\
\text { (males) } \\
\text { beta }=.14 \\
\text { (females) }\end{array}$ \\
\hline $\begin{array}{l}\text { Spakes } \\
\text { (1979) }\end{array}$ & $\begin{array}{l}55 \text { years and older } \\
\text { noninstitutionallzed } \\
\text { comparatively well } \\
\text { of } f \\
\text { stratified national } \\
\text { sample, el derly } \\
\text { subsample only } \\
(n=873)\end{array}$ & Income & $\begin{array}{l}\text { one item masuring } \\
\text { life satisfaction } \\
\text { (range: } 1 \text { to } 7 \text { ) }\end{array}$ & multivariate & beta $=.02$ \\
\hline $\begin{array}{l}\text { Jackson, Bacon, } \\
\text { and Feterson } \\
\text { (1978) }\end{array}$ & $\begin{array}{l}54 \text { and older } \\
\text { noninstitutionalized } \\
\text { elderly living in } \\
\text { the Detroit area } \\
\text { (1008 ret1red Blacks) } \\
\text { predominantly poor } \\
\text { average age: } 70 \\
\text { (age range: } 54 \text { to } 83 \text { ) } \\
\text { (728 female) } \\
\text { sample purposely } \\
\text { selected fram Black } \\
\text { older adult center } \\
\text { partictpants } \\
\text { (58 refusal rate) } \\
\text { (n=102) }\end{array}$ & income & LSIA & multivar late & beta $=-.01$ \\
\hline
\end{tabular}




\begin{tabular}{|c|c|c|c|c|c|}
\hline $\begin{array}{l}\text { Sauer } \\
\text { (1977) }\end{array}$ & $\begin{array}{l}65 \text { and older } \\
\text { noninstitutionalized } \\
\text { elderly from the low } \\
\text { sorineconomic areas } \\
\text { of Philadelphia } \\
\text { (568 female) } \\
\text { (778 Black elderly) } \\
\text { stratified random } \\
\text { gample } \\
\text { (n=1022 but nF } 932 \\
\text { for analysis due to } \\
\text { missing data) }\end{array}$ & Income & $\begin{array}{l}\text { 17-item index } \\
\text { medified version of } \\
\text { the Thiladelphia } \\
\text { Ger tatric Center } \\
\text { morale scale } \\
\text { (range: o to 17) } \\
\text { (alpha= .82) }\end{array}$ & multivar late & $\begin{array}{l}\text { beta }=.04 \\
\text { (entire } \\
\text { sample) } \\
\text { beta }=.04 \\
\text { (Black } \\
\text { subsample) } \\
\text { beta }=.06 \\
\text { (White } \\
\text { subsample) }\end{array}$ \\
\hline $\begin{array}{l}\text { Sauer, } \\
\text { Shehan, } \\
\text { and Boymel } \\
\text { (1976) }\end{array}$ & $\begin{array}{l}60 \text { and older } \\
\text { noninstitutionalized } \\
\text { subsample of } 1973 \\
\text { MorC data, national } \\
\text { probability sample } \\
\text { of per sons } 18 \text { and } \\
\text { older (n=1504) } \\
\text { ( } n=324 \text { for analysis) }\end{array}$ & income & $\begin{array}{l}\text { 6-item index } \\
\text { measuring } \\
\text { satisfaction } \\
\text { with income, } \\
\text { community, hobiles, } \\
\text { famlly, friends, and } \\
\text { global happiness } \\
\text { (alpha }=.68 \text { ) }\end{array}$ & multivar late & beta $=.15^{\star \star}$ \\
\hline $\begin{array}{l}\text { Medley } \\
(1976)\end{array}$ & $\begin{array}{l}65 \text { and older } \\
\text { noninstitutionalized } \\
\text { national probability } \\
\text { sample of per sons } \\
18 \text { and older }(n=2164) \\
178 \text { elderly }(n=362) \\
\text { median age: } 71 \\
\text { (648 female) } \\
\text { (n=301 for analysis } \\
\text { die to missing } \\
\text { data) }\end{array}$ & $\begin{array}{l}\text { Income } \\
\text { (range: } 0 \text { to } 17 \text { ) }\end{array}$ & $\begin{array}{l}\text { 9-1tem Index } \\
\text { measuring } \\
\text { life sat isfaction } \\
\text { (range: } 21 \text { to } 147 \text { ) }\end{array}$ & multivarlate & $\begin{array}{l}b=.79 \\
b e t a=.12 \\
\text { (males) } \\
b=.61 \\
\text { heta }=-.09 \\
\text { (females) }\end{array}$ \\
\hline
\end{tabular}




\begin{tabular}{|c|c|c|c|c|c|}
\hline $\begin{array}{l}\text { Spreltzer } \\
\text { and Snyder } \\
\text { (1974) }\end{array}$ & $\begin{array}{l}65 \text { and older } \\
\text { noninstitutionalized } \\
\text { (528 female) } \\
\text { subsample of married } \\
\text { and widowed persons } \\
\text { only } \\
\text { NoRC data } \\
\text { stratified random } \\
\text { sample, } 1972 \text { and } 1973 \\
\text { surveys pooled } \\
\text { (n=224 due to missing } \\
\text { data) }\end{array}$ & $\begin{array}{l}\text { income } \\
\text { (range: } 1 \text { to } 12 \text { ) }\end{array}$ & $\begin{array}{l}\text { one } 1 \text { tem measuring } \\
\text { happiness } \\
\text { (range: } 1 \text { to } 3 \text { ) }\end{array}$ & multivariate & beta $=-.04$ \\
\hline $\begin{array}{l}\text { Edwards and } \\
\text { Klemmack } \\
\text { (1973) }\end{array}$ & $\begin{array}{l}45 \text { and older } \\
\text { residents of four } \\
\text { count les in virginia } \\
\text { ( } 548 \text { female) } \\
\text { quota sample for } \\
\text { proportimate } \\
\text { representation of } \\
\text { those below and above } \\
65 \text { years } \\
\text { ( } n=507)\end{array}$ & Income & $\begin{array}{l}\text { 10-item index } \\
\text { modified LSIA } \\
\text { (alpha }=.90 \text { ) }\end{array}$ & multivariate & beta $=.34^{*}$ \\
\hline
\end{tabular}


STUDIES OF THE RELATIONSHIP BETWEEN SATISFACTION WITH FINANCINL STATUS ND SMJECTTE WRII-BEING

\begin{tabular}{|c|c|c|c|c|c|}
\hline $\begin{array}{l}\text { NTTHOR(S) } \\
\text { NDD DATE }\end{array}$ & SMMPLE & $\begin{array}{l}\text { MENSURE OF FINANCINL } \\
\text { RESCURCES }\end{array}$ & $\begin{array}{l}\text { MFASTIRE, Of } \\
\text { WESI-BEING }\end{array}$ & $\begin{array}{l}\text { TYPF. OF } \\
\text { ANNLYSIS }\end{array}$ & RFS几TS \\
\hline $\begin{array}{l}\text { Collette } \\
\text { (1984) }\end{array}$ & $\begin{array}{l}60 \text { and oister } \\
\text { noninstitutionalized } \\
\text { residents of Sidney, } \\
\text { Australia } \\
\text { (648 female) } \\
\text { cluster sampling } \\
\text { age stratified } \\
\text { (n=1048) }\end{array}$ & $\begin{array}{l}\text { one item measuring } \\
\text { how well one gets } \\
\text { along on income }\end{array}$ & $\begin{array}{l}\text { 14-item index } \\
\text { modif ind version } \\
\text { of the Fhiladelphia } \\
\text { Geriatric Center } \\
\text { morale scale }\end{array}$ & multivariate & $\begin{array}{l}b=.15 * * \\
b e t a=.14 * \star \\
\text { (females) } \\
b=.19 \\
\text { heta }=.17 * k \\
\text { (males) }\end{array}$ \\
\hline $\begin{array}{l}\text { Baur and } \\
\text { Okun } \\
\text { (1983) }\end{array}$ & $\begin{array}{l}66 \text { and older } \\
\text { apartment dwellers } \\
\text { of a retirement } \\
\text { community in Phoenix, } \\
\text { Arizona, who could } \\
\text { be reintervlewed } \\
\text { 3 years af ter the } \\
\text { first wave of data } \\
\text { collection } \\
\text { (age range: } 66 \text { to } 94 \text { ) } \\
\text { (808 fenale) } \\
\text { stratified random } \\
\text { sample } \\
\text { (178 attrition rate) } \\
\text { (n=87) }\end{array}$ & $\begin{array}{l}\text { one iten measuring } \\
\text { perceived adrequacy } \\
\text { of income } \\
\text { (range: } 0 \text { to } 1 \text { ) }\end{array}$ & $\begin{array}{l}\text { LSIB } \\
\text { (alpha= } .69, \text { wave 1) } \\
\text { (alpha= } .73, \text { wave } 2 \text { ) }\end{array}$ & multivariate & $\begin{array}{l}b=-1.51 \\
\text { beta }=-.18\end{array}$ \\
\hline $\begin{array}{l}\text { Rozma and } \\
\text { Stones } \\
\text { (1983) }\end{array}$ & $\begin{array}{l}65 \text { and older } \\
\text { urban, rural, and } \\
\text { institutionalized } \\
\text { residents of } \\
\text { Newfoundland } \\
\text { random selection } \\
\text { ( } n=600) \\
\text { rural (n=200) group 1 } \\
\text { urban (n=200) group } 2 \\
\text { institutional ized } \\
\text { ( } n=200) \text { group 3 }\end{array}$ & $\begin{array}{l}\text { one item measuring } \\
\text { financial } \\
\text { satisfaction }\end{array}$ & $\begin{array}{l}\text { 24-item index } \\
\text { measuring happiness }\end{array}$ & multivarlate & $\begin{array}{l}\text { beta=.11 } \\
\text { (entire sample) } \\
\text { beta= .15 } \\
\text { (group 1) } \\
\text { beta not } \\
\text { reported } \\
\text { (group 2) } \\
\text { beta not } \\
\text { reported } \\
\text { (group 3) }\end{array}$ \\
\hline
\end{tabular}




\begin{tabular}{|c|c|c|c|c|c|}
\hline \multirow[t]{4}{*}{$\begin{array}{l}\text { Liang and } \\
\text { Warfel } \\
\text { (1983) }\end{array}$} & $\begin{array}{l}65 \text { and older } \\
\text { predominantiy poor } \\
\text { (628 fomale) } \\
\text { state survey } \\
\text { in North Carolina } \\
\text { stratif ied random } \\
\text { sample ( } \mathrm{n}=961 \text { ) }\end{array}$ & $\begin{array}{l}2 \text { to } 4 \text {-item } \\
\text { index measuring } \\
\text { perceived income } \\
\text { adequacy, } \\
\text { satisfaction with } \\
\text { income, and } \\
\text { perceptions of }\end{array}$ & $\begin{array}{l}\text { 8-1tem index } \\
\text { measuring life } \\
\text { satisfaction } \\
\text { (alpha }=.77 \text { ) }\end{array}$ & multivariate & $b=.49 * * *$ \\
\hline & $\begin{array}{l}65 \text { and oider } \\
\text { predominantly poor } \\
\text { (588 f emale) } \\
\text { state survey } \\
\text { in wisconsin } \\
\text { stratifled multi- } \\
\text { stage cluster sample } \\
\text { (n=2000) }\end{array}$ & & $\begin{array}{l}\text { 8-item index } \\
\text { measuring life } \\
\text { satisfaction } \\
\text { (alpha }=.61 \text { ) }\end{array}$ & & $b=.23 * * *$ \\
\hline & $\begin{array}{l}65 \text { and older } \\
\text { predominantly poor } \\
\text { (608 female) } \\
\text { state survey } \\
\text { in Minnessota } \\
\text { stratified multi- } \\
\text { stage cluster } \\
\text { sample ( } n=1500 \text { ) }\end{array}$ & & $\begin{array}{l}\text { 8-item index } \\
\text { measuring life } \\
\text { satisfaction } \\
\text { (alpha= .62) }\end{array}$ & & $b=.42 * k \pi$ \\
\hline & $\begin{array}{l}65 \text { and older } \\
\text { predominantly poor } \\
\text { (618 fomale) } \\
\text { national survey } \\
(n=3996)\end{array}$ & & $\begin{array}{l}\text { 16-item index } \\
\text { modified version } \\
\text { of the phil adelphia } \\
\text { Geriatric Center } \\
\text { morale scale }\end{array}$ & & $b=.90 * * *$ \\
\hline $\begin{array}{l}\text { Fengler and } \\
\text { Danigelis } \\
(1982)\end{array}$ & $\begin{array}{l}65 \text { and older } \\
\text { residents of } 4 \\
\text { counties in } \\
\text { northwestern vermont } \\
\text { median age: } 72 \\
\text { (618 female) } \\
\text { cubsample of } \\
\text { female widows } \\
\text { systemat ic selection } \\
\text { ( } n=326)\end{array}$ & $\begin{array}{l}\text { one item measuring } \\
\text { how well money meets } \\
\text { needs }\end{array}$ & $\begin{array}{l}3 \text {-itesm index } \\
\text { measuring } \\
\text { life satisfaction }\end{array}$ & multivariate & beta $=.26$ \\
\hline
\end{tabular}




\begin{tabular}{|c|c|c|c|c|c|}
\hline $\begin{array}{l}\text { MCClelland } \\
(1982)\end{array}$ & $\begin{array}{l}65 \text { and older } \\
\text { subsample of } 1974 \\
\text { NoRC data, nat lonal } \\
\text { probabilitity sample } \\
\text { of persons } 18 \text { and } \\
\text { older (n=4254) } \\
\text { subdivided into two } \\
\text { groups, those who } \\
\text { prefer to interact } \\
\text { with people of all } \\
\text { ages (Eample 1, } \\
\text { n=1414) and those } \\
\text { who prefer to } \\
\text { interact with people } \\
\text { their owm age } \\
\text { (sample 2, } n=477 \text { ) }\end{array}$ & $\begin{array}{l}\text { one ftem measuring } \\
\text { whether or not } \\
\text { finances are a } \\
\text { problem }\end{array}$ & $\begin{array}{l}\text { 4-1tem index } \\
\text { measuring } \\
\text { Iife satisfaction }\end{array}$ & multivarlate & $\begin{array}{l}\text { beta }=-.07 \\
(\text { sample 1) } \\
\text { beta }=-.08 \\
(\text { sample 2) }\end{array}$ \\
\hline $\begin{array}{l}\text { Seleen } \\
\text { (1982) }\end{array}$ & $\begin{array}{l}55 \text { and older } \\
\text { noninstitutionalized } \\
\text { residents of Rhode } \\
\text { Island } \\
\text { (568 female) } \\
\text { random selection of } \\
6 \text { senior centers in } \\
\text { the state } \\
\text { urveyed persons } \\
\text { attending the noon } \\
\text { meal } \\
(n=205)\end{array}$ & $\begin{array}{l}\text { one item measuring } \\
\text { financial } \\
\text { satisfaction }\end{array}$ & $\begin{array}{l}\text { LSIA } \\
\text { Cantril Iadder }\end{array}$ & multivariate & $\begin{array}{l}\text { beta }=.18 \\
\text { beta }=.18\end{array}$ \\
\hline
\end{tabular}




\begin{tabular}{|c|c|c|c|c|c|}
\hline $\begin{array}{l}\text { Fengler and } \\
\text { Jensen } \\
\text { (1981) }\end{array}$ & $\begin{array}{l}65 \text { and older } \\
\text { noninstitutionalized } \\
\text { residents of four } \\
\text { counties in Nor thwest } \\
\text { Vermont } \\
\text { median age: } 72 \\
\text { (618 fenale) } \\
\text { random sample } \\
\text { (n=1400, analysis } \\
\text { based on nflo77) }\end{array}$ & $\begin{array}{l}\text { one iten measuring } \\
\text { how well income meets } \\
\text { one's needs }\end{array}$ & $\begin{array}{l}\text { 3-item index } \\
\text { measuring } \\
\text { unhappiness, } \\
\text { boredom, and } \\
\text { lonel iness } \\
\text { (range: } 0 \text { to } 3 \text { ) }\end{array}$ & multivariate & beta $=-.18$ \\
\hline $\begin{array}{l}\text { Fengler, } \\
\text { Danigelis, and } \\
\text { Grams } \\
(1980)\end{array}$ & $\begin{array}{l}65 \text { and older } \\
\text { noninstitutionalized } \\
\text { residents of four } \\
\text { counties in Northwest } \\
\text { Vermont } \\
\text { median age: } 72 \\
\text { ( } 618 \text { female) } \\
\text { random sample } \\
\text { (n=1400 but n=1036 } \\
\text { for analysis due to } \\
\text { missing data) } \\
\text { sample subdivided } \\
\text { into: } \\
\text { married (n=508, } \\
\text { group 1) } \\
\text { living with others } \\
\text { (n=246, group 2) } \\
\text { living alone } \\
\text { (n=282, group 3) }\end{array}$ & $\begin{array}{l}\text { one item measuring } \\
\text { how well lincome meets } \\
\text { one's needs }\end{array}$ & $\begin{array}{l}\text { 3-1ten index } \\
\text { measur ing } \\
\text { unhappiness, } \\
\text { boredom, and } \\
\text { lonel iness } \\
\text { (range: } 0 \text { to } 3 \text { ) }\end{array}$ & multivariate & $\begin{array}{l}\text { beta }=.19 \star \star \\
\text { (group 1) } \\
\text { beta not } \\
\text { reported } \\
\text { (group 2) } \\
\text { beta }=.28^{\star \star} \\
\text { (group 3) }\end{array}$ \\
\hline
\end{tabular}




\begin{tabular}{|c|c|c|c|c|c|}
\hline \multirow[t]{4}{*}{$\begin{array}{l}\text { Liang, Dvorkin, } \\
\text { Rahana, and } \\
\text { Mazian } \\
(1980)\end{array}$} & $\begin{array}{l}65 \text { and older } \\
\text { predaminantly poor } \\
\text { (628 female) } \\
\text { state survey in } \\
\text { North Carolina } \\
\text { stratified random } \\
\text { sample } \\
\text { (n=961) }\end{array}$ & $\begin{array}{l}\text { 4-item Index } \\
\text { measuring perception } \\
\text { of financial } \\
\text { situation, percelved } \\
\text { income adequacy, and } \\
\text { satisfaction with } \\
\text { income } \\
\text { (alphas .83) }\end{array}$ & $\begin{array}{l}\text { 8-iten Index } \\
\text { measuring life } \\
\text { satisf action } \\
\text { (alpha= .77) }\end{array}$ & multivariate & beta $=.24 * * *$ \\
\hline & $\begin{array}{l}65 \text { and older } \\
\text { predominantly poor } \\
\text { (588 female) } \\
\text { state survey in } \\
\text { Wisconsin } \\
\text { stratified multi- } \\
\text { stage cluster sample } \\
(n=2000)\end{array}$ & $\begin{array}{l}\text { 4-item Index } \\
\text { measuring perception } \\
\text { of financial } \\
\text { situation, perceived } \\
\text { income adequacy, and } \\
\text { satisfaction with } \\
\text { income } \\
\text { (alpha = .66) }\end{array}$ & $\begin{array}{l}\text { 8-item index } \\
\text { measur ing life } \\
\text { satisfaction } \\
\text { (alpha }=.61 \text { ) }\end{array}$ & & beta $=.17 * * *$ \\
\hline & $\begin{array}{l}65 \text { and older } \\
\text { predominantly poor } \\
\text { (608 female) } \\
\text { state survey in } \\
\text { Minnesota } \\
\text { stratified multi- } \\
\text { stage cluster sample } \\
\text { ( } n=1500)\end{array}$ & $\begin{array}{l}\text { 4-item index } \\
\text { measuring } \\
\text { perception of } \\
\text { financial } \\
\text { situation, percelved } \\
\text { income adequacy, and } \\
\text { satisfaction with } \\
\text { income } \\
\text { (alpha }=.77 \text { ) }\end{array}$ & $\begin{array}{l}\text { 8-item index } \\
\text { measuring life } \\
\text { satisfaction } \\
\text { (alpha }=.62 \text { ) }\end{array}$ & & beta $=.24 * * *$ \\
\hline & $\begin{array}{l}65 \text { and older } \\
\text { white, urban elderly } \\
\text { predominantly poor } \\
\text { (568 female) } \\
\text { convenience sample } \\
\text { from the Detroit } \\
\text { area } \\
\text { ( } n=402)\end{array}$ & $\begin{array}{l}\text { 3-item index } \\
\text { measuring } \\
\text { perception of } \\
\text { financial situation, } \\
\text { perceived income } \\
\text { adeguacy, and } \\
\text { satisfaction with } \\
\text { income } \\
\text { (alpha }=.54 \text { ) }\end{array}$ & $\begin{array}{l}\text { 16-item index } \\
\text { modified version of } \\
\text { the Philadelphia } \\
\text { Geriatric Center } \\
\text { morale scale } \\
\text { (alpha }=.81 \text { ) }\end{array}$ & & beta $=.18 * * \star$ \\
\hline $\begin{array}{l}\text { Medley } \\
(1980)\end{array}$ & $\begin{array}{l}65 \text { and older } \\
\text { noninstitutionalized } \\
\text { (648 female) } \\
\text { national probability } \\
\text { sample } \\
\text { (n=301, } 192 \text { fenales } \\
\text { and } 109 \text { males) }\end{array}$ & $\begin{array}{l}\text { one item measuring } \\
\text { satisfaction with } \\
\text { standard of living } \\
\text { (range: } 1 \text { to } 7 \text { ) }\end{array}$ & $\begin{array}{l}\text { 9-1tem Index } \\
\text { measuring life } \\
\text { satisfaction } \\
\text { (range: } 21 \text { to } 147 \text { ) }\end{array}$ & multivariate & $\begin{array}{l}\text { beta }=.17 \\
\text { (males) } \\
\text { beta= . } .32 \\
\text { (f fmales) }\end{array}$ \\
\hline
\end{tabular}




\begin{tabular}{|c|c|c|c|c|c|}
\hline $\begin{array}{l}\text { Tosel and } \\
\text { and Sykes } \\
\text { (1977) }\end{array}$ & $\begin{array}{l}55 \text { and older } \\
\text { noninst itutionalized } \\
\text { living in suburban } \\
\text { and rural areas near } \\
\text { Madison, wissconsin } \\
\text { ( } 318 \text { female) } \\
\text { systematic random } \\
\text { selection from a list } \\
\text { of participants and } \\
\text { nom-participants } \\
\text { at a senior center } \\
\text { (348 response rate) } \\
\text { (n=137) }\end{array}$ & $\begin{array}{l}\text { one } 1 \text { tem measuring } \\
\text { financial status } \\
\text { (range: o to } 26 \text { ) }\end{array}$ & $\begin{array}{l}\text { 13-item index } \\
\text { LSIZ }\end{array}$ & multivar iate & $b=-1.38$ \\
\hline $\begin{array}{l}\text { Lee } \\
\text { (1979) }\end{array}$ & $\begin{array}{l}60 \text { and older } \\
\text { survey in washington } \\
\text { state, two-stage } \\
\text { probability sample } \\
\text { ( } 758 \text { response rate) } \\
\text { subsample of married } \\
\text { persons only } \\
\text { (418 female) } \\
\text { (n=588 but } n=388 \\
\text { for analysis due to } \\
\text { missing data) }\end{array}$ & $\begin{array}{l}\text { one item measuring } \\
\text { satisfaction with } \\
\text { standard of living } \\
\text { (range: } 1 \text { to } 5 \text { ) }\end{array}$ & $\begin{array}{l}\text { 6-item index } \\
\text { measuring I1fe } \\
\text { satisfaction } \\
\text { (range: } 6 \text { to 24) } \\
\text { (alpha }=.85 \text { males) } \\
\text { (alpha= } .87 \text { females) }\end{array}$ & multivariate & $\begin{array}{l}b=.67 * \\
\text { beta }=.23 \\
\text { (males) } \\
b=.30 \\
\text { beta }=.08 \\
\text { (females) }\end{array}$ \\
\hline $\begin{array}{l}\text { Lee } \\
\text { (1978) }\end{array}$ & $\begin{array}{l}60 \text { and older } \\
\text { survey in Washington } \\
\text { state, two-stage } \\
\text { probabil ity sample } \\
\text { ( } 758 \text { response rate) } \\
\text { subsample of married } \\
\text { persons only } \\
\text { (398 female) } \\
\text { (n=588 but nfre439 } \\
\text { for analysis due to } \\
\text { missing data) }\end{array}$ & $\begin{array}{l}\text { one Iten measuring } \\
\text { satisfaction with } \\
\text { standard of living } \\
\text { (range: I to } 5 \text { ) }\end{array}$ & $\begin{array}{l}\text { 6-1tem index } \\
\text { measuring life } \\
\text { satisfaction } \\
\text { (range: } 6 \text { to 24) } \\
\text { (a)pha }=.85 \text { males) } \\
\text { (alpha }=.87 \text { females }\end{array}$ & multivariate & $\begin{array}{l}\text { beta }=.21 \\
\text { (males) } \\
\text { beta }=.13 \\
\text { (f emales) }\end{array}$ \\
\hline
\end{tabular}




\begin{tabular}{|c|c|c|c|c|c|}
\hline $\begin{array}{l}\text { Medley } \\
(1976)\end{array}$ & $\begin{array}{l}65 \text { and older } \\
\text { noninstitutionalized } \\
\text { national probahility } \\
\text { sample of persons } \\
18 \text { and older ( } n=2164) \\
178 \text { elder } 1 y \\
\text { median age of persons } \\
\text { in subsample: } 71 \\
\text { ( } 648 \text { female) } \\
\text { ( } \mathrm{n}=362 \text { but } n=301 \text { for } \\
\text { analysis due to } \\
\text { missing data) }\end{array}$ & $\begin{array}{l}\text { one item measuring } \\
\text { satisfaction with } \\
\text { standard of living } \\
\text { (range: } 1 \text { to } 7)\end{array}$ & $\begin{array}{l}\text { 9-item inclex } \\
\text { measuring global } \\
\text { life satisfaction } \\
\text { (range: } 21 \text { to } 147 \text { ) }\end{array}$ & multivariate & $\begin{array}{l}b=2.87 \star \\
b e t a=.17 \\
\text { (males) } \\
b=5.7 B^{*} \\
\text { beta }=.32 \\
\text { (females) }\end{array}$ \\
\hline $\begin{array}{l}\text { Spreltzer } \\
\text { and Snyder } \\
(1974)\end{array}$ & $\begin{array}{l}65 \text { and older } \\
\text { noninstitutionalized } \\
\text { ( } 528 \text { female) } \\
\text { subsample of married } \\
\text { and widowed persons } \\
\text { only } \\
\text { NORC data } \\
\text { stratif ied random } \\
\text { sample, } 1972 \text { and } 1973 \\
\text { surveys pooled } \\
\text { (n=224 due to missing } \\
\text { data) }\end{array}$ & $\begin{array}{l}\text { one item measuring } \\
\text { satisfaction with } \\
\text { standard of living } \\
\text { (range: I to } 3 \text { ) }\end{array}$ & $\begin{array}{l}\text { one item measuring } \\
\text { harpiness } \\
\text { (range: } 1 \text { to } 3 \text { ) }\end{array}$ & multivariate & beta $=.31$ \\
\hline
\end{tabular}


APPENDIX C

SUPPLEMENTARY TABLES 
TABLE LVI

DESCRIPTIVE STATISTICS FOR THE MEASURES OF CIANGE IN HEALTH, SOCIAL, FINANCIAL RESOURCES, AND SUBJECIIVE WELLL-BEING AS MEASURED BY DIFFERENCE' SOORE'S

\begin{tabular}{|c|c|c|c|c|c|c|c|c|c|c|}
\hline $\begin{array}{l}\text { Resource Area } \\
\text { Index/Iterm }\end{array}$ & Year & Mean & Median & Mode & $\begin{array}{l}\text { Standard } \\
\text { deviation }\end{array}$ & $\operatorname{Min}-\max$ & $\begin{array}{l}\text { Values } \\
\text { in range }\end{array}$ & Skewness & Kurtosis & $\begin{array}{l}\text { Percent } \\
\text { missing }\end{array}$ \\
\hline \multicolumn{11}{|c|}{ Heal th Resources } \\
\hline $\begin{array}{l}\text { General } \\
\text { Disability }\end{array}$ & $\begin{array}{l}69-71 \\
71-73 \\
69-73\end{array}$ & $\begin{array}{l}0.23 \\
0.54 \\
0.77\end{array}$ & $\begin{array}{l}0.11 \\
0.26 \\
0.41\end{array}$ & $\begin{array}{l}0.00 \\
0.00 \\
0.00\end{array}$ & $\begin{array}{l}3.73 \\
4.00 \\
4.16\end{array}$ & $\begin{array}{l}-10.00-10.00 \\
-10.00-10.00 \\
-10.00-10.00\end{array}$ & $\begin{array}{l}5 \\
5 \\
5\end{array}$ & $\begin{array}{l}0.14 \\
0.26 \\
0.23\end{array}$ & $\begin{array}{l}2.13 \\
1.34 \\
1.04\end{array}$ & $\begin{array}{l}0.4 \\
0.6 \\
0.3\end{array}$ \\
\hline $\begin{array}{l}\text { Overall } \\
\text { Disability }\end{array}$ & $\begin{array}{l}69-71 \\
71-73 \\
69-73\end{array}$ & $\begin{array}{l}0.25 \\
0.47 \\
0.72\end{array}$ & $\begin{array}{l}0.00 \\
0.00 \\
0.00\end{array}$ & $\begin{array}{l}0.00 \\
0.00 \\
0.00\end{array}$ & $\begin{array}{l}2.09 \\
2.38 \\
2.53\end{array}$ & $\begin{array}{l}-10.00-10.00 \\
-10.00-10.00 \\
-10.00-10.00\end{array}$ & $\begin{array}{r}138 \\
98 \\
137\end{array}$ & $\begin{array}{l}0.65 \\
0.57 \\
0.63\end{array}$ & $\begin{array}{l}4.58 \\
2.96 \\
2.24\end{array}$ & $\begin{array}{l}11.1 \\
11.0 \\
11.2\end{array}$ \\
\hline \multicolumn{11}{|c|}{ Soctal Resources } \\
\hline $\begin{array}{l}\text { Scope of } \\
\text { Immediate } \\
\text { Family }\end{array}$ & $\begin{array}{l}69-71 \\
71-73 \\
69-73\end{array}$ & $\begin{array}{l}-0.13 \\
-0.11 \\
-0.25\end{array}$ & $\begin{array}{l}-0.07 \\
-0.06 \\
-0.14\end{array}$ & $\begin{array}{l}0.00 \\
0.00 \\
0.00\end{array}$ & $\begin{array}{l}0.92 \\
0.88 \\
1.09\end{array}$ & $\begin{array}{l}-7.50-7.50 \\
-7.50=5.00 \\
-7.50-7.50\end{array}$ & $\begin{array}{l}7 \\
6 \\
7\end{array}$ & $\begin{array}{l}-0.89 \\
-0.94 \\
-0.87\end{array}$ & $\begin{array}{l}8.65 \\
8.79 \\
5.36\end{array}$ & $\begin{array}{l}2.5 \\
4.2 \\
2.6\end{array}$ \\
\hline $\begin{array}{l}\text { Size of } \\
\text { Immediate } \\
\text { Family }\end{array}$ & $\begin{array}{l}69-71 \\
71-73 \\
69-73\end{array}$ & $\begin{array}{l}-0.09 \\
-0.11 \\
-0.20\end{array}$ & $\begin{array}{r}-0.02 \\
0.00 \\
-0.02\end{array}$ & $\begin{array}{r}-0.04 \\
0.00 \\
-0.04\end{array}$ & $\begin{array}{l}0.73 \\
0.71 \\
0.82\end{array}$ & $\begin{array}{l}-6.38-6.39 \\
-5.50=5.50 \\
-5.47-5.50\end{array}$ & $\begin{array}{l}96 \\
44 \\
97\end{array}$ & $\begin{array}{r}0.06 \\
-0.09 \\
0.09\end{array}$ & $\begin{array}{r}12.40 \\
10.97 \\
8.14\end{array}$ & $\begin{array}{l}2.5 \\
4.2 \\
2.6\end{array}$ \\
\hline \multicolumn{11}{|c|}{ Subjective Well-being } \\
\hline Happiness & $\begin{array}{l}69-71 \\
71-73 \\
69-73\end{array}$ & $\begin{array}{r}0.30 \\
-0.08 \\
0.20\end{array}$ & $\begin{array}{r}0.24 \\
-0.05 \\
0.20\end{array}$ & $\begin{array}{l}0.00 \\
0.00 \\
0.00\end{array}$ & $\begin{array}{l}3.66 \\
3.74 \\
3.87\end{array}$ & $\begin{array}{l}-10.00-10.00 \\
-10.00-10.00 \\
-10.00-10.00\end{array}$ & $\begin{array}{l}5 \\
5 \\
5\end{array}$ & $\begin{array}{l}-0.03 \\
-0.04 \\
-0.10\end{array}$ & $\begin{array}{l}0.31 \\
0.34 \\
0.21\end{array}$ & $\begin{array}{l}1.2 \\
0.8 \\
1.3\end{array}$ \\
\hline
\end{tabular}

Note. All the measures are 1dentical across the 1969, 1971, and 1973 waves of data collection with the exception of

Income. For this measure, it is inappropriate to compare the means across the three waves of data collection. 
TABLE LVII

DESCRIPTIVE STATISTICS FOR THE MEASURES OF GIANGE IN HEALTH, SOCIAL, FINANCIAL RESOURCES, AND SUBJECTIVE WELL-BEING AS MEASURED BY RESIDUAL GIANGE SCORES

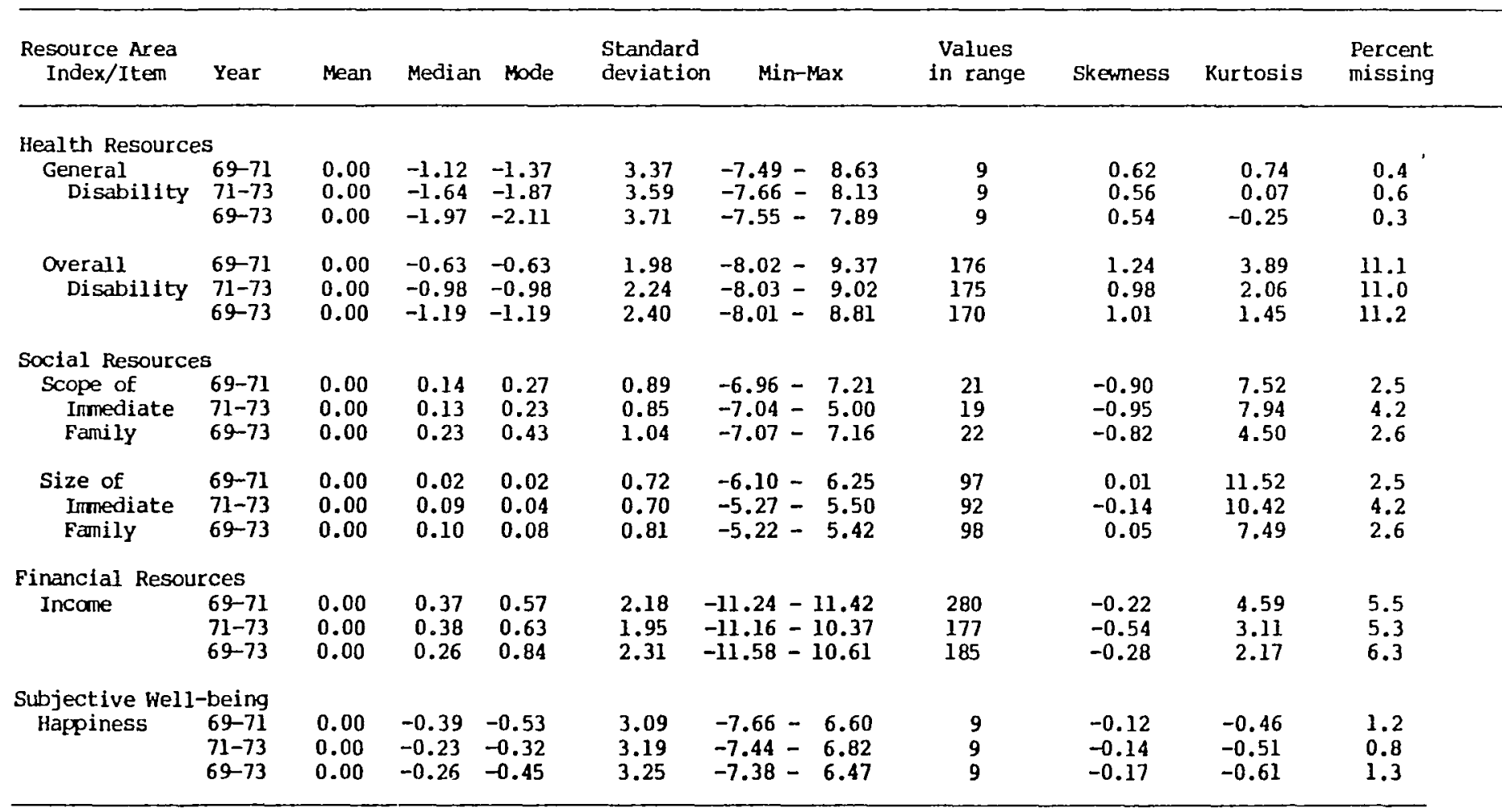

Note. All the measures are identical across the 1969, 1971, and 1973 waves of data collection with the exception of Income. For this measure, it is inappropriate to compare the means across the three waves of data collection. 
TABLE LVIII

DESCRIPTIVE STATISTICS FOR THE MEASURES OF CIANGE IN HEALTH, SOCIAL, FINANCIAL RESOURCES, AND SURJECTIVE WELLL-BEING AS MEASJRED BY PERCENIAGE GAIN SCORES

\begin{tabular}{|c|c|c|c|c|c|c|c|c|c|c|c|}
\hline $\begin{array}{l}\text { Resource Area } \\
\text { Index/Item }\end{array}$ & Year & Mean & Median & Mode & $\begin{array}{l}\text { Standard } \\
\text { deviation }\end{array}$ & & Min-Max & $\begin{array}{l}\text { Values } \\
\text { in range }\end{array}$ & Skewness & Kurtosis & $\begin{array}{l}\text { Percent } \\
\text { missing }\end{array}$ \\
\hline \multicolumn{12}{|c|}{ Health Resources } \\
\hline $\begin{array}{l}\text { General } \\
\text { Disability }\end{array}$ & $\begin{array}{l}69-71 \\
71-73 \\
69-73\end{array}$ & $\begin{array}{l}0.02 \\
0.05 \\
0.08\end{array}$ & $\begin{array}{l}0.01 \\
0.03 \\
0.04\end{array}$ & $\begin{array}{l}0.00 \\
0.00 \\
0.00\end{array}$ & $\begin{array}{l}0.46 \\
0.49 \\
0.50\end{array}$ & $\begin{array}{l}-1.00- \\
-1.00= \\
-1.00-\end{array}$ & $\begin{array}{l}-1.00 \\
=1.00 \\
-1.00\end{array}$ & $\begin{array}{l}5 \\
5 \\
5\end{array}$ & $\begin{array}{r}-0.06 \\
0.02 \\
-0.01\end{array}$ & $\begin{array}{l}1.21 \\
0.68 \\
0.48\end{array}$ & $\begin{array}{l}0.4 \\
0.6 \\
0.3\end{array}$ \\
\hline $\begin{array}{l}\text { Overall } \\
\text { Disability }\end{array}$ & $\begin{array}{l}69-71 \\
71-73 \\
69-73\end{array}$ & $\begin{array}{r}-0.02 \\
0.01 \\
0.04\end{array}$ & $\begin{array}{l}0.00 \\
0.00 \\
0.00\end{array}$ & $\begin{array}{l}0.00 \\
0.00 \\
0.00\end{array}$ & $\begin{array}{l}0.36 \\
0.38 \\
0.39\end{array}$ & $\begin{array}{l}-1.00- \\
-1.00- \\
-1.00-\end{array}$ & $\begin{array}{l}-1.00 \\
-\quad 1.00 \\
-\quad 1.00\end{array}$ & $\begin{array}{r}105 \\
98 \\
109\end{array}$ & $\begin{array}{l}-0.89 \\
-0.71 \\
-0.67\end{array}$ & $\begin{array}{l}3.00 \\
2.28 \\
2.17\end{array}$ & $\begin{array}{l}11.1 \\
11.0 \\
11.2\end{array}$ \\
\hline \multicolumn{12}{|c|}{ Social Resources } \\
\hline $\begin{array}{l}\text { Scope of } \\
\text { Immediate } \\
\text { Fanily }\end{array}$ & $\begin{array}{l}69-71 \\
71-73 \\
69-73\end{array}$ & $\begin{array}{l}-0.01 \\
-0.01 \\
-0.03\end{array}$ & $\begin{array}{l}-0.00 \\
-0.00 \\
-0.00\end{array}$ & $\begin{array}{l}0.00 \\
0.00 \\
0.00\end{array}$ & $\begin{array}{l}0.15 \\
0.15 \\
0.18\end{array}$ & $\begin{array}{l}-1.00- \\
-1.00= \\
-1.00-\end{array}$ & $\begin{array}{l}-1.00 \\
-\quad 1.00 \\
-\quad 1.00\end{array}$ & $\begin{array}{l}12 \\
12 \\
12\end{array}$ & $\begin{array}{r}0.26 \\
0.04 \\
-0.13\end{array}$ & $\begin{array}{r}15.32 \\
15.36 \\
9.41\end{array}$ & $\begin{array}{l}2.5 \\
4.2 \\
2.6\end{array}$ \\
\hline $\begin{array}{l}\text { Size of } \\
\text { Immediate } \\
\text { Family }\end{array}$ & $\begin{array}{l}69-71 \\
71-73 \\
69-73\end{array}$ & $\begin{array}{l}-0.02 \\
-0.03 \\
-0.05\end{array}$ & $\begin{array}{r}-0.01 \\
0.00 \\
-0.01\end{array}$ & $\begin{array}{r}-0.01 \\
0.00 \\
-0.01\end{array}$ & $\begin{array}{l}0.14 \\
0.15 \\
0.17\end{array}$ & $\begin{array}{l}-1.00- \\
-1.00- \\
-1.00-\end{array}$ & $\begin{array}{l}-\quad 0.80 \\
-\quad 1.00 \\
-\quad 1.00\end{array}$ & $\begin{array}{l}70 \\
57 \\
72\end{array}$ & $\begin{array}{l}-1.08 \\
-1.44 \\
-1.02\end{array}$ & $\begin{array}{r}10.91 \\
10.84 \\
7.00\end{array}$ & $\begin{array}{l}2.5 \\
4.2 \\
2.6\end{array}$ \\
\hline \multicolumn{12}{|c|}{ Financial Resources } \\
\hline Incame & $\begin{array}{l}69-71 \\
71-73 \\
69-73\end{array}$ & $\begin{array}{l}0.03 \\
0.04 \\
0.06\end{array}$ & $\begin{array}{l}0.00 \\
0.00 \\
0.00\end{array}$ & $\begin{array}{l}0.00 \\
0.00 \\
0.00\end{array}$ & $\begin{array}{l}0.33 \\
0.31 \\
0.35\end{array}$ & $\begin{array}{l}-1.00- \\
-1.00- \\
-1.00-\end{array}$ & $\begin{array}{l}-1.00 \\
-\quad 1.00 \\
-\quad 1.00\end{array}$ & $\begin{array}{l}106 \\
111 \\
111\end{array}$ & $\begin{array}{l}-0.36 \\
-0.13 \\
-0.08\end{array}$ & $\begin{array}{l}1.79 \\
1.78 \\
0.75\end{array}$ & $\begin{array}{l}5.5 \\
5.3 \\
6.3\end{array}$ \\
\hline \multicolumn{12}{|c|}{ Subjective Well-being } \\
\hline Happiness & $\begin{array}{l}69-71 \\
71-73 \\
69-73\end{array}$ & $\begin{array}{l}0.06 \\
0.01 \\
0.05\end{array}$ & $\begin{array}{r}0.02 \\
-0.00 \\
0.02\end{array}$ & $\begin{array}{l}0.00 \\
0.00 \\
0.00\end{array}$ & $\begin{array}{l}0.54 \\
0.54 \\
0.56\end{array}$ & $\begin{array}{l}-1.00- \\
-1.00- \\
-1.00-\end{array}$ & $\begin{array}{l}-1.00 \\
-\quad 1.00 \\
-\quad 1.00\end{array}$ & $\begin{array}{l}5 \\
5 \\
5\end{array}$ & $\begin{array}{r}0.11 \\
-0.04 \\
0.05\end{array}$ & $\begin{array}{r}-0.04 \\
0.12 \\
-0.25\end{array}$ & $\begin{array}{l}1.2 \\
0.8 \\
1.3\end{array}$ \\
\hline
\end{tabular}

Note. All the measures are identical across the 1969, 1971, and 1973 waves of data collection with the exception of

Income. For this measure, it is inappropriate to compare the means across the three waves of data collection. 
TABLE LIX

DESCRIPTIVE STATISTICS FOR THE CLANGE TTEMS IN HEALTH, FINANCIAL RESOURCES, AND SUBJECTIVE WEJL-BEING AS MEASURED BY DIFFERENCE SOORES

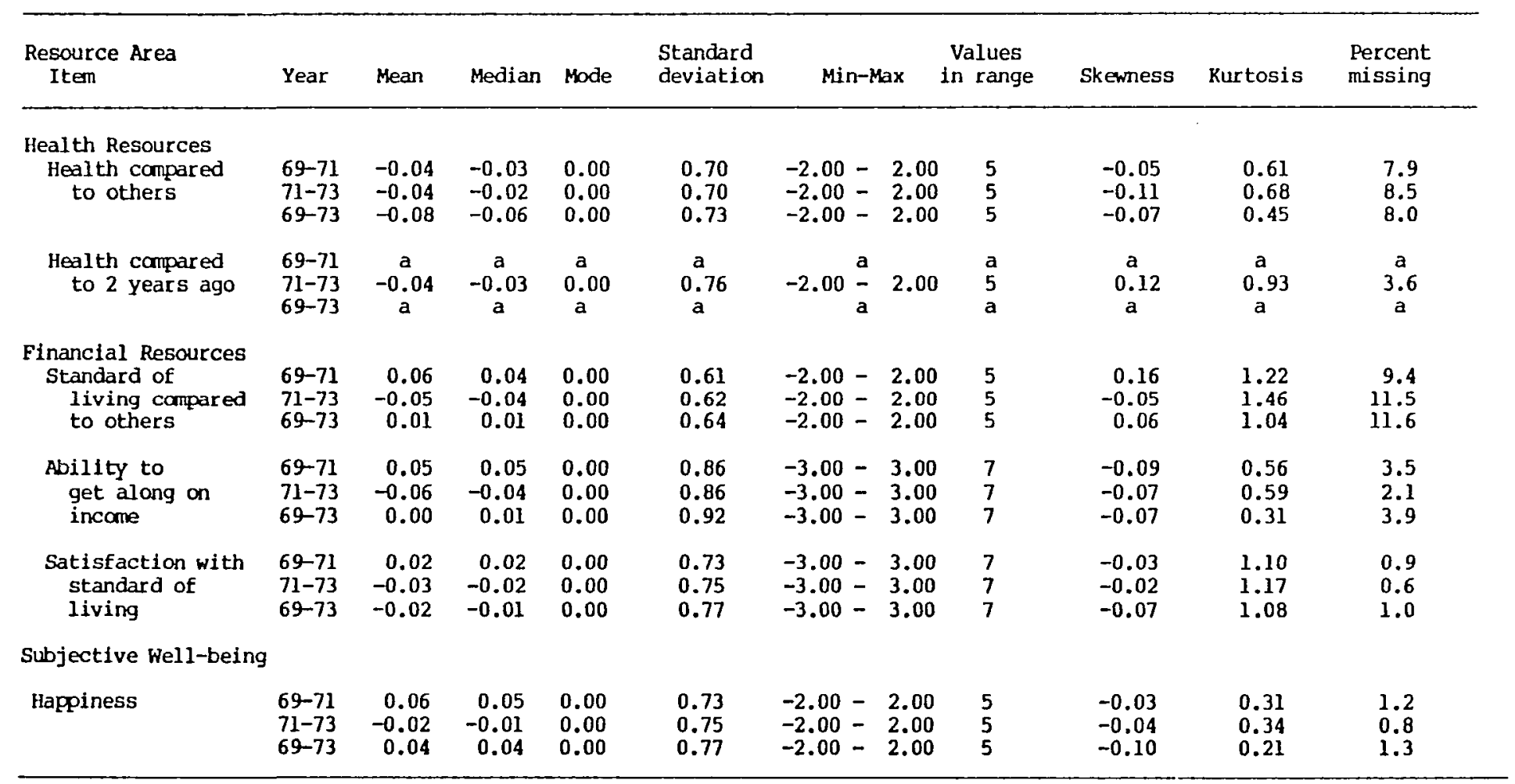

Note. All the items are identical across the three waves of data collection.

a This Item was not included in the 1969 wave of data collection. Therefore, a difference score could not be calculated between 1969 and 1971 and between 1969 and 1973. 
TABLE LXX

DESCRIPITIVE STATISTICS FOR THE ITEMS MEASURIAG CHANGE IN HEALTH, FINANCIAL RESOURCES, AND SUBJECTTIVE WEIL $r$ BEING AS MEASURED BY RESIDUAL CIIANGE SCORES

\begin{tabular}{|c|c|c|c|c|c|c|c|c|c|c|c|}
\hline $\begin{array}{l}\text { Resource Area } \\
\text { Item }\end{array}$ & Year & Mean & Median & Mode & $\begin{array}{l}\text { Standard } \\
\text { deviation }\end{array}$ & & In-Max & $\begin{array}{l}\text { Values } \\
\text { in range }\end{array}$ & Skewness & Kurtosis & $\begin{array}{l}\text { Percent } \\
\text { missing }\end{array}$ \\
\hline $\begin{array}{l}\text { Heal th Resources } \\
\text { Heal th compar ed } \\
\text { to others }\end{array}$ & $\begin{array}{l}69-71 \\
71-73 \\
69-73\end{array}$ & $\begin{array}{l}0.00 \\
0.00 \\
0.00\end{array}$ & $\begin{array}{l}-0.06 \\
-0.04 \\
-0.02\end{array}$ & $\begin{array}{l}-0.06 \\
-0.04 \\
-0.02\end{array}$ & $\begin{array}{l}0.60 \\
0.61 \\
0.62\end{array}$ & $\begin{array}{l}-1.56 \\
-1.54 \\
-1.48\end{array}$ & $\begin{array}{l}-1.44 \\
-\quad 1.50 \\
-\quad 1.44\end{array}$ & $\begin{array}{l}9 \\
9 \\
9\end{array}$ & $\begin{array}{l}-0.11 \\
-0.13 \\
-0.12\end{array}$ & $\begin{array}{l}-0.26 \\
-0.22 \\
-0.40\end{array}$ & $\begin{array}{l}7.9 \\
8.5 \\
8.0\end{array}$ \\
\hline $\begin{array}{l}\text { Health compared } \\
\text { to } 2 \text { years ago }\end{array}$ & $\begin{array}{l}69-71 \\
71-73 \\
69-73\end{array}$ & $\begin{array}{c}a \\
0.00 \\
a\end{array}$ & $\begin{array}{l}a \\
0.09 \\
a\end{array}$ & $\begin{array}{c}a \\
0.14\end{array}$ & $\begin{array}{c}a \\
0.62 \\
a\end{array}$ & -1.14 & $\begin{array}{ll}a \\
a\end{array}$ & $\begin{array}{l}\mathrm{a} \\
9 \\
\mathrm{a}\end{array}$ & $\begin{array}{l}a \\
0.26 \\
a\end{array}$ & $\begin{array}{l}a \\
-0.28 \\
a\end{array}$ & $\begin{array}{l}a \\
3.6 \\
a\end{array}$ \\
\hline $\begin{array}{l}\text { Financial Resources } \\
\text { Standard of } \\
\text { living campared } \\
\text { to others }\end{array}$ & $\begin{array}{l}69-71 \\
71-73 \\
69-73\end{array}$ & $\begin{array}{l}0.00 \\
0.00 \\
0.00\end{array}$ & $\begin{array}{r}-0.02 \\
0.02 \\
0.02\end{array}$ & $\begin{array}{r}-0.03 \\
0.04 \\
0.02\end{array}$ & $\begin{array}{l}0.50 \\
0.50 \\
0.51\end{array}$ & $\begin{array}{l}-1.38 \\
-1.29 \\
-1.27\end{array}$ & $\begin{array}{l}-1.33 \\
-\quad 1.37 \\
-\quad 1.32\end{array}$ & $\begin{array}{l}9 \\
9 \\
9\end{array}$ & $\begin{array}{r}0.14 \\
-0.02 \\
0.03\end{array}$ & $\begin{array}{l}0.64 \\
0.74 \\
0.64\end{array}$ & $\begin{array}{r}9.4 \\
11.5 \\
11.6\end{array}$ \\
\hline $\begin{array}{l}\text { Abllity to } \\
\text { get along on } \\
\text { income }\end{array}$ & $\begin{array}{l}69-71 \\
71-73 \\
69-73\end{array}$ & $\begin{array}{l}0.00 \\
0.00 \\
0.00\end{array}$ & $\begin{array}{r}0.10 \\
-0.13 \\
-0.22\end{array}$ & $\begin{array}{l}-0.24 \\
-0.17 \\
-0.23\end{array}$ & $\begin{array}{l}0.77 \\
0.75 \\
0.79\end{array}$ & $\begin{array}{l}-2.44 \\
-2.30 \\
-2.25\end{array}$ & $\begin{array}{l}-2.36 \\
-\quad 2.39 \\
-\quad 2.28\end{array}$ & $\begin{array}{l}16 \\
16 \\
16\end{array}$ & $\begin{array}{l}-0.10 \\
-0.00 \\
-0.02\end{array}$ & $\begin{array}{l}-0.08 \\
-0.09 \\
-0.30\end{array}$ & $\begin{array}{l}3.5 \\
2.1 \\
3.9\end{array}$ \\
\hline $\begin{array}{l}\text { Satisfaction with } \\
\text { standard of } \\
\text { living }\end{array}$ & $\begin{array}{l}69-71 \\
71-73 \\
69-73\end{array}$ & $\begin{array}{l}0.00 \\
0.00 \\
0.00\end{array}$ & $\begin{array}{l}0.09 \\
0.12 \\
0.13\end{array}$ & $\begin{array}{l}0.09 \\
0.14 \\
0.14\end{array}$ & $\begin{array}{l}0.63 \\
0.63 \\
0.65\end{array}$ & $\begin{array}{l}-2.38 \\
-2.28 \\
-2.24\end{array}$ & $\begin{array}{l}-2.02 \\
-\quad 1.98 \\
-\quad 1.90\end{array}$ & $\begin{array}{l}16 \\
16 \\
16\end{array}$ & $\begin{array}{l}-0.56 \\
-0.53 \\
-0.59\end{array}$ & $\begin{array}{l}0.91 \\
0.87 \\
0.80\end{array}$ & $\begin{array}{l}0.9 \\
0.6 \\
1.0\end{array}$ \\
\hline $\begin{array}{l}\text { Subjective Well-being } \\
\text { Happiness }\end{array}$ & $\begin{array}{l}69-71 \\
71-73 \\
69-73\end{array}$ & $\begin{array}{l}0.00 \\
0.00 \\
0.00\end{array}$ & $\begin{array}{l}-0.08 \\
-0.04 \\
-0.05\end{array}$ & $\begin{array}{l}-0.11 \\
-0.06 \\
-0.09\end{array}$ & $\begin{array}{l}0.62 \\
0.64 \\
0.65\end{array}$ & $\begin{array}{l}-1.53 \\
-1.49 \\
-1.48\end{array}$ & $\begin{array}{l}-1.32 \\
-\quad 1.36 \\
-1.30\end{array}$ & $\begin{array}{l}9 \\
9 \\
9\end{array}$ & $\begin{array}{l}-0.12 \\
-0.14 \\
-0.17\end{array}$ & $\begin{array}{l}-0.46 \\
-0.51 \\
-0.61\end{array}$ & $\begin{array}{l}1.2 \\
0.8 \\
1.3\end{array}$ \\
\hline
\end{tabular}

Note. All the items are Identical across the three waves of data collection.

a This item was not included in the 1969 wave of data collection. Therefore, a residual change score could not be calculated between the 1969 and 1971 and between the 1969 and 1973 waves of data collection. 
TABLE LXI

DESCRIPTIVE STATISTICS FOR THE ITEMS MEASURING CHANGE IN HEALTH, FINANCIAI, RESOURCES, AND SUBJECTIVE WELL-BEING AS MEASURED BY PERCENTAGE GAIN 'SOORES

\begin{tabular}{|c|c|c|c|c|c|c|c|c|c|c|c|}
\hline $\begin{array}{l}\text { Financial Resources } \\
\text { Standard of } \\
\text { living compared } \\
\text { to others }\end{array}$ & $\begin{array}{l}69-71 \\
71-73 \\
69-73\end{array}$ & $\begin{array}{r}0.04 \\
-0.04 \\
0.00\end{array}$ & $\begin{array}{r}0.02 \\
-0.02 \\
0.00\end{array}$ & $\begin{array}{l}0.00 \\
0.00 \\
0.00\end{array}$ & $\begin{array}{l}0.45 \\
0.45 \\
0.47\end{array}$ & $\begin{array}{l}-1.00- \\
-1.00= \\
-1.00-\end{array}$ & $\begin{array}{l}1.00 \\
1.00 \\
1.00\end{array}$ & $\begin{array}{l}5 \\
5 \\
5\end{array}$ & $\begin{array}{r}0.11 \\
-0.07 \\
-0.06\end{array}$ & $\begin{array}{l}1.16 \\
1.21 \\
0.95\end{array}$ & $\begin{array}{r}9.4 \\
11.5 \\
11.6\end{array}$ \\
\hline $\begin{array}{l}\text { Ability to } \\
\text { get along on } \\
\text { incame }\end{array}$ & $\begin{array}{l}69-71 \\
71-73 \\
69-73\end{array}$ & $\begin{array}{l}0.03 \\
-0.03 \\
-0.00\end{array}$ & $\begin{array}{r}0.01 \\
-0.01 \\
0.00\end{array}$ & $\begin{array}{l}0.00 \\
0.00 \\
0.00\end{array}$ & $\begin{array}{l}0.48 \\
0.46 \\
0.49\end{array}$ & $\begin{array}{l}-1.00- \\
-1.00= \\
-1.00-\end{array}$ & $\begin{array}{l}1.00 \\
1.00 \\
1.00\end{array}$ & $\begin{array}{l}9 \\
9 \\
9\end{array}$ & $\begin{array}{r}-0.05 \\
0.02 \\
-0.02\end{array}$ & $\begin{array}{l}0.29 \\
0.43 \\
0.09\end{array}$ & $\begin{array}{l}3.5 \\
2.1 \\
3.9\end{array}$ \\
\hline $\begin{array}{l}\text { Subjective Well-being } \\
\text { Happiness }\end{array}$ & $\begin{array}{l}69-71 \\
71-73 \\
69-73\end{array}$ & $\begin{array}{l}0.06 \\
0.01 \\
0.05\end{array}$ & $\begin{array}{r}0.02 \\
-0.00 \\
0.02\end{array}$ & $\begin{array}{l}0.00 \\
0.00 \\
0.00\end{array}$ & $\begin{array}{l}0.54 \\
0.54 \\
0.56\end{array}$ & $\begin{array}{l}-1.00- \\
-1.00- \\
-1.00-\end{array}$ & $\begin{array}{l}1.00 \\
1.00 \\
1.00\end{array}$ & $\begin{array}{l}5 \\
5 \\
5\end{array}$ & $\begin{array}{l}0.11 \\
0.12 \\
0.05\end{array}$ & $\begin{array}{r}-0.04 \\
-0.04 \\
0.25\end{array}$ & $\begin{array}{l}1.2 \\
0.8 \\
1.3\end{array}$ \\
\hline
\end{tabular}

Nete. All the items are identical across the three waves of data collection.

a This item was not included in the 1969 wave of data collection. Therefore, a percentage gain score could not be computed between the 1969 and 1971 and between the 1969 and 1973 waves of data collection. 
TABLE LXII

MEANS, STANDARD DEVIATIONS, AND INTERCORREJ.ATIONS AMONG SJBJECTTVE WETL-BEING, HEALTH, SOCIAL, AND FINANCIAL RESOURCES FOR 1969, 1971, AND 1973

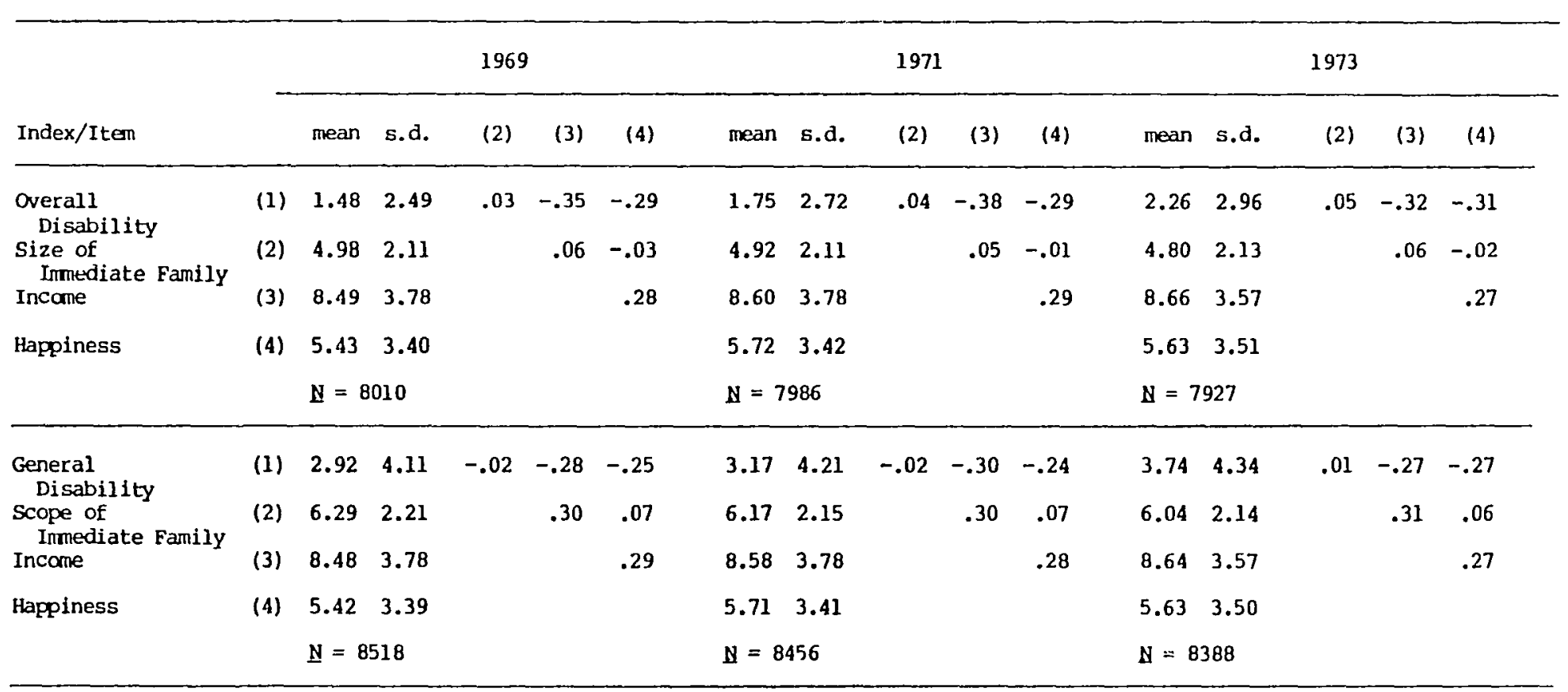

Note. The means, standard deviations, and correlation coefficients may differ slightly froin those presented previously due to the listwise deletion of cases with a missing value on one or more variables. 
MEANS, STANDARD DEVIATIONS, AND INIEROORRET_ATTONS AMONG SUBJECTTVE WEIL-BEING, IEALTH, AND FINANCIAL ITEMS FOR 1969, 1971, AND 1973

\begin{tabular}{|c|c|c|c|c|c|c|c|c|c|}
\hline Item & & year & mean & s.d. & (2) & (3) & (4) & (5) & (6) \\
\hline $\begin{array}{l}\text { Heal th compared } \\
\text { to others }\end{array}$ & (1) & $\begin{array}{l}1969 \\
1971 \\
1973\end{array}$ & $\begin{array}{l}1.18 \\
1.15 \\
1.11\end{array}$ & $\begin{array}{l}0.72 \\
0.69 \\
0.70\end{array}$ & $\begin{array}{l}- \\
.38 \\
.42\end{array}$ & $\begin{array}{l}.28 \\
.22 \\
.24\end{array}$ & $\begin{array}{l}.31 \\
.28 \\
.29\end{array}$ & $\begin{array}{l}.30 \\
.26 \\
.26\end{array}$ & $\begin{array}{l}.33 \\
.28 \\
.31\end{array}$ \\
\hline $\begin{array}{l}\text { Heal th campared } \\
\text { to } 2 \text { years ago }\end{array}$ & (2) & $\begin{array}{l}1969 \\
1971 \\
1973\end{array}$ & $\begin{array}{c}a \\
0.87 \\
0.82\end{array}$ & $\begin{array}{c}a \\
0.61 \\
0.64\end{array}$ & & $\begin{array}{l}a \\
.14 \\
.17\end{array}$ & $\begin{array}{l}a \\
.19 \\
.20\end{array}$ & $\begin{array}{c}a \\
.19 \\
.21\end{array}$ & $\begin{array}{l}a \\
.21 \\
.24\end{array}$ \\
\hline $\begin{array}{l}\text { Standard of living } \\
\text { compared to others }\end{array}$ & (3) & $\begin{array}{l}1969 \\
1971 \\
1973\end{array}$ & $\begin{array}{l}0.95 \\
1.02 \\
0.96\end{array}$ & $\begin{array}{l}0.54 \\
0.54 \\
0.53\end{array}$ & & & $\begin{array}{l}.39 \\
.34 \\
.34\end{array}$ & $\begin{array}{l}.47 \\
.43 \\
.44\end{array}$ & $\begin{array}{l}.29 \\
.28 \\
.30\end{array}$ \\
\hline $\begin{array}{l}\text { Ability to get along } \\
\text { on income }\end{array}$ & (4) & $\begin{array}{l}1969 \\
1971 \\
1973\end{array}$ & $\begin{array}{l}1.50 \\
1.56 \\
1.50\end{array}$ & $\begin{array}{l}0.95 \\
0.95 \\
0.92\end{array}$ & & & & $\begin{array}{l}.53 \\
.52 \\
.51\end{array}$ & $\begin{array}{l}.34 \\
.34 \\
.34\end{array}$ \\
\hline $\begin{array}{l}\text { Satisfaction with } \\
\text { standard of living }\end{array}$ & (5) & $\begin{array}{l}1969 \\
1971 \\
1973\end{array}$ & $\begin{array}{l}1.81 \\
1.83 \\
1.80\end{array}$ & $\begin{array}{l}0.66 \\
0.70 \\
0.69\end{array}$ & & & & & $\begin{array}{l}.41 \\
.47 \\
.45\end{array}$ \\
\hline Happiness & (6) & $\begin{array}{l}1969 \\
1971 \\
1973\end{array}$ & $\begin{array}{l}1.10 \\
1.16 \\
1.14\end{array}$ & $\begin{array}{l}0.68 \\
0.68 \\
0.70\end{array}$ & & & & & \\
\hline
\end{tabular}

Note. The means, standard deviations, and correlation coefficients may differ slightly from those presented previously due to the listwise deletion of cases with a missing value on one or more variables.

The sample sizes are 7956 in 1969, 7957 in 1971 and 7728 in 1973.

a This item was not included in the 1969 wave of data collection. 
TABLE LXIV

MULTTPLE LINEAR REGRESSION FOR PREDICTING SUBJECTTVE WEIL-BEING FROM GHANGE IN HEALTH, SOCIAL, AND FINANCIAL RESOURCES AS MEASURED BY DIFFERENCE SCORES

\begin{tabular}{|c|c|c|c|c|c|c|c|c|c|c|c|c|}
\hline \multirow[b]{2}{*}{ Index/Item } & \multicolumn{4}{|c|}{$1969-1971$} & \multicolumn{4}{|c|}{$1971-1973$} & \multicolumn{4}{|c|}{$1969-1973$} \\
\hline & $\begin{array}{l}\text { Order of } \\
\text { entry }\end{array}$ & $\mathrm{b}$ & beta & $\triangle \mathrm{R} 2$ & $\begin{array}{l}\text { Order of } \\
\text { entry }\end{array}$ & $\mathbf{b}$ & beta & $\Delta \mathrm{R} 2$ & $\begin{array}{l}\text { Order of } \\
\text { entry }\end{array}$ & $\mathbf{b}$ & beta & $\Delta \mathrm{R} 2$ \\
\hline $\begin{array}{l}\text { Overall } \\
\text { Disability }\end{array}$ & 1 & -0.13 & -0.08 & 0.01 & 1 & -0.12 & -0.08 & 0.01 & 1 & -0.19 & -0.14 & 0.02 \\
\hline \multirow{3}{*}{$\begin{array}{l}\text { Size of } \\
\text { Immediate Family } \\
\text { Income }\end{array}$} & 3 & 0.16 & 0.03 & 0.00 & 2 & 0.17 & 0.03 & 0.00 & 2 & 0.19 & 0.04 & 0.00 \\
\hline & 2 & 0.06 & 0.04 & 0.00 & - & - & - & - & 3 & 0.03 & 0.02 & 0.00 \\
\hline & Total & $\mathrm{R} 2=0.01$ & \multicolumn{2}{|c|}{$N=7303$} & Total & $\mathrm{R} 2=0.01$ & \multicolumn{2}{|c|}{$\mathbf{N}=7207$} & \multicolumn{4}{|c|}{ Total $R 2=0.02$} \\
\hline $\begin{array}{l}\text { General } \\
\text { Disability }\end{array}$ & 3 & -0.03 & -0.04 & 0.00 & 1 & -0.05 & -0.05 & 0.01 & 1 & -0.07 & -0.08 & 0.01 \\
\hline \multirow{3}{*}{$\begin{array}{l}\text { Scope of } \\
\text { Immediate Fanily } \\
\text { Income }\end{array}$} & 2 & 0.15 & 0.04 & 0.00 & 2 & 0.21 & 0.05 & 0.00 & 2 & 0.19 & 0.06 & 0.00 \\
\hline & 1 & 0.06 & 0.04 & 0.01 & - & - & - & - & 3 & 0.03 & 0.02 & 0.00 \\
\hline & \multicolumn{2}{|c|}{ Total R2 $=0.01$} & \multicolumn{2}{|c|}{$\mathrm{N}=8172$} & Total & $\mathrm{R} 2=0.01$ & \multicolumn{2}{|c|}{$N=8044$} & Total & $R 2=0.01$ & \multicolumn{2}{|c|}{$\mathbf{N}=8108$} \\
\hline
\end{tabular}

Note. The outcome in the 1969-1971 analysis is the happiness 1tem in 1971. Likewise, the outcome in the 1971-1973 and in the 1969-1973 analyses is the happiness item in 1973.

The dash ( - ) Indicates that the variable did not reach the level of statistical significance $(p<.05)$ necessary to be entered in the regression analysis. 
TABLE IXXV

MEANS, STANDARD DEVIATIONS, AND INTERCORREJATIONS AMONG SUBJECTIVE WETL-BEING AND CHAAGE IN HEALTH, SOCIAL, AND FINANCIAL RESUURCES AS MEASURED BY DIFFERENCE SOORES

\begin{tabular}{|c|c|c|c|c|c|c|c|c|c|c|c|c|c|c|}
\hline \multirow[b]{2}{*}{ Index/Item } & & \multicolumn{5}{|c|}{$1969-1971$} & \multicolumn{4}{|c|}{$1971-1973$} & \multicolumn{4}{|c|}{$1969-1973$} \\
\hline & & mean & s.d. & (2) & (3) & (4) & mean s.d. & (2) & (3) & (4) & mean s.d. & (2) & (3) & (4) \\
\hline $\begin{array}{l}\text { Overall } \\
\text { Disability }\end{array}$ & (1) & 0.25 & 2.07 & .01 & -.10 & -.08 & $0.48 \quad 2.37$ & -.00 & -.11 & -.08 & 0.732 .52 & .01 & -.14 & -.14 \\
\hline $\begin{array}{l}\text { Size of } \\
\text { Immediate Family }\end{array}$ & (2) & -0.09 & 0.71 & & .04 & .03 & -0.110 .69 & & .04 & .04 & -0.210 .80 & & .04 & .04 \\
\hline Incame & (3) & 0.13 & 2.32 & & & .05 & 0.102 .08 & & & .01 & 0.232 .57 & & & .05 \\
\hline \multirow[t]{2}{*}{ Happiness } & (4) & 5.73 & 3.41 & & & & 5.663 .50 & & & & 5.663 .50 & & & \\
\hline & & $\mathbf{N}=$ & 7303 & & & & $N=7207$ & & & & $N=7233$ & & & \\
\hline $\begin{array}{l}\text { General } \\
\text { Disability }\end{array}$ & (1) & 0.23 & 3.73 & .02 & -.06 & -.04 & 0.564 .00 & .00 & -.09 & -.05 & $0.80 \quad 4.15$ & .02 & -.09 & -.08 \\
\hline $\begin{array}{l}\text { Scope of } \\
\text { Inmediate Family }\end{array}$ & (2) & -0.14 & 0.90 & & .04 & .04 & $-0.11 \quad 0.87$ & & .06 & .05 & -0.251 .08 & & .05 & .06 \\
\hline Income & (3) & 0.12 & 2.31 & & & .05 & 0.092 .07 & & & .02 & $0.21 \quad 2.55$ & & & .04 \\
\hline \multirow[t]{2}{*}{ Happiness } & (4) & 5.72 & 3.41 & & & & 5.643 .49 & & & & 5.633 .50 & & & \\
\hline & & $\mathbf{N}=\mathbf{8}$ & 8172 & & & & $N=8044$ & & & & $N=8108$ & & & \\
\hline
\end{tabular}

Note. The means, standard deviations, and correlation coefficients may differ slightly from those presented previously due to the listwise deletion of cases with a missing value on one or more variables. 
TABLE LXVI

MUTTPLE LINEAR REGRESSION FOR PREDICTING SUBJECTTVE WEIL-BEING FROM CHANGE IN HEALTH, SOCIAL, AND FINANCIAL RESOURCES AS MEASURED BY RESIDUAL CJIANGE SOORES

\begin{tabular}{|c|c|c|c|c|c|c|c|c|c|c|c|c|}
\hline \multirow[b]{2}{*}{ Index/Item } & \multicolumn{4}{|c|}{$1969-1971$} & \multicolumn{4}{|c|}{$1971-1973$} & \multicolumn{4}{|c|}{$1969-1973$} \\
\hline & $\begin{array}{l}\text { Order of } \\
\text { entry }\end{array}$ & $b$ & beta & $\Delta \mathrm{R} 2$ & $\begin{array}{l}\text { Order of } \\
\text { entry }\end{array}$ & $b$ & beta & $\Delta \mathrm{R} 2$ & $\begin{array}{l}\text { Order of } \\
\text { entry }\end{array}$ & b & beta & $\triangle \mathrm{R} 2$ \\
\hline $\begin{array}{l}\text { Overall } \\
\text { Disability }\end{array}$ & 1 & -0.27 & -0.15 & 0.03 & 1 & -0.26 & -0.17 & 0.03 & 1 & -0.30 & -0.20 & 0.05 \\
\hline $\begin{array}{l}\text { Size of } \\
\text { Immediate Family }\end{array}$ & 3 & 0.14 & 0.03 & 0.00 & 3 & 0.12 & 0.02 & 0.00 & 3 & 0.15 & 0.03 & 0.00 \\
\hline \multirow[t]{2}{*}{ Incame } & 2 & 0.18 & 0.11 & 0.01 & 2 & 0.17 & 0.09 & 0.01 & 2 & 0.18 & 0.12 & 0.01 \\
\hline & Total & $\mathrm{R} 2=0.04$ & \multicolumn{2}{|c|}{$N=7303$} & \multicolumn{4}{|c|}{$\mathbf{N}=7207$} & \multicolumn{2}{|c|}{ Total R2 $=0.06$} & \multicolumn{2}{|c|}{$\mathbf{N}=7233$} \\
\hline $\begin{array}{l}\text { General } \\
\text { Disability }\end{array}$ & 1 & -0.13 & -0.13 & 0.02 & 1 & -0.16 & -0.16 & 0.03 & 1 & -0.17 & -0.18 & 0.04 \\
\hline $\begin{array}{l}\text { Scope of } \\
\text { Immediate Family }\end{array}$ & 3 & 0.20 & 0.05 & 0.00 & 3 & 0.23 & 0.06 & 0.00 & 3 & 0.21 & 0.06 & 0.00 \\
\hline \multirow[t]{2}{*}{ Income } & 2 & 0.18 & 0.11 & 0.02 & 2 & 0.18 & 0.10 & 0.01 & 2 & 0.18 & 0.12 & 0.02 \\
\hline & Total & $\mathrm{R} 2=0.04$ & \multicolumn{2}{|c|}{$\mathbf{N}=8172$} & Total & $\mathrm{R} 2=0.04$ & \multicolumn{2}{|c|}{$N=8044$} & Total & $\mathrm{R} 2=0.06$ & \multicolumn{2}{|c|}{$N=8108$} \\
\hline
\end{tabular}

Note. The outcome in the 1969-1971 analysis is the happiness 1tem in 1971. Likewise, the outcome in the 1971-1973 and in the 1969-1973 analyses is the happiness iten in 1973. 
TABLE LXVII

MEANS, STAARDARD DEVIATIONS, AND INIERCORREIATTONS AMONG SUBJECTIVE WEIL-BEING, AND CHANGE IN HEALTH, SOCIAL, AND FINANCIAL RESOURCES AS MEASURED BY RESIDUAL CHANGE SOORES

\begin{tabular}{|c|c|c|c|c|c|c|c|c|c|c|c|c|c|}
\hline \multirow[b]{2}{*}{ Index/Item } & \multicolumn{5}{|c|}{$1969-1971$} & \multicolumn{4}{|c|}{$1971-1973$} & \multicolumn{4}{|c|}{$1969-1973$} \\
\hline & & mean s.d. & (2) & (3) & (4) & mean s.d. & (2) & (3) & (4) & mean s.d. & (2) & (3) & (4) \\
\hline $\begin{array}{l}\text { Qverall } \\
\text { Disability }\end{array}$ & (1) & 0.001 .97 & .01 & -.16 & -.17 & 0.012 .23 & .00 & -.12 & -.18 & 0.012 .40 & .02 & -.18 & -.22 \\
\hline $\begin{array}{l}\text { Size of } \\
\text { Immediate Family }\end{array}$ & (2) & $0.00 \quad 0.70$ & & .03 & .03 & 0.000 .68 & & .05 & .03 & $-0.00 \quad 0.79$ & & .05 & .04 \\
\hline Income & (3) & $0.02 \quad 2.19$ & & & .14 & 0.031 .92 & & & .11 & 0.042 .31 & & & .16 \\
\hline \multirow[t]{2}{*}{ Happiness } & (4) & 5.733 .41 & & & & 5.663 .50 & & & & 5.663 .50 & & & \\
\hline & & $\mathbb{N}=7303$ & & & & $N=7207$ & & & & $\mathbf{N}=7233$ & & & \\
\hline $\begin{array}{l}\text { General } \\
\text { Disability }\end{array}$ & (1) & -0.003 .36 & .02 & -.12 & -.14 & 0.023 .59 & .01 & -.10 & -.17 & 0.023 .71 & .02 & -.13 & -.19 \\
\hline $\begin{array}{l}\text { Scope of } \\
\text { Inmediate Fanily }\end{array}$ & (2) & $0.00 \quad 0.87$ & & .06 & .06 & $-0.00 \quad 0.85$ & & .08 & .06 & -0.001 .03 & & .08 & .07 \\
\hline Income & (3) & 0.002 .19 & & & .13 & 0.021 .92 & & & .12 & 0.022 .29 & & & .15 \\
\hline \multirow[t]{2}{*}{ Happiness } & (4) & 5.723 .41 & & & & 5.643 .49 & & & & 5.633 .50 & & & \\
\hline & & $\underline{N}=8172$ & & & & $\mathrm{~N}=8044$ & & & & $\mathbb{N}=8108$ & & & \\
\hline
\end{tabular}

Note. The means, standard deviations, and correlation coefficients may differ slightly from those presented previously due to the listwise deletion of cases with a missing value on one or more variables. 
TABLE LXVIII

MLTIPLE LINEAR REGRESSION FOR PREDICTING SUBJECTTVE WELL-BEING FROM CIANGE IN HEALTH, SOCIAL, AND FINANCIAL RESQURCES AS MEASURED BY PERCENTAGE GAIN SOORES

\begin{tabular}{|c|c|c|c|c|c|c|c|c|c|c|c|c|}
\hline \multirow[b]{2}{*}{ Index/Item } & \multicolumn{4}{|c|}{$1969-1971$} & \multicolumn{4}{|c|}{$1971-1973$} & \multicolumn{4}{|c|}{$1969-1973$} \\
\hline & $\begin{array}{l}\text { Order of } \\
\text { entry }\end{array}$ & $\mathrm{b}$ & beta & $\Delta \mathrm{R} 2$ & $\begin{array}{l}\text { Order of } \\
\text { entry }\end{array}$ & $\mathbf{b}$ & beta & $\Delta \mathrm{R} 2$ & $\begin{array}{l}\text { Order of } \\
\text { entry }\end{array}$ & $b$ & beta & $\triangle \mathrm{R} 2$ \\
\hline $\begin{array}{l}\text { Overall } \\
\text { Disability }\end{array}$ & 2 & -0.70 & -0.07 & 0.00 & 1 & -0.80 & -0.09 & 0.01 & 1 & -1.17 & -0.13 & 0.02 \\
\hline \multirow{3}{*}{$\begin{array}{l}\text { Size of } \\
\text { Immediate Family } \\
\text { Incame }\end{array}$} & 3 & 0.76 & 0.03 & 0.00 & 3 & 0.80 & 0.03 & 0.00 & 3 & 0.91 & 0.04 & 0.00 \\
\hline & 1 & 1.28 & 0.12 & 0.02 & 2 & 0.81 & 0.07 & 0.01 & 2 & 1.02 & 0.10 & 0.01 \\
\hline & Total & $\mathrm{R} 2=0.02$ & \multicolumn{2}{|c|}{$\mathbf{N}=7303$} & \multicolumn{4}{|c|}{ Total $\mathrm{R} 2=0.02$} & \multicolumn{2}{|c|}{ Total R2 $=0.03$} & \multicolumn{2}{|c|}{$\mathbf{N}=7233$} \\
\hline $\begin{array}{l}\text { General } \\
\text { Disability }\end{array}$ & 3 & -0.30 & -0.04 & 0.00 & 2 & -0.46 & -0.06 & 0.00 & 2 & -0.63 & -0.09 & 0.01 \\
\hline $\begin{array}{l}\text { Scope of } \\
\text { Immediate Family }\end{array}$ & 2 & 1.04 & 0.04 & 0.00 & 3 & 1.12 & 0.05 & 0.00 & 3 & 1.10 & 0.05 & 0.00 \\
\hline \multirow[t]{2}{*}{ Income } & 1 & 1.23 & 0.12 & 0.02 & $I$ & 0.88 & 0.08 & 0.01 & 1 & 1.00 & 0.10 & 0.01 \\
\hline & Total & $\mathrm{R} 2=0.02$ & \multicolumn{2}{|c|}{$N=8172$} & Total & $R 2=0.01$ & \multicolumn{2}{|c|}{$N=8044$} & Total & $\mathrm{R} 2=0.02$ & \multicolumn{2}{|c|}{$\mathrm{N}=8108$} \\
\hline
\end{tabular}

Nete. The outcome in the 1969-1971 analysis is the happiness item in 1971. Likewise the outcome in the 1971-1973 and in the 1969-1973 analyses is the happiness item in 1973. 
TABLE LXIX

MEANS, STANDARD DEVIATIONS, ANDD INTERCORREIATIONS AMONG SUBJECTIVE WELL-BEING, AND CHANGE IN HEALTH, SOCIAL, AND FINANCIAL RESOURCES AS MEASURED BY PERCENTAGE GAIN SOORES

\begin{tabular}{|c|c|c|c|c|c|c|c|c|c|c|c|c|c|}
\hline \multirow[b]{2}{*}{ Index/Iten } & \multicolumn{5}{|c|}{$1969-1971$} & \multicolumn{4}{|c|}{$1971-1973$} & \multicolumn{4}{|c|}{$1969-1973$} \\
\hline & & mean's.d. & (2) & (3) & (4) & mean s.d. & (2) & (3) & (4) & mean s.d. & $(2)$ & $(3)$ & (4) \\
\hline $\begin{array}{l}\text { Overall } \\
\text { Disability }\end{array}$ & (1) & $-0.02 \quad 0.36$ & .02 & -.07 & -.08 & $0.01 \quad 0.38$ & .02 & -.07 & -.09 & 0.050 .39 & .02 & -.11 & -.14 \\
\hline $\begin{array}{l}\text { Size of } \\
\text { Immediate Family }\end{array}$ & (2) & $-0.02 \quad 0.14$ & & .05 & .04 & $-0.03 \quad 0.14$ & & .05 & .04 & $-0.05 \quad 0.16$ & & .04 & .04 \\
\hline Incame & (3) & $0.04 \quad 0.33$ & & & .13 & $0.04 \quad 0.30$ & & & .08 & $0.06 \quad 0.35$ & & & .12 \\
\hline \multirow[t]{2}{*}{ Happiness } & (4) & 5.733 .41 & & & & 5.663 .50 & & & & 5.663 .50 & & & \\
\hline & & $\underline{N}=7303$ & & & & $\mathbf{N}=7207$ & & & & $N=7233$ & & & \\
\hline $\begin{array}{l}\text { General } \\
\text { Disability }\end{array}$ & (1) & 0.020 .46 & .02 & -.04 & -.04 & $0.05 \quad 0.49$ & .00 & -.07 & -.07 & $0.08 \quad 0.50$ & .02 & -.08 & -.10 \\
\hline $\begin{array}{l}\text { Scope of } \\
\text { Immediate Fanily }\end{array}$ & (2) & $-0.02 \quad 0.15$ & & .05 & .05 & $\begin{array}{lll}-0.01 & 0.15\end{array}$ & & .06 & .05 & $\begin{array}{lll}-0.03 & 0.17\end{array}$ & & .05 & .06 \\
\hline Income & (3) & $0.03 \quad 0.33$ & & & .12 & 0.040 .30 & & & .08 & $0.06 \quad 0.35$ & & & .11 \\
\hline \multirow[t]{2}{*}{ Happiness } & (4) & 5.723 .41 & & & & 5.643 .49 & & & & 5.633 .50 & & & \\
\hline & & $\underline{\mathrm{N}}=8172$ & & & & $\mathbf{N}=8044$ & & & & $\mathrm{~N}=8108$ & & & \\
\hline
\end{tabular}

Note. The means, standard deviations, and correlation coefficients may differ slightly from those presented previously due to the listwise deletion of cases with a missing value on one or more variables. 
TABLE LXX

MULTTPLE LINEAR REGRESSION FOR PREDICTING CHANGE IN SUBJECTTVE WEJL-BEING FROM GIANGE IN HEALTH, SOCIAL, AND FINANCIAL RESOURCES AS MEASJRED BY DIFFERENCE SCORES

\begin{tabular}{|c|c|c|c|c|c|c|c|c|c|c|c|c|}
\hline \multirow[b]{2}{*}{ Index/Item } & \multicolumn{4}{|c|}{$1969-1971$} & \multicolumn{4}{|c|}{$1971-1973$} & \multicolumn{4}{|c|}{$1969-1973$} \\
\hline & $\begin{array}{l}\text { Order of } \\
\text { entry }\end{array}$ & $\mathbf{b}$ & beta & $\Delta R 2$ & $\begin{array}{l}\text { Order of } \\
\text { entry }\end{array}$ & $\mathrm{b}$ & beta & $\Delta \mathrm{R} 2$ & $\begin{array}{l}\text { Order of } \\
\text { entry }\end{array}$ & $\mathrm{b}$ & beta & $\Delta_{\mathrm{R} 2}$ \\
\hline $\begin{array}{l}\text { Overall } \\
\text { Disability }\end{array}$ & 1 & -0.14 & -0.08 & 0.01 & 1 & -0.16 & -0.10 & 0.01 & 1 & -0.19 & -0.12 & 0.02 \\
\hline $\begin{array}{l}\text { Size of } \\
\text { Innediate Fandly }\end{array}$ & 3 & 0.12 & 0.02 & 0.00 & - & - & - & - & 3 & 0.19 & 0.04 & 0.00 \\
\hline \multirow[t]{2}{*}{ Incame } & 2 & 0.05 & 0.103 & 0.00 & 2 & 0.07 & 0.04 & 0.00 & 2 & 0.09 & 0.06 & 0.00 \\
\hline & Total & $\mathrm{R} 2=0.01$ & \multicolumn{2}{|c|}{$\mathbf{N}=7255$} & \multicolumn{4}{|c|}{$\mathbf{N}=7190$} & \multicolumn{2}{|c|}{ Total $\mathrm{R} 2=0.02$} & \multicolumn{2}{|c|}{$N=7183$} \\
\hline $\begin{array}{l}\text { General } \\
\text { Disability }\end{array}$ & 1 & -0.06 & -0.06 & 0.01 & 1 & -0.07 & -0.08 & 0.01 & 1 & -0.10 & -0.10 & 0.01 \\
\hline $\begin{array}{l}\text { Scope of } \\
\text { Immediate Family }\end{array}$ & 3 & 0.11 & 0.03 & 0.00 & 3 & 0.14 & 0.03 & 0.00 & 3 & 0.16 & 0.04 & 0.00 \\
\hline \multirow[t]{2}{*}{ Income } & 2 & 0.05 & 0.03 & 0.00 & 2 & 0.09 & 0.05 & 0.00 & 2 & 0.09 & 0.06 & 0.01 \\
\hline & Total & $\mathrm{R} 2=0.01$ & \multicolumn{2}{|c|}{$\mathrm{N}=\mathrm{B120}$} & Total & $\mathrm{R} 2=0.01$ & \multicolumn{2}{|c|}{$\mathbf{N}=8023$} & Total & $\mathrm{R} 2=0.02$ & \multicolumn{2}{|c|}{$N=8055$} \\
\hline
\end{tabular}

Note. The outcane in the 1969-1971 analysis is change in happiness from 1969 to 1971. Likewise, the outcome in the 1971-1973 and in the 1969-1973 analyses is change in happiness from 1971 to 1973 and from 1969 to 1973 respectively.

The dash (-) indicates that the varlable did not reach the level of statistical significance $(p<.05)$ necessary to be entered into the regression analysis. 
TABLE LXXI

MEANS, STANDARD DEVIATTONS, AND INTERCORRELATIONS AMONG CHANGE IN SUBJECTIVE WEJL-BEING, HEALTH, SOCLAL, AND FINANCIAL, RFSOURCES AS MEASURED BY DIFFERERCE SCORES

\begin{tabular}{|c|c|c|c|c|c|c|c|c|c|c|c|c|c|}
\hline \multirow[b]{2}{*}{ Index/Item } & & \multicolumn{4}{|c|}{$1969-1971$} & \multicolumn{4}{|c|}{$1971-1973$} & \multicolumn{4}{|c|}{$1969-1973$} \\
\hline & & mean s.d. & (2) & (3) & (4) & mean s.d. & (2) & (3) & (4) & mean s.d. & $(2)$ & (3) & (4) \\
\hline $\begin{array}{l}\text { Overall } \\
\text { Disability }\end{array}$ & (1) & $0.25 \quad 2.07$ & .01 & -.10 & -.08 & $0.48 \quad 2.37$ & .00 & -.11 & -.10 & 0.742 .52 & .01 & -.14 & -.13 \\
\hline $\begin{array}{l}\text { Size of } \\
\text { Irmediate Family }\end{array}$ & (2) & -0.090 .71 & & .04 & .02 & $-0.11 \quad 0.69$ & & .04 & .01 & $-0.21 \quad 0.80$ & & .04 & .04 \\
\hline Incame & (3) & 0.122 .31 & & & .04 & 0.092 .08 & & & .05 & 0.232 .57 & & & .08 \\
\hline \multirow[t]{2}{*}{ Happiness } & (4) & $0.28 \quad 3.63$ & & & & -0.103 .72 & & & & 0.183 .85 & & & \\
\hline & & $\underline{N}=7255$ & & & & $\mathbf{N}=7190$ & & & & $\mathbf{N}=7183$ & & & \\
\hline $\begin{array}{l}\text { General } \\
\text { Disability }\end{array}$ & (1) & $0.23 \quad 3.73$ & .03 & -.06 & -.06 & 0.564 .00 & .00 & -.09 & -.08 & 0.814 .15 & .02 & -.09 & -.11 \\
\hline $\begin{array}{l}\text { Scope of } \\
\text { Immediate Family }\end{array}$ & (z) & -0.140 .90 & & .04 & .03 & $-0.11 \quad 0.87$ & & .06 & .04 & -0.251 .08 & & .05 & .04 \\
\hline Incane & (3) & 0.122 .31 & & & .04 & 0.092 .07 & & & .06 & 0.212 .54 & & & .07 \\
\hline \multirow[t]{2}{*}{ Happiness } & (4) & 0.303 .63 & & & & -0.093 .73 & & & & 0.193 .85 & & & \\
\hline & & $\mathbf{N}=8120$ & & & & $\mathbf{N}=8023$ & & & & $\mathbf{N}=8055$ & & & \\
\hline
\end{tabular}

Note. The means, standard deviations, and correlation coefficients may differ slightly from those presented previously due

to the listwise deletion of cases with a missing value on one or more vartables. 
TABLE LXXII

MULTIPLE LINEAR REGRESSION FOR PRETICTING CHANGE IN SUBJECTIVE WEIL-BEING FBOM OLANGE

IN HEALTH, SOCIAL, AND FINANCIAL RESOURCES AS MEASURED BY RESIDUAL GIAN:BE SCORES

\begin{tabular}{|c|c|c|c|c|c|c|c|c|c|c|c|c|}
\hline \multirow[b]{2}{*}{ Index/Item } & \multicolumn{4}{|c|}{$1969-1971$} & \multicolumn{4}{|c|}{$1971-1973$} & \multicolumn{3}{|c|}{$1969-1973$} & \multirow[b]{2}{*}{$\Delta \mathrm{R} 2$} \\
\hline & $\begin{array}{l}\text { Order of } \\
\text { entry }\end{array}$ & b & beta & $\triangle \mathrm{R} 2$ & $\begin{array}{l}\text { Order of } \\
\text { entry }\end{array}$ & b & beta & $\Delta \mathrm{R} 2$ & $\begin{array}{l}\text { Order of } \\
\text { entry }\end{array}$ & b & beta & \\
\hline \multirow{4}{*}{$\begin{array}{l}\text { Overall } \\
\text { Disability } \\
\text { Size of } \\
\text { Immediate Fanily } \\
\text { Income }\end{array}$} & 1 & -0.21 & -0.13 & 0.02 & 1 & -0.22 & -0.16 & 0.02 & 1 & -0.25 & -0.19 & 0.04 \\
\hline & 3 & 0.14 & 0.03 & 0.00 & - & - & - & - & 3 & 0.17 & 0.04 & 0.00 \\
\hline & 2 & 0.12 & 0.08 & 0.01 & 2 & 0.12 & 0.07 & 0.01 & 2 & 0.14 & 0.10 & 0.01 \\
\hline & Total & $\mathrm{R} 2=0.03$ & \multicolumn{2}{|c|}{$\mathbf{N}=7255$} & \multicolumn{4}{|c|}{ Total R2 $=0.03$} & \multicolumn{2}{|c|}{ Total $R 2=0.05$} & \multicolumn{2}{|c|}{$N=7183$} \\
\hline $\begin{array}{l}\text { General } \\
\text { Disability }\end{array}$ & 1 & -0.10 & -0.11 & 0.01 & 1 & -0.13 & -0.14 & 0.02 & 1 & -0.14 & -0.16 & 0.03 \\
\hline $\begin{array}{l}\text { Scope of } \\
\text { Immediate Family }\end{array}$ & 3 & 0.16 & 0.04 & 0.00 & 3 & 0.18 & 0.05 & 0.00 & 3 & 0.18 & 0.06 & 0.00 \\
\hline \multirow[t]{2}{*}{ Incame } & 2 & 0.12 & 0.08 & 0.01 & 2 & 0.13 & 0.08 & 0.01 & 2 & 0.14 & 0.10 & 0.01 \\
\hline & Total & $R 2=0.02$ & \multicolumn{2}{|c|}{$\mathbf{N}=8120$} & Total & $\mathrm{R} 2=0.03$ & \multicolumn{2}{|c|}{$\mathbf{N}=8023$} & Total & $\mathrm{R} 2=0.04$ & \multicolumn{2}{|c|}{$\mathbf{N}=8055$} \\
\hline
\end{tabular}

Note. The outcome in the 1969-1971 analysis is change in happiness from 1969 to 1971 . Likewise, the outcome in the 1971-1973 and in the 1959-1973 analyses is change in happiness fram 1971 to 1973 and from 1969 to $1973^{\circ}$ respectively.

The dash ( - ) Indicates that the variable did not reach the level of statistical significance $(p<.05)$ necessary to be entered into the regression analysis. 
TABLE LXXIII

MEANS, STANDARD DEVIATIONS, AND INTERCORREJATIONS AMONG CHANGE IN SUBJECTTVE WEIL-BEING, HEALTH, SOCIAL, AND FINANCIAL RESOURCES AS MEASURED BY RESIDUAL CTIANGE SOORES

\begin{tabular}{|c|c|c|c|c|c|c|c|c|c|c|c|c|c|}
\hline \multirow[b]{2}{*}{ Index/Itern } & \multicolumn{5}{|c|}{$1969-1971$} & \multicolumn{4}{|c|}{ 1971-1973 } & \multicolumn{4}{|c|}{$1969-1973$} \\
\hline & & mean s.d. & (2) & (3) & (4) & mean s.d. & (2) & (3) & (4) & mean s.d. & (2) & (3) & (4) \\
\hline $\begin{array}{l}\text { Overall } \\
\text { Disability }\end{array}$ & (1) & 0.001 .97 & .01 & -.16 & -.14 & 0.012 .23 & .00 & -.12 & -.16 & $0.02 \quad 2.40$ & .02 & -.17 & -.20 \\
\hline $\begin{array}{l}\text { Size of } \\
\text { Immediate Family }\end{array}$ & (2) & $0.00 \quad 0.70$ & & .03 & .03 & 0.000 .68 & & .05 & .02 & $-0.00 \quad 0.79$ & & .05 & .04 \\
\hline Incone & (3) & 0.022 .19 & & & .11 & 0.031 .92 & & & .09 & 0.042 .31 & & & .13 \\
\hline \multirow[t]{2}{*}{ Happiness } & (4) & 0.013 .08 & & & & 0.023 .18 & & & & $0.02 \quad 3.24$ & & & \\
\hline & & $\mathbb{N}=7255$ & & & & $\mathbf{N}=7190$ & & & & $\mathbf{N}=7183$ & & & \\
\hline $\begin{array}{l}\text { General } \\
\text { Disability }\end{array}$ & (1) & $-0.00 \quad 3.37$ & .02 & -.12 & -.12 & 0.023 .59 & .01 & -.10 & -.15 & $0.03 \quad 3.71$ & .02 & -.13 & -.18 \\
\hline $\begin{array}{l}\text { Scope of } \\
\text { Immediate Family }\end{array}$ & (2) & $0.00 \quad 0.87$ & & .06 & .05 & $-0.00 \quad 0.85$ & & .08 & .05 & -0.001 .03 & & .08 & .06 \\
\hline Income & (3) & 0.002 .18 & & & .10 & 0.021 .92 & & & .10 & 0.022 .29 & & & .12 \\
\hline \multirow[t]{2}{*}{ Happiness } & (4) & 0.013 .08 & & & & 0.023 .18 & & & & 0.013 .24 & & & \\
\hline & & $N=8120$ & & & & $N=8023$ & & & & $N=8055$ & & & \\
\hline
\end{tabular}

Note. The means, standard deviations, and correlation coefficients may differ slightly from those presented previously due to the listwise deletion of cases with a missing value on one or more variables. 
TABLE LXXTV

MULTIPLE LINEAR REGRESSION FOR PREDICTING CHANGE IN SUBJECTTVE WEIL-BEING FROM CHANGE IN HEALTH, SOCIAL, AND FINANCIAL FESOURCES AS MEASURED BY PERCENTAGE GAIN SOORES

\begin{tabular}{|c|c|c|c|c|c|c|c|c|c|c|c|c|}
\hline \multirow[b]{2}{*}{ Index/Item } & \multicolumn{4}{|c|}{$1969-1971$} & \multicolumn{4}{|c|}{$1971-1973$} & \multicolumn{3}{|c|}{$1969-1973$} & \multirow[b]{2}{*}{$\Delta R 2$} \\
\hline & $\begin{array}{l}\text { Order of } \\
\text { entry }\end{array}$ & $b$ & beta & $\Delta \mathrm{R} 2$ & $\begin{array}{l}\text { Order of } \\
\text { entry }\end{array}$ & b & beta & $\Delta \mathrm{R} 2$ & $\begin{array}{l}\text { Order of } \\
\text { entry }\end{array}$ & $b$ & beta & \\
\hline $\begin{array}{l}\text { Overall } \\
\text { Disability }\end{array}$ & 1 & -0.09 & -0.06 & 0.01 & 1 & -0.12 & -0.08 & 0.01 & 1 & -0.16 & -0.11 & 0.01 \\
\hline $\begin{array}{l}\text { Size of } \\
\text { Immediate Fanily }\end{array}$ & 3 & 0.11 & 0.03 & 0.00 & 3 & 0.09 & 0.02 & 0.00 & 3 & 0.15 & 0.04 & 0.00 \\
\hline \multirow[t]{2}{*}{ Income } & 2 & 0.08 & $0.05^{\circ}$ & 0.00 & 2 & 0.08 & 0.04 & 0.00 & 2 & 0.11 & 0.07 & 0.01 \\
\hline & Total & $\mathrm{R} 2=0.01$ & \multicolumn{2}{|c|}{$\mathrm{N}=7255$} & Total & $\mathrm{R} 2=0.01$ & \multicolumn{2}{|c|}{$\mathrm{N}=7190$} & \multicolumn{4}{|c|}{ Total $\mathrm{R} 2=0.02$} \\
\hline $\begin{array}{l}\text { General } \\
\text { Disability }\end{array}$ & 2 & -0.05 & -0.04 & 0.00 & 1 & -0.08 & -0.07 & 0.01 & 1 & -0.12 & -0.10 & 0.01 \\
\hline $\begin{array}{l}\text { Scope of } \\
\text { Immediate Fanily }\end{array}$ & 3 & 0.11 & 0.03 & 0.00 & 3 & 0.12 & 0.03 & 0.00 & 3 & 0.15 & 0.04 & 0.00 \\
\hline \multirow[t]{2}{*}{ Income } & 1 & 0.07 & 0.05 & 0.00 & 2 & 0.10 & 0.05 & 0.00 & 2 & 0.11 & 0.07 & 0.01 \\
\hline & Total & $\mathrm{R} 2=0.00$ & \multicolumn{2}{|c|}{$N=8120$} & Total & $\mathrm{R} 2=0.01$ & \multicolumn{2}{|c|}{$N=8023$} & Total & $R 2=0.02$ & \multicolumn{2}{|c|}{$N=8055$} \\
\hline
\end{tabular}

Note. The outcone in the 1969-1971 analysis is change in happiness from 1969 to 1971. Likewise, the outcome in the 1971-1973 and in the 1969-1973 analyses is change in happiness from 1971 to 1973 and from 1969 to 1973 respectively. 
TABLE LXXXV

MEANS, STANIDARD DEVIATIONS, AND INTERCORRFJATIONS AMONG CHANGE IN SUBJECTTVE WEJLL-BEING, HEALIY, SOCIAL, AND FINANCIAL RESOURCES AS MEASURED BY PERCENTAGE GAIN SOORES

\begin{tabular}{|c|c|c|c|c|c|c|c|c|c|c|c|c|c|}
\hline \multirow[b]{2}{*}{ Index/Item } & \multicolumn{5}{|c|}{1969} & \multicolumn{4}{|c|}{1971} & \multicolumn{4}{|c|}{1973} \\
\hline & & mean s.d. & (2) & (3) & (4) & mean s.d. & (2) & (3) & (4) & mean s.d. & $(2)$ & (3) & $'(4)$ \\
\hline $\begin{array}{l}\text { Overall } \\
\text { Disability }\end{array}$ & (1) & -0.020 .36 & .02 & -.07 & -.06 & $0.01 \quad 0.38$ & .02 & -.07 & -.08 & $0.05 \quad 0.39$ & .02 & -.11 & -.12 \\
\hline $\begin{array}{l}\text { Size of } \\
\text { Immediate Family } \\
\text { Income }\end{array}$ & $\begin{array}{l}\text { (2) } \\
\text { (3) }\end{array}$ & $\begin{array}{rr}-0.02 & 0.14 \\
0.04 & 0.33\end{array}$ & & .05 & $\begin{array}{l}.03 \\
.05\end{array}$ & $\begin{array}{r}-0.030 .14 \\
0.040 .30\end{array}$ & & .05 & $\begin{array}{l}.02 \\
.05\end{array}$ & $\begin{array}{rr}-0.05 & 0.16 \\
0.06 & 0.35\end{array}$ & & .04 & $\begin{array}{l}.04 \\
.08\end{array}$ \\
\hline \multirow[t]{2}{*}{ Happiness } & (4) & $0.06 \quad 0.53$ & & & & 0.010 .54 & & & & 0.050 .56 & & & \\
\hline & & $\mathbf{N}=7255$ & & & & $\mathbf{N}=7190$ & & & & $\mathrm{~N}=7183$ & & & \\
\hline $\begin{array}{l}\text { General } \\
\text { Disability }\end{array}$ & (I) & 0.020 .46 & .02 & -.04 & -.04 & 0.050 .49 & .00 & -.07 & -.08 & 0.080 .50 & .02 & -.08 & -.11 \\
\hline $\begin{array}{l}\text { Scope of } \\
\text { Immediate Family }\end{array}$ & (2) & $-0.02 \quad 0.15$ & & .05 & .03 & $-0.01 \quad 0.15$ & & .06 & .04 & $-0.03 \quad 0.17$ & & .05 & .05 \\
\hline Income & (3) & $0.03 \quad 0.33$ & & & .05 & $0.04 \quad 0.30$ & & & .06 & $0.06 \quad 0.35$ & & & .08 \\
\hline \multirow[t]{2}{*}{ Happiness } & (4) & 0.070 .53 & & & & $0.01 \quad 0.54$ & & & & 0.050 .56 & & & \\
\hline & & $N=8120$ & & & & $\mathbf{N}=8023$ & & & & $\mathbf{N}=8055$ & & & \\
\hline
\end{tabular}

Note. The means, standard deviations, and correlation coefficients may differ slightly from those presented previously due to the listwise deletion of cases with a missing value on one or more variables. 
MULTIPLE LINEAR REGRESSION FOR PREDICITNG SUBJECTTVE WEIL-BEING FROM CHANGE IN HEALIH AND FINANCIAL ITEMS AS MEASURED BY DIFFERENCE SCORES

\begin{tabular}{|c|c|c|c|c|c|c|c|c|c|c|c|c|}
\hline \multirow[b]{2}{*}{ Item } & \multicolumn{4}{|c|}{$1969-1971$} & \multicolumn{4}{|c|}{$1971-1973$} & \multicolumn{4}{|c|}{$1969-1973$} \\
\hline & $\begin{array}{l}\text { Order of } \\
\text { entry }\end{array}$ & $\mathbf{b}$ & beta & $\Delta \mathrm{R} 2$ & $\begin{array}{l}\text { Order of } \\
\text { entry }\end{array}$ & $\mathbf{b}$ & beta & $\Delta \mathrm{R} 2$ & $\begin{array}{l}\text { Order of } \\
\text { entry }\end{array}$ & $\mathrm{b}$ & beta & $\triangle \mathrm{R} 2$ \\
\hline $\begin{array}{l}\text { Heal th compared } \\
\text { to others }\end{array}$ & - & - & - & - & - & - & - & - & - & - & - & - \\
\hline $\begin{array}{l}\text { Health cormared } \\
\text { to } 2 \text { years ago }\end{array}$ & $\mathbf{a}$ & $\mathbf{a}$ & $a$ & $\mathbf{a}$ & 3 & 0.04 & 0.05 & 0.00 & a & $\mathbf{a}$ & $a$ & $\mathrm{a}$ \\
\hline $\begin{array}{l}\text { Standard of living } \\
\text { compared to others }\end{array}$ & $\mathbf{s}$ & - & - & - & 2 & 0.06 & 0.05 & 0.01 & 2 & 0.04 & 0.04 & 0.00 \\
\hline $\begin{array}{l}\text { Ability to get along } \\
\text { on income }\end{array}$ & g & 0.02 & 0.03 & 0.00 & - & - & - & - & - & - & - & - \\
\hline \multirow{2}{*}{$\begin{array}{l}\text { Satisfaction with } \\
\text { standard of living }\end{array}$} & 1 & 0.15 & 0.16 & 0.03 & 1 & 0.09 & 0.09 & 0.01 & 1 & 0.14 & 0.15 & 0.03 \\
\hline & Total & $R 2=0.03$ & \multicolumn{2}{|c|}{$N=7329$} & Total & $\mathrm{R} 2=0.02$ & \multicolumn{2}{|c|}{$\mathbf{N}=7026$} & Total & $R 2=0.03$ & \multicolumn{2}{|c|}{$\mathbf{N}=7132$} \\
\hline
\end{tabular}

Note. The outcome in the 1969-1971 analysis is the happiness item in 1971. Likewise, the outcome in the 1971-1973 and in the

1969-1973 analyses is the happiness item in 1973.

The dash ( - ) indicates that the variable did not reach the level of statistical significance (p<.05) necessary to be entered into the regression analysis.

anis item was not included in the 1969 wave of data collection. 
TABLE LXXVII

MEANS, STANDARD DEVIATIONS, AND INTERCORRETATTONS AMONG SUBJECTTVE WETLL-BEING, AND CIANGE IN HEALTH, AND FINANCIAL ITEMS AS MFASURED BY DIFFERENCE SCORES

\begin{tabular}{|c|c|c|c|c|c|c|c|c|c|}
\hline Itern & & year & mean & s.d. & (2) & (3) & (4) & (5) & (6) \\
\hline $\begin{array}{l}\text { Heal th compared } \\
\text { to others }\end{array}$ & (I) & $\begin{array}{l}1969-1971 \\
1971-1973 \\
1969-1973\end{array}$ & $\begin{array}{l}-0.04 \\
-0.04 \\
-0.08\end{array}$ & $\begin{array}{l}0.69 \\
0.69 \\
0.72\end{array}$ & $\begin{array}{l}\mathrm{a} \\
.26 \\
\mathrm{a}\end{array}$ & $\begin{array}{l}.10 \\
.08 \\
.13\end{array}$ & $\begin{array}{l}.06 \\
.10 \\
.12\end{array}$ & $\begin{array}{l}.09 \\
.09 \\
.10\end{array}$ & $\begin{array}{l}.02 \\
.04 \\
.04\end{array}$ \\
\hline $\begin{array}{l}\text { Health conpared } \\
\text { to } 2 \text { years ago }\end{array}$ & (2) & $\begin{array}{l}1969-1971 \\
1971-1973 \\
1969-1973\end{array}$ & $\begin{array}{c}a \\
-0.04 \\
a\end{array}$ & $\begin{array}{c}a \\
0.75 \\
a\end{array}$ & & $\begin{array}{l}a \\
.06 \\
a\end{array}$ & $\begin{array}{l}a \\
.06 \\
a\end{array}$ & $\begin{array}{l}a \\
.07 \\
a\end{array}$ & $\begin{array}{l}a \\
.06 \\
a\end{array}$ \\
\hline $\begin{array}{l}\text { Standard of living } \\
\text { corpared to others }\end{array}$ & (3) & $\begin{array}{l}1969-1971 \\
1971-1973 \\
1969-1973\end{array}$ & $\begin{array}{r}0.06 \\
-0.05 \\
0.01\end{array}$ & $\begin{array}{l}0.61 \\
0.61 \\
0.63\end{array}$ & & & $\begin{array}{l}.14 \\
.13 \\
.19\end{array}$ & $\begin{array}{l}.25 \\
.25 \\
.31\end{array}$ & $\begin{array}{l}.04 \\
.08 \\
.08\end{array}$ \\
\hline $\begin{array}{l}\text { Ability to get along } \\
\text { on income }\end{array}$ & (4) & $\begin{array}{l}1969-1971 \\
1971-1973 \\
1969-1973\end{array}$ & $\begin{array}{r}0.06 \\
-0.06 \\
-0.00\end{array}$ & $\begin{array}{l}0.86 \\
0.84 \\
0.91\end{array}$ & & & & $\begin{array}{l}.23 \\
.20 \\
.26\end{array}$ & $\begin{array}{l}.07 \\
.03 \\
.05\end{array}$ \\
\hline $\begin{array}{l}\text { Satisfaction with } \\
\text { standard of living }\end{array}$ & (5) & $\begin{array}{l}1969-1971 \\
1971-1973 \\
1969-1973\end{array}$ & $\begin{array}{r}0.02 \\
-0.03 \\
-0.01\end{array}$ & $\begin{array}{l}0.71 \\
0.74 \\
0.76\end{array}$ & & & & & $\begin{array}{l}.17 \\
.11 \\
.16\end{array}$ \\
\hline Happiness & (6) & $\begin{array}{l}1969-1971 \\
1971-1973 \\
1969-1973\end{array}$ & $\begin{array}{l}1.17 \\
1.16 \\
1.15\end{array}$ & $\begin{array}{l}0.67 \\
0.69 \\
0.70\end{array}$ & & & & & \\
\hline
\end{tabular}

Note. The means, standard deviations, and correlation coefficients may differ slightly from those presented previously due to the listwise deletion of cases with a missing value on one or more variables.

The sample sizes are 7329 in 1969, 7026 in 1971 and 7132 in 1973.

a This item was not included in the 1969 wave of data collection. 
TABLE LXXVIII

MULTIPLE LINEAR RBGRESSION FOR PRFJICTING SUBJECTIVE WEIL-BEING FROM GIANGE IN HEALTH AND FINANCIAL ITEMS AS MEASURED BY RESIDUAL CHANGE SCORES

\begin{tabular}{|c|c|c|c|c|c|c|c|c|c|c|c|c|}
\hline \multirow[b]{2}{*}{ Item } & \multicolumn{4}{|c|}{$1969-1971$} & \multicolumn{4}{|c|}{$1971-1973$} & \multicolumn{4}{|c|}{ 1969-1973 } \\
\hline & $\begin{array}{l}\text { rder of } \\
\text { entry }\end{array}$ & $b$ & beta & $\triangle \mathrm{R} 2$ & $\begin{array}{l}\text { Order of } \\
\text { entry }\end{array}$ & $\mathbf{b}$ & beta & $\triangle \mathrm{R} 2$ & $\begin{array}{l}\text { Order of } \\
\text { entry }\end{array}$ & $b$ & beta & $\Delta \mathrm{R} 2$ \\
\hline $\begin{array}{l}\text { Health campared } \\
\text { to others }\end{array}$ & 2 & 0.12 & 0.11 & 0.01 & 4 & 0.11 & 0.10 & 0.01 & 2 & 0.15 & 0.14 & 0.02 \\
\hline $\begin{array}{l}\text { Heal th compared } \\
\text { to } 2 \text { years ago }\end{array}$ & a & a & a & $a$ & 2 & 0.12 & 0.11 & 0.02 & $a$ & $\mathrm{a}$ & $\mathbf{a}$ & $\mathrm{a}$ \\
\hline $\begin{array}{l}\text { Standard of living } \\
\text { compared to others }\end{array}$ & 4 & 0.11 & 0.08 & 0.01 & 3 & 0.16 & 0.11 & 0.01 & 3 & 0.15 & 0.11 & 0.01 \\
\hline $\begin{array}{l}\text { Ability to get along } \\
\text { on income }\end{array}$ & 3 & 0.08 & 0.10 & 0.01 & 5 & 0.07 & 0.07 & 0.01 & 4 & 0.06 & 0.07 & 0.01 \\
\hline $\begin{array}{l}\text { Satisfaction with } \\
\text { standard of living }\end{array}$ & $\begin{array}{l}1 \\
\text { Total }\end{array}$ & $\begin{array}{c}0.32 \\
\mathrm{R} 2=0.16\end{array}$ & $\begin{array}{r}0.29 \\
N=\end{array}$ & $\begin{array}{l}0.13 \\
7329\end{array}$ & $\begin{array}{l}1 \\
\text { Total }\end{array}$ & $\begin{array}{c}0.28 \\
22=0.17\end{array}$ & $\begin{array}{r}0.25 \\
N=\end{array}$ & $\begin{array}{l}0.12 \\
7026\end{array}$ & $\begin{array}{l}1 \\
\text { Total }\end{array}$ & $\begin{array}{c}0.31 \\
2=0.18\end{array}$ & $\begin{array}{r}0.29 \\
N=\end{array}$ & $\begin{array}{c}0.14 \\
7132\end{array}$ \\
\hline
\end{tabular}

Note. The outcome in the 1969-1971 analysis is the happiness item in 1971. Likewtse, the outcome in the 1971-1973 and in the 1969-1973 analyses is the happiness 1 tem in 1973.

The dash ( - ) indicates that the variable did not reach the level of statistical significance (p<.05) necessary to be entered into the regression analysis.

a This item was not included in the 1969 wave of data collection. 
TABLE LXXIX

MEANS, STANIARD DEVIATIONS, AND INIEROORRETATIONS AMONG SUBJECTIVE WEIL-BEING, AND CHANGE IN HEALTH, AND FINANCIAL ITEMS AS MEASURED BY RESIDUAL CHANGE SCORES

\begin{tabular}{|c|c|c|c|c|c|c|c|c|c|}
\hline Itern & & year & mean & s.d. & (2) & (3) & (4) & (5) & (6) \\
\hline $\begin{array}{l}\text { Health compared } \\
\text { to others }\end{array}$ & (1) & $\begin{array}{l}1969-1971 \\
1971-1973 \\
1969-1973\end{array}$ & $\begin{array}{l}0.01 \\
0.00 \\
0.00\end{array}$ & $\begin{array}{l}0.59 \\
0.60 \\
0.61\end{array}$ & $\begin{array}{l}a \\
.34 \\
a\end{array}$ & $\begin{array}{l}.13 \\
.14 \\
.16\end{array}$ & $\begin{array}{l}.11 \\
.16 \\
.16\end{array}$ & $\begin{array}{l}.14 \\
.15 \\
.15\end{array}$ & $\begin{array}{l}.17 \\
.20 \\
.21\end{array}$ \\
\hline $\begin{array}{l}\text { Heal th campared to } \\
2 \text { years ago }\end{array}$ & (2) & $\begin{array}{l}1969-1971 \\
1971-1973 \\
1969-1973\end{array}$ & $\begin{array}{c}a \\
0.01 \\
a\end{array}$ & $\begin{array}{c}a \\
0.61 \\
a\end{array}$ & & $\begin{array}{c}a \\
.12 \\
a\end{array}$ & $\begin{array}{c}\mathrm{a} \\
.11 \\
\mathrm{a}\end{array}$ & $\begin{array}{c}a \\
.14 \\
a\end{array}$ & $\begin{array}{l}a \\
.20 \\
a\end{array}$ \\
\hline $\begin{array}{l}\text { Standard of living } \\
\text { compared to others }\end{array}$ & (3) & $\begin{array}{l}1969-1971 \\
1971-1973 \\
1969-1973\end{array}$ & $\begin{array}{l}0.00 \\
0.00 \\
0.00\end{array}$ & $\begin{array}{l}0.50 \\
0.50 \\
0.50\end{array}$ & & & $\begin{array}{l}.19 \\
.20 \\
.24\end{array}$ & $\begin{array}{l}.33 \\
.34 \\
.37\end{array}$ & $\begin{array}{l}.21 \\
.24 \\
.26\end{array}$ \\
\hline $\begin{array}{l}\text { Ability to get along } \\
\text { on income }\end{array}$ & (4) & $\begin{array}{l}1969-1971 \\
1971-1973 \\
1969-1973\end{array}$ & $\begin{array}{l}0.02 \\
0.02 \\
0.02\end{array}$ & $\begin{array}{l}0.77 \\
0.74 \\
0.78\end{array}$ & & & & $\begin{array}{l}.32 \\
.30 \\
.36\end{array}$ & $\begin{array}{l}.22 \\
.20 \\
.22\end{array}$ \\
\hline $\begin{array}{l}\text { Satisfaction with } \\
\text { standard of living }\end{array}$ & (5) & $\begin{array}{l}1969-1971 \\
1971-1973 \\
1969-1973\end{array}$ & $\begin{array}{l}0.02 \\
0.02 \\
0.02\end{array}$ & $\begin{array}{l}0.62 \\
0.63 \\
0.64\end{array}$ & & & & & $\begin{array}{l}.36 \\
.34 \\
.37\end{array}$ \\
\hline Happiness & (6) & $\begin{array}{l}1969-1971 \\
1971-1973 \\
1969-1973\end{array}$ & $\begin{array}{l}1.17 \\
1.16 \\
1.15\end{array}$ & $\begin{array}{l}0.67 \\
0.69 \\
0.70\end{array}$ & & & & & \\
\hline
\end{tabular}

Note. The means, standard deviations, and correlation coefficients may differ slightly from those presented previously due to the listwise deletion of cases with a missing value on one or more vartables.

The sample sizes are 7329 for the 1969-1971 analysis, 7026 for the 1971-1973 analysis, and 7132 for the 1969-1973 analysis.

ahis item was not included in the 1969 wave of data collection. 
TABLE LXXX

MULTIPLE LINEAR REGRESSION FOR PREDICTING SUBJECTTVE WEIL-BEING FROM OLANGE IN HEALTH AND FINANCIAL ITEMS AS MEASURED BY PERCENTAGE GAIN SCORES

\begin{tabular}{|c|c|c|c|c|c|c|c|c|c|c|c|c|}
\hline \multirow[b]{2}{*}{ Item } & \multicolumn{4}{|c|}{$1969-1971$} & \multicolumn{4}{|c|}{$1971-1973$} & \multicolumn{4}{|c|}{$1969-1973$} \\
\hline & $\begin{array}{l}\text { order of } \\
\text { entry }\end{array}$ & $\mathrm{b}$ & beta & $\Delta_{\mathrm{R} 2}$ & $\begin{array}{l}\text { Order of } \\
\text { entry }\end{array}$ & $b$ & beta & $\Delta \mathrm{R} 2$ & $\begin{array}{l}\text { Order of } \\
\text { entry }\end{array}$ & $\mathrm{b}$ & beta & $\triangle \mathrm{R} 2$ \\
\hline $\begin{array}{l}\text { Health compared } \\
\text { to others }\end{array}$ & 4 & 0.04 & 0.03 & 0.00 & 5 & 0.07 & 0.05 & 0.00 & 3 & 0.07 & 0.05 & 0.00 \\
\hline $\begin{array}{l}\text { Health compared } \\
\text { to } 2 \text { years ago }\end{array}$ & $\mathbf{a}$ & $a$ & $a$ & $a$ & 3 & 0.07 & 0.06 & 0.01 & $\mathbf{a}$ & $\mathbf{a}$ & $a$ & a \\
\hline $\begin{array}{l}\text { Standard of living } \\
\text { compared to others }\end{array}$ & 3 & 0.05 & 0.03 & 0.00 & 2 & 0.12 & 0.08 & 0.01 & 2 & 0.10 & 0.07 & 0.01 \\
\hline $\begin{array}{l}\text { Ability to get along } \\
\text { on incame }\end{array}$ & 2 & 0.11 & 0.08 & 0.01 & 4 & 0.08 & 0.05 & 0.00 & 4 & 0.07 & 0.05 & 0.00 \\
\hline \multirow{2}{*}{$\begin{array}{l}\text { Satisfaction with } \\
\text { standard of living }\end{array}$} & 1 & 0.36 & 0.23 & 0.06 & 1 & 0.27 & 0.16 & 0.04 & 1 & 0.34 & 0.21 & 0.06 \\
\hline & Total & $\mathrm{R} 2=0.07$ & $\mathbf{N}=$ & 7329 & Total & $R 2=0.06$ & $\mathbf{N}=$ & 7026 & Total & $\mathrm{R} 2=0.07$ & $\mathbf{N}=$ & 7132 \\
\hline
\end{tabular}

Note. The outcome in the 1969-1971 analysis is the happiness 1tem in 1971. Likewise, the outcome in the 1971-1973 and in the 1969-1973 analyses is the happiness 1 tem in 1973.

This iten was not included in the 1969 wave of data collection. 


\section{TABLE LXXXXI}

MEANS, STANDARD DEVIATIONS, AND INTEROORREIATIONS AMONG SUBJECTIVE WEJL-BEING, AND CIANGE IN HEALTH, AND FINANCIAL ITEMS AS MEASURED BY PERCENTAGE GAIN SCORES

\begin{tabular}{|c|c|c|c|c|c|c|c|c|c|}
\hline Item & & year & mean & s.d. & (2) & (3) & (4) & (5). & (6) \\
\hline $\begin{array}{l}\text { Healt th compared } \\
\text { to others }\end{array}$ & (1) & $\begin{array}{l}1969-1971 \\
1971-1973 \\
1969-1973\end{array}$ & $\begin{array}{r}0.01 \\
0.00 \\
-0.02\end{array}$ & $\begin{array}{l}0.49 \\
0.50 \\
0.50\end{array}$ & $\begin{array}{l}a \\
.26 \\
a\end{array}$ & $\begin{array}{l}.08 \\
.07 \\
.12\end{array}$ & $\begin{array}{l}.05 \\
.10 \\
.11\end{array}$ & $\begin{array}{l}.09 \\
.09 \\
.09\end{array}$ & $\begin{array}{l}.05 \\
.09 \\
.08\end{array}$ \\
\hline $\begin{array}{l}\text { Heal th campared } \\
\text { to } 2 \text { years ago }\end{array}$ & (2) & $\begin{array}{l}1969-1971 \\
1971-1973 \\
1969-1973\end{array}$ & $\begin{array}{c}a \\
-0.05 \\
a\end{array}$ & $\begin{array}{c}a \\
0.53 \\
a\end{array}$ & & $\begin{array}{l}a \\
.06 \\
a\end{array}$ & $\begin{array}{l}a \\
.06 \\
a\end{array}$ & $\begin{array}{l}\mathrm{a} \\
.08 \\
\mathrm{a}\end{array}$ & $\begin{array}{l}a \\
.09 \\
a\end{array}$ \\
\hline $\begin{array}{l}\text { Standard of living } \\
\text { calpared to others }\end{array}$ & (3) & $\begin{array}{l}1969-1971 \\
1971-1973 \\
1969-1973\end{array}$ & $\begin{array}{r}0.05 \\
-0.04 \\
-0.00\end{array}$ & $\begin{array}{l}0.45 \\
0.45 \\
0.46\end{array}$ & & & $\begin{array}{l}.12 \\
.13 \\
.18\end{array}$ & $\begin{array}{l}.24 \\
.23 \\
.29\end{array}$ & $\begin{array}{l}.10 \\
.13 \\
.14\end{array}$ \\
\hline $\begin{array}{l}\text { Abllity to get along } \\
\text { on income }\end{array}$ & (4) & $\begin{array}{l}1969-1971 \\
1971-1973 \\
1969-1973\end{array}$ & $\begin{array}{r}0.04 \\
-0.02 \\
0.00\end{array}$ & $\begin{array}{l}0.48 \\
0.46 \\
0.49\end{array}$ & & & & $\begin{array}{l}.22 \\
.19 \\
.25\end{array}$ & $\begin{array}{l}.13 \\
.10 \\
.12\end{array}$ \\
\hline $\begin{array}{l}\text { Satisfaction with } \\
\text { standard of living }\end{array}$ & (5) & $\begin{array}{l}1969-1971 \\
1971-1973 \\
1969-1973\end{array}$ & $\begin{array}{l}0.04 \\
0.01 \\
0.02\end{array}$ & $\begin{array}{l}0.42 \\
0.41 \\
0.42\end{array}$ & & & & & $\begin{array}{l}.26 \\
.20 \\
.24\end{array}$ \\
\hline Happiness & (6) & $\begin{array}{l}1969-1971 \\
1971-1973 \\
1969-1973\end{array}$ & $\begin{array}{l}1.17 \\
1.16 \\
1.15\end{array}$ & $\begin{array}{l}0.67 \\
0.69 \\
0.70\end{array}$ & & & & & \\
\hline
\end{tabular}

Note. The means, standard deviations, and correlation coefficients may differ slightly from those presented previously due to the listwise deletion of cases with a missing value on one or more variables.

The sample sizes are 7329 for the 1969-1971 analysis, 7026 for the 1971-1973 analysis, and 7132 for the 1969-1973 analysis.

ahis item was not included in the 1969 wave of data collection. 
TABLE LXXXII

MULTTPLE I,INEAR REGRESSION FOR PREDICTING CHANGE IN SUBJECTTVE WEIL-BEING FROM CHANGE IN HEALTH AND FINANCIAL ITDMS AS MEASURED BY DIFFERENCE SCORES

\begin{tabular}{|c|c|c|c|c|c|c|c|c|c|c|c|c|}
\hline \multirow[b]{2}{*}{ Item } & \multicolumn{4}{|c|}{$1969-1971$} & \multicolumn{4}{|c|}{$1971-1973$} & \multicolumn{4}{|c|}{ 1969-1973 } \\
\hline & $\begin{array}{l}\text { brder of } \\
\text { entry }\end{array}$ & $\mathbf{b}$ & beta & $\Delta_{\mathrm{R} 2}$ & $\begin{array}{l}\text { Order of } \\
\text { entry }\end{array}$ & b & beta & $\Delta \mathrm{R} 2$ & $\begin{array}{l}\text { Order of } \\
\text { entry }\end{array}$ & $\mathrm{b}$ & beta & $\triangle R 2$ \\
\hline $\begin{array}{l}\text { Health conpared } \\
\text { to others }\end{array}$ & 2 & 0.09 & 0.08 & 0.01 & 4 & 0.06 & 0.05 & 0.00 & 2 & 0.12 & 0.11 & 0.01 \\
\hline $\begin{array}{l}\text { Health compared } \\
\text { to } 2 \text { years ago }\end{array}$ & a & a & $\mathbf{a}$ & a & 2 & 0.06 & 0.06 & 0.01 & $\mathbf{a}$ & $\mathbf{a}$ & $\mathbf{a}$ & $a$ \\
\hline $\begin{array}{l}\text { Standard of living } \\
\text { compared to others }\end{array}$ & 3 & 0.05 & 0.04 & 0.00 & 3 & 0.07 & 0.05 & 0.00 & 3 & 0.09 & 0.07 & 0.01 \\
\hline $\begin{array}{l}\text { Ability to get along } \\
\text { on income }\end{array}$ & 4 & 0.04 & 0.04 & 0.00 & 5 & 0.03 & 0.04 & 0.00 & 4 & 0.02 & 0.03 & 0.00 \\
\hline \multirow{2}{*}{$\begin{array}{l}\text { Satisfaction with } \\
\text { standard of living }\end{array}$} & 1 & 0.18 & 0.17 & 0.04 & 1 & 0.20 & 0.20 & 0.06 & 1 & 0.18 & 0.18 & 0.05 \\
\hline & \multicolumn{2}{|c|}{ Total R2 $=0.05$} & \multicolumn{2}{|c|}{$\mathbf{N}=7301$} & \multicolumn{2}{|c|}{ Total $\mathrm{R} 2=0.07$} & \multicolumn{2}{|c|}{$\mathrm{N}=7017$} & \multicolumn{2}{|c|}{ Total R2 $=0.07$} & \multicolumn{2}{|c|}{$N=7103$} \\
\hline
\end{tabular}

Note. The outcome in the 1969-1971 analysis is change in happiness from 1969 to 1971 . Likewise, the outcome in the 19711973 and in the 1969-1973 analyses is change in happiness from 1971 to 1973 and from 1969 to 1973 respectively. anis item was not included in the 1969 wave of data collection. 
TABLE LXXXIII

MEANS, STANDARD DEVIATIONS, AND INTEROORRETATIONS AMONG CHANGE IN SUBJECTIVE WETLI-BEING, GIANGE IN HEALTH, AND CIIANGE IN FINUANCIAL ITEMS AS MEASURED BY DIFFERENCE SCORES

\begin{tabular}{|c|c|c|c|c|c|c|c|c|c|}
\hline Item & & year & mean & s.d. & (2) & (3) & (4) & (5) & (6) \\
\hline $\begin{array}{l}\text { Heal th campared } \\
\text { to others }\end{array}$ & (1) & $\begin{array}{l}1969-1971 \\
1971-1973 \\
1969-1973\end{array}$ & $\begin{array}{l}-0.04 \\
-0.04 \\
-0.08\end{array}$ & $\begin{array}{l}0.69 \\
0.69 \\
0.72\end{array}$ & $\begin{array}{l}- \\
.26\end{array}$ & $\begin{array}{l}.10 \\
.08 \\
.13\end{array}$ & $\begin{array}{l}.06 \\
.10 \\
.12\end{array}$ & $\begin{array}{l}.09 \\
.09 \\
.10\end{array}$ & $\begin{array}{l}.11 \\
.10 \\
.14\end{array}$ \\
\hline $\begin{array}{l}\text { Health compared } \\
\text { to } 2 \text { years ago }\end{array}$ & (2) & $\begin{array}{l}1969-1971 \\
1971-1973 \\
1969-1973\end{array}$ & $\begin{array}{c}a \\
-0.04 \\
a\end{array}$ & $\begin{array}{c}a \\
0.75 \\
a\end{array}$ & & $\begin{array}{l}a \\
.06 \\
a\end{array}$ & $\begin{array}{l}a \\
.06 \\
a\end{array}$ & $\begin{array}{l}a \\
.07 \\
a\end{array}$ & $\begin{array}{l}a \\
.10 \\
a\end{array}$ \\
\hline $\begin{array}{l}\text { Standard of living } \\
\text { compared to others }\end{array}$ & (3) & $\begin{array}{l}1969-1971 \\
1971-1973 \\
1969-1973\end{array}$ & $\begin{array}{r}0.06 \\
-0.05 \\
0.01\end{array}$ & $\begin{array}{l}0.61 \\
0.61 \\
0.63\end{array}$ & & & $\begin{array}{l}.14 \\
.13 \\
.19\end{array}$ & $\begin{array}{l}.25 \\
.25 \\
.31\end{array}$ & $\begin{array}{l}.10 \\
.12 \\
.14\end{array}$ \\
\hline $\begin{array}{l}\text { Ability to get along } \\
\text { on income }\end{array}$ & (4) & $\begin{array}{l}1969-1971 \\
1971-1973 \\
1969-1973\end{array}$ & $\begin{array}{r}0.06 \\
-0.06 \\
-0.00\end{array}$ & $\begin{array}{l}0.86 \\
0.84 \\
0.91\end{array}$ & & & & $\begin{array}{l}.23 \\
.20 \\
.26\end{array}$ & $\begin{array}{l}.09 \\
.10 \\
.10\end{array}$ \\
\hline $\begin{array}{l}\text { Satisfaction with } \\
\text { standard of living }\end{array}$ & (5) & $\begin{array}{l}1969-1971 \\
1971-1973 \\
1969-1973\end{array}$ & $\begin{array}{r}0.02 \\
-0.03 \\
-0.01\end{array}$ & $\begin{array}{l}0.71 \\
0.74 \\
0.76\end{array}$ & & & & & $\begin{array}{l}.20 \\
.23 \\
.22\end{array}$ \\
\hline Happiness & (6) & $\begin{array}{l}1969-1971 \\
1971-1973 \\
1969-1973\end{array}$ & $\begin{array}{r}0.06 \\
-0.01 \\
0.05\end{array}$ & $\begin{array}{l}0.72 \\
0.74 \\
0.77\end{array}$ & & & & & \\
\hline
\end{tabular}

№te. The means, standard deviations, and correlation coefficients may differ slightly from those presented previously due to the listwise deletion of cases with a missing value on one or more variables.

The sample sizes are 7301 for the 1969-1971 analysis, 7017 for the 1971-1973 analysis, and 7103 for the 1969-1973 analysis.

This item was not included in the 1969 wave of data collection. 
TABLE LXXXIV

MLTTPLE LINEAR REGRESSION FOR PREDICTING CHANGE IN SUBJECTTVE WEIL-BEING FROM CHANGE IN HEALTH AND FINANCIAL ITEMS AS MEASURED BY RESIDUAL GHANGE SCORES

\begin{tabular}{|c|c|c|c|c|c|c|c|c|c|c|c|c|}
\hline \multirow[b]{2}{*}{ Item } & \multicolumn{4}{|c|}{$1969-1971$} & \multicolumn{4}{|c|}{$1971-1973$} & \multicolumn{4}{|c|}{$1969-1973$} \\
\hline & $\begin{array}{l}\text { Order of } \\
\text { entry }\end{array}$ & $\mathrm{b}$ & beta & $\Delta \mathrm{R} 2$ & $\begin{array}{l}\text { Order of } \\
\text { entry }\end{array}$ & b & beta & $\Delta \mathrm{R} 2$ & $\begin{array}{l}\text { Order of } \\
\text { entry }\end{array}$ & $\mathrm{b}$ & beta & $\triangle \mathrm{R} 2$ \\
\hline $\begin{array}{l}\text { Heal th compared } \\
\text { to others }\end{array}$ & 2 & 0.10 & 0.10 & 0.01 & 3 & 0.09 & 0.09 & 0.01 & 2 & 0.14 & 0.13 & 0.02 \\
\hline $\begin{array}{l}\text { Health compared } \\
\text { to } 2 \text { years ago }\end{array}$ & a & $\mathbf{a}$ & $a$ & $\mathbf{a}$ & 2 & 0.10 & 0.10 & 0.02 & $\mathbf{a}$ & $a$ & $\mathbf{a}$ & $\mathrm{a}$ \\
\hline $\begin{array}{l}\text { Standard of living } \\
\text { compared to others }\end{array}$ & $s$ & 0.07 & 0.06 & 0.00 & 4 & 0.10 & 0.08 & 0.01 & 3 & 0.12 & 0.10 & 0.01 \\
\hline $\begin{array}{l}\text { Ability to get along } \\
\text { on income }\end{array}$ & 3 & 0.06 & 0.07 & 0.01 & 5 & 0.05 & 0.05 & 0.00 & 4 & 0.04 & 0.05 & 0.00 \\
\hline \multirow{2}{*}{$\begin{array}{l}\text { Satisfaction with } \\
\text { standard of living }\end{array}$} & 1 & 0.26 & 0.27 & 0.10 & 1 & 0.25 & 0.25 & 0.10 & 1 & 0.27 & 0.27 & 0.12 \\
\hline & \multicolumn{2}{|c|}{ Total $\mathrm{R} 2=0.12$} & \multicolumn{2}{|c|}{$\underline{N}=7301$} & \multicolumn{2}{|c|}{ Total $\mathrm{R} 2=0.14$} & \multicolumn{2}{|c|}{$\mathbf{N}=7017$} & \multicolumn{2}{|c|}{ Total $\mathrm{R} 2=0.15$} & \multicolumn{2}{|c|}{$\mathrm{N}=7103$} \\
\hline
\end{tabular}

Note. The outcome in the 1969-1971 analysis is change in happiness from 1969 to 1971 . Likewise, the outcome in the 1971-

1973 and in the 1969-1973 analyses is change in happiness from 1971 to 1973 and from 1969 to 1973 respectively.

This item was not included in the 1969 wave of data collection. 
TABLE LXXXXV

MEANS, STANDARD DEVIATTONS, AND INTEROORRETATIONS AMONG CHANGE IN SUBJECTTVE WEIL-BETNG, CHANGE IN HEALTH, AND CHANGE IN FINANCIAL ITEMS AS MEASURED BY RESIDUAL CHANGE SOORES

\begin{tabular}{|c|c|c|c|c|c|c|c|c|c|}
\hline Iten & & year & mean & s.d. & (2) & (3) & (4) & (5) & (6) \\
\hline $\begin{array}{l}\text { Health cormared } \\
\text { to others }\end{array}$ & (1) & $\begin{array}{l}1969-1971 \\
1971-1973 \\
1969-1973\end{array}$ & $\begin{array}{l}0.01 \\
0.00 \\
0.00\end{array}$ & $\begin{array}{l}0.59 \\
0.60 \\
0.61\end{array}$ & $\begin{array}{l}a \\
.34 \\
a\end{array}$ & $\begin{array}{l}.13 \\
.14 \\
.16\end{array}$ & $\begin{array}{l}.11 \\
.16 \\
.16\end{array}$ & $\begin{array}{l}.15 \\
.15 \\
.15\end{array}$ & $\begin{array}{l}.15 \\
.18 \\
.19\end{array}$ \\
\hline $\begin{array}{l}\text { Health compared } \\
\text { to } 2 \text { years ago }\end{array}$ & (2) & $\begin{array}{l}1969-1971 \\
1971-1973 \\
1969-1973\end{array}$ & $\begin{array}{c}a \\
0.01 \\
a\end{array}$ & $\begin{array}{c}a \\
0.61 \\
a\end{array}$ & & $\begin{array}{l}a \\
.12 \\
a\end{array}$ & $\begin{array}{c}a \\
.11 \\
a\end{array}$ & $\begin{array}{c}a \\
.14 \\
a\end{array}$ & $\begin{array}{l}a \\
.18 \\
a\end{array}$ \\
\hline $\begin{array}{l}\text { Standard of living } \\
\text { compared to others }\end{array}$ & (3) & $\begin{array}{l}1969-1971 \\
1971-1973 \\
1969-1973\end{array}$ & $\begin{array}{l}0.00 \\
0.00 \\
0.00\end{array}$ & $\begin{array}{l}0.50 \\
0.50 \\
0.50\end{array}$ & & & $\begin{array}{l}.20 \\
.20 \\
.24\end{array}$ & $\begin{array}{l}.33 \\
.34 \\
.37\end{array}$ & $\begin{array}{l}.17 \\
.20 \\
.23\end{array}$ \\
\hline $\begin{array}{l}\text { Ability to get along } \\
\text { on income }\end{array}$ & (4) & $\begin{array}{l}1969-1971 \\
1971-1973 \\
1969-1973\end{array}$ & $\begin{array}{l}0.02 \\
0.02 \\
0.02\end{array}$ & $\begin{array}{l}0.77 \\
0.74 \\
0.78\end{array}$ & & & & $\begin{array}{l}.32 \\
.30 \\
.36\end{array}$ & $\begin{array}{l}.18 \\
.17 \\
.19\end{array}$ \\
\hline $\begin{array}{l}\text { Satisfaction with } \\
\text { standard of living }\end{array}$ & (5) & $\begin{array}{l}1969-1971 \\
1971-1973 \\
1969-1973\end{array}$ & $\begin{array}{l}0.02 \\
0.02 \\
0.02\end{array}$ & $\begin{array}{l}0.62 \\
0.63 \\
0.64\end{array}$ & & & & & $\begin{array}{l}.32 \\
.32 \\
.34\end{array}$ \\
\hline Happiness & (6) & $\begin{array}{l}1969-1971 \\
1971-1973 \\
1969-1973\end{array}$ & $\begin{array}{l}0.02 \\
0.03 \\
0.02\end{array}$ & $\begin{array}{l}0.61 \\
0.64 \\
0.65\end{array}$ & & & & & \\
\hline
\end{tabular}

Nete. The means, standard deviations, and correlation coefficients may differ slightly from those presented previously due to the listwise deletion of cases with a missing value on one or more varlables.

The sample sizes are 7301 for the 1969-1971 analysis, 7017 for the 1971-1973 analysis, and 7103 for the 1969-1973 analysis.

This item was not included in the 1969 wave of data collection. 
TABLE LXXXVI

MLTTPLE LINEAR REGRESSION FOR PREDICTING CHANGE IN SUBJECTTVE WEIL-BEING FROM CHANGE IN HEALTH AND FINANCIAL ITEMS AS MEASURED BY PERCENIAGE GAIN SCORES

\begin{tabular}{|c|c|c|c|c|c|c|c|c|c|c|c|c|}
\hline \multirow[b]{2}{*}{ Item } & \multicolumn{4}{|c|}{ 1969-1971 } & \multicolumn{4}{|c|}{$1971-1973$} & \multicolumn{4}{|c|}{$1969-1973$} \\
\hline & $\begin{array}{l}\text { rder of } \\
\text { entry }\end{array}$ & b & beta & $\Delta_{\mathrm{R} 2}$ & $\begin{array}{l}\text { Order of } \\
\text { entry }\end{array}$ & $\mathbf{b}$ & beta & $\Delta \mathrm{R} 2$ & $\begin{array}{l}\text { Order of } \\
\text { entry }\end{array}$ & $\mathrm{b}$ & beta & $\Delta \mathrm{R} 2$ \\
\hline $\begin{array}{l}\text { Heal th conpared } \\
\text { to others }\end{array}$ & 2 & 0.07 & 0.07 & 0.01 & 2 & 0.07 & 0.07 & 0.01 & 2 & 0.11 & 0.10 & 0.01 \\
\hline $\begin{array}{l}\text { Heal th compared } \\
\text { to } 2 \text { years ago }\end{array}$ & $\mathbf{a}$ & $\mathrm{a}$ & $\mathrm{a}$ & $\mathbf{a}$ & 4 & 0.06 & 0.06 & 0.00 & $\mathbf{a}$ & $\mathbf{a}$ & $\mathbf{a}$ & $\mathbf{a}$ \\
\hline $\begin{array}{l}\text { Standard of living } \\
\text { compared to others }\end{array}$ & 4 & 0.05 & 0.04 & 0.00 & 3 & 0.08 & 0.06 & 0.01 & 3 & 0.08 & 0.07 & 0.01 \\
\hline $\begin{array}{l}\text { Ability to get along } \\
\text { on income }\end{array}$ & 3 & 0.05 & 0.04 & 0.00 & 5 & 0.07 & 0.06 & 0.00 & 4 & 0.04 & 0.04 & 0.00 \\
\hline \multirow{2}{*}{$\begin{array}{l}\text { Satisfaction with } \\
\text { standard of living }\end{array}$} & 1 & 0.22 & 0.17 & 0.04 & 1 & 0.24 & 0.18 & 0.05 & 1 & 0.24 & 0.18 & 0.05 \\
\hline & Total & $2=0.05$ & \multicolumn{2}{|c|}{$\underline{N}=7301$} & \multicolumn{2}{|c|}{ Total R2 $=0.07$} & \multicolumn{2}{|c|}{$\mathbf{N}=7017$} & Total & $R 2=0.07$ & \multicolumn{2}{|c|}{$\mathrm{N}=7103$} \\
\hline
\end{tabular}

Note. The outcome in the 1969-1971 analysis is change in happiness from 1969 to 1971. Likewise, the outcome in the 19711973 and in the 1969-1973 analyses is change in happiness from 1971 to 1973 and from 1969 to 1973 respectively.

a This item was not included in the 1969 wave of data collection. 
TABLE LXXXVII

MEANS, STANIARD DEVIATIONS, AND INTEROORREIATIONS AMONG CHANGE IN SUBJECTIVE WEIL-BEING, CHANGE IN HEALTH, AND CIANGE IN FINANCIAL ITEMS AS. MEASURED BY PERCENTAGE GAIN SOORES

\begin{tabular}{|c|c|c|c|c|c|c|c|c|c|}
\hline Item & & year & mean & s.d. & (2) & (3) & (4) & (5) & (6) \\
\hline $\begin{array}{l}\text { Health compared } \\
\text { to others }\end{array}$ & (1) & $\begin{array}{l}1969-1971 \\
1971-1973 \\
1969-1973\end{array}$ & $\begin{array}{r}0.01 \\
0.00 \\
-0.02\end{array}$ & $\begin{array}{l}0.49 \\
0.50 \\
0.50\end{array}$ & $\begin{array}{l}a \\
.26 \\
a\end{array}$ & $\begin{array}{l}.08 \\
.07 \\
.12\end{array}$ & $\begin{array}{l}.05 \\
.10 \\
.11\end{array}$ & $\begin{array}{l}.09 \\
.09 \\
.09\end{array}$ & $\begin{array}{l}.09 \\
.11 \\
.13\end{array}$ \\
\hline $\begin{array}{l}\text { Health compared } \\
\text { to } 2 \text { years ago }\end{array}$ & (2) & $\begin{array}{l}1969-1971 \\
1971-1973 \\
1969-1973\end{array}$ & $\begin{array}{c}a \\
-0.05 \\
a\end{array}$ & $\begin{array}{l}a \\
0.53 \\
a\end{array}$ & & $\begin{array}{l}a \\
.06 \\
a\end{array}$ & $\begin{array}{l}a \\
.06 \\
a\end{array}$ & $\begin{array}{l}a \\
.08 \\
a\end{array}$ & $\begin{array}{l}\mathrm{a} \\
.10 \\
\mathrm{a}\end{array}$ \\
\hline $\begin{array}{l}\text { Standard of living } \\
\text { compared to others }\end{array}$ & (3) & $\begin{array}{l}1969-1971 \\
1971-1973 \\
1969-1973\end{array}$ & $\begin{array}{r}0.05 \\
-0.04 \\
-0.00\end{array}$ & $\begin{array}{l}0.45 \\
0.45 \\
0.46\end{array}$ & & & $\begin{array}{l}.13 \\
.13 \\
.18\end{array}$ & $\begin{array}{l}.24 \\
.23 \\
.29\end{array}$ & $\begin{array}{l}.09 \\
.12 \\
.14\end{array}$ \\
\hline $\begin{array}{l}\text { Ability to get along } \\
\text { on income }\end{array}$ & (4) & $\begin{array}{l}1969-1971 \\
1971-1973 \\
1969-1973\end{array}$ & $\begin{array}{r}0.04 \\
-0.02 \\
0.00\end{array}$ & $\begin{array}{l}0.48 \\
0.46 \\
0.49\end{array}$ & & & & $\begin{array}{l}.22 \\
.19 \\
.25\end{array}$ & $\begin{array}{l}.09 \\
.11 \\
.10\end{array}$ \\
\hline $\begin{array}{l}\text { Satisfaction with } \\
\text { standard of living }\end{array}$ & (5) & $\begin{array}{l}1969-1971 \\
1971-1973 \\
1969-1973\end{array}$ & $\begin{array}{l}0.04 \\
0.01 \\
0.02\end{array}$ & $\begin{array}{l}0.42 \\
0.41 \\
0.42\end{array}$ & & & & & $\begin{array}{l}.20 \\
.22 \\
.22\end{array}$ \\
\hline Happiness & (6) & $\begin{array}{l}1969-1971 \\
1971-1973 \\
1969-1973\end{array}$ & $\begin{array}{l}0.07 \\
0.02 \\
0.06\end{array}$ & $\begin{array}{l}0.53 \\
0.55 \\
0.56\end{array}$ & & & & & \\
\hline
\end{tabular}

Note. The means, standard deviations, and correlation coefficients may differ slightly from those presented previously due to the listwise deletion of cases with a missing value on one or more variables.

The sample sizes are 7301 for the 1969-1971 analysis, 7017 for the 1971-1973 analysis, and 7103 for the 1969-1973 analysis.

ahis item was not included in the 1969 wave of data collection. 
Baur, P. A., \& Okum, M. A. (1983). Stability of life satisfaction in late life. Gerontologist, 23 (3), 261-265.

Beckman, L. J., \& Houser, B. B. (1982). The consequences of childessness on the social-psychological well-being of older women. Journal of Gerontology, 37 (2), 243-250.

Bild, B. R., \& Havighurst, R. J. (1976). Senior citizens in great cities: The case of Chicago. Gerontologist, 16 (1), Part 2, $70-75$.

Brand, F. N., \& Smith, R. T. (1974). Life adjustment and relocation of the elderly. Journal of Gerontology, 29 (3), 336-340.

Brawn, J.S., Perman, B. S., \& Dobbs, J. L. (1981). The will-to-live. Research on Aging, 3 (2), 182-201.

Bultena, G. L. (1969). Life continuity and morale in old age. Gerontologist, 2 (4), Part 1, 251-253.

Bultena, G. L., \& Oyler, R. (1971). Effects of health on disengagement and morale. Aging and Human Development, 2 (2), 142-148.

Carp, F. M. (1968). Person-situation congruence in engagement. Gerontologist, 8 (3) Part 1, 184-188.

Chapman, N. J., \& Beaudet, M. (1983). Environmental predictors of well-being for at-risk older adults in a mid-sized city. Journal of Gerontology, 38 (2), 237-244.

Collette, J. (1984). Sex differences in life satisfaction: Australian data. Journal of Gerontology, $39(2), 243-245$.

Conner, K. A., \& Powers, E. A. (1975). Structural effects and life satisfaction among the aged. International Journal of Aging and Human Development, 6 (4), 321-327.

Conner, R. A., Powers, E. A., \& Bultena, G. L. (1979) . Social interaction and life satisfaction: An empirical assessment of late-life patterns. Jounal of Gerontology, 34 (1), 116-121.

Curry, T. J., \& Ratliff, B. W. (i 973). The effects of nursing home size on resident isolation and life satisfaction. Gerontologist, 13 (3), Part 1, 295-298. 
Cutler, S. J. (1972). The availability of personal transportation, residential location, and life satisfaction among the aged. Journal of Gerontology, 27 (3), 383-389.

Deimling, G., Harel, Z., \& Noelker, L. (1983). Racial differences in social integration and life satisfaction among aged public housing residents. International Journal of Aging and Human Development, 17 (3), 203-212.

Duff, R. W., \& Hong, L. K. (1980). Quality and quantity of social interactions in the life satisfaction of older Americans. Paper presented at the 33rd annual meeting of the Gerontological Society, San Diego.

Edwards, J. N., \& Klemmack, D. L. (1973). Correlates of life satisfaction: A reexamination. Journal of Gerontology, 28 (4), 497-502.

Elwell, F., \& Maltbie- Crannell, A. D. (1981). The impact of role loss upon coping resources and life satisfaction of the elderly. Journal of Gerontology, 36 (2), 223-232.

Fawcett, G., Stonner, D., Zepelin, H. (1980). Locus of control, perceived constraint, and morale among institutionalized aged. International Journal of Aging and Human Development, 11 (1), 13-23.

Felton, B. J., Hinrichsen, G. A., \& Tsemberis, S. (1981). Urbansuburban differences in the predictors of morale among the aged. Journal of Gerontology, 36 (2), 214-222.

Fengler, A. P., \& Danigelis, N. (1982). Residence, the elderly widow, and life satisfaction. Research on Aging, 4 (1), 113-135.

Fengler, A. P., \& Jensen, L. (1981). Perceived and objective conditions as predictors of the life satisfaction of urban and nonurban elderly. Journal of Gerontology, 36 (6), 750-752.

Fengler, A. P., Danigelis, N., Grams, A. (1980). Later life satisfaction and family structure: Living with others and living alone. Paper presented at the 33rd annual scientific meeting of the Gerontological Society, San Diego, California.

Fine, M. (1975). Interrelationships among mobility, health and attitudinal variables in an urban elderly population. Human Relations, 28 (5), 451-474.

Fox, J. H. (1977). Effects of retirement and former work life on women's adaptation in old age. Journal of Gerontology, 32 (2), 196-202. 
George, L. R. (1978). The impact of personality and social status factors upon levels of activity and psychological well-being. Journal of Gerontology, $33(6), 840-847$.

Gubrium, J. F. (1970). Environmental effects on morale in old age and the resources of health and solvency. Gerontologist, 10 (4), Part 1, 294-297.

Harel, Z., \& Noelker, L. (1982). Social integration, health, and choice. Research on Aging, 4 (1), 97-111.

Harel, 2., Sollod, R. N., \& Bognar, B. J. (1982). Predictors of mental health among semi-rural aged. Gerontologist, 22 (6), 499-504.

Hooker, K., \& Ventis, D. G. (1984). Work ethic, daily activities, and retirement satisfaction. Journal of Gerontology, 39 (4), 478484.

Hoyt, D. R., Kaiser, M. A., Peters, G. R., \& Babchuk, N. (1980). Life satisfaction and activity theory: A multi-dimensional approach. Journal of Gerontology, 35 (6), 935-941.

Hutchison III, I. W. (1975). The significance of marital status for morale and life satisfaction among lower-income elderly. Journal of Marriage and the Family, 37, 287-293.

Jackson, J. S., Bacon, J. D., \& Peterson, J. (1977-78). Life satisfaction among Black urban elderly. International Journal of Aging and Human Development, 8 (2), 169-179.

Jeffers, F., \& Nichols, C. (1961). The relationship of activities and attitudes to physical well-being in older people. Journal of Gerontology, 16 (1), 67-70.

Keith, P. M., Hill, K., Goudy, W. J., \& Powers, E. A. (1984). Confidants and well-being: A note on male friendship in old age. Gerontologist, 24 (3), 318-320.

Knapp, M. R. J. (1976). Predicting the dimensions of life satisfaction. Journal of Gerontology, 31 (5), 595-604.

Knapp, M. R. J. (1977). The activity theory of aging: An examination in the English context. Gerontologist, 17 (6), 553-559.

Kozma, A., \& Stones, M. J. (1983). Predictors of happiness. Journal of Gerontology, $38(5), 626-628$. 
Lawton, M. P., Nahemow, L., \& Teaff, J. (1975). Housing characteristics and the well-being of elderly tenants in federally assisted housing. Journal of Gerontology, 30 (5), $601-607$.

Lee, G. R. (1978). Marriage and morale in later life. Journal of Marriage and the Family, 40 (2), 131-139.

Lee, G. R. (1979). Children and the elderly: Interaction and morale. Research on Aging, 1 (3), 335-360.

Lee, G. R., \& Ellithorpe, E. (1980). Intergenerational exchange and quality of life among the elderlty. Paper presented at the annual meeting of the National council on Family Relations, Portland, Oregon, October.

Lee, G. R. , \& Ihinger-Tallman, M. (1980). Sibling interaction and morale: The effects of family relations on older people. Research on Aging, 2 (3), 367-391.

Leonard II, W. M. (1981-82). Successful aging: An elaboration of social and psychological factors. International Journal of Aging and Human Development, 14 (3), 223-232.

Lepkowski, J. R. (1956). The attitudes and adjustments of institutionalized and non-institutionalized catholic aged. Journal of Gerontology, 11 (2), 185-191.

Liang, J., \& Warfel, B. L. (1983). Urbanism and life satisfaction among the aged. Journal of Gerontology, 38 (1), 97-106.

Liang, J., Dvorkin, L., Kahana, E., \& Mazian, F. (1980). Social integration and morale: A reexamination. Journal of Gerontology, 35 (5), 746-757.

Longino, C. F., \& Kart, C. S. (1982). Explicating activity theory: A formal replication. Jeurnal of Gerontology, 37 (6), 713-722.

Maddox, G. L. (1963). Activity and morale: A Iongitudinal study of selected elderly subjects. Social Forces, 42, 195-204.

Maddox, G. L., \& Eisdorfer, C. (1962). Same correlates of activity and morale among the elderly. Social Forces, 41, 254-260.

Mancini, J. A. (1978). Leisure satisfaction and psychologic well-being in old age: Effects of health and income. Journal of the American Geriatrics Society, 26 (12), 550-552.

Mancini, J. A. (1980). Friend interaction, competence, and morale in old age. Research on Aging, 2 (4), 416-431. 
Mancini, J. A., Quinn, W., Gavigan, M. A., \& Franklin, H. (1980). Social network interaction among older adults: Implications for life satisfaction. Human Relations, 33 (8), 543-554.

Markides, K. S., \& Martin, H. W. (1979). A causal model of life satisfaction among the elderly. Journal of Gerontology, 34 (1), 86-93.

Markides, K. S., Costley, D. S., \& Rodriguez, L. (1981). Perceptions of intergenerational relations and psychological well-being among elderly Mexican Americans: A causal model. International Journal of Aging and Human Development, 13 (1), 43-52.

Martin, W. C. (1973). Activity and disengagement: Life satisfaction of in-movers into a retirement community. Gerontologist, $13(2), 224-227$.

Mason, E. P. (1954). Some correlates of self-judgments of the aged. Journal of Gerontology, 2 (3), 324-338.

McClelland, K. A. (1982). Self-conception and life satisfaction: Integrating aged subculture and activity theory. Journal of Gerontology, 37 (6), 723-732.

Medley, M. L. (1976). Satisfaction with life among persons sixty-five years and older. Journal of Gerontology, 31 (4), 448-455.

Medley, M. L. (1980). Life satisfaction across four stages of adult life. International Journal of Aging and Human Development, il (3), 193-209.

Messer, M. (1968). Race differences in selected attitudinal dimensions of the elderly. Gerontologist, \& (4), 245-249.

Moriwaki, S. Y. (1973). Self-disclosure, significant others and psychological well-being in old age. Journal of Health and Social Behavior, 14, 226-232.

Mutran, E., \& Reitzes, D. C. (1981). Retirement, identity and wellbeing: Realignment of role relationships. Journal of Gerontology, $36(6), 733-740$.

Myles, J. F. (1978). Institutionalization and sick role identification among the elderly. American Socielogical Revien, 43 (4), 508521 .

Noelker, L., \& Harel, Z. (1978). Predictors of well-being and survival among institutionalized aged. Gerontologist, 18 (6), 562-567. 
Ory, M. G., \& Goldberg, E. L. (1983). Pet possession and well-being in elderly women. Research on Aging, 5 (3), 389-409.

Palmore, E. B. (1968). The effects of aging on activities and attitudes. Gerontologist, 8 (4), 259-263.

Palmore, E., \& Kivett, V. (1977). Change in life satisfaction: A longitudinal study of persons aged 46-70. Journal of Gerontology, 32 (3), 311-316.

Palmore, E., \& Luikart, C. (1972). Health and social factors related to life satisfaction Journal of Health and Social Behavior, $13,68-80$.

Parmelee, P. A. (1982). Social contacts, social instrumentality, and adjustment of institutionalized aged. Research on Aging, 4 (2), 269-280.

Reid, D. W., \& Ziegler, M. (1980). Validity and stability of a new desired control measure pertaining to psychological adjustment of the elderly. Journal of Gerontology, 35 (3), 395-402.

Sauer, W. (1977). Morale of the urban aged: A regression analysis by race. Journal of Gerontology, 32 (5), 600-608.

Sauer, W. J., Shehan, C., \& Boymel, C. (1976). Rural-urban differences in satisfaction among the elderly: A reconsideration. Rural Sociology, 41, 269-275.

Seleen, D. R. (1982). The congruence between actual and desired use of time by older adults: A predictor of life satisfactiohn. Gerontologist, 22 (1), 95-99.

Sherman, S. R. (1974) . Leisure activities in retirement housing. Journal of Gerontology, 29 (3), 325-335.

Smith, R. T., \& Brand, F. N. (1975). Effects of enforced relocation on life adjustment in a nursing home. International Journal of Aging and Human Develogment, 6 (3), 249-259.

Snow, R., \& Crapo, L. (1982). Enotional bondness, subjective wellbeing, and health in elderly medical patients. Journal of Gerontology, 37 (5), 609-615.

Spakes, P. R. (1979). Family, friendship, and community interaction as related to life satisfaction of the elderly. Journal of Gerontological social Work, 1 (4), 279-293. 
Spreitzer, E., \& Snyder, E. E. (1974). Correlates of life satisfaction among the aged. Journal of Gerontology, 29 (4), 454-458.

Strain, L. A., \& Chappell, N. L. (1982). Confidants: Do they make a difference in quality of life. Research on Aging, 4 (4), 479502 .

Streib, G. F. (1956). Morale of the retired. Socjal Problems, 3, 270276 .

Tesch, S., \& Whitbourne, S. K., \& Nehrke, M. F. (1981). Friendship, social interaction and subjective well-being of older men in an institutional setting. International Journal of Aging and Human Development, $13(4), 317-327$.

Thompson, G. B. (1973). Work versus leisure roles: An investigation of morale among employed and retired men. Iournal of Gerontology, 28 (3), 339-344.

Toseland, R., \& Sykes, J. (1977). Senior citizens center participation and other correlates of life satisfaction. Gerontologist, 17 (3), 235-241.

Usui, W. M., Reil, T. J., \& Phillips, D. C. (1983). Determinants of life satisfaction: A note on a race-interaction hypothesis. Journal of Gerontology, 38 (1), 107-110.

Ward, R.A. (1979). The meaning of voluntary association participation to older people. Journal of Gerontology, 34 (3), 438-445.

Ward, R. A. (1979). The never-married in later life. Journal of Gerontology, $34(6), 861-869$.

Ward, R. A., \& Kilburn, H. (1983). Community access and satisfaction: Racial differences in later life. International Journal of Aging and Human Development, 16 (3), 209-219.

Ward, R. A., Sherman, S. R., \& LaGory, M. (1984). Subjective network assessments and subjective well-being. Journal of Gerontology, 39 (1), 93-101.

Wolk, S., \& Telleen, S. (1976). Psychological and social correlates of life satisfaction as a function of residential constraint. Journal of Gerontology, 31 (1), 89-98.

Wylie, M. L. (1970). Life satisfaction as a program impact criterion. Journal of Gerontology, 25 (1), 36-40. 
Ziegler, M., \& Reid, D. W. (1983). Correlates of changes in desired control scores and in life satisfaction scores among elderly persons. International Journal of Aging and Human Development, 16 (2), 135-146. 